\title{
Interrupted Innovation: Emerging economies in the structure of the global aerospace industry
}

Citation for published version (APA):

Vértesy, D. (2011). Interrupted Innovation: Emerging economies in the structure of the global aerospace industry. [Doctoral Thesis, Maastricht University]. Datawyse / Universitaire Pers Maastricht. https://doi.org/10.26481/dis.20110930dv

Document status and date:

Published: 01/01/2011

DOI:

$10.26481 /$ dis.20110930dv

Document Version:

Publisher's PDF, also known as Version of record

\section{Please check the document version of this publication:}

- A submitted manuscript is the version of the article upon submission and before peer-review. There can be important differences between the submitted version and the official published version of record.

People interested in the research are advised to contact the author for the final version of the publication, or visit the DOI to the publisher's website.

- The final author version and the galley proof are versions of the publication after peer review.

- The final published version features the final layout of the paper including the volume, issue and page numbers.

Link to publication

\footnotetext{
General rights rights.

- You may freely distribute the URL identifying the publication in the public portal. please follow below link for the End User Agreement:

www.umlib.nl/taverne-license

Take down policy

If you believe that this document breaches copyright please contact us at:

repository@maastrichtuniversity.nl

providing details and we will investigate your claim.
}

Copyright and moral rights for the publications made accessible in the public portal are retained by the authors and/or other copyright owners and it is a condition of accessing publications that users recognise and abide by the legal requirements associated with these

- Users may download and print one copy of any publication from the public portal for the purpose of private study or research.

- You may not further distribute the material or use it for any profit-making activity or commercial gain

If the publication is distributed under the terms of Article $25 \mathrm{fa}$ of the Dutch Copyright Act, indicated by the "Taverne" license above, 


\section{Interrupted Innovation}

Emerging economies in the structure of the global aerospace industry

Dániel Vértesy 
(C) Dániel Vértesy, 2011

All rights reserved. No part of this publication may be reproduced, stored in a retrieval system, or transmitted, in any form, or by any means, electronic,mechanical, photocopying, recording or otherwise, without the prior permission in writing from the author.

Interrutpted Innovation: Emerging economies in the structure of the global aerospace industry/ by Dániel Vértesy. - Maastricht: University of Maastricht, 2011. - Proefschrift. -

Keywords: aerospace industry; sectoral innovation system dynamics; latecomer industrialization; Brazil; China; Singapore; Indonesia; Argentina;

ISBN 9789461590862

Cover design: Dániel Vértesy

Publisher: Datawyse bv | Universitaire Pers Maastricht 


\section{Interrupted Innovation Emerging economies in the structure of the global aerospace industry}

\section{DISSERTATION}

to obtain the degree of Doctor at Maastricht University, on the authority of the Rector Magnificus Prof. dr. G.P.M.F. Mols, in accordance with the decision of the Board of Deans, to be defended in public on Friday 30 September 2011, at 10:00 hours.

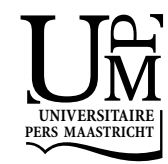




\section{Supervisor:}

Prof. dr. Adam Szirmai

Assessment Committee:

Prof. dr. Robin Cowan (chairman)

Prof. dr. Gerlach J. N. Cerfontaine

Prof. dr. Ernst Homburg

Prof. dr. Franco Malerba (Bocconi University, Italy)

This research has been conducted with financial support by UNU-MERIT. 


\section{Table of Contents}

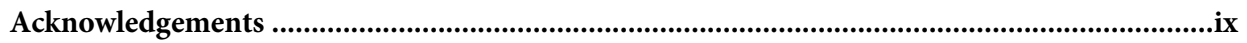

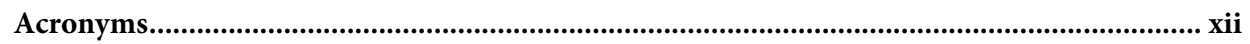

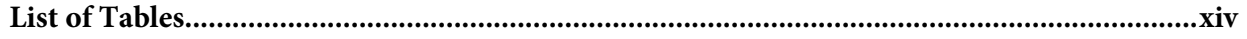

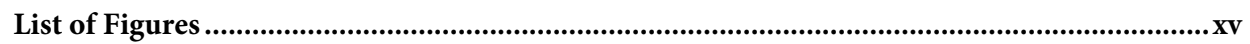

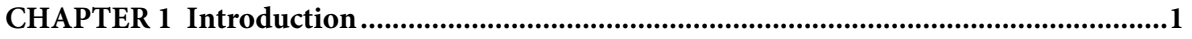

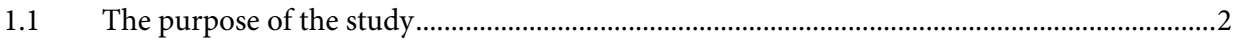

1.2 Research methods............................................................................................................

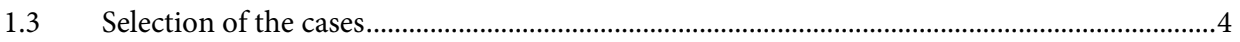

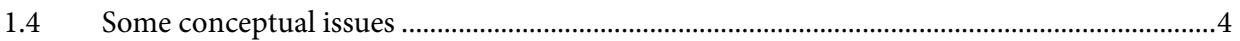

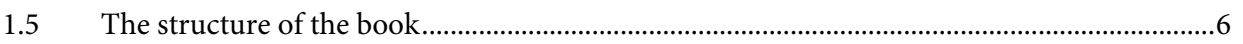

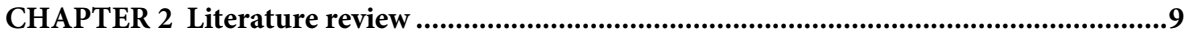

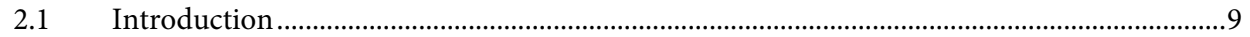

2.2 Latecomer advantages and how to benefit from them ........................................................

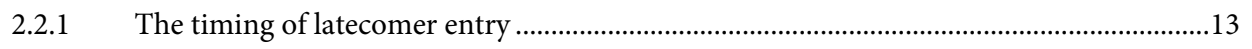

$2.3 \quad$ Technological capabilities ...................................................................................................

2.3.1 Technological capabilities, stage models, and their relevance for the aerospace industry ..16

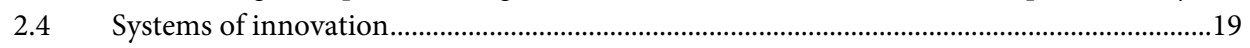

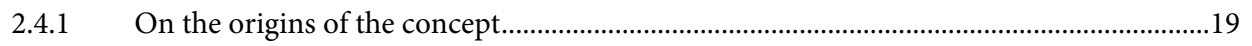

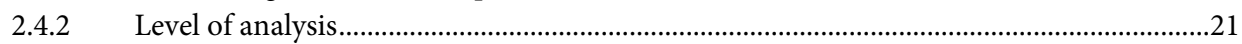

2.4.3 Applying a sectoral systems of innovation approach for latecomer aerospace industries...22

2.4.4 Incremental and radical changes in innovation systems .....................................................23

2.4.5 The punctuated equilibrium model of innovation dynamics ..............................................25

2.5 Previous studies on innovation and growth in latecomer aerospace industries....................26

2.5.1 On the evolution of the aerospace industry at the frontier .................................................26

2.5.2 On the aerospace industry in latecomer economies.............................................................28

2.6 Technological change and industrial dynamics in the jet age ...............................................29

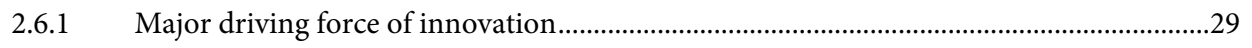

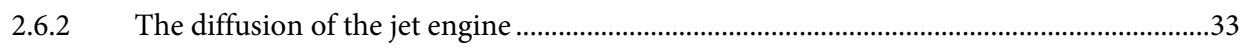

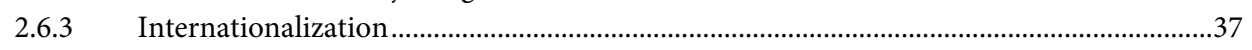

2.6.4 The diffusion of technologies to emerging economies ........................................................40

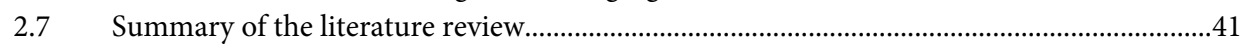

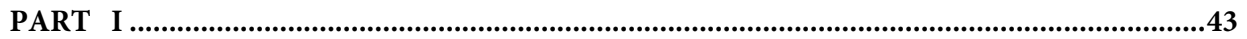

CHAPTER 3 The evolution of the global aerospace manufacturing industry.....................45

3.1 Statistical sources on aerospace manufacturing ………............................................................

3.2 Methodological considerations for projecting and aggregating time series data .................47

3.3 The growth of the global aerospace industry in a historical perspective .................................50

3.4 The main incumbents and emerging aerospace producers ....................................................54

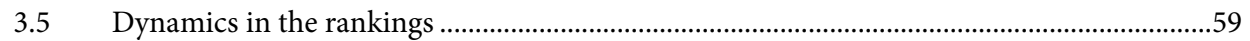

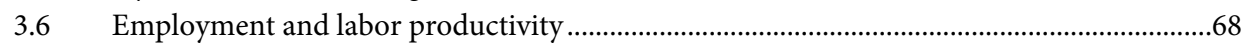

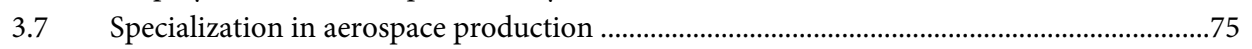

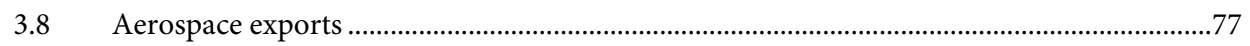




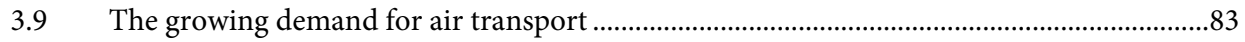

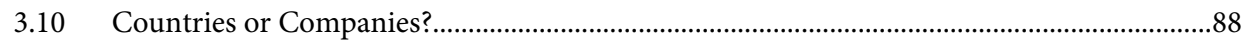

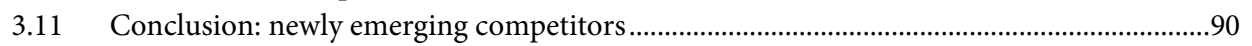

CHAPTER 4 A Brazil/USA comparison of output and productivity.................................93

4.1 An industry of origin approach to output and productivity comparisons.............................93

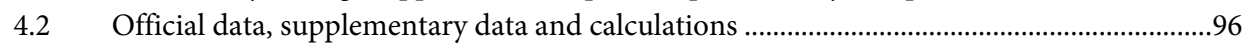

4.2.1 Adjustments and calculation of unit value ratios for Brazilian aircraft production.........97

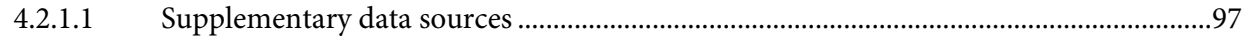

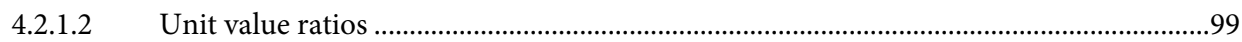

4.2.2 Adjustments and calculation of unit value ratios for production in the United States. 100

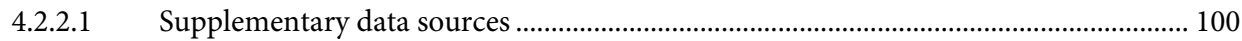

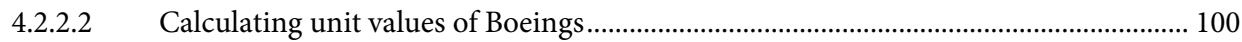

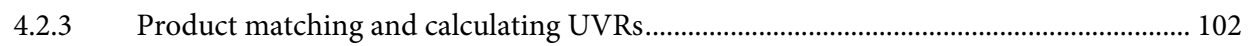

4.2.4 Comparing small apples with big apples: adjustments for product size differences ..... 104

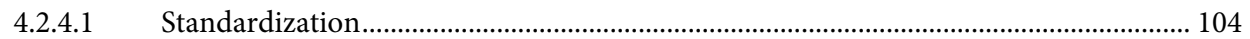

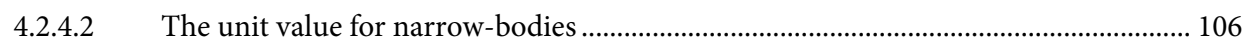

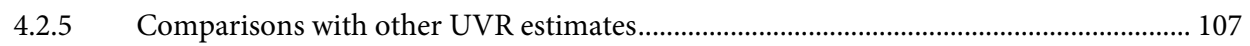

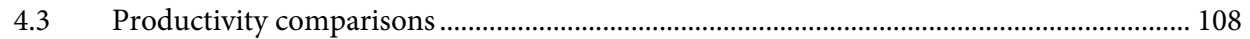

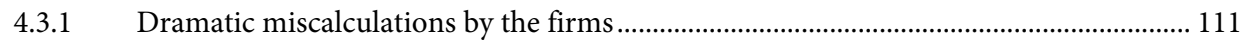

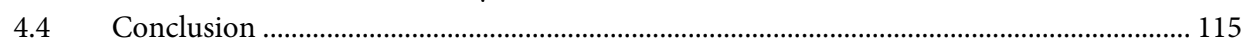

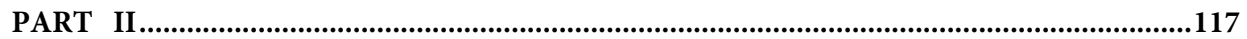

CHAPTER 5 A conceptual framework of interrupted innovation....................................119

5.1 Introduction: A new perspective on Innovation Systems Dynamics ................................... 119

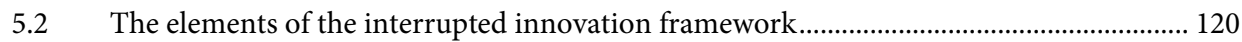

5.2.1 The main components of the framework of interrupted innovation .............................. 120

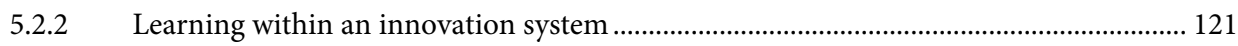

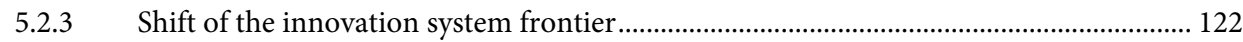

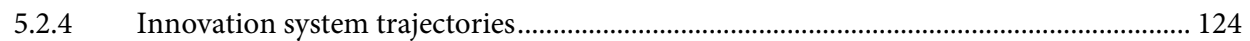

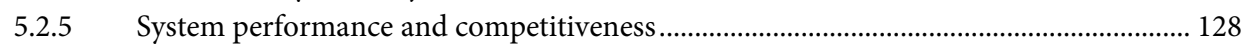

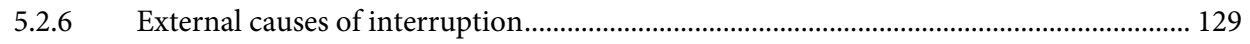

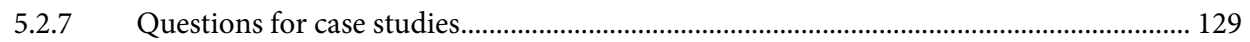

CHAPTER 6 Case studies on latecomer aerospace industry development .........................131

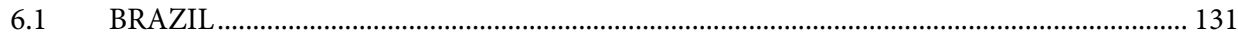

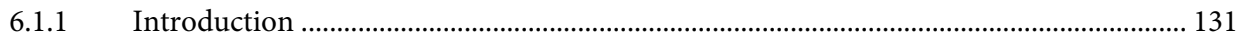

6.1.2 The origins of aircraft manufacturing in Brazil ............................................................ 131

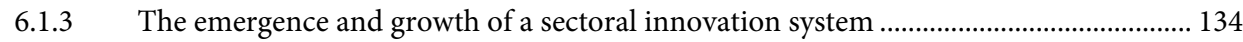

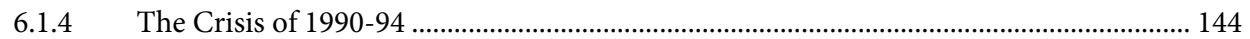

6.1.5 A radical change in the Brazilian sectoral innovation system............................................ 146

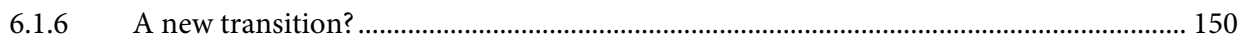

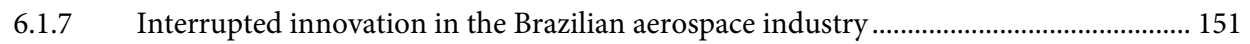

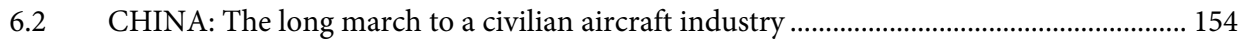

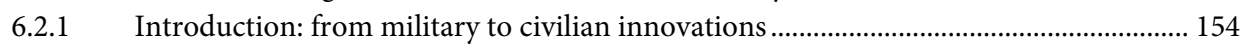

6.2.2 The emergence and fall of a Soviet enclave in China (1950s) .......................................... 154

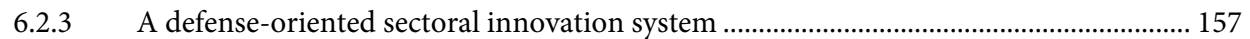

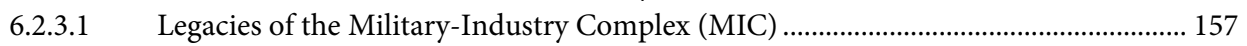


6.2.3.2 The origins of commercial production ......................................................................... 160

6.2.3.3 Main features of the innovation system before the changes of the 1990s..................... 161

6.2.4 The crisis in the inward-looking innovation system ....................................................... 162

6.2.5 A radical change in the Chinese sectoral innovation system in the 1990s ...................... 163

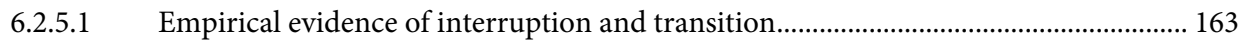

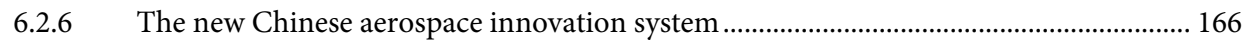

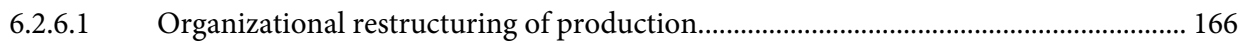

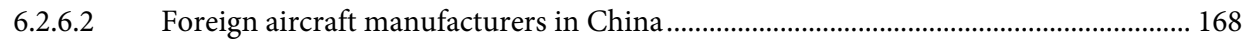

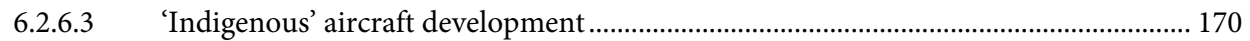

6.2.7 Interrupted innovation in the Chinese aerospace industry .............................................. 173

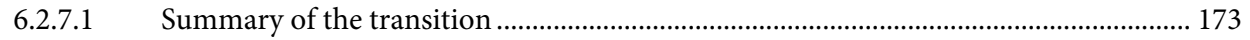

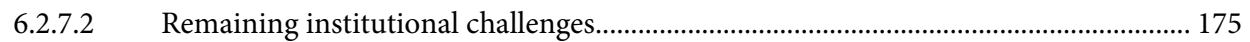

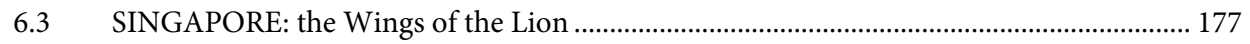

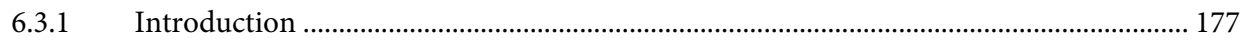

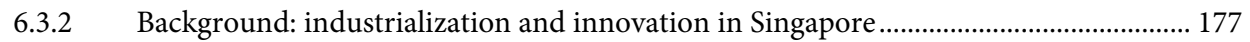

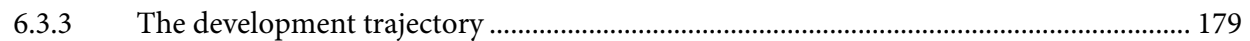

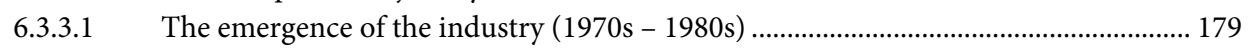

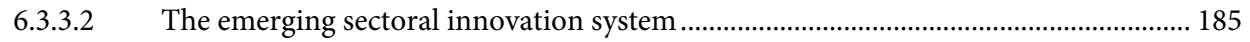

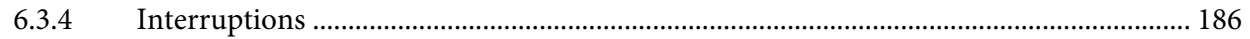

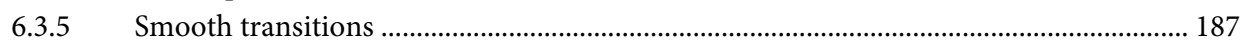

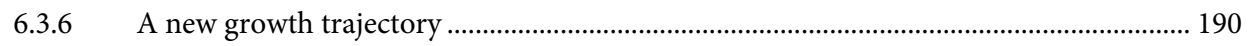

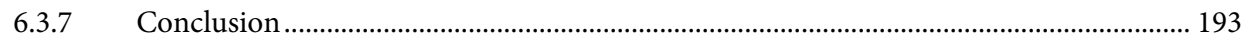

6.4 ARGENTINA: The case of a languishing aerospace innovation system ............................... 197

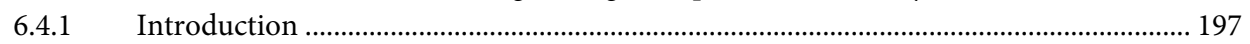

6.4.2 The emergence of a sectoral aerospace innovation and production system in Argentina 198

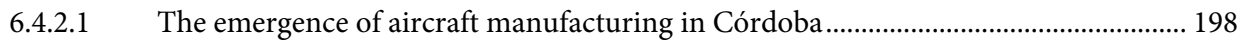

6.4.2.2 Incomplete emergence (1927-1952) ........................................................................... 203

6.4.3 Crisis in the Industry: Replacing wings with wheels ........................................................ 205

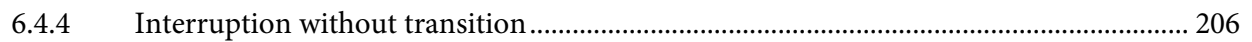

6.4.4.1 The first interruption in the innovation system: the 1950s........................................... 206

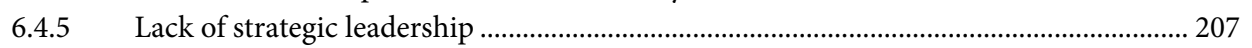

6.4.5.1 Renewed efforts to build up domestic technological capabilities in aerospace........... 209

6.4.5.2 An incrementally changed innovation system (1960s-1983) ........................................ 213

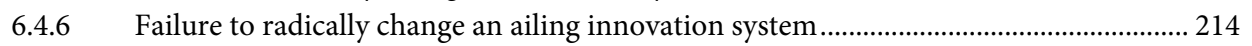

6.4.6.1 A new crisis: the end of the military regime and struggles with privatization ............. 214

6.4.6.2 Failed transitions to a more open innovation system (after 1983) .............................. 216

6.4.7 Interrupted innovation in Argentina: The rise and fall of an innovation system ........... 217

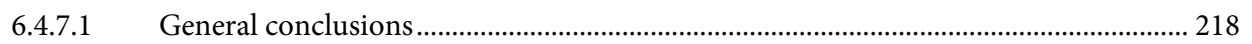

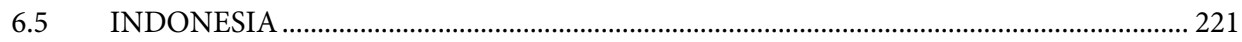

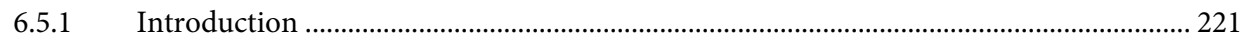

6.5.2 The emergence of the Indonesian aerospace industry and innovation system.............. 221

6.5.2.1 The origins of Indonesian aircraft manufacturing .......................................................... 221

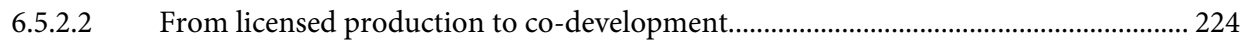

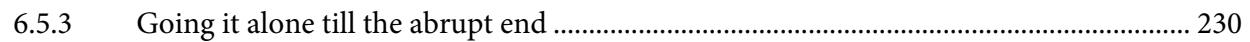

6.5.3.1 The emerging innovation system: increases in size and performance .......................... 232

6.5.4 Crisis and interruption without transition .................................................................. 235 


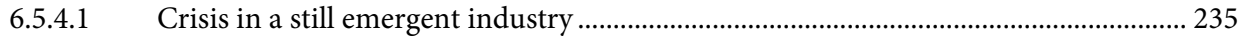

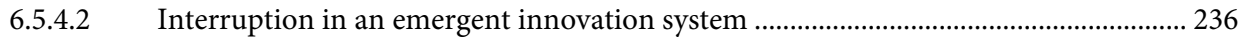

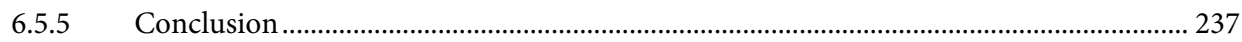

6.5.5.1 Emergence and interruption........................................................................................ 237

6.5.5.2 Why did Indonesia fail to make the transition to a new growth trajectory?................ 238

CHAPTER 7 The evaluation of the case studies and policy conclusions ...........................241

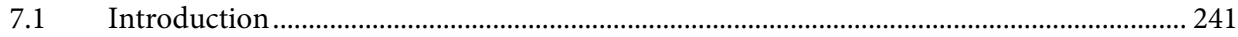

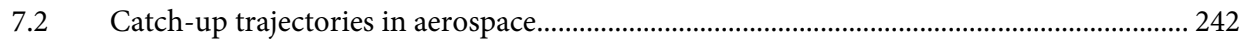

7.2.1 Latecomer performance and evidence of catch-up............................................................ 242

7.2.2 Emergence of the aerospace industry in emerging economies ......................................... 243

7.2.3 Accumulation of technological capabilities over time .................................................... 244

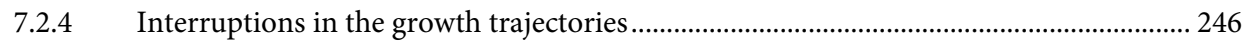

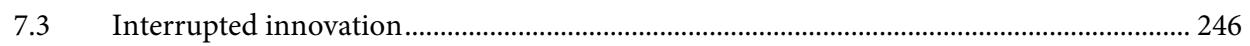

7.3.1 The explanation of radical innovation system changes ................................................... 247

7.3.2 National-sectoral innovation systems in latecomer aerospace industries........................ 247

7.3.3 A note on the measurement of innovation systems performance...................................... 249

7.3.4 Periods of incremental and radical innovation system dynamics .................................... 249

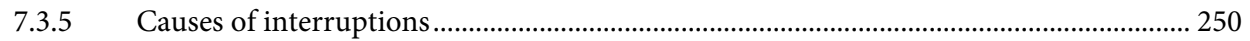

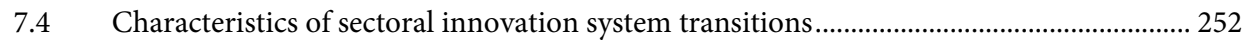

7.4.1 Interruptions, transitions and the accumulation of technological capabilities ............... 252

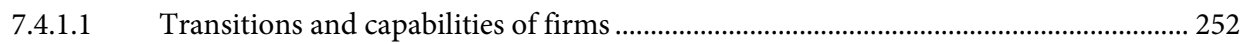

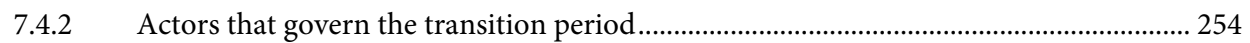

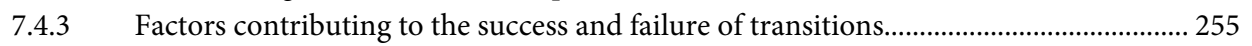

7.4.3.1 Successful Transition - with coordinated intervention.................................................... 255

7.4.3.2 Failure of transition: interruption during the emergent phase ...................................... 256

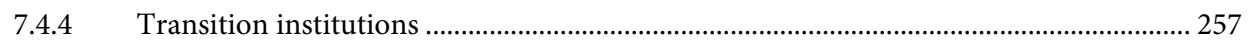

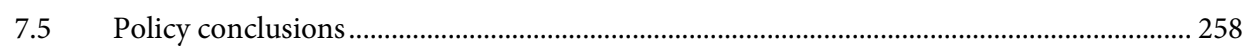

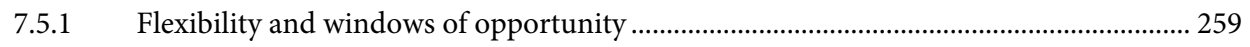

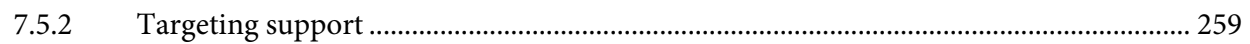

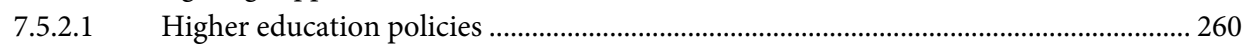

7.5.2.2 Science, technology and innovation policies.................................................................. 261

7.5.2.3 Trade and public procurement policies ...................................................................... 261

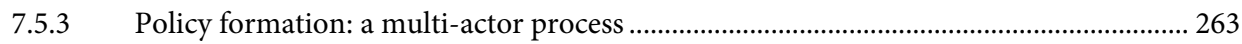

7.5.3.1 The role of the military .............................................................................................. 263

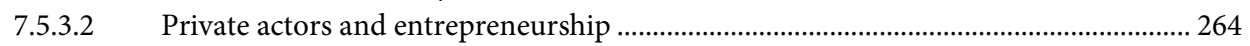

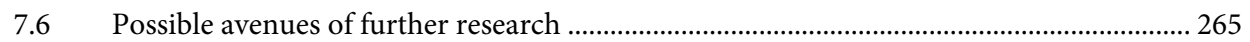

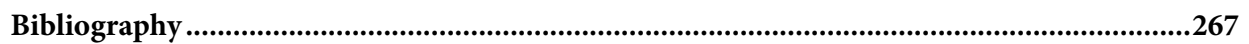

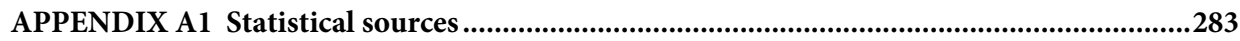

APPENDIX A2 Methodological Annex to Chapter 4 ..................................................................295

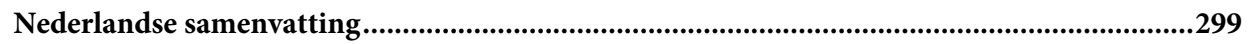

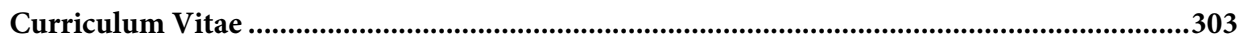

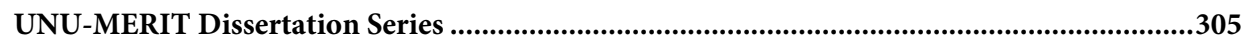




\section{Acknowledgements}

$\mathrm{PhD}$ students are, by definition, latecomers - to a field of science, or to the industry of academics. At the beginning of the PhD trajectory, as a latecomer I was inspired by the ideas of all the leading professors and tried to learn from them. The aim was to implement some of this knowledge in a product which would ideally be very innovative. It was my latecomer advantage having had access to vast libraries full of fancy theories ready to be applied. However, only through interactions with "established industrialists" and fellow latecomers would a path open up in what in fact was a jungle full of wild ideas. As I am finishing the thesis and losing some of the latecomer status, I'd like to express my gratitude to everyone with whom I had the opportunity to exchange thoughts and who thus contributed to the accomplishment of this thesis.

I am most grateful to Eddy Szirmai, for the trust he vested in my initial vague ideas, and for taking the role of supervision incredibly seriously. Eddy was always available for help. He would read and comment on each and every sentence in immeasurable amount of drafts (and patiently correct my persistent errors in grammar and style, and break up all the long sentences like this one). He would actively support my field trips to gain a first-hand look at what I am writing about and push me to present work in progress. It has been a real pleasure collaborating with Eddy, and hope this will continue beyond this thesis as well, without any interruption.

I also thank Anthony Bartzokas and Luc Soete for giving me a chance to enter the academic world of innovation at UNU-MERIT. Anthony was also the first who puzzled me why nobody had ever done a research on the global aerospace industry before. In those early formative weeks discussions with Kaushalesh Lal and Ionara da Costa were instrumental; I am also indebted to Ionara for helping with (among others) the field trip to Brazil and gaining access to and understanding empirical data in Portuguese.

Research visits to Brazil and China were crucial to the realization of this work. This place is too limited to give due credit to everyone who provided help and guidance for my explorations of aerospace innovation systems. I would like to express my special thanks to Julio Milko and Ozires Silva, to Alessandro Oliveira, Arnold Cabral, Maria Gracas Peixoto, Walter Bartels, Aloisio Campelo, Hilton Notini, Carlos Moraes, Elyas Medeiros, Marco Chamon, Luiz Antonio Gargione, Paolo Lourencao, Marcel Devresse, Feng Zhen, Wang Ling and Yang Xi for the visits, the arrangements, the interviews, or the data. I am similarly thankful to Prof. Chen Xiangdong for hosting me at the Beihang University, and to Robin Tao and other industry experts who preferred not to be named but helped me understand the some of the complexities of the Chinese aircraft industry.

The thesis has greatly benefitted from comments and fruitful discussions on earlier versions presented at meetings of Research Group II and $\mathrm{PhD}$ presentations at UNU-MERIT, at the DIMETIC training session 2008 in Strasbourg, at the Globelics Academy 2009 at ISEG/UTL in Lisbon, at the Globelics Conference 2010 in Kuala 
Lumpur, and at the Montreal Aerospace conference in 2011. I am especially thankful to Laurent Bach, Jose Cassiolato, Manuel Mira Godinho, Gabriela Dutrénit, Alexander Vera Cruz, Jorge Niosi and Sunil Mani. I remain indebted to the late Angus Maddison for his inspiring ideas and comments on drafts, and for helping me with compiling historical statistics. I regret he couldn't see the end result. I am thankful to Thomas Scheetz and Ricardo Runza for their comments and for readily sharing their vast knowledge on the Argentine case study. Any mistakes are, of course, my own.

I would like to thank the members of the reading committee, Robin Cowan, Gerlach Cerfontaine, Ernst Homburg and Franco Malerba for their ideas and suggestions, and for approving this thesis.

Every time I entered the gate in the hidden corner of Keizer Karel(pseudo-)plein and left my bike at the mercy of pigeons, I was happy to find a genuinely international atmosphere welcoming me at UNU-MERIT. Throughout the various metamorphoses of the buildings what remained constant were the outstanding people from all continents. I learned at lot from discussions at seminars, conferences or corridor talks from Théophile Azomahou, René Belderbos, Robin Cowan, Geert Duysters, Micheline Goedhuys, René Kemp, Pierre Mohnen, Shyama Ramani, Gerald Siverberg, Luc Soete, Bart Verspagen and Thomas Ziesemer. I am also grateful to Can Huang, Michiko Iizuka, Jojo Jacobs, Bulat Sanditov, Lili Wang and Marco Capasso for always being available to exchange ideas or help in other ways. I am particularly thankful to Hugo Hollanders for taking me onboard a research project on the aerospace industry which allowed me some extra-time, and thanks to whom I already have an exciting job at the time when I am finishing the PhD.

To Eveline in de Braek, Wilma Coenegrachts, Monique Raedts, Mark Vleugels, Mourik Jan Heupink, Herman Pijpers and Eric Engelen: hartelijk bedankt for the continued support from the background. To Ad Notten: thanks for helping me dig up books from hidden corners of the world, and for the critical interpretation of the phenomena some call the 'Dutch way of life'.

$\mathrm{A} \mathrm{PhD}$ is a lengthy transition from student life to grown-up life. I found this quite appealing already at the beginning. But this theory would not have been justified without all the friends I found in the town I slowly learned to love: in the PhD Factory, the Ivory Tower, at The Coffee Machine and other mythical places where the Merit Spirit lives, in the uninviting corridors of Teikyo, at $\mathrm{PhD}$ academy events, in initially smoky Maastricht bars, at birthday parties, at Asel's, at Flavia's, or at Guillaume's next door. You all know who you are - Thanks! I really hope we can stay in touch, even in a future when facebook will be history. The hardships of Factory life were always softened by the presence of amazing co-workers. Thanks to Flavia Carvalho (for the cakes and for keeping spirits high), Nora Engel (for the quotes and for reminding me that technology is not just airplanes), to Shuan SadreGhazi (for always being there, till the very end), to Bilal Mirza (for the chats and for the language course), to Thanh Le Phuoc (and the Dog on the desk) and to Ibrahim Bolat (for the deep discussions). It was nice to share time 
and AH-cookies with all of you!;) The constant global flow stimulated social life at MERIT. Knowing that there are so many friends to keep in touch with is a great reward for all the struggles. Therefore, thanks to... Abraham Garcia, Semih Akçomak, Fernando Santiago, Ezekiel Tacsir, Asel Doranova, Zakaria Babutsidze, Sergey Filippov, Donatus Ayitey, Evans Mupela, Tina Saebi, Noi Kwanjai, Alexis Habiyaremye, Marion Motari, Kirsten Haaland, Lina Sönne, Radhika Perrot, Saurabh Arora, Branka Urem, Hezekiah Agwara, Ivan Kulis, Lilia Stubrin, Jun Hou, Anant Kamath, Rodolfo Lauterbach, Ying Zhang, Muhammad Shafique, Jinjin Zhao, Kirsten Wiebe, Baseer Qazi, Iman Rajabzadeh, Conrad Schmidt-Bens, Francesca Guadagno, François Lafond, Alejandro Lavopa, Jocelyn Olivari, Daniel Opolot, Tatevik Poghosyan, Giorgio Triulzi, Eduardo Urias, Michael Verba; to the special guests at MERIT, Luciana Marins, Maurizio Cortesi, Claudio Fassio; and to the 'newly-merited': Ilire Agimi, Luciana Cingolani, Andrea Franco, Metka Hercog, Paula Nagler, Cheng Ong. Cohorts and schools all blend into one. I am very proud to join the list of graduates at the back of the book, hope all the others will follow soon! I'm also grateful to Norman Dytianquin for the opportunity to experience PBL and join the faculty for a short time. (Speaking of SBE, I enjoyed playing games with game theorists from my country, Helga Habis and Péter Csóka.)

To all the fellow young scholars searching for the meaning of 'innovation', 'networks' or 'knowledge', counting patents, or are busy running regressions and simulations: I enjoyed learning from you under the influence of Dimetic spirit or the banner of Globelics. I hope to keep on learning from you as you all become Big Fishes.

When I started the PhD in Maastricht, I was sure I'll stay out of student organizations. I'm glad it didn't happen that way. I am thankful to Saskia Bonjour, Mariolina Eliantonio, Kees Saarloos and Gjalt-Jorn Peters for integrating me into another kind of Maastricht PhD life. Further down this road, I enjoyed working with fellow board members (Erik Pot, Adrienne Goebbels, Siu Hing Lo, Stephanie van Nispen and Marco Zinzani) and other volunteers of $\mathrm{PhD}$ Academy. It was good to achieve short term goals while being obsessed with a long term one. Regrettably, I hardly write in Dutch. Thanks to Stephanie van Nispen, Nico Rasters and Antoine Simons for translating the summary and to Eddy and Eveline for the proofreading.

Of course, it all began in Budapest. I am grateful to Professors András Blahó, Benő Pemete and Mihály Simai for supporting me to embark on this international research trajectory.

It goes without saying that special thanks go to my family. They learned to live with my absence, kept me going by reminding me to finish, but constantly supported me in their own different ways. In particular, thanks to my parents, Anna and Gyula, thanks to Vizs, and my sister Juli (and her dog)! Most of all, many many thanks to Kinga, who stood by me even after experiencing this thesis-life, patiently waiting for me to finish just one more sentence, or paragraph, or draft. Even if she knew it would be endless.

Ispra, August 2011 


\section{Acronyms}

ACAC AVIC-I Commercial Aircraft Company (P.R. China)

AIA Aerospace Industries

Association (USA)

AMC Area de Material Córdoba

(Argentina)

ASM Annual Surveys of

Manufacturing

A-Star Agency for Science, Technology and Research

AVIC Aviation Industries of China

BEA Bureau of Economic Analysis

BNDES Brazilian Economic and Social Development Bank

BRL Brazilian reais

CAGR compound annual average growth rate

CAP Aeronautical Company of Sao Paulo (Brazil)

CASA Aeronautical Manufacturing Company (Spain)

CATIC China National Aero-

Technology Import and Export

Corporation

CEE Central and Eastern Europe

CGS Cost of goods sold

CIR Current Industry Reports

CIS Community of Independent

States

CNAE National Classification of Industrial Activities of Brazil

CNBS Chinese National Bureau of Statistics

COMAC Commercial Aircraft

Corporation of China

CTA Aerospace Technical Center (Brazil)

DINFIA National Directorate for Aeronautical Production and Research (Argentina)

EADS European Aeronautic Defence and Space Company
EAY Ypiranga Aeronautical

Enterprise (Brazil)

EDB Economic Development Board (Singapore)

ERJ Embraer Region Jets

EX Exports

FAA US Federal Aviation Authority

FAB Brazilian Air Force

FAdeA Argentine Aircraft Factory

FAMA Argentine Aeronautical Materials Factory (Argentina)

FGV Getulio Vargas Foundation (Brazil)

FMA Military Aircraft Factory (Argentina)

GDP Gross Domestic Product

GE General Electric

GERD Gross expenditure on Research \& Development

GGDC Groningen Growth and Development Centre

Globelics Global Network for Economics of Learning, Innovation, and Competence Building Systems

GO gross output

IAe Aero-technical Institute (Argentina)

IAe Indonesian Aerospace (Indonesia)

IAME Aeronautical and Mechanical Industries of the State (Argentina)

IBGE Brazilian Institute of Geography and Statistics

ICOP International Comparison of Output and Productivity

ICT Information and Communication Technologies

IMF International Monetary Fund

IPD Research and Development Institute (of CTA, Brazil) 


\begin{tabular}{|c|c|c|c|}
\hline IPTN & $\begin{array}{l}\text { Nusantara Aircraft Industry } \\
\text { (Indonesia) }\end{array}$ & $\begin{array}{l}\mathrm{R} \& \mathrm{D} \\
\mathrm{RCA}\end{array}$ & $\begin{array}{l}\text { Research and Development } \\
\text { Revealed Comparative }\end{array}$ \\
\hline IS & innovation system & & Advantage \\
\hline ITA & $\begin{array}{l}\text { Aeronautics Technology } \\
\text { Institute (Brazil) }\end{array}$ & RSAF & $\begin{array}{l}\text { Republic of Singapore Air } \\
\text { Force }\end{array}$ \\
\hline LAPIP & $\begin{array}{l}\text { Preparatory Agency for } \\
\text { Aviation Industry (Indonesia) }\end{array}$ & $\begin{array}{l}\text { SA } \\
\text { SAI }\end{array}$ & $\begin{array}{l}\text { Sales } \\
\text { Singapore Aircraft Industries }\end{array}$ \\
\hline LIPNUR & $\begin{array}{l}\text { Nurtanio Aviation Industrial } \\
\text { Institution (Indonesia) }\end{array}$ & SAMCO & $\begin{array}{l}\text { Singapore Aerospace } \\
\text { Maintenance Company }\end{array}$ \\
\hline LMAASA & $\begin{array}{l}\text { Lockheed Martin Aircraft } \\
\text { Argentina S.A. }\end{array}$ & $\begin{array}{l}\text { SASCO } \\
\text { SIA }\end{array}$ & $\begin{array}{l}\text { Singapore Aviation Services } \\
\text { Singapore Airlines }\end{array}$ \\
\hline MBB & $\begin{array}{l}\text { Messerschmitt-Bölkow-Blohm } \\
\text { (Germany) }\end{array}$ & SIPRI & $\begin{array}{l}\text { Stockholm International } \\
\text { Peace Research Institute }\end{array}$ \\
\hline $\begin{array}{l}\text { MIC } \\
\text { MRO }\end{array}$ & $\begin{array}{l}\text { military-industry complex } \\
\text { Maintenance, repair and }\end{array}$ & SITC & $\begin{array}{l}\text { Standard International Trade } \\
\text { Classification }\end{array}$ \\
\hline n.a. & $\begin{array}{l}\text { overhaul } \\
\text { not available }\end{array}$ & SSI & $\begin{array}{l}\text { Sectoral System Of } \\
\text { Innovation }\end{array}$ \\
\hline NAICS & $\begin{array}{l}\text { North American Industry } \\
\text { Classification System }\end{array}$ & STAN & $\begin{array}{l}\text { Structural Analysis Database } \\
\text { of the OECD }\end{array}$ \\
\hline NSTB & $\begin{array}{l}\text { National Science and } \\
\text { Technology Board (Singapore) }\end{array}$ & UN Comtra & $\begin{array}{l}\text { leUN Commodity Trade } \\
\text { Statistics Database }\end{array}$ \\
\hline OECD & $\begin{array}{l}\text { Organisation for Economic Co- } \\
\text { operation and Development }\end{array}$ & UNCTAD & $\begin{array}{l}\text { United Nations Conference } \\
\text { on Trade and Development }\end{array}$ \\
\hline OEW & operational empty weight & UNDP & United Nations Development \\
\hline PAP & $\begin{array}{l}\text { People's Action Party } \\
\text { (Singapore) }\end{array}$ & UNIDO & $\begin{array}{l}\text { Programme } \\
\text { United Nations Industrial }\end{array}$ \\
\hline PEIAB & $\begin{array}{l}\text { Embraer Programme for the } \\
\text { Expansion of the Brazilian } \\
\text { Aerospace Industry }\end{array}$ & UNU-MER & $\begin{array}{l}\text { Development Organization } \\
\text { TUnited Nations University } \\
\text { Maastricht Economic and }\end{array}$ \\
\hline PIA & $\begin{array}{l}\text { Annual industrial survey of } \\
\text { Brazil }\end{array}$ & & $\begin{array}{l}\text { Social Research Institute on } \\
\text { Innovation and Technology }\end{array}$ \\
\hline PLA & $\begin{array}{l}\text { People's Liberation Army (P.R. } \\
\text { China) }\end{array}$ & $\begin{array}{l}\text { USD } \\
\text { UVR }\end{array}$ & $\begin{array}{l}\text { US dollars } \\
\text { unit value ratio }\end{array}$ \\
\hline PLAAF & $\begin{array}{l}\text { The Air Force of the People's } \\
\text { Liberation Army (P.R. China) } \\
\text { purchasing power parity }\end{array}$ & $\begin{array}{l}\text { VA } \\
\text { WDI }\end{array}$ & $\begin{array}{l}\text { value added } \\
\text { World Development } \\
\text { Indicators of the World Bank }\end{array}$ \\
\hline
\end{tabular}




\section{List of Tables}

Table 2.1 Overview of major new-to-the-world innovations in civilian aircraft. .32

Table 3.1 Conversion Ratios for the benchmark year 2000 (UVRs and PPPs, local currencies / USD)

Table 3.2 Performance of the aerospace manufacturing industry, 1960-2007 (Million USD at constant 2000 prices) . .51

Table 3.3 Value Added in Aerospace Manufacturing, 1960-2007 (Million USD at constant $=2000$ prices) .57

Table 3.4 Gross output of aerospace manufacturing, 1960-2007 (Million USD at constant $=2000$

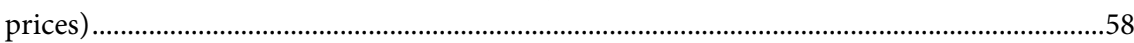

Table 3.5 Aerospace value added changes, 1960-2007 (compound growth rates, \%).......................64

Table 3.6 Value added as \% of US value added, 1960-2007 (compound growth rates, \%) ..............65

Table 3.7 Employment in Aerospace Manufacturing, 1960-2007 (thousands) ..................................67

Table 3.8 Major Regions' share in global aerospace employment (\%)................................................68

Table 3.9 Labor Productivity in Aerospace Manufacturing, 1973-2007 (Thousand USD per person engaged at constant $=2000$ prices) ...........................................................................

Table 3.10 Labor Productivity in Comparison with the US Levels (USA = 100) .................................73

Table 3.11 Changes in comparative labor productivity levels relative to the USA, 1960-2007 (compound growth rates, \%) ....................................................................................................

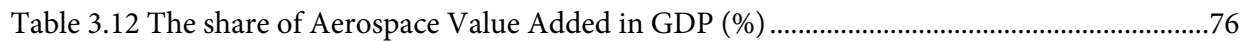

Table 3.13 Global Distribution of Aerospace Exports (Million USD at constant 2000 prices).......79

Table 3.14 Export of Aircraft and Spacecraft Parts and Components, 2007 (Million USD at

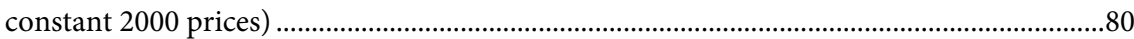

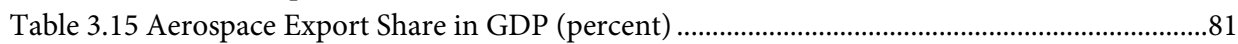

Table 3.16 Revealed Comparative Advantage (RCA) in Aircraft ........................................................83

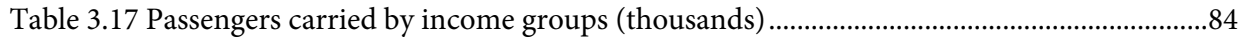

Table 3.18 Growth of Air Traffic in Selected Countries (million passenger-kilometers) .................84

Table 3.19 Passengers Carried by Countries of Departure, Selected Emerging Economies and the

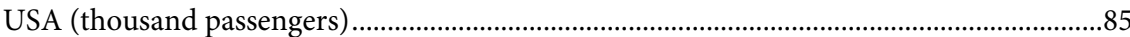

Table 3.20 Growth of Air Traffic: Registered Carrier Departures, 1960-2007 (thousands) .............87

Table 3.21 Demand Forecast for New Aircraft by Major Manufacturers.............................................8

Table 3.22 Top 25 Aerospace Producer Companies and Countries, 2007 (Values are in USD millions at constant $=2000$ prices)

Table 4.1 Industrial Census Information on the Aerospace industry and Commercial Aircrafts (2005)

Table 4.2 Supplementary Data on list prices and output value of commercial aircraft produced in

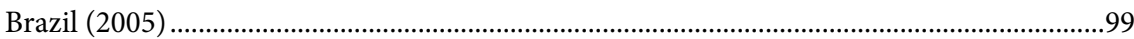

Table 4.3 Supplementary Data on List Prices and Output Value of Aircraft Produced in the United States (2005) 101

Table 4.4 Results of Quantity and Unit Value Adjustments for the Production of 100-Seat Equivalent Aircraft (100SE) in the USA ............................................................................. 105

Table 4.5 Results of Quantity and Unit Value Adjustments for the Production of 100-seat equivalent Aircraft (100SE) in Brazil 106 
Table 4.6 Brazil-USA Product Matching for Calculating Unit Value Ratios ................................ 107

Table 6.1 First series production of airplanes in Brazil, 1936-51 ................................................... 132

Table 6.2 The main products of Embraer...................................................................................... 149

Table 6.3 Main indicators on the national innovation system of Singapore, 1990-2009 ............. 179

Table 6.4 Major local assembly and upgrading projects at ST Aerospace (1974-2007) ................ 182

Table 6.5 Growth of passenger and cargo air traffic in Singapore, 1973-2006 ............................ 182

Table 6.6 General Statistics of the Singapore Aircraft Industry (1977-2007) ............................... 187

Table 6.7 Argentina's Aerospace production in comparison, selected years (USD mln at constant

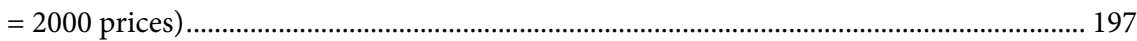

Table 6.8 Name and size changes of the aircraft manufacturing plant of Córdoba....................... 198

Table 6.9 Serial Aircraft Production in Argentina ............................................................................... 200

Table 6.10 Stock of aeronautical engineers in Argentina (1950-2007) ....................................... 202

Table 6.11 Military aircraft import to Argentina (1950-2009) ......................................................... 208

Table 6.12 Main features of the Guarani II in comparative perspective......................................... 210

Table 6.13 Key financial data of IPTN, 1976-89, compared with the first years of Embraer ........ 224

Table 6.14 Number of aircraft and helicopters delivered by IPTN (1975-98) .............................. 225

Table 6.15 Key performance characteristics of IPTN's and competing aircraft ............................ 2228

Table 6.16 IPTN's machinery for aircraft manufacturing................................................................ 234

\section{List of Figures}

Figure 3.1 Schematic evolution of the global aerospace industry .53

Figure 3.2 Value added in aerospace by major country groups, 1955-2007 (Million USD at constant 2000 prices)

Figure 3.3 Trends in aerospace value added of country groups compared with the US, 1960-2007 (USA $=100 \%)$

Figure 3.4 Dynamics in catch-up vis-à-vis the US, 1990-2007........................................................66

Figure 4.1 Comparative Labour Productivity Trends in Aerospace in Brazil and the USA, 19702007 (1000 USD/Employee; constant prices 2000=100, 3-year moving average) ..... 109

Figure 4.2 Comparison of Labour Productivity Levels in Transport Equipment and Aerospace,

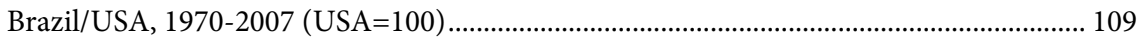

Figure 4.3 Gross output and value added in the Brazilian aerospace industry, (1996-2002; BRL millions at constant $=2000$ prices)

Figure 4.4 The production cycle of the E-135/145 and E-170/190 families and gross output and value added in the Brazilian aerospace industry (1996-2007). 112

Figure 4.5 The evolution of sales and employment of Embraer and the Brazilian Aerospace industry excluding Embraer (1996-2007) ............................................................................. 114

Figure 5.1 Performance in a given innovation system.................................................................. 122

Figure 5.2. Radical Change of the Sectoral Innovation System: Transition .................................. 123

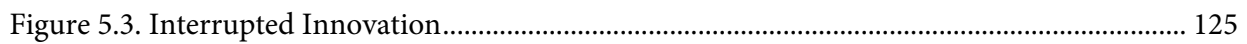

Figure 5.4. Interruption followed by successful transition to a new innovation system ............... 126

Figure 5.5. A learning trajectory: interruption and successful transition ..................................... 127

Figure 6.1 The evolution of aircraft production in Brazil, 1936-2010 ........................................ 135 
Figure 6.2 Embraer's sales, exports and number of employees, 1970-2007 (Million USD at constant $=2000$ prices)

141

Figure 6.3 Trends of catch-up: aerospace value added of Brazil, China and Indonesia compared to the US, 1970-2007 (\%) 142

Figure 6.4 R\&D Expenditure and R\&D intensity of Embraer, 1983-2007 (Million USD at constant $=2000$ prices) 144

Figure 6.5 Number of patents in the field of aerospace granted by year of application (1974-2007) 145

Figure 6.6 Aerospace industry Value Added in Brazil, China and Indonesia, 1970-2007 (Million USD at constant $=2000$ prices) 150

Figure 6.7 The interrupted trajectory of the development of the Brazilian aerospace industry (1930s-2007) 152

Figure 6.8 Estimated Chinese Jet Fighter Production, 1960-1995 ................................................ 160

Figure 6.9 Military aircraft export from China, 1960-2008 ……………......................................... 160

Figure 6.10 Export of Chinese Military and Commercial Aircraft, 1955-2008 (USD Millions, Constant $=2000)$ 164

Figure 6.11 R\&D Expenditure and R\&D per Sales in Chinese Aerospace Industry, 1995-2007

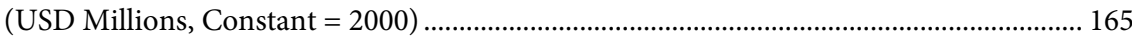

Figure 6.12 Patent statistics of aerospace enterprises .................................................................... 166

Figure 6.13 The structure of the Chinese aircraft industry in 2008 ................................................ 167

Figure 6.14 Employment and Labour Productivity Growth in the Chinese Aerospace Industry, 1995-2007 (Thousand USD at constant $=2000$ prices) ........................................................ 168

Figure 6.15 Interruptions and transition in the Chinese aircraft innovation system ..................... 174

Figure 6.16 Gross Output, Value Added and Employment in the Singapore Aerospace Industry, 1977-2007 183

Figure 6.17 Maintenance, repair and overhaul revenues of ST Aerospace and Singapore Airlines Engineering, 1996-2008 190

Figure 6.18 The National Innovation System of Singapore - R\&D Expenditures, 1981-2009 ...... 191

Figure 6.19 Radical innovation system change in Singapore's sectoral innovation system in Aerospace 194

Figure 6.20 Comparison of annual production of commuter-size aircraft by FMA, Embraer and Nurtanio (first 20 years of production) 211

Figure 6.21 Argentine Military Expenditures, in millions of constant (1970) Australs (1969-1987)

Figure 6.22 The Emergence of the Argentine Aerospace innovation system ................................. 218

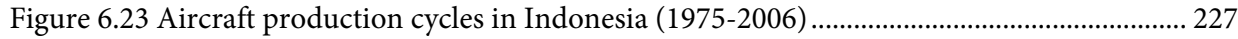

Figure 6.24 Comparison of cumulative aircraft production in Spain and Indonesia ..................... 229

Figure 6.25 Emergence of the Indonesian aerospace innovation system ....................................... 238

Figure 7.1 The evolution of the global aerospace industry, 1970-2007 (value added, USD millions

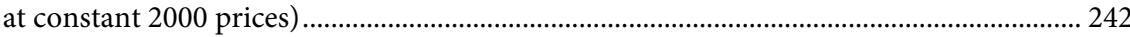

Figure 7.2 Parallel evolution of emerging aerospace industries in 4 selected countries.................. 243 


\section{CHAPTER 1}

Introduction

The global division of labor is in constant change as countries dynamically acquire new technological capabilities. Many Asian countries that were relatively latecomers in industries such as semiconductors, electronics, pharmaceuticals or automobiles have become globally competitive producers. Their growth trajectories, industrial and innovation policies have been at the center of scholarly attention (Amsden 1989, 2001; Fagerberg 2000; Hobday 1995, 2003; Kim 1980, 1997, 1998; Kim and Nelson 2000; Lee and von Tunzelmann 2005; Mathews 2002; Westphal 2002). The accelerated growth in high-tech industries and their effects on economic and social development in these countries offered interesting cases for revisiting old debates on industrial as well as science and technology or higher education policies. In this context it is surprising how little similar systematic work has been done on the aerospace industry, despite the fact that hardly any other sector offers as much scope for policy debate as aerospace.

There is plenty of evidence of advanced aircraft manufacturing capabilities in emerging economies. The world's third largest producer in terms of commercial aircraft is Embraer of Brazil. Hundreds of their ERJ regional jets are flown by airlines from all continents. Structural parts of the Boeing and Airbus planes we fly today are made in various locations around China, India or Singapore. The maiden flight of the Chinese made ARJ-21 regional jet made it to the front pages around the world in late 2008, but so did the Indonesian-built N-250 twin-propeller in the 1990s or Embraer's Bandeirante and Brasilia commuters in the 1970s and 1980s. There are similar achievements in space technology. The first Chinese satellite launched in 1970 transmitted the song the "East is Red". In the framework of the Shenzhou program, China became the third country to accomplish a manned space mission in 2003. The Polar Satellite Launch Vehicle of the Indian Space Research Organization has successfully put dozens of satellites into orbit. Both China and India have succeeded in sending spacecraft into lunar orbit.

Many of the countries that at one point in time realized prestigious aerospace projects could not keep up the momentum. Amidst changing technological, market and geopolitical conditions, only a few sustained continuous innovation. The history of the aerospace industry in emerging economies is littered with failed massive investment 
projects. Continuous financing of these projects were often associated with corruption and war-mongering. At the same time, nurturing successful achievements requires continued support. The technology intensity of the industry alone demands the existence of complex local technological capabilities, and make the lead time to realize a prototype and to start commercialization long. It follows that sustained learning and innovation is crucial to realize the high-value-added production potential the industry offers. If we focus at aerospace manufacturing as an industrial activity, we have to distinguish a first successful flying prototype from a serially produced model, the test design of parts and components from those that have already been certified and incorporated on a serially produced plane. These latter products will have the real economic impact as innovations. These may be less visible achievements, but these are potentially the real sources of growth for aerospace producing economies, emerging and industrialized alike.

The three key themes that will be discussed in this book are the following:

(1) latecomer industrialization in aerospace;

(2) accumulation of technological capabilities and innovation in emerging aerospace producers; and

(3) the sustainability of growth in the industry.

\subsection{The purpose of the study}

This study aims at exploring and explaining success and failure in the development of latecomer aerospace industries in emerging economies. What distinguishes this study from previous work is the comparative analysis of latecomer development trajectories, and the combination of a long-run view on both industrial dynamics and radical and incremental sectoral innovation system changes. Past analyses with rich insights into innovation in the sector have been hampered by a lack of comprehensive longitudinal statistical data. Based on primary sources and secondary literature, this study provides a statistical overview of the evolution of the aerospace industry in over 40 countries over a period of over 40 years. In the past, explorative studies on aerospace industries have benefitted from the sectoral systems of innovation approach. This research aims at comparing successful and failed catch-up trajectories in light of sectoral innovation system dynamics. Therefore, the following research questions are scrutinized in the study:

1. What are the characteristics of the evolution of the global aerospace industry in the second half of the $20^{\text {th }}$ century in terms of value added, gross output, employment and exports? 
2. What sectoral development trajectories in aerospace characterized latecomer economies?

3. How did sectoral innovation systems emerge and evolve in successful and failed cases of latecomer industrialization in aerospace?

Answering the first question also sheds light on any geographical redistribution of global aerospace manufacturing and how the emergence of new aerospace producers affected incumbents in North America and Western Europe. It also reveals instances of accelerated growth and catch-up in the long term. Investigation into the second question provides insights into the dynamics of technological capabilities accumulation and industrial development in a broad context in selected emerging economies. In connection with the third question, this study intends to provide a better understanding of the co-evolution of the institutional framework, technological capabilities, innovation and industrial production. Finally, the purpose of this research is to understand what happened in the past. By no means does it intend to offer a 'do-it-yourself manual' for developing an aerospace industry. Nevertheless, understanding the history can inform future policy makers and managers on best practices to follow or failed strategies to avoid, within a given environment.

\subsection{Research methods}

In the first part of the book, we develop and describe a comprehensive dataset for aerospace manufacturing. Time series of value added, output and employment for the sector are compiled from international and national statistical sources and complemented with data from the secondary literature. We calculate global aggregate output levels using industry-of-origin conversion ratios. These are available at the sectoral or branch level for benchmark years for many countries as a result of researches following the International Comparison of Output and Productivity (ICOP) methodology (discussed in Chapter 3). In the case of Brazil we provide an alternative calculation of unit value ratios for aircraft manufacturing using augmented output data.

In the second part we apply a national and sectoral innovation systems dynamics framework and analyze five case studies in order to investigate latecomer development trajectories in aerospace. The literatures on catch-up, on technological paradigm shifts or regime changes and on product and industry life cycles all identify two types of change in the long run. One is an incremental change, and the other is a radical change or acceleration. These two types of change also characterize the evolution of innovation systems over time. We develop a conceptual framework of "interrupted innovation" which captures radical changes in innovation systems in the long-run. We closely look 
at case studies of aircraft industries from five emerging economies and follow the patterns of the evolution of technological capabilities, innovation performance and industrial growth.

\subsection{Selection of the cases}

Our primary concern for selecting cases for in-depth study was to include not only countries where the emergence and growth of the industry was successful, but also cases where the industry languished after significant efforts had been made. Successful development was defined in terms of growth of value added in aerospace. The choice was rather straightforward as three countries stood out from the emerging economies group: China, Brazil and Singapore. These countries showed a huge variation in regional location, territorial size and product structure, but looked back to a relatively long history of industrial growth. Failed cases were selected to match the continental variation of the successful countries. Argentina was a neighbor of Brazil and started industrialization around the same time. Indonesia was a neighbor of Singapore and a country large enough to benefit from the development of an aircraft industry. Another selection criterion was the availability of a body of secondary literature.

To keep the book manageable, we decided to limit the number of cases to five. Three emerging economies with some tangible production results but relatively low output, India, Mexico and South Korea, are not covered. The reasons for not including India here are the rather low aerospace value added levels until 2007 and the overwhelming dominance of the space sector (Baskaran 2005; Mani 2010). Mexico presently has a rapidly growing parts manufacturing base and maintenance, repair and overhaul sector. This made the country an interesting case if one was interested in the emergence of a sectoral innovation system today, but it is less relevant for a long-run historical study. Finally, South Korea is not covered due to reasons of length; however, an insightful case study on the emergence of the industry via the diversification of heavy industries into aerospace is provided by Texier (2000).

\subsection{Some conceptual issues}

The focus of this study is the aerospace manufacturing industry. By definition, this excludes air transport services, but includes aircraft maintenance, repair and overhaul (MRO). These latter activities require engineering and technical skills which are also required for parts and components manufacturing or aircraft assembly, but are much less capital intensive and research intensive. They do require specialized education and training, but far less than manufacturing. Since a limited level of MRO work is carried 
out at every major airport, countries with no other production facilities seem to be aerospace producers due to this MRO-bias.

Aerospace manufacturing includes the manufacturing of aircraft and spacecraft, as well as their engines or propulsion units. In the global statistical overview we have no means to distinguish aircraft and spacecraft production within the aerospace industry. Nevertheless, since the space industry is not characterized by mass production, even in countries with space programs the largest part of aerospace value added originates from the aircraft segment. ${ }^{1}$ In the case studies we focus on the more narrowly defined aircraft manufacturing industries, which are more comparable across emerging economies.

The term innovation is central to this book. Following Schumpeter's definition, innovation includes new products, new production processes, new supply sources, the creation of new markets and new forms of business organization (Schumpeter 1934). These innovations can be new to the firm or new to the world. What is similar in all types of innovation is the combination of an element of invention as well as implementation. (This was highlighted earlier when we emphasized the difference between a prototype airplane and a production model). It is easy to realize that the aerospace manufacturing industry, which involves creating complex technologies, is full of innovation up to the point where it might lose its meaningfulness. Due to the complex, modular product structure that characterizes the aerospace industry, innovation can take place in various locations. For the aircraft maker a new product can be a new regional jet. For the component manufacturer that specializes in landing gear for aircraft, a new product is for instance a new shock-absorbing landing gear. The same logic applies for the tire maker and the fastener maker companies. Aggregate innovation at the sectoral level hence includes all these new technologies of different degrees of complexity. The more complex a product, the more learning it needs and the longer it potentially takes to diffuse the technology. These aspects also highlight that innovation itself is a creative process which has a time dimension and involves learning. Central to the entire innovation process is the interaction of ideas. Therefore, without a systemic view, the concept of innovation becomes meaningless. In this study we discuss aerospace innovation within a national and sectoral environment in which we can pay due attention to the actors involved, their interactions and the institutions that shape these interactions.

Finally, the use of the term catch-up in the context of this study requires some explanation. In the original economic growth context catch-up refers to a convergence of per capita income due to a relatively faster per capita income growth in poorer

\footnotetext{
${ }^{1}$ According to Chinese National Bureau of Statistics, spacecraft manufacturing accounted for an average of $10.5 \%$ of total aerospace value added between 2000 and 2006.
} 
countries than in richer ones (i.e. Abramovitz 1986; Szirmai 2005). Since this involves output growth acceleration due to the use of more advanced technologies (Fagerberg 1994), some authors also refer to catch-up in a sectoral context either as technological catch-up or as a convergence of market shares (e.g. Dalum et al 1999; Lee and Lim 2001). In this study we define catch up in terms of increasing value added shares in global aerospace. The rationale for this is that in an industry that demands hightechnology and high quality standards from producers, it is impossible to increase market share without technological catch-up.

\subsection{The structure of the book}

Following this introductory chapter, we provide a survey of the literature in Chapter 2. The chapter discusses theories of latecomer industrialization, technological capabilities and innovation system dynamics and studies of the aerospace industry in emerging economies. The glasses through which this book looks at industrial development are those of a social scientist. Yet since it deals with technological development, a section is added to the literature survey providing a general overview of paradigm shifts in aircraft technology and in the organization of production.

The rest of the book is divided into two parts. The first part looks at the evolution of the aerospace industry measured by value added, gross output, employment and exports. This reflects an understanding that in retrospect the ultimate measure of catchup in emerging economies and of sectoral innovation system performance is industrial value added growth. In Chapter 3 we describe the statistics we compiled on long-run production dynamics in the global aerospace industry. Global aggregation of output was made possible by the use of industry-of-origin conversion ratios wherever possible. In Chapter 4 we calculate new unit value ratios for the aerospace sector in a binary BrazilUSA comparison based on ex-factory price and quantity data using the International Comparison of Output and Productivity method.

The second part of the book takes a closer look at the development of the aerospace industry through the co-evolution of industrial actors, technological capabilities and institutions in specific country contexts. It takes a new perspective on learning and innovation processes occurring over a long time span from the first emergence of the industry through moments of acceleration and crises to sustained development or terminal stagnation. The framework of interrupted innovation is presented in Chapter 5. The framework is based on the conclusions from the literature review and allows for a historical overview of incremental and radical changes in the aerospace industry. In Chapter 6 we present five case studies of successful and failed industrial development from Latin America and Asia. Although with very different 
historical backgrounds, Brazil (section 6.1), China (6.2) and Singapore (6.3) all exemplify a successful emergence of the industry as well as successful radical innovation system transitions that led to accelerated growth. The cases of Argentina (6.4) and Indonesia (6.5) provide insights into failed development trajectories.

In Chapter 7 we provide an overview of the various development trajectories, and discuss the relevance of radical innovation system changes to tackle interruptions and achieve sustained growth in the industry. Based on a set of questions raised at the end of Chapter 5, we focus on the development trajectories, the interruptions and the nature of innovation system transitions. Finally we provide some policy conclusions. 



\section{CHAPTER 2 \\ Literature review}

\section{$2.1 \quad$ Introduction}

This section provides an overview of the literature on latecomer industrialization, technological capabilities and innovation systems. Its purpose is to identify the main theoretical foundations for a framework of analysis of latecomer industrialization in aerospace.

The literature review starts in section 2.2 with the old problem of technological learning and latecomer industrialization. The basic question that was raised: is there an advantage in being a latecomer? According to the Gerschenkronian tradition, being a latecomer country holds a potential. First movers have to pay the price of developing a new technology, test its applicability in practice, while latecomers can readily take the results and avoid the first movers' costs. As many examples from East Asia have shown, latecomers with lower production costs can indeed gain large market shares. But historical experience also shows that acquiring technology is not automatic, and is more than simply following a pre-written recipe. The second strand of literature we look at addresses the difficulties in accumulating technological capabilities and some of the actual disadvantages of latecomers (section 2.3). Many authors devised stage models to highlight the progress of technological learning in a variety of industries. The appropriateness of stage models for the analysis of latecomer aerospace innovation is examined in section 2.4. The following section (2.5) discusses the systems of innovation approach from a dynamic perspective. Section 2.6 provides a survey of the existing literature on innovation, technological change and economic growth in the aerospace industry both in countries at the technological frontier and in developing economies. Section 2.7 looks at another body of existing works. Here we focus on technological development in aerospace, which helps the reader better understand the "big picture", the major trends of technological change at the frontier since the 1950s. The summarizing section 2.8 provides an overview of the main conclusions of the literature review and highlights the questions so far unanswered.

\subsection{Latecomer advantages and how to benefit from them}

The idea that economic backwardness may be an asset for latecomer industrialization has been at the center of debates on economic development. Building on the work of 
Veblen $(1919)^{2}$, Gerschenkron (1962) argued that the more economically backward a country is, the greater "the opportunities inherent in industrialization" are. The idea behind this is that technologically backward countries can potentially apply existing technologies at much lower costs than the countries that developed them. Catch-up at the country level occurs as productivity increases due to more advanced technology and the per capita income difference narrows between leaders and followers. The larger the initial productivity gap (or the greater the distance to the technological frontier), the greater is the potential for growth. This happens because latecomers can enter directly into large-scale production in the most dynamic industries and take advantage of their lack of institutional inertia. The tension between the "great promise" of economic development demonstrated by the leading countries and the reality of stagnation is an important motivating factor for institutional change in the follower. However, due to institutional obstacles catch up cannot occur (such an obstacle was serfdom in Russia or the lack of political unity in Germany). In the $19^{\text {th }}$ century, in industrializing Russia state intervention compensated for (or substituted) the insufficient (or inadequate) physical, human and technological resources required to catch-up. Establishing appropriate institutions and organizations are crucial for the successful substitution of missing prerequisites. In Gerschenkron's examples these functions were provided by development banks in France, universal banks in Germany and government investment in infrastructure in Russia in the late $19^{\text {th }}$ century. ${ }^{3}$

The rapid development of many East Asian economies in the second half of the twentieth century (Hong Kong, Singapore, South Korea or Taiwan) testifies to the possibility of reaping latecomer advantages, providing evidence of dynamic developments at firm and sectoral levels in industries such as automobiles, electronics and semiconductors (Kim 1980, 1997, 1998; Kim and Nelson 2000; Fagerberg 2000; Hobday 1995, 2003; Amsden 1989, 2001; Mathews 2002; Westphal 2002). In a broader context, it was found that accelerated growth is achievable with latecomer industrialization. Fagerberg and Verspagen (1999) empirically showed that manufacturing had been an engine of growth in the late industrialization of East Asia and Latin America. Szirmai $(2005,2011)$ concluded that no developing country achieved successful economic development without industrialization.

\footnotetext{
${ }^{2}$ It should be noted that Veblen's view was in many ways sharply different from Gerschonkron's thesis, e.g. considering technology transfer as a more automatic mechanism possibly driven by market forces. (c.f. Fagerberg 2005)

${ }^{3}$ Another often cited example from post-World War II Japan is the Ministry of International Trade and Industry (MITI).
} 
Gerschenkron underlined the importance of removing institutional obstacles and establishing institutions and organizations to realize latecomer advantages. Latecomer firms actually also face some significant disadvantages. According to Hobday (1995), they are dislocated from technology sources as well as from advanced markets. ${ }^{4}$ It has remained a central problem in the literature on latecomer industrialization to identify the role of state and private actors in starting and carrying out the institutional changes, which can address these disadvantages. The same historical development paths of East Asian countries have been interpreted in very different ways depending on the spectacles observers were looking through. On the one hand, according to the neoliberal view summarized in a widely cited World Bank (1993) report 'The East Asian Miracle', the success of governments was their ability to provide a stable macroeconomic environment and to follow market-friendly policies. This entailed limited inflation, only limited appreciation of real effective exchange rate, only brief periods of import substitution industrialization, and earnings from exports motivating technological upgrading in trading sectors. Additionally, public measures were concerned with human capital formation, establishing openness to international trade and a strong bureaucracy that relied on contests when making selective supporting measures.

On the other hand, both sectoral level and macro level studies (Amsden 1989, 2001; Chang 1993; Hobday 2003; Wade 1990) found historical evidence of strong state intervention. Amsden (2001) showed that "getting the control mechanisms right" was the key to the successful "Rise of the Rest". Recently Chang (2003) and Cimoli et al (2009) have further argued (along the lines of Gerschenkron) that no backward country has ever developed without a relatively high degree of government intervention to facilitate technological accumulation and change the organization of production. Reinert (2009) showed how protecting infant industries in areas at the forefront of technological progress helped latecomers emulate the richer leaders of their time and reduce the asymmetries in knowledge and technological capabilities, and made technology transfer profitable. Only after some measure of parity is achieved could partners specialize and trade according to their comparative advantages and could (neo) colonialist structures be prevented. This reconfirms the theses of Friedrich List presented most notably in his 1841 volume 'The National System of Political Economy'. List also argued that latecomers need protectionist measures to raise infant industries

\footnotetext{
${ }^{4}$ On the other hand, Mathews $(2002,2006)$ optimistically argued that latecomer firms are not bound by organizational inertia. This allows them to shift quickly from being imitators to innovators, by benefiting of the ' 3 Ls': linkage, leverage, learning in the age of globalization, which enhances their dynamic capabilities. (Linking up to global value chains, offering lower costs and gaining access to knowledge, technology, or markets. The gains exceed their inputs, offering firms greater leverage. As they do this strategy in a sustained way, they learn.)
} 
and new competitors, because free trade hampered progress by freezing existing trading structure. $^{5}$

As latecomer industries mature over time, the need for interventions and the nature of interventions change as well. ${ }^{6}$ Gerschenkron interpreted the "the gradual diminution of backwardness" (infrastructural development and industrial growth) with the redefinition of the relationships between the German industry and development banks on the one hand and between the Russian state and the industry on the other hand. German enterprises were increasingly collaborating with a number of banks (including banks they established) as opposed to being subjected to one single bank. Following a reduction of state intervention in Russia, universal banks emerged to take on long-run investment financing. Notice that while the backwardness of a country was being reduced gradually, the change of interventions was not similarly gradual. On the contrary, state intervention in Russia at the turn of the $20^{\text {th }}$ century was reduced radically amidst depression and social unrest, as Gerschenkron presented it, but growth only followed after years of interruption.

It clearly remains puzzle for policy design how to deal with similar transitions. Lall (2004) argued that there is no uniform way. Intervention (industrial policies) needs to be selective, since learning depends on the complexity of technology, on the availability of information and extent of externalities. At the same time, policies need to learn as well. For the case of contemporary China, Gu and Lundvall (2006) showed how policy learning co-evolved with the development of industries. It is a question when interventions should be phased out or reduced.

The underlying assumption behind these arguments for protectionism is a dynamic understanding of competitiveness, which involves the possibility for latecomers to accumulate the technological capabilities that more advanced producing countries are applying are applying. Before entering into a more detailed discussion of the literature

\footnotetext{
5 "Any nation which by means of protective duties and restrictions on navigation has raised her manufacturing power and her navigation to such a degree of development that no other nation can sustain free competition with her, can do nothing wiser than to throw away these ladders of her greatness, to preach to other nations the benefits of free trade, and to declare in penitent tones that she has hitherto wandered in the paths of error, and has now for the first time succeeded in discovering the truth." (List 1841, Book 4, Ch.33, English translation by S.S. Lloyd, 1885.)

${ }^{6}$ The idea that infant industries can be protected as long as it is temporary has long been accepted by classical economist thinkers, such as J.S. Mill (quoted by Lall 2004, note 20). Neoclassical economics argues that protection is not justified anymore when a decrease in the long-term average costs causes no more losses for producers. Theory leaves the question open how to manage the transition from a state of protection to a state of no protection.
} 
on technological capabilities in section 2.3, we make a detour to address an often neglected question with regard to latecomer entry.

\subsubsection{The timing of latecomer entry}

Does the timing of entry into a new industry matter? There are three reasons why timing matters. First, the nature of competition and characteristics of innovation varies over an industry's life cycle (Abernathy and Utterback 1978; Utterback and Abernathy 1975; Gort and Klepper 1982; Malerba and Orsenigo 1996a; Klepper 1996, 1997). In these models, barriers to entry are usually lower at the initial phases of an industry's development, but there is uncertainty about market demand and potentials of technological improvements. Despite the easier access, companies in developing countries with lower levels of technological capabilities face a disadvantage, because the codification of technology is low at this 'fluid' early stage. High capital and technological entry barriers keep firms from developing countries away from entering at an early stage. On the other hand, when a dominant design has emerged and the industry is more consolidated, high concentration of powerful market actors can virtually impede new entry. In spite of this, successful latecomers from emerging economies have usually entered the industry in the mature phase. Hobday (1995) showed how latecomer firms made use of the price competition during latter stages by focusing on process innovation as opposed to product innovation. Perez and Soete (1988) brought this idea further by suggesting that rather than looking implications of life-cycles of products seen as independent radical innovations, technological paradigms should be the guiding posts for identifying "windows of opportunities" for latecomers. Latecomers that developed capabilities to produce products according to a previous paradigm will at a later point have to pay the price of unlearning vintage technologies and re-learning new ones. They can, however, take advantages of learning while everybody else is learning and entering while the threshold is lower at the onset of a new paradigm. The authors acknowledge that a certain level of existing knowledge and resources are necessary to make use of the opportunities. This suggests that the question is two-fold: timing may matter not only with regards to entry, but also with regards to responding fast to a changing paradigm and redefining the growth trajectory.

Second, similar windows of opportunities may exist from an institutional point of view. Timing, we argue, matters because the global political landscape and international trade regimes changed over time and as do the volume and pattern of international trade. All these changes influence the potential of firms to access technology and information as well as the channels through which they can learn. With the emergence of the regulation on tariff and non-tariff barriers, intellectual property 
rights and new quality standards, technological learning of firms from developing countries has changed significantly even over the last fifty years. In short, countries starting the catch-up process now face a different environment than those starting in the fifties and sixties.

Finally, in light of these changes the ability of governments to devise and implement supportive policies has also been changing. The volume of trade realized within different units of transnational corporations has increased exponentially (UNCTAD 1997, 2009). The significance of borders is clearly diminishing. International political scientists have highlighted a power shift from central governments to a variety of domestic and foreign social and economic actors (Mathews 1997). Both political and economic developments increased the interdependencies between all these actors have increased, which in turn also increased the complexity of governance tasks (i.e. Rosenau 1997; Simai 1994; Skolnikoff 1993). Yet, at the same time governments have new tools to tackle the increased challenges. For instance, the diffusion of information and communication technologies (ICTs) offers a greater potential to oversee cross-border factor flows and achieve governance outcomes more efficiently (OECD 2003). We conclude that the broader political economic context in which catch-up latecomer industrialization takes place potentially affects its course and pace.

\section{$2.3 \quad$ Technological capabilities}

The Gerschenkronian growth potential notwithstanding, the economic backwardness of latecomers is a source of disadvantages in terms of capabilities. Leading producers can already benefit from scale economies, have access to advanced markets, and also have the power to influence suppliers. They can do so because of their mastery of technologies. They have also mastered the knowledge of how to develop new, commercially applicable technologies that can sustain their leading position on the technological frontier. According to Ames and Rosenberg (1963), the lack of latecomers' technological capabilities gives them a disadvantage which may outweigh other potential advantages described earlier. Using empirical data on structural change and comparative levels of total factor productivity, Timmer (2000) showed that investments do not necessary lead to catch-up if they are not associated with the assimilation of more advanced technology. This proved the argument of Nelson and Pack (1999) that rapid development requires not only capital (including human capital) investment, but also learning about and learning to use new technologies, as well as entrepreneurship and innovation.

For neoclassical economists, technology was an exogenous resource, or 'manna from heaven', which producers could directly acquire and apply, 'transfer' from one 
country to another. In this simple and abstract scheme previous experience in the use or creation of technologies did not matter. However, seminal studies on the nature of knowledge and technology point out the tacit element of knowledge (Polanyi 1967), the importance of learning by doing (Arrow 1962) and of the historical and institutional embeddedness of technology (Rosenberg 1982). Consequently, if a latecomer producer decides to apply already existing machinery or methods of production, they not only have to invest in acquiring the machines and the training to operate them, but a 'receptive soil' is also required in order to assimilate the technologies. In contrast with the neoclassical view, evolutionary economics offers a 'learning-friendly' explanation of the processes the creation, assimilation of technology in economic processes (Nelson and Winter 1982; Dosi et al. 1988). The evolution of the concept of technological capabilities should be viewed against this changed intellectual context.

Abramovitz (1989) argued that the realization of the potential for catch-up in a latecomer depends on how advanced its 'social capabilities' are. Hence the difference in the age of technologies across countries will not lead to more rapid growth in the follower unless there is technical competence (educated human resources) as well as physical infrastructure and appropriate political, commercial, industrial and financial institutions. These are not static but change over time in an interactive way, should a technological opportunity arise. Several other authors have also attempted to specify the most important capabilities for catch-up. For Dahlman et al. (1987) technological development required production, investment and innovation capabilities. Hobday (1995) found production and innovation capabilities to be crucial for development. Cohen and Levinthal (1990) argued that firms' innovative capabilities are influenced by their 'absorptive capacity', the ability to evaluate, assimilate and apply knowledge that is new to them. Lall (1992) made a distinction between technological capabilities at the firm level and at the national level. At the firm level, successful commercial operation depends on investment, production and linkage capabilities, as well as on the national institutional environment and infrastructure. Development, or capability accumulation at the national level is the outcome of an interplay of national technological capabilities (physical investment, human capital and technological effort), incentives (macroeconomic or competitive and the efficiency of factor markets) and institutions (including market and non-market ones).

Bell and Pavitt (1993) distinguished technological capabilities from production capabilities at the firm level based on the resources used to produce industrial goods 
from those needed to generate and manage technological change. ${ }^{7}$ In practice, however, such a distinction is less than straight-forward, but it may help recognize the need to investment into technology accumulation in developing countries. Archibugi and Coco (2005) acknowledged that at the macro level technological and production capabilities were interdependent. Nevertheless, they attempted to separate them in order to compare composite technological capabilities indicators of the World Economic Forum, UNDP, RAND and their own ArCo index. The rank correlation showed that although there was a general agreement on the main components of the indices, different methods of weighting and aggregation made a significant difference. Measurement is nevertheless important if it can provide an indicator for technology accumulation. Nevertheless, Bell (2006) pointed out that the time dimension of the accumulation process has remained under-researched.

As the concept of technological capabilities broadened in scope, it became more ambiguous. Fagerberg and Srholec (2008) applied factor analysis to identify the factors in overlapping 'capability' concepts to highlight four groups of indicators that matter most for economic development. Their results point to the importance of capabilities associated with innovation ("innovation system") and governance.

\subsubsection{Technological capabilities, stage models, and their relevance for the aerospace industry}

It follows from the preceding argument that catch-up by latecomers is not possible without the accumulation of technological capabilities, which is a learning-intensive process. Gerschenkron already pointed out the role of locally existing technological knowledge, or, even more, innovative activities. ${ }^{8}$ Lall $(2001,2004)$ argued that there is a potential for underinvestment in advancing capabilities in developing countries, because technological learning is risky and unpredictable. Learning only succeeds if firms do it deliberately, but firms possess imperfect information and knowledge about the technological alternatives from which they can choose. There are several domestic and foreign channels through which learning can take place (through interactions with customers, input suppliers, technology institutes, universities, consultants, competitors), as well as several levels within an organization or in an industry. Once a minimum level of know-how to perform industrial activities has been acquired, there are also different

\footnotetext{
${ }^{7}$ See also Dutrénit (2004) on capabilities accumulation over time in latecomer firms, or Romijn (1999) for an overview on the use of the technological capability concept, on capability building and its importance in economic development.

8 "What makes it so difficult for an advanced country to appraise properly the industrialization policies of its less fortunate brethren is the fact that, in every instance of industrialization, imitation of the evolution in advanced countries appears in combination with different, indigenously determined element." (Gerschenkron 1962, p.26)
} 
learning paths to follow, depending on how much firms invest in learning. In short, firms need to learn the process of learning. At the industry level, since firms do not operate in isolation, their interactions with their environment at various levels offer externalities of learning and capabilities accumulation. The outcome of capability accumulation at the firm level will be catch-up at the sectoral or national level.

Observers of the successful catch-up of latecomers to high-tech industries in Southeast Asia have pointed out commonalities in the various learning trajectories. ${ }^{9}$ There is a rich literature on stage models that explain catch-up of successful latecomers by their ability to progressively reach technologically more advanced stages of production.

In the model of Kim (1980), South Korean firms first had to implement imported technologies before the scientific and engineering staff could assimilate them and acquired the capacity to improve them. Throughout this process, firms became increasingly competitive, although not without considerable government support in the early phases. The learning trajectory described by Dahlman et al (1987) runs from production capabilities through investment capabilities to innovation capabilities. Lall (1982) emphasized that industries progressed from elementary through intermediate to advanced learning capabilities. Hobday (1995, p.1185) has argued that progression is not necessarily linear, since research and development (R\&D) may be undertaken at an early stage. Nevertheless, he found a general tendency of firms starting up simple activities systematically at an early stage and gradually accumulating capabilities to perform complex activities at a later stage. Chaminade and Vang (2008) argue that developing country ICT firms start with competing with low-cost products and advance to become knowledge providers in the global value chain. In this transition regional innovation systems play a crucial role.

We argue that these stage models are not applicable to the aerospace industry for two main reasons. First, they do not match the distinctive features of the sector. Aerospace manufacturing is highly technology- (Smith 2005) and capital intensive. New entrants face a very steep learning curve (Frischtak 1994). Access to technology for latecomers is limited by the very high entry costs, rather than through patents. The industry is characterized by imperfect competition, non-homogenous products and major economies of scale. Fixed initial development costs are extremely high (Beaudry 2001). To overcome private underinvestment in new technology, governments have to support manufacturers, either through launch subsidies, export subsidies, military procurement or market protection. Arguments of national security, prestige and

\footnotetext{
${ }^{9}$ Some authors are debating whether policy makers and managers consciously followed pre-defined strategies or were merely experimenting (Hobday 2009).
} 
expected spillovers ${ }^{10}$ to downstream industries and services ${ }^{11}$ and to other sectors of the economy serve as justification for government intervention. Governments can influence the sector through industrial, trade, higher education as well as science, technology and innovation policies. Intervention is also needed due to the severe demand fluctuations for aerospace products, closely correlated with fluctuations in global economic growth. Aerospace firms face cyclical changes in demand and recurrent crises within the lifetimes of their products.

Second, stage models are not applicable for aerospace because the sector's high quality requirements demand firms to possess advanced capabilities early on. The technological complexity of aerospace products is rather high in even simpler modules (Dosi et al. 2003; Hobday et al. 2005). There is a tradeoff between cost and quality at the core of many stage models of catch-up. A cheaper but less reliable consumer electronics product can be sold in large numbers if the cost is low enough. This trade-off does not exist for aerospace products. Quality standards for firms entering the market, even at the lower end, are higher than in many other sectors, given that an aircraft or spacecraft is as reliable as its weakest component. Latecomer firms can only sell their products if they meet the high standards set by the global industry leaders. When producing under license for foreign system assemblers, component suppliers are meticulously screened by the buyers. In cases of domestic procurement governments have little room for relaxing product standards without jeopardizing public safety. The threshold level of production capabilities is thus very high. Consequently, what would be categorized as a basic stage in terms of development in the stage models presented above in fact show characteristics of more advanced stages. Both the acquiring of threshold level production capabilities as well as sustained further growth require intensive investment capabilities, advanced technological learning in related fields, and (at least new to the country) innovation on behalf of latecomer firms.

Therefore, it is sufficient to distinguish only two stages over the evolution of latecomer aerospace industries. An emergent phase in which some companies find a niche for their products, and the subsequent phase in which companies aim for sustained competitiveness, which is needed to sustain sectoral growth in order to catchup with the leaders. For example, the maiden flight of a locally designed new aircraft prototype may signal the successful accomplishment of the emergent phase, but it is not

\footnotetext{
${ }^{10}$ The measurement of spillover effects related to the aerospace industry is difficult, especially in emerging economies. In the case of the Swedish 'JAS Gripen' fighter program Eliasson (2010) applied a spillover multiplier and estimated that the social returns above the opportunity costs were at least 2.6 times greater than the original investment.

${ }^{11}$ Downstream industries and services include transport, telecommunications, navigation, media or earth observation, many of which also offer benefits for public bodies.
} 
sufficient to ensure sustained growth. Further innovation in the long run needs to be financed from sales, which depends on whether a market niche has been found for the new product. Government financing of 'infant' firms in the sector is widely accepted. But unless state-sponsored producers generate sufficient sales in markets independent from procurement by the respective governments, they will not be financially sustainable. Eventually, governments and domestic transport firms will be forced to purchase high quality aerospace products from foreign competitors.

It is by no means guaranteed that the second phase follows progressively from the first one, or that competitiveness can be sustained. In successful cases of aerospace development, there is a transition to sustained competitiveness. But this transition can also fail in which case the industry will languish or disappear altogether.

\subsection{Systems of innovation}

The literature on technological capabilities offered a richer understanding of the learning mechanisms or technology accumulation. Authors argued that the simplified description of development processes as passive transfers of embodied and disembodied technologies from leading countries is misleading. The cornerstone of latecomer catchup was active learning, which is realized through interactions. Successful latecomers were not simply imitators but organized production and distribution in innovative ways, often using advanced science and technology to move into nascent industries (Freeman and Soete 1997; Fagerberg and Godinho 2005). Some authors stressed that one should not distinguish between the processes of innovation and diffusion, since "diffusion involves more than the acquisition of machinery or product designs and related know-how. It also involves continuing, often incremental, technical change to fit specific situations and to attain higher performance standards" (Bell and Pavitt 1993, p.259). If that is the case, understanding the functioning of innovation systems brings us closer to understanding latecomer dynamics.

\subsubsection{On the origins of the concept}

An innovation system is generally defined as a set of actors from whose interactions new knowledge, technology and products are generated, diffused and applied. The 'systems of innovation approach' received increased interest of scholars and policy makers in recent decades for two main reasons: in order to better understand (1) the differences in growth performance of countries, and (2) the processes of technological change and innovation at various levels. Concerning the first aim, the results of evolutionary economics, new growth theory and the economics of knowledge provided very clear evidence on the importance of innovation and technological factors to growth. 
Furthermore they highlighted the crucial role of interaction among firms and other organizations for innovation, which are conditioned by institutional environment. To offer an alternative to "reductionist" models, the IS approach emerged to offer a broad framework of analysis for technological, economic and institutional change.

Seen from a different angle, scholarly interest in technology and growth shifted away from specific sectors to a broader focus on national institutions and networks in which all elements play their parts in growth. This happened at a time when Western Europe and North America experienced a slowdown in growth and saw the rapid rise of Japan. A seminal study was the analysis of Japan by Freeman (1987). Complemented with the volumes by Lundvall (1992) and Nelson (1993), these are the 'Triad' of basic references on innovation systems (Edquist 1997; Lundvall 2007; or Soete et al. 2010). The innovation systems approach was primarily influenced by the results from evolutionary economics and science and technology studies. Results include the ideas that innovating actors face uncertainty and bounded rationality, that innovation requires interactions, that institutions and history matter, or the dynamics of technoeconomic paradigms. Already from the very beginning, innovation systems have been a very inclusive (or 'holistic') concept. It has attempted to map 'the big picture' by looking at as large a set of determinants of innovation as possible. In response to studies that only treated limited data on $R \& D$ inputs and personnel or patents, the growing literature has accommodated various narrower and broader definitions of innovation. This 'catch-all' nature of the concept has not diminished over time, despite some authors' attempt to introduce greater methodological rigor (see the 'comparability' critique below).

At the macro level, List's systemic view of a developing economy is clearly reflected in the innovation systems concept. With regard to the micro level, the systemic view of the innovation process can be traced to the synthesis of debates in innovation studies (such as the 'technology push' vs. 'market pull') or the idea behind the 'chain linked' models of innovation (Kline and Rosenberg 1986). Moreover, due to their interaction, the macro and micro levels co-evolve. Seen from a firm's point of view, innovation depends on technological opportunities, the availability of loans and (venture) capital, a legal regime guaranteeing the appropriation of results, many of which lies beyond their control. On the other hand, if governments strive to become competitive and achieve growth in their countries, they need to provide a favorable institutional environment for firms to innovate.

The recognition of these interdependencies resulted in an increased scholarly interest in comprehensive, descriptive studies of the processes of social, economic and technological change in a historical and institutional context, or appreciative theorizing, 
combining elements of political economy, evolutionary economics, history of technology and social constructivism. At the 'meso level' the analysis of industrial dynamics found support in empirical and modeling works on interactions between consumers and producers or knowledge actors (Malerba 2007).

Following from the understanding that interactions are at the heart of the innovative processes, institutions, the rules and norms that govern them are central to the IS approach. There is a clear agreement that institutions cover market as well as non-market interactions and provide the 'fiber' of innovation, unfortunately there is no single definition of institutions. Some authors refer to educational or research institutes as institutions (i.e. Nelson 1993) while others call them organizations. Institutions in this book are defined according to North (1990) as "rules of the game", and are distinguished from organizations which are considered as actors of the system.

\subsubsection{Level of analysis}

The National innovation systems perspective, which associated differences in growth across countries with institutional differences affecting creation and diffusion of new technologies, assumed that national borders mattered. Based on Landes (1969), Nelson and Rosenberg (1993) argued that historical and cultural differences, the timing of industrialization process and government policies shaped national institutions, laws and policies. This gave rise to a debate from two directions. First, it was questioned whether innovation activities and their effects were bound by national borders. Ideas and research results are easily exchanged in a global community of researchers and are difficult to appropriate, firms technological collaboration are often international, and regional integration often also covers science and technology (see i.e. Freeman and Soete (2009) or Caracostas and Soete (1997) on 'post-national systems of innovation'). Shifting the geographical focus to sub-national level of clusters and regions revealed differences in innovative activities due to institutional differences in the 'regional innovation systems' literature (Cooke 1996, 2008; Maskell and Malmberg 1999; Malmberg and Maskell 2002; Asheim and Gertler 2005; Doloreux and Parto 2005).

Second, it was debated whether differences between innovation systems were technology-specific or sector-specific. This was primarily a methodological "point of entry" problem about whether the dynamics of a technology domain or the dynamics of an industry are of interest. Two different strands of literature emerged. The 'technologyspecific innovation system' strand is concerned with the systemic explanations of technological change as well as their societal implications (Carlsson and Stankiewicz 1995; Jacobsson and Johnson 2000). The 'sectoral innovation systems' literature (Breschi and Malerba 1997; Malerba 2002, 2004) focuses on questions of innovation, 
competitiveness and industrial performance in a sector which is defined by a set of products.

Malerba (2004) argued that differences in the sectoral environment explain differences in the processes of learning and innovations. Sectoral systems of innovation (SSI) are defined by three major 'building blocks': (1) actors, (2) the knowledge base and the technological domain and (3) their systematic interactions and institutions. Actors encompass not only firms, but also non-firm organizations as well as individuals. They range from producers to users, input suppliers, universities and research organizations, financial institutes, trade unions, technology associations, entrepreneurs and scientists. The importance in the innovation process of different types of actors differs from sector to sector. Actors in a sector are heterogeneous, and their different technological and learning capabilities, beliefs, objectives and organizational structures are all sources of sectoral dynamics. Their behavior and interactions take place in an environment that is shaped by different institutions: norms, routines, common habits, established practices, rules, laws, standards, etc (see North 1990). Some rules are more binding than others; some are more formal than others.

\subsubsection{Applying a sectoral systems of innovation approach for latecomer aerospace industries}

The sectoral systems of innovation approach can add useful insights to a study on sectoral growth and catch-up in latecomer aerospace industries. First, it offers a "mapmaking" tool for an exploratory study. In an industry where history plays an important role in explaining industrial dynamics, it duly focuses on the heterogeneity of actors, their changing capabilities, the quality and frequency of their interactions. A detailed, qualitative study is crucial to understand why the industry is performing well in one country and what structural failures or institutional blockages hamper innovation and growth in others. It can also reveal what actual tradeoffs innovating firms or policy makers face.

Second, the sectoral innovation systems approach is suitable because it focuses on the "meso-level". If innovations in complex products were the object of our research, the recent work of Hobday et al (2005) and Dosi et al (2003) could be an alternative point of entry. ${ }^{12}$ But innovation and growth in a sector are of course influenced by firmlevel dynamics, and similarly by macro-level national policies. Our approach thus needs

\footnotetext{
${ }^{12}$ The 'complex product systems' (CoPS) literature on system integration which takes place within as well as between firms. It also explains industrial dynamics since modularity in complex products is reflected in industrial structures and alliance formation. The aerospace industry is often showcased as an example for such a system.
} 
to be more comprehensive, beyond the micro level but below the national level, and can be called as a national-sectoral approach.

Innovation systems approaches have often been criticized for the lack of a clear definition on what belongs to the system and what remains outside its borders. Lundvall's suggestion to overcome this problem was to identify the core and the wider setting of an innovation system (Lundvall 2007). The newly emerged 'functional strand' of innovation systems literature suggested focusing on key functions which systems fulfill (Liu and White 2001; Carlsson et al. 2002; Hekkert et al. 2007; Bergek et al. 2008). Seen from a different angle, a set of products can also define sectoral system boundaries (Malerba 2004), although radical innovations in the long-run will most likely modify them. Nevertheless, a product-core can also be applicable in the long-run in case of a catching-up industry, where this core is 'extrernally-given' by those at the technology frontier. ${ }^{13}$

Another point of criticism of innovation systems studies is their lack of comparability over time and space. This can be an important methodological problem, since the framework only defines the building blocks of systems in general, but there is large variation within the categories. Those studies that take a comparative perspective employ indicators on building blocks and innovation in a systematic way and offer valuable insights (at the national level e.g. Nelson (1993), or at the sectoral level (Mani 2005, 2009; Intarakumnerd and Fujita 2009). This is definitely a direction worth pursuing. Nevertheless, one should exercise caution when trying to measure the performance of an innovation system in transition, for Szalavetz (1998) pointed out that "hard indicators" can be misleading.

\subsubsection{Incremental and radical changes in innovation systems}

From the very origins of the concept, innovation systems have conceptually been associated with socio-economic change. With the increasing availability of longitudinal data on innovative performance of interrelated actors, there is increased interest in understanding how systems change over time, both in qualitative and quantitative terms (Lundvall et al. 2006; Dodgson et al. 2008). Fundamental changes in the economy as a result of creative destruction (Schumpeter 1934) or the emergence of new technological paradigms (Dosi 1982; Freeman and Perez 1988; von Tunzelmann et al. 2008) have been widely discussed. These theoretical works focus on an aggregate level. We still need to expand our understanding of the co-evolution of science and technology, innovation and production and the relevant institutional arrangements at sectoral levels. In other

\footnotetext{
${ }^{13}$ The fact that technology applied for aerospace production may originate from other sectors does not reduce the power of the approach, as long as the technology flows are carefully considered.
} 
words, how are changes in the innovation system connected to changes in a sector's physical production?

Evolutionary aspects of innovation systems have received increased attention in recent years. ${ }^{14}$ Two distinct patterns of system change are crystallizing from these works. The first type of change refers to incremental changes along a given trajectory (bounded by path dependence). The study of the Taiwanese integrated circuit industry by Lee and von Tunzelmann (2005) provides useful insights into this type of dynamics, in which the interplay of sub-systems and major actors are at the core of a more gradual system change.

The second type of innovation system change refers to a more fundamental system transition. In the 'appreciative theorizing' model of Galli and Teubal (1997) paradigmatic changes and structural adjustments of national innovation systems are driven by exogenous environmental pressures. The changes involve restructuring of networks, changing openness to the outside world, increased interactions between the subsystems (i.e. inter-firm relations evolve beyond simple market-based transactions), and the creation of new technology interface units. Lundvall et al (2006) singled out institutional rigidity as the key barrier to growth of a NIS beyond a certain point. System transitions refer to changes in the "constellation of institutions" and changes "in the relationship between producers and users of knowledge". A system transition is required to overcome a contingency mismatch (when change in the environment makes the existing institutional set-up ill-suited for new conditions) or when a system reaches its inherent limits as a result of endogenous growth. In the domain of technological systems, in the multi-level framework proposed by Geels and Kemp (2006), transitions are shifts between technological trajectories, which involve the emergence of a radical innovation incubated in a 'technological niche'. Transitions are also discussed in the functional dynamics literature, where the authors associate the fulfillment and interaction of functions as a prerequisite for systemic change (Hekkert et al. 2007; Bergek et al. 2008). Considering that functions are inherent in all institutions, it is fair to say regardless of the perspective, all strands of literature appear to agree that following a successful transition, the basic functions or structure (or architecture ${ }^{15}$ ) of a new system will look fundamentally different from the previous one.

\footnotetext{
${ }^{14}$ (C.f. Galli and Teubal 1997; Lee and von Tunzelmann 2005; Lundvall et al. 2006; McKelvey and Holmén 2006; Geels and Kemp 2007; Edquist and Hommen 2008; Dodgson et al. 2008; Dolata 2009; Malerba and Mani 2009),

15 The management literature offers interesting insights as well. The concept of architectural innovation, introduced by Henderson and Clark (1990) originally refers to changes on the product level in the way the main components are linked together. Consider the product design architecture as a simple system, a
} 
The cyclical nature of the aerospace industry requires a model that incorporates not only incremental but also radical innovation system change to explain latecomer development. Recurrent booms and slumps in demand regularly pose challenges to both production and innovation. It is reasonable to assume that not only firms, but the system as a whole is affected by demand fluctuations. The industry's performance depends on how the innovation system as a whole manages to cope with these fluctuations.

A central problem with quantitative analysis of radical and incremental innovation system changes is often the lack of detailed long-term data. Nevertheless, change in inputs, demand and output; changes in the number of actors or changes in the intensity of interactions (network characteristics) are indicative of the dynamics on innovation system. But in addition to looking at such indicators, qualitative analysis is required to highlight changes in the knowledge base and learning processes, changes in the nature of interactions among actors (including change network hub change), institutional change, changing processes of variety generation and selection.

\subsubsection{The punctuated equilibrium model of innovation dynamics}

The punctuated equilibrium theory on innovations assumes that there are two kinds of changes defining long-run technological development. The more subtle incremental innovation is from time to time punctuated by discontinuities and radical change. The theory originates from evolutionary biology and gained popularity in the innovation and especially in the management literature after the 1970s.

Abernathy and Utterback (1978) linked the two types of technological changes to the maturity of enterprises. Early on, new firms enter the market with radical product innovations. If these innovations become dominant designs, their producers shift focus from product to process innovations. Tushman and Anderson (1986) demonstrated at the industry level in three cases (minicomputer, cement and airlines) that technological innovation follows a punctuated pattern. They also showed that major technological breakthroughs in a sector do not necessarily result in high environmental turbulence, as long as these are initiated by incumbent firms. However, if new entrants introduce radically new technology, it will be competence destroying for existing firms and will increase competitive uncertainty. Romanelli and Tushman (1994) showed that a similar pattern of changes characterizes organizational development. Equilibrium periods, which are relatively long periods of stability, are punctuated by "relatively short bursts of fundamental change". These radical changes create new activity patterns for the

structural change of the linkages of the system that offers a competitive edge to a firm is analogous to architectural innovation in a national or sectoral innovation system. 
organization and settle into a new equilibrium. Their reasoning why stability periods emerge can be relevant for the industry level as well, not only at the organizational level. They argued that actors (buyers, suppliers, financiers) are legally and normatively linked to one another and these relationships constrain their activities. In short, institutional inertia is an important source of stability. A further explanation of institutional stability is found in technological community dynamics. Rosenkopf and Tushman (1998) show that cooperative technological organizations emerge in times of radical change (in periods of 'ferment') and become dominant communities for over a longer period while technology changes incrementally.

Combining these results has important consequences for long-run sectoral innovation systems dynamics. According to the theory, two of the key components of sectoral innovation systems, the technology base and the actors evolve along a trajectory characterized by incremental changes punctuated or interrupted by radical changes. Malerba and Orsenigo (1996a, 1996b) confirmed that the interacting technological, organizational and institutional changes as well as changing demand define the internal dynamics of industries. It follows that radical changes should also characterize the evolution of sectoral innovation systems. There are two questions. First, is it possible to identify these changes? Second, do such radical changes occur in technology followers or only at the technological frontier, to which the previous studies referred to?

\subsection{Previous studies on innovation and growth in latecomer aerospace industries}

Scholars of innovation, economics of technological change, industrial organization, political science and sociology have all found ample room for research in the aerospace industry. The factors that influence the creation of a new aerospace product are just as much technological as economical or political. The multifaceted nature of the industry offers various points of entries for research which we briefly present in this section. Approaches concerned here are those focusing on innovation, technological change and industrial growth in the long run. ${ }^{16}$ First we look at studies on countries at the technological frontier, next at studies of latecomers.

\subsubsection{On the evolution of the aerospace industry at the frontier}

For much of the second half of the $20^{\text {th }}$ century, developments in the US were equivalent to developments at the technological frontier. Mowery and Rosenberg (1985) studied

\footnotetext{
${ }^{16}$ This also implies that important issues such as market dynamics and firm behavior, competition and collaboration (Golich 1992; Hayward 1994) or strategic trade theory (Brander 1981; Brander and Spencer 1985; Lawrence 2001) are left outside the scope of this investigation.
} 
innovation and institutional development in the commercial aircraft industry in the US. They showed a long-run transformation in the innovative performance and industry behavior due to changing policy regimes. A shift from public to private funding and deregulation at the end of the 1970s increased development costs and financial risks for aircraft and engine producers, who in turn found a solution in multinational collaboration. Subsequently international collaborative ventures have increased competitive pressure on components and parts manufacturers. Mowery (1987) and Esposito (2004) take a closer look at alliance formation in the sector.

The effect of the aerospace industry on economic growth has puzzled many economists. Surprisingly, no one ventured to measure its contribution to GDP growth in the same way Fogel (1964) has analyzed the contribution of railroads. ${ }^{17}$ But there are a number of other attempts that led to interesting results. In a historical approach Ruttan (2006) argued that in the US general purpose technologies developed due to defense purposes (such as satellites or the internet) spurred economic growth. Poole and Bernard (1992) found a negative impact of military production on total factor productivity growth in aircraft manufacturing in Canada. Eliasson (2010) calculated positive spillover effects of a Swedish fighter jet development program.

The growth effects of the industry are most clearly visible at the regional level. There is a growing literature on aerospace clusters, ranging from Seattle (Erickson 1974) and Montreal (Niosi and Zhegu 2005, 2010) to Southern UK and Wales (Beaudry 2001; Cooke and Ehret 2008, 2009).

The aircraft industry has long inspired scholars of technological change and evolutionary economists (see e.g. technological paradigm shifts in (Dosi 1982). In a series of articles Vincenti discussed the evolutionary nature of development in technologies such as air propellers (1979), flush riveting (Vincenti 1984), airfoil design (1986) and retractable landing gear (1994). Frenken et al. (1999) tracked variety and niche creation, Frenken and Leydesdorff (2000) studied scaling trajectories. Benkard (2000) showed that technological accumulation is not simply a process of constant learning, but as firms evolve they make strategic choices on both learning and forgetting certain production technology.

Aerospace firms in countries such as Canada or Japan are also relative latecomers compared to the US and provide interesting insights into understanding technological learning and capabilities accumulation (see Lukasiewicz (1986) on the failed fighter jet development in Canada; Mowery and Rosenberg (1985), Kimura (2006, 2007), McGuire

\footnotetext{
${ }_{17}$ Such a calculation is not without challenges. Time saving due to air travel in contrast with rail or intercontinental sea travel could reveal some of the effects.
} 
(2007), King and Nowack (2003) on the accumulation of technological capabilities in Japan).

\subsubsection{On the aerospace industry in latecomer economies}

The historical experience of Latin American and Asian countries with the aerospace industry since the 1960s and 1970s has been increasingly studied to answer questions such as why countries chose to enter the sector; how they managed technology accumulation in aerospace and in related industries; how clusters were formed; what government policies and firm strategies were followed.

The early realization of the importance of institution building in the development of the sector allowed for a political economy perspective, especially if these studies focused on government policies. In addition, insights from the management literature were used to explain firm strategies. The export success of Brazil made it one of the benchmark cases (Sarathy 1985; Moxon 1987; Ramamurti 1987; Frischtak 1992, 1994; Goldstein 2002a, 2002b; Goldstein and McGuire 2004). Other countries and companies studied included Indonesia (McKendrick 1992; Eriksson 2003), China (Nolan and Zhang 2002; Goldstein 2006), and Argentina (Hira and Oliveira 2007). Texier (2000) provides insights on South Korea by explaining a conglomerate's diversification into aerospace.

Product and industry life cycle theories (Vernon 1966; Abernathy and Utterback 1978; Utterback and Abernathy 1975; Gort and Klepper 1982) offered a generic explanation as to how and why aerospace products diffuse to developing countries during the more mature phase of their life cycle. Niosi and Zhegu (2008) show that these theories are only partially appropriate to explain developments in the industry. They are valid to the extent that developing countries only entered the industry after a shakeout occurred during and after the Second World War. However, there was no clear evidence of a shift of production and innovation to new competitors in developing countries as new competitors mostly emerged in industrialized countries. Moreover, there were several cycles during the 100-year development of the industry, and at least two dominant designs emerged. They conclude that product and industry life cycle approaches should be complemented with a look at sectoral innovation systems. The studies by Marques (2004), Marques and Oliveira (2009) and Mani (2010) are good examples of how the sectoral innovation system facilitated technological capabilities accumulation in Brazil and India. Baskaran (2001) and Steenhuis et al. (2007) emphasized the importance of both indigenous efforts as well as interactions between domestic and foreign actors, because a strategy of self-reliance is bound to fail. Romero (2010) discussed the recent trend of foreign aerospace firms moving to a developing country (Mexico), and shows the attracting force of clusters. 
All these studies have expanded our understanding of the aerospace industry in emerging economies. They provide for the insights and short-term data needed for analyzing long-run catch-up patterns. But the possibilities for further research remain ample. First, firm or country-level case studies on company growth or innovative performance are most meaningful in an international comparison. This has not been possible due to lack of comparative data, as many of the studies explicitly point out. Ideally, a comparison should be comprehensive and take into account industry leaders as well as other latecomers. It should - ideally - also cover measures of industrial and innovative performance. A second possible direction for research is to explore and explain industrial dynamics of the sector across countries, over a long time-span. The aim would be to shed light on the co-evolutionary processes in national-sectoral innovation systems. It also opens a window on understanding how emerging companies succeed over time on the local and global market.

\subsection{Technological change and industrial dynamics in the jet age}

The technological frontier in aircraft manufacturing was shifted outwards again and again by innovators located in the advanced industrialized economies, creating a moving target for latecomers to catch up with. In order to see what the benchmark for latecomer innovators was in a given period we provide here a general overview of major changes in key technological domains, including changes in the organization of production. A detailed study of technological development in the global aerospace industry is beyond the scope of this book. Rather, we will discuss major technological leaps in a stylized manner. Next we turn to major milestones in the global aircraft industry (mainly in the commercial industry), which happened in what many (i.e. Frenken 2006) called the paradigmatic phase of the jet era. The diffusion of the jet engine, increased intercontinental air traffic, and major changes in financing aerospace innovation has led to innovation in the organization of the industry. Understanding the main drivers of internationalization for leading producers is important to understand the context in which latecomers can operate.

\subsubsection{Major driving force of innovation}

Innovation in aircraft manufacturing took place in four domains: propulsion, applied materials, avionics, and the organization of the design and production process.

The importance of demand in driving innovation can be seen in the first row of Table 2.1 which summarizes the generic considerations driving technological advance in aircraft and engine development. Of course, demand is specified in light of what is technologically feasible, but at the aggregate level of the industry, there are a few rather distinct goals. 
It is interesting to see on the one hand that from the 1970s further speed increase lost its importance, which happened at the time when jet technology became mature with the diffusion of the turbofan engine. On the other hand, the oil crisis and subsequent decrease in military spending directed attention to energy efficiency and cost reduction.

Propulsion in aircraft manufacturing has undergone a radical change from propeller to jet technology (discussed in section 2.6.2). Since the 1950s itdeveloped along a single trajectory and innovation was primarily incremental (see discussion above in turbojet and turbofan technology). ${ }^{18}$ The maturity of the engine industry is reflected in the small number of turbofan, turboprop and turboshaft (for helicopters) engine producers. ${ }^{19}$ Propulsion of rockets, missiles and spacecraft has seen more radical innovation, although liquid fuel systems still represent the dominant design, despite their disadvantages (cannot be turned off after ignition, relatively low thrust per quantity of fuel consumed).

The choice of materials not only defines strength and durability, ${ }^{20}$ but it is also central to efficiency in aerospace. One way to boost efficiency is to create more powerful engines using metal alloys ${ }^{21}$ that can withstand very high temperatures (over $1000^{\circ} \mathrm{C}$ ). Another way is to reduce structural weight by using composites. Composites are materials combining two or more (in)organic components. They offer the advantage of light weight, yet still strong structure and thus help reduce operating costs. Fiberglass was already applied in the automobile industry in the 1950s. During the 1960s and 70s, new materials such as boron/epoxy, graphite/epoxy; kevlar/epoxy were diffusing to secondary aircraft structures, originating mostly from military programs. Despite the promising weight reduction they offer, composites have serious drawbacks that explain why so many producers have chosen not to use them in primary structures. In

\footnotetext{
${ }^{18}$ There were of course other more significant technological innovations, such as the application of results from turbojet technology to propeller systems, by creating turboprop engines instead of piston engines.

19 As discussed above, the three major manufacturers are General Electric Aircraft Engines and Pratt \& Whitney (United Technologies) in the United States and Rolls-Royce in the UK. In addition to these companies (and their joint ventures) who are controlling the large civil aircraft market, smaller engines producers (for commuters, executive jets or military aircraft) include SNECMA and Turboméca of France; MTU (DaimlerChrysler) of Germany; Volvo Flygmotor of Sweden; FiatAvio of Italy; Aero Engine Corporation in Japan; Williams International, Textron Lycoming, Honeywell of the US, and Klimov, Kuznetsov, Aviadvigatel, and Saturn of Russia.

${ }^{20}$ Strength and durability requirements have led to the increased use of steel and titanium. Titanium and its alloys have a high strength/density ration, are corrosion resistant, high operating temperature and are compatible with composites, yet they are difficult to form and have high machining costs and high notch sensitivity. (For more on materials used in aerospace, see Mortensen (2007).)

${ }^{21}$ Metal alloys are substances composed of two or more metals or of a metal and a nonmetal; mostly created by melting and dissolving the components.
} 
comparison with metal components, inspection of flaws in composites is more difficult and production is more costly because of its labor-intensity. Maintenance costs are also higher because, unlike with metal, repair of composites is not possible, and replacement parts are once again more expensive. Boeing aircraft produced in the 1970s and 80s were using composites accounting for hardly more than $3 \%$ of total weight, and the first Airbus model contained around 5\% composites. The A-320 of the mid 1980s was the first commercial aircraft to have $10 \%$ composite share, the first Boeing with a similar share was the B-777 (Table 2.1). Military aircraft, mostly because of different MRO requirements and stealth considerations, were more ready to use composites, the F-18 $\mathrm{E} / \mathrm{F}$ and the F-22 of the 1990s had 19 and $24 \%$ share respectively. ${ }^{22}$ Boeing took a large step with the launch of the B-787 Dreamliner which has a fuselage made of carbon fiber, and a composite share of over $50 \% .^{23}$

Technological advance in avionics has accelerated in the past decades. A substantial share of the information and communication technologies and electronics used in our daily life include parts or solutions that were developed in aerospace applications. Before the 1960s onboard sensors, displays and controls were analogue and independent from one another. The mechanical instruments were gradually replaced by computers with increased interconnectedness. Avionics are used for a broad range of functions, including navigation and communication, flight control, engine control, flight management, subsystem monitoring and control, collision avoidance and weather detection. Additional functions in military aircraft include radar, infrared and other target sensors, weapon management, electronic countermeasures, mission planning, or formation flight control. By architecture, they encompass displays, controls, computation, data buses, safety partitioning, environment, standards (Kayton and Fried 1996).

\footnotetext{
22 Deo, Ravi B. et al "Low-Cost Composite Materials and Structures for Aircraft Applications" http://ftp.rta.nato.int/public/PubFullText/RTO/MP/RTO-MP-069\%28II\%29/MP-069\%28II\%29\%28SM1\%29-01.pdf

${ }^{23}$ The composite structure has been a source of significant delays in the launch of the B-787. Boeing dismissed the criticism concerning maintenance difficulties, but the plane is currently undergoing testing and is yet to see daily commercial operations.
} 
Table 2.1 Overview of major new-to-the-world innovations in civilian aircraft

\begin{tabular}{|c|c|c|c|c|c|}
\hline & 1950s & $1960 \mathrm{~s}$ & $1970 \mathrm{~s}-80 \mathrm{~s}$ & 1990s & $2000 \mathrm{~s}$ \\
\hline $\begin{array}{l}\text { Major goals for } \\
\text { innovators }^{a}\end{array}$ & Speed increase & $\begin{array}{l}\text { speed and } \\
\text { capacity } \\
\text { increase }\end{array}$ & $\begin{array}{l}\text { Economical use, } \\
\text { fuel efficiency } \\
\text { increase }\end{array}$ & $\begin{array}{l}\text { Cost reduction, } \\
\text { noise reduction, } \\
\text { capacity increase }\end{array}$ & $\begin{array}{l}\text { environmental } \\
\text { considerations } \\
\text { (Lower } \mathrm{CO}_{2} \\
\text { emissions), } \\
\text { increase airline } \\
\text { revenue, cost } \\
\text { reduction }\end{array}$ \\
\hline $\begin{array}{l}\text { Major innovations in } \\
\text { aircraft propulsiona }\end{array}$ & $\begin{array}{l}\text { Turbojet: } \\
\text { P\&W JT3C } \\
\text { (1952); } \\
\text { Turbofan: } \\
\text { P\&W JT3D } \\
\text { (1958) }\end{array}$ & \begin{tabular}{|l|} 
Turbofan: \\
P\&W JT8D \\
(1964), JT9D \\
$(1966) ;$ \\
RR RB211 \\
(1969) \\
GE CF6 (1971);
\end{tabular} & $\begin{array}{l}\text { Turbofan: } \\
\text { CFM56 (1974); } \\
\text { P\&W PW2000 } \\
\text { (1979), PW4000 } \\
\text { (1987); } \\
\text { RR RB211-535 } \\
\text { (1983); } \\
\text { IAE V2500 (1983) }\end{array}$ & $\begin{array}{l}\text { Turbofan: } \\
\text { RR Trent 700 } \\
\text { (1990); -800 } \\
\text { (1993); } \\
\text { P\&W PW4000-100 } \\
\text { (1994), } \\
\text { GE90 (1995) }\end{array}$ & $\begin{array}{l}\text { Turbofan: } \\
\text { RR Trent } 900 \\
(2004)\end{array}$ \\
\hline $\begin{array}{l}\text { Most advanced } \\
\text { aircraft types }\end{array}$ & $\begin{array}{l}\text { Comet I; } \\
\text { Caravelle; Tu-104 }\end{array}$ & $\begin{array}{l}\text { B-707, DC-8; } \\
\text { B-727; B-737; } \\
\text { Concorde }\end{array}$ & $\begin{array}{l}\text { B-747; DC-9; } \\
\text { B-737; A-300; } \\
\text { L-1010; DC-10; } \\
\text { B-757; B-767 }\end{array}$ & $\begin{array}{l}\text { MD-11; B-777; } \\
\text { A-330; A-340 }\end{array}$ & $\begin{array}{l}\text { A-380 } \\
\text { B-787 }\end{array}$ \\
\hline $\begin{array}{l}\text { Applied materials; } \\
\text { (Composite share of } \\
\text { weight) }\end{array}$ & $\begin{array}{l}\text { Aluminum; steel; } \\
\text { metal alloys }\end{array}$ & \begin{tabular}{|l|} 
Aluminum; steel; \\
metal alloys, \\
composites \\
(fiberglass; \\
boron/epoxy)
\end{tabular} & \begin{tabular}{|l|} 
Aluminum, steel; \\
titanium, metal \\
alloys, Composites \\
(boron/epoxy; \\
graphite/epoxy; \\
Kevlar/epoxy): \\
B-737: $3 \%$; \\
B-747: 2\%; B-757, \\
B-767: 3\%; A-300: \\
5\%; A-310: 7\%; \\
A-320: 15\%;
\end{tabular} & $\begin{array}{l}\text { Aluminum, steel; } \\
\text { titanium, metal } \\
\text { alloys, Composites: } \\
\text { B-777: } 10 \% \\
\text { composite; } \\
\text { A-330/340: } 12 \%\end{array}$ & $\begin{array}{l}\text { Aluminum, steel; } \\
\text { titanium; metal } \\
\text { alloys, } \\
\text { Composites: A- } \\
380: 20 \% \\
\text { B-787: } 50+\%\end{array}$ \\
\hline $\begin{array}{l}\text { Internationalization of } \\
\text { production }^{b, c}\end{array}$ & & $\begin{array}{l}\text { Share of foreign } \\
\text { components: } \\
\text { B-707: } 0 \% \\
\text { B-727: } 2 \%\end{array}$ & $\begin{array}{l}\text { Share of foreign } \\
\text { components: } \\
\text { B-737: } 10 \% \\
\text { (1970s) } \\
\text { B-767: } 15 \% \\
(1980 \text { s) }\end{array}$ & $\begin{array}{l}\text { Share of foreign } \\
\text { components: } \\
\text { B- } 777: 30 \%\end{array}$ & $\begin{array}{l}\text { Share of foreign } \\
\text { components: } \\
\text { B-787: } 70 \% \\
\text { (60\% of all } \\
\text { products) }\end{array}$ \\
\hline Avionics & $\begin{array}{l}\text { None } \\
\text { (Independent, } \\
\text { analogue } \\
\text { instruments) }\end{array}$ & $\begin{array}{l}\text { First } \\
\text { appearance of } \\
\text { on-board } \\
\text { electronics }\end{array}$ & $\begin{array}{l}\text { Fly-by-wire; (first- } \\
\text { all-digital: A320 } \\
\text { 1984) } \\
\text { CRT electronic } \\
\text { flight displays; } \\
\text { inertial navigation } \\
\text { systems, auto- } \\
\text { landing systems }\end{array}$ & $\begin{array}{l}\text { LCD display; } \\
\text { satellite } \\
\text { communication, } \\
\text { GPS navigation; } \\
\text { integrated modular } \\
\text { avionics }\end{array}$ & $\begin{array}{l}\text { Electronic flight } \\
\text { bags; air-ground } \\
\text { data link; terrain } \\
\text { awareness } \\
\text { system; }\end{array}$ \\
\hline
\end{tabular}

Source: Own compilation based on (a) Sehra and Whitlow (2004, Fig.1); (b) Craypo and Wilkinson (2003, p.294); (c) "Globalization Bites Boeing” Businessweek 13 Mar 2008; Mortensen (2007);

Flight data processing and instrument panel displays have changed radically in recent decades. During the 1960s and 1970s, R\&D focused on onboard computers ad cathoderay tube (CRT) technology. By the 1980s the first 'glass cockpit' aircraft were introduced (B-757/767, A-320). Flight management computers and displays giving feedback on 
engine and subsystem performance significantly reduced cockpit workload and made a separate flight engineer unnecessary in the cockpit. ${ }^{24}$ CRT displays were heavy and bulky, and were replaced by LCD screens in the 1990s. They became also very popular in general aviation, where single-pilot operations were fundamental.

Commercial aircraft today contain over a thousand sensors and boxes of electrical components. The very high reliability, safety and testing requirements (both in hardware and software) and complex architecture make avionics very costly aircraft components, typically amounting to 30 percent of aircraft costs. (In advanced military aircraft they can even reach even exceed 50 percent, in some spacecraft 70 percent. $)^{25}$ Today the market is dominated by Rockwell Collins or Honeywell of the United States, Thales Avionics in France, and BAe Systems of the UK. A burgeoning set of international suppliers and partners provide sub-systems.

\subsubsection{The diffusion of the jet engine}

The rapid expansion of the industry is related to the radical changes brought about by the jet engine in military and commercial aviation. The resulting expansion of air transport in turn has shrunk the planet and allowed an unprecedented scale of international collaboration in development, production and marketing in all industries, including aerospace itself.

The jet engine was first patented by Sir Frank Whittle in 1930, but in 1939 Hans von Ohain was the first to design one that actually powered an aircraft, the Heinkel He178. ${ }^{26}$ The main advantage of the jet technology ${ }^{27}$ over the dominant piston engine of the era was a significantly greater power to weight ratio. Given its strategic potential, the turbojet technology diffused rather fast across countries during World War II. In Germany, Messerschmitt 262 flew for the first time in 1942. In the same year in the United States the GE I-A engine mounted on a Bell P-59 made its maiden flight. In 1943 the British De Havilland Vampire fighter flew for the first time and in the following year

\footnotetext{
${ }^{24}$ Most airliners in the 1950s flew with a crew of 3 or 4 . New displays reduced pilot eye scanning cycle by providing primary data on a single screen. The basic concept of Boeing's Engine Indication and Crew Alert System developed the B-757/767s can be found in the latest models.

${ }^{25}$ The increased complexity of avionics software development can be seen in two indicators: cost of software development for U.S. defense programs rose from \$5 to \$35 billion between 1985 and 1995; Military aircraft of the 1960s had 20,000 lines of codes, modern fighters and commercial transports have several million. (“Aerospace industry” Encyclopaedia Britannica Online. Retrieved: 22 Oct 2010)

${ }^{26}$ Constant (1980) provides a careful study of the evolutionary development of the turbojet engine. The author makes a case for the parallel development both in the UK and Germany.

${ }^{27}$ A jet engine (or gas turbine) operates based on the principle of Newton's third law (for every reaction there is an equal, opposite reaction). Air taken in goes through a compressor and is mixed with fuel in a combustion chamber. Rapidly expanding exhausted gas then rotates the turbine blades and thus provides thrust for forward movement.
} 
Rolls Royce started to work on the Nene engine. The first Soviet jet fighter, the MiG-9 followed suit in 1946.

Only after the war did the jet technology diffuse in civil aviation. In 1949 the first commercial jet to fly was the British De Havilland Comet 1. The aircraft debuted in 1952 in scheduled service between London to Johannesburg, ${ }^{28}$ heralding the age of jet transportation. However, the first-mover had to pay a high price because of repeated crashes due, as it was eventually diagnosed, to metal fatigue (see Rosenberg 1976; Verspagen 1999). The reengineered Comet 3 plane was less successful than the new designs developed by the follower competitors ${ }^{29}$ from the US, and thus Comets lost the market to the Boeing B-707 and the Douglas DC-8. ${ }^{30}$

Almost at the same time, in the Eastern bloc, the Soviet Tupolev Tu-104 flew for the first time in 1955. The Comet and the Tu-104 had many similar features, including the wing-root mounted engines, the Tu-104 was a larger, faster and stronger construction. More importantly, the plane had rounded windows and was thus not vulnerable to metal fatigue. Both of these aircraft represented a milestone in aviation history, half-way between the propeller-age and the jet-age. They were pioneers of a new concept, yet in many ways (e.g. wing loading or control systems) reflected the old philosophy of propeller-driven aircraft (Loftin 1985).

Following the introduction of the technology in Europe, a new dominant design emerged in the USA. This was the Boeing B-707, which first flew in 1954 and entered into service in 1958. Boeing's design incorporated the lessons learnt from own military aircraft production (e.g. the B-47) and from European pioneers in commercial aircraft. Low-positioned, sweepback wings offered efficiency at high-altitude, high-speed cruise. Four turbojet engines attached underneath in single nacelles made repair easier. The plane could carry a maximum of 189 passengers to a maximum distance of nearly 12,800 kilometers, allowing non-stop travel over almost all the oceans and continents. The B-707 soon became the most successful jet plane of its age, with over a thousand

\footnotetext{
${ }^{28}$ In the same year the London-Ceylon and London-Singapore, in the following year the London-Tokyo routes were opened. Flying time between these latter two cities dropped from 85 hours to 36 hours (Loftin 1985).

${ }^{29}$ The technological leadership of Europe over the US before World War II is undoubted (Moran and Mowery 1991). Nothing reveals better the nature of the competition between the UK and the US than the diplomatic row between the two countries. The Americans may have been trying to win time by tying up British aircraft sales efforts "in security red tape", arguing that the Rolls-Royce Avon axial engine powering the Comet 2 as well as military jets constitutes a secret that should be kept out of reach of the Soviets (Engel 2000).

${ }^{30}$ The last of the 114 aircraft produced were delivered in 1964. It is also interesting to see that the nose section and cockpit layout of the Comet was used for the French Sud Aviation's Caravelle that flew for the first time in 1955 and entered into service in 1959 and became more successful on shorter routes and at airport with shorter runways. The plane could carry 80 passengers (later Super -12 models were increased to 140). A total of 280 were built.
} 
built by 1979. Frenken and Leydesdorff (2000) showed empirically how the company could exploit the design principles of the B-707 in subsequent rescaled models built to meet user needs (along what the authors called a 'scaling trajectory').

With a very similar design but a longer fuselage, the DC- 8 could carry 60 more passengers than the 707 (although at a cost of offering a shorter maximum range: 11,300 $\mathrm{km}$ ). It first flew in 1958 and entered into service in 1959. In a relatively short production cycle - it was produced until 1972 - a total of 550 were built. These two planes (and a few very similar followers) ${ }^{31}$ brought revolutionary changes to the air transport industry. Trans- and intercontinental travel grew rapidly as it became faster and more accessible to large part of society. In the US high fuel consumption, at least before the oil crisis, was a less important issue. The long take-off runway requirement (3 $\mathrm{km}$ ) of these jets triggered the development and construction of new airports. As Moran and Mowery (1991) note, the US federal government was always ready to bail out defense contractors (such as Douglas or Lockheed) when they were overrunning costs with commercial aircraft development. Moreover, the world's largest market, the US, was highly regulated, spurring competition not in price, but in service and quality, which in turn boosted the development of new technologies and their rapid adoption. As a result US manufacturers gained a dominant position in the world which they were keen on exploiting for exports as well.

Improvements in engine technology, the development of the more efficient turbofan engine ${ }^{32}$, allowed the construction of a second generation of jetliners in the 1960s. New metal alloys made airframes stronger; the introduction of composites (fiberglass and boron/epoxy) made airframes lighter. The introduction of supercritical wing design allowed better performance at higher speeds and lower wing weight. Manufacturers could offer a wider selection of jets to meet various airline preferences based on route length, payload, speed, or runway requirement. Three US designs of this era, the B-727 (first flight in 1963) the DC-9 (first flight in 1965) and the B-737 (first flight in 1967) have become extremely successful and widely used planes around the world. ${ }^{33}$ But technological knowledge was not restricted to the US. Other major aircraft sharing the basic knowledge were produced in the UK (the British Aircraft Corporation VC-10 and BAC-111, or the Hawker Siddeley HS.121 Trident), in the Netherlands

\footnotetext{
${ }^{31}$ The Convair 880 (first flew in 1959) and the 990 (1961) were from the same school; the development concept opted for a faster design at the cost of payload capacity and range. These considerations eventually did not make it as popular as the B-707 and DC-8.

${ }^{32}$ By adding another fan in front of, and creating bypassing air around the turbojet core engine, significant additional thrust (and lower noise) can be achieved with only a small increase in fuel flow.

${ }^{33}$ More than 1800 of the B-727 were built by 1984, almost 1000 of the DC-9s and more than 6000 (and still produced) of the B-737s, in a number of gradually improvements in structure and onboard systems.
} 
(Fokker F-28), and very successfully in the Soviet Union (The Tupolev Tu-134 and Tu154 models or Yakovlev Yak-40). Most of these aircraft (except for the B-737) have two or three aft-mounted ${ }^{34}$ engines (Loftin 1985).

Another direction of technology development was increased carrying capacity during the 1970s, resulting in wide-body models ${ }^{35}$ such as the Boeing B-747 Jumbo, the McDonnell Douglas DC-10 and the Lockheed L-101 TriStar. The new designs offered significant increases in payload and seating capacity. ${ }^{36}$ Larger engines with high bypass ratio and compressor pressure ratio also provided fuel efficiency increases in the range of $20 \%$ compared to previous models, combined with lower noise levels.

Increased fuel efficiency was the driver of aircraft development in the 1980s. High by-pass ratio engines power the two new models of Boeing (B-767 and B-757), and these aircraft represent a clear change of track from the previous "faster, bigger and further" plane making strategy. ${ }^{37}$ The major innovations incorporated in these aircraft were in avionics and computers. ${ }^{38}$ This direction of innovation is even more visible on the models of the era offered by the newly created European competitor, Airbus, which offered for the first time in commercial aviation a fly-by-wire system on the A-320 that first flew in 1987. But this already marks a new wave of increased technological competition in avionics. Instead of conceptual changes the jet technology saw further advancement in refinement, typical of a mature technology.

In sum, technological changes due to the jet engine made the world smaller; transoceanic and transcontinental flights became faster and more accessible. Rapid growth in the number of people transported followed. One of the best indicators of technological progress is the decrease in direct operating costs of aircraft. ${ }^{39}$

\footnotetext{
${ }^{34}$ Advantages of the aft arrangement of engines, according to Loftin (1985) include increased stability in case of engine failure, lower noise levels, and also allow smaller sized planes; however the advantages of a T-tail design are debatable.

35 The wide-body design offers greater cabin diameter, the two aisles allow faster loading, serving and evacuation time, but come at a cost of increased skin friction drag.

${ }^{36}$ These aircraft offered a maximum seating capacity of 550, 386 and 400, respectively.

${ }^{37}$ Compared with the latest model of the B-707-320B, the B-767 has nearly the same empty weight yet it can carry 100 more passengers - on shorter routes. The B-767 is also 40 miles slower than the previous model, but allows shorter landing and take-off field lengths (Loftin 1985).

${ }^{38}$ Automatic flight control systems and computers offer automatic guidance and control of these aircraft from takeoff to landing. More advanced lateral navigation functions as well as vertical flight-path control provide a new way to minimize fuel consumption. Pilots have cathode-ray-tube displays at their disposal instead of traditional electromechanical instruments.

${ }^{39}$ From 7.47 USD/seat in case of the DC-3 it went down to 2.61 with the introduction of the B-707 and further to 1.3 with the B-747 and 1.65 USD/seat with the B-757 (Mowery and Rosenberg 1989, Table 7.1.,p.175).
} 


\subsubsection{Internationalization}

Aircraft design and production before the 1960s was primarily done in-house with little collaboration among manufacturers. In the US the development of generic technology received significant boosts from NASA and Department of Defense research funding, in Western Europe national champion companies were nurtured (Moran and Mowery 1991).

The emergence of cross-country collaboration was driven by two main reasons (based on Mowery and Rosenberg 1985; or Mowery 1987). First, as a response to high development costs and the limitations of domestic markets, international alliances were seen as a way to share the costs of commercial aircraft development and benefit from economies of scale in production. Already in the 1960s, European producers were starting to explore possibilities to respond to US competitors by setting up joint ventures. One such venture was the Aérospatiale-BAC Concorde ${ }^{40}$ project of 1962; another was the British, French and West German and Spanish "Airbus Industrie Economic Interest Group" of 1970. Similar projects in the military segment saw more hurdles on the road as projects became more costly and delivery times increased since sharing of technology remained a sensitive issue for competitive reasons even among members of NATO.

Internationalization of production was also driven by government procurement, both by air forces and by state-owned airlines. Because these orders involved high costs and frontier-technologies, government buyers, especially of countries already having an aerospace industry, could bargain for offset agreements. One solution was the local assembly of aircraft from kits under license. This allowed for access to technologies and improvement of skills, but in a more limited way since it did not cover aircraft development or more detailed engineering work. Offset agreements often made arrangements for manufacturing components locally for aircraft purchased from abroad. As a result of growing specialization, joint production programs started already in the 1970s. One example is the General Dynamics F-16 fighter, which included European companies that were also producing components for planes sold in the US. ${ }^{41}$ Collaboration at first in production, later in design, to have market access became the general practice in the industry, already by the end of the 1980s. It paved the way for the R\&D alliances in risk sharing partnerships to spread development costs. ${ }^{42}$ The advance of information and communication technologies in the 1990s allowed arm's length

\footnotetext{
${ }^{40}$ The supersonic transport aircraft first flew in 1969 and entered into scheduled service in 1976.

${ }^{41}$ See Moran and Mowery (1991, p.141) for details on the program.

${ }^{42}$ Boeing, for instance, offered full partnership to some subcontractors during the development of the B-777, Japanese partners held a 20 percent share in the airframe structure.
} 
cooperation in all phases of production and a major global consolidation following the drop in military spending at the end of the Cold War.

Alliances and global consolidation were nowhere as visible as in engine manufacturing. Already during the "age of national champions" the huge development costs and economies of scale forced mainframe manufacturers to look beyond national borders for jet engines. Engine production itself is a high value added activity since engines could cost around 15-20 percent the value of a new aircraft. European and American countries were keen on retaining part of the work in local companies. This led to the creation of three major joint ventures. The CFM consortium was formed in 1974 by General Electric (GE) of the US and the French SNECMA with equal ownership. CFM engines power major workhorses such as the Boeing B-737 and Airbus A-320 family. The International Aero Engine (IAE) venture of 1983 brought together the competence of the British Rolls Royce, the American Pratt \& Whitney (P\&W), the MTU of Germany and the Japanese Aero Engine Corporation consortium to power singleaisle aircraft in the 150 seat category. Its V2500 engine soon won the support of Airbus and McDonnell Douglas. More recently GE and P\&W formed a 50-50 joint venture, the Engine Alliance to supply the high-capacity long range aircraft, such as the Airbus A380 superjumbo. But besides these alliances, each company also has their own engine product lines (in a broad range, from regional or executive jets to wide-body aircraft). This duality has led to delays and frictions among partners, as producers imposed restrictions on independent use of acquired technologies, especially if technology was developed for military programs (Moran and Mowery 1991).

During the 1990s, new possibilities opened up for collaboration between the former West and countries of the former Eastern bloc. However, the promises of drawing upon Russian expertise brought only modest results in joint aircraft development. Russia, with a previous annual production of hundreds of commercial aircraft, only produced a dozen commercial aircraft in a decade after the collapse of communism. Unlike Tupolev or Ilyushin, Sukhoi and MiG in the military segment still held on to their markets. Collaboration with Russia was more successful in space research and launches, where fuel efficiency and economic operation was less of a consideration and where Russia still possessed frontier technological capabilities.

The latest aircraft designs of the 1990s and 2000s included Boeing's B-777 and Airbus A-330 and 340 long-range, wide-body jets that achieved increased efficiency by using $10-12 \%$ composite material in their airframe and cabin structures. Boeing led the strategy of using international partnerships to reduce $\mathrm{R} \& \mathrm{D}$ and production costs. Foreign components made up nearly a third of the value of the B-777, and this share has grown to more than $70 \%$ in the B-787 currently in the testing phase. The strategic 
competition of Boeing and Airbus resulted in Boeing going for a radical new design with the B-787 which, for the first time, incorporates a composite airframe raising the composites rate above $50 \%$ of the total structure. Airbus on the other hand saw more potential in the large capacities and aimed at size. Its latest A-380 superjumbo is, from the use of composite materials point of view, not a radical departure from the previous trajectory.

In sum, the aerospace industry has shifted towards an internationalized production structure where key assets of producers are core competencies in component or structure design and manufacturing, or system assembly. This further strengthened the pyramid-like hierarchical structure, in which system assemblers are on top, followed by firms that develop and produce primary structures and systems in the second tier below. Subsystem ${ }^{43}$ and components manufacturers supply them from lower tiers. Aerospace companies with expertise in different segments can at the same time participate as system assemblers in one program and as co-developers and producers of components (risk-sharing partners) in another, creating multi-tier competition in an oligopolistic market. It is important to understand how the industrial structure has changed by the 1990s, because latecomer producers trying to penetrate the industry today have substantially different competitive challenges to tackle than in the 1960 s or 70 s.

\footnotetext{
${ }^{43}$ Encyclopedia Britannica provides a rich sample of what may belong here. "Aircraft secondary systems are reflected in an extensive industrial infrastructure, with products falling largely into four categories: (1) structural and mechanical, (2) propulsion and power-related, (3) environmental control, and (4) communications and navigation. The first category encompasses aerodynamic controls and actuators (mechanical or fly-by-wire systems), doors, engine nacelles and pylon fairings, control surfaces, and takeoff-and-landing-gear systems (including nosewheel steering, brakes, shock absorbers, and tires). The second category covers propellers, thrust reversers, fuel tanks and fuel-management systems, engine starters, auxiliary power units, air-driven generators, and electrical systems. The third category includes pressurization and air-conditioning equipment, ice-detection and anti-icing systems, electronic flight-instrumentation systems, engine-indication and crew-alerting systems, conventional cockpit instruments, and autopilots and flight directors. The fourth category encompasses communication systems, navigation equipment (including radio, optical, electronic, and inertial-reference systems; instrument-landing systems; receivers for satellite-based global positioning systems; traffic-alert and collision-avoidance systems; and heads-up displays), and cockpit voice and flight data recorders. Commercial aircraft add galleys and toilets, onboard entertainment and announcement systems, emergency slides and rafts, and other equipment for passenger comfort and safety. Special subsystems in military aircraft include ejection seats and separable cabins, multimode radar, armament, stores stations for external weapons, electronic countermeasure systems for confusing enemy defenses, arrester hooks for aircraft carrier landings, braking parachutes, identification friend or foe (IFF) systems, and photographic, infrared imaging, and other sensory devices for intelligence gathering together with onboard intelligence-processing equipment." ("Aerospace industry" Encyclopedia Britannica Online, retrieved: 22 Oct 2010)
} 


\subsubsection{The diffusion of technologies to emerging economies}

The case studies in Chapter 6 will discuss the evolution of technological capabilities in greater details. Here we provide a brief overview focusing on the key technologies we presented above. We use the case of the Brazilian producer Embraer to show how certain technologies diffused gradually to an emerging producer.

Diffusion of the jet engine: The first aircraft Embraer started to produce in 1969, the EMB-110 Bandeirante, was powered by turboprop engines produced by Pratt \& Whitney Canada. Of course, the capability of producing jet aircraft did not necessarily require the capability to produce jet engines even for companies on the technological frontier. Embraer accumulated the jet technology step by step. It assembled its first jet aircraft in 1971. This was a fighter aircraft, the EMB-326 Xavante, a 1957 model of the Italian Aeromacchi which was assembled under license in Brazil. The two companies jointly developed the AMX jet fighter in 1984 using a Rolls Royce Spey 807 turbofan engine. The first locally designed jet (with also a Rolls Royce engine) was the ERJ-145 commercial regional jet introduced in 1995. At the same time, the production of commercial jetliners requires pressurized cabins. The first Embraer civilian aircraft with pressurized cabin was the executive turboprop EMB-121 Xingu (1976).

Composite materials: Simple composites were already used in the first plane, the EMB110 Bandeirante. 'Wet/hand lay-up' technique was applied on a few non-structural components and on fairings ${ }^{44}$. Structural bonding was introduced with the AMX fighter and composites in integrated structures were first used on the ERJ-145 family. Embraer acquired this latter technology when it was producing outboard flaps for the MD-11 and through the eventually failed project of the CBA-123 in the late 1980s. The latest executive jets of Embraer, the Phenom (2007) have totally integrated composite structures made with thermoplastic. ${ }^{45}$

Avionics and glass cockpit: Due to the modular design, the diffusion of avionic suits and on-board computers to Embraer aircraft was relatively fast. The joint ItalianBrazilian AMX fighter already had two computers and state-of-the art displays on board. Embraer was cooperating with Rockwell for the avionics on the Brasilia commuter. Through a partnership with Honeywell, the ERJ-145 regional jets were equipped with the latest "glass-cockpit". The ERJ-190 jet was one of the first commercial aircraft to use head-up display. The latest Phenom executive jets are equipped to enable

\footnotetext{
${ }^{44}$ Fairings on aircraft create smoother surfaces in order to reduce drag.

${ }^{45}$ This paragraph was based on Arakaki, F.K. and Goncalves W.G., 2007, "Embraer Composite Material Application", paper presented at the $16^{\text {th }}$ International Conference on Composite Materials, 8-13 Jul 2007, Kyoto.

Most recently, in 2010, Embraer began to construct its own facility in Portugal to produce composite structures and components.
} 
single-pilot operations, which is an increasingly important requirement in the business jet market. Despite the rather fast diffusion of avionics technology to Brazilian aircraft, the technologies continued to be developed elsewhere in the advanced economies. Of course, the technologies have to be tailor-made and adapted locally, but no Brazilian companies emerged as competitors of global avionics suppliers. But this is related to the nature of the Brazilian aerospace innovation system which we shall discuss in greater details in Chapter 6, along with further historical details on technology diffusion in other countries.

\subsection{Summary of the literature review}

Here we summarize the key conclusions we gained from a survey of the literature, including the problems that remain open for further study of latecomer industrialization in aerospace.

1. In order to realize latecomer advantages, serious efforts are required to acquire missing technological capabilities that include not only codified (not only the transfer of machines and blueprints), but tacit elements, which can be learnt by doing. This makes the accumulation process costly and uncertain.

2. Realization of latecomer advantages depends on how missing institutions can be substituted for. In this process the state intervention plays a major role in creating or stimulating the creation of new institutions that can spur growth in industries considered most promising.

3. The role of infant industry protection is crucial during the accumulation of technological capabilities. However, the extent and duration of protection and the way to reduce them along with the "gradual diminution of backwardness" is open for debate, since there is no clear borderline between infant industries and mature ones. There are historical examples of both radical and incremental reduction of infant industry protection.

4. Capability accumulation is a multi-level and multi-actor process. Learning and accumulation takes place at the level of the firm, the organization, the industry and the nation ("national capabilities are not simply the sum of ... firm level capabilities developed in isolation." (Lall 1992 p.169). Capabilities at various levels may be very different and the analysis of evolution requires a comprehensive approach.

5. Stage models of the gradual accumulation of technological capabilities appear not to be applicable to aerospace where the minimum threshold of production is very high due to technological complexity and non-negotiable international standards. 
Since assimilation and local adaptation of technologies are crucial for catch-up and involve active learning, aerospace producers need well-developed innovative capacities already at the emergent phase. Consequently, the main strategic challenge for latecomers is to lay the foundations for innovative activities and subsequently maintain them.

6. Product and industry life cycle theories suggest that latecomers enter the aerospace industry in the mature phase of its respective life cycle and carry out process innovations. Due to the complexity and modularity of aerospace technologies products cycles are hard to distinguish. But if the industry life cycle theory holds and if the aerospace industry indeed entered a mature phase of the jet-based paradigmatic stage by the 1960s, we should observe a shift of process innovations to developing countries..

7. The sectoral innovation system approach provides a useful tool for explorative studies on the industrial development in a latecomer industry. In line with the latest conclusions on the nature of the evolution of technological capabilities, it provides a comprehensive look at the technological domain, at actors (domestic and foreign, firms, educational institutes and research organizations, etc.), their interactions as defined by institutions. The innovation systems approach takes the historical context into considerations for understanding institutions, which makes the approach relevant for studying long-run industrial growth.

8. The converging literature on punctuated equilibrium and paradigm shifts in the long-run evolution of firms, industries, organizations and technological regimes suggests that innovation systems, in which all these co-evolve, should also undergo radical changes from time to time. As a consequence, one cannot restrict oneself to studying incrementally change systems in order to understand acceleration, slowdown and other aspects of catch-up dynamics in a changing environment.

The existing literature provides little explanation of why and how radical system changes occur. This thesis tries to make a contribution to answering these questions. 


\section{PART I}

THE PERFORMANCE

OF EMERGING ECONOMIES

IN AEROSPACE MANUFACTURING 



\section{CHAPTER 3 \\ The evolution of the global aerospace manufacturing industry}

\subsection{Statistical sources on aerospace manufacturing}

Despite the considerable public interest in aerospace production, there is surprisingly little consistent statistical data available to compare the performance of the aerospace industry around the world. A recent OECD publication on the space economy (OECD 2007) is one of the first attempts to fill this gap. This is an unrivalled source of information on OECD countries, especially together with the underlying industry-level Structural Analysis (STAN) database. But how does aerospace in OECD countries compare with the aerospace production of the rest of the world? Are there producers from emerging economies that fit in the top ranks of producers in the industrialized countries? There are no studies to answer these simple questions or to provide an overview of historical development trends.

When it comes to measuring the growth of manufacturing output in various industries, aerospace easily qualifies for the title of the most challenging one. The source of difficulties range from disaggregation problem as to what belongs to aerospace manufacturing ${ }^{46}$ to the lack of published sectoral statistical data. The reasons for the lack of available data differ from country to country. For most of the industrialized countries (members of OECD) data is available since 1970, but for earlier years it is mostly published as part of the transport equipment manufacturing branch. Former socialist countries (from Central Eastern Europe to China) have been carefully limiting access to information during the Cold War years since all of the sector's products were considered strategic assets for national security. Even the otherwise highly insightful estimates in declassified CIA reports (Maddison 1998)) do not offer data on this industry in the USSR. (Spy agencies appear to have only been interested in aerospace as a source of military capabilities and less as a source of wealth creation.) Even today the

\footnotetext{
${ }^{46}$ Since the core manufacturing activities have not changed substantially over the years in international and national classifications, this may be less of a problem for gauging industry-level output for air and space segments together. However, if one is interested in only one of the two or the impact of the manufacturing on related services, the problems to solve are enormous.
} 
Russian Federation does not publish sectoral value added or sales figures thus impeding historical extrapolations. The high degree of concentration of industrial activity is another major difficulty, especially in newly industrializing economies. Often there is only a single enterprise. In order not to jeopardize the respondents' anonymity in industrial surveys, statistical offices often only publish branch level figures for the transport equipment sector. In other cases the manufacturing activity in the sector was simply too small to be tracked separately. A further source of headache for any analyst of long-term development is that in some countries (for example Indonesia) statistical bureaus revise the series from time to time without sufficient explanation. In sum, it is not surprising that no comparative study was ever published on the growth of aerospace manufacturing.

Our aim was to put together a comprehensive set of output data, along with data on labor inputs in order to be able to compare countries in terms of labor productivity. The most meaningful output concept is value added since it avoids double counting of intermediate inputs (which can also show up as final products of another producer in the same sector). In certain cases only gross output figures were available, in the form of aerospace revenues. These do involve double-counting.

The difficulty of obtaining data on certain input resources forced us to make certain compromises. Employment series were more widely available, but data on capital stock or capital formation and annual investment in R\&D were too incomplete to be able to provide systematic, comparable data series. Incidental figures are meaningless, since aerospace manufacturing facilities demand heavy investment in precision machinery and equipment that companies can use for decades, as well as frequent investments to modify existing installations to accommodate new models. Therefore we will not estimate multi-factor productivity in this study and will only be able to make rough comparisons of labor productivity. We hope that transparency in the sector will increase (at least in the archives) so that future research on the sector will be able fill this gap.

The statistics described here offer a historical overview of the growth of the aerospace industry since 1950 in 45 countries. It is based on national statistical publications, obtained directly from yearbooks and manufacturing surveys or indirectly through UNIDO, OECD and other international statistical sources, or compiled datasets of the Groningen Growth and Development Center (GGDC). These datasets have been scrutinized and adjusted for purposes of cross-country comparisons and serve as the basis for our 45 country dataset. When extrapolating existing series forward or backward with additional series, these additional series were applied as indices of production or employment in order to avoid trend breaks in the final dataset. 
Save for a few exceptions (including the USA, UK and Canada), country time series are not available for the whole period, 1950-2007. Our decision was to provide as reliable data as possible for the overall time span and as data complete as possible for the last 25 years. Most of the OECD countries are tracked from 1970 while the data for most of the Central Eastern European countries from the former Eastern European bloc are recorded from the early 1990s onwards. The UNIDO dataset on output and employment in developing countries is incomplete. The reason for the this varies from country to country. In many cases measurable domestic aircraft manufacturing activities were short-lived (i.e. some Latin American countries) and the industry otherwise consisted of maintenance, repair and overhaul activities that were not to disaggregated from the 'transport equipment manufacturing' branch. In a few cases, national statistical data was available either at the sectoral or at a more aggregate level. We decided to extrapolate benchmark years where more aggregate series on transport equipment manufacturing, or sales of the dominant company were available (see section 3.2 below; see Appendix 1 for detailed information on data sources and methods used for each country.)

\subsection{Methodological considerations for projecting and aggregating time series data}

Some historical output figures had to be estimated through extrapolation or interpolation. When extrapolating and interpolating, we used the following methods:

1) Extrapolating aerospace value added (or gross output) with constant price series of value added (or gross output at aggregate branch level ('transport equipment' or 'other transport equipment manufacturing'), according to equation (3.1). ${ }^{47}$ This method makes a rather strong assumption that the share of aerospace in branch value added does not change over time.. There are two major shortcomings of this method. First, the demand for aircraft and cars, trucks or ships are influenced by different factors, so their production does not necessarily co-evolve. Automobile production responds faster to demand shocks than aircraft production which has a longer backlog of orders. Second, in industrial classification definitions preceding ISIC Rev. 3, communication satellites and some missiles and rockets were categorized in a different sector. Yet the benefit of using a more aggregate branch data is still considerable in spite of these shortcomings, as they provide an absolute upper limit for production.

In some cases the share of aerospace in the branch value added in the last year for which shares are available was an outlier compared to previous ones. To overcome this,

\footnotetext{
${ }^{47}$ For gross output and employment, value added is replaced by the respective series in the equation.
} 
we used the average share in a five year period as basis for the extrapolations (see equation 3.2).

$V A_{t}^{353}=V A_{0}^{353} \cdot \frac{V A_{t}^{35}}{V A_{0}^{35}}$

$V A_{t}^{353}=V \hat{A}_{0}^{353} \cdot \frac{V A_{t}^{35}}{V A_{0}^{35}}$, where $V \hat{A}_{0}^{353}=V A_{0}^{35} \cdot \frac{\sum_{1}^{n} \frac{V A_{i}^{353}}{V A_{i}^{35}}}{n}$

$V A_{t}$ refers to value added in year $t ; V A_{0}$ refers to the base year; Superscript 35 indicates branch level data, 353 stands for aerospace (ISIC Rev. 3.). Values in the base year were deflated to constant 2000 prices.

2) Extrapolation using the dominant company's sales or production figures (see equation (3.3)). While statistics were not published in many emerging countries at the 3-digit level, records of the single most important company in the country or secondary literature offered valuable insights. Bearing in mind that in many countries a national champion dominated almost the entire industry (and smaller suppliers depended solely on contracts with that company), we recreated time series using such production or sales indices (adjusted for constant prices). We used this method to extrapolate for historical production in Brazil and Indonesia. The assumption in this method is that the value added per sales ratio does not change over time, which might not be true in different phases of product cycles. ${ }^{48}$ In theory, adjustments could be made if consistent time-series had been available and intermediate inputs, but these were not available.

$V A_{t}^{353}=V A_{0}^{353} \cdot \frac{S A_{t}^{\text {Company }}}{S A_{0}^{\text {Company }}}$

$\mathrm{SA}_{t}$ refers to the dominant company's sales value in year $t$.

3) In the special case of the People's Republic of China where branch level data differed significantly from fighter and bomber production series derived from the secondary literature, an estimated sales index was used for extrapolation. Sales values were estimated using quantity of output estimates adjusted with relative price index weights, obtained from secondary sources. This method provides only a very rough estimate, but since it might be the only way to present historical levels of production, we opted for this in order not to leave out a major producer. Calculations are described in the source note in Appendix A.1.

\footnotetext{
${ }^{48}$ The share of intermediate inputs in different products or product families varies, as will be shown in the case of the ERJ-145 and E-jet families in Brazil in Chapter 4.
} 
4) Linear interpolation using time series at the more aggregate level. The following formula (3.4) was applied to estimate figures for gaps in a time series $A^{353}$ where data was available for a more aggregate series $A^{35}$ :

$$
A_{t}^{353}=A_{0}^{353}+\left(A_{t}^{35}-A_{0}^{35}\right)\left(\frac{\left(A_{k}^{353}-A_{0}^{353}\right)}{\left(A_{k}^{35}-A_{0}^{35}\right)}\right)
$$

$A_{0}$ and $A_{k}$ refer to the two known lower and upper end of the interpolation period.

Output values in national currencies have to be converted to a common currency (US dollars) for cross-country comparison and aggregation of national production to the global level. Excluding the option of applying the official exchange rates (which are biased due to their high volatility and the fact that they do not necessarily reflect the relative price levels across countries), there are two ways to estimate conversion factors. One way is to compare real expenditure on certain goods (the so-called expenditurebased approach) resulting in purchasing power parities (PPPs) $;{ }^{49}$ another one is to compare ex-factory production values (in an industry-of-origin approach) resulting in unit value ratios (UVRs). The results of the two may differ. There is now an extensive literature on the merits of the industry of origin approach for sectoral comparison, as elaborated in the International Comparison of Output and Productivity (ICOP) project (Ark 1993; Maddison and Ark 1988; O'Mahony and Timmer 2009; Timmer 2000). Branch-level conversion ratios for transport equipment manufacturing were available in various publications following the ICOP method for 27 of the countries in our database. For the remaining countries we simply used PPPs published in the World Bank's World Development Indicators as a first approximation..$^{50}$ Both value added and gross output conversion ratios were available for countries covered in previous ICOP studies. In these cases we could apply specific gross output conversion factors when aggregating gross output series. The differences between gross output and value added ratios are rooted in differences in value ratios of intermediate inputs. Where such additional information was unavailable, we applied the value added ratio for all conversions. ${ }^{51}$ Table 3.1 gives an overview of the conversion rates that were used. In the case of Brazil, the only country

\footnotetext{
${ }^{49}$ This builds on a method developed by Kravis et al (1982) in the International Comparisons Project (ICP) and is followed by the World Bank, OECD and Eurostat.

${ }^{50}$ Inklaar and Timmer (2010) recently proposed a method to adjust expenditure-based PPPs to closer match the output concept. This is done by computing export PPPs by peeling off domestic retailer margin rates using data from national supply tables and import PPPs by adjusting them with a weight and exchange rates.

${ }^{51}$ This may result in an overestimation of the value added series in countries where a single ratio was applied to value added, given the fact that where both single deflated and double deflated conversion factors are available, the gross output ratios are significantly lower than the value added ratios.
} 
for which adequate production data was at hand, we calculated our own industry-oforigin conversion ratios. The methodology and the results are discussed at greater length in the following chapter.

Table 3.1 Conversion Ratios for the benchmark year 2000 (UVRs and PPPs, local currencies / USD)

\begin{tabular}{crrrrr}
\hline Country & VA & GO & Country & VA & GO \\
\hline ARG & 0.85 & 0.85 & ITA & 0.52 & 0.74 \\
AUS & 2.82 & 1.83 & JPN & 140.24 & 137.59 \\
AUT & 2.46 & 1.38 & KOR & 989.59 & 867.24 \\
BEL & 3.27 & 1.36 & LUX & 2.78 & 1.34 \\
BRA & 1.09 & 1.09 & MEX & 12.73 & 12.73 \\
CAN & 1.55 & 1.2 & MYS & 1.69 & 1.69 \\
CHL & 284.1 & 284.1 & NLD & 3.39 & 1.43 \\
CHN & 4.6 & 4.6 & NZL & 1.45 & 1.45 \\
HKG & 7.5 & 7.5 & NOR & 9.14 & 9.14 \\
COL & 867.3 & 867.3 & PER & 1.47 & 1.47 \\
CZE & 31.7 & 27.33 & PHL & 18.86 & 18.86 \\
DNK & 46.27 & 14.12 & POL & 5.5 & 3.58 \\
FIN & 4.67 & 1.65 & PRT & 7.05 & 1.62 \\
FRA & 1.96 & 1.25 & ROM & 0.63 & 0.63 \\
DEU & 1.95 & 1.2 & SGP & 1.2 & 1.2 \\
GRC & 2.61 & 1.27 & SVK & 38.96 & 35.08 \\
HUN & 758.4 & 289.4 & SVN & 2.07 & 0.98 \\
ISL & 84.42 & 84.42 & ZAF & 5.89 & 5.89 \\
ISR & 4.97 & 4.97 & ESP & 1.03 & 0.94 \\
IND & 13.61 & 13.61 & SWE & 30.07 & 13.04 \\
IDN & 4201.18 & 4201.18 & TUR & 0.28 & 0.28 \\
IRN & 1338.18 & 1338.18 & UKR & 1.06 & 1.06 \\
IRL & 4.39 & 1.63 & GBR & 1.95 & 0.96 \\
\hline
\end{tabular}

Source: see Appendix A.1

Notes: VA = Value added; GO = Gross value of output. Numbers in bold indicate ICOP-based unit value ratios, non-bolds are PPP values from World Bank WDI. All conversion ratios were updated or backdated to 2000 .

\subsection{The growth of the global aerospace industry in a historical perspective}

The upcoming sections provide a decription of the evolution of the global ${ }^{52}$ aerospace industry between 1960 and 2007. Over these nearly five decades, value added increased

\footnotetext{
${ }^{52}$ Global refers to the total output of countries for which production data was available (See Appendix A.1 for the exact coverage). The Soviet Union is the only major producer which had to be omitted due to lack of statistical information.
} 
by a factor 3.5 to 135 billion USD, gross output increased four-fold to 312 billion USD (Table 3.2). This growth has not been linear. Figure 3.1 shows a cyclical pattern with peaks in 1966-67, 1973-74, 1980-81 and 1991, followed by periods of decline. The most rapid increase in value added took place between 1995 and 2007 (annual average of $6.8 \%$ ), the largest of the drops occurred in the years following the end of the Cold War (in average 7.7\% annually between 1990 and 1995). Currently aerospace globally accounts for over 1.4 million jobs, 23\% lower level than the peak in 1990. Between 1990 and 2007 more than 400 thousand aerospace jobs were lost around the world..$^{53}$

Table 3.2 Performance of the aerospace manufacturing industry, 1960-2007 (Million USD at constant 2000 prices)

\begin{tabular}{|c|c|c|c|c|c|c|c|c|}
\hline & 1960 & 1973 & 1985 & 1990 & 1995 & 2000 & 2005 & 2007 \\
\hline Total Value of Output (GO) & 78,978 & 110,435 & 168,218 & 218,993 & 166,650 & 234,153 & 268,007 & 312,480 \\
\hline Gross Value Added (VA) & 38,586 & 56,568 & 75,846 & 91,878 & 61,593 & 77,716 & 100,359 & 135,090 \\
\hline Total Employees & 952,569 & $1,074,788$ & $1,679,910$ & $1,839,438$ & $1,668,799$ & $1,530,874$ & $1,364,133$ & $1,435,041$ \\
\hline Nr. countries in GO sample & 15 & 20 & 27 & 33 & 38 & 40 & 40 & 39 \\
\hline $\begin{array}{l}\text { missing data for } \\
\text { significant producers }\end{array}$ & 6 & 6 & 7 & 5 & 1 & 0 & 0 & 0 \\
\hline Nr. countries in VA sample & 16 & 23 & 31 & 34 & 40 & 42 & 43 & 43 \\
\hline $\begin{array}{l}\text { missing data for } \\
\text { significant producers }\end{array}$ & 3 & 4 & 4 & 3 & 0 & 0 & 0 & 0 \\
\hline
\end{tabular}

Source: See Appendix A.1

Notes: For a list of countries see Appendix A.1.

(a) Countries in the sample with missing data most likely exceeding 100 million USD and value added exceeding 50 million USD.

The evolution of the global industry closely reflects the macroeconomic, technological and political events of the same period. In Chapter 2 we discussed the major technological changes in aircraft manufacturing. The rapid expansion of air transportation was made possible by technological innovations such as the jet engine after World War II. With the onset of the Cold War, rockets and missiles became more sophisticated and were produced in great numbers. The satellite industry took off with the launch of Sputnik in 1957, although the scale of production was significantly lower than in the aircraft segment. Nevertheless, the industry can be treated as a single entity given the large overlap between aeronautics and astronautics, and commercial and defense production.

The dual use of aerospace products for commercial aviation and military purposes is clearly visible in the patterns of change in aerospace production (Figure 3.1).

\footnotetext{
${ }^{53}$ Once again, excluding the former Soviet Union, where another 300,000 jobs were cut according to conservative estimates.
} 
Major armed conflicts and escalation of international political tension such as the Vietnam War and the Space Races of the 1960s and 1980s appear as production peaks. The end of the Cold War appears as a steep downward slope. This production landscape is further shaped by periods of economic expansion and recession in major producing countries, such as the expansion periods of the late 1970s, the second half of the 1980s or the late 1990s, or the recessions following the oil crisis (1973-75) and during the early 1980s. Our consistent time series ends in 2007, but the effects of the most recent global financial crisis are already apparent for 2008-10.

During the four decades of the Cold War, the industry benefited greatly from high defense expenditures and from the fact that national security considerations often overrode economic considerations. However, it is noteworthy that the growth resulting from the increasing commercial sales during the post-Cold War era was more rapid than ever before. Global production in terms of value added increased 2.2-fold over merely 12 years between 1995 and 2007. To put this expansion in perspective, it took 30 years to achieve a 2.4-fold increase between 1960 and 1990.

The aggregate figures presented in this chapter provide the most comprehensive overview of the industry so far, as our scope is not limited to the largest North American and European producers. Nevertheless, there are a few countries that are not included in the sample, and this has an impact on the aggregate figures. As discussed above, the Russian Federation (and the former Soviet Union) has not published comparable output value figures for the industry. We estimate that Russian output may have matched US levels during the Cold War in military production, but commercial production was significantly lower given the more limited air transport industry in former communist countries. It is impossible to estimate how the inclusion of the Russia and the Soviet Union would influence global aggregate figures. ${ }^{54}$

\footnotetext{
${ }^{54}$ The rough military aircraft export trend indicator values published by SIPRI show the highest export activity between 1972 and 1989, with a peak in 1980. This corresponds to the production pattern observable in the most successful commercial planes (the Tu-134 and -154). The drop by the 1990s in both military and commercial production may have been as much as two-third the previous rates. If we added these trends to the global aggregate figures, the 1970 s and 80 s levels would be higher at least by $50 \%$ and the slump between 1990 and 1995 would look even more dramatic. The impact would be far less significant from the 1990s onward.
} 
Figure 3.1 Schematic evolution of the global aerospace industry

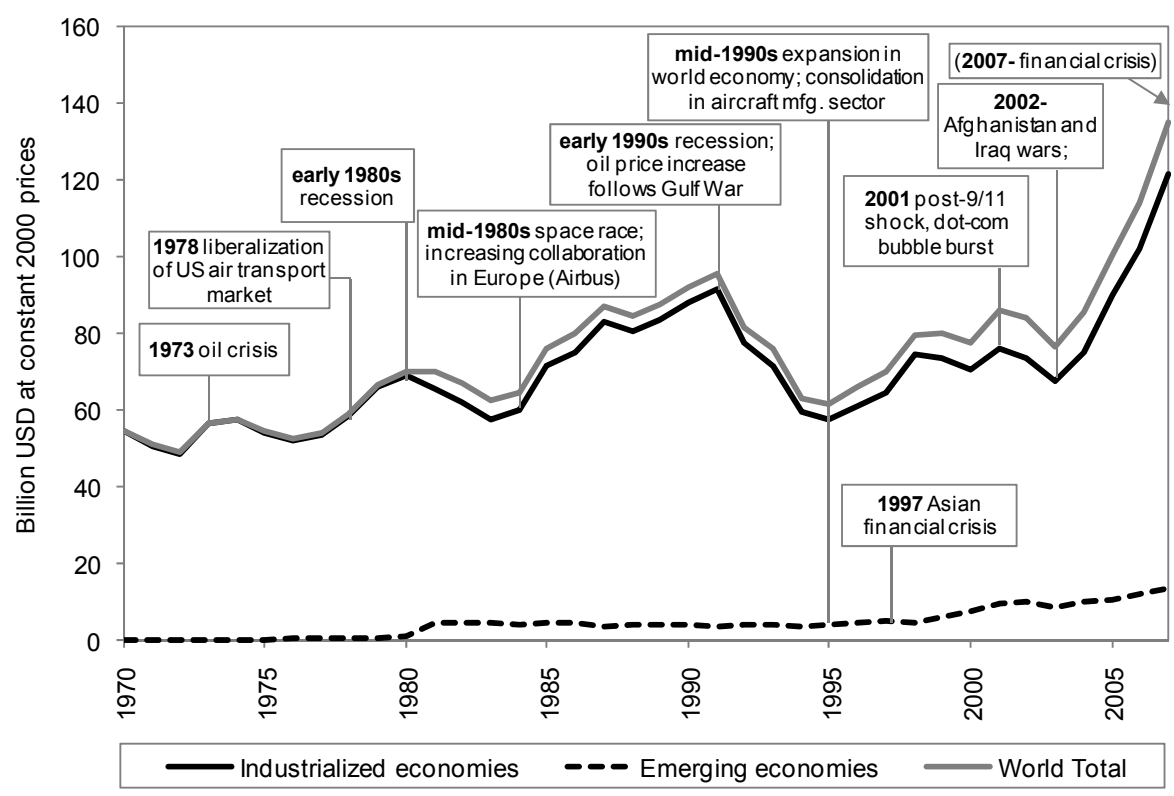

Source: same as Table 3.3

Although the sample size has increased over time (Table 3.2), this is more an indicator of the diffusion of the industry than of missing data and has only a limited impact on the global aggregate. Countries missing from the sample are China, the former socialist countries of Central Eastern Europe and Israel. China is the main source of inconsistencies over time, because our time series data begins with $1981 .{ }^{55}$ China was responsible for $4.7 \%$ of global production in 1981, and 3.9\% in 1985 . The exact volume of production is unknown as no official statistics were published on the sector. Secondary sources suggest that military aircraft production (by far the largest share of total output) started to increase in the mid 1960s and peaked around 1980 (Frankenstein and Gill, 1996). We estimate that the inclusion of China would only increase the 1960 levels by $1-2 \%$ and the 1973 values by $2-4 \%$. Other countries excluded from the sample for some years include Israel (with no data before 1990) and Central Eastern European producers responsible for a significant amount of fighter and trainer production (Czechoslovakia, Poland, Romania, with no data before 1995). At this point we cannot estimate their significance, but it is reasonable to believe that their aggregate would be less than that the Chinese output in 1973 but higher than China in 1960. In sum, the

\footnotetext{
${ }^{55}$ Official series begin only with 1995. For details on Chinese extrapolation see Appendix A.1.2.1.
} 
margin of error for our output estimates could be between $5-8 \%$ for the years before 1981.

Figure 3.2 Value added in aerospace by major country groups, 1955-2007 (Million USD at constant 2000 prices)

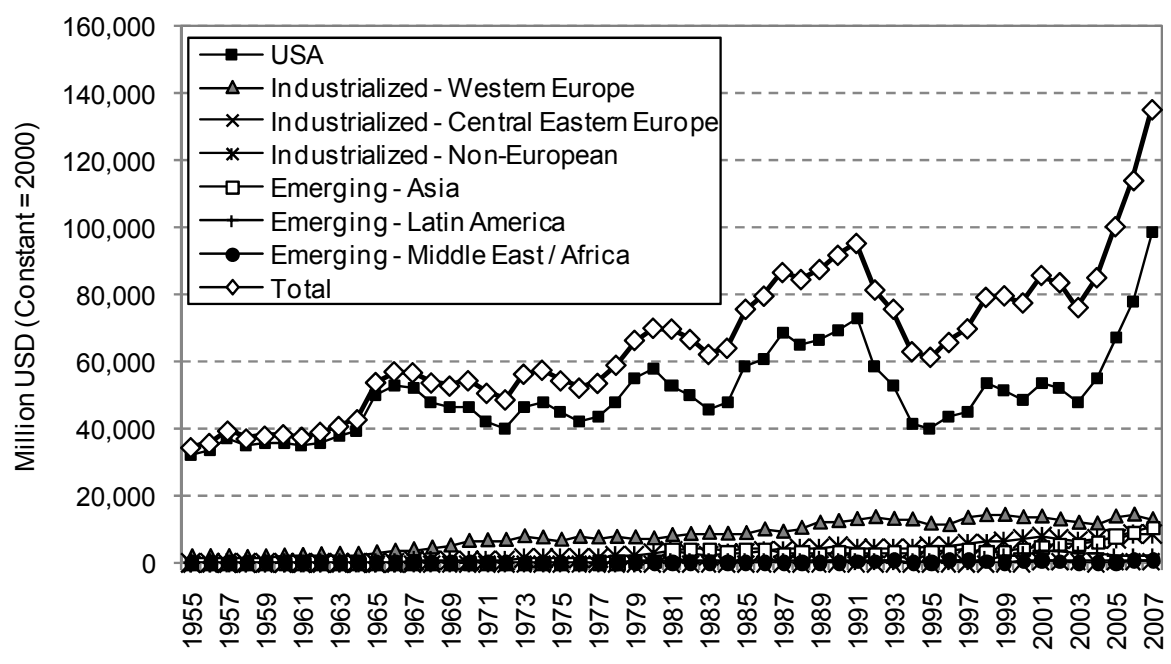

Source: See Table 3.3.

\subsection{The main incumbents and emerging aerospace producers}

Aerospace production has been extremely concentrated. In 2007 there were around 40 countries in the world that produced aircraft and spacecraft or engines and parts thereof. In only 25 of them did value added exceed 100 million dollars. Production reaching or exceeding one billion dollar is concentrated to merely 11 countries. These 11 countries accounted for $97 \%$ of total production value in 2007 . The USA stands out with its commanding dominance of the industry, it alone produced more than the rest of the world combined. In 2007, the turnover of US producers was 161 billion USD and value added was 99 billion, which accounted for $52 \%$ and $73 \%$ of global production, respectively.

Table 3.3 presents figures for value added and Table 3.4 for gross output in the industry. For analytical reasons, industrialized and emerging countries have been divided into three subgroups in these tables. The main rationale behind the groupings was to follow regional boundaries, but exceptions had to be made in the case of a few industrialized countries. The largest producers are shown separately. Europe is divided into West and East based on historical considerations. Countries of the East are particular because of their common heritage of socialist industrialization and the lack of 
information on production before 1990. Ukraine, which can be considered as an incumbent and is the only CIS country for which gross output and employment data was available (at least for the last decade), is also grouped here due to its proximity. The geographically heterogeneous group of 'other industrialized countries' includes four current or future OECD members on three continents (Australia, Canada, Japan, and Israel), all with a relatively long history of aircraft manufacturing.

Emerging economies represent an even more diverse group of countries encompassing very different levels of income, industrialization, geographical location, or the aerospace output today. For the purposes of this study, countries qualify as emerging if they were low or middle income countries at the time of entry into the aerospace industry. However, there are two further criteria: (1) being a latecomer in the aerospace industry and (2) a non-European or North American location. Latecomer status refers to a relatively shorter history in aerospace manufacturing, with significant manufacturing activity not starting before the Second World War. There is of course a degree of arbitrariness in every classification and this one is no exception. In Argentina and Brazil, for instance, small planes were already designed and produced locally during and before the 1930s. Yet, as we shall show, industrial-scale production started in the second half of the $20^{\text {th }}$ century. The second qualification, location, is also important. Despite the fact that many European or North American countries were latecomers (a famous example is Canada), they were already relatively high-income countries with a high level of industrialization at the time they entered the industry, which distinguishes them from countries in the developing world. As the name implies, the emergent economies experienced a dynamic growth period during the second half of the $20^{\text {th }}$ century. As a result historical classification does not necessarily overlap with the current one. Considering the World Bank's income-based classification, some countries (such as China, India, Indonesia) currently belong to the lower-middle-income economies, others (such as Brazil, Chile, Turkey, South Africa) belong to the upper-middle-income economies; two economies (Hong Kong and South Korea) even fall into the highincome ones. ${ }^{56}$ In the course of the past decades not only positions but also criteria of classification changed. Emerging economies are divided into three regional subgroups: Asia, Latin America and Middle East/Africa. Geographical location makes the distinction rather straightforward, leaving probably the sole significant African producer, South Africa as an outlier. (Egypt, which also has a history in aircraft assembly, could serve as a bridge should statistical data become available one day.)

\footnotetext{
${ }^{56}$ The Republic of Korea became an OECD member in 1996, but it is still a relative newcomer in the aerospace industry. The same is true for Turkey, which, based on its long OECD membership could also end up in the 'other industrialized countries' group.
} 
In 2007, firms of industrialized economies produced $86 \%$ of global output and $90 \%$ of global value added. The USA was followed by Western Europe, which accounted for $27 \%$ of global output, but only $10 \%$ of global value added. In absolute terms the gross output of Western Europe was 85 billion dollars (of which France accounted for 37.7, Germany 16.6 and the UK for 14.6 billion USD). Western European producers sold more than twice as many as their emerging Asian counterparts and four times as much as other industrialized producers. When comparing value added, Western Europe has a rather sluggish position with only $13 \%$ of US levels. At 13 billion USD Western Europe value added is about the same as that of the emerging economies. Canada follows Western Europe, although if countries are considered separately, Canada's 5 billion USD value added exceeded that of the best performers in Western Europe.

In 2007, the total gross output of emerging economies reached a new record high of 43.4 billion USD, which amounted to $14 \%$ of world production. If production is measured in terms of value added, their share is only $10 \%$. China is the largest producer with 7 billion dollars ( 7.5 billion if combined with Hong Kong), followed by Singapore (2.1 billion), Brazil (1.9 billion) and the smaller Asian and Latin American producers, South Korea, Turkey, Mexico, India and Malaysia. Other South American and East Asian countries report rather low aerospace production. This does not necessarily refer to production capabilities, it is rather a result of the fact that maintenance, repair and overhaul activities are included in aerospace manufacturing.

The snapshot of the industry production in terms of value added in 2007 thus shows a very uneven landscape. In the shadow of the towering leadership of the United States, there is a fierce competition in the middle-ranks. Currently the greatest rivals are interestingly not the USA and Europe, but rather Europe and the other industrialized countries, and the best performing emerging countries. In the top ten ranks positions in terms of value added we already find three emerging economies that outperformed a number of experienced industrialized countries. It might come as a surprise to observers of the industry who dismissed newcomers' attempts that the second place in terms of value added is occupied by China. Established producers from the North AmericanEuropean core, such as Canada, the United Kingdom, Italy and France were neck and neck with Singapore, Japan and Brazil. This is remarkable since some of these countries do not have an emblematic aircraft assembler. While it is easy to associate Western Europe with EADS/Airbus, Canada with Bombardier, Brazil with Embraer, the success of Japan and Singapore indicates that parts and components producers can be as successful as system assemblers. 
Table 3.3 Value Added in Aerospace Manufacturing, 1960-2007

(Million USD at constant $=2000$ prices)

\begin{tabular}{|c|c|c|c|c|c|c|c|c|c|}
\hline & 1960 & 1973 & 1985 & 1990 & 1995 & 2000 & 2005 & 2007 & $\begin{array}{c}\text { Global Share } \\
\text { in } 2007(\%)\end{array}$ \\
\hline Global & 38,586 & 56,568 & 75,846 & 91,878 & 61,593 & 77,716 & 100,359 & 135,090 & 100.0 \\
\hline Industrialized Countries & 38,586 & 56,351 & 71,407 & 87,912 & 57,530 & 70,277 & 89,755 & 121,540 & 90.0 \\
\hline United States & 35,987 & 46,749 & 58,918 & 69,868 & 40,160 & 48,926 & 67,853 & 99,144 & 73.4 \\
\hline Western Europe & 2,369 & 8,098 & 9,044 & 12,624 & 11,856 & 13,771 & 13,978 & 13,161 & 9.7 \\
\hline France & 245 & 801 & 1,978 & 1,820 & 4,514 & 3,018 & 3,009 & 2,428 & 1.8 \\
\hline Germany & 82 & 581 & 984 & 1,364 & 1,335 & 2,803 & 3,520 & 3,169 & 2.3 \\
\hline Italy & 305 & 3,876 & 3,641 & 5,349 & 3,123 & 3,677 & 2,839 & 2,597 & 1.9 \\
\hline United Kingdom & 1,648 & 2,130 & 1,583 & 2,912 & 1,870 & 2,776 & 2,868 & 3,223 & 2.4 \\
\hline Other Western Europe & 89 & 711 & 858 & 1,179 & 1,013 & 1,496 & 1,742 & 1,744 & 1.3 \\
\hline Central/Eastern Eur./CIS & n.a. & n.a. & n.a. & 281 & 106 & 295 & 359 & 501 & 0.4 \\
\hline CEE, EU Members & n.a. & n.a. & n.a. & 281 & 106 & 295 & 359 & 501 & 0.4 \\
\hline Ukraine & n.a. & n.a. & n.a. & n.a. & n.a. & n.a. & n.a. & n.a. & 0.0 \\
\hline Other Industrialized & 230 & 1,504 & 3,445 & 5,139 & 5,408 & 7,285 & 7,565 & 8,735 & 6.5 \\
\hline Australia & n.a. & 161 & 215 & 234 & 248 & 337 & 548 & 636 & 0.5 \\
\hline Canada & 228 & 1,050 & 1,652 & 2,951 & 2,622 & 4,124 & 3,847 & 5,221 & 3.9 \\
\hline Israel & n.a. & n.a. & n.a. & 488 & 510 & 637 & 505 & 794 & 0.6 \\
\hline Japan & 2 & 293 & 1,578 & 1,466 & 2,028 & 2,187 & 2,665 & 2,084 & 1.5 \\
\hline Emerging Economies & n.a. & 217 & 4,439 & 3,966 & 4,063 & 7,438 & 10,604 & 13,550 & 10.0 \\
\hline Asia & n.a. & 112 & 3,934 & 3,119 & 3,218 & 4,325 & 8,216 & 10,718 & 7.9 \\
\hline China (People's Rep. of) & n.a. & n.a. & 2,928 & 2,118 & 1,587 & 2,297 & 5,098 & 7,072 & 5.2 \\
\hline China (Hong Kong SAR) & n.a. & 104 & 242 & 212 & 228 & 205 & 420 & 480 & 0.4 \\
\hline India & n.a. & n.a. & 60 & 87 & 275 & 46 & 174 & 134 & 0.1 \\
\hline Indonesia & n.a. & n.a. & 22 & 48 & 206 & 227 & 37 & 73 & 0.1 \\
\hline Korea, Rep. of & n.a. & 9 & 130 & 197 & 198 & 446 & 479 & 704 & 0.5 \\
\hline Malaysia & n.a. & n.a. & n.a. & 38 & 43 & 71 & 128 & 133 & 0.1 \\
\hline Philippines & n.a. & n.a. & 6 & 14 & 8 & n.a. & n.a. & n.a. & 0.0 \\
\hline Singapore & n.a. & n.a. & 545 & 403 & 673 & 1,034 & 1,880 & 2,121 & 1.6 \\
\hline Latin America & n.a. & 104 & 505 & 847 & 763 & 2,778 & 2,070 & 2,257 & 1.7 \\
\hline Argentina & n.a. & n.a. & n.a. & n.a. & n.a. & n.a. & n.a. & n.a. & 0.0 \\
\hline Brazil & n.a. & 104 & 280 & 630 & 278 & 2,348 & 1,783 & 1,924 & 1.4 \\
\hline Chile & n.a. & n.a. & 41 & 55 & 17 & 137 & 26 & 18 & 0.0 \\
\hline Colombia & n.a. & n.a. & 70 & 70 & 144 & 72 & 39 & 79 & 0.1 \\
\hline Mexico & n.a. & n.a. & 115 & 92 & 325 & 221 & 222 & 236 & 0.2 \\
\hline Peru & n.a. & n.a. & n.a. & n.a. & n.a. & n.a. & 0 & 1 & 0.0 \\
\hline Africa \& Middle East & n.a. & n.a. & n.a. & n.a. & 82 & 336 & 319 & 575 & 0.4 \\
\hline Iran (Islamic Rep. of) & n.a. & n.a. & n.a. & n.a. & 13 & 30 & 100 & 100 & 0.1 \\
\hline South Africa & n.a. & n.a. & n.a. & n.a. & 70 & 55 & 37 & 38 & 0.0 \\
\hline Turkey & n.a. & n.a. & n.a. & n.a. & n.a. & 251 & 182 & 438 & 0.3 \\
\hline
\end{tabular}

Sources: Appendix A.1;

Notes: "Other Western Europe" includes Austria, Belgium, Denmark, Finland, Greece, Iceland, Ireland, Luxembourg, The Netherlands, Norway, Portugal, Spain and Sweden. "Central Eastern Europe” includes the Czech Republic, Hungary, Poland, Romania, Slovakia and Slovenia. (n.a. = not available) 
Table 3.4 Gross output of aerospace manufacturing, 1960-2007

(Million USD at constant $=2000$ prices)

\begin{tabular}{|c|c|c|c|c|c|c|c|c|c|}
\hline & 1960 & 1973 & 1985 & 1990 & 1995 & 2000 & 2005 & 2007 & $\begin{array}{l}\text { Global share } \\
\text { in } 2007(\%)\end{array}$ \\
\hline Global & 78,978 & 110,435 & 167,726 & 218,602 & 165,984 & 233,946 & 267,664 & 312,480 & 100.0 \\
\hline Industrialized Countries & 78,978 & 110,102 & 155,476 & 207,613 & 155,437 & 214,100 & 232,870 & 269,043 & 86.1 \\
\hline United States & 67,800 & 80,328 & 109,397 & 146,827 & 98,394 & 118,629 & 134,201 & 161,081 & 51.5 \\
\hline Western Europe & 10,544 & 26,042 & 37,820 & 47,785 & 41,700 & 71,948 & 76,088 & 85,156 & 27.3 \\
\hline France & 1,583 & 4,530 & 12,437 & 14,005 & 13,253 & 27,889 & 33,247 & 37,768 & 12.1 \\
\hline Germany & 134 & 2,627 & 4,241 & 6,790 & 6,285 & 13,640 & 15,453 & 16,600 & 5.3 \\
\hline Italy & 630 & 4,931 & 7,998 & 8,745 & 6,832 & 8,061 & 7,202 & 8,623 & 2.8 \\
\hline United Kingdom & 8,020 & 11,356 & 9,626 & 13,297 & 10,466 & 16,474 & 13,526 & 14,666 & 4.7 \\
\hline Other Western Europe & 178 & 2,599 & 3,518 & 4,948 & 4,864 & 5,884 & 6,660 & 7,499 & 2.4 \\
\hline Central/Eastern Eur./CIS & n.a. & n.a. & n.a. & 650 & 1,496 & 2,185 & 1,114 & 1,594 & 0.5 \\
\hline CEE, EU Members & n.a. & n.a. & n.a. & 650 & 499 & 866 & 1,114 & 1,594 & 0.5 \\
\hline Ukraine & n.a. & n.a. & n.a. & n.a. & 996 & 1,319 & n.a. & n.a. & n.a. \\
\hline Other Industrialized & 634 & 3,732 & 8,258 & 12,351 & 13,847 & 21,338 & 21,467 & 21,212 & 6.8 \\
\hline Australia & n.a. & 442 & 515 & 758 & 899 & 1,129 & 1,731 & 1,424 & 0.5 \\
\hline Canada & 628 & 1,919 & 3,518 & 5,959 & 6,726 & 12,384 & 10,978 & 12,370 & 4.0 \\
\hline Israel & n.a. & n.a. & n.a. & 948 & 993 & 1,262 & 1,096 & 1,720 & 0.6 \\
\hline Japan & 5 & 1,371 & 4,226 & 4,686 & 5,228 & 6,563 & 7,662 & 5,697 & 1.8 \\
\hline Emerging Economies & n.a. & 333 & 12,250 & 10,989 & 10,547 & 19,846 & 34,794 & 43,437 & 13.9 \\
\hline Asia & n.a. & 137 & 11,506 & 9,160 & 8,863 & 13,463 & 28,141 & 35,664 & 11.4 \\
\hline China (People's Rep. of) & n.a. & n.a. & 10,077 & 7,289 & 5,345 & 8,426 & 19,445 & 24,802 & 7.9 \\
\hline China (Hong Kong SAR) & n.a. & 132 & 298 & 261 & 281 & 620 & 1,270 & 1,636 & 0.5 \\
\hline India & n.a. & n.a. & 308 & 414 & 869 & 116 & 330 & 402 & 0.1 \\
\hline Indonesia & n.a. & n.a. & 71 & 146 & 336 & 230 & 188 & 222 & 0.1 \\
\hline Korea, Rep. of & n.a. & 5 & 46 & 199 & 747 & 1,557 & 1,610 & 2,347 & 0.8 \\
\hline Malaysia & n.a. & n.a. & n.a. & 67 & 76 & 123 & 791 & 823 & 0.3 \\
\hline Philippines & n.a. & n.a. & 15 & 24 & 31 & n.a. & n.a. & 0 & 0.0 \\
\hline Singapore & n.a. & n.a. & 692 & 759 & 1,179 & 2,391 & 4,508 & 5,432 & 1.7 \\
\hline Latin America & n.a. & 196 & 744 & 1,693 & 1,508 & 5,806 & 6,001 & 6,648 & 2.1 \\
\hline Argentina & n.a. & n.a. & n.a. & n.a. & n.a. & n.a. & n.a. & 0 & 0.0 \\
\hline Brazil & n.a. & 196 & 527 & 1,187 & 523 & 4,976 & 5,224 & 5,702 & 1.8 \\
\hline Chile & n.a. & n.a. & 46 & 62 & 66 & 57 & 66 & 46 & 0.0 \\
\hline Colombia & n.a. & n.a. & 171 & 245 & 241 & 138 & 132 & 186 & 0.1 \\
\hline Mexico & n.a. & n.a. & n.a. & 199 & 678 & 635 & 577 & 710 & 0.2 \\
\hline Peru & n.a. & n.a. & n.a. & n.a. & n.a. & n.a. & 1 & 3 & 0.0 \\
\hline Africa \& Middle East & n.a. & n.a. & n.a. & 137 & 176 & 578 & 652 & 1,125 & 0.4 \\
\hline Iran (Islamic Rep. of) & n.a. & n.a. & n.a. & n.a. & 14 & 56 & 118 & 118 & 0.0 \\
\hline South Africa & n.a. & n.a. & n.a. & n.a. & 161 & 128 & 85 & 89 & 0.0 \\
\hline Turkey & n.a. & n.a. & n.a. & 137 & n.a. & 394 & 449 & 918 & 0.3 \\
\hline
\end{tabular}

Source: See Appendix A.1

Notes: See Table 3.3 Notes. 


\subsection{Dynamics in the rankings}

For many much of its history, aerospace has been an industry of the West. But what are the long-term trends? Has there been evidence of emerging latecomers catching up with the industrialized countries?

Catch-up is generally understood as a relatively faster per capita income growth in poorer countries compared to richer countries, leading to a convergence in their per capita incomes. In the context of the aerospace industry, we refer to catch-up as a convergence of value added shares. Catch-up in general entails reducing of the technology gap between countries, and this is inherent in significant value added growth in latecomer aerospace production, given the high-tech nature of the products.

As Figure 3.2 shows, the dominance of the United States has been unchallenged during the last five decades. Due to its sheer size, changes in the United States production shaped the pattern of the global industry. Only between 1998 and 1999 could a $28 \%$ increase in emerging countries (mostly due to Brazil) offset on the global level a $3.4 \%$ decline in the USA. Over periods of growth and decline, US production in average increased annually by $2.3 \%$ between 1955 and 1991. The first acceleration of growth occurred after 1964, peaking in 1966 (at 53 billion dollars) as defense spending due to the Vietnam War and the major space programs. The growth ran out of steam and output decreased at an average rate of $4.3 \%$ until 1972. The subsequent growth period triggered by fiscal stimulus and the devaluation of the dollar came to an end with the oil crisis. Between 1972 and 74 the industry grew by $9 \%$ on average and declined by $6 \%$ over the following two years. The deregulation of the domestic air transport market in 1978 had a significant impact and the industry reached a historical high in 1980 over three years with an average of $10 \%$ growth. Yet another recession and high oil prices during the early Reagan years resulted in a 7.6\% decline over the following 3 years. The trend turned around in 1983, and the falling oil prices and increased defense spending resulted in 8 years of growth, aerospace production increased at an annual average of $6 \%$ to another historical peak of 73.3 billion dollars at the end of the Cold War. The subsequent decline of defense budgets and increase in oil prices due to the Gulf War triggered a decline in production steeper than ever before. Within only 4 years US value added fall back to 1972 levels, at a rate of 14\% per year. As a result, the US industry experienced a previously unseen number of high-profile mergers and acquisitions during the 1990s. McDonnell-Douglas was taken over by Boeing, Lockheed merged with Martin-Marietta, Raytheon with Hughes. This was followed by a shake-out of hundreds of smaller firms (Lazonick, 2002). The effects of this deep-cutting consolidation started to become evident from 1995, but a real growth was spurred after 2003, once again as the US defense budget skyrocketed and the industry witnessed a $20 \%$ average annual growth until 2007. Only after this acceleration period did the industry return to the 
long-term growth trajectory. Comparing the 1990 and 2007 levels reveals a compound growth of $2.1 \%$.

Against this background we try to identify whether the country groups were catching up with the USA in terms of increasing relative value added. Figure 3.3 shows the share of value added of the various country groups compared to the US. (The 1981 trend break in the emerging economies series is a result of missing Chinese data before 1980, see discussion above.)

Figure 3.3 Trends in aerospace value added of country groups compared with the US, 1960$2007($ USA $=100 \%)$

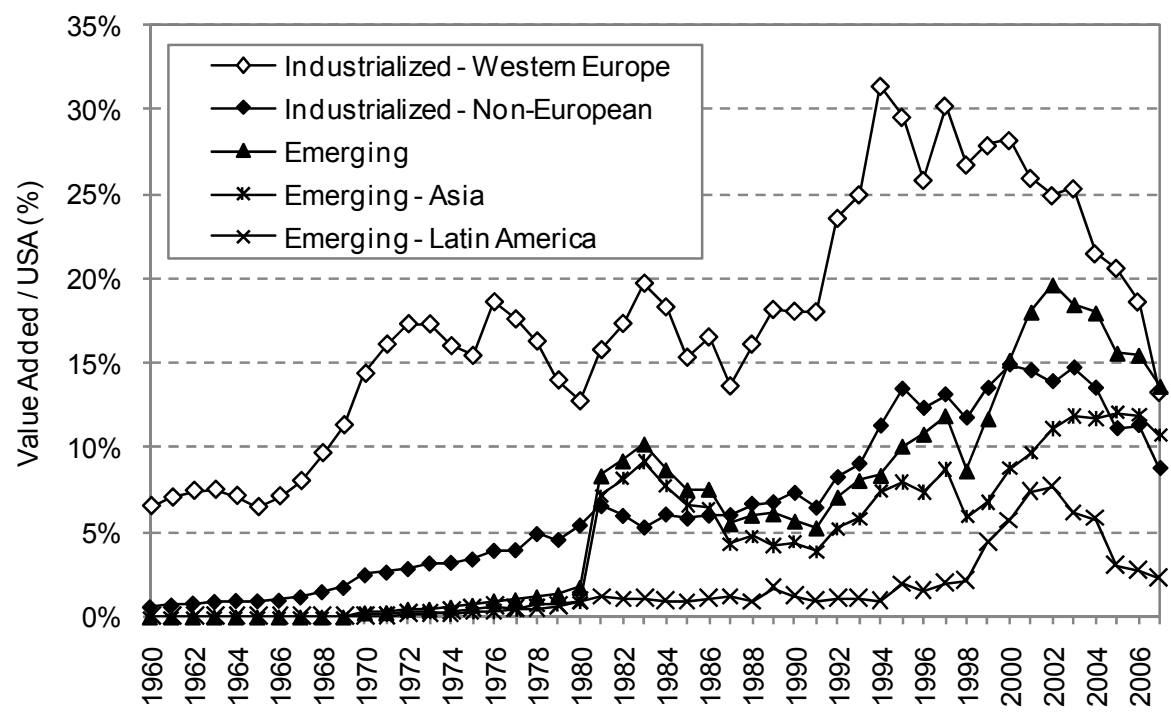

Source: See Appendix A.1;

Note: Value added in constant 2000 dollars.

Western Europe started out with less than $10 \%$ of US value added in the 1960s. In absolute terms this group followed a growth pattern that was formed by macroeconomic and political events (e.g. after the slump following the oil crisis the 1973 peak was only exceeded in 1981). In relative terms, the most significant growth of Western Europe's ratio compared to the US took place after 1987 with the realization of the common market and the flagship joint project the Airbus. From 6.7 billion dollars and a relative share of $15 \%$, the Western Europe aerospace sector expanded production to 13.8 dollars by the peak of 1992. It reached nearly a quarter of the US production level. The above $30 \%$ relative share was caused by the crisis that hit the USA much harder than Europe, which was hit less severe in 1995 and 1996. But the decline in value added between 1992 
and 1996 from 14 to 11 billion dollars was significant and not without consequences for even the largest of the companies. The Dutch producer Fokker went bankrupt and the Swedish Saab stopped the production of commuter planes. In France, two giants, Aerospatiale and Matra merged, and the previous cooperation in the Airbus consortium was taken to a new level with the creation of EADS, a single corporation. Since the 1990s, Western European aerospace output is increasingly experiencing fluctuations and was unable to exceed 14.5 billion dollars in value added terms. In comparison with the continuously growing US production, Western Europe's share once again declined to $13 \%$ by 2007.

Countries in "the other industrialized" group experienced a rather smooth and uninterrupted growth during the 1970-90s. From 1973 to 1985 total value added increased from 1.5 to 3.5 billion dollars and further grew to 5.1 billion by 1990 . During the global industry's crisis in the early 1990s, they only experienced an $8 \%$ decline, and continued on their growth trajectory after 1994. Comparing the group's value added with the USA, this group advanced its position from $3 \%$ in 1973 to $15 \%$ in 2000 , only to decline to $9 \%$ by 2007 as a result of accelerated growth in the USA.

Excluding China, production in emerging economies (Hong Kong, Brazil, Singapore) was rather insignificant in the 1970s. In 1973, value added amounted to 217 million USD, a mere $0.5 \%$ of the US level. Although Brazil, Hong Kong and Singapore showed quite significant growth by 1980, this was only enough to reach 1 billion dollars (hardly $2 \%$ of the US) together with Colombia, India, South Korea and Malaysia. Including China, the emergent group's production reached 4.4 billion dollars by 1985 (without China 1.5 billion), which was already $7.5 \%$ of US output (without China only $2.5 \%)$. Since Chinese military production declined over the $1980 \mathrm{~s}$, the total production of emerging countries shrank to 4 billion by 1990 going against the global trend (although other emerging countries were still experiencing over $20 \%$ growth). There was a reshuffling in the emerging block as Brazil became the second largest producer (with 630 million dollars) overtaking Singapore and Hong Kong (403 and 212 million dollars, respectively). The troubled years after the end of the Cold War meant a 19\% decline of value added for the emerging countries by 1994. Already growing in 1995, the group reached $10 \%$ of US value added levels and by 2000 reached $15 \%$ topping with a historical peak of $20 \%$ in 2003. Between 1995 and 2007 the average annual growth rate of value added was $7.8 \%$ in the USA and $10.6 \%$ in emerging economies (Table 3.5). Once again there was some turbulence in the ranking. As Brazilian value added declined, Singapore has been holding the second place since 2005 .

Three of the emerging economies were strikingly successful in securing their position among the top ten global producers in terms of value added. Already in 1985 (the defense oriented) Chinese aerospace industry was the third largest in the world. But 
as the industry was scaling down fighter jet production and shifting to civilian products, it fell back during the 1980s and 90s and was only the $8^{\text {th }}$ in 2000 . However, after successfully turning around, China forged ahead and by 2003 had become the world's second largest producer. It has since then retained the leading position among the middle-range players, owing it primarily to its ever increasing share in global aircraft component supply chains.

Brazil showed a steady growth during the 1970s and 1980s by producing commuter aircraft and an even greater expansion with regional jets from the mid 1990s. From the $9^{\text {th }}$ place in 1990, the country climbed to the $7^{\text {th }}$ place by the year 2000 . At its peak in 2003, Brazil narrowly overtook Canada and China and took the $2^{\text {nd }}$ place. For reasons to be discussed in the following chapter, value added decreased dramatically thereafter, landing Brazil in the $10^{\text {th }}$ place, but still among the major players.

Producers of Singapore chose a different approach. Instead of making complete planes, the city state became a South East Asian hub for maintenance, repair and overhaul, and a manufacturer of parts and component for the major global players. This was deemed successful for a continuous growth and a secure position among the top ten.

Apart from these three most successful countries, about a dozen other emerging producers appear on the lower strata of the radar. South Korea reached the 100 million dollar mark in 1984 and grew slowly to exceed half a billion by 2004. From a relatively small producer it increasingly won contracts and used offset agreements that realized a historical maximum of 704 million dollars in 2007. Indonesia shows another interesting growth path. Following a slow but steady growth, the country reached a maximum of 433 million dollars in 1996 before it came to a sudden halt. Today value added hardly reaches 73 million dollars. Despite the high profile experiments in air and space, India is less significant when it comes to mass-production and the industry is still waiting to take off. India was reporting small scale activities below 100 million dollars until 1989 and grew to a historical peak of 295 in 1997. Following a steep reduction in the years that followed it has been slowly resuming growth since 2001. Although beyond the timeframe of the present study, aerospace exports appear to have suddenly risen exponentially in 2008 and the industry is expected to embark on a new growth path. Another smaller Southeast Asian player is Malaysia, keen on expanding high-tech activities, including aerospace. Value added (mostly MRO) exceeded the 100 million mark in 2003 and continues to grow. Among the Middle Eastern countries, Iran and Turkey are the most significant producers. Turkey has made attempts to increasing parts and components manufacturing and local assembly of military aircraft in offset agreements. The African outlier, South Africa gained experience in producing missiles 
and assembling military aircraft and helicopters during the apartheid regimes (Goldstein 2002). Production has been declining since 1993.

In South America no other country with production or repair capacities has reached the level of Brazilian output. Argentina, a promising military aircraft producer after the Second World War, is hardly showing up in the statistics; in 1984 when the industry was relatively larger, it was $1 / 6^{\text {th }}$ of Brazil's at that time. Colombia and Chile, producers of small aircraft home to MRO facilities, reported fluctuations, hardly exceeding 100 million dollars.

Table 3.6 shows that all of the countries that increased their global value added share experienced interuptions in their growth. Even at the global level where the general trend was one of narrowing the value added gap vis-à-vis the USA, the gap in fact increased over the periods 2000-05 and 1995-2007. This global trend was because Western Europe and other industrialized economies were falling behind, but Latin American latecomers were showing even more sluggish performance. Emerging economies on the whole show a different trend. Except in the period 1985-90 which saw an absolute decline of the Chinese, Singaporean and some Latin American industries, the group achieved high rates of catch-up. At the end of the 1990s, the rapid growth in most of Asia was large enough to offset the general decline in Latin America.

Highly fluctuating trends can be observed in all emerging economies. The annual average "catch-up rate" (narrowing the value added gap with the US) for Brazil over the period 1973 through 1990 was 8.6\%. After major struggles during the Post-Cold War global crisis, Brazil once again powered its engine in 1995 and achieved spectacular growth by the year 2000 (with as much as $47.3 \%$ annual growth in this share of US output). This was followed by another double-digit (-11.4\%) decline during the 2000-05 period. However, the overall trend between 1995 and 2007 was positive with a nearly $9 \%$ annual growth (Table 3.6). Other Latin American producers ${ }^{57}$ show very high rates of catch-up during one of the 5-year periods (i.e. Chile during 1995-2000 and Colombia and Mexico during 1990-95). However, these were only ad-hoc events where maximum value added did not exceed 0.3, 0.4 and 0.8 per cent of US value added levels, respectively. Mexico was the only other Latin American country besides Brazil with a positive annual average "catch-up rate" to the USA was during the period 1990-2007.

\footnotetext{
${ }^{57}$ Value added data is not available for Argentina. It is doubtful that it would show convergence in any of the periods.
} 
Table 3.5 Aerospace value added changes, 1960-2007 (compound growth rates, \%)

\begin{tabular}{|c|c|c|c|c|c|c|c|c|}
\hline & $1960-73$ & $1973-85$ & $1985-90$ & $1990-95$ & $1995-2000$ & $2000-05$ & 1973-90 & 1995-2007 \\
\hline Global & 2.99 & 2.47 & 3.91 & -7.69 & 4.76 & 5.25 & 2.89 & 6.76 \\
\hline Industrialized Countries & 2.96 & 1.99 & 4.25 & -8.13 & 4.08 & 5.01 & 2.65 & 6.43 \\
\hline United States & 2.03 & 1.95 & 3.47 & -10.48 & 4.03 & 6.76 & 2.39 & 7.82 \\
\hline Western Europe & 9.92 & 0.92 & 6.90 & -1.25 & 3.04 & 0.30 & 2.65 & 0.87 \\
\hline France & 9.54 & 7.83 & -1.66 & 19.93 & -7.74 & -0.06 & 4.95 & -5.04 \\
\hline Germany & 16.21 & 4.49 & 6.75 & -0.43 & 15.99 & 4.66 & 5.15 & 7.47 \\
\hline Italy & 21.61 & -0.52 & 7.99 & -10.20 & 3.32 & -5.05 & 1.91 & -1.53 \\
\hline United Kingdom & 1.99 & -2.44 & 12.96 & -8.48 & 8.23 & 0.65 & 1.86 & 4.64 \\
\hline Other Western Europe & 17.29 & 1.58 & 6.57 & -2.98 & 8.10 & 3.09 & 3.02 & 4.63 \\
\hline Central/Eastern Eur./CIS & n.a. & n.a. & n.a. & -17.69 & 22.68 & 4.03 & n.a. & 13.80 \\
\hline CEE, EU Members & n.a. & n.a. & n.a. & -17.69 & 22.68 & 4.03 & n.a. & 13.80 \\
\hline Ukraine & n.a. & n.a. & n.a. & n.a. & n.a. & n.a. & n.a. & n.a. \\
\hline Other Industrialized & 15.53 & 7.15 & 8.33 & 1.03 & 6.14 & 0.75 & 7.50 & 4.08 \\
\hline Australia & n.a. & 2.44 & 1.73 & 1.14 & 6.33 & 10.18 & 2.23 & 8.16 \\
\hline Canada & 12.46 & 3.85 & 12.30 & -2.34 & 9.48 & -1.38 & 6.27 & 5.91 \\
\hline Israel & n.a. & n.a. & n.a. & 0.88 & 4.57 & -4.53 & n.a. & 3.76 \\
\hline Japan & 45.90 & 15.07 & -1.46 & 6.71 & 1.52 & 4.03 & 9.94 & 0.23 \\
\hline Emerging Economies & n.a. & 28.62 & -2.23 & 0.48 & 12.86 & 7.35 & n.a. & 10.56 \\
\hline Asia & n.a. & n.a. & -4.54 & 0.63 & 6.09 & 13.69 & n.a. & 10.55 \\
\hline China (P.R.) & n.a. & n.a. & -6.27 & -5.61 & 7.67 & 17.29 & n.a. & 13.26 \\
\hline China (Hong Kong SAR) & n.a. & 7.30 & -2.58 & 1.45 & -2.10 & 15.42 & 4.29 & 6.40 \\
\hline India & n.a. & n.a. & 7.46 & 25.94 & -30.02 & 30.50 & n.a. & -5.80 \\
\hline Indonesia & n.a. & n.a. & 17.05 & 33.68 & 1.94 & -30.22 & n.a. & -8.28 \\
\hline Korea, Rep. of & n.a. & 25.45 & 8.62 & 0.07 & 17.63 & 1.43 & 20.25 & 11.15 \\
\hline Malaysia & n.a. & n.a. & n.a. & 2.40 & 10.26 & 12.56 & n.a. & 9.78 \\
\hline Philippines & n.a. & n.a. & 17.47 & -10.50 & -100.00 & n.a. & n.a. & -100.00 \\
\hline Singapore & n.a. & n.a. & -5.82 & 10.77 & 8.98 & 12.70 & n.a. & 10.04 \\
\hline Latin America & n.a. & n.a. & n.a. & -2.08 & 29.50 & -5.71 & n.a. & 9.46 \\
\hline Argentina & n.a. & n.a. & n.a. & n.a. & n.a. & n.a. & n.a. & n.a. \\
\hline Brazil & n.a. & 8.60 & 17.62 & -15.12 & 53.26 & -5.36 & 11.18 & 17.50 \\
\hline Chile & n.a. & n.a. & 6.16 & -21.24 & 52.33 & -28.27 & n.a. & 0.78 \\
\hline Colombia & n.a. & n.a. & 0.09 & 15.52 & -13.02 & -11.45 & n.a. & -4.90 \\
\hline Mexico & n.a. & n.a. & -4.31 & 28.67 & -7.37 & 0.05 & n.a. & -2.62 \\
\hline Peru & n.a. & n.a. & n.a. & n.a. & n.a. & n.a. & n.a. & n.a. \\
\hline Africa \& Middle East & n.a. & n.a. & n.a. & n.a. & 32.44 & -1.05 & n.a. & 17.58 \\
\hline Iran (Islamic Rep. of) & n.a. & n.a. & n.a. & n.a. & 18.48 & 27.44 & n.a. & 18.73 \\
\hline South Africa & n.a. & n.a. & n.a. & n.a. & -4.53 & -7.86 & n.a. & -4.88 \\
\hline Turkey & n.a. & n.a. & n.a. & n.a. & n.a. & -6.20 & n.a. & n.a. \\
\hline
\end{tabular}

Source: Derived from Table 3.3

Note: Totals for (sub)groups with too many missing data are shown as not available (n.a.). 
Table 3.6 Value added as \% of US value added, 1960-2007

(compound growth rates, \%)

\begin{tabular}{|c|c|c|c|c|c|c|c|c|c|}
\hline & $1960-73$ & $1973-85$ & $1985-90$ & $1990-95$ & $1995-2000$ & $2000-05$ & $1973-90$ & $1990-2007$ & $1995-2007$ \\
\hline Global & 0.93 & 0.52 & 0.43 & 3.12 & 0.70 & -1.42 & 0.49 & 0.21 & -0.98 \\
\hline Industrialized Countries & 0.90 & 0.05 & 0.75 & 2.63 & 0.05 & -1.63 & 0.25 & -0.15 & -1.29 \\
\hline United States & 0.00 & 0.00 & 0.00 & 0.00 & 0.00 & 0.00 & 0.00 & 0.00 & 0.00 \\
\hline Western Europe & 7.73 & -1.00 & 3.31 & 10.32 & -0.95 & -6.05 & 0.25 & -1.80 & -6.44 \\
\hline France & 7.36 & 5.77 & -4.95 & 33.97 & -11.31 & -6.39 & 2.50 & -0.36 & -11.93 \\
\hline Germany & 13.90 & 2.49 & 3.17 & 11.23 & 11.50 & -1.96 & 2.69 & 2.94 & -0.33 \\
\hline Italy & 19.18 & -2.42 & 4.37 & 0.31 & -0.68 & -11.06 & -0.47 & -6.11 & -8.67 \\
\hline United Kingdom & -0.04 & -4.30 & 9.18 & 2.24 & 4.04 & -5.72 & -0.52 & -1.45 & -2.95 \\
\hline Other Western Europe & 14.96 & -0.36 & 3.00 & 8.38 & 3.92 & -3.44 & 0.62 & 0.25 & -2.96 \\
\hline Central/Eastern Eur./CIS & n.a. & n.a. & n.a. & -8.05 & 17.93 & -2.56 & n.a. & 1.35 & 5.55 \\
\hline CEE, EU Members & n.a. & n.a. & n.a. & -8.05 & 17.93 & -2.56 & n.a. & 1.35 & 5.55 \\
\hline Ukraine & n.a. & n.a. & n.a. & n.a. & n.a. & n.a. & n.a. & n.a. & n.a. \\
\hline Other Industrialized & 13.22 & 5.11 & 4.70 & 12.86 & 2.03 & -5.62 & 4.99 & 1.07 & -3.47 \\
\hline Australia & n.a. & 0.49 & -1.68 & 12.99 & 2.22 & 3.21 & -0.15 & 3.89 & 0.31 \\
\hline Canada & 10.22 & 1.87 & 8.54 & 9.10 & 5.24 & -7.63 & 3.79 & 1.31 & -1.77 \\
\hline Israel & n.a. & n.a. & n.a. & 12.69 & 0.52 & -10.58 & n.a. & 0.81 & -3.77 \\
\hline Japan & 43.00 & 12.87 & -4.77 & 19.21 & -2.41 & -2.55 & 7.37 & 0.01 & -7.04 \\
\hline Emerging Economies & n.a. & n.a. & -5.51 & 12.25 & 8.49 & 0.55 & 15.88 & 5.31 & 2.54 \\
\hline Asia & n.a. & n.a. & -7.74 & 12.41 & 1.99 & 6.50 & 18.74 & 5.34 & 2.53 \\
\hline China (P.R.) & n.a. & n.a. & -9.41 & 5.45 & 3.50 & 9.86 & n.a. & 5.16 & 5.05 \\
\hline China (HKG) & n.a. & 5.25 & -5.85 & 13.33 & -5.89 & 8.11 & 1.86 & 2.78 & -1.32 \\
\hline India & n.a. & n.a. & 3.86 & 40.68 & -32.73 & 22.24 & n.a. & 0.51 & -12.63 \\
\hline Indonesia & n.a. & n.a. & 13.12 & 49.34 & -2.01 & -34.64 & n.a. & 0.38 & -14.94 \\
\hline Korea, Rep. of & n.a. & 23.05 & 4.98 & 11.79 & 13.08 & -4.99 & 17.44 & 5.58 & 3.09 \\
\hline Malaysia & n.a. & n.a. & n.a. & 14.39 & 5.99 & 5.43 & n.a. & 5.37 & 1.82 \\
\hline Philippines & n.a. & n.a. & 13.53 & -0.02 & -100.00 & n.a. & n.a. & -100.00 & -100.00 \\
\hline Singapore & n.a. & n.a. & -8.98 & 23.74 & 4.76 & 5.56 & n.a. & 8.01 & 2.06 \\
\hline Latin America & n.a. & n.a. & 7.18 & 9.39 & 24.49 & -11.68 & n.a. & 3.78 & 1.52 \\
\hline Argentina & n.a. & n.a. & n.a. & n.a. & n.a. & n.a. & n.a. & n.a. & n.a. \\
\hline Brazil & n.a. & 6.52 & 13.67 & -5.18 & 47.33 & -11.35 & 8.58 & 4.61 & 8.98 \\
\hline Chile & n.a. & n.a. & 2.60 & -12.02 & 46.43 & -32.81 & n.a. & -8.18 & -6.53 \\
\hline Colombia & n.a. & n.a. & -3.26 & 29.05 & -16.39 & -17.06 & n.a. & -1.35 & -11.80 \\
\hline Mexico & n.a. & n.a. & -7.51 & 43.74 & -10.95 & -6.28 & n.a. & 3.54 & -9.68 \\
\hline Peru & n.a. & n.a. & n.a. & n.a. & n.a. & n.a. & n.a. & n.a. & n.a. \\
\hline Africa \& Middle East & n.a. & n.a. & n.a. & n.a. & 27.31 & -7.32 & n.a. & n.a. & 9.05 \\
\hline Iran (Islamic Rep. of) & n.a. & n.a. & n.a. & n.a. & 13.90 & 19.37 & n.a. & n.a. & 10.12 \\
\hline South Africa & n.a. & n.a. & n.a. & n.a. & -8.23 & -13.69 & n.a. & n.a. & -11.78 \\
\hline Turkey & n.a. & n.a. & n.a. & n.a. & n.a. & -12.14 & n.a. & n.a. & n.a. \\
\hline
\end{tabular}

Note: A (sub)group total value is shown as not available (n.a.) if it includes significant missing country data.

Source: Derived from Table 3.3

In East Asia, the best performing China experienced an average annual decline of more than 10\% vis-à-vis the USA between 1985 and 1990. After the turn-around, its annual average rate of catch-up to the leader was 4.4\% between 1990 and 2007, and 
accelerated to nearly $10 \%$ after 2000 . After the rapid growth in the early 1980 s, Singapore was falling behind the leader at an annual rate of $9 \%$ during the period $1985-$ 90 , but it very quickly recovered and has been narrowing the gap at an average $8 \%$ rate since 1990. South Korea has been one of the steadiest catching-up countries, with $19.1 \%$ and 5.6\% annual rate between $1973-90$ and 1990-2007 and a relative decline only between 2000 and 2005 .

Figure 3.4 Dynamics in catch-up vis-à-vis the US, 1990-2007

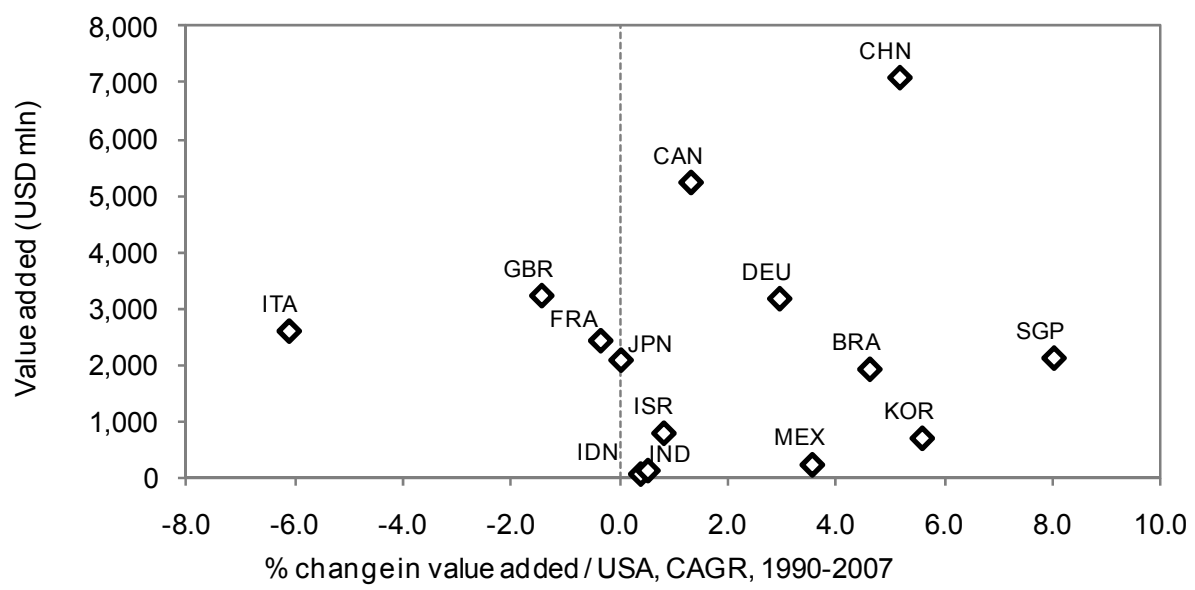

Source: Derived from Table 3.3 and Table 3.6.

Note: In comparison, USA value added is 99,100 . Countries right of the dotted line grew faster than the USA.

Figure 3.4 shows that between 1990 and 2007, the best performers were emerging economies, Singapore, South Korea, China and Brazil. They are positioned to challenge single European producers, many of whom (Italy, UK, but even France) have not been able to keep the same rate of growth as the US. The graph also shows that many emerging economies (including India, Indonesia, Mexico) are at very low levels of production to challenge status quo.

In sum, the dynamics show that interruptions are typical in the growth trajectory, and the heterogeneity of patterns suggests the importance of country-specific factors. 
Table 3.7 Employment in Aerospace Manufacturing, 1960-2007 (thousands)

\begin{tabular}{|c|c|c|c|c|c|c|c|c|c|c|}
\hline & \multicolumn{8}{|c|}{ Number of Employees } & \multicolumn{2}{|c|}{$\begin{array}{c}\text { Growth/Decline of } \\
\text { employment (CAGR) }\end{array}$} \\
\hline & 1960 & 1973 & 1985 & 1990 & 1995 & 2000 & 2005 & 2007 & 1985-1990 & 1990-2007 \\
\hline Global & 952.6 & $1,074.8$ & $1,679.9$ & $1,839.4$ & $1,668.8$ & $1,530.9$ & $1,364.1$ & $1,435.0$ & 1.83 & -1.45 \\
\hline Industrialized Countries & 944.6 & $1,061.1$ & $1,220.8$ & $1,335.0$ & $1,009.4$ & $1,007.8$ & 962.4 & $1,016.6$ & 1.80 & -1.59 \\
\hline United States & 725.7 & 591.0 & 746.0 & 816.0 & 501.2 & 495.2 & 436.6 & 459.3 & 1.81 & -3.32 \\
\hline Western Europe & 217.7 & 408.4 & 399.4 & 417.6 & 315.8 & 341.4 & 316.1 & 344.5 & 0.89 & -1.12 \\
\hline France & 38.0 & 113.1 & 106.2 & 88.1 & 64.9 & 64.8 & 62.1 & 67.2 & -3.68 & -1.57 \\
\hline Germany & 8.6 & 57.0 & 66.1 & 81.0 & 63.6 & 74.4 & 73.6 & 79.4 & 4.16 & -0.12 \\
\hline Italy & 4.6 & 30.8 & 30.0 & 49.1 & 40.6 & 33.3 & 30.8 & 36.4 & 10.38 & -1.74 \\
\hline United Kingdom & 151.9 & 151.8 & 139.5 & 136.0 & 90.0 & 109.8 & 89.9 & 93.5 & -0.51 & -2.18 \\
\hline Other Western Europe & 14.6 & 55.8 & 57.6 & 63.4 & 56.8 & 59.0 & 59.7 & 68.0 & 1.93 & 0.41 \\
\hline Central/Eastern Eur./CIS & n.a. & n.a. & n.a. & n.a. & 106.9 & 74.6 & 113.6 & 109.3 & n.a & n.a \\
\hline CEE, EU Members & n.a. & n.a. & n.a. & n.a. & 41.9 & 25.6 & 32.9 & 36.2 & n.a & n.a \\
\hline Ukraine & n.a. & n.a. & n.a. & n.a. & 65.0 & 49.0 & 80.6 & 73.1 & n.a & n.a \\
\hline Other Industrialized & 1.1 & 61.6 & 75.4 & 101.4 & 85.5 & 96.6 & 96.1 & 103.5 & 6.10 & 0.12 \\
\hline Australia & n.a. & 11.7 & 10.8 & 22.4 & 13.3 & 10.8 & 11.9 & 13.1 & 15.71 & -3.11 \\
\hline Canada & n.a. & 25.7 & 33.8 & 46.4 & 38.9 & 49.8 & 38.1 & 42.7 & 6.54 & -0.49 \\
\hline Israel & n.a. & n.a. & n.a. & n.a. & n.a. & n.a. & n.a. & n.a. & n.a & n.a \\
\hline Japan & 1.1 & 24.2 & 30.8 & 32.6 & 33.3 & 36.1 & 46.1 & 47.7 & 1.14 & 2.26 \\
\hline Emerging Economies & 8.0 & 13.7 & 459.1 & 504.4 & 659.4 & 523.1 & 401.8 & 418.4 & 1.90 & -1.09 \\
\hline Asia & n.a. & 3.6 & 442.2 & 485.8 & 641.2 & 498.6 & 352.6 & 348.9 & 1.90 & -1.93 \\
\hline China (P.R.) & n.a. & n.a. & 410.6 & 446.8 & 590.7 & 456.5 & 304.7 & 301.4 & 1.70 & -2.29 \\
\hline China (HKG) & n.a. & n.a. & 4.0 & 4.9 & 5.2 & 4.2 & 3.9 & 4.6 & 4.14 & -0.32 \\
\hline India & n.a. & n.a. & 5.9 & 6.1 & 10.7 & 3.5 & 3.7 & 5.6 & 0.53 & -0.47 \\
\hline Indonesia & n.a. & n.a. & 12.6 & 14.5 & 15.7 & 10.3 & 9.8 & 4.0 & 2.84 & -7.29 \\
\hline Korea, Rep. of & n.a. & 3.6 & 4.8 & 6.6 & 8.1 & 12.2 & 10.3 & 10.7 & 6.82 & 2.89 \\
\hline Malaysia & n.a. & n.a. & n.a. & 0.8 & 1.1 & 1.6 & 3.8 & 3.7 & n.a & 9.25 \\
\hline Philippines & n.a. & n.a. & 0.3 & 0.5 & 0.6 & n.a. & n.a. & n.a. & 10.76 & -100.00 \\
\hline Singapore & n.a. & n.a. & 4.0 & 5.7 & 9.2 & 10.3 & 16.5 & 18.8 & 7.26 & 7.29 \\
\hline Latin America & 8.0 & 10.1 & 16.9 & 16.3 & 11.6 & 16.9 & 36.7 & 53.7 & -0.77 & 7.28 \\
\hline Argentina & 8.0 & 7.0 & 3.1 & 2.8 & 1.3 & 1.0 & 1.0 & 1.0 & -1.96 & -5.88 \\
\hline Brazil & n.a. & 3.1 & 11.8 & 10.0 & 7.6 & 13.6 & 23.5 & 30.7 & -3.19 & 6.83 \\
\hline Chile & n.a. & n.a. & n.a. & 1.7 & 1.2 & 1.4 & 1.5 & 1.2 & n.a & -2.09 \\
\hline Colombia & n.a. & n.a. & 2.1 & 1.7 & 1.6 & 0.9 & 0.7 & 0.8 & -3.22 & -4.76 \\
\hline Mexico & n.a. & n.a. & n.a. & n.a. & n.a. & n.a. & 10.0 & 20.0 & n.a & n.a \\
\hline Peru & n.a. & n.a. & n.a. & n.a. & n.a. & n.a. & n.a. & n.a. & n.a & n.a \\
\hline Africa \& Middle East & n.a. & n.a. & n.a. & 2.3 & 6.5 & 7.6 & 12.5 & 15.8 & n.a & 11.89 \\
\hline Iran (Islamic Rep. of) & n.a. & n.a. & n.a. & n.a. & 0.1 & 1.8 & 3.2 & 3.2 & n.a & n.a \\
\hline South Africa & n.a. & n.a. & n.a. & n.a. & 6.4 & 3.2 & 5.8 & 6.5 & n.a & n.a \\
\hline Turkey & n.a. & n.a. & n.a. & 2.3 & n.a. & 2.6 & 3.6 & 6.1 & n.a & 5.83 \\
\hline
\end{tabular}

Source: See Appendix A.1

Note: Persons engaged concept used wherever available. 
Table 3.8 Major Regions' share in global aerospace employment (\%)

\begin{tabular}{|c|c|c|c|c|c|c|c|c|}
\hline & 1960 & 1973 & 1985 & 1990 & 1995 & 2000 & 2005 & 2007 \\
\hline Global & 100.0 & 100.0 & 100.0 & 100.0 & 100.0 & 100.0 & 100.0 & 100.0 \\
\hline Industrialized Countries & 99.2 & 98.7 & 72.7 & 72.6 & 60.5 & 65.8 & 70.5 & 70.8 \\
\hline United States & 76.2 & 55.0 & 44.4 & 44.4 & 30.0 & 32.3 & 32.0 & 32.0 \\
\hline Western Europe & 22.9 & 38.0 & 23.8 & 22.7 & 18.9 & 22.3 & 23.2 & 24.0 \\
\hline France & 4.0 & 10.5 & 6.3 & 4.8 & 3.9 & 4.2 & 4.6 & 4.7 \\
\hline Germany & 0.9 & 5.3 & 3.9 & 4.4 & 3.8 & 4.9 & 5.4 & 5.5 \\
\hline Italy & 0.5 & 2.9 & 1.8 & 2.7 & 2.4 & 2.2 & 2.3 & 2.5 \\
\hline United Kingdom & 15.9 & 14.1 & 8.3 & 7.4 & 5.4 & 7.2 & 6.6 & 6.5 \\
\hline Other Western Europe & 1.5 & 5.2 & 3.4 & 3.4 & 3.4 & 3.9 & 4.4 & 4.7 \\
\hline Central/Eastern Eur./CIS & 0.0 & n.a. & n.a. & n.a. & 6.4 & 4.9 & 8.3 & 7.6 \\
\hline CEE, EU Members & 0.0 & n.a. & n.a. & n.a. & 2.5 & 1.7 & 2.4 & 2.5 \\
\hline Ukraine & n.a. & n.a. & n.a. & n.a. & 3.9 & 3.2 & 5.9 & 5.1 \\
\hline Other Industrialized & 0.1 & 5.7 & 4.5 & 5.5 & 5.1 & 6.3 & 7.0 & 7.2 \\
\hline Australia & 0.0 & 1.1 & 0.6 & 1.2 & 0.8 & 0.7 & 0.9 & 0.9 \\
\hline Canada & 0.0 & 2.4 & 2.0 & 2.5 & 2.3 & 3.3 & 2.8 & 3.0 \\
\hline Israel & 0.0 & n.a. & n.a. & n.a. & n.a. & n.a. & n.a. & n.a. \\
\hline Japan & 0.1 & 2.3 & 1.8 & 1.8 & 2.0 & 2.4 & 3.4 & 3.3 \\
\hline Emerging Economies & n.a. & 1.3 & 27.3 & 27.4 & 39.5 & 34.2 & 29.5 & 29.2 \\
\hline Asia & n.a. & 0.3 & 26.3 & 26.4 & 38.4 & 32.6 & 25.8 & 24.3 \\
\hline China (People's Rep. of) & n.a. & n.a. & 24.4 & 24.3 & 35.4 & 29.8 & 22.3 & 21.0 \\
\hline China (Hong Kong SAR) & n.a. & n.a. & 0.2 & 0.3 & 0.3 & 0.3 & 0.3 & 0.3 \\
\hline India & n.a. & n.a. & 0.4 & 0.3 & 0.6 & 0.2 & 0.3 & 0.4 \\
\hline Indonesia & n.a. & n.a. & 0.7 & 0.8 & 0.9 & 0.7 & 0.7 & 0.3 \\
\hline Korea, Rep. of & n.a. & 0.3 & 0.3 & 0.4 & 0.5 & 0.8 & 0.8 & 0.7 \\
\hline Malaysia & n.a. & n.a. & n.a. & 0.0 & 0.1 & 0.1 & 0.3 & 0.3 \\
\hline Philippines & n.a. & n.a. & 0.0 & 0.0 & 0.0 & n.a. & n.a. & n.a. \\
\hline Singapore & n.a. & n.a. & 0.2 & 0.3 & 0.6 & 0.7 & 1.2 & 1.3 \\
\hline Latin America & 1 & 0.9 & 1.0 & 0.9 & 0.7 & 1.1 & 2.7 & 3.7 \\
\hline Argentina & 0.8 & 0.7 & 0.2 & 0.2 & 0.1 & 0.1 & 0.1 & 0.1 \\
\hline Brazil & n.a. & 0.3 & 0.7 & 0.5 & 0.5 & 0.9 & 1.7 & 2.1 \\
\hline Chile & n.a. & n.a. & n.a. & 0.1 & 0.1 & 0.1 & 0.1 & 0.1 \\
\hline Colombia & n.a. & n.a. & 0.1 & 0.1 & 0.1 & 0.1 & 0.0 & 0.1 \\
\hline Mexico & n.a. & n.a. & n.a. & n.a. & n.a. & n.a. & 0.7 & 1.4 \\
\hline Peru & n.a. & n.a. & n.a. & n.a. & n.a. & n.a. & n.a. & n.a. \\
\hline Africa \& Middle East & n.a. & n.a. & n.a. & 0.1 & 0.4 & 0.5 & 0.9 & 1.1 \\
\hline Iran (Islamic Rep. of) & n.a. & n.a. & n.a. & n.a. & 0.0 & 0.1 & 0.2 & 0.2 \\
\hline South Africa & n.a. & n.a. & n.a. & n.a. & 0.4 & 0.2 & 0.4 & 0.5 \\
\hline Turkey & n.a. & n.a. & n.a. & 0.1 & n.a. & 0.2 & 0.3 & 0.4 \\
\hline
\end{tabular}

Source: Derived from Table 3.7

\subsection{Employment and labor productivity}

Aerospace manufacturing provides jobs directly for some 1.4 million people globally. About 1 million people work in industrialized economies, the rest mostly in Asia and Latin America (see Table 3.7). Two interesting developments can be observed over the 
last three or four decades. First, the level of employment in industrialized economies in 1973 was very similar to the levels of 2007 . The peak employment at the end of the Cold War, (1.34 million) decreased already by 1995 to a stable 1 million. Second, the trend for emerging countries was different from this, even opposite in some cases. Latin America incrementally increased its number of aerospace employees and so did Asia excluding China. (The developments in China deserve a closer look.)

In all cases where the distinction was possible, statistical data on 'persons engaged' was used for the employment series, which covers employees as well as selfemployed. For many of the emerging economies such a distinction was not available. The inclusion of data on the armed forces was also not known in most cases.

The ranking of countries according to the number of employees is somewhat different from their order based on production. The leadership of the United States was undisputed until 1990, when the cyclically changing, but by and large growing level of employment reached 816 thousand. However, simultaneously with the consolidation of the industry in the USA during the post-Cold War years, a new challenger arose. China (due to the enterprise-based approach) has been reporting a vast amount of aerospace jobs, exceeding half a million in 1995. In that year it forged well ahead of the United States, accounting for over one-third of global aerospace jobs. China is now virtually on par with Western Europe, which retains $20-25 \%$ of global jobs. At least a quarter of the world's aerospace jobs have been located in emerging economies if China is included, today this ratio is nearly one-third (Table 3.8). While the immense size of Chinese industry is unquestionable, one should read the official figures with caution, since, especially as the industry was transforming in the 1980s and 1990s, many employees in aerospace plants were producing non-aviation products, albeit with an unknown share.

Does the data justify the fear in industrialized countries of job flights to the developing world (e.g. Barber and Scott, 1995)? In 1960 and 1973 nearly 99\% of the capitalist world's aerospace jobs were located in industrialized countries, with Argentina, Brazil, India and Singapore accounting for a very small share, producing only for the domestic market. Not counting China (which had still rather insignificant levels of export at the time, but employed - on paper - close to one out of four aerospace employees in the world), in 1985 and 1990 the share of emerging countries still accounted for only around 4\%. Owing to the employment growth in Brazil, Singapore, Korea and Malaysia, this share increased to $6 \%$ by 2000 and to $10 \%$ by 2007 . In the emerging economies excluding China the absolute number of jobs expanded by $15 \%$ from 1990 to 2000 and by 103\% from 1990 to 2007, compared to a contraction in the industrialized economies by $24 \%$ and $23 \%$ respectively. Including China somewhat distorts this picture. Possibly due to the ongoing structural change in the employment in the sector, the total figure grew only very modestly between 1990 and 2000 (4\%), but 
declined by $17 \%$ between 1990 and 2007 . This decline was significantly smaller than the $23 \%$ in the West. However, the "flight of jobs" in absolute terms looks rather different: 313 thousand jobs were made redundant in the "West" during 1990-2007, while only 59 thousand were created in the "Rest", not counting China. But given the start of the consolidation in China, the emerging world also lost 86 thousand aerospace jobs in total, questioning at least some of the Western concerns of job flight. Nevertheless, there are other real concerns which refer to the age structure of the labor force: a large share (in Europe as much as a half) of the employees is expected to retire in the next decade, resulting in a skill loss. ${ }^{58}$

Labor productivity statistics have to be regarded with caution. First, because the meaning of labor productivity measures for the comparison of efficiency in the aerospace industry is questionable. In general, aerospace manufacturing is a capital intensive industry. However, the quality of labor and capital intensity of production is not the same in different aerospace manufacturing activities. For instance, producing fuselage parts requires multi-million dollars worth of machinery and precision tooling. But is less demanding on the labor force than producing and testing instruments or assembling parts and components. Labor productivity in itself gives little indication of the quality of the work force, and is meaningless as an indicator of technological progress. In the words of Kronemer and Henneberger, labor productivity reflects "the joint effect of such factors as changes in technology, capital investment, capacity utilization, plant design and layout, skill and effort of the work force, managerial ability, and labor-management relations" (Kronemer and Henneberger 1993:33).

Data constraints, as already discussed above preclude the application of other measures of productivity. Capital stock and capital formation statistical series for the industry are disappointingly incomplete. Second, productivity figures are incomplete because of the insufficient overlap between available employment and value added figures, especially in the case of emerging economies (c.f. Table 3.3 and Table 3.7). This reduces significantly the number of countries in the sample. Thus in the absence of total factor productivity data, only a rough comparison of output per person engaged in aerospace is provided here over time and space, based on Table 3.9.

\footnotetext{
${ }^{58}$ A concern voiced in: European Economic and Social Committee 3-4 Dec 2008 "The European aeronautics industry: current situation and prospects." Opinion Aeronautics Industry. CESE 1921/2008
} 
Table 3.9 Labor Productivity in Aerospace Manufacturing, 1973-2007 (Thousand USD per person engaged at constant $=2000$ prices)

\begin{tabular}{|c|c|c|c|c|c|c|c|}
\hline & 1973 & 1985 & 1990 & 1995 & 2000 & 2005 & 2007 \\
\hline Industrialized Countries & 53.1 & 58.5 & 65.9 & 57.0 & 69.7 & 93.3 & 119.6 \\
\hline United States & 79.1 & 79.0 & 85.6 & 80.1 & 98.8 & 155.4 & 215.9 \\
\hline Western Europe & 19.8 & 22.6 & 30.2 & 37.5 & 40.3 & 44.2 & 38.2 \\
\hline France & 7.1 & 18.6 & 20.7 & 69.6 & 46.6 & 48.4 & 36.1 \\
\hline Germany & 10.2 & 14.9 & 16.8 & 21.0 & 37.7 & 47.8 & 39.9 \\
\hline Italy & 126.0 & 121.5 & 108.9 & 76.9 & 110.3 & 92.2 & 71.3 \\
\hline United Kingdom & 14.0 & 11.3 & 21.4 & 20.8 & 25.3 & 31.9 & 34.5 \\
\hline Other Western Europe & 12.7 & 14.9 & 18.6 & 17.9 & 25.4 & 29.2 & 25.6 \\
\hline Central/Eastern Eur./CIS & n.a. & n.a. & n.a. & n.a. & 4.0 & 3.2 & 4.6 \\
\hline CEE, EU Members & n.a. & n.a. & n.a. & 2.5 & 11.5 & 10.9 & 13.8 \\
\hline Ukraine & n.a. & n.a. & n.a. & n.a. & n.a. & n.a. & n.a. \\
\hline Other Industrialized & 24.4 & 45.7 & 50.7 & 63.3 & 75.4 & 78.7 & 84.4 \\
\hline Australia & 13.8 & 20.0 & 10.5 & 18.7 & 31.3 & 45.9 & 48.7 \\
\hline Canada & 40.9 & 48.9 & 63.6 & 67.5 & 82.9 & 100.9 & 122.3 \\
\hline Israel & n.a. & n.a. & n.a. & n.a. & n.a. & n.a. & n.a. \\
\hline Japan & 12.1 & 51.2 & 44.9 & 60.9 & 60.6 & 57.9 & 43.7 \\
\hline Emerging Economies & n.a. & n.a. & 7.9 & 6.2 & 14.2 & 26.4 & 32.4 \\
\hline Asia & n.a. & n.a. & 6.4 & 5.0 & 8.7 & 23.3 & 30.7 \\
\hline China (People's Rep. of) & n.a. & 7.1 & 4.7 & 2.7 & 5.0 & 16.7 & 23.5 \\
\hline China (Hong Kong SAR) & n.a. & 60.5 & 43.3 & 43.9 & 48.9 & 108.9 & 103.6 \\
\hline India & n.a. & 10.2 & 14.3 & 25.7 & 13.4 & 47.0 & 23.9 \\
\hline Indonesia & n.a. & 1.7 & 3.3 & 13.2 & 22.1 & 3.8 & 18.2 \\
\hline Korea, Rep. of & 2.4 & 27.4 & 29.8 & 24.4 & 36.6 & 46.6 & 65.6 \\
\hline Malaysia & n.a. & n.a. & 46.3 & 41.0 & 44.6 & 33.9 & 35.5 \\
\hline Philippines & n.a. & 21.3 & 28.6 & 13.7 & n.a. & n.a. & n.a. \\
\hline Singapore & n.a. & 136.2 & 71.1 & 73.0 & 100.1 & 114.0 & 113.0 \\
\hline Latin America & n.a. & 29.9 & 52.1 & 65.5 & 164.0 & 56.4 & 42.0 \\
\hline Argentina & n.a. & n.a. & n.a. & n.a. & n.a. & n.a. & n.a. \\
\hline Brazil & 33.7 & 23.8 & 63.0 & 36.5 & 172.4 & 75.8 & 62.6 \\
\hline Chile & n.a. & n.a. & 31.9 & 13.4 & 97.5 & 17.1 & 15.2 \\
\hline Colombia & n.a. & 33.9 & 40.1 & 92.8 & 77.8 & 57.7 & 103.3 \\
\hline Mexico & n.a. & n.a. & n.a. & n.a. & n.a. & 22.2 & 11.8 \\
\hline Peru & n.a. & n.a. & n.a. & n.a. & n.a. & n.a. & n.a. \\
\hline Africa \& Middle East & n.a. & n.a. & n.a. & 12.6 & 44.4 & 25.5 & 36.5 \\
\hline Iran (Islamic Rep. of) & n.a. & n.a. & n.a. & 181.3 & 16.9 & 31.3 & 31.3 \\
\hline South Africa & n.a. & n.a. & n.a. & 10.8 & 17.1 & 6.4 & 5.9 \\
\hline Turkey & n.a. & n.a. & n.a. & n.a. & 97.3 & 51.3 & 71.4 \\
\hline
\end{tabular}

Source: Derived from Table 3.3 and Table 3.7

Notes: Regional aggregate figures were calculated by dividing regional aggregate value added with regional aggregate employment. Many of the figures are unreliable because employment data was not available for a number of emerging economies: Africa and Middle East until 1990; Mexico until 2000; China and Hong Kong before 1985; Philippines before 1985 and after 2000. For Ukraine and Argentina, value added data was unavailable. Central Eastern Europe is only available from 1995 onwards. 
In 2007 the productivity levels were the highest in the USA, at an unprecedented 203 thousand dollars per employee. Even more remarkable is the 2.6-fold growth $(8.3 \%$ annual average) achieved in hardly more than a decade after the low of 78 thousand dollars in 1995, compared with the mere $0.4 \%$ annual growth achieved over the period 1973 through 1990. This shifting in the gear in the 1990s fits well in the consolidation and restructuring of the industry that took place in the USA at that time. We expected to see a similar trend in Europe, but that is not supported by the data. Between 1995 and 2007 labor productivity doubled in Germany, but halved in France. Italy, the best performer in the block, also showed a declining trend. The UK showed some growth and so did other Western European countries. In total none of this was sufficient to reach more than a third of US labor productivity by 2007. The most successful industrialized country to follow the leader was Canada, where labor productivity increased at a rather stable rate from a 1973 low of 40.9 to a 2007 high of 122.3 thousand USD per employee. However, the rate of growth in the last decade was slower than that of its southern neighbor as the USA accelerated. Japan has relatively low productivity values as well, and has shown a declining trend since 1995, falling from 60.9 to 43.7 thousand USD per employee, a level in the same range as many Western European countries.

The differences between emerging and industrialized countries were striking even in 2007, although there is also a large variation within the emerging group. Among the bigger producers, Singapore (113.0) and Hong Kong SAR (103.6) were closely following Canada (122.3) in 2007. Countries where the industry consists mainly of maintenance and repair activities generate high value added which explains the outstanding performance of Singapore and Hong Kong and to a large extend South Korea (65.6). It is more interesting to find Brazil (62.6) with "core" manufacturing activities still ahead of Western European countries. Because of its immense level of employment, China is still trailing behind with 23.5 thousand dollars per person. On the whole, emerging economies showed large fluctuations before the 1990s, but also clear signs of growth after 1990. Most remarkable is the progress (among the more significant producers) in the case of South Korea (from 2.4 in 1973 to 65.6 in 2007), Brazil (33.7 in 1973 to 172.4 in 2000) and Hong Kong (from 43.3 in 1990 to 103.6 in 2007). Other producers show modest progress, such as India (10.2 in 1985, to 47 in 2005). But many countries that started low remained low (such as Indonesia, reaching a maximum of 22.1). As long as there is no consolidation in the industry, China remains in the lower ranks. 
Table 3.10 Labor Productivity in Comparison with the US Levels

$(\mathrm{USA}=100)$

\begin{tabular}{|c|c|c|c|c|c|c|c|c|}
\hline & 1960 & 1973 & 1985 & 1990 & 1995 & 2000 & 2005 & 2007 \\
\hline Global & 81.7 & 66.5 & 57.2 & 58.3 & 46.1 & 51.4 & 47.3 & 43.6 \\
\hline Industrialized Countries & 82.4 & 67.1 & 74.1 & 76.9 & 71.1 & 70.6 & 60.0 & 55.4 \\
\hline United States & 100.0 & 100.0 & 100.0 & 100.0 & 100.0 & 100.0 & 100.0 & 100.0 \\
\hline Western Europe & 22.0 & 25.1 & 28.7 & 35.3 & 46.8 & 40.8 & 28.5 & 17.7 \\
\hline France & 13.0 & 8.9 & 23.6 & 24.1 & 86.8 & 47.2 & 31.1 & 16.7 \\
\hline Germany & 19.3 & 12.9 & 18.9 & 19.7 & 26.2 & 38.1 & 30.8 & 18.5 \\
\hline Italy & 134.6 & 159.3 & 153.8 & 127.2 & 96.0 & 111.6 & 59.3 & 33.0 \\
\hline United Kingdom & 21.9 & 17.7 & 14.4 & 25.0 & 25.9 & 25.6 & 20.5 & 16.0 \\
\hline Other Western Europe & 12.3 & 16.1 & 18.8 & 21.7 & 22.3 & 25.7 & 18.8 & 11.9 \\
\hline Central/Eastern Eur./CIS & n.a. & n.a. & n.a. & n.a. & 1.2 & 4.0 & 2.0 & 2.1 \\
\hline CEE, EU Members & n.a. & n.a. & n.a. & n.a. & 3.2 & 11.7 & 7.0 & 6.4 \\
\hline Ukraine & n.a. & n.a. & n.a. & n.a. & 0.0 & 0.0 & 0.0 & 0.0 \\
\hline Other Industrialized & 407.8 & 30.9 & 57.8 & 59.2 & 79.0 & 76.3 & 50.6 & 39.1 \\
\hline Australia & n.a. & 17.4 & 25.3 & 12.2 & 23.3 & 31.7 & 29.5 & 22.5 \\
\hline Canada & n.a. & 51.7 & 61.9 & 74.3 & 84.2 & 83.9 & 64.9 & 56.6 \\
\hline Israel & n.a. & n.a. & n.a. & n.a. & n.a. & n.a. & n.a. & n.a. \\
\hline Japan & 3.8 & 15.3 & 64.8 & 52.5 & 75.9 & 61.3 & 37.2 & 20.2 \\
\hline Emerging Economies & 0.0 & 19.9 & 12.2 & 9.2 & 7.7 & 14.4 & 17.0 & 15.0 \\
\hline Asia & n.a. & 39.0 & 11.3 & 7.5 & 6.3 & 8.8 & 15.0 & 14.2 \\
\hline China (People's Rep. of) & n.a. & n.a. & 9.0 & 5.5 & 3.4 & 5.1 & 10.8 & 10.9 \\
\hline China (Hong Kong SAR) & n.a. & n.a. & 76.6 & 50.6 & 54.8 & 49.5 & 70.1 & 48.0 \\
\hline India & n.a. & n.a. & 13.0 & 16.7 & 32.1 & 13.5 & 30.2 & 11.1 \\
\hline Indonesia & n.a. & n.a. & 2.2 & 3.9 & 16.4 & 22.3 & 2.5 & 8.4 \\
\hline Korea, Rep. of & n.a. & 3.0 & 34.8 & 34.9 & 30.4 & 37.0 & 30.0 & 30.4 \\
\hline Malaysia & n.a. & n.a. & n.a. & 54.1 & 51.2 & 45.1 & 21.8 & 16.5 \\
\hline Philippines & n.a. & n.a. & 27.0 & 33.4 & 17.1 & n.a. & n.a. & n.a. \\
\hline Singapore & n.a. & n.a. & 172.4 & 83.0 & 91.1 & 101.3 & 73.3 & 52.3 \\
\hline Latin America & 0.0 & 13.0 & 37.8 & 60.8 & 81.8 & 166.0 & 36.3 & 19.5 \\
\hline Argentina & 0.0 & 0.0 & 0.0 & 0.0 & 0.0 & 0.0 & 0.0 & 0.0 \\
\hline Brazil & n.a. & 42.6 & 30.2 & 73.6 & 45.6 & 174.5 & 48.8 & 29.0 \\
\hline Chile & n.a. & n.a. & n.a. & 37.3 & 16.8 & 98.7 & 11.0 & 7.0 \\
\hline Colombia & n.a. & n.a. & 42.9 & 46.8 & n.a. & 78.7 & 37.1 & 47.9 \\
\hline Mexico & n.a. & n.a. & n.a. & n.a. & n.a. & n.a. & 14.3 & 5.5 \\
\hline Peru & n.a. & n.a. & n.a. & n.a. & n.a. & n.a. & n.a. & n.a. \\
\hline Africa \& Middle East & n.a. & n.a. & n.a. & 0.0 & 15.8 & 44.9 & 16.4 & 16.9 \\
\hline Iran (Islamic Rep. of) & n.a. & n.a. & n.a. & n.a. & n.a. & 17.1 & 20.2 & 14.5 \\
\hline South Africa & n.a. & n.a. & n.a. & n.a. & 13.5 & 17.3 & 4.1 & 2.7 \\
\hline Turkey & n.a. & n.a. & n.a. & n.a. & n.a. & n.a. & 33.0 & 33.1 \\
\hline
\end{tabular}

Source: Derived from Table 3.9. 
Table 3.11 Changes in comparative labor productivity levels relative to the USA, 1960-2007 (compound growth rates, \%)

\begin{tabular}{|c|c|c|c|c|c|c|c|c|}
\hline & $1960-73$ & $1973-85$ & $1985-90$ & 1990-95 & $1995-2000$ & $2000-05$ & $1990-2007$ & $1995-2007$ \\
\hline Global & -1.6 & -1.3 & 0.4 & -4.6 & 2.2 & -1.6 & -1.7 & -0.5 \\
\hline Industrialized Countries & -1.6 & 0.8 & 0.8 & -1.6 & -0.2 & -3.2 & -1.9 & -2.1 \\
\hline United States & 0.0 & 0.0 & 0.0 & 0.0 & 0.0 & 0.0 & 0.0 & 0.0 \\
\hline Western Europe & 1.0 & 1.1 & 4.3 & 5.8 & -2.7 & -7.0 & -4.0 & -7.8 \\
\hline France & -2.8 & 8.4 & 0.5 & 29.2 & -11.5 & -8.0 & -2.1 & -12.8 \\
\hline Germany & -3.1 & 3.2 & 0.8 & 5.9 & 7.8 & -4.2 & -0.4 & -2.9 \\
\hline Italy & 1.3 & -0.3 & -3.7 & -5.5 & 3.1 & -11.9 & -7.6 & -8.5 \\
\hline United Kingdom & -1.6 & -1.7 & 11.7 & 0.7 & -0.3 & -4.3 & -2.6 & -4.0 \\
\hline Other Western Europe & 2.1 & 1.3 & 2.9 & 0.5 & 2.9 & -6.1 & -3.5 & -5.1 \\
\hline Central/Eastern Eur./CIS & n.a. & n.a. & n.a. & n.a. & 26.4 & -12.6 & n.a. & 4.6 \\
\hline CEE, EU Members & n.a. & n.a. & n.a. & n.a. & 29.8 & -9.6 & n.a. & 6.1 \\
\hline Ukraine & n.a. & n.a. & n.a. & n.a. & n.a. & n.a. & n.a. & n.a. \\
\hline Other Industrialized & -18.0 & 5.4 & 0.5 & 5.9 & -0.7 & -7.9 & -2.4 & -5.7 \\
\hline Australia & n.a. & 3.2 & -13.5 & 13.7 & 6.3 & -1.4 & 3.7 & -0.3 \\
\hline Canada & n.a. & 1.5 & 3.7 & 2.5 & -0.1 & -5.0 & -1.6 & -3.3 \\
\hline Israel & n.a. & n.a. & n.a. & n.a. & n.a. & n.a. & n.a. & n.a. \\
\hline Japan & 11.3 & 12.8 & -4.1 & 7.7 & -4.2 & -9.5 & -5.4 & -10.4 \\
\hline Emerging Economies & n.a. & -4.0 & -5.6 & -3.5 & 13.4 & 3.4 & 2.9 & 5.7 \\
\hline Asia & n.a. & -9.8 & -7.8 & -3.5 & 7.0 & 11.3 & 3.8 & 7.1 \\
\hline China (People's Rep. of) & n.a. & n.a. & -9.3 & -9.5 & 8.7 & 16.2 & 4.0 & 10.3 \\
\hline China (Hong Kong SAR) & n.a. & n.a. & -8.0 & 1.6 & -2.0 & 7.2 & -0.3 & -1.1 \\
\hline India & n.a. & n.a. & 5.2 & 14.0 & -15.9 & 17.5 & -2.4 & -8.5 \\
\hline Indonesia & n.a. & n.a. & 12.0 & 33.4 & 6.3 & -35.6 & 4.7 & -5.4 \\
\hline Korea, Rep. of & n.a. & 22.7 & 0.1 & -2.7 & 4.0 & -4.1 & -0.8 & 0.0 \\
\hline Malaysia & n.a. & n.a. & n.a. & -1.1 & -2.5 & -13.5 & -6.8 & -9.0 \\
\hline Philippines & n.a. & n.a. & 4.4 & -12.6 & n.a. & n.a. & n.a. & n.a. \\
\hline Singapore & n.a. & n.a. & -13.6 & 1.9 & 2.1 & -6.3 & -2.7 & -4.5 \\
\hline Latin America & n.a. & 9.3 & 10.0 & 6.1 & 15.2 & -26.2 & -6.5 & -11.3 \\
\hline Argentina & n.a. & n.a. & n.a. & n.a. & n.a. & n.a. & n.a. & n.a. \\
\hline Brazil & n.a. & -2.8 & 19.5 & -9.1 & 30.8 & -22.5 & -5.3 & -3.7 \\
\hline Chile & n.a. & n.a. & n.a. & -14.8 & 42.6 & -35.5 & -9.3 & -7.0 \\
\hline Colombia & n.a. & n.a. & 1.8 & n.a. & n.a. & -14.0 & 0.1 & -7.1 \\
\hline Mexico & n.a. & n.a. & n.a. & n.a. & n.a. & n.a. & n.a. & n.a. \\
\hline Peru & n.a. & n.a. & n.a. & n.a. & n.a. & n.a. & n.a. & n.a. \\
\hline Africa \& Middle East & n.a. & n.a. & n.a. & n.a. & 23.3 & -18.2 & n.a. & 0.6 \\
\hline Iran (Islamic Rep. of) & n.a. & n.a. & n.a. & n.a. & -40.3 & 3.3 & n.a. & -20.5 \\
\hline South Africa & n.a. & n.a. & n.a. & n.a. & 5.1 & -25.0 & n.a. & -12.5 \\
\hline Turkey & n.a. & n.a. & n.a. & n.a. & n.a. & n.a. & n.a. & n.a. \\
\hline
\end{tabular}

Source: Derived from Table 3.10

Another interesting conclusion is that in terms of labor productivity, Europe is directly challenged by latecomers. Western Europe fall back from half the US productivity levels in 1995 to one-fifth by 2007 (Table 3.10). Other successful industrialized economies, 
Canada and Japan had significantly closed their gap relative to the USA by 1995, reaching 86 and $78 \%$ of the US levels, respectively. Yet these countries have fallen back to 60 and $22 \%$ by 2007. Singapore and Hong Kong have been fluctuating between the extremes of 55 and 168 percent (Singapore) and 51 and 75 percent (Hong Kong) of US productivity levels (again, at least the high extremes are explained by the MROefficiency effect). Brazil similarly shows no sign of stability with its fluctuations between 29 and $182 \%$ of US values.

Are there signs of catch up? The US technological leadership is so definite and sustained that not even industrialized countries can keep up the pace (Table 3.10). On the whole, the USA is more than twice as productive as any other country in the world. While Western European countries have caught up significantly until 1995 (from 22\% to $48 \%$ ), they have now fallen considerably behind: the 2005 levels are hardly higher than the 1985 levels, the 2007 levels are lower than of 1973. Other industrialized countries have similarly caught up to $81 \%$ by 1995 from $31 \%$ in 1973 , but have now fallen behind to $42 \%$.

Emerging countries decreased their productivity gap vis-à-vis the USA from a low of $8 \%$ in 1995 to $18 \%$ in 2005 . But as the USA increased its productivity, they stood at $16 \%$ of the US level in 2007 . It is noteworthy that in some years Singapore (in 2000) and Brazil (also in 2000) exceeded the US labor productivity level. ${ }^{59}$

\subsection{Specialization in aerospace production}

So far we have compared the size and growth of the aerospace industry across countries, now we turn to specialization. Specialization is addressed from two perspectives. The first question is, how important is aerospace within the economy of a country. Next we explore aerospace exports specialization.

On average, aerospace's share in GDP is approximately three times as high in industrialized economies as in emerging ones (Table 3.12). It appears that for the largest aerospace producers, the industry is also relatively substantial domestically. In the USA, for instance, aircraft manufacturing alone was the fifth largest manufacturing activity in $2007,{ }^{60}$ or the third if the whole aerospace sector was considered. In Brazil aircraft production was also among the top 10 manufacturing activities.

\footnotetext{
${ }^{59}$ As for the smaller producer, value added data might be exaggerated and labor data underreported, so productivity data should be read with caution.

${ }^{60}$ According to data from the 2007 Economic census, following Petroleum refineries, Pharmaceutical preparation manufacturing, Semiconductor and related device manufacturing, Light truck and utility vehicle manufacturing (US Census Bureau).
} 
Table 3.12 The share of Aerospace Value Added in GDP (\%)

\begin{tabular}{|c|c|c|c|c|c|c|c|c|}
\hline & 1960 & 1973 & 1985 & 1990 & 1995 & 2000 & 2005 & 2007 \\
\hline Global & 0.66 & 0.44 & 0.42 & 0.42 & 0.25 & 0.26 & 0.30 & 0.38 \\
\hline Industrialized Countries & 0.74 & 0.49 & 0.45 & 0.46 & 0.27 & 0.29 & 0.33 & 0.43 \\
\hline United States & 1.41 & 1.09 & 0.98 & 0.99 & 0.50 & 0.50 & 0.62 & 0.86 \\
\hline Western Europe & 0.13 & 0.19 & 0.16 & 0.19 & 0.17 & 0.17 & 0.16 & 0.14 \\
\hline France & 0.07 & 0.11 & 0.21 & 0.17 & 0.39 & 0.23 & 0.21 & 0.16 \\
\hline Germany & n.a. & 0.06 & 0.07 & 0.09 & 0.08 & 0.15 & 0.18 & 0.15 \\
\hline Italy & 0.10 & 0.67 & 0.45 & 0.57 & 0.31 & 0.34 & 0.25 & 0.22 \\
\hline United Kingdom & 0.30 & 0.26 & 0.16 & 0.25 & 0.15 & 0.19 & 0.17 & 0.18 \\
\hline Other Western Europe & 0.01 & 0.06 & 0.05 & 0.06 & 0.05 & 0.06 & 0.06 & 0.06 \\
\hline Central/Eastern Eur./CIS & n.a. & n.a. & n.a. & 0.07 & 0.03 & 0.08 & 0.07 & 0.09 \\
\hline CEE, EU Members & n.a. & n.a. & n.a. & 0.07 & 0.03 & 0.08 & 0.07 & 0.09 \\
\hline Ukraine & n.a. & n.a. & n.a. & n.a. & n.a. & n.a. & n.a. & n.a. \\
\hline Other Industrialized & 0.03 & 0.05 & 0.09 & 0.10 & 0.10 & 0.12 & 0.12 & 0.13 \\
\hline Australia & n.a. & 0.09 & 0.09 & 0.08 & 0.08 & 0.08 & 0.12 & 0.13 \\
\hline Canada & 0.14 & 0.32 & 0.35 & 0.54 & 0.44 & 0.57 & 0.47 & 0.60 \\
\hline Israel & n.a. & n.a. & n.a. & 0.68 & 0.52 & 0.51 & 0.36 & 0.52 \\
\hline Japan & 0.00 & 0.01 & 0.05 & 0.04 & 0.05 & 0.05 & 0.05 & 0.04 \\
\hline Emerging Economies & n.a. & 0.02 & 0.18 & 0.13 & 0.10 & 0.15 & 0.16 & 0.18 \\
\hline Asia & n.a. & 0.02 & 0.41 & 0.23 & 0.15 & 0.16 & 0.21 & 0.23 \\
\hline China (People's Rep. of) & n.a. & n.a. & 0.96 & 0.48 & 0.20 & 0.19 & 0.27 & 0.30 \\
\hline China (Hong Kong SAR) & n.a. & 0.31 & 0.30 & 0.18 & 0.15 & 0.12 & 0.20 & 0.20 \\
\hline India & n.a. & n.a. & 0.03 & 0.03 & 0.08 & 0.01 & 0.03 & 0.02 \\
\hline Indonesia & n.a. & n.a. & 0.03 & 0.04 & 0.13 & 0.14 & 0.02 & 0.03 \\
\hline Korea, Rep. of & n.a. & 0.01 & 0.07 & 0.07 & 0.05 & 0.08 & 0.07 & 0.10 \\
\hline Malaysia & n.a. & n.a. & n.a. & 0.08 & 0.06 & 0.08 & 0.11 & 0.10 \\
\hline Philippines & n.a. & n.a. & 0.01 & 0.03 & 0.01 & n.a. & n.a. & n.a. \\
\hline Singapore & n.a. & n.a. & 1.83 & 0.90 & 0.99 & 1.12 & 1.64 & 1.58 \\
\hline Latin America & n.a. & 0.01 & 0.04 & 0.07 & 0.05 & 0.16 & 0.11 & 0.10 \\
\hline Argentina & n.a. & n.a. & n.a. & n.a. & n.a. & n.a. & n.a. & n.a. \\
\hline Brazil & n.a. & 0.04 & 0.06 & 0.13 & 0.05 & 0.36 & 0.24 & 0.24 \\
\hline Chile & n.a. & n.a. & 0.14 & 0.14 & 0.03 & 0.18 & 0.03 & 0.02 \\
\hline Colombia & n.a. & n.a. & 0.12 & 0.10 & 0.16 & 0.08 & 0.03 & 0.06 \\
\hline Mexico & n.a. & n.a. & 0.03 & 0.02 & 0.07 & 0.04 & 0.03 & 0.03 \\
\hline Peru & n.a. & n.a. & n.a. & n.a. & n.a. & n.a. & 0.00 & 0.00 \\
\hline Africa \& Middle East & n.a. & n.a. & n.a. & n.a. & 0.02 & 0.07 & 0.05 & 0.08 \\
\hline Iran (Islamic Rep. of) & n.a. & n.a. & n.a. & n.a. & 0.02 & 0.03 & 0.07 & 0.07 \\
\hline South Africa & n.a. & n.a. & n.a. & n.a. & 0.06 & 0.04 & 0.02 & 0.02 \\
\hline Turkey & n.a. & n.a. & n.a. & n.a. & n.a. & 0.09 & 0.05 & 0.12 \\
\hline
\end{tabular}

Source: Value added data from Table 3.3, GDP data (at constant 2000 USD) from World Development Indicators Online.

The relative share of aerospace has not been constant over the years in most of the countries. In the USA for instance, aerospace accounted for $1.4 \%$ of total value added in 1960 and retained a rather high share of nearly $1 \%$ until 1990. The crisis of the industry 
in the early 1990s halved its share and the recovery was slow; only reaching $0.9 \%$ in 2007. Still this share is unmatched in any of the European or other industrialized countries. The next highest shares are found in Canada (0.6\% in 2007, home to the aircraft manufacturer Bombardier and several engine manufacturers) and in Italy, where aerospace accounted for $0.45-0.67 \%$ of the production during the $1970 \mathrm{~s}-80 \mathrm{~s}$ but dropped significantly afterwards to $0.22 \%$ by 2007 . Aerospace is also rather important for Israel $(0.5 \%)$. The significance of the sector has clearly declined in France (from $0.39 \%$ in 1995 to $0.16 \%$ in 2007 , also in absolute terms) and to some degree in the UK (from $0.3 \%$ in 1960 to $0.18 \%$ in 2007 , despite the production growth in absolute levels). At the same time the absolute value added growth in Germany also became apparent in the relative share of the sector which increased from $0.08 \%$ in 1995 to $0.15 \%$ in 2007.

The relative size of the industry in Singapore is not only the largest among the emerging countries but it also exceeds that of the USA. Today $1.6 \%$ of all value added is associated with aerospace manufacturing which is not new for the city state. After a peak of $1.8 \%$ in 1985 the share fell to $0.9 \%$ in 1990 but recovered rather rapidly. The industry's importance in China is once again in the rise following a restructuring crisis that started in the mid 1980s and lasted for nearly two decades. Even amidst rapid expansion of the whole economy, the growth of aerospace was above average and soared from $0.2 \%$ in 1995 to $0.3 \%$ of GDP in 2007 . The Brazilian industry is characterized by a changing share, with a peak in $2000(0.36 \%)$. Today it accounts for around quarter of a percent of total production. Other noteworthy emerging economies are Hong Kong, with $0.3 \%$ in the 1980 s and $0.2 \%$ in recent years, and Indonesia, with $0.13 \%$ in 1995 . Of course, the contribution of the aerospace industry to GDP goes beyond manufacturing activities. This overview does not cover services or the air transport industry, moreover, the importance of aerospace may be more than what is indicated by its share in GDP (c.f. Eliasson 2010).

\subsection{Aerospace exports}

While products of the aerospace industry have undoubtedly been an engine of globalization, the aerospace industry itself is, interestingly, is only beginning to spread globally. Table 3.13 shows that today, similarly to two decades ago, leading industrialized countries dominate global aerospace exports. ${ }^{61}$ In 1985 industrialized countries realized $96 \%$ of world trade, and the figure decreased only to $92 \%$ by 2007 . In

\footnotetext{
${ }^{61}$ In order to remain consistent with the production statistics discussed in this chapter, aerospace exports combine products of aircraft, spacecraft as well as engines. If engines (and their parts) are not counted, the five largest aerospace exporters in 2007 were the USA, France, Germany, Canada and Brazil with 62.0, 26.2, 21.7, 7.8 and 4.2 billion USD, respectively.
} 
1985 the top 5 aerospace exporters, the USA, Germany, the UK, France and Canada accounted for $87 \%$ of exports. In 2007 the top 5 countries, the USA, France, Germany, the UK and Canada accounted for $76 \%$ of aerospace exports.

On average, two-third of global production (gross output) was sold abroad in 2007. Some countries have much lower export rate than the global average. China, for instance, exported only 7\% of what it produced, while the USA exported 52\% in 2007.

Among the emerging economies Brazil, Singapore, China and Mexico exported over a billion dollars. South Korea, Malaysia, South Africa, and most recently, India, are also notable exporters. The last twenty years saw a reshuffle in country rankings. In 1985 and 1990, the only significant exporters were Singapore, Korea and Brazil. By 2000 Brazil forged far ahead of South Korea, Mexico and Singapore. By 2007 Singapore returned to the second place, with almost equal to Brazil's export values (4.36 and 4.34) while China forged ahead of Mexico (1.73 and 1.70 respectively).

In Chapter 2 we discussed the internationalization of value chains in the last decades. Table 3.14 provides interesting evidence for that by showing the major parts and components exporters. At the top of the list we find the USA and the two major European countries, Germany and France, responsible for 58\% of global trade. The largest emerging exporters are Singapore, followed (surprisingly) by Thailand, China, Malaysia and South Korea. The occasional sales of used aircraft can show non-producer countries as large exporters - this may well be the case in Thailand. For emerging economies, the majority of aerospace exports are parts and components. The only emerging producer that is not specializing in parts and components is Brazil.

The absolute value of aerospace export does not tell much about how important the sector is for an economy, or whether a given country has comparative advantage in aerospace products. Table 3.15 presents the share of aerospace exports in the GDP. Relatively speaking, aerospace export is a more important source of income for Western Europe and Canada, than for the USA $(0.95 \%, 1.23 \%$ and $0.73 \%$ in 2007 , respectively). The size of the export sector for the USA and Western Europe were equally $0.66 \%$ in 1990, but increased in Europe to $0.95 \%$ while it only increased to $0.77 \%$ in the USA. This may indicate both the sales growth of Airbus aircraft and a growing internal trade. The Embraer sales effect on the other hand is clearly visible in the sectoral export growth in Brazil (from $0.14 \%$ in 1990 to $0.54 \%$ in 2007). The only other emerging economy where aerospace export is a significant income generator is Singapore. The island state has the highest GDP share of aero exports, 3.24\% in 2007. 
Table 3.13 Global Distribution of Aerospace Exports (Million USD at constant 2000 prices)

\begin{tabular}{|c|c|c|c|c|c|c|c|c|c|c|c|}
\hline & \multicolumn{6}{|c|}{ Export value, Million USD } & \multicolumn{5}{|c|}{ Global share (\%) } \\
\hline & 1985 & 1990 & 1995 & 2000 & 2005 & 2007 & 1985 & 1990 & 1995 & 2000 & 2007 \\
\hline Total Sample & 40,232 & 99,349 & 99,014 & 143,382 & 164,127 & 210,021 & 100.0 & 100.0 & 100.0 & 100.0 & 100.0 \\
\hline Industrialized Countries & 38,766 & 96,440 & 94,578 & 134,375 & 153,872 & 193,634 & 96.4 & 97.1 & 95.5 & 93.7 & 92.2 \\
\hline United States & 20,526 & 46,484 & 36,113 & 54,927 & 61,044 & 83,516 & 51.0 & 46.8 & 36.5 & 38.3 & 39.8 \\
\hline Western Europe & 15,718 & 43,427 & 51,162 & 64,642 & 77,417 & 90,400 & 39.1 & 43.7 & 51.7 & 45.1 & 43.0 \\
\hline France & 3,501 & 11,590 & 18,059 & 20,877 & 26,495 & 32,850 & 8.7 & 11.7 & 18.2 & 14.6 & 15.6 \\
\hline Germany & 4,821 & 9,683 & 10,690 & 20,067 & 24,092 & 26,689 & 12.0 & 9.7 & 10.8 & 14.0 & 12.7 \\
\hline Italy & 1,536 & 4,263 & 2,829 & 4,999 & 4,728 & 5,868 & 3.8 & 4.3 & 2.9 & 3.5 & 2.8 \\
\hline United Kingdom & 4,504 & 10,750 & 11,917 & 9,731 & 12,051 & 12,550 & 11.2 & 10.8 & 12.0 & 6.8 & 6.0 \\
\hline Other Western Europe & 1,356 & 7,142 & 7,667 & 8,968 & 10,051 & 12,443 & 3.4 & 7.2 & 7.7 & 6.3 & 5.9 \\
\hline Central/Eastern Eur./CIS & 87 & 42 & 156 & 719 & 1,619 & 2,292 & 0.2 & 0.0 & 0.2 & 0.5 & 1.1 \\
\hline CEE, EU Members & 87 & 42 & 156 & 452 & 1,186 & 1,794 & 0.2 & 0.0 & 0.2 & 0.3 & 0.9 \\
\hline Ukraine & n.a. & n.a. & n.a. & 267 & 434 & 498 & n.a. & n.a. & n.a. & 0.2 & 0.2 \\
\hline Other Industrialized & 2,435 & 6,486 & 7,146 & 14,087 & 13,792 & 17,426 & 6.1 & 6.5 & 7.2 & 9.8 & 8.3 \\
\hline Australia & 55 & 201 & 297 & 412 & 602 & 622 & 0.1 & 0.2 & 0.3 & 0.3 & 0.3 \\
\hline Canada & 1,801 & 4,916 & 4,833 & 9,362 & 8,872 & 10,654 & 4.5 & 4.9 & 4.9 & 6.5 & 5.1 \\
\hline Israel & 391 & 460 & 635 & 1,041 & 1,012 & 1,549 & 1.0 & 0.5 & 0.6 & 0.7 & 0.7 \\
\hline Japan & 188 & 910 & 1,382 & 3,271 & 3,306 & 4,600 & 0.5 & 0.9 & 1.4 & 2.3 & 2.2 \\
\hline Emerging Economies & 1,466 & 2,909 & 4,436 & 9,007 & 10,254 & 16,387 & 3.6 & 2.9 & 4.5 & 6.3 & 7.8 \\
\hline Asia & 1,219 & 1,985 & 3,272 & 3,022 & 4,826 & 8,671 & 3.0 & 2.0 & 3.3 & 2.1 & 4.1 \\
\hline China (P.R.) & n.a. & n.a. & 178 & 639 & 954 & 1,729 & n.a. & n.a. & 0.2 & 0.4 & 0.8 \\
\hline China (HKG) & 2 & n.a. & n.a. & n.a. & n.a. & n.a. & 0.0 & n.a. & n.a. & 0.0 & 0.0 \\
\hline India & 25 & 7 & 10 & 74 & 129 & 415 & 0.1 & 0.0 & 0.0 & 0.1 & 0.2 \\
\hline Indonesia & 1 & 19 & 22 & 31 & 118 & 184 & 0.0 & 0.0 & 0.0 & 0.0 & 0.1 \\
\hline Korea, Rep. of & 362 & 718 & 974 & 847 & 580 & 791 & 0.9 & 0.7 & 1.0 & 0.6 & 0.4 \\
\hline Malaysia & 167 & 450 & 1,537 & 583 & 655 & 958 & 0.4 & 0.5 & 1.6 & 0.4 & 0.5 \\
\hline Philippines & n.a. & n.a. & 2 & 54 & 348 & 249 & 0.0 & n.a. & 0.0 & 0.0 & 0.1 \\
\hline Singapore & 663 & 792 & 549 & 794 & 2,042 & 4,344 & 1.6 & 0.8 & 0.6 & 0.6 & 2.1 \\
\hline Latin America & 246 & 924 & 1,131 & 4,918 & 4,474 & 6,479 & 0.6 & 0.9 & 1.1 & 3.4 & 3.1 \\
\hline Argentina & 3 & n.a. & 30 & 281 & 70 & 300 & 0.0 & n.a. & 0.0 & 0.2 & 0.1 \\
\hline Brazil & 241 & 695 & 443 & 3,685 & 3,275 & 4,356 & 0.6 & 0.7 & 0.4 & 2.6 & 2.1 \\
\hline Chile & 1 & 35 & 3 & 43 & 26 & 33 & 0.0 & 0.0 & 0.0 & 0.0 & 0.0 \\
\hline Colombia & 1 & n.a. & 4 & 51 & 58 & 87 & 0.0 & n.a. & 0.0 & 0.0 & 0.0 \\
\hline Mexico & 0 & 194 & 649 & 857 & 1,039 & 1,702 & n.a. & 0.2 & 0.7 & 0.6 & 0.8 \\
\hline Peru & 1 & 0 & 2 & 1 & 5 & 2 & 0.0 & n.a. & 0.0 & 0.0 & 0.0 \\
\hline Africa \& Middle East & 1 & 1 & 33 & 1,068 & 955 & 1,237 & 0.0 & 0.0 & 0.0 & 0.7 & 0.6 \\
\hline Iran (Islamic Rep. of) & n.a. & n.a. & n.a. & n.a. & n.a. & n.a. & n.a. & n.a. & n.a. & 0.0 & n.a. \\
\hline South Africa & n.a. & n.a. & n.a. & 320 & 629 & 491 & n.a. & n.a. & n.a. & 0.2 & 0.2 \\
\hline Turkey & 1 & 1 & 33 & 748 & 325 & 747 & 0.0 & 0.0 & 0.0 & 0.5 & 0.4 \\
\hline
\end{tabular}

Source: UN Comtrade Online

Notes: The industry was defined according to SITC Rev.3. classes 713.1, 714 and 792; for definition see Appendix A.1.5. Figures exclude re-export where such data was available. 
Table 3.14 Export of Aircraft and Spacecraft Parts and Components, 2007 (Million USD at constant 2000 prices)

\begin{tabular}{|c|c|c|c|c|c|}
\hline \multirow[b]{2}{*}{ Rank \# } & \multirow[b]{2}{*}{ Country } & \multirow{2}{*}{$\begin{array}{l}\text { Export value } \\
\text { (Million USD) }\end{array}$} & \multicolumn{2}{|c|}{ Global share (\%) } & \multirow{2}{*}{$\begin{array}{c}\text { Share of parts \& } \\
\text { components in aircraft } \\
\text { exports }(\%)\end{array}$} \\
\hline & & & Country & Cumulated & \\
\hline 1 & USA & $17,775.0$ & 38.1 & 38.1 & 28.7 \\
\hline 2 & Germany & $4,829.8$ & 10.3 & 48.4 & 22.2 \\
\hline 3 & France & $4,491.0$ & 9.6 & 58.0 & 17.2 \\
\hline 4 & Japan & $2,142.5$ & 4.6 & 62.6 & 94.8 \\
\hline 5 & * Singapore & $2,104.2$ & 4.5 & 67.1 & 81.0 \\
\hline 6 & Spain & $1,614.0$ & 3.5 & 70.5 & n.a. \\
\hline 7 & Canada & $1,578.5$ & 3.4 & 73.9 & 20.2 \\
\hline 8 & Italy & $1,476.3$ & 3.2 & 77.1 & 46.5 \\
\hline 9 & ${ }^{*}$ Thailand & $1,379.7$ & 3.0 & 80.0 & n.a. \\
\hline 10 & Israel & $1,233.6$ & 2.6 & 82.7 & 98.2 \\
\hline 11 & ${ }^{*}$ China (P.R.) & $1,037.7$ & 2.2 & 84.9 & 88.1 \\
\hline 12 & Netherlands & 837.3 & 1.8 & 86.7 & n.a. \\
\hline 13 & Belgium & 811.9 & 1.7 & 88.4 & n.a. \\
\hline 14 & * Malaysia & 659.4 & 1.4 & 89.8 & 94.0 \\
\hline 15 & ${ }^{*}$ Korea & 480.1 & 1.0 & 90.9 & 92.3 \\
\hline 16 & Austria & 420.8 & 0.9 & 91.8 & n.a. \\
\hline 17 & Switzerland & 389.1 & 0.8 & 92.6 & n.a. \\
\hline 18 & Norway & 351.3 & 0.8 & 93.4 & n.a. \\
\hline 19 & Australia & 344.8 & 0.7 & 94.1 & 78.3 \\
\hline 20 & * India & 309.5 & 0.7 & 94.8 & 99.1 \\
\hline 21 & ${ }^{*}$ Brazil & 243.8 & 0.5 & 95.3 & 5.8 \\
\hline 22 & * Philippines & 239.6 & 0.5 & 95.8 & 96.5 \\
\hline 23 & Sweden & 205.6 & 0.4 & 96.2 & n.a. \\
\hline 24 & ${ }^{*}$ Turkey & 176.2 & 0.4 & 96.6 & 39.7 \\
\hline 25 & * Indonesia & 133.0 & 0.3 & 96.9 & 81.7 \\
\hline 26 & Czech Rep. & 117.7 & 0.3 & 97.1 & n.a. \\
\hline 27 & Poland & 116.1 & 0.2 & 97.4 & n.a. \\
\hline 28 & ${ }^{*}$ Mexico & 113.3 & 0.2 & 97.6 & 19.9 \\
\hline 29 & Ireland & 103.9 & 0.2 & 97.9 & n.a. \\
\hline 30 & Denmark & 103.6 & 0.2 & 98.1 & n.a. \\
\hline 31 & Portugal & 101.7 & 0.2 & 98.3 & n.a. \\
\hline 32 & ${ }^{*}$ South Africa & 80.5 & 0.2 & 98.5 & 17.9 \\
\hline \multirow[t]{3}{*}{33} & ${ }^{*}$ Colombia & 71.6 & 0.2 & 98.6 & 98.9 \\
\hline & OTHERS & 640.8 & 1.4 & 100.0 & \\
\hline & TOTAL & $46,714.0$ & 100.0 & & \\
\hline
\end{tabular}

Source: UN Comtrade Online

Notes: $\left.{ }^{*}\right)$ indicates emerging economies. Values exclude re-export of same year where data was available. The industry was defined according to SITC Rev.3. class 7929 (parts) and 792 (aircraft). 
Table 3.15 Aerospace Export Share in GDP (percent)

\begin{tabular}{|c|c|c|c|c|c|c|}
\hline & 1985 & 1990 & 1995 & 2000 & 2005 & 2007 \\
\hline Total Sample & 0.22 & 0.45 & 0.40 & 0.49 & 0.49 & 0.59 \\
\hline Industrialized Countries & 0.25 & 0.50 & 0.45 & 0.55 & 0.57 & 0.68 \\
\hline United States & 0.34 & 0.66 & 0.45 & 0.56 & 0.56 & 0.73 \\
\hline Western Europe & 0.28 & 0.66 & 0.72 & 0.78 & 0.86 & 0.95 \\
\hline France & 0.38 & 1.06 & 1.56 & 1.57 & 1.84 & 2.18 \\
\hline Germany & 0.37 & 0.63 & 0.62 & 1.06 & 1.23 & 1.29 \\
\hline Italy & 0.19 & 0.45 & 0.28 & 0.46 & 0.41 & 0.49 \\
\hline United Kingdom & 0.46 & 0.93 & 0.95 & 0.66 & 0.72 & 0.71 \\
\hline Other Western Europe & 0.09 & 0.39 & 0.38 & 0.37 & 0.36 & 0.42 \\
\hline Central/Eastern Eur./CIS & 0.07 & 0.01 & 0.04 & 0.17 & 0.31 & 0.38 \\
\hline CEE, EU Members & 0.07 & 0.01 & 0.05 & 0.12 & 0.25 & 0.33 \\
\hline Ukraine & n.a. & n.a. & n.a. & 0.85 & 0.96 & 0.95 \\
\hline Other Industrialized & 0.06 & 0.13 & 0.13 & 0.24 & 0.22 & 0.26 \\
\hline Australia & 0.02 & 0.07 & 0.09 & 0.10 & 0.13 & 0.12 \\
\hline Canada & 0.38 & 0.90 & 0.82 & 1.29 & 1.08 & 1.23 \\
\hline Israel & 0.68 & 0.64 & 0.65 & 0.83 & 0.73 & 1.01 \\
\hline Japan & 0.01 & 0.02 & 0.03 & 0.07 & 0.07 & 0.09 \\
\hline Emerging Economies & 0.06 & 0.10 & 0.11 & 0.18 & 0.16 & 0.22 \\
\hline Asia & 0.13 & 0.14 & 0.16 & 0.11 & 0.12 & 0.18 \\
\hline China (People's Rep. of) & n.a. & n.a. & 0.02 & 0.05 & 0.05 & 0.07 \\
\hline China (Hong Kong SAR) & 0.00 & n.a. & n.a. & 0.00 & 0.00 & 0.00 \\
\hline India & 0.01 & 0.00 & 0.00 & 0.02 & 0.02 & 0.05 \\
\hline Indonesia & 0.00 & 0.02 & 0.01 & 0.02 & 0.06 & 0.08 \\
\hline Korea, Rep. of & 0.19 & 0.24 & 0.23 & 0.16 & 0.09 & 0.11 \\
\hline Malaysia & 0.49 & 0.95 & 2.07 & 0.62 & 0.55 & 0.72 \\
\hline Philippines & 0.00 & n.a. & 0.00 & 0.07 & 0.37 & 0.23 \\
\hline Singapore & 2.23 & 1.77 & 0.80 & 0.86 & 1.78 & 3.24 \\
\hline Latin America & 0.02 & 0.07 & 0.08 & 0.28 & 0.23 & 0.30 \\
\hline Argentina & 0.00 & n.a. & 0.01 & 0.10 & 0.02 & 0.08 \\
\hline Brazil & 0.05 & 0.14 & 0.08 & 0.57 & 0.44 & 0.54 \\
\hline Chile & 0.00 & 0.09 & 0.01 & 0.06 & 0.03 & 0.03 \\
\hline Colombia & 0.00 & n.a. & 0.00 & 0.05 & 0.05 & 0.07 \\
\hline Mexico & n.a. & 0.05 & 0.15 & 0.15 & 0.16 & 0.25 \\
\hline Peru & 0.00 & n.a. & 0.00 & 0.00 & 0.01 & 0.00 \\
\hline Africa \& Middle East & 0.00 & 0.00 & 0.01 & 0.21 & 0.15 & 0.18 \\
\hline Iran (Islamic Rep. of) & n.a. & n.a. & n.a. & 0.00 & 0.00 & n.a. \\
\hline South Africa & n.a. & n.a. & n.a. & 0.24 & 0.39 & 0.28 \\
\hline Turkey & 0.00 & 0.00 & 0.02 & 0.28 & 0.10 & 0.20 \\
\hline
\end{tabular}

Sources: UN Comtrade Online and World Development Indicators Online

The revealed comparative advantage (RCA) captures countries' relative export performance. The index is defined according to Balassa (1965) and shown in equation (3.5). In the present case it compares the share of aerospace in a country's national 
exports with the share of aerospace in the total export of the set of sample countries. If $\mathrm{RCA}>1$, a country has a specialization in aerospace product exports.

$$
R C A=\frac{E X_{i}^{A E R O}}{E X_{i}^{T O T}} / \frac{\sum_{i} E X^{A E R O}}{\sum_{i} E X^{T O T}}
$$

In Table 3.16 we can observe specialization (values larger than one for at least three successive years ${ }^{62}$ ) for only a handful of industrialized countries (the USA, France, Germany, the UK, Canada and Israel, with values 4.19, 3.81, 1.28, 1.6963, 1.46 and 1.83 in 2007, respectively), and for only one in the emerging group: Brazil (2.07 in 2007). There are only two newcomers that gained competitiveness after 1990 and sustained it by over the following years. One was Canada and the other was Brazil.

Interestingly, none of the Asian emerging economies show comparative advantage in aerospace. Among the major exporters Singapore experienced a significant increase in RCA in aerospace since the 1990s. ${ }^{64}$ Despite the almost 8 -fold expansion of China aerospace exports between 1995 and 2007, the comparative disadvantage hardly improved over the same period. At the same time other emerging countries that made significant efforts to enter the industry, such as Argentina, Indonesia, India, Korea and Mexico have clear disadvantage in aerospace. This is also the case in Japan. In general, if one was to determine specialization according to Ricardian principles, the answer is rather clear. Industrialized economies should specialize in aerospace products and emerging economies had better choose other commodities. Yet, as the next section will show, the growing demand for aerospace products in emerging countries suggests that comparative advantage should not only be seen in the static sense.

\footnotetext{
${ }^{62}$ With this criterion we try to overcome the bias caused by used aircraft sales in the amount of millions of dollars in a single year.

${ }^{63}$ Values only available for 1995

${ }^{64}$ If we look at RCA in aerospace parts and components export, two of the emerging block, Singapore and the Philippines had values greater than 1 in 2007 (1.8 and 1.22 respectively). Other advantageous locations were Israel (5.84), the USA (3.91), France (2.13) and Spain (1.63).
} 
Table 3.16 Revealed Comparative Advantage (RCA) in Aircraft

\begin{tabular}{|c|c|c|c|c|c|}
\hline & 1990 & 1995 & 2000 & 2005 & 2007 \\
\hline Industrialized Countries & 1.12 & 1.23 & 1.23 & 1.33 & 1.33 \\
\hline United States & 2.69 & 2.69 & 2.88 & 3.81 & 4.19 \\
\hline Western Europe & 0.91 & 1.16 & 0.97 & 1.04 & 0.95 \\
\hline France & 1.15 & 3.04 & 3.09 & 4.02 & 3.81 \\
\hline Germany & n.a. & 0.96 & 1.51 & 1.41 & 1.28 \\
\hline Italy & 0.61 & 0.44 & 0.84 & 0.63 & 0.50 \\
\hline United Kingdom & 0.68 & 1.69 & n.a. & n.a. & n.a. \\
\hline Other Western Europe & 0.35 & 0.52 & 0.31 & 0.32 & 0.28 \\
\hline Central/Eastern Eur./CIS & 0.17 & 0.06 & 0.18 & 0.14 & 0.17 \\
\hline CEE, EU Members & 0.17 & 0.06 & 0.13 & 0.12 & 0.15 \\
\hline Ukraine & n.a. & n.a. & 0.54 & 0.30 & 0.33 \\
\hline Other Industrialized & 0.27 & 0.38 & 0.62 & 0.66 & 0.68 \\
\hline Australia & 0.11 & 0.28 & 0.31 & 0.32 & 0.25 \\
\hline Canada & 0.75 & 0.99 & 1.37 & 1.51 & 1.46 \\
\hline Israel & 0.85 & 1.56 & 1.67 & 1.56 & 1.83 \\
\hline Japan & 0.05 & 0.09 & 0.18 & 0.17 & 0.25 \\
\hline Emerging Economies & 0.20 & 0.19 & 0.31 & 0.22 & 0.26 \\
\hline Asia & 0.17 & 0.18 & 0.13 & 0.13 & 0.16 \\
\hline China (People's Rep. of) & n.a. & 0.06 & 0.12 & 0.07 & 0.08 \\
\hline China (Hong Kong SAR) & n.a. & n.a. & n.a. & n.a. & n.a. \\
\hline India & 0.01 & 0.01 & 0.08 & 0.05 & 0.17 \\
\hline Indonesia & 0.02 & 0.02 & 0.02 & 0.10 & 0.11 \\
\hline Korea, Rep. of & 0.10 & 0.14 & 0.21 & 0.08 & 0.11 \\
\hline Malaysia & 0.32 & 1.11 & 0.17 & 0.19 & 0.31 \\
\hline Philippines & n.a. & 0.01 & 0.02 & 0.60 & 0.39 \\
\hline Singapore & 0.29 & 0.21 & 0.27 & 0.47 & 0.68 \\
\hline Latin America & 0.35 & 0.23 & 0.83 & 0.59 & 0.66 \\
\hline Argentina & n.a. & 0.07 & 0.57 & 0.12 & 0.39 \\
\hline Brazil & 0.62 & 0.38 & 3.65 & 1.99 & 2.07 \\
\hline Chile & 0.11 & 0.01 & 0.11 & 0.04 & 0.03 \\
\hline Colombia & n.a. & 0.02 & 0.21 & 0.15 & 0.19 \\
\hline Mexico & 0.10 & 0.27 & 0.10 & 0.10 & 0.16 \\
\hline Peru & n.a. & 0.02 & 0.00 & 0.02 & 0.00 \\
\hline Africa \& Middle East & n.a. & 0.01 & 0.67 & 0.32 & 0.41 \\
\hline Iran (Islamic Rep. of) & n.a. & n.a. & n.a. & n.a. & n.a. \\
\hline South Africa & n.a. & n.a. & 0.66 & 0.99 & 0.55 \\
\hline Turkey & n.a. & 0.01 & 1.37 & 0.16 & 0.33 \\
\hline
\end{tabular}

Source: UN Comtrade Online

Notes: Excludes engines. RCA $>1$ indicates comparative advantage. For calculations see equation (3.5);

\subsection{The growing demand for air transport}

World air traffic has been growing rapidly in the last four decades. Since 1970, the number of air passengers has grown more than six-fold. If every air passenger only flew once a year, close to every third citizen of the world could have flown in 2006, while only 
every eighth person could have experienced this fastest means of travel in 1970. In reality however, citizens of high income countries are much more likely to travel by air than citizens of other countries (see Table 3.17). Until as recently as the year 2000, some $90 \%$ of the world's air passengers came from high or upper middle income countries. Only by 2006 did this proportion decline to $83 \%$. Yet it was the lower middle income group that experienced the largest growth since 1980, a more than 7 -fold increase was 3.3 times the global growth rate of air travel. Such a growth is a clear indication of increased demand for aircraft and parts in countries of this group. It also indicates their leverage potential in attracting foreign producers to manufacture at least some parts and components locally.

Table 3.17 Passengers carried by income groups (thousands)

\begin{tabular}{lrrrrr}
\hline & \multicolumn{1}{c}{$\mathbf{1 9 7 0}$} & \multicolumn{1}{c}{$\mathbf{1 9 8 0}$} & \multicolumn{1}{c}{$\mathbf{2 0 0 0}$} & \multicolumn{1}{c}{$\mathbf{2 0 0 6}$} \\
\hline World Total & 310,441 & 641,873 & $1,024,977$ & $1,673,922$ & $2,072,237$ \\
High income & 270,301 & 528,450 & 846,971 & $1,351,239$ & $1,538,348$ \\
Upper middle income & 18,932 & 57,481 & 79,139 & 141,008 & 182,911 \\
Lower middle income & n.a. & 43,712 & 82,852 & 160,170 & 322,855 \\
Low income & 6,470 & 12,230 & 16,015 & 21,505 & 28,123 \\
\hline
\end{tabular}

Source: World Development Indicators Online

Note: classification refers to standing as of Mar 2009

Table 3.18 Growth of Air Traffic in Selected Countries

(million passenger-kilometers)

\begin{tabular}{|c|c|c|c|c|c|c|c|}
\hline & $\begin{array}{l}\text { United } \\
\text { States }\end{array}$ & France & $\begin{array}{c}\text { (West) } \\
\text { Germany }\end{array}$ & $\begin{array}{c}\text { United } \\
\text { Kingdom }\end{array}$ & Japan & P.R.China & Brazil \\
\hline 1952 & 23,014 & 1,460 & $78^{a}$ & 2,000 & 69 & 24 & n.a. \\
\hline 1962 & 60,350 & 6,116 & 2,098 & 8,760 & 2,474 & 117 & n.a. \\
\hline 1970 & 190,868 & 13,587 & 8,255 & 18,953 & 15,459 & 179 & n.a. \\
\hline 1975 & 238,666 & 23,277 & 13,634 & 30,192 & 32,800 & 1,539 & n.a. \\
\hline 1980 & 352,607 & 34,130 & 21,056 & 56,746 & 53,490 & 3,956 & n.a. \\
\hline 1985 & 466,871 & 39,559 & 24,431 & 63,809 & 65,922 & 11,672 & n.a. \\
\hline 1990 & 577,594 & 52,912 & 42,387 & 104,999 & 101,733 & 23,048 & n.a. \\
\hline 1993 & 598,885 & 59,455 & 52,941 & 124,882 & 108,996 & 47,760 & n.a. \\
\hline 1995 & 667,376 & n.a. & n.a. & n.a. & 134,231 & 68,130 & $49,501^{b}$ \\
\hline 2000 & 855,091 & n.a. & n.a. & 260,675 & 176,629 & 97,054 & 37,973 \\
\hline 2005 & 939,467 & n.a. & n.a. & 287,399 & 169,216 & 204,493 & 58,741 \\
\hline 2007 & 977,750 & n.a. & n.a. & 314,245 & 163,508 & 279,173 & 58,675 \\
\hline \multicolumn{8}{|c|}{ Compound average annual growth (\%) } \\
\hline $1952-1990$ & 8.9 & 9.9 & 18.0 & 11.0 & 21.2 & 19.8 & n.a. \\
\hline $1990-2007$ & 3.1 & n.a. & n.a. & 6.7 & 2.8 & 15.8 & $1.9 c$ \\
\hline
\end{tabular}

Sources: Mitchell 1998; US Bureau of Transportation Statistics, UK British Transport Statistics; Japan Statistical Yearbook, various years; CNBS Statistical Yearbook of China, various years, ANAC Brazil.

Note: a) refers to 1955 ; b) refers to 1998 ; c) refers to the period 1998 to 2007 
Table 3.19 Passengers Carried by Countries of Departure, Selected Emerging Economies and the USA (thousand passengers)

\begin{tabular}{lrrrrr}
\hline & \multicolumn{1}{c}{1970} & \multicolumn{1}{c}{1980} & \multicolumn{1}{c}{1990} & \multicolumn{1}{c}{$\mathbf{2 0 0 0}$} & \multicolumn{1}{c}{$\mathbf{2 0 0 6}$} \\
\hline World Total & 310,441 & 641,873 & $1,024,977$ & $1,673,922$ & $2,072,237$ \\
United States & 163,449 & 295,329 & 464,574 & 665,327 & 725,531 \\
Brazil & 3,340 & 13,008 & 19,150 & 31,288 & 40,945 \\
China & n.a. & 2,568 & 16,596 & 61,892 & 158,013 \\
India & 2,672 & 6,603 & 10,862 & 17,299 & 40,289 \\
Korea, Rep. & 1,208 & 3,567 & 15,685 & 34,331 & 34,843 \\
Indonesia & 826 & 5,059 & 9,223 & 9,916 & 29,867 \\
\hline
\end{tabular}

Source: World Development Indicators Online

For a long time, the aviation market was very limited in many of the emerging economies, despite their large territories. China was one of the best examples of a "nonflying country". Even in 1980 it showed passenger-kilometer levels similar to European countries before the jet age (Table 3.18). The number of air passengers in China in 1990 was similar to that of South Korea (Table 3.19). The passenger levels of 2006 are still lower than the US levels of 1970. Nevertheless, the growth of air traffic within and out of the country exceeded that of many countries with the largest air transport markets. Annual average growth in China between 1990 and 2007 was nearly 15.8\%, while it was only $6.7 \%$ in the UK and $3.1 \%$ in the USA. It was only China that managed to sustain high growth rates -due in part to the very low initial levels of air transport.

Global air transportation has clearly gained speed after 1980. A major reason for this was a 1978 deregulation in USA resulting in the entry of new airlines and the expansion of services. Similar deregulation took place in Europe in the 1990s, but many of the emerging air transport markets remain highly regulated even today. To a large extent the growth is constrained by infrastructural limitations and airport and air traffic management capacities. Nevertheless, many of the Asian emerging economies have made large investments into tackling these issues and have nurtured the largest airport development projects in recent decades (e.g. Singapore Changi, Hong Kong International, Shanghai Pudong, Beijing Capital, Bangkok Suvarnabhumi, Kuala Lumpur International, to mention but a few). They have accelerated growth despite ongoing pilot shortages or airspace restrictions.

Another way to measure the volume of air traffic is by looking at the sheer number of departures. In emerging economies air traffic has been expanding at a much faster rate than in industrialized economies. The average growth rate for the period 1973-1990 was $4.5 \%$ for emerging and only $2 \%$ for industrialized economies (Table 3.20). For the period $1990-2007$ it was $5.8 \%$ and $3.8 \%$, respectively. This is the reason why the emerging markets are moving to the center of attention of current and future producers. Demand for air transportation has been closely linked to GDP levels and the 
rapid growth in air traffic in China is explained by the high economic growth. Yet growth rates easily exaggerate demand for countries with low initial levels, considering that the sum of departures in emerging economies in 2007 was less than that in industrialized economies in 1973. Even in the case of China, the number of airline departures in 2007 (1.75 million) was still lower than that in Western Europe (1.85 million) in 1973, not to mention the USA (7.93 million). But the near future will very likely bring about substantial changes in the global demand pattern. Assuming that the growth rates of 2007 remain stable (which now know in the middle of the financial crisis to be unrealistic, especially for Europe), within a decade Asia and even China alone can overtake Europe in terms of number of air departures. This certainly gives a solid footing for the dreams of Asian aircraft industries.

The efforts to bring aircraft manufacturing to Asia can also be backed by the economic growth predictions (Maddison 2007) and (related to these predictions) new aircraft delivery forecast of the world's four largest manufacturers (see Table 3.21). The Asia-Pacific region is expected to take up 29-33 per cent of all new aircraft deliveries, becoming the largest buyer. Calculating in 2009 dollars, aircraft sales to Asia will be in the range of 1 trillion US dollars over the next 20 years. According to all major manufacturers, China, specifically, is expected to receive 11-14 per cent of all aircraft deliveries and 14-15 per cent of new regional aircraft in the next two decades. North America and Europe will be neck and neck in the total forecast of both large civil aircraft manufacturers accounting for 23 to 25 per cent of global demand. North America will remain the largest market for regional aircraft (including both jets and turboprops), but predictions differ significantly with regard to the shares (between 35-47 per cent). According to three of the producers, around one in every four new regional aircraft will land in Asia, only Airbus predicts a somewhat different share (17 per cent).

If the predicted market values in the forecasts are correct, every percentage point of market share translates into 3.1-3.6 billion dollars worth of aircraft acquisition over the upcoming two decades. Considering the additional maintenance, repair and overhaul services demand, developing aircraft manufacturing capabilities has a definite appeal beyond static comparative advantages. 
Table 3.20 Growth of Air Traffic: Registered Carrier Departures, 1960-2007

(thousands)

\begin{tabular}{|c|c|c|c|c|c|c|c|c|c|}
\hline & \multirow{2}{*}{1973} & \multirow{2}{*}{1985} & \multirow{2}{*}{1990} & \multirow{2}{*}{1995} & \multirow{2}{*}{2000} & \multirow{2}{*}{2005} & \multirow{2}{*}{2007} & \multicolumn{2}{|c|}{ CAGR, $\%$} \\
\hline & & & & & & & & $1973-90$ & $90-2007$ \\
\hline World & 9,765 & 11,898 & 14,584 & 18,008 & 22,009 & 24,229 & 24,654 & 2.4 & 3.1 \\
\hline Sample Total & 8,841 & 10,414 & 12,996 & 15,573 & 19,407 & 21,741 & 22,273 & 2.3 & 3.2 \\
\hline Industrialized Countries & 7,931 & 8,812 & 11,063 & 12,767 & 16,169 & 17,426 & 17,224 & 2.0 & 2.6 \\
\hline United States & 5,058 & 5,554 & 6,849 & 7,682 & 8,821 & 9,970 & 9,816 & 1.8 & 2.1 \\
\hline Western Europe & 1,849 & 2,137 & 3,014 & 3,687 & 5,110 & 5,095 & 4,892 & 2.9 & 2.9 \\
\hline France & 231 & 261 & 442 & 482 & 812 & 728 & 825 & 3.9 & 3.7 \\
\hline Germany & 152 & 215 & 344 & 527 & 738 & 1,024 & 1,127 & 4.9 & 7.2 \\
\hline Italy & 446 & 472 & 671 & 725 & 876 & 1,018 & 1,045 & 2.4 & 2.6 \\
\hline United Kingdom & 185 & 175 & 229 & 280 & 368 & 446 & 432 & 1.3 & 3.8 \\
\hline Other Western Europe & 835 & 1,014 & 1,328 & 1,674 & 2,316 & 1,879 & 1,463 & 2.8 & 0.6 \\
\hline Central/Eastern Eur./CIS & 86 & 90 & 92 & 135 & 190 & 315 & 270 & 0.4 & 6.6 \\
\hline CEE, EU Members & 86 & 90 & 92 & 112 & 162 & 273 & 240 & 0.4 & 5.8 \\
\hline Ukraine & n.a. & n.a. & n.a. & 23 & 28 & 42 & 30 & n.a. & n.a. \\
\hline Other Industrialized & 937 & 1,031 & 1,108 & 1,263 & 2,047 & 2,047 & 2,246 & 1.0 & 4.2 \\
\hline Australia & 257 & 239 & 256 & 396 & 383 & 343 & 354 & 0.0 & 1.9 \\
\hline Canada & 349 & 352 & 347 & 283 & 963 & 1,018 & 1,189 & 0.0 & 7.5 \\
\hline Israel & 20 & 23 & 30 & 48 & 56 & 34 & 47 & 2.3 & 2.8 \\
\hline Japan & 312 & 418 & 476 & 536 & 645 & 652 & 657 & 2.5 & 1.9 \\
\hline Emerging Economies & 910 & 1,602 & 1,933 & 2,806 & 3,238 & 4,315 & 5,049 & 4.5 & 5.9 \\
\hline Asia & 328 & 661 & 878 & 1,505 & 1,521 & 2,657 & 3,174 & 6.0 & 8.0 \\
\hline China (People's Rep. of) & n.a. & 102 & 196 & 398 & 573 & 1,349 & 1,754 & 13.9 & 13.8 \\
\hline China (Hong Kong SAR) & n.a. & n.a. & n.a. & 194 & 79 & 123 & n.a. & n.a. & n.a. \\
\hline India & 94 & 140 & 126 & 168 & 198 & 330 & 569 & 1.7 & 9.3 \\
\hline Indonesia & 43 & 186 & 205 & 262 & 159 & 321 & 358 & 9.7 & 3.3 \\
\hline Korea & 40 & 49 & 120 & 189 & 227 & 221 & 243 & 6.7 & 4.2 \\
\hline Malaysia & 63 & 95 & 131 & 178 & 169 & 176 & 185 & 4.3 & 2.1 \\
\hline Philippines & 67 & 58 & 70 & 64 & 45 & 59 & 65 & 0.3 & -0.4 \\
\hline Singapore & 21 & 31 & 31 & 52 & 71 & 77 & n.a. & 2.1 & 6.1 \\
\hline Latin America & 475 & 818 & 886 & 1,100 & 1,404 & 1,243 & 1,388 & 3.7 & 2.7 \\
\hline Argentina & 71 & 101 & 114 & 112 & 169 & 81 & 79 & 2.8 & -2.1 \\
\hline Brazil & 173 & 335 & 416 & 454 & 628 & 515 & 650 & 5.3 & 2.7 \\
\hline Chile & 21 & 25 & 40 & 78 & 88 & 93 & 101 & 3.8 & 5.6 \\
\hline Colombia & 103 & 124 & 117 & 194 & 199 & 162 & 186 & 0.7 & 2.8 \\
\hline Mexico & 91 & 205 & 177 & 225 & 290 & 331 & 310 & 4.0 & 3.3 \\
\hline Peru & 15 & 29 & 22 & 37 & 29 & 61 & 62 & 2.2 & 6.3 \\
\hline Africa \& Middle East & 107 & 123 & 168 & 201 & 313 & 415 & 487 & 2.7 & 6.5 \\
\hline Iran (Islamic Rep. of) & 22 & 27 & 40 & 49 & 83 & 121 & 138 & 3.5 & 7.6 \\
\hline South Africa & 48 & 64 & 84 & 74 & 110 & 148 & 153 & 3.4 & 3.6 \\
\hline Turkey & 37 & 32 & 44 & 79 & 120 & 146 & 197 & 1.1 & 9.2 \\
\hline
\end{tabular}

Source: World Development Indicators Online 
Table 3.21 Demand Forecast for New Aircraft by Major Manufacturers

\begin{tabular}{|c|c|c|c|c|c|c|c|c|}
\hline $\begin{array}{l}\text { Company } \\
\text { Outlook Period }\end{array}$ & \multicolumn{2}{|c|}{$\begin{array}{c}\text { Boeing } \\
2009-2029\end{array}$} & \multicolumn{2}{|c|}{$\begin{array}{c}\text { Embraer } \\
2010-2029\end{array}$} & \multicolumn{2}{|c|}{$\begin{array}{c}\text { Airbus } \\
2009-2028\end{array}$} & \multicolumn{2}{|l|}{$\begin{array}{c}\text { Bombardier } \\
2010-2029\end{array}$} \\
\hline \multicolumn{9}{|l|}{ A. Regional Aircraft } \\
\hline Seating capacity definition: & \multirow{2}{*}{\multicolumn{2}{|c|}{$\begin{array}{c}<90 \text { seats } \\
60\end{array}$}} & \multirow{2}{*}{\multicolumn{2}{|c|}{$\begin{array}{c}30-120 \text { seats } \\
200\end{array}$}} & \multirow{2}{*}{\multicolumn{2}{|c|}{$\begin{array}{c}<100 \text { seats } \\
\text { n.a. }\end{array}$}} & \multirow{2}{*}{\multicolumn{2}{|c|}{$\begin{array}{c}20-99 \text { seats } \\
\sim 239\end{array}$}} \\
\hline Market value (USD bln) & & & & & & & & \\
\hline Regional Market Size & Tot & (Share) & Tot & (Share) & & & & \\
\hline (new deliveries next 20 & 1920 & $100 \%$ & $\underline{6875}$ & $100 \%$ & $\underline{8321}$ & $100 \%$ & $\underline{6,100}$ & $100 \%$ \\
\hline North America & 800 & $42 \%$ & 2400 & $35 \%$ & 2899 & $35 \%$ & 2,860 & $47 \%$ \\
\hline Latin America & 20 & $1 \%$ & 575 & $8 \%$ & 661 & $8 \%$ & 350 & $6 \%$ \\
\hline Europe & 310 & $16 \%$ & 1510 & $22 \%$ & 2160 & $26 \%$ & (incl. CIS) 950 & $16 \%$ \\
\hline Asia-Pacific & 470 & $24 \%$ & 575 & $22 \%$ & 1374 & $17 \%$ & 1580 & $26 \%$ \\
\hline Of which P.R. China & 280 & $15 \%$ & 950 & $14 \%$ & n.a. & n.a. & 860 & $14 \%$ \\
\hline Russia/CIS & 200 & $10 \%$ & 405 & $6 \%$ & 467 & $6 \%$ & n.a. & $0 \%$ \\
\hline Middle East & 70 & $4 \%$ & 240 & $3 \%$ & 154 & $2 \%$ & (incl. Afr.) & $6 \%$ \\
\hline Africa & 50 & $3 \%$ & 220 & $3 \%$ & 506 & $6 \%$ & n.a. & \\
\hline \multicolumn{9}{|c|}{ B. Total Commercial Aircraft Market } \\
\hline Total Market value (USD & \multicolumn{2}{|c|}{3,590} & \multicolumn{2}{|c|}{ n.a. } & \multicolumn{2}{|c|}{3,100} & n.a. & \\
\hline All new deliveries next 20 & $\underline{30,900}$ & $100 \%$ & & & 30,175 & $100 \%$ & & \\
\hline North America & 7,200 & $23 \%$ & & & 7,675 & $25 \%$ & & \\
\hline Latin America & 2,180 & $7 \%$ & & & 2,090 & $7 \%$ & & \\
\hline Europe & 7,190 & $23 \%$ & & & 7,585 & $25 \%$ & & \\
\hline Asia-Pacific & 10,320 & $33 \%$ & & & 8,726 & $29 \%$ & & \\
\hline Of which China & 4,330 & $14 \%$ & & & 3,272 & $11 \%$ & & \\
\hline Russia/CIS & 960 & $3 \%$ & & & 1,332 & $4 \%$ & & \\
\hline Middle East & 2,340 & $8 \%$ & & & 1,497 & $5 \%$ & & \\
\hline Africa & 710 & $2 \%$ & & & 1,270 & $4 \%$ & & \\
\hline
\end{tabular}

Source: Boeing Current Market Outlook 2009-2029; Embraer Market Outlook 2010-2029; Airbus Global Market Forecast 2009-2028; Bombardier Commercial Aircraft Market Forecast 2010-2029

\subsection{Countries or Companies?}

This book focuses primarily on countries and argues that for the growth of latecomer industries the institutional framework is of key importance. Nevertheless, it was discussed earlier that during the 1990s the global industry underwent a dramatic consolidation process which resulted in the formation of vast transnational corporations that integrate a large variety of aerospace and defense production activities and services. The turnover and labor force of these companies exceeds the aerospace manufacturing turnover and employment of many of the largest aerospace producing countries. Table 3.22 compares the turnover and employment of companies and countries in 2007. Of the top 25 producing entities, 18 are companies based on annual turnover, and 17 based on number of persons engaged.

Not surprisingly, the largest companies are headquartered in the USA (Boeing, Lockheed Martin, General Dynamics, Northrop Grumman, United Technologies, Raytheon, General Electric, to mention a few) and Europe (e.g. the European Aeronautic Defence and Space Company, EADS, BAe Systems, Finmeccanica, Thales, 
Safran). But the size of their turnover indicates that a significant share of it is originating from subsidiaries all over the world.

Evidence also shows that a few emerging economies have made it to the top 25. In 2007 China was the $7^{\text {th }}$ largest aerospace producer in terms of sales and the $3^{\text {rd }}$ largest in terms of employment. Embraer of Brazil was the $23^{\text {rd }}$ largest aerospace and defense producer based on sales, in fact, the third largest aircraft manufacturer, leading over rival Bombardier of Canada.

Table 3.22 Top 25 Aerospace Producer Companies and Countries, 2007

(Values are in USD millions at constant $=2000$ prices)

\begin{tabular}{|c|c|c|c|c|c|}
\hline & $\begin{array}{l}\text { Ranking of countries and } \\
\text { companies by turnover }\end{array}$ & $\begin{array}{l}\text { Turnover } \\
\text { (USD mln) }\end{array}$ & & $\begin{array}{c}\text { Ranking of countries and } \\
\text { companies by persons engaged }\end{array}$ & Personnel \\
\hline 1 & United States & 161,081 & 1 & United States & 459,270 \\
\hline 2 & Boeing (USA) & 55,472 & 2 & General Electric (USA) & 326,923 \\
\hline 3 & EADS (NL) & 44,732 & 3 & China & 301,418 \\
\hline 4 & France & 37,768 & 4 & United Technologies (USA) & 225,581 \\
\hline 5 & Lockheed Martin (USA) & 34,979 & 5 & Boeing (USA) & 159,332 \\
\hline 6 & General Dynamics (USA) & 26,595 & 6 & Lockheed Martin (USA) & 139,981 \\
\hline 7 & China & 24,802 & 7 & Honeywell International (USA) & 122,021 \\
\hline 8 & Northrop Grumman (USA) & 23,919 & 8 & Northrop Grumman (USA) & 120,000 \\
\hline 9 & United Technologies (USA) & 18,845 & 9 & EADS (NL) & 116,485 \\
\hline 10 & Raytheon (USA) & 17,799 & 10 & BAE Systems (UK) & 97,612 \\
\hline 11 & BAE Systems (UK) & 17,799 & 11 & United Kingdom & 93,475 \\
\hline 12 & Germany & 16,600 & 12 & General Dynamics (USA) & 83,529 \\
\hline 13 & Finmeccanica (Italy) & 15,354 & 13 & Germany & 79,379 \\
\hline 14 & United Kingdom & 14,666 & 14 & Ukraine & $73,113^{a}$ \\
\hline 15 & Thales (France) & 14,297 & 15 & Raytheon (USA) & 72,134 \\
\hline 16 & General Electric (USA) & 14,062 & 16 & France & 67,231 \\
\hline 17 & Canada & 12,370 & 17 & L-3 Communications (USA) & 64,612 \\
\hline 18 & L-3 Communications (USA) & 11,665 & 18 & Thales (France) & 61,168 \\
\hline 19 & Safran (France) & 11,048 & 19 & Finmeccanica (Italy) & 60,760 \\
\hline 20 & Honeywell International & 10,224 & 20 & Bombardier (Canada) & 59,963 \\
\hline 21 & Rolls-Royce (UK) & 8,950 & 21 & Safran (France) & 52,496 \\
\hline 22 & Italy & 8,623 & 22 & Japan & 47,725 \\
\hline 23 & Embraer (Brazil) & 8,351 & 23 & Textron (USA) & 44,012 \\
\hline 24 & Bombardier (Canada) & 8,116 & 24 & Canada & 42,703 \\
\hline 25 & Textron (USA) & 7,449 & 25 & ITT (USA) & 39,689 \\
\hline
\end{tabular}

Source: Flight International and PWC "Aerospace and Defence Top 100 Special Report" in Flight International, 8-14 Sep 2009, as well as Table 3.4 and Table 3.7.

Notes: Companies are bolded; headquarter country shown in brackets. Turnover figures refer to aerospace sales only; figures on personnel include none-aerospace activities as well. a) 2006 value shown for Ukraine.

If we look at the list of the Top 100 aerospace companies (based on sales), we find three other producers from emerging countries in 2007. Hindustan Aeronautics of India was the $40^{\text {th }}$ largest company with 1,742 million USD turnover, Singapore Technologies Engineering the $51^{\text {st }}$ with 1,019 million, and Korea Aerospace Industry of South Korea the $63^{\text {rd }}$ with 715 million. 


\subsection{Conclusion: newly emerging competitors}

In this chapter, we presented a novel dataset of global aerospace production between 1960 and 2007 across 45 countries, including a number of emerging producers. We demonstrated that the global aerospace industry has grown rapidly over the past half a century, yet in a cyclical pattern with major upswings and downswings. The industry is to a great extent "owned" by industrialized countries, yet a few emerging economies have made significant inroads. This concluding section briefly highlights the key findings concerning the emerging economies.

a. Only a few successful latecomers have become significant producers on a global scale. These are China, Singapore and Brazil. A few others have become regional players, such as South Korea, Hong Kong SAR and, to a certain degree, India in Asia, and Mexico in Latin America. The emerging players directly challenge established producers of leading OECD countries, either with their final products (Brazil and, in a limited way, China) or by parts and components manufacturing (Singapore and China). Regional players have the potential to grow by attracting producers of industrialized economies, offering more competitive production costs. Strange enough, the consolidation of the industry in the early 1990s primarily affected the companies of the "traditional" producing countries. The internationalization it brought about was limited to international collaboration (risk sharing partnerships) between producers of North America, Europe and Japan. It did not expand to lower or middle income countries in what was a first wave. However, there appears to be a second wave of internationalization with the onset of the $21^{\text {st }}$ century which especially accelerated the growth of East Asian aerospace industries.

b. Although global competition has increased in the past decade, industrialized economies continue to have a competitive edge in the sector. Amongst the emerging countries only Brazil and Singapore (in parts and components) have achieved sustained competitiveness in aerospace exports. Yet competition can be very highly distorted in the presence of large domestic markets by the use of government procurement or offset strategies. This explains why so many of the emerging economies, e.g. China, are more significant producers than exporters. Labor productivity, a very crude measure of efficiency, has caught up more with the USA in recent years more in emerging economies than in industrialized economies. 
c. Today the most dynamic countries are from the lower to middle income group. On average these countries achieved an annual growth rate in value added of $7.5 \%$ between 1990 and 2007, in contrast with a growth rate of 1.92\% in industrialized economies. This resulted in a significant catch up with the US value added levels. Relative value added shares in Asian countries increased at an annual rate of 5.3\%, in Latin American countries at 3.8\%. In the same period the relative value added was decreasing in Western Europe by $1.8 \%$ per year. This implies an increasing competition, to which North America was much faster to respond than Europe.

d. An additional factor for increasing competition is the more rapid growth of air traffic in Asia, Africa and the Middle East in comparison with other parts of the world, due to the higher rates of economic growth in these regions. This is also reflected in the expected future demand for new aircraft, where Asia has moved to second place after North America.

e. These changes notwithstanding, the corporate landscape is still ruled by giants with headquarters located in the USA and Europe. However, these transnational companies have recently started to play an increased role in the growth of the industry in emerging country clusters. These companies possess the technologies and investment capabilities needed for further growth in emerging economies. The concern of many of these companies, to avoid nurturing emerging competitors, is mitigated by their need to enter markets which inevitably includes political bargaining.

f. These most recent, promising developments aside, the longer term history of the global aerospace industry calls for caution with regard to the prospects of developing countries. Many developing countries have seen aerospace as a strategic industry worth supporting. Yet too many of them failed. India, Indonesia, Argentina, Chile, Colombia, South Africa have all had grand projects that included aircraft development but even if there was an upswing in the growth of the domestic industry, this could not be sustained. Even those countries that became more successful have had serious difficulties in sustaining growth, especially during recurrent down-cycles of the global industry. The key question for further investigation is: why did some countries succeed in sustaining growth in the industry why so many others have not managed to do so? This will be tackled in subsequent chapters. 



\section{CHAPTER 4 \\ A Brazil/USA comparison of output and productivity ${ }^{65}$}

\subsection{An industry of origin approach to output and productivity comparisons}

The basic problem with aggregating output or comparing the levels of labour productivity of an industry across countries is the conversion of values to a common currency. The various shortcomings of official exchange rates and aggregate, expenditure-based purchasing power parities (PPPs) are well established (Ark 1993; Maddison and Ark 1988). According to Timmer (2000), the main arguments against using official exchange rates for comparing industries can be summarized as follows. First, they indicate the relative price levels of internationally tradable goods and services in an economy and disregard non-tradables. Next exchange rates are often distorted by governments for domestic political and economic reasons. Exchange rates are also influenced by speculation and rapid international capital movements. Finally, exchange rates provide a single converter for all goods and services produced in the economy. They do not allow for sector specific converters.

Purchasing power parities, such as the ones published by the World Bank, OECD or Eurostat address a number of these shortcomings. PPPs are calculated in the tradition of Kravis, Heston and Summers (1982) and are based on consumer prices and expenditure categories in national accounts. There are, however, several problems with the use of PPPs for sectoral productivity comparisons. They include trade and transport margins and indirect taxes and subsidies; they include import prices but exclude export prices, but most importantly, PPPs are based on final expenditures. They are useful for converting expenditure categories, but do not provide industry-specific conversion factors from the production side.

Therefore, when possible, sectoral unit value ratios (UVRs) derived from the International Comparison of Output and Productivity (ICOP) methodology are used to convert output values and value added in national currencies for purposes of sectoral

\footnotetext{
${ }^{65}$ This chapter has also been published as a UNU-MERIT Working Paper 2010-32 (Vertesy and Szirmai 2010a).
} 
international comparisons. In short, according to this tradition developed by Maddison and van Ark (1988), Szirmai and Pilat (1990); van Ark (1993) and advanced by Timmer (1996) a sample of products from the countries in a comparison are matched and UVRs are calculated using ex-factory unit values. These UVRs provide conversion ratios at the industry and branch level, and can be aggregated to the national level. Since the technical details of the ICOP methodology have been presented in dozens of studies, ${ }^{66}$ we refrain from further detail here; interested readers can find a summary in Appendix A.2 at the end of the book.

A major advantage of this method is that it offers industry-specific unit value ratios based on production data, which is ideal for sectoral comparisons between countries.

Since the 1980s, UVRs have been meticulously calculated and published at the two-digit branch level for a wide range of countries. ${ }^{67}$ (The aerospace industry forms part of transportation equipment manufacturing both in the ISIC Rev.2 and Rev.3 classification.)

The feasibility of industry-of-origin comparisons may be constrained by the availability of product-level output data in official statistical sources. Industries characterized by monopolies are very likely to remain beyond the scope of comparison because their production data are not disclosed in national statistics in order to avoid identification of a single firm. Thus, it is not surprising that the aerospace industry, especially in emerging economies, is missing from all cross-country comparisons. Comparisons for the more aggregate 'transportation equipment industry' are based on samples of products from automobile manufacturing, railway manufacturing or ship building industries. The assumption is made that the unit values ratios derived from matches in these industries are also applicable to Aerospace output. The technologically complex nature of the products and the existence of comparable safety standards arguably make these 'sister sectors' acceptable proxies. However, the assumption that unit value ratios in aerospace are similar to those for other transport subsectors remains to be tested empirically.

The limited number of firms in a sector can result in non-disclosure of data in national statistics, but this can also be a virtue. Production statistics can be traced from published company figures to form the basis of alternative calculations. If company

\footnotetext{
${ }^{66}$ The richest collection of such studies has been published in the Research Memoranda series of the Groningen Growth and Development Centre (GGDC).

${ }^{67}$ For a complete list of countries, please refer to the GGDC ICOP Database 1997 Benchmark, http://www.ggdc.net. The following selected papers summarize the latest calculation for emerging countries in our scope: Brazil and Mexico (Mulder et al. 2002), China (Szirmai et al. 2005), Indonesia, South Korea and Taiwan (Stuivenwold and Timmer 2003) and South Africa (Dijk 2002).
} 
reports reveal the value and volume of the annual production of certain major products, a sample is at hand to execute the ICOP-style calculations.

Unfortunately, in the case of an industry that is considered strategic for national security, such as aerospace, further obstacles emerge. Production detail of defense equipment is rarely revealed, and state-owned companies are often less obliged to publish reports as detailed as those published by joint-stock companies. Companyreport-based data will most likely be only available for countries where the bulk of production caters to the civilian market, rather than to military demand.

In 1994, the largest state-owned aircraft producing company of Brazil (Embraer) ${ }^{68}$ was privatized and its shares have since been traded on Wall Street. The history of aircraft manufacturing in Brazil and of Embraer is discussed at length in Chapter 6. Let it suffice here to state that this act made the company successful once again, as many observers have noted (Cassiolato et al. 2002; Goldstein 2002a, 2002b; Goldstein and McGuire 2004; Marques 2004; Montoro and Migon 2009) and, most importantly, as is shown by evidence from annual reports. Based on available company data, we make an attempt in this paper to estimate industry-specific unit value ratios to convert the value added of Brazilian aerospace industry into US dollars for the benchmark year 2005. These unit values ratios will be compared with updated unit value ratios for the transportation equipment sector, estimated by Mulder et al (2002), as well as with the official exchange rate.

In this paper, we estimate unit value ratios in order to compare the output and productivity of the Brazilian and United States' aerospace industries. There are three main reasons for using the US as a benchmark. First, the USA accounts for the largest share of the global aerospace production. Second, reliable, detailed product-level manufacturing statistics are available over a longer time span. Finally, the USA has been the benchmark country for the majority of comparisons in the ICOP literature.

2005 was selected as the benchmark year. The choice of an appropriate benchmark year is of crucial importance for a volatile industry such as aerospace, especially if the business cycles of the two countries being compared do not coincide. The choice for 2005 was motivated by four arguments. First, production in Brazil in 2005 was substantial in volume and offered a broad variety of products, indicative of the capabilities of the industry. Second, it is a relatively recent year, which comes after the currency crises which affected Brazil so heavily and after the industrial reorganization following the privatization of Embraer. (The previous study by Mulder et al (2002) took 1985 as its benchmark year, since when the Brazilian currency has been devalued by 13

\footnotetext{
${ }^{68}$ Although the number of enterprises in the sector has been well over a hundred, Embraer clearly dominates the industry (see Appendix Table A.4.2).
} 
orders of magnitude.) Next, the industry was in equilibrium in that year, with little or no excess capacity. Finally, and most importantly, detailed data for that year were available from company and independent sources.

The reliability of UVRs at the industry level depends primarily on the coverage of the matched sample (i.e. the share of the output value of matched products in the total industry output) and the variation of UVRs within a sector. The coverage ratio in the larger, more diversified aerospace industry of the USA is obviously expected to be rather low. But for Brazil high coverage rates can be achieved. The most appropriate product match shall thus include a set of products that offers the highest possible coverage ratio for Brazil.

\subsection{Official data, supplementary data and calculations}

The ICOP methodology requires manufacturing statistics (on produced quantities and output values) at both product and industry level in the countries compared. The usual sources for such data are economic censuses (carried out typically in a 5-10 year intervals) or manufacturing surveys (annual in non-census years). The United States Census Bureau tracks industry output data up to 6 digits in the Annual Surveys of Manufacturing (ASM) and up to 10 digits in the Current Industry Reports (CIR). The relevant figures for the most detailed classification are however withheld for reasons of confidentiality. Figures are presented only up to 8 digits.

In Brazil, the Instituto Brasileiro de Geografia e Estatística (Brazilian Institute of Geography and Statistics, IBGE) collects data up to the 8-digit level (corresponding to the 10-digit level of the US), but most of the values in the Pesquisa Industrial Anual (PIA) are only shown up to 4 digits in the case of the aerospace industry. (The only exception refers to a small share of aircraft parts, amounting to $8 \%$ of total output value.)

Officially published figures for the year 2005 for the United States and Brazil are presented in Table 4.1. The table clearly indicates that the lack of product level data is a major limitation for ICOP-type comparisons. The only comparable figures from the national manufacturing surveys indicate that Brazil produced a total of 8.2 billion BRL worth of aerospace products in 2005, while the United States' production totaled 133,0 billion USD.

Similar limitations have already been addressed in the ICOP literature. Maddison and Van Ark (1988, pp.114-119) made adjustments for the automobile manufacturing industry based on additional data on the technical specification of products and retail value figures published in industry journals to compare the sector in Brazil, Mexico and the USA. The analogy of cars appears to be appropriate for the aerospace industry. On 
the one hand, the number of aircraft produced is much smaller than the number of cars, but, on the other hand, the products are much more visible. In other words, while the figures can be concealed in national statistics, it is hard to hide the products physically. We thus looked beyond national statistics and investigated alternative sources: industry journals, industry associations' statistics, independent NGO publications, company statements, or environment reports and accident statistics to locate and cross-check output quantity data and indications of producer prices or retail prices. The additional figures collected and the adjustments made are discussed in the following section.

Table 4.1 Industrial Census Information on the Aerospace industry and Commercial Aircrafts (2005)

\begin{tabular}{|c|c|c|c|c|}
\hline & \multirow{2}{*}{$\begin{array}{l}\text { Output } \\
\text { Quantity } \\
\text { (units) }\end{array}$} & \multicolumn{3}{|c|}{ Gross Output Value Added Unit value } \\
\hline & & \multicolumn{3}{|c|}{ (million in national currency) } \\
\hline \multicolumn{5}{|l|}{ United States (USD) } \\
\hline Aerospace product \& parts mfga & $\mathrm{n} / \mathrm{a}$ & 132,977 & 72,090 & $\mathrm{n} / \mathrm{a}$ \\
\hline Complete civil aircraft mfgb & 4,288 & 27,019 & $\mathrm{n} / \mathrm{a}$ & 6.3 \\
\hline Unladen weight not exceeding 2 tons & 1,357 & 458 & $\mathrm{n} / \mathrm{a}$ & 0.3 \\
\hline Unladen weight exceeding 2 tons but not exceeding 15 tons & (D) & (D) & $\mathrm{n} / \mathrm{a}$ & (D) \\
\hline Unladen weight exceeding 15 tons & (D) & (D) & $\mathrm{n} / \mathrm{a}$ & (D) \\
\hline \multicolumn{5}{|l|}{ Brazil (BRL) } \\
\hline Aerospace manufacturingc & $\mathrm{n} / \mathrm{a}$ & 8,196 & $\mathrm{n} / \mathrm{a}$ & $\mathrm{n} / \mathrm{a}$ \\
\hline Unladen weight not exceeding 2 tons & (D) & (D) & $\mathrm{n} / \mathrm{a}$ & (D) \\
\hline Unladen weight exceeding 2 tons but not exceeding 15 tons & (D) & (D) & $\mathrm{n} / \mathrm{a}$ & (D) \\
\hline Unladen weight exceeding 15 tons & (D) & (D) & $\mathrm{n} / \mathrm{a}$ & (D) \\
\hline \multicolumn{5}{|c|}{ Sources: a) (NAICS 3364) Annual Survey of Manufactures 2005, U.S. Census Bureau; b) (NAICS 33641131) } \\
\hline \multirow{2}{*}{\multicolumn{5}{|c|}{$\begin{array}{l}\text { Current Industry Report M336G(05)-13, U.S. Census Bureau, Issued: August 2006; c) (CNAE 3531) Pesquisa } \\
\text { Industrial Produto 2005, vol. 24, No.2., IBGE. }\end{array}$}} \\
\hline & & & & \\
\hline \multicolumn{5}{|c|}{$\begin{array}{l}\text { Notes: (D) Withheld to avoid disclosing data for individual companies. N/a = not available; a) includes all } \\
\text { products of the aerospace industry as specified in NAICS } 3364 \text { (see detailed definition in Appendix A.2); b) } \\
\text { includes civil aircrafts (fixed wing, powered), helicopters and other civil aircrafts (non-powered) and kits) but } \\
\text { excludes aircraft engine. }\end{array}$} \\
\hline
\end{tabular}

\subsubsection{Adjustments and calculation of unit value ratios for Brazilian aircraft production}

\subsubsection{Supplementary data sources}

The actual sales price of an aircraft is confidential information. Producer prices in local currency are similarly not accessible, especially given the fact that nearly all aircraft produced in 2005 were exported.

In 2005, the only producer (final assembler) of commercial aircraft in Brazil was Embraer. The Financial Statements for the Years Ended December 31, 2006 and 2005 and Independent Auditors' Report of the company provides indirect information on the value 
of aircraft production. The "cost of goods sold" figures (CGS), broken down by commercial/defence/ executive/services segments and presented in BRL in the reports, were used as a proxy for the ex-factory output value of Embraer aircraft for the year 2005. This figure comes closest to the ex-factory value of output. As far as we could ascertain, it does not contain sales taxes and other duties. The figure for cost of goods sold amounted to 6,269 million BRL, which compares realistically to the 8,196 billion BRL value published in the Pesquisa Industrial Anual (PIA) statistics, which also includes other aerospace segments such as helicopters, light aircrafts, aircraft parts and components.

The quantity of physical output of airplanes was obtained from the delivery figures for 2005 published in the 2006 Embraer Annual Report (p.74). The date of production and the date of delivery of an aircraft may differ, but interviews with company managers and the amount of backlog confirmed that Embraer was producing for direct delivery. (In other words, there were no "white tail" planes in 2005.) The difference between date of production and date of delivery is the testing period following a plane's roll out from the plant, which is not more than a few weeks.

We make the assumption that relative sales prices are proportional to the relative ex-factory prices. Thus, the actual unit value of each type of aircraft can be estimated if the total ex factory value of Embraer aircraft produced and their list prices are known. Aircraft Value News (AVN) publishes the list prices of new aircraft in USD (including Embraer as well as Boeing planes) and estimates the prices of used aircraft on a yearly basis. Where this data was not available, data from the Aviation Industry Group was used. Aircraft producers sometimes offer significant discounts (up to around 20\%, according to industry experts) to customers based on the size of order and delivery arrangements. List prices are thus not the actual selling prices, but they do reflect the value of an aircraft - the larger the demand the closer selling prices will be to the list prices. Given a firm backlog of nearly 500 aircraft for Embraer, the demand can be considered high enough. Where maximum and minimum list prices, were published, we used the average of maximum and minimum prices. ${ }^{69}$ Columns 2 and 3 of Table 4.2 presents the data collected in this fashion.

\footnotetext{
${ }^{69}$ List prices were not available for the Legacy executive jets, since they are primarily sold individually. We assumed that additional, tailor-made design features make the Legacy jets fit more appropriately in the ERJ145 category, even if their size is more similar to the ERJ-135s, (Should they be categorised as ERJ-135s, only the output value shares change, the effect on the final results is within $2 \%$.)
} 
Table 4.2 Supplementary Data on list prices and output value of commercial aircraft produced in Brazil (2005)

\begin{tabular}{lcccc}
\hline Aircraft type & $\begin{array}{c}\text { Quantity of } \\
\text { Output }\end{array}$ & $\begin{array}{c}\text { Average list price } \\
\text { (USD millions) }\end{array}$ & $\begin{array}{c}\text { Unit values } \\
\text { (BRL millions) }\end{array}$ & $\begin{array}{c}\text { Output Value } \\
\text { (BRL millions) }\end{array}$ \\
\hline ERJ-135 & $(\mathbf{1})$ & $\mathbf{( 2 )}$ & $\mathbf{( 3 )}$ & $\mathbf{( 4 )}$ \\
ERJ-140 & 2 & 16.1 & 28.1 & 56.1 \\
ERJ-145a & 0 & $\mathrm{n} / \mathrm{a}$ & $\mathrm{n} / \mathrm{a}$ & 0 \\
ERJ-170 & 67 & 22.2 & 38.7 & $2,592.8$ \\
ERJ-175 & 46 & 27.5 & 47.9 & $2,205.1$ \\
ERJ-190 & 14 & 29.6 & 51.6 & 722.4 \\
ERJ-195 & 12 & 33.1 & 57.7 & 692.4 \\
\hline Total & 0 & 34.9 & 60.8 & 0 \\
\hline
\end{tabular}

Source: Col. 2 from Embraer 2006 Annual Report; Col. 3 from Aircraft Value News and Aviation Industry Group, Total Col. 5 from Embraer; Col. 4 and the rows of Col 5 except total, own calculations as described in main text section 4.2.1.1.

Note: (a) ERJ-145s also include modified versions of the aircraft: 20 Legacy executive jets and an R-99A sold for the Brazilian government.

\subsubsection{Unit value ratios}

The final step of data preparation before unit value ratios can be calculated is the estimation of unit values of aircraft produced in the two countries. Based on the assumption that relative list prices indicate relative ex-factory unit values of an aircraft, we derived unit values in Brazilian Reais from the list prices in US dollars, according to equation (4.1) below. The resulting unit values are reproduced in column 4 of Table 4.2.

$u v_{i}^{B R L}=\left(\frac{l p_{i}^{U S D} q_{i}}{\sum l p_{i}^{U S D} q_{i}} \cdot C G S^{B R L}\right) / q_{i}=l p_{i}^{U S D} \cdot \frac{C G S^{B R L}}{\sum l p_{i}^{U S D} q_{i}}$

Where $u v_{i} \quad=$ unit value of an aircraft type $i$ in year 2005

$l p_{i}=$ list price of an aircraft type $i$ in year 2005 in USD

$q_{i}=$ quantity of output (number of aircraft produced in year 2005)

$C G S=$ costs of goods sold in the commercial segment, proxy for gross output $\left(\mathrm{GO}^{\mathrm{BRL}}\right)$

The gross output values in column 4 of Table 4.2 are calculated by multiplying numbers of planes with the unit values in column 3 . 


\subsubsection{Adjustments and calculation of unit value ratios for production in the United States}

\subsubsection{Supplementary data sources}

The Aerospace Industries Association (AIA) of the US collects and publishes a rich set of statistics that include yearly production data of civil transport aircraft ${ }^{70}$ by type, including physical output quantity and aggregate value. According to AIA figures, the total value of civil jet transport aircraft (or airliner) production in 2005 was 18.7 billion USD (see Table 4.3). This amounts to some $70 \%$ of the 27.0 billion USD output value presented in the Current Industry Report (CIR) for 2005. The difference is explained by the fact that the CIR includes not only airliners, but light and general aviation aircraft that fall in the less than 2 ton and the 2-15 ton class category, as well as helicopters and other (non-powered) aircraft.

Neither AIA, nor other sources publish price or unit value data for specific aircraft types. Assuming once again that the proportions of list prices are identical to proportions of ex-factory unit values, we used list prices of US airplanes published in AVN to estimate ex factory unit values, as in the case of Brazil.

The first row of Table 4.3 shows the aggregate quantity and value data for all aircraft from the CIR, the bottom row the quantity and value data for narrow and wide bodied aircraft. Produced quantities of the various aircraft types as published by AIA, together with the list price information as reported in AVN are shown in the second and fourth column of the table. By 2005, B-717s and 757s are no longer included in the list prices for newly produced planes. The latest quotations from 2004 and 2002, respectively, have been used to price these models. Of the narrow-body aircraft, the B717 and 757 families only included one model each (the 717-200 and the 757-300). The 737 family however varies considerably in size, so the quantities for the Boeing 737-600, 700,800 and 900 series were additionally obtained directly from the manufacturer.

\subsubsection{Calculating unit values of Boeings}

Ex-factory unit values of the various types were calculated for Boeings in the same way as described above in the case of Brazil, the only difference was that total gross output value of the 290 commercial aircraft was directly available. Based on the assumption that relative list prices indicate relative ex-factory unit values of an aircraft, we derived unit values in US dollars from the list prices in US dollars, according to equation (4.2).

\footnotetext{
${ }^{70}$ A substantial part of the U.S. industry output consists of military aircraft that we do not include in this study, considering that there is no Brazilian product to match them. This fact is expected to result in a lower coverage ratio of matched products in the total U.S. output.
} 
$u v_{i}=\left(\frac{l p_{i}^{U S D} q_{i}}{\sum l p_{i}^{U S D} q_{i}} \cdot G O^{U S D}\right) / q_{i}=l p_{i} \frac{\sum u v_{i} q_{i}}{\sum l p_{i} q_{i}}=l p_{i} \frac{G O}{\sum l p_{i} q_{i}}$

Where $\mathrm{uv}_{\mathrm{i}}=$ unit value of an aircraft type $i$

$\mathrm{lp}_{\mathrm{i}}=$ average list price of an aircraft type $i$

GO = Gross value of output for all aircraft

$\mathrm{q}_{\mathrm{i}}=$ produced quantity of an aircraft type $i$

The obtained unit values of the aircraft types produced in 2005 are shown in the third column of Table 4.3. Our estimates of ex-factory prices are $71 \%$ of average list prices. On a side note, it is interesting to see that even if producers offer a $20 \%$ discount, they still retain a margin over the ex-factory price. Gross output values for different types of aircraft were obtained by multiplying the quantities with our estimated unit values. The quantities are reproduced in column 1 of Table 4.3.

Table 4.3 Supplementary Data on List Prices and Output Value of Aircraft Produced in the United States (2005)

\begin{tabular}{|c|c|c|c|c|}
\hline \multirow[t]{2}{*}{ Aircraft type } & Quantity of Output & $\begin{array}{c}\text { Average } \\
\text { List Price } \\
\text { (USD Millions) }\end{array}$ & $\begin{array}{l}\text { Unit values (USD } \\
\text { millions) }\end{array}$ & $\begin{array}{l}\text { Total output value } \\
\text { (USD millions) }\end{array}$ \\
\hline & (1) & (2) & (3) & (4) \\
\hline Aircrafts & 4,288 & & 6.3 & 27,018 \\
\hline Narrow-bodies & $\underline{227}$ & & $\underline{43.3}$ & 9,839 \\
\hline B-717 & 13 & $40.0^{b}$ & 28.3 & 368 \\
\hline B-737 & 212 & 61.4 & 43.4 & 9,202 \\
\hline-600 & 3 & 49.5 & 35.0 & 105 \\
\hline-700 & 98 & 56.5 & 39.9 & 3,914 \\
\hline-800 & 105 & 67.8 & 47.9 & 5,032 \\
\hline-900 & 6 & 71.8 & 50.8 & 305 \\
\hline B-757 & 2 & $81.4^{c}$ & 57.5 & 115 \\
\hline Wide-bodies & $\underline{63}$ & & $\underline{141.2}$ & $\underline{8,897}$ \\
\hline B-747 & 13 & 221.8 & 156.8 & 2,038 \\
\hline B-767 & 10 & 135.5 & 95.8 & 958 \\
\hline B-777 & 40 & 208.7 & 147.5 & 5,901 \\
\hline Total & 290 & & 64.6 & 18,736 \\
\hline
\end{tabular}

Sources: First row and row total from: Current Industry Report, U.S. Census Bureau, August 2006; Columns 2 and 4 from Aerospace Industries Association (2008) (a) and Aircraft Value News, 2005 (and 2004) Quantities of B-737 series from Boeing Online Query for Orders and Deliveries, URL: http://www.boeing.com (retrieved: 12 September 2008) Columns 5 and 3: Own calculations as described in main text.

Notes: (a) includes all civilian aircraft and helicopters produced; (b) list prices of 2004; (c) list prices of 2002.

Some further steps are required before Brazilian and US-produced aircraft can be compared. In the comparison, the difference in aircraft size is striking. It is not realistic 
to match Brazilian regional jets with US jumbo jets. The difference is less pronounced if we compare the Brazilian planes with the smaller Boeing aircraft. On the US side, we therefore distinguished between wide-bodies and narrow-bodies. Narrow-bodies are aircraft with an average seating capacity of 130-150 and an average range of 4,500 kilometres are normally used for interregional as well as regional travel and compose the bulk of airliners sold. Wide-bodies are the workhorses of long-range, intercontinental air transportation and as our estimated unit values show their average unit values are about 100 million dollars higher than narrow-bodies. These jets can most likely be excluded from any potential product matching since no emerging country has so far been able to produce series of this category.

The average unit value for the narrow-body class was 43.3 million dollars; its total produced value was 9,839 million dollars in 2005. (The Boeing 737 family is evidently the most representative of this class.)

\subsubsection{Product matching and calculating UVRs}

A key reason of Embraer's success was entering the market niche for regional aircraft. However, as discussed above, this poses significant challenges when it comes to comparing its production with producers in the larger segments. The ICOP methodology suggests that once the product unit values are available, UVRs can be calculated by matching products based on "broadly defined classes". The fact that aircraft size differs in the two countries calls for caution but is not considered an impediment as long as similar product characteristics can be used for classification. van Ark and Gersbach (1994) have addressed a somewhat similar problem that could be triggered by high-tech products that either have different product descriptions in the two countries; where (possibly due to issues of confidentiality) no information is available on value or quantity of production; are unique to one country; or where there is a different product mix in the industry. Following their suggestion, we looked for additional industry data to obtain the best matches - data on the technical specifications of aircraft. Based on such features, we have looked into possible alternatives of matching to achieve the highest possible number of products included.

Two possible dimensions for matching are plane size (wide bodied, narrow bodied, or number of seats) or plane weight. International trade and production statistics distinguishes airplanes weighing less than 2 tons, between 2-15 tons and more than 15 tons (unladen). ${ }^{71}$

Size is a better criterion for matching than weight. Most Brazilian-made jetliners fall in the category of 2-15 tons, close to the upper limit, with only the largest ones of the

\footnotetext{
${ }^{71}$ See e.g. SITC Rev. 3 codes 792.2., -3 and -4 .
} 
E-170/90 family weighting more than 15 tons. On the other hand, all US-produced planes weigh more than 15 tons. The best purely weight-based match would only involve two products: the Brazilian ERJ-190 jets and the US B-717.

There are several reasons why we choose not to limit matching to these products. First, the product match would only include 13 out of the 290 planes produced in the USA. and 13 out of the 142 planes produced in Brazil. Moreover, the significance of this product match is questionable since the B-717s are the last planes of an outgoing model (in fact, it is just a new name given to the old MD-95s after Boeing acquired McDonnell Douglas), while the ERJ-190s are the first of a new series of planes. The prices and values of these non-representative items may well be biased. Thirdly, weight-based approaches have the shortcoming that they do not necessarily reflect the technological sophistication of a product. Producers often cut costs with the use of stretched versions of aircrafts with the same technologies involved, same avionics and highly similar aerodynamic features and most importantly, with interchangeable parts and components. ${ }^{72}$ Furthermore, with the use of advanced light materials (composites), more sophisticated planes are not necessary heavier than their smaller, older counterparts.

Body breadth classifications distinguish between narrow-body (single-aisle) and wide-body aircraft. This feature turned out to be useful for matching because it creates a clear distinction between long-haul jets and the short- to medium-haul ones that require different production capacities and differ in durability. (Even if a few of the narrowbody category planes can be fitted for long-range operations, they represent a very small share of the output in both countries.) We therefore matched Brazilian narrow body aircraft with US narrow body aircraft.

The body breadth classification is useful, since it also provides a solution to the weight delimitation issue by setting the boundary at 64 tons (or 45 tons without the B757s). (All Embraer jets have single aisle; see Table 4.3 for Boeing single-aisles). Narrowbodies cover $76 \%$ of Brazilian aerospace industry output compared to $8 \%$ in the United States. This is not surprising, since the Brazilian industry is specialized in the manufacturing of commercial jets while the United States output is far more diverse and consists of a whole range of other products including military aircraft, engines, missiles and space vehicles - as well as parts and components for Brazilian planes.

\footnotetext{
72 See e.g. aircraft families such as New Generation Boeing 737s, where operational empty weights vary between 36.3 and 45.4 tons (with the -600 and -800 respectively)
} 


\subsubsection{Comparing small apples with big apples: adjustments for product size differences}

Even when jumbos and other wide-body jets are excluded from direct product comparison, regional jets of Embraer and single-aisles planes of Boeing differ significantly in number of seats. Given these differences, we followed two alternative ways to calculate the unit value ratio. (1) First, we directly matched the two groups of narrow-body jetliners, disregarding differences in size. The rationale behind this approach is to compare actual products, without any modification of the figures. As the planes produced in the United States are larger than in Brazil, Brazilian output will be overestimated and US output will be underestimated. (2) The second alternative is to standardize all the narrow-body commercial aircraft produced in the two countries to 100-seat equivalents and then make a product match. In this way, size differences are taken into consideration. But as the quality differences between smaller and larger single aisle airplanes are likely to be smaller than indicated by the number of seats, Brazilian output will tend to be underestimated relative to US output. There is a substantial difference between the unit value ratios calculated according to these two approaches. We decided to take the geometric average of the standardised and non-standardised estimates. $^{73}$

The plausibility of our results can be checked by comparing them with the results Mulder et al (2002) as well as with the relative "sales price level" which refers to the relative list prices of standardized aircraft.

\subsubsection{Standardization}

Standardizing is a solution to eliminate the size differences across the products of the two countries. We looked at two attributes: operational empty weight (OEW) and maximum number of seats of the single-aisles jets ${ }^{74}$ manufactured in 2005. The correlation with unit values was high in both instances, but the number of seats showed marginally higher correlation with the unit values than weight ( 0.98 vs. 0.96 for the combined data of both countries). As discussed above, seating capacity is the most meaningful criterion for standardization. For practical reasons, we chose to standardise planes at 100 seats, which is less than the US average and more than the Brazilian. The choice of number of seats over OEW or other technical characteristics as a proxy for value of an aircraft is also supported in the airplanes marketing literature (see Ferreri 2003, p.219).

\footnotetext{
${ }^{73}$ As there is only a single large product match, there is no need to calculate a Paasche and a Laspeyres unit value ratio (see methodology in Appendix A.2.1).

${ }^{74}$ Includes the single-aisles jets manufactured in the year 2005, B717, B737-600, -700, -800 and -900, but excludes the B757-200s as outlier.
} 
There are two ways to obtain unit values for the 100 seat equivalent (100SE) jets. First, assuming that the size ratio of an actual plane compared to 100SE equals the seating capacity ratio (i.e. a Boeing 717 with 117 seats is $1.17 \mathrm{x} 100 \mathrm{SE}$ ), the produced quantity of 100SEs can be calculated for both countries. The unit values of the 100SEs are then calculated by dividing the (unchanged) total value of ex-factory output by the modified total quantity of production of narrow-bodies.

Alternatively, the association between seating capacity and unit value of a plane can also be the basis for obtaining unit values of the 100SE using a simple kind of hedonic regression. We estimated a linear function to predict the unit value of the 100SE and then calculated the quantity of 100 SE planes produced by dividing the unit value into the total value of ex-factory output. The two methods rendered somewhat different results, reproduced in Table 4.4 and Table 4.5. Since the regression method makes more optimal use of all information, we used the regression method for standardising output. The calculations (for both methods) are presented below in greater detail.

The adjusted quantity figures for the USA are shown in column 3 of Table 4.4. Since the average seating capacity grew by two-third after the standardization, the unit value of the narrow-bodies category decreased by some $40 \%$ from 43.3 to 25.8 million USD. Following the seat-based hedonic regression method, equation (4.3) estimates a unit value of the 100SE of 26.5 million USD reproduced in column (6).

$$
\begin{aligned}
& u v=0.233 * \text { seats }+3.19 ; R^{2}=0.97 \\
& u v(100 S E)=26.5 m \text { USD; } \\
& Q(100 S E)=9839 / 26.5=371.0 m \text { USD }
\end{aligned}
$$

Table 4.4 Results of Quantity and Unit Value Adjustments for the Production of 100-Seat Equivalent Aircraft (100SE) in the USA

\begin{tabular}{lcc|cc|cc}
\hline Aircraft type & $\begin{array}{c}\text { Maximum } \\
\text { seating }\end{array}$ & $\begin{array}{c}\text { Produced } \\
\text { quantity }\end{array}$ & $\begin{array}{c}\text { Simple re- } \\
\text { weighted } \\
\text { output quantity } \\
\text { of 100SE }\end{array}$ & $\begin{array}{c}\text { Unit value of } \\
\text { 100SE }\end{array}$ & $\begin{array}{c}\text { Re-weighted } \\
\text { output quantity } \\
\text { of 100SE } \\
\text { (hedonic) } \\
\text { (5) }\end{array}$ & $\begin{array}{c}\text { Unit value of } \\
\text { 100SE } \\
\text { (hedonic) }\end{array}$ \\
\hline B717 & $\mathbf{( 1 )}$ & $\mathbf{( 2 )}$ & $\mathbf{( 4 )}$ & $\mathbf{( 5 )}$ & $(6)$ \\
B737-600 & 117 & 13 & 15.2 & & & \\
B737-700 & 132 & 3 & 4.0 & & & \\
B737-800 & 149 & 98 & 146.0 & & & \\
B737-900 & 189 & 105 & 198.5 & & & \\
B757 & 215 & 6 & 12.9 & & & \\
\hline Total & 228 & 2 & 4.6 & & & \\
\hline
\end{tabular}

Source: as described in text 
Applying the first method for Brazil reduces the total production quantity from 142 to 87.6 planes and increases the unit value from 44.1 to 71.5 million BRL (see Table 4.5). The difference is smaller if the second method is used according to equation (4.4), which predicts a unit value of 62.1 million BRL for the standardized 100-seater aircraft and a standardised number of 101 planes.

$$
\begin{aligned}
& u v=0.478^{*} \text { seats }+12.95 ; R^{2}=0.97 \\
& u v(100 S E)=60.8 \mathrm{mBRL} ; \\
& Q(100 S E)=6269 / 60.8=103.2 \mathrm{mBRL}
\end{aligned}
$$

Table 4.5 Results of Quantity and Unit Value Adjustments for the Production of 100-seat equivalent Aircraft (100SE) in Brazil

\begin{tabular}{lcc|cccc}
\hline $\begin{array}{c}\text { Aircraft } \\
\text { type }\end{array}$ & $\begin{array}{c}\text { Maximum } \\
\text { seating }\end{array}$ & $\begin{array}{c}\text { Produced } \\
\text { quantity }\end{array}$ & $\begin{array}{c}\text { Simple re- } \\
\text { weighted output } \\
\text { quantity of } \\
\text { 100SE }\end{array}$ & $\begin{array}{c}\text { Unit value of } \\
\text { 100SE }\end{array}$ & $\begin{array}{c}\text { Re-weighted } \\
\text { output } \\
\text { quantity of } \\
\text { 100SE } \\
\text { (hedonic) }\end{array}$ & $\begin{array}{c}\text { Unit value } \\
\text { of 100SE } \\
\text { (hedonic) }\end{array}$ \\
\hline ERJ-135 & $\mathbf{( 1 )}$ & $\mathbf{( 2 )}$ & $\mathbf{( 3 )}$ & $\mathbf{( 4 )}$ & $\mathbf{( 5 )}$ & $\mathbf{( 6 )}$ \\
ERJ-145 & 37 & 2 & 0.7 & & & \\
ERJ-170 & 50 & 67 & 33.5 & & & \\
ERJ-175 & 70 & 46 & 32.2 & & & \\
ERJ-190 & 78 & 14 & 10.9 & & & \\
\hline Total & 98 & 12 & 11.8 & & & \\
\hline
\end{tabular}

Source: as described in text

\subsubsection{The unit value for narrow-bodies}

First we directly matched the two groups of single-aisles aircraft produced in the two countries. This resulted in a unit value of 1.03 reproduced in the first row of Table 4.6. This value is lower than the official exchange rate of 2.43 Reais to the US dollar for 2005). This means that using the exchange rate would lead to an undervaluation of Brazilian aerospace manufacturing output.

Matching standardized 100SE planes results in a much higher unit value ratio of 2.29 BRL/USD according to the hedonic method (and 2.72 if one would choose the simple method), as shown in Table 4.6.

There is a large difference between the unit value ratios derived by matching standardized and non-standardized aircraft. The unit value ratio for the nonstandardised match is far below the exchange rate, the unit value for the hedonic match is only slightly lower than the exchange rate. As explained at the beginning of section 4.2.4, we decided to take the geometric average of the non-standardised and hedonic standardised matches, as both have bias in an opposite direction. The geometric average of the two UVRs is $1.54 \mathrm{BRL} / \mathrm{USD}$. 
Table 4.6 Brazil-USA Product Matching for Calculating Unit Value Ratios

\begin{tabular}{|c|c|c|c|c|c|c|c|c|c|c|c|}
\hline \multirow[b]{2}{*}{$\begin{array}{l}\text { 을 } \\
\text { E્ } \\
\text { E }\end{array}$} & \multicolumn{5}{|c|}{ Brazil } & \multicolumn{5}{|c|}{ USA } & \multirow[b]{2}{*}{$\begin{array}{c}\text { Unit } \\
\text { Value } \\
\text { Ratios }\end{array}$} \\
\hline & Product & $Q(B R A)$ & V(USD) & uv(USD) & $\begin{array}{c}\text { Q(BRA) } \\
\text { @USA } \\
\text { uvs }\end{array}$ & Type & $Q($ USA) & V(USD) & uv(USD) & $\begin{array}{c}\text { Q(USA) } \\
@ \text { BRA } \\
\text { uvs }\end{array}$ & \\
\hline 1 & Emb.NB & 141 & 6,269 & 44.5 & 6,111 & Boeing NB. & 227 & 9,839 & 43.3 & 10,092 & 1.03 \\
\hline $2 / a$ & Emb.100SE & 89.1 & 6,269 & 70.3 & 2,301 & Boeing-100SE & 381.1 & 9,839 & 25.8 & 26,807 & 2.72 \\
\hline \multirow[t]{4}{*}{$2 / b$} & Emb.100SE & 103.2 & 6,269 & 60.8 & 2,736 & Boeing-100SE & 371.0 & 9,839 & 26.5 & 22,546 & 2.29 \\
\hline & \multicolumn{5}{|c|}{ Geometric average of $1 \& 2 / \mathrm{b}$ : } & & & & & & 1.53 \\
\hline & \multicolumn{5}{|c|}{ Exchange rate } & & & & & & 2.45 \\
\hline & \multicolumn{5}{|c|}{ Updated UVR for transport equipment industry, based } & & & & & & 1.94 \\
\hline
\end{tabular}

Notes: Emb.NB = Embraer narrow-bodies; Boeing NB = Boeing narrow-bodies; 100SE = 100-seat equivalent; Method 1 refers to the direct matching of Brazilian and US-made narrow body aircraft; Method 2/a refers to matching standardized 100SE planes on the basis of seat numbers Method 2/b refers to matching standardize 100SE planes on the basis of a hedonic regression (see section 4.2.4.1).

\subsubsection{Comparisons with other UVR estimates}

The official exchange rate for 2005 averaged $2.45 \mathrm{BRL}$ to a dollar. ${ }^{75}$ Thus our preferred UVR estimate of $1.53 \mathrm{BRL} / \mathrm{USD}$ is well below the exchange rate. The study of Mulder et al (2002, Table 3, p.13) comparing Brazil with the USA presents unit value ratios for 18 manufacturing branches, including transport equipment for the benchmark year 1985. Their unit value ratio for the transport equipment sector in 1985 was 2,689 BRZ/USD. This unit value ratio is based on 7 product matches covering $56.3 \%$ of Brazilian output and $25.4 \%$ of US output. The coefficient of variation of the UVRs within the branch was $\operatorname{low}^{76}$ (Mulder et al, 2002, Table 3, p.13). We updated the 1985 UVR to 2005, using price indices from both countries. ${ }^{77}$ This resulted in a UVR of 1.94 BRL/USD, which is still below the official exchange rate, but $26 \%$ higher than our 2005 UVR of the aerospace industry of $1.53 \mathrm{BRL} / \mathrm{USD}$. Such a difference seems reasonable, given that almost all of the aerospace products are intended for export, while a greater share of other transport equipments, including cars, serves the domestic market. Though not identical, the two estimates are clearly in the same ballpark.

\footnotetext{
${ }^{75}$ Annual average BRL/USD exchange rate for 2005 (IMF)

${ }^{76}$ Coefficients of variation indicate to the reliability of the aggregate ratios as they refer to the homogeneity of the product UVRs in a branch. Its value increases with the coverage ratio. The ICOP literature considers variations below 0.1 reliable, which is clearly the case of this industry with a variation of 0.01 if Brazilian quantity weights and 0.0 if US weights are applied.

77 We applied an industry level wholesale price index for Brazil from FGV $\left(3.64^{\star} 10^{-10}\right)$ and industry level producer price index for the USA from BEA (0.72), and accounted for the currency devaluation in Brazil $\left(\left(1 /\left(2.75^{\star} 10^{12}\right)\right)\right.$.
} 


\subsection{Productivity comparisons}

Consistent published series of value added and employment in aerospace manufacturing are not available. Our time series for the two countries have been constructed from a variety of sources (see Chapter 3). For Brazil, official gross value of output (GVO), value added (VA) and employment figures are available from IBGE from 1996 onwards. Value added time series were extrapolated backwards in time, using the index of total sales values of Embraer and the ratios of value added to gross output from IBGE for the transport equipment industry, as follows. First, the gross value of output was extrapolated from 1996 to 1970 using a index of total sales values of Embraer ${ }^{78}$. Subsequently, value added output ratios for the total transport equipment industry were applied to estimate the VA series. The data collected by the Aerospace Industry Association of Brazil (AIAB) were used for the employment series between 1986 and 1995. The employment level of 1986 has been extrapolated back to 1973 based on the time series of Embraer's labour force for the years 1973-1985 from Cabral (1987).

For the USA, our value added series combines figures from the EU KLEMS (SIC based, 1970-84) and the OECD STAN (1985-2006) database; the value of 2007 is derived from the value for 2006 from STAN by applying the 2006-2007 index from the Annual Survey of Manufacturing. The employment series combine the following sources: the Groningen Growth and Development Centre's 60-industry database (1970-1980), UNIDO Industrial Statistics (1981-1990), the OECD's (STAN) for 1991-2006; this was extrapolated to 2007 using the employment index from the Annual Survey of Manufacturing.

The trends in labour productivity in the aerospace industry in Brazil and the United States are charted in Figure 4.1. Labour productivity series were calculated by dividing value added at constant prices with number of employees. The benchmark productivity comparison for 2005 has been extrapolated using constant price time series of the two countries.

The study by Mulder et al (2002, Fig.4, p.19) showed that the Brazilian transport equipment sector was outperforming other Brazilian manufacturing sectors, with a significant productivity lead from 1987 onwards. It was the only sector which attained the productivity levels of the USA (from 1996 to 2002). But they make cautionary remarks about the reliability of Brazilian time series (ibid, p.20).

\footnotetext{
${ }^{78}$ sales values in USD for 1970-82 from Ramamurti (1987, Table 5.5, p.193); 1983-84 from Cabral (1987); 1985-91 Frischtak (1992); and 1992-96 Embraer Annual Reports; World Bank WDI GDP deflators were applied
} 
Figure 4.1 Comparative Labour Productivity Trends in Aerospace in Brazil and the USA, 1970-2007

(1000 USD/Employee; constant prices $2000=100,3$-year moving average)

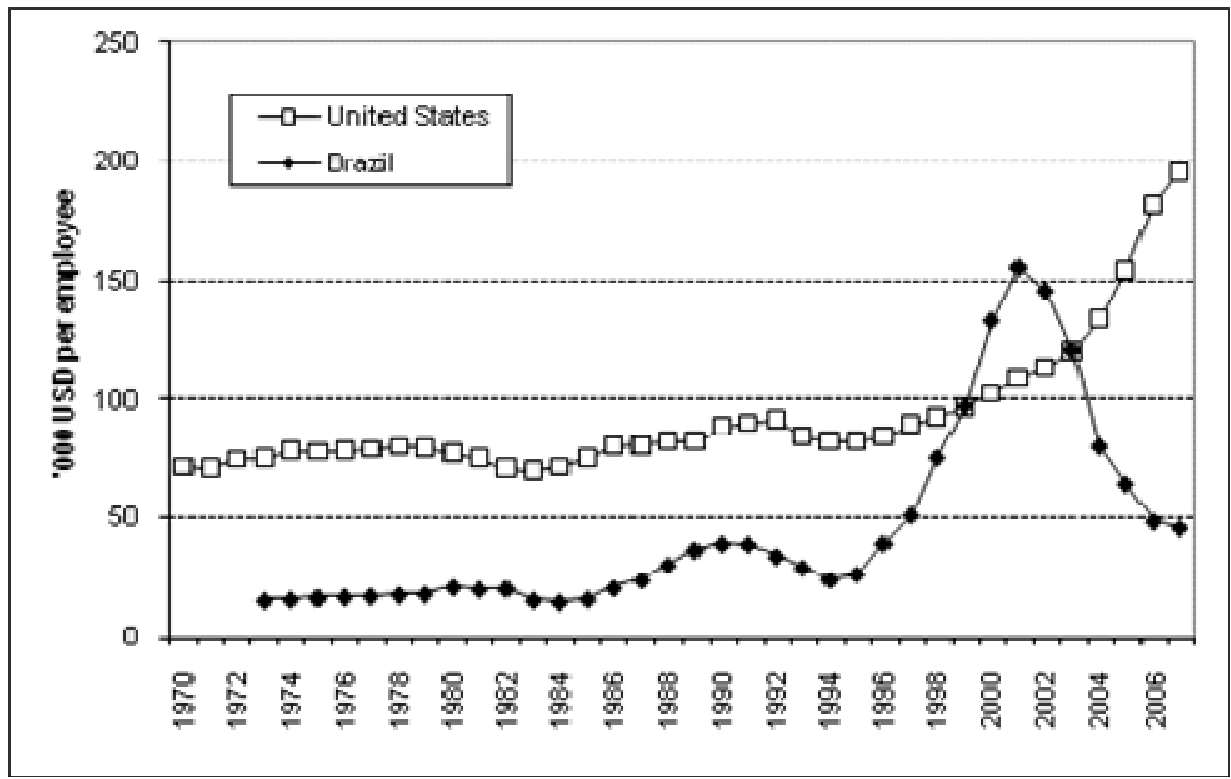

Sources: See text. Note: For actual figures please refer to Appendix Table A.2.1.

Figure 4.2 Comparison of Labour Productivity Levels in Transport Equipment and Aerospace, Brazil/USA, 1970-2007 (USA=100)

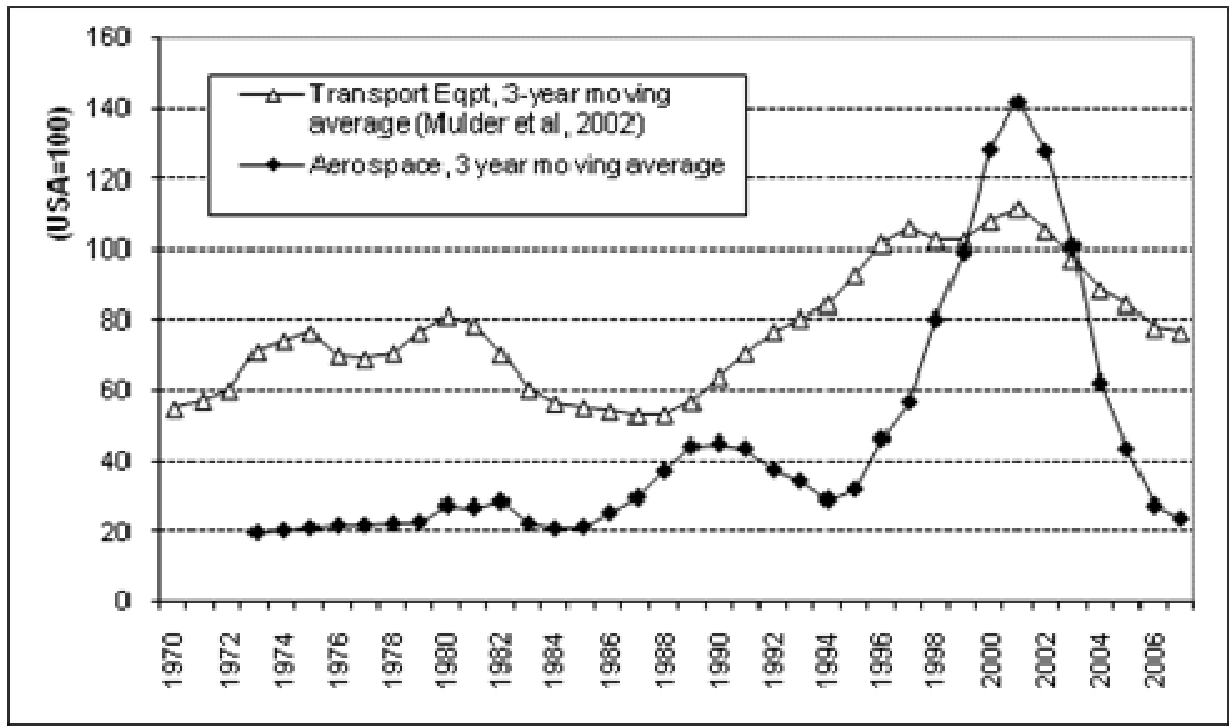

Sources: Transport equipment manufacturing industry figures from Mulder et al, (2002, Fig,4, p.19), updated with recent data from IBGE after 1999; aerospace industry values from own calculations.

Note: Actual figures are available in Appendix Table A.2.1. 
Our study indicates that the Brazilian aerospace industry was not performing as well as the transport equipment sector as a whole before the late 1990s. Except for a peak reached in 1989, labour productivity of the aerospace sector was on average half the levels of the aggregate transport branch (Figure 4.2). However, from the mid-1990s onwards, the aerospace industry experienced more rapid productivity growth that resulted in its overtaking the transport equipment manufacturing branch between 2000 and $2003 .^{79}$

In an international comparison with the US aerospace industry, Brazilian productivity exceeded the level of the US between 1999 and 2003. In 2001 and 2002 labour productivity exceeded the US level by no less than 40 per cent., before suddenly collapsing to around 20 percent in 2007 (Figure 4.2).

The US productivity trend shows much more stability over time than that of Brazil, with a rapid growth spurt during the last decade as result of consolidation in the sector. Productivity growth in Brazil is marked by fluctuations, with value added per employee varying between 12 and 176 thousand dollars per worker. Given that series production and foreign sales of Brazilian commercial aircraft only started in 1970, it is no surprise that for the first two decades, the newly emerging industry remained less productive than its US counterpart. The relatively low value added levels were related to Embraer's strategy of acquiring foreign technology (see Cassiolato et al, 2002, pp.9-10). There are two significant downturns: between 1990 and 1994 and after 2002. The productivity decline in the early 1990s is related to the crisis in the aerospace industry (see Frischtak, 1992 and case study in Chapter 6). Value added declined from a peak value of 560 million USD in 1989 to 130 million in 1994. This was only partly offset by the decrease in employment from 13,700 to 6,900 persons. The productivity growth in the subsequent period was achieved by steep increases in value added, followed by increases in the labour force at a much slower pace. However, the number of employees continued to grow steadily even when value added started to decline in 2003, due to the fact that Embraer repositioned itself as a system integrator importing over $90 \%$ of its aircraft parts and components from overseas (see Figueiredo et al. 2008). This resulted in a very sharp drop in productivity, by some 180 thousand dollars per employee.

\footnotetext{
${ }^{79}$ We have extrapolated the transport equipment series of Mulder et al (2002, Fig.4, p.19) from 1999 onwards using updated value added and employment series from the same sources (IBGE for Brazil and BEA for the USA).
} 


\subsubsection{Dramatic miscalculations by the firms}

The dramatic drop in labour productivity since 2001 is so striking that it calls for a careful analysis of the changes in the underlying value added and employment trends. The changes in the share of value added in gross output in the Brazilian aerospace industry are shown in Figure 4.3. In 1998 value added amounted to 39\% of total output, but over the next four years its share increased to 55\%. (In comparison, this ratio for the entire Brazilian manufacturing industry remains constantly around $45 \%$ (Barbieri et al. 2008, Fig.6, p.15).) The period between 1998 and 2002 is characterized by two opposing forces. Embraer witnessed the success of its E-135/145 family, which contained parts and components overwhelmingly manufactured abroad. The company retained design, assembly and marketing activities and increased competitiveness. A study on the sector (Barbieri et al. 2008) explains the fact that value added grew at a faster pace than gross output by the business cycle effect. The success of the ERJ-135/145 family strengthened the local supply chain; new small businesses were formed, mainly by former employees of Embraer (the number of enterprises in the sector grew from 76 in 1996 to 111 in 2002).

Figure 4.3 Gross output and value added in the Brazilian aerospace industry, (1996-2002;

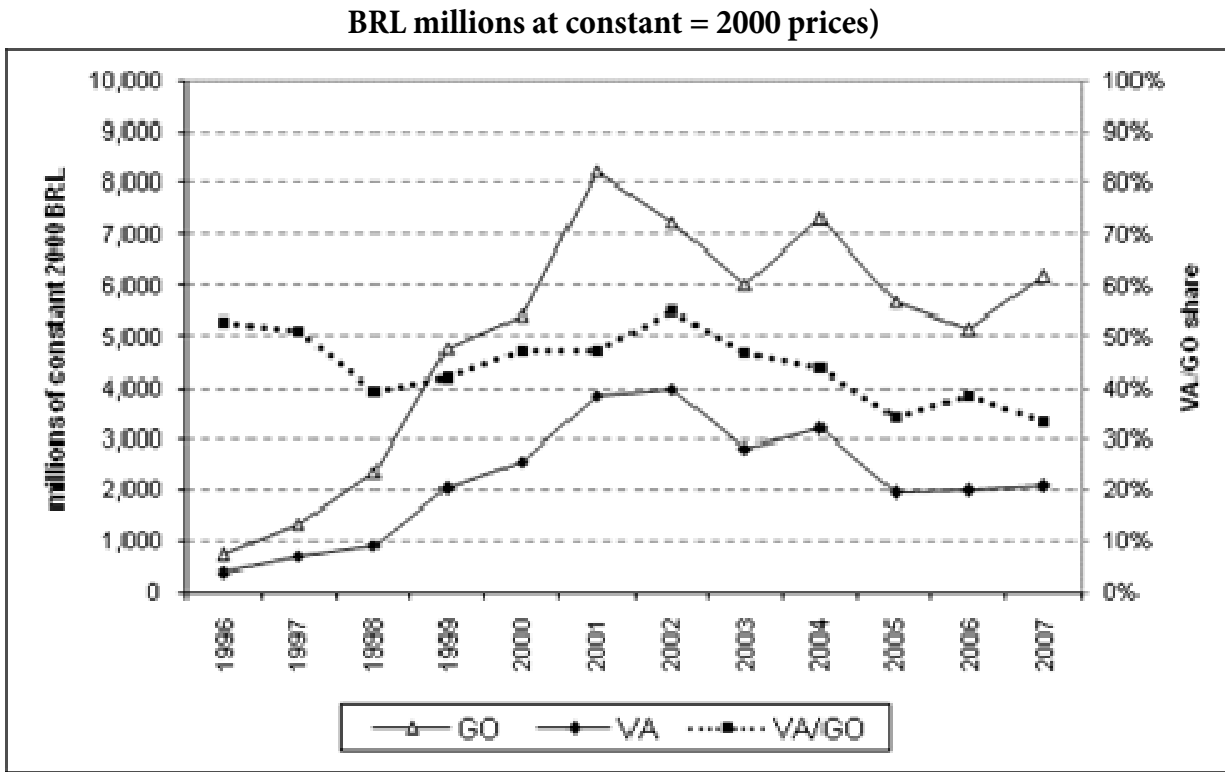

Sources: IBGE, FGV

Note: $\mathrm{GO}=$ Gross Output; VA = Value Added; FGV transport sector whole-sale price deflators applied. For actual figures please refer to Appendix Table A.2.2.

Between 2002 and 2005 industry value added declined by more than $50 \%$ while gross output only declined by $20 \%$, resulting in a decline of the value add/output ratio to 
around 33 per cent. The reason for these changes has to do with changes in the structure of production. Figure 4.4 illustrates that the peak in value added between 1999 and 2003 is associated with the production cycle of the E-135/145 family of regional jets. Since the development costs of the E-170/190 family were expected to be nearly 3 times as high as that of the E-135/145 family, estimated to be around 300 million USD in 2002 (Goldstein, 2002b), Embraer decided to rely more heavily on foreign risk sharing partners. This resulted in a decline in the local content of the aircraft produced. Despite the fact that Embraer required foreign components suppliers to transfer at least a small share of production to Brazil, value added did not increase when the E-170/190 jets' production cycle took off.

Figure 4.4 The production cycle of the E-135/145 and E-170/190 families and gross output and value added in the Brazilian aerospace industry (1996-2007)

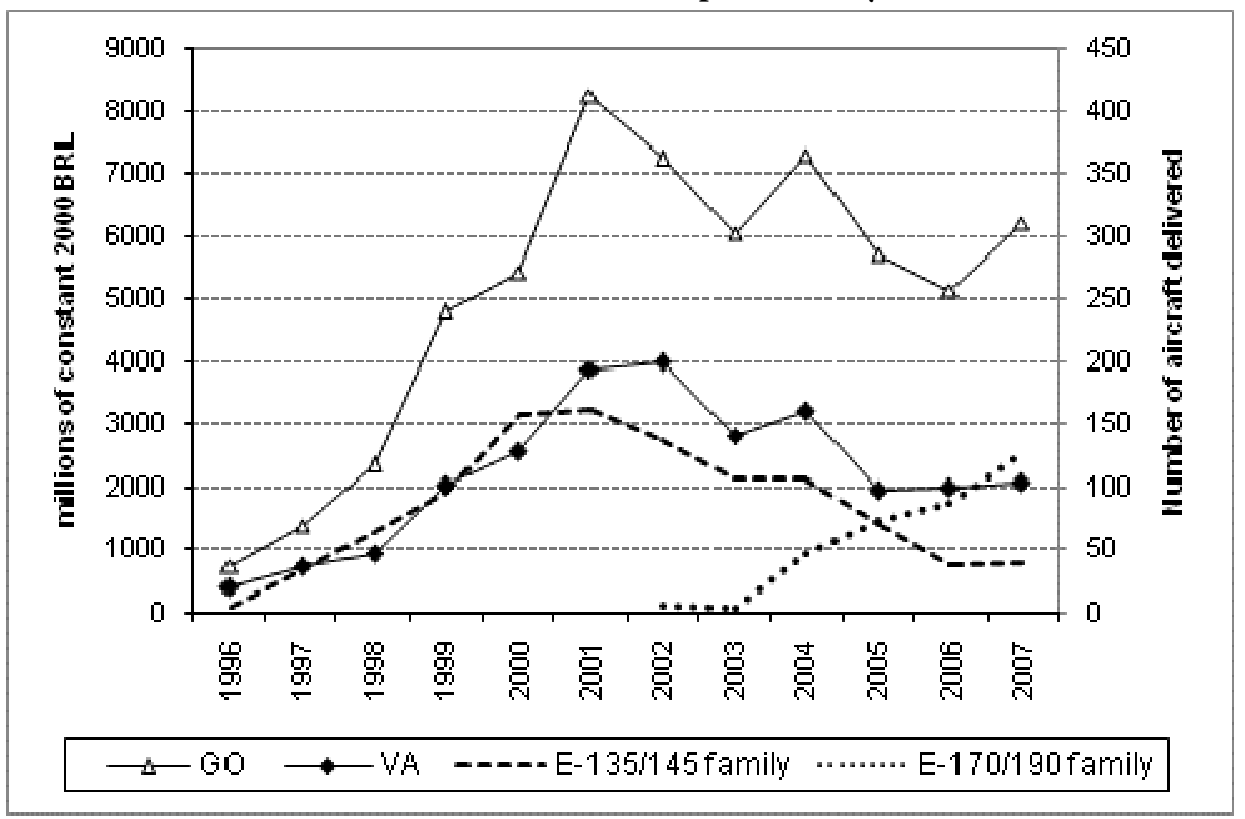

Sources: IBGE, Embraer

Notes: values in constant 2000 BRL; number of deliveries in units

The more than twofold increase in employment between 2002 and 2007 is even more puzzling in light of the decrease in value added during the same period. Firms need to cover wages and profits from their value added. The fact that over this period total employment increased by $110 \%$ and total wages increased by $60 \%$ while value added decreased by $50 \%$ and total sales decreased by $10 \%$ indicates that - if the statistics are correct - the firms behaved in a rather irrational fashion. 
We can distinguish the performance of Embraer from the rest of the industry. Embraer nearly doubled its labour force from 12,227 in 2002 to 23,734 in 2007 . At the same time, its sales increased by $80 \%$ and its net income increased by $90 \%$ (see Appendix Table A.2.2). The net income per employee figures may be more meaningful the increasing cost of human resources. These values averaged at nearly 30 thousand USD at the peak of 1999-2001 and abruptly plummeted to as low as 10 thousand in 2003. As the successful launch of the E-170/190 jets secured a profit growth in 2004, net income per employee grew rapidly to 24 thousand USD in a year, justifying Embraer's investment in employees in order to meet the increased demand and reduce the backlog. Although profits continued to rise until 2007, the continued job increase was disproportionate, resulting in a steady decline of net income per employees to 17 thousand USD. (The decline continued until 2009 to 12 thousand USD, even after the labour force, mostly production workers, was reduced by nearly $30 \%$ as a response to the falling demand caused by the global financial crisis.)

The employment trend in the rest of the industry, primarily the local suppliers of Embraer, appears even more puzzling. The right panel of Figure 4.5 shows the major increase in employment between 2002 and 2003. Between 1996 and 2002 the industry excluding Embraer employed on average 3,400 persons, after 2003 the labour force averaged 7,200 persons. It is interesting to see that the nearly 7 -fold sales increase of these local suppliers between 1998 and 2002 was not accompanied by a similar increase in employment. Employment started to increase in 2003 (a nearly 3-fold increase from 2002 to 2004), just when sales started to shrink. Employment stabilized at a high level, while sales continued to decline. By 2007 they were 60\% lower than in 2004. Part of the explanation may lie in the rigidity of labour laws in Brazil that make job cuts rather costly for companies, ${ }^{80}$ and in the high training costs companies already invested in their employees. $^{81}$

\footnotetext{
${ }^{80}$ When in 2009 Embraer announced what looked like a $20 \%$ job cut as a response to the global financial crisis, trade unions as well as the federal government were both trying to block the move. The labour court however approved the dismissals if Embraer was paying the required compensation ("Embraer comes to terms with job cuts" Financial Times, 2 June 2009).

${ }^{81}$ This makes labor force a 'quasi-fixed' production factor (Kronemer and Henneberger 1993).
} 
Figure 4.5 The evolution of sales and employment of Embraer and the Brazilian Aerospace industry excluding Embraer (1996-2007)

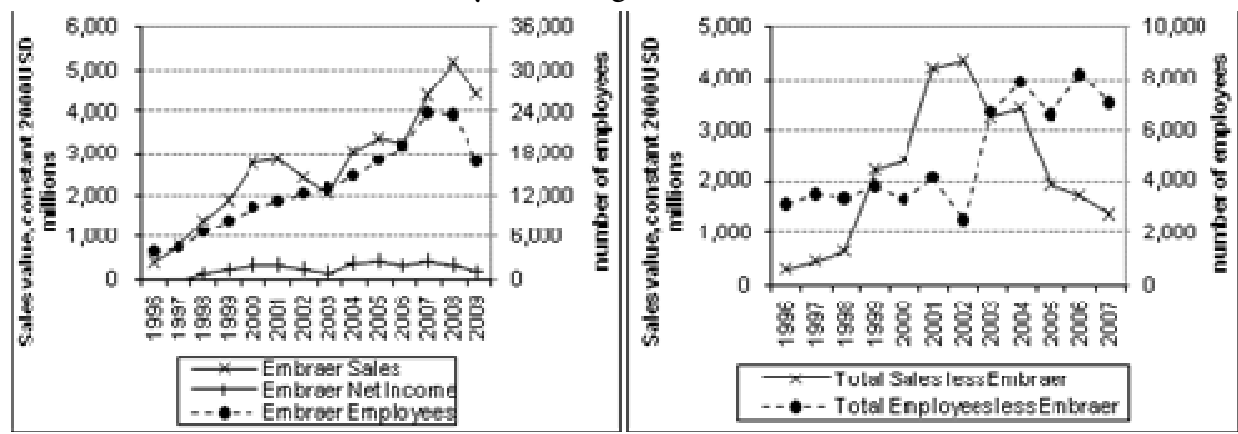

Sources: IBGE, Embraer.

Notes: Sales in millions of constant 2000 USD; average annual number of employees. For actual figures please refer to Appendix Table A.2.2.

The increases in the number of employees may to some extent originate in government policies (at the municipal, state and federal levels) aiming to strengthen the sector and the Embraer Programme for the Expansion of the Brazilian Aerospace Industry (PEIAB) (for details, see Cassiolato et al, 2002, p.47). As a result, new foreign investment came to the Sao Jose dos Campos cluster, e.g. by Latecoere, Sonaca (Sobraer), Liebherr (ELEB). The PEIAB team estimated that the number of new jobs associated with the new industrial policy was less than 2000 (Cassiolato et al, 2002, p.50). Thus, even if the expected increase in employment was fully realised, this can hardly account for the overall increase of employment in 2003 by more than 4000 persons.

Another explanation of these puzzling phenomena may have to do with the lack of data on hours worked. Employment figures in this study refer to annual average number of persons employed. Full-time equivalent values are unfortunately not available. Assuming that the growth period of 1999-2002 was characterized by excessive overtime work, which was subsequently reduced in 2003 by hiring more employees might explain some of the peculiarities of the employment trend. The observed labour productivity decline may be exaggerated. But this explains at best part of the trend. The fact remains that employment is inflexible vis-à-vis the decline of sales and value added.

There are also structural explanations for the significant fluctuations in labour productivity in the aerospace industry in Brazil. The upswings during the late 1980s and the 1990s coincide with a significant change in the composition of the labour force, brought about by advances in computer aided design and other technological transformations that resulted in the downsizing of the blue-collar workforce and requiring very different knowledge and skills on the part of engineers. 
However, there continues to be a number of institutional factors that work against the sustained growth of productivity. In an interview, the founder and long-time director of Embraer, Ozires Silva, highlighted that "the Brazilian cost" of bureaucracy and taxes significantly decrease the efficiency of producing in Brazil, requiring " 20 people in Brazil for the job of 3-5 in the US". ${ }^{22}$ Thus, even if aerospace engineers in Brazil have acquired skills and competences that are globally competitive, long-term productivity growth in the industry depends to a great extent on the relaxation of institutional constraints.

\subsection{Conclusion}

The Brazilian aerospace sector is often seen as one of the star performers in latecomer economies. In this paper, we have for the first time succeeded in calculating a US/Brazil conversion factor, specific to the aerospace industry. The ICOP methodology has informed the approach. However, the lack of officially published statistical data could only be overcome by consulting a variety of alternative sources, including company financial reports, industry association data and data collected by "independent enthusiasts". With such data at hand, the focus on a single industry allowed us to pay special attention to product characteristics in the product matching procedures. Our resulting UVRs for the benchmark year 2005 proved to be somewhat lower than, but not inconsistent with the extrapolated 1985 UVRs for the transport equipment manufacturing industry from Mulder et al. (2002).

Applying the UVRs in order to compare labour productivity levels and trends in Brazil and the USA provides us with interesting insights in Brazil's comparative productivity performance. The rapid growth in the 1980s resulted in a first catch-up episode from 1985 to 1990 that came to an end during the crisis years of the Brazilian aircraft industry in the mid-nineties. The late 1990s brought a second and more rapid productivity spurt that resulted in Brazil temporarily overtaking the USA. However this productivity growth proved to be a bubble that burst after 2002 . The industry as a whole, and especially the subcontracting segment, appears to have been oblivious to the economic realities of a declining value added. Firms continued to increase the number of jobs for over five years. The result was a rapid and deep drop in productivity, both in absolute terms and in comparison with to the USA.

\footnotetext{
${ }^{82}$ Interview with Ozires Silva, Sao Paolo, 6 Apr 2009.
} 



\section{PART II}

SECTORAL INNOVATION SYSTEM DYNAMICS

IN LATECOMER AIRCRAFT INDUSTRIES 



\section{CHAPTER 5 \\ A conceptual framework of interrupted innovation}

\subsection{Introduction: A new perspective on Innovation Systems Dynamics}

Based on the conclusions from the literature review presented in Chapter 2, and on the observed evolution of output and employment in the aerospace industry in Chapter 3 , we make the following assumptions on which a conceptual framework for the analysis of innovation systems will subsequently be developed.

We can distinguish to phases in the development of a latecomer aerospace industry an emergence phase and a catch up phase. Firms in an 'emerging' industry have to overcome several barriers to entry: high capital requirements, lack of technological capabilities, lack of access to technology and market-dislocation. Technological barriers are gradually overcome through access to foreign embodied and disembodied technologies and indigenous efforts to adopt and adapt them. This process can greatly benefit from spillovers from other domestic industries. Initially, in the emergence phase, the disadvantages latecomer firms face outweigh the advantages and sustained growth depends on the ability of public actors to support the emergence of a sectoral innovation system. But can a fully-developed innovation system ensure sustained competitiveness subsequently? Considering that the long-term evolution of innovation systems include both incremental and radical institutional changes, it is fair to assume that during the catch up phase the innovation system periodically needs to be reinvented and restructured. Such radical system changes involve a fundamental restructuring of institutions that define the interactions within an innovation system. This is because technology at the world frontier develops in a discontinuous manner and similarly, discontinuities were found in the long-run evolution of actors, firms, organizations and industries. More specifically in the aerospace industry, market volatility and changing demand conditions create recurrent crises which call for radical response from innovation system actors.

A combination of these forces has the potential to create major discontinuities in the catch-up trajectory of a latecomer aerospace industry and interruptions in the innovative processes. We have observed declines and acceleration of growth in the sector in almost all countries in Chapter 3. We are now turning toward the evolution of 
sectoral innovation systems in late entrants to aerospace manufacturing. ${ }^{83}$ We propose a conceptual framework to analyze the evolution of latecomer aerospace industries which builds on the sectoral systems of innovation approach and is sensitive to interruptions and radical system changes.

In the following sections we give an overview of the main components of the 'interrupted innovation' framework. Next we discuss how incremental and radical innovation system changes feature in the framework, and how we can map country trajectories. Finally we propose a number of questions for the five country case studies which w explore in the subsequent chapter.

\subsection{The elements of the interrupted innovation framework}

\subsubsection{The main components of the framework of interrupted innovation}

As a metaphor to visualize innovation system dynamics, we can simplify inputs to innovation processes and innovative outcomes at the sectoral level to two dimensions, which we term the size and performance of a sectoral system of innovation in aerospace. The size of an innovation system is defined by the input of resources into innovation and technological change (investment in $\mathrm{R} \& \mathrm{D}$, training and education, human capital stock engaged in the development of new products and processes or organizational change as well as marketing or economically applicable knowledge). Increase in the amount of inputs implies an increase in the size of the innovation system.

We refer to the performance of the innovation system as the volume of innovative outputs which can be applied in production (knowledge about new products, new processes, organizational innovations, discovery of new resources, patents, and so forth). The maximum amount of innovative outputs a sectoral system of innovation can attain with a given combination of inputs under a given institutional structure defines the performance frontier of the system.

Innovation performance is difficult to measure in an unambiguous fashion, partly because there are so many dimensions of innovative performance which are hard to aggregate. ${ }^{84}$ Indicators characterizing innovation performance could include the number of new product designs, the share of new products in sales or the number of patents, citations and trademarks. In the absence of direct performance measures, one could also use proxy indicators of innovative performance such as the industrial sales

\footnotetext{
${ }^{83}$ While we refer to 'sectoral systems of innovation', we bear in mind the conclusion from the literature review that in the context of latecomer aerospace industries both national and sectoral characteristics matter.

${ }^{84}$ The literature does not provide a clear definition of the performance of a sectoral innovation system. Nor does it provide simple ways to measure it over a long time period.
} 
performance (including sales on domestic and export markets) and market shares of final products. This is based on the reasoning that in aerospace increases in market shares can only be realized through increased innovative performance.

When the innovation system is supplied with additional resources, innovation performance will tend to increase. But within the limits of a given innovation system, long-run performance is constrained by diminishing returns - similar to a production function with diminishing returns to scale. ${ }^{85}$ The larger the size of the system, the more complex it becomes, and the more costly and difficult it will be to coordinate the use of resources effectively.

Below, we attempt to visualize the relationship between size and performance of a sectoral innovation system and the effect of institutional change in a set of graphs. These graphs should be seen as metaphors, given that we do not yet have precise operational measures of aggregate innovation system performance.

\subsubsection{Learning within an innovation system}

Figure 5.1 shows the evolution of the performance frontier curve $p$ in relation to innovation system size (resources available for innovation) increases. There is no reason to assume that the sectoral innovation system in any country performs at the maximum of its potential capacity. As it has been often shown since Nelson and Winter (1982), "producing" innovation is difficult. It requires tacit and codified knowledge. Agents make choices based on imperfect information. Whether the effort brings successful outcome is uncertain. How close a country performs relative to the innovation performance frontier thus depends on the amount of learning taking place in the system. Learning takes place through interaction of the actors in the system. In a simplified way, a country's vertical movement from point $A$ to $B$ on the graph corresponds to increased intensity of interactions among actors. It shows the system's success in learning the art of innovation, or utilizing the capacity given the amount of resources invested in the system (horizontal axis).

\footnotetext{
${ }^{85}$ New growth theory (see Romer 1986, 1990, Lucas 1988) states that there are no diminishing returns to increasing knowledge inputs. We argue that this view needs to be modified. Increasing inputs into a given static system of innovation are subject to diminishing returns. Only if the innovation system succeeds in continuously reinventing itself and changing its nature dynamically will diminishing returns be overcome. This requires a kind of transitions from one innovation system to another.
} 
Figure 5.1 Performance in a given innovation system

(author's compilation)

\subsubsection{Shift of the innovation system frontier}

A shift of the innovation system performance frontier requires radical institutional change.

This is different from smaller adjustments in the institutions which facilitate capacity utilization given an innovation system setup. Smaller changes in tax or trade legislation are institutional changes that might affect system performance. Yet they are limited in scope and do not alter the fundamental structure and key channels of interactions of a system.

A radical shift of the system is caused by a more fundamental, qualitative change in its institutional set up. These changes include the entry of new actors with new capabilities that affect existing relations in a fundamental way, a significant change in the technological base of the system, and, crucially, a change of institutional characteristics. Figure 5.2. depicts this radical change as the transition from frontier curve $I$ to $I I$. Such a shift to a higher performance frontier curve will not only allow an industry to increase its competitiveness, but given diminishing returns to innovation inputs, it is the only source of knowledge-based competitiveness gain beyond a certain size of the innovation system. This is why continued advance in innovation performance requires periodic radical restructuring of the innovation system.

There are a number of empirical issues in innovation system dynamics that this simple model can illustrate. For instance, shifts from defense-oriented to commercial 
innovation systems, shifts from systems founded on a strategy of import substitution to open systems, or the shift to the hierarchical, risk-sharing-partnership based innovation system structure which characterizes the global industry today.

The aim of any competitive industry is to continue to increase its innovative performance with a given set of resources, in other words, to shift the innovation performance curve upwards. But, the establishment of a new system based on new combinations of resources and new institutions is a very uncertain and risky process, which may well fail. If the institutional memory is destroyed due to external shocks and the inflow of recourses is drastically reduced, the system may not be able to transform itself. The actors in the system may realize that change is necessary, but they also will only be able to realize change if the institutional set up permits them to do so and new resources are forthcoming).

Figure 5.2. Radical Change of the Sectoral Innovation System: Transition

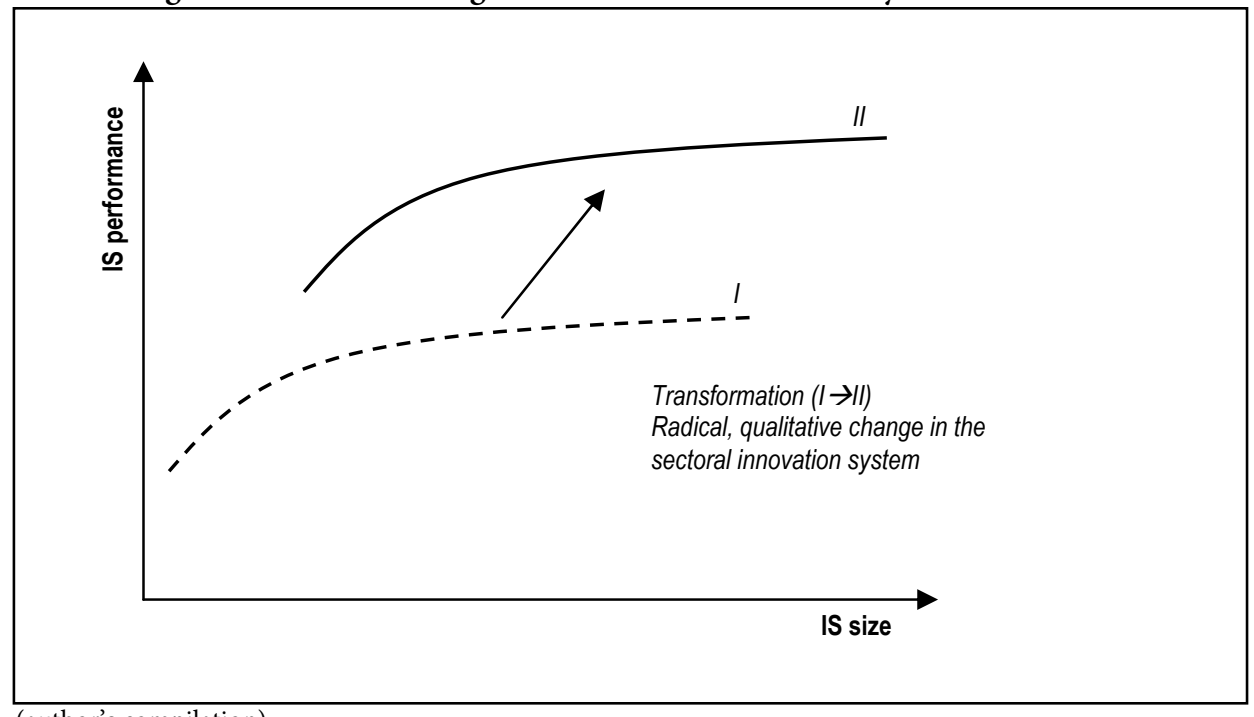

(author's compilation)

The causes of radical innovation system change in a latecomer industry are most likely exogenous to the system. External macroeconomic, political or technological shocks cause crises and interruptions in the productive activities. If these events are longer lasting, private and public financial resources available as inputs for innovation will be depleted. This depletion can also happen if the innovation system fails to meet the demands of the competitive environment. Technological change outside the system (i.e. in leading countries) can similarly be detrimental to competitiveness of the latecomer 
system as such changes make the existing knowledge base obsolete. ${ }^{86}$ In behind-theglobal frontier latecomer systems exogenous causes of interruption are more likely than causes endogenous to the system, which are more typically found in situations where the industry is already operating at the global technological frontier. In advanced economies, innovation at the knowledge frontier may lead to creative destruction, resulting in endogenously driven interruptions.

\subsubsection{Innovation system trajectories}

Figures 5.3 and 5.4 show alternative responses to an interruption in the innovation system. Figure 5.56 plots how the size and performance of a sectoral innovation system in a country changes over time as a result of learning within the system, interruptions and radical institutional changes. The trajectory of a country is indicative of the way its institutions function and reveals the major constraints to and opportunities for industrial competitiveness, related to the functioning of the innovation system.

Figure 5.3. represents the case of a latecomer industrialiser that fails to make the transition to a new system of innovation. As resources available for the sectoral innovation system increase, its actors learn to utilize the institutional setup to reach near-frontier performance with their interactions. The system will move closer to the frontier (movement over time from $T_{1}$ to $T_{3}$ ). What happens when the system reaches the frontier? Assuming that its aim is to increase performance, staying on a frontier where the returns to additional resources decline to zero, would marshal internal forces for institutional change.

\footnotetext{
${ }^{86}$ Here we are primarily referring to radical technological changes at the frontier which pose challenges to a latecomer that is trying to close the technology gap. But of course, this is not necessarily the case. If the latecomer is not catching up and the technology gap is not being closed, even incremental change at the frontier can cause the latecomers's knowledge base to become obsolete.
} 
Figure 5.3. Interrupted Innovation

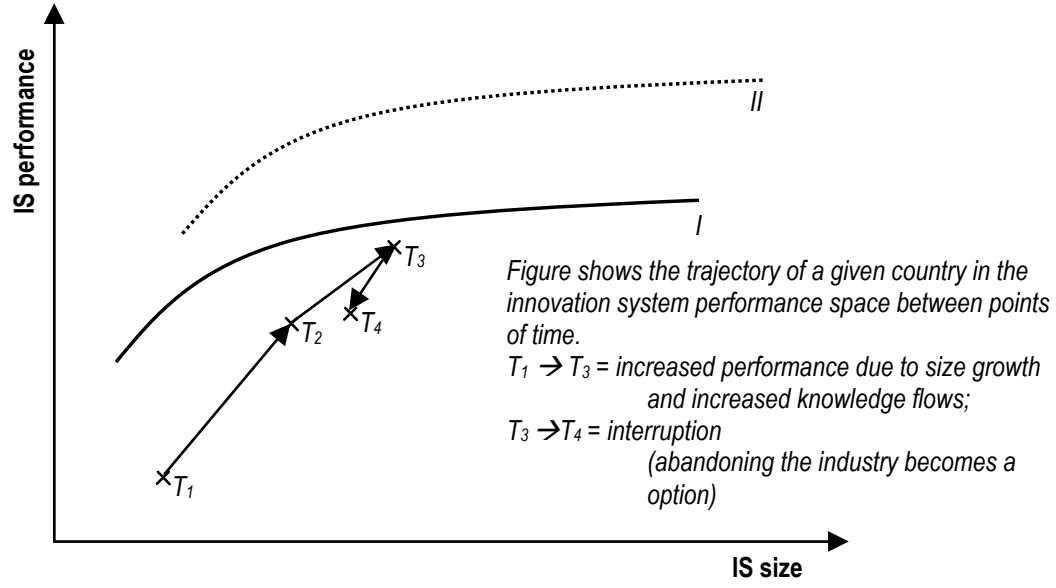

(author's compilation)

If these changes could be realized in a short time, the sectoral system could smoothly jump to a new growth path without significant performance loss and any further increase will be relative to the new performance frontier.

But such a smooth transition is very unlikely in an industry prone to huge sudden fluctuations in demand. A decline in demand will indirectly result in shrinking resources available for innovative activity, which provides an exogenous shock to the innovation system. Thus the system is faced with a double challenge: changing external circumstances and diminishing returns to investment in innovation within the existing system. The innovation system's performance will decline and an interruption occurs. This is illustrated by the movement from $T_{3}$ to $T_{4}$ in Figure 5.3. .

Should the drop in innovative performance in a latecomer country become too big and should the chances to mobilize resources for a recovery be too dim, the interruption may result in the abandonment of further efforts to develop this industry. Both the innovation system and the productive system will collapse. The emergence of an aerospace industry has then failed. 
Figure 5.4. Interruption followed by successful transition to a new innovation system

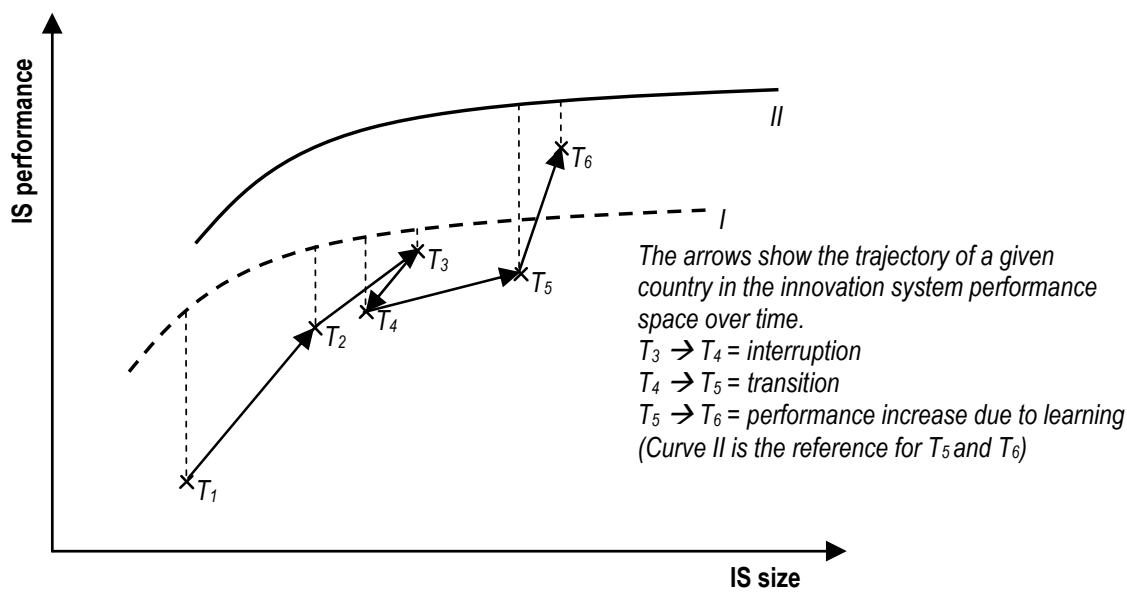

(author's compilation)

Figure 5.4. shows the case of a successful transition to a new system defined by frontier curve II. Recovery after an interruption will not immediately show higher performance even if a successful transition to a new system of innovation has been achieved. Increased performance can only be realized over time as the actors learn how to achieve best practice relative to a new performance frontier. Note that at $\mathrm{T}_{5}$, the new system will not necessarily be performing better than the old one at $\mathrm{T}_{3}$. The new system will only start to perform better than the old one as the actors learn to work the new system and we approach $\mathrm{T}_{6}$. 
Figure 5.5. A learning trajectory: interruption and successful transition

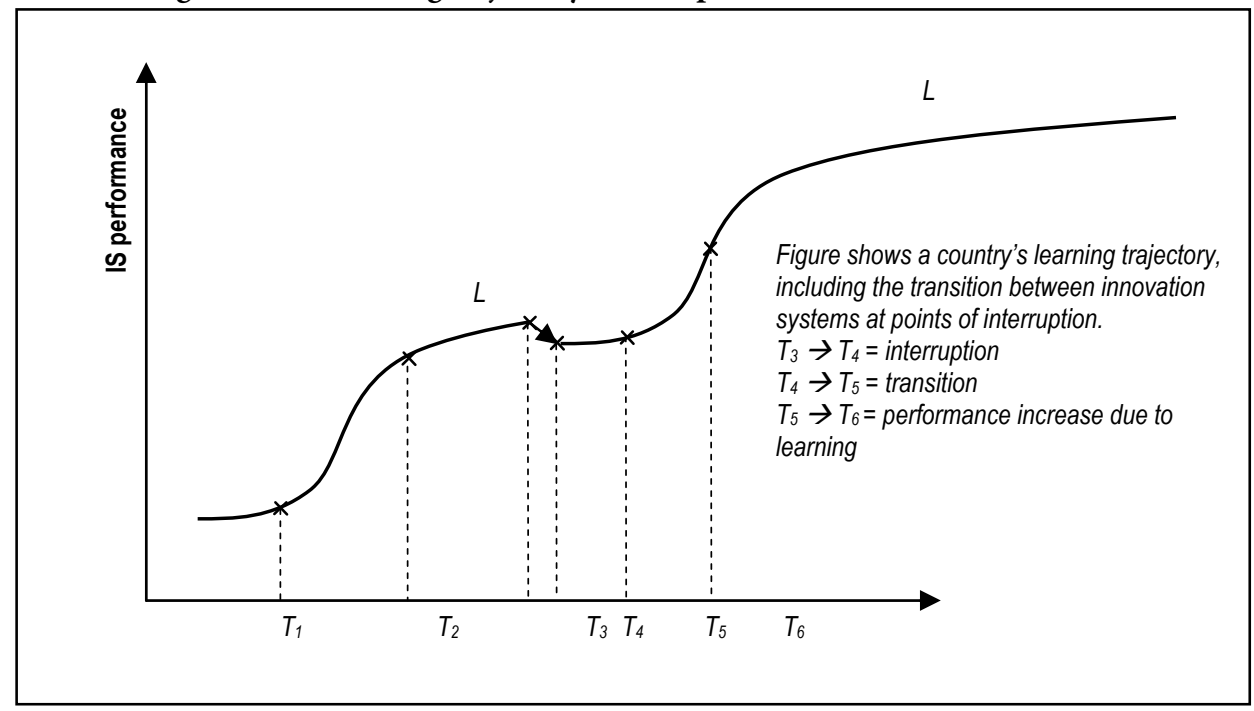

Source: author's compilation

In Figure 5.5., we plot innovation system performance of a country against time on the horizontal axis, rather than against innovation system size as in the previous figures. Here, the development trajectory of a successful transition from one innovation system to another will take the form of a set of S-curves. Up to the point of interruption, the industry follows a learning curve in its attempt to approach frontier performance. The interruption results in an abrupt decline in innovation performance.

In Figure 5.5., $L$ refers to the actual learning trajectory of the country (frontier performance is not reproduced here). The interval $T_{1}$ to $T_{3}$ refers to the learning curve of an emerging system prior to the first transition. $T_{3}$ to $T_{4}$ refers to an interruption. $T_{4}$ to $T_{6}$ refers to the successful transition from the innovation system with performance frontier $I$ to a new innovation system with a performance frontier curve $I I$. At $T_{6}$ we see the beginning of a new learning curve.

In the interruption period $T_{1}-T_{4}$ there is a crucial challenge for the relevant actors to react to the crisis by reconfiguring the institutions in an innovation system and possibly expanding it with new resources. This is necessary in order to redirect learning efforts onto a trajectory that produces the supply of innovations required by the changed demand conditions facing the industry. After the system transition, the actors in the sectoral system of innovation try to move towards a new performance frontier, hence the emergence of a new S-curve.

The time between the point of interruption and that of system change depends on the readiness and capability of the actors to react to changes in the environment. It is 
thus an indication of the flexibility and adaptability of the innovation system of an industry.

A crucial difference between well established or mature innovation systems ${ }^{87}$ and emerging ones is the greater vulnerability of emerging innovation systems to external shocks. These shocks cause interruptions during which previously acquired technological capabilities are lost. Even leading producers have found to be prone to 'organizational forgetting', but to a lesser extent that latecomer producers. ${ }^{88}$

\subsubsection{System performance and competitiveness}

The long-run competitiveness of a high-tech industry depends on the capacity of its sectoral innovation system to provide cost-reducing and productivity-increasing innovations and new products with technological features superior to those of its competitors. How does competition feature in our framework?

Competition is a key driver of improvements in innovation system performance. Suppose that industries from two different countries competing to supply the same market face similar frontier curves for innovation performance. The industry that is closer to the frontier has a higher propensity to innovate, hence a higher chance to be more competitive in a knowledge based industry.

However, the performance frontier curves differ from country to country. Countries may not only compete in their relative distance from a given innovation performance frontier, but also in the position of the frontier itself (e.g. innovation frontier $I$ and innovation frontier $I I$ in Figure 5.4.). They can increase their competitiveness in two ways. First, by learning within a system, what corresponds to moving closer to an existing performance frontier as shown in Figure 5.1. Second, by making the transition to a radically new performance frontier which is superior to the previous one (Figure 5.2.).

This implies two different kinds of costs: first, the learning costs associated with narrowing the distance to the frontier; and second, the transition costs from one frontier to another. These costs have to be borne by the entire innovation and production system. Only if the industry is selling competitive products can these costs be recovered. A key dilemma for the governance of innovation systems is to find the most costefficient way to manage system transitions. Incremental changes will not bring about as great gains as radical ones, but the costs of radical institutional changes may well be high. Path dependence, the comfort of established routines, the lack of information

\footnotetext{
${ }^{87}$ Chaminade and Vang (2008) use the term 'mature innovation systems'.

${ }^{88}$ Production experience can depreciate, not only appreciate over time (Benkard, 2000)
} 
about the alternatives, the uncertainty concerning outcomes of institutional change reduces the likelihood of the occurrence of major institutional changes.

Finally, there is another element of competitiveness: the speed of reaction to global declines in the demand for aerospace products, in case of crises. Competitiveness in these instances is measured by the flexibility of the industry, or its ability to respond in a timely fashion to the changing demand conditions by changing its institutions. McKelvey et al (2006a,b) discuss rigidity and flexibility of innovation systems and identify the period of adjustment to new demand conditions (both external and internal to the industry) critical moments. ${ }^{89}$

\subsubsection{External causes of interruption}

A major difference between innovation system change at the technological frontier and innovation system change in latecomer countries is the most likely cause of interruption. Latecomers by definition enter an industry characterized by Schumpeter Mark II competition ${ }^{90}$ and focus their learning efforts on acquiring and improving already proven technologies. This entails investment in physical and human capital which, especially during the early phases depends on the government's financing abilities. Consequently macroeconomic and political crises and changing competitive environments are all potential external causes of interruption and have a far greater likelihood of causing interruptions than endogenous technological factors.

\subsubsection{Questions for case studies}

Times of crisis offer ideal points of entry to observe innovation system change. The drop in demand puts both the production and the innovation systems to a test. Since it jeopardizes survival, it triggers responses from the system. As pointed out earlier, crises are cyclically returning challenges in the aerospace industry, and stakeholders need to be prepared for slumps and need to learn how to respond and find innovative solutions to weather the crises and set the industry on a growth path more rapidly than its competitors.

In the following section we present five country case studies of how crises triggered changes in of the sectoral innovation systems in the aerospace industry. The cases are those of Brazil, China, Indonesia and Argentina. The first two cases are cases of

\footnotetext{
${ }^{89}$ Also at firm level, Yuan et al (2010) showed that strategic flexibility matters; it is reasonable to assume that a first mover advantage exists when it comes to competition between firms. The producerthat first embarks on the new innovation path has the highest likelihood of recovering from a major interruption.

90 'Schumpeter Mark II' refers to a consolidated structure where a few large firms make benefit of economies of scale and finance R\&D investments to maintain their leading position (Nelson and Winter, 1982 and Malerba and Orsenigo, 1996).
} 
successful development of the aerospace industry in a developing country context. The last two cases are cases where the aerospace industry has so far failed to take off.

Based on the conceptual framework of interrupted innovation developed above, we examine the following analytic questions in the country case studies:

1. What trajectories did the latecomers in aerospace follow?

a. How can these trajectories be measured and analysed?

b. To what extent is the end of the emergence phase associated with interruptions and transitions?

2. What caused the interruptions in the development of the sectoral innovation system? What is the balance between internal endogenous sources of interruption and exogenous system shocks?

3. What were the characteristics of the transition period?

a. How did interruptions and transitions affect the accumulation of latecomers' technological capabilities?

b. Who where the actors governing the transition period?

c. What were the factors contributing to the success or failure of transition from one innovation system to another?

d. Are there ways in which 'transition-institutions' can minimize the negative effects of interruption causing erosion of capabilities in an innovation system? 


\section{CHAPTER 6 \\ Case studies on latecomer aerospace industry development}

\subsection{BRAZIL}

\subsubsection{Introduction}

The aircraft industry of Brazil has received more attention than that of any other emerging economies. This is not surprising, since its flagship company, Embraer has made it to the top three companies producing commercial aircraft, and has been among the top five manufactured product exporters of Brazil. This case shows that Embraer's years of success and failure were all closely linked to the performance of the Brazilian sectoral system of innovation in aerospace.

We provide a detailed historical overview of the origins of aircraft manufacturing in Brazil in the 1930s and 1940s and the associated innovative activities, of the emergence of a new innovation system in the 1950s and 60s, of the subsequent growth period led by a state-owned enterprise, the crisis years of the early 1990s, the transition to a new system along with the privatization of Embraer, until the crisis in the first decade of the new millennium.

\subsubsection{The origins of aircraft manufacturing in Brazil}

"On a continent where the civilizing influences of even the crudest forms of transportcanoes, horses and dogs-are still exercised in reclaiming the hinterlands of Canada and South America, the airplane as a vehicle of commerce has, I believe, an arresting interest for the philosophic mind." (Biddlecombe 1928, p.297)

"It is conceivable that, within a favorable framework of forces, aircraft can give that impetus to the utilization of Brazil's extensive and diverse wealth which may allow her to achieve the status of the dominant industrial reservoir (despite limitations of fuel) of a much more developed South America." (Isard and Isard 1945, p.169) 
The development of the Brazilian aircraft manufacturing industry during the Embraer era has been studied extensively (Sarathy 1985; Cabral 1987; Mowery 1987; Ramamurti 1987; Frischtak 1992, 1994; Cassiolato et al. 2002; Goldstein 2002a; Marques 2004). However, the origins of aircraft manufacturing on an industrial scale and the origins of an aerospace innovation system date back to decades before the foundation of Embraer.

The 1930s brought about accelerated industrialization in Brazil in a wide range of sectors, including airplane production. This was a departure from earlier experimental efforts of pioneer aviators such as Santos Dumont, since it now involved serial production. Industrialists, the military as well as the administration of Getulio Vargas saw potential in larger scale aircraft production. Antonio G. Muniz, a military official and aircraft designer trained in France emphasized the benefits of locally training engineers. He argued that establishing research, design and manufacturing capabilities would reduce dependence on foreign countries (Viegas 1989).

One of the first aircraft manufacturing companies, the Fabrica Brasileira de Aviones (Brazilian Airplane Factory, FBA) was a subsidiary of the air transport company $^{91}$ owned by the entrepreneur Henrique Lage. The FBA was established in Rio de Janeiro and designed a dozen of aircraft for aero clubs and the military using the skills of Muniz and Belgian and French engineers. Between 1936 and 1948 over 200 aircraft were built (See Table 6.1).

Table 6.1 First series production of airplanes in Brazil, 1936-51

\begin{tabular}{llllr}
\hline Year & Model & Designer & Manufacturer & Nr. produced \\
\hline $1936-41$ & M-7 & Muniz / Henrique Lage & Fabrica Brasileira de Aviones / CNNA & 26 \\
$1939-43$ & M-9 & Muniz / Henrique Lage & Fabrica Brasileira de Aviones / CNNA & 40 \\
$1940-41$ & HL-1 & Muniz / Henrique Lage & Companhia Nacional de Navegação Aérea & 108 \\
$1942-48$ & HL-6 & Muniz / Henrique Lage & CNNA & 60 \\
$1940-42$ & 1FG & Focke Wulf Fw-44) & Fabrica do Galeão & 40 \\
$1940-42$ & 2 FG & Focke Wulf (Fw-58) & Fabrica do Galeão & 25 \\
$1942-43$ & 3 FG & Fairchild (PT-19) & Fabrica do Galeão & 232 \\
$1942-43$ & CAP-1 & Grupo Pignetari & Companhia Aeronautica Paulista & 9 \\
1945 & CAP-3 & Grupo Pignetari & Companhia Aeronautica Paulista & 8 \\
$1943-48$ & CAP-4 & Grupo Pignetari & Companhia Aeronautica Paulista & 777 \\
$1946-51$ & T-6 & Texan (license) & Lagoa Santa/Companhia Aeronautica & 81 \\
\hline
\end{tabular}

Source: Cabral (1987) Tab. II.1. and Viegas (1989)

The approach of World War II increased demand for aircraft. The FBA received a number of military launch orders, but same models were also sold to civilian aero clubs. Meanwhile, production facilities were set up at the Fabrica do Galeão in Rio de Janeiro

\footnotetext{
${ }^{91}$ The Companhia Nacional de Navegação Aérea (National Air Navigation Company, CNNA), 1935.
} 
with German technical assistance to produce Focke-Wulf trainers under license. ${ }^{92}$ Brazil's shift from a German orientation to the Allies brought along changes in aircraft production. The Fabrica do Galeão was selected to produce the Fairchild PT-19 trainers under license (local designation 3 FG). During 1942-43 the factory produced on average 116 of these planes.

There were a number of other companies trying to enter aircraft manufacturing. The Empresa Aeronáutica Ypiranga (EAY) was set up in 1931. The company intended to produce glider planes and copied two German models of which only a few were manufactured. There was another design that was very influential: the EAY-201, a single engine, two-seater plane with wings placed high, based on the successful US model, the Taylor Cub. Interestingly, EAY, the innovator, did not have much success with the plane. It eventually sold the designs to Companhia Aeronautica Paulista (Aeronautical Company of Sao Paulo, CAP).

CAP was founded in the state of Sao Paulo as the aviation section of the Pignatari Group in 1942. This company commenced operations with the production of a successful German model, the Alcatraz, and the Saracura before producing a locally designed 2-seater, single-engine plane, the CAP-1 (and a more advanced CAP-3) "Planalto". Including the prototypes, around 20 of these planes were built. CAP quickly accumulated manufacturing capabilities which proved to be most successful when it acquired the manufacturing rights for the EAY-201 model from the Ypiranga company. After a few modifications the CAP-4 Paulistinha became the best selling Brazilian plane of its time. A total of 777 planes rolled out of the plant at Santo André between 1942 and 1948. Except for the engines, the Paulistinha was made of Brazilian materials and parts and has also been exported to South American countries and Portugal. CAP never managed to develop (or acquire) a successful model after the Paulistinha, despite efforts to design modified versions. The end of the war brought the end of the company as well. The decline in military orders and the dumping of cheap second hand North-American planes on the Brazilian market resulted in the closure of the plant in 1949.

The Brazilian aircraft manufacturing capabilities of the 1940s were far behind the capabilities of European or US plane makers of the era, but they still managed to sell their planes due to the wartime demand for "anything that flies". The technology gap became apparent in peacetime. The numerous commercial airlines of Brazil (Aerovias Brasil, Cruzeiro do Sul, Varig, VASP $)^{93}$ flew medium sized and larger propeller planes

\footnotetext{
${ }^{92}$ Two models, the Fw 44 and 58 (local designation 1 FG and 2 FG) were produced with 40 and 25 pieces during 1940-42.

${ }^{93}$ Many of these originated from before the WWII when they were only providing domestic services. Between the two world wars, airlines associated with European governments were fighting for a leading position in the
} 
(DC-3s, DC-4s, Junkers Ju 52, Convair 240s, Lockheed Super Constellations) and even jets from 1959 (Caravelles and later B-707s). The small planes built in Brazil had no market outside flying clubs.

The industry was entering a long decline period during the late 1940s. Postwar periods pose a reorganization challenge for industries, a need to shift from quantity-to quality oriented production during times of "demobilization instability" (Higham 1968). The end of World War II offered a moment for Brazil to reconsider the strategies concerning the aeronautical industry. The transportation infrastructure was underdeveloped, especially in the vast continental lands of Brazil. Air transportation and supplying industries had a huge potential, but also required infrastructural investments.

\subsubsection{The emergence and growth of a sectoral innovation system}

The long transition period over the 1950s and 60s until the establishment of Embraer marks a crisis in the industry, but also the emergence of a sectoral innovation system. As Figure 6.1 shows, no significant new products were launched. Production involved small planes representing older technology. Why did it take over 20 years before a new company could emerge from the ruins?

There was no overarching strategy on how to develop the sector. The government's hesitation to outline any strategy and appropriate large sums in the budget for indigenous aircraft development appeared to be vindicated by the failure of aircraft development projects in neighboring Argentina. Competing with foreign producers in the commercial air transport market was far beyond the financing ability of local entrepreneurs. Before the war, previous experience in the steel or automobile industries sufficed to produce simpler small planes, but more sophisticated products required a larger pool of aeronautics engineers, technicians and physical capital investments. Industrialists instead focused on serving the general aviation market. A famous entrepreneur of the time was José Carlos de Barros Neiva, who founded a homonymous company in Rio in 1954 and manufactured glider planes. Two years later the company moved to Botocatu and produced the Paulistinha and Regente, for which it acquired licenses. Although it did roll out a trainer for the air force which was its own design, Neiva remained the producer of gliders, single-engine general aviation or agricultural planes, and later a component manufacturer of Embraer (which eventually acquired it in 1980 following financial difficulties).

Trans-South-Atlantic passenger and mail services. For a thorough account of the fierce competition even within French companies, see de Bure (2006). 
Figure 6.1 The evolution of aircraft production in Brazil, 1936-2010

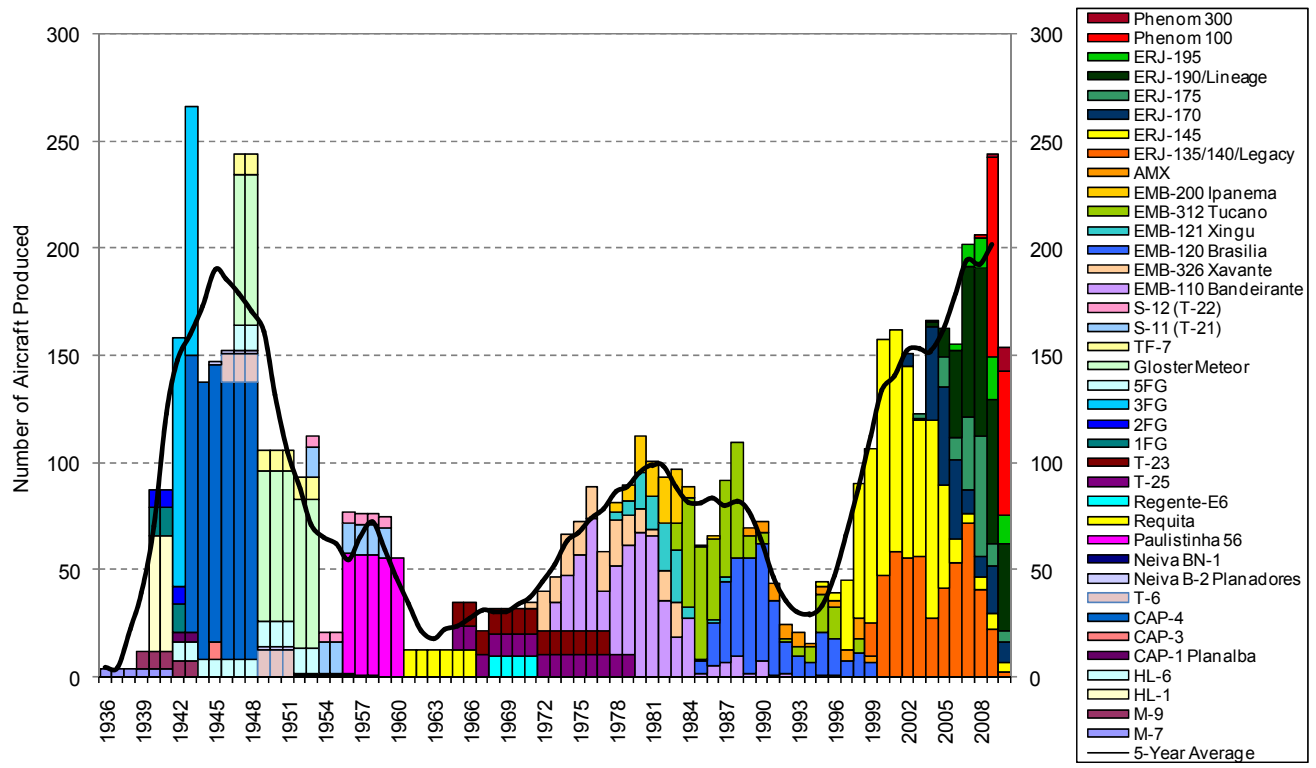

Source: own compilation based on Cabral (1987); Cassiolato et al (2002), Embraer Annual Reports, The Airlinerlist database <http://www.airlinerlist.com> (downloaded 2009 Feb); and Flight International, various issues.

Note: Since exact annual production is unknown before 1969, the total number produced was spread evenly over the estimated years of production. Figures after 1970 exclude new general aviation aircraft production runs, among others the license-produced Pipers and the upgraded versions of the Ipanema (EMB-201 and 202). For colors see digital version.

The government did not invest in major aircraft development projects, but it did agree to finance the education and training of aeronautical engineers and technicians. Specialized training was already available at the army's technical school established in 1939, and at the Escola de Aeronáutica (School of Aeronautics Engineering) at Campo dos Afonsos in Rio de Janeiro. ${ }^{94}$ In 1946 this was transformed into the Instituto Tecnologico da Aeronautica (Aeronautics Technology Institute, or ITA in short), which became the "alma mater" of all the key persons in the sectoral innovation system. ${ }^{95}$

Between the two most influential cities, Sao Paulo and Rio de Janeiro, Sao José dos Campos, a town in the Paraiba valley was chosen as the strategic location ${ }^{96}$ for the

94 Colonel Casimiro Montenegro Filho played a crucial role in its foundation.

95 "ITA was inspired by the MIT model and in fact, a number of professors from the Aeronautics department of MIT (as well as German engineers) went to work at ITA in the early years. By 1988 ITA had trained more than 3000 engineers, 800 of which were in the aeronautics field" (Frischtak 1992, p.5)

96 Motivations for selecting Sao Jose are numerous, including favorable climate and topographical conditions, the accessibility to energy and means of communications, the relative remoteness from urban centers while 
newly established Centro Tecnico Aeroespacial (Aerospace Technical Center, CTA). As a branch of the military, CTA was inaugurated in 1950 to conduct and oversee research in aviation and space flight in Brazil. It offered post-graduate research positions for engineers from ITA, especially in the Instituto de Pesquisa e Desenvolvimento (Research and Development Institute, or IPD). IPD was one of the four institutes subordinated to CTA, as was ITA which was moved to the grounds of CTA. The two other institutes apart from ITA and IPD were the Institute for Space Activities and the Institute for Development and Industrial Coordination.

It was IPD's mission to develop aircraft locally. It housed several promising experimental projects, including a vertical take-off aircraft and the hummingbird helicopter involving experienced German engineers. However, neither of the two projects advanced to commercialization because of design failures. Other projects were more successful and CTA followed a strategy of spinning them off into aircraft producer companies. The air force ran CTA, but was not commercializing the results of development projects. Aerotec, one of the first spin-offs, was founded in 1962 to produce the Uirapuru for air force to replace its aging Fokker trainers (150 planes between 1968 and 1977). The most famous spin-off company was Embraer, which was a result of a transport aircraft development project.

The story of Embraer began when the Brazilian Air Force (FAB) commissioned CTA to develop a twin-engine, non-pressurized 8-10 seater turboprop transport. IPD launched the 'IPD-6504' project under the leadership of air force officer and aeronautical engineer Ozires Silva. ${ }^{97}$ The celebrated French aircraft designer, Max Holste was hired to lead the design work. The prototype of the IPD-6504 successfully accomplished its maiden flight in October 1968. But it took substantial organizational efforts to transform the prototype into a product later known as the Bandeirante and required entrepreneurial skills on top of technical skills, and no company in Brazil possessed the capabilities to manage a commercial aircraft producing venture. ${ }^{98}$

\footnotetext{
being not too far from Sao Paulo (with the newly built President Dutra highway providing easy access to Sao Paolo) and the possibilities for further growth.

${ }^{97}$ In 1965, a group of engineers from CTA were investigating the causes of another accident in the interior of Brazil. Among them was Silva, an outstanding graduate of the Escola de Aeronáutica and ITA (and later of Calthech). Silva recalled in an interview (Silva, 2009) that it was during this investigation when he realized that there was a market niche for smaller transport aircraft with lower servicing and airport infrastructural needs. The number of towns with operating airports had sharply decreased in preceding years (from a height of 360 to only 45 in 1956). The potential replacement models for the aging planes servicing these small airports (mostly DC-3s) required more sophisticated airport infrastructure. Brazil eventually chose a path to develop an aircraft instead of spending on the development of a large number of airports.

${ }^{98}$ Max Holste for instance was skeptical of the project's success and left the team for Uruguay.
} 
The commercialization of the IPD-6504 project did not go to existing companies, because both Neiva and Aerotec found the endeavor too risky, fearing too high dependence on government contracts ${ }^{99}$. Even the Dutch manufacturer Fokker turned down the offer. Silva (2002) noted that given the risk-aversion of Brazilian private investors, the only solution was to create Embraer as a state-owned enterprise in 1969. Many of the later observers overlook the fact that if it wasn't for the entrepreneurial designers, the military government would not have pushed for establishing a commercial company. Instrumental in this endeavor was the "social capital" (in the sense of Akçomak and ter Weel (2009) of Silva and other members of the team. By the end of the 1960s, members of the class graduating from ITA in 1962 had already established key positions in the administration and in the military. It is also interesting to note that Embraer developed a corporate culture that motivated employees despite their relatively low financial compensation. Embraer was also working on another spinoff project, a small agricultural airplane, for which the funding came from the Ministry of Agriculture. The EMB-200 Ipanema became the most successful single model of which over a thousand has been produced (and is still in production, certified also to consume ethanol in 2004).

The Bandeirante prototype that flew in 1968 underwent a number of modifications in size and performance before certification and the finalization of the serial production design at the newly founded test facilities of Embraer. The final commercial version was a 19 -seater model, of which a total of 500 planes were produced between 1972 and 1990 .

The task to mass produce commuter airplanes required capabilities that did not exist in Brazil. So far, CTA had successfully accumulated the capabilities to absorb technology by establishing a strong engineer training program at ITA, by cooperating successfully with foreign institutes (MIT), scientists and engineers. But no Brazilian enterprise had experience in producing and selling commuter planes to airlines. Frischtak (1992, p.17) and Moxon (1987) note that Embraer chose a unique development trajectory as it skipped the step of locally assembling planes under license. This is true to the extent that Embraer and the government of Brazil did cooperate when it came to targeting capabilities required to fill gaps in the capabilities.

The entire innovation system responded in a very flexible way: the channels among the different actors were open, open also to reach out to and include new actors. First of all, the military (after some persuasion) provided the source of finance through a military commission for the production of 80 Bandeirantes. Apart from the labor force

\footnotetext{
${ }^{99}$ Neiva had been following the IPD-6504 project from the very beginning, and even arranged the historic meeting between Max Holste and Ozires Silva, as the latter recounted in his memoirs (Silva 2002).
} 
trained at ITA, the required technical knowledge for mass-production was furnished from external sources. One of the most important sources was a licensing agreement with the Italian manufacturer Aermacchi on the production of Xavante (EMB-326), a jet trainer and fighter. ${ }^{100}$

Aermacchi designers were physically present in Sao Jose dos Campos to provide assistance with design of certain parts and solving various tasks; it was a 10 years deal that followed through the whole learning curve of Bandeirante production. Another source of technological know-how was an offset contract with the American company Northrop. While procuring $50 \mathrm{~F}-5 \mathrm{~s}$ for the Brazilian Air Force, Embraer was commissioned to produce vertical fins, rudders, wings and belly pylons for a 100 of this model. It provided Embraer with technologies such as chemical milling, metal-to-metal and honeycomb bonding as well as working with composite materials. ${ }^{101}$

A major foreign source for marketing, sales and support know-how was the "collaboration" with US general aviation producer Piper. The process through which the Brazilian government selected Embraer's collaborating partner was more an ultimatum than a real competitive deal. As a result of the economic boom of the early 1970s demand for small planes grew substantially ${ }^{102}$, and as a result of the foreign exchange crisis following the oil crisis of 1973, the government was ready to bring production of these planes to Brazil - to Embraer. It followed a strategy of giving monopoly licenses to one producer and deterring imports from all the others. The deal offered to three top US general aviations producers was as follows: (1) allow Embraer to progressively manufacture a greater share of the planes' components and parts in Brazil; (2) do not oblige Embraer to pay any royalties; (3) allow Embraer to make modifications on the models; (4) expect collaboration on future aircraft design, production and marketing. Despite being the biggest exporter to Brazil, Cessna was opposed to most of the demands so an agreement was concluded with the most cooperative company, Piper. As promised, import taxes on planes for general aviation were raised from 7 to 50 percent in line with the new import substitution policy. Over the years, from 1975 Embraer produced thousands of Piper models (under local names and designation: EMB-710, $711,-712,-720,-721,-810$ and -820$)$.

\footnotetext{
${ }^{100}$ Ramamurti quoted Pessotti, Embraer's technical director: "It was a very interesting cooperation, because it brought a lot of technology and expertise that we did not have at that time in Brazil-for example, in areas such as tracing technology, assembly of planes, organization of procurement of materials, quality control, technical documentation, organization of assembly lines, etc." (Ramamurti 1987, p.185).

101 "In addition, the contract also forced Embraer to improve on its tool design, quality assurance and other production techniques, while stimulating the use of numerically-controlled machine tools" (Frischtak 1992, p.18).

${ }^{102}$ Import from the US was 540 planes in 1974 in the value of 150 million USD (Ramamurti 1987, p.190)
} 
The rather flexible response and reorganization of the innovation system to accommodate mass production owes much to the cooperation of a number of actors, who were all motivated by the vision of creating a functioning aircraft industry in Brazil. Institutional actors, companies, government agencies in the country were dominated ultimately at the individual level by ITA graduates who were ready to cooperate in their various specialized positions. Coordinating all these actors and having strong negotiating powers vis á vis external actors was the Ministry of Aeronautics. The ministry did not shy away from implementing protectionist trade agreements and providing support to Embraer in a various ways, be it technical, financial, marketing or regulatory assistance. Embraer was also given preferential treatment, and was exempted from import taxes and duties on materials, parts and components that were not available locally.

The government also played a crucial role in providing finance. First, by controlling 51 percent of the so called 'voting shares' of Embraer; second, indirectly, by establishing a tax incentive scheme that solved the problem of the unavailability of venture capital and making it interesting for private companies to own a share of the new state-owned enterprise. Companies (of all sizes, ranging from large state-owned enterprises to SMEs) could invest every year up to 1 percent of their federal income tax in Embraer shares - on which they could even receive dividends (which they in fact received from 1974 onwards). These preferential shares were nonvoting shares. Thus they did provide influence on company decisions (the government always maintained at least 51 percent of the votes), but they did bring in substantial amounts of capital. Ramamurti (1987, pp.192-4) shows that the government's share in total equity fell from 82 percent in 1970 to 7 percent in 1981. Additionally, Embraer received further support from the air force through procurements and direct R\&D support.

Why did the Bandeirante succeed? All the efforts to enter the phase of mass production would have been in vain, if Embraer had not rolled out a model that actually responded to a market needs. The Bandeirante was capable to operate in extreme conditions, with minimal ground support and low maintenance requirements and with a flexibility of configurations. All this was provided at a very competitive price, a rather fast (45 day) delivery time and appealing financing conditions ( 9 percent interest rate as opposed to almost double that amount offer by US competitors). The only disadvantage compared to similar models was higher fuel consumption and shorter range.

The success in finding a niche market explains a lot of the success of Bandeirante. Kimura (2006) shows how a commercial aircraft development project failed in Japan after the Second World War. Driven partly by the same need to replace aging DC-3s, partly by national pride and nostalgia, the public-private consortium NAMCO developed a 64-seater turboprop airliner, the YS-11. The cooperating companies 
(Mitsubishi, Kawasaki and Fuji Heavy Industries) developed significant technological capabilities in aircraft manufacturing, and 182 planes were sold until the project was terminated in 1974. But the project was a commercial failure; the plane was obsolete by the time it was introduced. It was competing in a market segment that was being taken over by jets. As a result, the Japanese industry had to transform and gain competitive competences in component manufacturing. The similarities between the Brazilian and the Japanese endeavors are striking: both countries had experience in large scale production of planes during the war, but production was discontinued after the war. Both countries saw the strategic significance of the aircraft industry, leading to significant government investments into $R \& D$ and a high reliance on initial military procurement at the start of production. Both countries were facing the high prices of late entrants: a steep learning curve, high development costs. But while Japan chose the path of indigenous production, Brazil successfully invited foreign experts and paid close attention to market demands.

Internationalization of sales was the natural way of securing sales. Serving the American market was already a strategy in mind at the design phase of the Bandeirantes. ${ }^{103}$ Following the oil crisis, airlines in the US showed great interest in the newly developed plane. But it took quite some diplomatic efforts by Brazil to finally receive the FAA certification in 1978, due to strong objections by US producers who were lobbying for retaliation against the discriminatory import tariffs imposed by Brazil. By then, the plane had received foreign certifications in a number of countries and was sold to Uruguay (1975) and France, the United Kingdom and Australia (1977). The most important market turned to be the United States. The timing of the entry was well chosen, as it also coincided with a deregulation of the US market in 1978, which resulted in the closure of jet service to smaller airports, thus opening a niche for shorter and cheaper commuter service by turboprop planes. An additional feature making the Bandeirante cheaper to operate was its 19-seater configuration, since planes above 20 passengers were supposed to have an additional flight attendant. The market expanded fast, but Embraer was among the first movers. The only US-made direct competitor was the Fairchild Metro III. To meet the increased demand, the production of the Bandeirante reached a rate of over 5 planes a month in 1980 and 1981. Exports amounted to nearly $50 \%$ of total sales in these years and, (102.7 million USD in 1981).

\footnotetext{
${ }^{103}$ According to Silva (interview, 2009), instead of responding to the request of Brazilian associations to have the metric system on board, they implemented US standards.
} 
Figure 6.2 Embraer's sales, exports and number of employees, 1970-2007 (Million USD at constant $=2000$ prices)

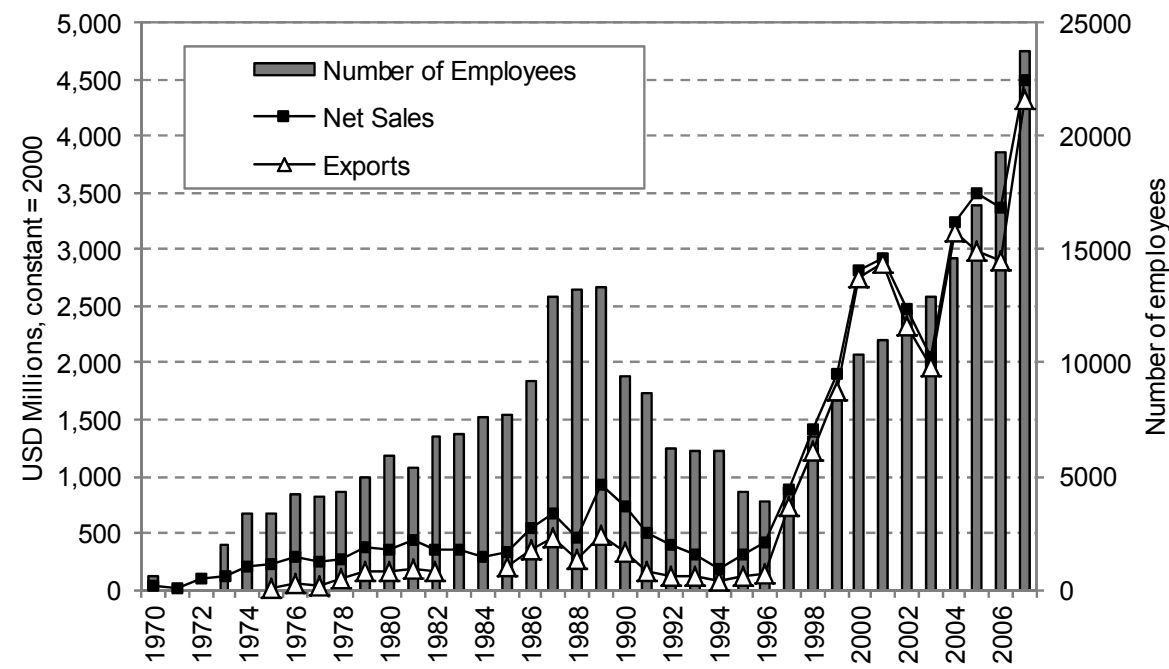

Sources: Embraer, Frischtak 1992, Ramamurti 1987, Cassiolato et al. 2002.

To sum up, during the 1950s and 1960s the basic elements of an emerging sectoral innovation system were established. The emergence of its main actors and linkages happened slowly and without a clear central mission. Investment in aerospace education and research provided an important breeding ground. A sectoral innovation system emerged slowly, and in it entrepreneurial engineers played a crucial role as "system brokers". The system broker, Ozires Silva ${ }^{104}$ and his team at CTA played a central role in (1) finding a market niche (commuter aircraft capable of serving airports with poor infrastructure); (2) channelling finance and design efforts to successfully develop a new product for this niche (IPD-6504); (3) establishing a company to ensure commercial valorisation of innovations (Embraer, 1969); (4) creating new linkages to provide capital (government launch support, government commissioning of 80 Bandeirantes and subsequently new planes, and a corporate tax incentive scheme channelling private capital to Embraer) and (5) creating linkages to access technology (through an exclusive contract with Piper, a deal with Italian producer Aermacchi, an offset contract with Northrop and collaboration with the Canadian engine manufacturer Pratt \& Whitney).

The empirical evidence of successful system transition is ample. On the output side, Figure 6.1 shows the production cycles of major new products: the EMB-110 Bandeirante 19-seat commuter plane, the EMB-312 Tucano (single-engine military basic

${ }^{104}$ An air force pilot, ITA (and later Caltech) graduate aeronautical engineer, founder and president of Embraer (1969-86), who also played a key role in its privatization in 1994. 
trainer), the EMB-121 Xingu (a pressurized executive twin-turboprop), and the EMB120 Brasilia (a pressurized 30-seater twin-turboprop commuter). Figure 6.2 shows the increase of sales revenues of Embraer (to a historical maximum of 924 million USD in 1989) and the growth of exports (nearly two-third of sales revenues by mid-1980s; growing to 486 million USD in 1989). This shows that Embraer's strategy of aiming at the commercial commuter market ${ }^{105}$ paid off, especially after the liberalization of the US market. In 1981, Bandeirante had a 37.8\% share in the 15-19 seat segment (Sarathy 1985). Brazilian aerospace value added grew to 220 million by 1980 and 790 million USD by 1989. This growth is especially remarkable when contrasted to the global industrial landscape, shaken by the oil crisis of 1973. Brazilian growth in aerospace was nearly 10-times the growth of the global industry (in capitalist economies) during the 1970s. Even after the start-up decade, the 258\% expansion of production between 1981 and 1989 still overshadows the global average expansion of 122\% (and 125\% of the USA), providing a clear evidence of catch-up (Figure 6.3).

Figure 6.3 Trends of catch-up: aerospace value added of Brazil, China and Indonesia compared to the US, 1970-2007 (\%)

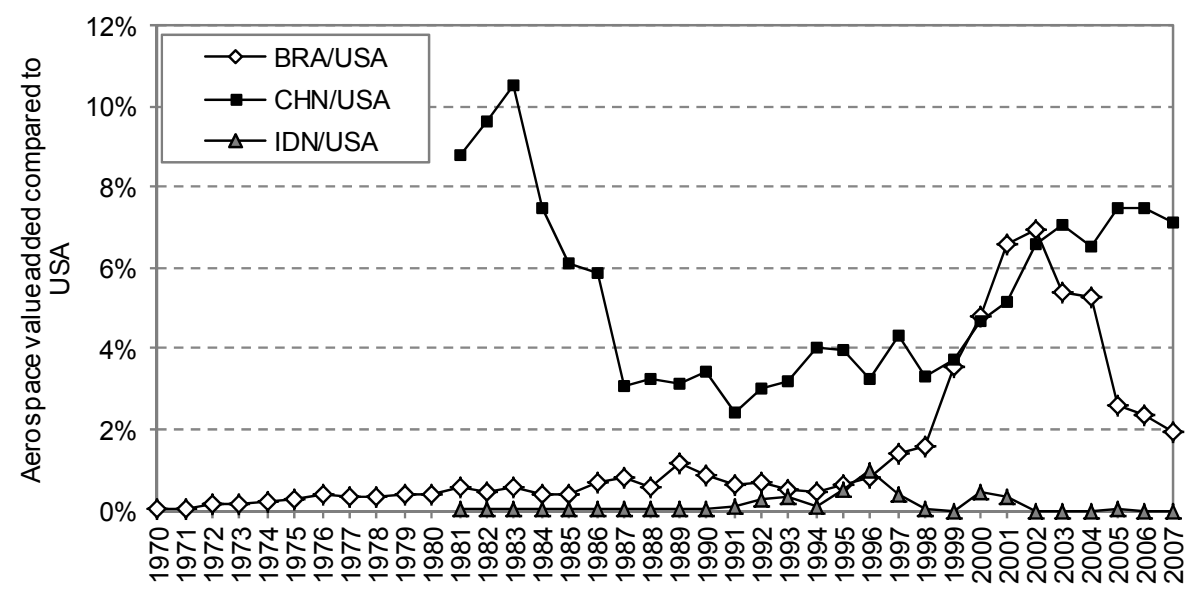

Sources: Chinese National Bureau of Statistics, IBGE, UNIDO. See Appendix A.1.

We argue that the emergence of the innovation system and its institutional set-up was a necessary precondition for the accelerated growth of the industry. We do not debate the crucial role of Embraer's management in successful formulating and executing a sound

\footnotetext{
${ }^{105}$ Already at the development of the Bandeirante, US FAA guidelines were fully observed to facilitate certification, which is essential for exports. Airworthiness certificate was given by France in 1977, by the UK and the US in 1978. Feedback from regional airlines and other users was considered seriously for the development of subsequent models.
} 
strategy for increased sales performance and growth. However, the physical and human resources and the general institutional arrangement for performing innovative activities were available before the creation of Embraer. The government and other systemic actors provided key elements such as an affordable supply of skilled labour, R\&D activities (results of which Embraer commercialized), openness to foreign technological sources, military procurement to support new aircraft development, export credits and protectionist trade policies.

The establishment of Embraer as a state-owned enterprise ${ }^{106}$ was the final institutional innovation in the formative phase of the sectoral system of innovation (SSI). A national champion allowed Brazil to reap the benefits of an already existing SSI and to set the forces of innovation in motion. It was a necessary condition for the increase of innovative performance, since much of the tacit knowledge required for competitive production based on up-to-date technology needed to be acquired through 'learning by doing'.

State ownership did not preclude the Embraer management from governing certain functions of the innovation system. The successful emergence of the Embraerchampioned aircraft industry in Brazil - what Ramamurti (1987) aptly refers to as a combination of public power and private initiative - was in fact the result of shared governance of the innovation system. Following the typology of Hekkert et al. (2007), certain functions such as 'knowledge development' and 'knowledge diffusion' were shared between CTA and Embraer's R\&D departments or foreign sources. 'Guidance of search' for new technologies and 'market formation' were jointly influenced by the marketing strategy of Embraer and the procurement policies of the Air Force and the Aeronautical Ministry. The government played a decisive role (especially at the beginning) in 'resource mobilization' (including capital, skilled labour and technology). Embraer (and other smaller companies) provided 'entrepreneurial activities' for the system. ${ }^{107}$

This governing structure remained in place until the next major transition of the SSI. Over the years as production increased smaller adjustments were made in the institutional framework (often to meet the needs of Embraer). This indicates an incremental 'co-evolution' of technology, institutions and organizations. However, the performance of the innovation system increased and so did its size, without any significant trend break.

\footnotetext{
${ }^{106}$ State ownership was a last resort to overcome the lack of private venture capital (Silva 2002)

${ }^{107}$ It is an interesting problem whether the emergence of a system broker was a historical accident or whether it was a product of the system. We argue that the more advanced the educational and research organizations are in the system, the higher the chances for entrepreneurs to emerge.
} 


\subsubsection{The Crisis of 1990-94}

The period 1990-94 marks the second crisis of the Brazilian aircraft industry. While global recession caused value added for the global aerospace industry to decline by $30 \%$, Brazil was hit more severely. Sales plummeted by some $75 \%$ and exports by $80 \%$ from the level of 1990. Figure 6.1 does not only reveal the reduced production of the EMB120 Brasilia, but also shows that there was a gap during which no new aircraft was introduced to the market. This therefore indicates a crisis of the innovation system. ${ }^{108}$

The primary cause of the crisis was a daunting lack of financial resources. The preceding years saw the end of the military dictatorship and a financial and economic crisis in Brazil. The previous practice of financing new product development with government launch support was no longer an option. Financing R\&D for a new regional turboprop plane from own resources was beyond the capacity of the heavily indebted Embraer, and collaboration with the Argentinean FAMA turned out to be too costly. By 1994 R\&D expenditures of Embraer exceeded 30\% of its sales (Figure 6.4). The company had to reduce its workforce to less than half the 1989 levels.

Figure 6.4 R\&D Expenditure and R\&D intensity of Embraer, 1983-2007

(Million USD at constant $=2000$ prices)

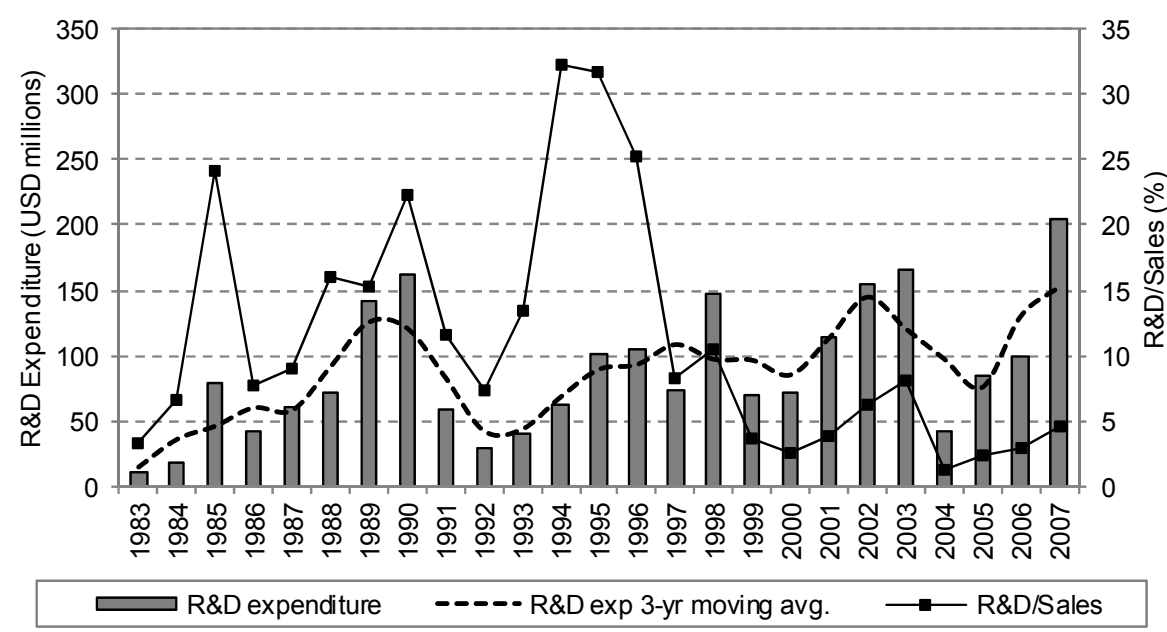

Source: own compilation based on Embraer annual reports and Frischtak (1992)

The survival of the production and innovation system was at stake. A more than $40 \%$ drop in patenting by foreign companies marks a significant lack of trust in the Brazilian SSI (Figure 6.5). Although patents are not the most appropriate measure of

\footnotetext{
${ }^{108}$ See Frischtak (1992) for a comprehensive analysis of the crisis.
} 
innovativeness in the aerospace industry ${ }^{109}$, the trend of foreign companies patenting ${ }^{110}$ in Brazil is a crude indicator of technology flows and technological learning in the innovation system. Given a strict intellectual property regime, foreigner's patenting activity reflects their estimation of local technological capabilities. During the 1980s nearly 40 patents a year were added to the stock (Figure 6.5), followed by a sharp, fouryear interruption.

Figure 6.5 Number of patents in the field of aerospace granted by year of application (19742007)

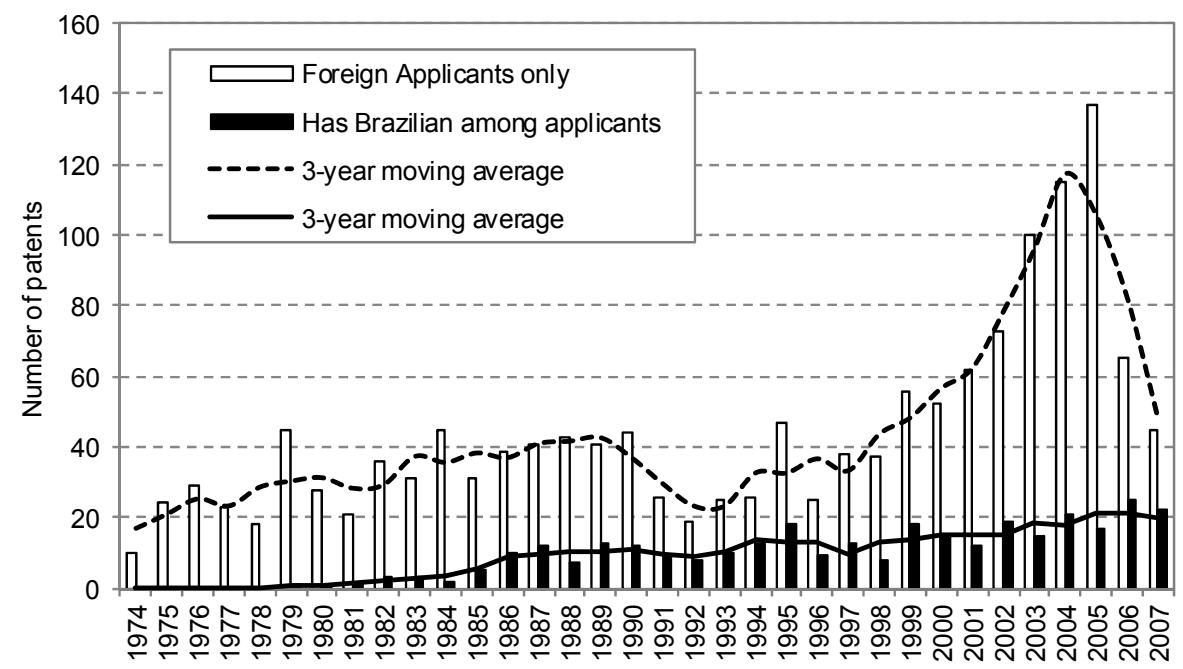

Source: Brazilian Patent Office via Esp@cenet

By that time, the technological challenges of aircraft manufacturing changed from priorities of fuel efficiency to cost reduction in all operational aspects, noise reduction and capacity increase (Sehra and Whitlow Jr 2004). The global industry had already introduced new ways to cut costs. These included the geographical expansion of supply chains and sharing development costs with component manufacturers, and the development of aircraft families with high commonalities between the different models produced. Embraer still vertically integrated all design and production phases and

\footnotetext{
${ }^{109}$ Patents are less important as indicators of innovative performance in the aerospace industry as compared to other high-tech industries such as biotech, since innovations are preferably protected by secrecy (Niosi and Zhegu 2005), which is a quite efficient given the high capital barriers.

${ }^{110}$ We distinguished patents in aerospace (classification B64) filed at the Brazilian patent office by the nationality of applicants. The two groups are: all-foreign, where there is no Brazilian applicant, and the rest, where there is at least one Brazilian applicant. Note that change in the trend can also be caused by an overall change in innovative performance of foreign firms.
} 
performed R\&D activities in too many different directions (Frischtak 1992). In short, following an external political and macro-economic shock the Brazilian aerospace industry lost its competitive edge and the innovation system was not able to help it regain.

\subsubsection{A radical change in the Brazilian sectoral innovation system}

The solution to overcome the crisis was a change in ownership that fundamentally altered the pattern of interdependencies in the sectoral innovation system. In 1994 Embraer was privatized to a consortium of Brazilian enterprises and pension funds, led by the Bozano Simonsen Group, while the government retained a "golden share" and a seat on the board of governors. ${ }^{11}$

Although the government did not use military procurement for launch support, it continued to fund part of Embraer's R\&D activities and exports ${ }^{112}$ (through FINEP, the Brazilian Economic and Social Development Bank (BNDES) and Banco do Brasil). At the same time, spin-off enterprises (with former Embraer employees) joined the local supply chain. Privatization resulted in capital injections as well as greater flexibility to sign partnership agreements to jointly develop a family of regional jets. But the most important organizational innovation to regain competitiveness was the creation of a system of risk-sharing partnerships (see Cassiolato et al. 2002; Marques 2004; Goldstein 2002a; Figueiredo et al. 2008). This was already the common practice of leading aerospace producers in Europe and the US who realized the need to cut costs by focusing on core competences and sharing R\&D costs with component suppliers. Adoption of this new form of organization allowed shorter lead times due to parallel manufacturing, but also ensured that Embraer applied the latest technologies, given the fact that many of its partners were suppliers of the leading global producers. Embraer thus changed redefined its core competence as aircraft designer and system assembler. At the same time, this posed new challenges for other companies in the sector, who needed the capital and technology to compete with major foreign parts and components suppliers to win long-term contracts.

The hallmark of the new period is the realization of the ERJ-145 regional jet program. It was already underway from the end of the 1980s, with numerous changes in designs. Interest in the design of a regional jet was already high at the 1989 and 1991 Le Bourget air shows. The project could not have been financed without privatization of

\footnotetext{
${ }^{111}$ The former founding CEO of Embraer, Silva was instrumental in the privatization of the company. As he noted in an interview (Silva 2009) that the company was not intended to be sold to foreign competitors and in many cases, personal relations helped convince investors.

112 The PROEX export financing scheme was contested in a WTO trade dispute by Canada, but after the settlement a slightly modified version still remains in place (Goldstein and McGuire 2004).
} 
Embraer and without four foreign companies, Gamesa (Spain), ENAer (Chile), Sonaca (Belgium) and C\&D Interiors (USA) teaming up as risk sharing partners. ${ }^{113}$ The plane completed its first flight in August 1995 and was first delivered to ExpressJet in the US (the regional division of Continental Airlines). The US had been the biggest market for the ERJ-145s. The relatively low price, low operational and maintenance costs combined with the export financing scheme offered by BNDES and Banco do Brasil made the planes especially competitive over Bombardier's CRJ series regional jets. The direct export financing and interest equalization program triggered harsh criticism by Bombardier that escalated to an intergovernmental trade dispute in 1996 between Canada and Brazil at the WTO. ${ }^{114}$

Embraer made use of the family concept and introduced shorter versions of the ERJ-145. The 37-seater ERJ-135 only differed in fuselage length. This latter model also appeared in a business jet configuration as Embraer Legacy. A transport model, an airborne early warning model and a remote sensing and a maritime patrol model were also introduced and sold to military operators on three continents. The high degree of communality allowed for reductions in design and certification time, in production costs as well as costs for training flight crew and operations for airlines. The ERJ-145 family has sold with huge success; over a thousand planes have rolled out in little more than a decade.

It did not take Embraer long to start on the development of a family of even larger sized regional jets, the ERJ-170/190s, serving the 70-110 seats range. (Embraer's marketing experts developed the "rule of 70/110", the important commuter market underserved by other producers.) The idea of risk sharing partnerships was at the core of this program as well, with an even higher degree of integration and sophistication of strategic partners. The planes were truly co-designed by the partners, with Embraer taking a $45 \%$ stake in the project, and the rest taken by the 16 partners chosen in a competitive selection process. One of the biggest partners was GE, the producer of engines (a package worth around $20 \%$ of the plane price). Honeywell (a GE subsidiary by now) was responsible for avionics, Gamesa of Spain for the tail section and rear fuselage. Liebherr supplied the landing gear and Kawasaki Heavy Industries of Japan was in charge of parts of the wing control surfaces made using composite materials and

\footnotetext{
${ }^{113}$ Gamesa was responsible for the production of the wings, engine nacelles, fairings of the wing and fuselage junction and the doors of the main landing gear; Sonaca for the production of the luggage, service and main doors on the fuselage, a front and rear section of the fuselage and the two motor pylons; ENAer produced the horizontal stabilizers and rudder controls; C\&D Interiors designed and produced the interior of the passenger cabin and luggage compartment. For a visual depiction of division of labor, see Cassiolato et al. 2002, Fig.1, p.31).

${ }^{114}$ For a details recount of the "export subsidies saga", see Goldstein and McGuire (2004).
} 
pylons. Indicating the efficiency with which Embraer engineers and management have "learned" to benefit from risk sharing partners, the project phases have progressed tightly according to schedule. The preliminary studies, partner selection, joint definition and development phases all involved intensive interactions between the partners, facilitated by the use of software allowing entirely digital design and data sharing and utilization of a Virtual Reality Center. These changes not only raised the level of technological precision, but also significantly reduced development time and costs. The 80-seater ERJ-170 first flew in February 2002. After a two-year certification process, the first plane was delivered to LOT Polish Airlines. A slightly stretched version with 88 seats, the ERJ-175 was introduced a year later. Another step forward was the launch of the ERJ-190 program in 2004. The first 110seater ERJ-190 flew in 2004, followed by the 122-seater ERJ-195 a few months later. The American low-cost carrier JetBlue became the launch customer with an order of 100 and option for another 100 planes. The 190/195 planes have a longer redesigned wing and greater engine thrust. With these planes Embraer has directly become a competitor of the larger plane makers Airbus and Boeing, challenging their smallest models (the A318 and the B717 and 737-600s respectively).

Additionally, a fleet of business jets complemented the product list available from Embraer: the Lineage jet is an ERJ-190 with redesigned interior, while the Legacy 600 is based on the ERJ-145, with increased range and performance. There is a new family under development: the smaller Legacies are newly made mid-light jets whereas the Phenom 100 and 300 are (very) light jets in production since 2007 and 2008. Table 6.2 provides a historical overview of the aircraft produced by Embraer over 40 years.

Embraer has been expanding its capacity; apart from the original plant ('Faria Lima') at the airport of Sao José dos Campos (near CTA/ITA), Embraer opened another site in Eugenio de Melo in 2001, specializing in the development and manufacture of tools and tubing, welded and forged parts, as well as large cabling projects. This site also hosts a school for the Engineer Specialization Program, a postgraduate, in-house interdisciplinary training for future aircraft designers. Another location, opened also in 2001 in the State of Sao Paulo is the newly developed Gaviao Peixoto plant where the planes for the defense and executive markets are assembled. Neiva's previous facility near the city of Botocatu is the third manufacturing center in the state. The most important aerospace cluster nevertheless remains Sao Jose dos Campos, home to most of Embraer's suppliers in the lower tiers, many of them spin-off of CTA or Embraer. Apart from the CTA-developed technology commercialized through the establishment of a new company, the streamlining of Embraer's activities resulted in a number of employees creating their own company as service providers on the second or third tier. 
Table 6.2 The main products of Embraer

\begin{tabular}{|c|c|c|c|c|c|c|}
\hline \multirow[b]{2}{*}{ Type (first flight) } & \multicolumn{2}{|c|}{ Production } & \multicolumn{4}{|c|}{ Specification } \\
\hline & Years & $\begin{array}{l}\text { Total nr. } \\
\text { produced }\end{array}$ & $\begin{array}{l}\text { Seats } \\
\text { (max) }\end{array}$ & $\begin{array}{c}\text { Range } \\
(\mathrm{nm})\end{array}$ & $\begin{array}{l}\text { Maximum } \\
\text { Speed (kts) }\end{array}$ & Altitude (ft) \\
\hline EMB-110 Bandeirante (1968) & $1972-90$ & 500 & 19 & 1,060 & 250 & 22,500 \\
\hline EMB-200 Ipanema agro (1970) & $1972-$ & $1,000+$ & 1 & 330 & 120 & 11,400 \\
\hline EMB-326 Xavante fighter & $1971-83$ & 181 & 2 & 900 & 436 & 41,000 \\
\hline EMB-121 Xingu(1976) & $1977-87$ & 141 & 9 & 1,270 & 250 & 26,000 \\
\hline EMB-312 Tucano (1980) trainer & $1983-98$ & 320 & 2 & 1,000 & 242 & 30,000 \\
\hline EMB-120 Brasilia (1983) & $1985-98$ & 330 & 30 & 550 & 300 & 32,000 \\
\hline AMX (1984) fighter & 1989-99 & 56 & 2 & 1,800 & 626 & 43,000 \\
\hline ERJ-145 (1995) & 1996- & 1 & 50 & 1,320 & 450 & 37,000 \\
\hline ERJ-135 (1998) & 1999 & 1,215 & 37 & 1,430 & 450 & 37,000 \\
\hline ERJ-140 (2000) & $2001-$ & 1 & 44 & 1,630 & 450 & 37,000 \\
\hline ERJ-170 (2002) & 2004- & 1 & 80 & 2,100 & 481 & 41,000 \\
\hline ERJ-175 (2003) & $2005-$ & 1 & 88 & 2,000 & 481 & 41,000 \\
\hline ERJ-190 (2004) & $2005-$ & 002 & 114 & 2,400 & 481 & 41,000 \\
\hline ERJ-195 (2004) & $2006-$ & 1 & 122 & 2,200 & 481 & 41,000 \\
\hline Phenom 100 & $2008-$ & 170 & 6 & 1,200 & 390 & 41,000 \\
\hline Phenom 300 & 2009 & 110 & 8 & 1,970 & 453 & 45,000 \\
\hline
\end{tabular}

Source: own compilation based on Embraer.com, Frischtak (1992), Ramamurti (1987)

Notes: number produced as of Q3 2010; includes commercial, executive and defense sales.

The results of these institutional changes were remarkable. Between 1994 and 2000 sales rose on the wings of the ERJ-145 regional jet family from less than 200 million to over 2.8 billion US dollars, more than $97 \%$ of which came from exports. Value added increased to 2.3 billion USD (Figure 6.6). But while Embraer's absolute R\&D expenditure increased, the $\mathrm{R} \& \mathrm{D} /$ Sales ratio decreased from over $30 \%$ to less than $5 \%$ (Figure 6.4), even though Embraer was developing a new family of planes. The larger E170-190 product line can accommodate up to 120 passengers making Embraer a direct competitor of Airbus and Boeing in their smaller product lines. Embraer introduced over a dozen new models of regional and executive jets since the system transition and became third largest manufacturer of jet aircraft worldwide in terms of delivery. 
Figure 6.6 Aerospace industry Value Added in Brazil, China and Indonesia, 1970-2007 (Million USD at constant $=2000$ prices)

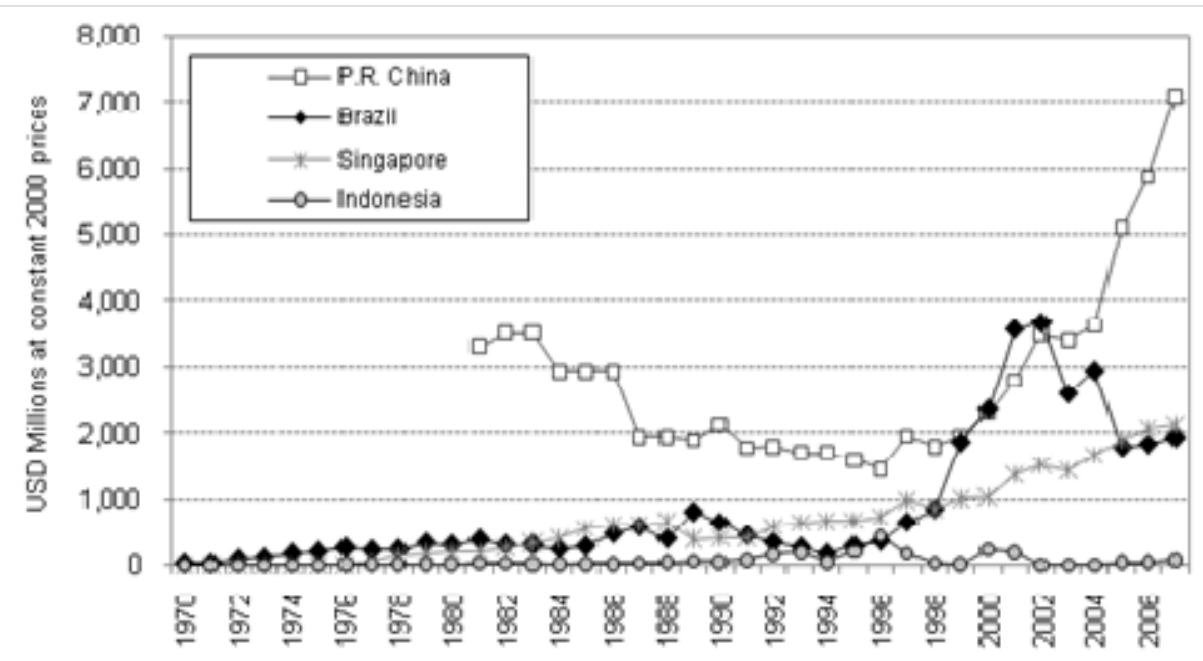

Source: Brazil: IBGE yearbooks, China: CNBS yearbooks, Indonesia: UNIDO yearbooks.

Note: The following industry-specific conversion ratios were applied (updated or backdated to 2000): BRL/USD: 1.09 (see Chapter 4); CNY/USD: 4.6 (Szirmai et al. 2005); IDR/USD: 4201 (Stuivenwold and Timmer 2003).

\subsubsection{A new transition?}

Companies in the Brazilian supply chain benefited from the growth during the late 1990s. However, the share of Brazilian content decreased with the new product line and between 2002 and 2005 value added fell back to 2 billion USD. ${ }^{115}$ There are several signs of shortcomings of the SSI that may signal some further changes, albeit less fundamental than those in the 1950-60s or in 1994.

The Brazilian aerospace industry recovered from the post-9/11 demand shock relatively rapidly. However, the crisis of 2008-09 showed greater vulnerability of an industry dependent on regional and executive jets. The relatively outdated technological capabilities, the lack of sufficient credit lines and venture capital make it difficult for local SMEs to become competitive and join global supply chains as risk sharing partners (ABDI 2009). To boost the competitiveness of local SMEs is a major concern for the government. There is a growing consensus about the need to modernize the education and training system, to support innovativeness through new aircraft development and procurement policies or offset agreements targeting the supplier chain to create a

\footnotetext{
${ }^{115}$ For a discussion of trends in value added and labour productivity, see Chapter 4.
} 
globally competitive center of excellence in aerospace. ${ }^{116}$ As a first response, in 2009 the government officially commissioned Embraer to development a military transport and tanker aircraft (the K/C-390).

In the meantime, the global competitive landscape is changing and new planes need to be even more fuel efficient to reduce operations costs and greenhouse gas emissions. The latest large civilian aircraft designs use composite materials at an unprecedented scale, in which Embraer is lagging behind. ${ }^{117}$ The cost share of avionics in a new aircraft has reached unprecedented heights. Brazilian companies in these two rapidly growing technology domains have no frontier capabilities to offer for foreign system assemblers. In the regional aircraft market new players (including Comac in China, the Russian Sukhoi and Mitsubishi in Japan) have made significant investments to break the Bombardier-Embraer duopoly. Thus the competitiveness challenge might call for a new innovation system transition.

We have yet to see major institutional changes in the Brazilian innovation system. What changed after the crisis was the launch of the military transport project which indicates a replacement of commercial investments with (potentially in the short term) public investments (to be phased out by export to the military market in the long run).

\subsubsection{Interrupted innovation in the Brazilian aerospace industry}

The overview of the history of the industry helped us identify historical turning points of interruption, crisis and transition. Such turning points (often not single moments but periods lasting several years) are the post-WWII crisis in the early 1950s, the creation of Embraer in 1969, the interruption following the financial crisis in 1989-90 and the transition connected to the privatization of Embraer in 1994. Using the interrupted innovation framework developed in chapter 5 , the changes in innovation system size and performance are charted in Figure 6.7.

\footnotetext{
${ }^{116}$ Clearly indicated by recent detailed, comprehensive studies, see ABDI (2009) and Montoro and Migon (2009).

${ }^{117}$ When deciding for the use of composite materials, there is of course a tradeoff between production and spare-parts costs and operating costs.
} 
Figure 6.7 The interrupted trajectory of the development of the Brazilian aerospace industry (1930s-2007)

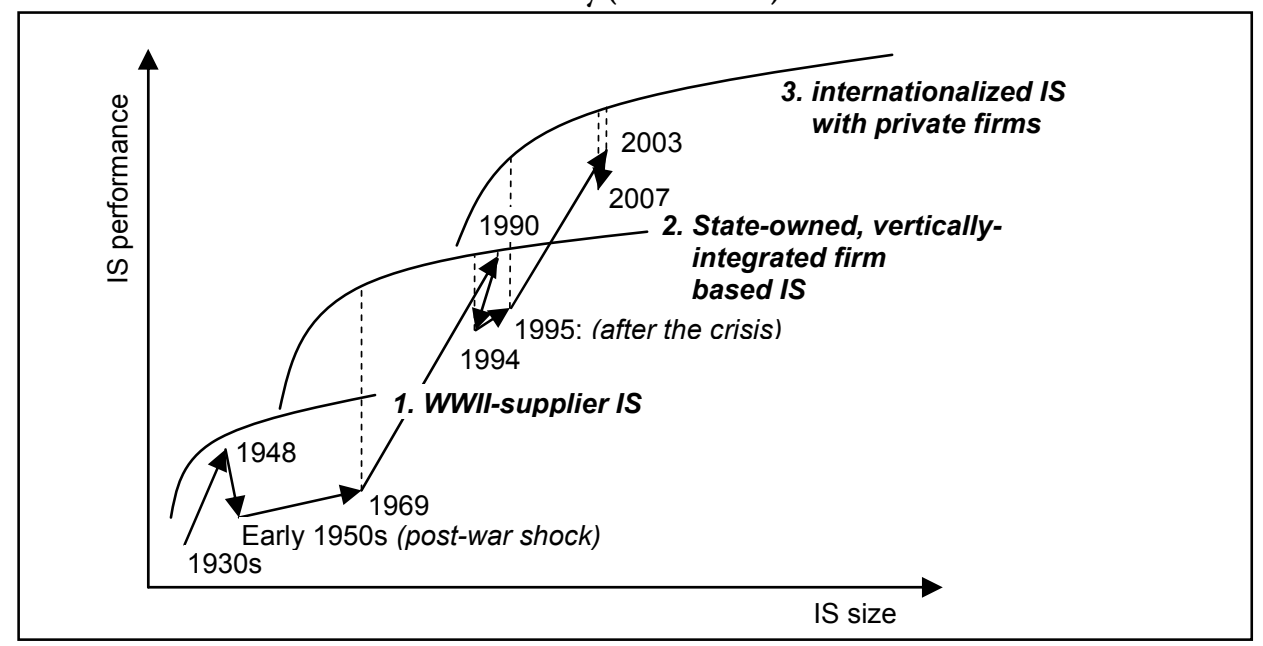

(Author's compilation)

1. From the 1950s until 1969, the growth in size of the system exceeded its performance growth, although both were positive. Size expanded due to technology inputs from foreign designers and the work of CTA and new skilled labor inputs from ITA. The performance increased owing to a few new designs, but as production was limited to a few small planes, we assume that less process innovation took place.

2. A transition to another innovation system was finalized in 1969. A state-owned company was created that specialized in commercial and military aircraft development, production and marketing. Embraer became the single most important corporate actor in the system receiving most inputs into innovation.

3. From 1969 and 1990, both the size and the performance of the system increased hugely. (This trend is not linear. The figures presented earlier showed that R\&D, employees, new products, patents, and sales fluctuated from year to year.) Based on the relatively high global market share of two of Embraer's commuter aircraft, we conclude that the performance of the innovation system was close to its frontier. ${ }^{118}$

4. The interruption between 1990 and 1994 is evidenced by the decrease in system size (due to decrease of R\&D expenditures, employment and increase of debts) and performance (lack of new patents, new product sales or new process innovation). It

\footnotetext{
${ }^{118}$ See Marques 2004 for more details on the system.
} 
became clear to the major actors that a return to the old system of innovation would be insufficient to sustain competitive advantage.

5. After 1994, both the size and the performance of the innovation system grew at an unprecedented rate, made possible by a transition to a new system based on strategic alliances in $R \& D$ as well as in production, which allowed the input of frontier technologies from the best global suppliers. The increase in size and performance was once again not linear (with a significant break in 2002-3), but overwhelmingly the trends were positive.

6. The 2003 drop in value added indicates a new crisis in the industry. This primarily concerns companies other than Embraer (which still increased sales and export until 2007). However, Embraer's R\&D intensity remained at a low level. Until now, no fundamental institutional changes have occurred. 


\subsection{CHINA: The long march to a civilian aircraft industry}

\subsubsection{Introduction: from military to civilian innovations}

After entering into military aircraft manufacturing in the 1950s with the assistance of the Soviet Union, China developed capabilities to produce and modify similar fighter jets, bombers and light transport aircraft. A defense-oriented innovation system was established in the 1960s and dominated the industry until the 1990s with a relatively low level of performance. With the opening up of China and the expansion of the market economy, firms of the Chinese aeronautical conglomerates joined global supply chains as manufacturer of commercial aircraft parts and components for western producers, including Airbus and Boeing. During the last decade foreign manufacturers (Embraer, Airbus) brought final assembly work to China and a Chinese company (Comac) designed and produced a prototype of a regional jet.

The emergence of the aircraft industry and innovation system and the transition from a defense-oriented, local modification based to a dualist defense- and commercialoriented innovation system followed a very unique development trajectory. In this case study we focus on the emergence of a defense aircraft industry, its crisis and the slow transition that started in the late 1980s. The opening up of the military-industry complex (MIC) and the expansion of civilian production brought along fundamental institutional and organizational changes in an aerospace industry that employed over half a million people in the late 1990s and which is the largest among the emerging economies today.

\subsubsection{The emergence and fall of a Soviet enclave in China (1950s)}

The origins of aircraft manufacturing in China are connected to the Korean War. The People's Republic of China entered the Korean War in 1950 with virtually no air force. The Soviet Union had a relatively advanced air force but did not wish directly to send planes to the war. Instead, Stalin made an offer to China to repaint the most advanced Soviet fighter jets, the MiG-15s into the colors of the Chinese Air Force. The conflict provided the Soviets with an opportunity to test the planes in combat and to learn about the capabilities of the United States. The MiGs proved to pose a significant threat to United States-United Nations bombers and fighters in the North Eastern part of Korea which earned it the name of "MiG Alley". ${ }^{119}$ The first aircraft factories in China were repair facilities built and run by Soviet engineers and experts, located in Manchuria close to Korea. Over 800 Soviet engineers and specialists were sent to Shenyang to

\footnotetext{
${ }^{119}$ These were the first jet "dog-fights", between MiG-15s and the F-86 Sabres of the US Air Force.
} 
establish capabilities for repairing and assembling MiG-15 jet fighters ${ }^{120}$. At the beginning of the decade China received around 800 of these planes in form of Soviet aid. A trainer version of this aircraft was subsequently produced in Shenyang, known as the $J J-2^{121}$. There are no reliable figures ${ }^{122}$ for the production and repair capacity of the plant, but over five hundred MiGs are estimated to have been repaired there.

The local capabilities in China were lagging far behind in comparison to the advanced technology brought to Shenyang. It was lacking aircraft engineers, technicians, and even pilots. The facilities were managed by the Soviet experts. Knowledge exchanges were rather limited, partly due to strategic reasons, but also due to a lack of absorptive capacities. The effects of technological learning can only be measured indirectly. First, based on the number of Chinese-Soviet aircraft flying in Korea and requiring maintenance or serious repair, it is fair to assume that there were substantial opportunities to gain assembly, repair and overhaul capabilities through "learning by doing". This was sufficient at least to make some advances in local capabilities and to start licensed production. The first real fighter jets built in China were the successors of the MiG-15s. The Shenyang plant acquired a license to produce the MiG-17s, or J-5s according to the Chinese designation. The industry experience rapid improvements in its production capabilities. According to CIA estimates, the delivery of the first J-5 planes in 1957 was followed by around 120 planes the next year and over 150 planes in $1959 .{ }^{123}$ In the meantime, Soviet technology advanced at a fast rate and the MiG-17 that was entrusted on Shenyang was not the most advanced model of the Soviet Mikoyan-Gurevich bureau. The supersonic MiG-19 and MiG-21 blueprints were only offered to China with a few years delay.

A parallel production center was set up in Nanchang in South-West China. This plant specialized on transport planes and helicopters. The first model of the Y-5, a small piston transport plane, copy of the Antonov An-2 was built in 1957, followed by 56 in 1958. Until 1961, almost 150 Y-5s had been manufactured ${ }^{124}$. China also acquired a license to produce the Tu-16 bomber in Xian, as the H-6 under local designation,

\footnotetext{
${ }^{120}$ The MiG-15s have already illustrated that technological information knows no borders. These planes were powered by the exact copies of the British Nene jet engines that have been exported to the USSR two years earlier with the hope of the British government that the USSR is far from ready to produce such an advanced technology (Engel 2000, p.49).

${ }^{121}$ Some sources question whether any versions of MiG-15s were produced at that time (Eriksson 1995). SIPRI (2008) estimates the acquisition of the license in 1955 and the delivery of about 150 between 1959 and 1961.

${ }^{122}$ The various sources used for the history of military production include SIPRI (2008), Eriksson (1995), $<$ http://www.sinodefense.com> (retreived: March 2009), and interviews with unnamed Chinese experts.

${ }^{123}$ CIA 1959, Quarterly Estimate of Production of Aircraft in the Sino-Soviet Bloc July-September. $<\mathrm{http}: / /$ www.foia.cia.gov> (retreived: March 2009).

124 CIA 1959, Quarterly Estimate of Production of Aircraft in the Sino-Soviet Bloc July-September. $<$ http://www.foia.cia.gov> (retreived: March 2009)
} 
although serial production did not start until 1968. Observers were impressed by the rapid pace of development: a country with no experience in serial aircraft manufacturing at the beginning of the 1950s appeared to have learnt to produce a jet fighter and a piston aircraft in just a few years time and was also starting to produce helicopters (Mi-4s) by 1959.

The industry's actual production activities were organized within a number of "Machine Building Industries" (MBIs), of which Aviation Industries at Shenyang, Nanchang, Shanghai (and later also at Harbin and Xian) constituted the Aviation group and a separate one was created for rockets and spacecraft. Initially, there was a division of labor based on uses of aircraft. Shenyang was the primary site for fighter production, complemented later by a new plant in Chengdu. The Xian factory was responsible for bombers and transport planes. The primary source of finance for these MBIs was the People's Liberation Army (PLA). However, the State Council shared supervision of the industry with the PLA in unclear division of responsibilities. The State Council exercised its control through the National Defense Science and Technology Commission, the PLA's parallel office was the National Defense Industry Office. A coordination body was set up which was also a center to supervise the industries and to decide on strategy and direction of R\&D.

During the Sino-Soviet split it became clear that the Chinese aircraft industry was over-reliant on Soviet technologies. In 1960, China's relations deteriorated with the Soviet Union up to a point that Moscow decided abruptly to withdraw almost its entire technical assistance staff from China. Aircraft production projects in Shenyang and Nanchang were not the only complex technological projects affected, another such project was the construction of the Three Gate Gorge dam on the Yellow River. In most cases Soviet staff returned home not only taking their "tacit knowledge" with them, but also the codified blueprints for production. Production was suspended at the aircraft plants and it took years before it could resume. The technicians' sudden departure revealed the lack of an indigenous Chinese aerospace innovation system.

The recovery after the split was slow as there were not enough established institutes that could have "stored" the required knowledge. Of course, not all of the capabilities were lost because some organizations had been formed that became the backbones of an innovation system. The Beijing Aeronautical College was established in 1952 and basic scientific research related to aerodynamics had predated that. There is evidence of a growing Chinese scientific and engineering staff at the aeronautical plants in Shenyang or Nanchang, although their size is unknown. In any case, the effects of the interruption are striking. The Chinese staff had to reverse-engineer the planes and to reinvent the production processes. It took two years in the case of the less sophisticated 
Y-5 light transport planes and the almost five years for the first MiG fighter jet variations to resume production after the shock. In 1963 and 64, there were virtually no new planes produced. The H-6 bomber production in Xian resumed only in 1968.

One of the reasons for the setback of the military aircraft industry was that China was focusing its technological efforts on the development of the space and nuclear programs. In Mao's view this could potentially guarantee China more security in a time of increased nuclear armament. China also had a long history in rocketry, although only at low altitudes. There was active collaboration with the Soviet Union in astronautics (China received a soviet 'R-2' rocket and student training in Moscow), so these programs were also interrupted following the Sino-Soviet split. Although Mao was keen on demonstrating China's capability to launch rockets within weeks after the departure of Soviet experts, these were only a short range Soviet R-2 rocket and a Chinese copy (DF-1). A medium range version of this (DF-2) first failed in 1962 and was only launched successfully two years later.

\subsubsection{A defense-oriented sectoral innovation system}

\subsubsection{Legacies of the Military-Industry Complex (MIC)}

China at its peak in the late 1970s was estimated to produce over 400 aircraft a year (see Figure 6.8). But despite the large quantities, Chinese military aircraft technology maintained at least a generation's lag compared to the benchmark Soviet frontier technology, due to difficulties in acquiring the required technologies (Frankenstein and Gill 1996). Chinese design and production plants had to substitute the previously available Soviet technology through reverse-engineering after the 1961 Sino-Soviet split. The military-industry complex, created but also hindered by national security concerns, has never emerged as a fully functional sectoral innovation system. Unlike in Brazil where the aerospace industry concentrated around the single Sao Jose dos Campos cluster, at least a dozen centers involved with aeronautical $\mathrm{R} \& \mathrm{D}$, maintenance and production work were created all over China. The most important production facilities were located in Shenyang and Harbin in the northeast, Chengdu in the southwest, as well as around Shanghai, Xian and Taiyuan. Aircraft factories oversaw hundreds of enterprises and also produced non-aviation products to utilize idle capacity. Productivity was not a major concern for the division of labor between these factories and multiplication of tasks was common due to lack of linkages between parallel projects. The organization of the industry showed a 'satellite pattern', decisions were made in Beijing and there was little interaction among the facilities.

Supervision and coordination of $\mathrm{R} \& \mathrm{D}$ and production activities was the responsibility of the Commission on Science, Technology and Industry for National 
Defence (COSTIND), a body reporting both to the PLA as well as to the State Council. The only source of finance was the government (the Military or State Council), and the expenditures on various projects remained concealed. The production cycle of military aircraft is clearly influenced by political events (Figure 6.8).

While research and engineer training was located around the production facilities, university level education in disciplines related to aerospace were offered in Beijing (BUAA) and Nanjing (NUAA).

Over these inward-looking years Chinese plants developed significant technological capabilities to introduce mostly "new-to-the-country" innovations based on reverse-engineering and local development efforts. The MiG-19 served as the base of two planes: the Shenyang J-6 fighter and the Nanchang Q-5 ground attack aircraft. The J-6 shows little difference from the Mig-19s and was already introduced before the SinoSoviet split. This supersonic fighter jet was originally designed with a rather short operational life and Mikoyan administration in the Soviet Union replaced the Soviet version very soon. But in China the older version was the most advanced model fully available at the time of the split and this model was produced in great numbers in Shenyang ${ }^{125}$. A redesigned, ground-attack version of the MiG-19 included modifications such as a longer fuselage, larger wings, an internal weapons bay able to accommodate even nuclear weapons; air intakes put to the sides but fitted with the same "Liming Wopen" turbojet engine (a copy of the Soviet Tumansky). This model could reach higher altitudes, but lower speeds than the MiG-19. The prototype was already completed in 1960 in Shenyang. However, the project was moved to Nanchang in 1963 after loss of political support. It first flew in 1965 and series production started in 1969. About a thousand planes were built and a few were exported (as A-5s) to Pakistan, Bangladesh, Myanmar and North Korea.

The J-7 fighter jet was based on the Soviet MiG-21. Initially, the technology was intended to be transferred to China, but the political split affected this project as well. However, after two years, a new deal was signed in 1962. Some kits and parts were indeed delivered, but some of the documentation was missing and Chinese engineers had to fill in the gaps with a number of technical solutions until the plane could commence its first flight in 1966 (at which time the Cultural Revolution caused further delays.) Series production started only in 1980; more than 2,400 planes were produced over 25 years. Despite its older technology (the Soviet MiG-21 production ended in 1985), the J-7 (or F-7, according to its export name), became a rather successful model, owing much to the successful design of the original MiG-21 and the relatively lower

\footnotetext{
${ }^{125}$ About 3000 planes are believed to have been built between 1958 and 1981.
} 
price China asked. The J-6 and J-7s were China's most successful export models. It is estimated that around $680 \mathrm{~J}-6 \mathrm{~s}$ and $520 \mathrm{~J}-7 \mathrm{~s}$ were sold, bartered or donated to other countries (including the trainer version). Figure 6.9 indicates the annual number of planes exported.

The development and the modifications of the Shenyang J-8 fighter characterize the functioning of a defense-oriented innovation system. The original model largely resembled the MiG-21 based J-7, except for the larger delta wings, and additional engine and a very simple radar, making it a more capable interceptor at higher altitudes and faster speeds. It first flew in 1969, but it didn't enter into serial production before 1979 due to the Cultural Revolution. But the plane fell short of the expectations of the PLA Air Force (PLAAF) which was looking for all-weather, high-altitude, and beyond-visualrange interception capabilities that could counter foreign spy-planes. Even with incremental improvements in armament and avionics during the 1980s, the plane remained an obsolete model. It is estimated that hardly more than 50 of these J-8I planes were produced. A radical modification of the original design involved replacing the nose air intake for the engines with side air intake, which allowed the solid nose to host a more advanced radar system. The resulting J-8 II showed little resemblance to the original J-8, except for the tail section and the delta wings. The new nose design was apparently largely inspired by the Soviet MiG-23 and Su-15 fighters. This model accomplished its maiden flight in 1984 and was developed parallel with the J-8I upgrades. The original $40 \mathrm{~km}$ radar range of the J-8IIs was replaced by $70 \mathrm{~km}$ radar in a 1989 batch, still not capable of locating beyond visual range. Maneuverability was also slightly improved and so were avionics. But incremental innovations in its modules were relatively slow during the 1980s and 1990s as cooperation with the US was terminated after the Tiananmen Square incidents. By the time upgrades were made with Israeli and Russian technology, the newer plane J-11 fighter was already available. Nevertheless, an upgraded version of the plane was displayed even as recently as in 2006. It is estimated that $300-350$ of these planes have been produced. 
Figure 6.8 Estimated Chinese Jet Fighter Production, 1960-1995

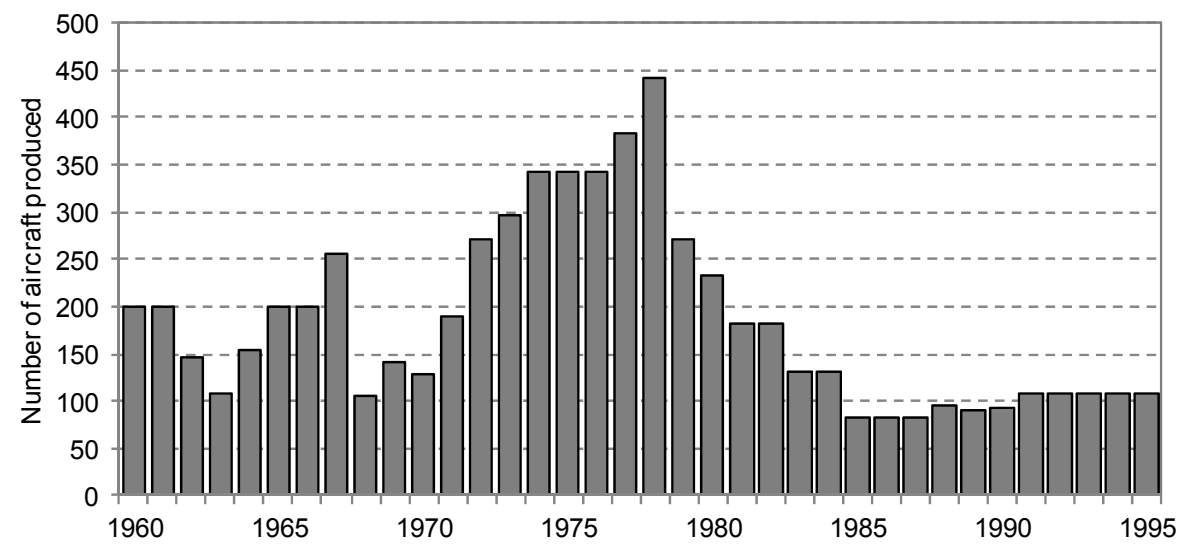

Source: Allen et al. (1995 Fig.17, p.162)

Notes: This figure clearly indicates the influence of major political events: the Sino-Soviet split of 1961, the Cultural Revolution during the late 1960s and the reforms of Deng Xiaoping following 1978.

Figure 6.9 Military aircraft export from China, 1960-2008

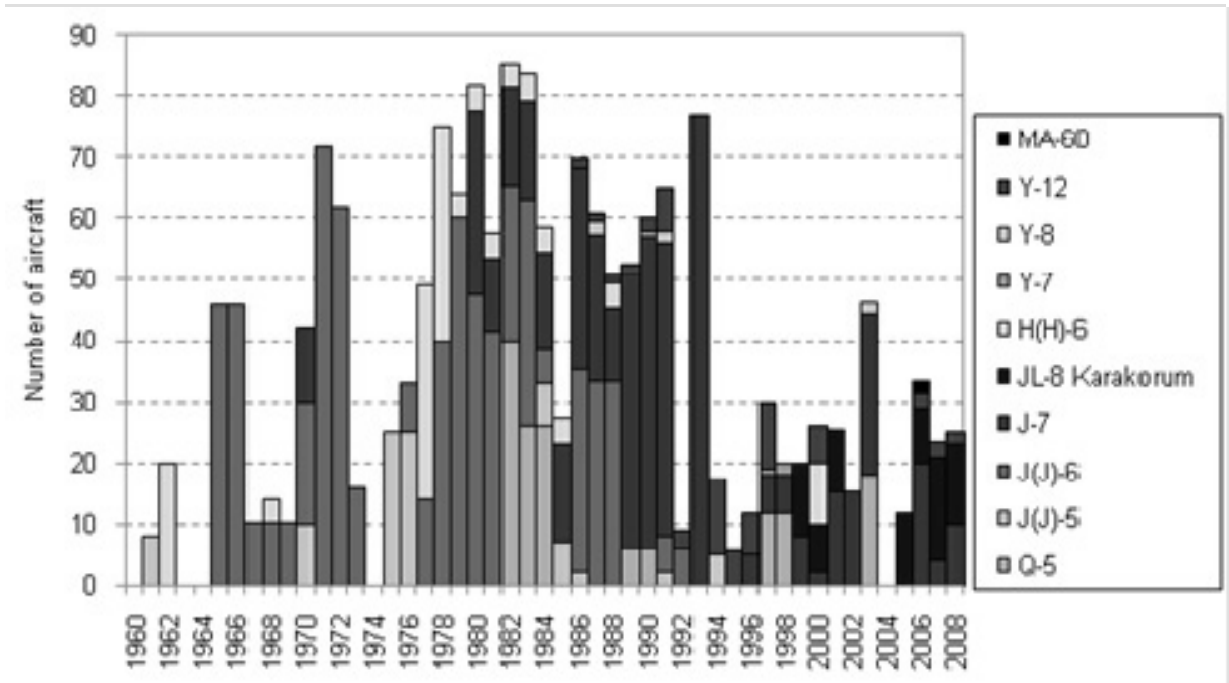

Source: SIPRI

Notes: $\mathrm{Q}$ refers to ground attack class, J refers to fighters; $\mathrm{H}$ refers to bombers and $\mathrm{Y}$ refers to transport aircraft. Double letters indicate trainer versions.

\subsubsection{The origins of commercial production}

Even before the more fundamental institutional changes of the 1990s, there were several attempts to diversify into the production of commercial aircraft. The Y-10 project of the 
1970s proved that Chinese engineers were capable of designing prototypes of a large civil aircraft that were able to fly. ${ }^{126}$ However, the project never reached the phase of series production and was cancelled in 1983. It did not turn out to be commercially viable and the Aviation Administration of China preferred to import more modern planes. $^{127}$

The MD-80 assembly project was the first bold sign of opening up the industry to western technology and commercial production. In 1985 China signed a license agreement with McDonnell Douglas (MD) to assemble the MD-80-series medium range jets in Shanghai. The airplanes were assembled from kits with some components fabricated in China. MD provided technical data, training, and on-site assistance. 35 planes were produced between 1985 and 1994, mostly for the local market (30 were sold to China Northern and China Eastern and 5 were exported to the US). The Shanghaiproduced planes were however repeatedly experiencing technical failures and clocked only a modest amount of flying hours. A renewed contract for 20 Chinese MD-90s Trunkliner with an indigenously produced share of $80 \%$ resulted in only 2 planes delivered for China Northern in 2000. Despite low productivity ${ }^{128}$ and quality problems, the technology acquired through this endeavor gave a major push to the industry, and also found its way to the first indigenous design, the ARJ-21 regional jet.

Quality problems hampered the success of a smaller-scale project, the multiuse turboprop military / civilian transport plane based on Soviet Antonov design, the Xian Y-7, later the MA-60. These projects already included collaboration with Western partners. But these Chinese made planes had limited success on the export markets since western administrations did not certify the planes due to quality concerns. Most of them were eventually grounded for safety reasons or lack of spare parts.

\subsubsection{Main features of the innovation system ${ }^{129}$ before the changes of the 1990s} The PLA Air Force (PLAAF), established in 1949 has accounted for a large share of the Chinese defense budget and was a power center from time to time even competing with

\footnotetext{
${ }^{126}$ Although the Y-10 shows a high degree of similarity to the Boeing B-707, Chen (2009) argues that some of its features even outperformed the B-707. Thus it was innovation, not merely imitation.

${ }^{127}$ It was based on 1950s technology and Boeing stopped producing the 707 in 1979 due to its high fuel consumption. Political reasons might also have played a part: possible pressure from the US as well as the end of influence of the 'Gang of Four' who were behind the project.

${ }^{128}$ During the twenty years period of its production, the US produced over 1000 of these planes making it the third most successful jets in history, China only assembled 35, most of which were very soon grounded.

129 The pragmatic approach of Radosevic (1997) to see socialist techno-economic networks as innovation systems is applicable in the Chinese case as well, since knowledge creation and new product design was an explicit aim, even if the incentives and a number of institutions differed profoundly from a capitalist system.
} 
the State Council. It supervised much of the aeronautics, astronautics and pilot education. The Air Force Command College, Air Force Engineering University, Air Force Aviation University, Air Force Radar College, Air Force College at Guilin, Air Force College at Xuzhou, Air Force School for Noncommissioned Officers at Dalian and seven flying colleges were under its command. Defense budget was as high as from $4.6 \%$ of the GDP in 1978 but declined to $1.7 \%$ in one decade ${ }^{130}$. After 1978, the new strategy subordinated defense development to be in the service of the country's overall economic development; allowing commercial interests slowly to gain more solid ground from the mid 1980s.

Self-reliance was the most primary goal underlying innovative activities in Communist China before the 1990s, for considerations of national defense. This did not preclude cross-border technology flows and even import of components such as jet engines for Chinese-made fighter jets, or the use of reverse-engineering of imported aircraft (in order not to reinvent the wheel). However, channels were not established for intensive knowledge exchange and new aircraft development was a rather isolated activity, resulting in innovations being at least a generation behind the global frontier. Secrecy prevailed and hampered interactions even between various regional aerospace clusters. A division of labor based on the purpose of aircraft ${ }^{131}$ resulted in duplications of tasks and lack of use of economies of scope - again, for strategic reasons. Financing of innovative and productive activities by the state council or the PLA was not transparent.

\subsubsection{The crisis in the inward-looking innovation system}

By the early 1990s, the mismatch between the institutions of the inward-looking innovation system and the competitive landscape became unsustainable. The Chinese aircraft manufacturing factories were producing a wide range of non-aviation products for which demand was higher. Locally designed planes were not economical and not safe to operate. Chinese fighters and transport planes would not sell on foreign markets, not even in the most price-sensitive Third World countries. Despite the remarkable efforts of producing and upgrading planes, the industry was increasing the gap compared to the technological leaders. The innovation system which was based on reverse-engineering and local improvements became increasingly inappropriate in a new era of opening trade relations.

\footnotetext{
${ }^{130}$ China's National Defense in 2008

< http://news.xinhuanet.com/english/2009-01/20/content_10688124.htm> (Retreived: March 2009)

${ }^{131}$ For example, fighter aircraft was produced in Shenyang, Chengdu, Guiyang and Nanchang; light and medium transport aircraft in Harbin and Xian; helicopters in Harbin and Jingdezhen; bombers in Xian. (Medeiros 2005) (And this list is not complete).
} 
Yet producers were lacking state-of-the art knowledge, skills and financial capabilities to join the newly emerging global supply chains. At the same time, the demand for commercial aircraft in China grew sharply which could only be met realistically with Western imports in medium term. China had no options but to rethink its aircraft industry development strategy.

\subsubsection{A radical change in the Chinese sectoral innovation system in the 1990s}

The transition in the aerospace industry and innovation system was part of broader market reforms in China. The iterative but fundamental institutional changes in the national innovation system were correctly described as 'adaptive learning' (Gu and Lundvall 2006). Certain heavy industries (including automobiles) were consolidated in a shorter time, but aerospace remains a slow mover, given its sheer size (it employed nearly 600,000 workers in 1995) and the reluctance of chief financing and regulating bodies of the military to change their mindset. Following a 1991 order of a more demand-conscious government, the PLA was to shift $80 \%$ of defense manufacturing projects to commercial products (Allen et al. 1995), in order to tackle financial difficulties. The successful transition of other industries certainly serves as an example for aerospace.

The increasing demand for air travel spurred by the growth of the economy has been a major driving factor of industrial change. Both international and domestic air traffic have increased dramatically since the late 1980s. ${ }^{132}$ The number of civilian airports also increased along with major infrastructural improvements. A significant improvement could be observed as of the late 1980s. The average of 3 routes per airport increased to over 8 . However, the Chinese air transport market remains tightly regulated and aircraft load factors and flying hours remain suboptimal, airport capacities underused (Goldstein 2006).

\subsubsection{Empirical evidence of interruption and transition}

Value added: Aerospace value added exceeded 3.5 billion dollars in 1983. Following a sudden drop in fighter aircraft production, it fell to 1.9 billion by 1987 and continued to decrease to a low of 1.4 billion USD in 1996. After a turnaround, with an average growth of over $16 \%$, the value added of Chinese aerospace industry exceeded the levels of the early 1980s by 2005. In 2007, it reached a historic 7.1 billion USD (Chapter 3 ).

\footnotetext{
${ }^{132}$ Passenger air traffic doubled between 1985 and 1990 to 23 billion passenger kilometer. This value nearly tripled by 1995 to 68 billion, still merely 10\% of US air traffic. It further tripled to 200 billion by 2005 and latest figures show 290 billion by 2008 (CNBS).
} 
Export structure: The composition of the industry's exports shows a striking change. Between 1970 and 90, China exported an annual average of 0.5 billion dollars worth of (mostly locally manufactured) military planes. During the following two decades this amount was halved. At the same time commercial aircraft parts and components exports grew from some 100 million dollars at the beginning of the 1990s to over 1 billion USD by 2007 (Figure 6.10). Nevertheless, China continues to import almost all of its commercial aircraft ${ }^{133}$;

Figure 6.10 Export of Chinese Military and Commercial Aircraft, 1955-2008 $($ USD Millions, Constant $=2000)$

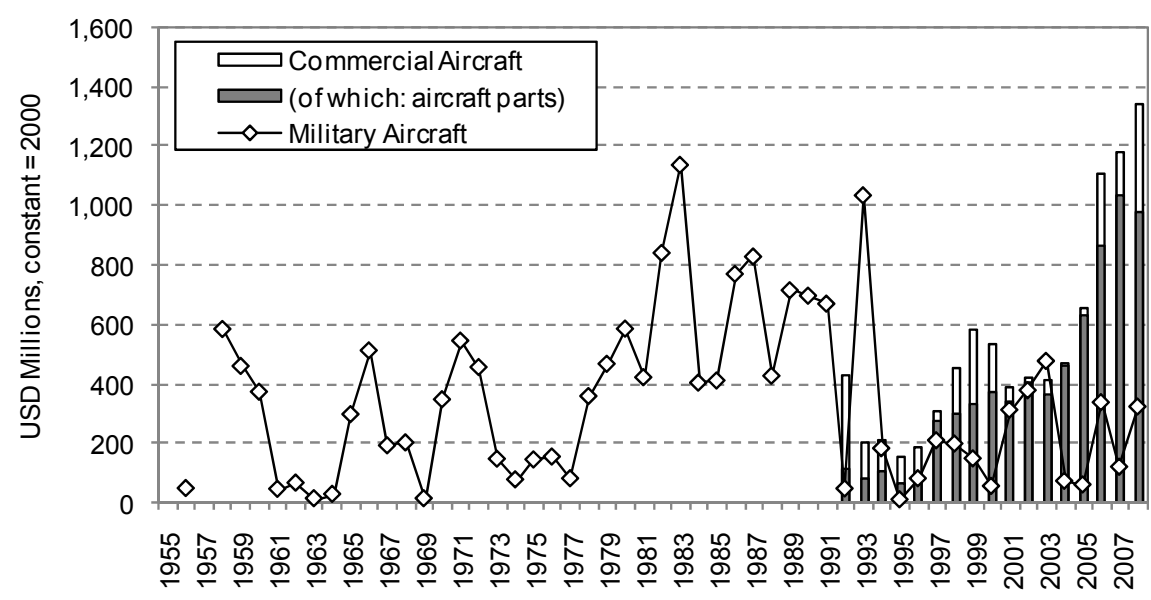

Source: SIPRI; UN COMTRADE (data only available from 1992)

R\&D expenditure: Data on aerospace R\&D is available from 1995. From an annual average of 100 million USD until $1999^{134}$ the launch of major national aircraft development projects led by 2007 to an increased R\&D expenditure of 430 million $\mathrm{USD}^{135}$. Similarly, there is also a significant increase in new product development expenditures starting from 2002 (China National Bureau of Statistics). Comparing industrial R\&D expenditure to aggregate sales shows relatively little fluctuation and an increasing share of $\mathrm{R} \& \mathrm{D}$ (Figure 6.11). ${ }^{136}$

\footnotetext{
${ }^{133}$ Import (of mostly complete aircraft) grew from 1.6 billion in 1992 to over 8.4 billion USD in 2006.

${ }^{134}$ For a comparison, during the same period Embraer alone spent the same amount on R\&D.

${ }^{135}$ In comparison, in 2000 the US spent a total of 10.3 billion USD on aerospace R\&D, and 14 billion in 2006.

${ }^{136}$ At the same time the R\&D staff levels decreased. In terms of full time equivalent, the level of R\&D personnel in the sector decreased from a level of 30,800 in 2000 to 27,200 man years by 2007.
} 
Figure 6.11 R\&D expenditure in the Chinese aerospace industry, 1995-2007

$($ USD Millions, Constant $=2000)$

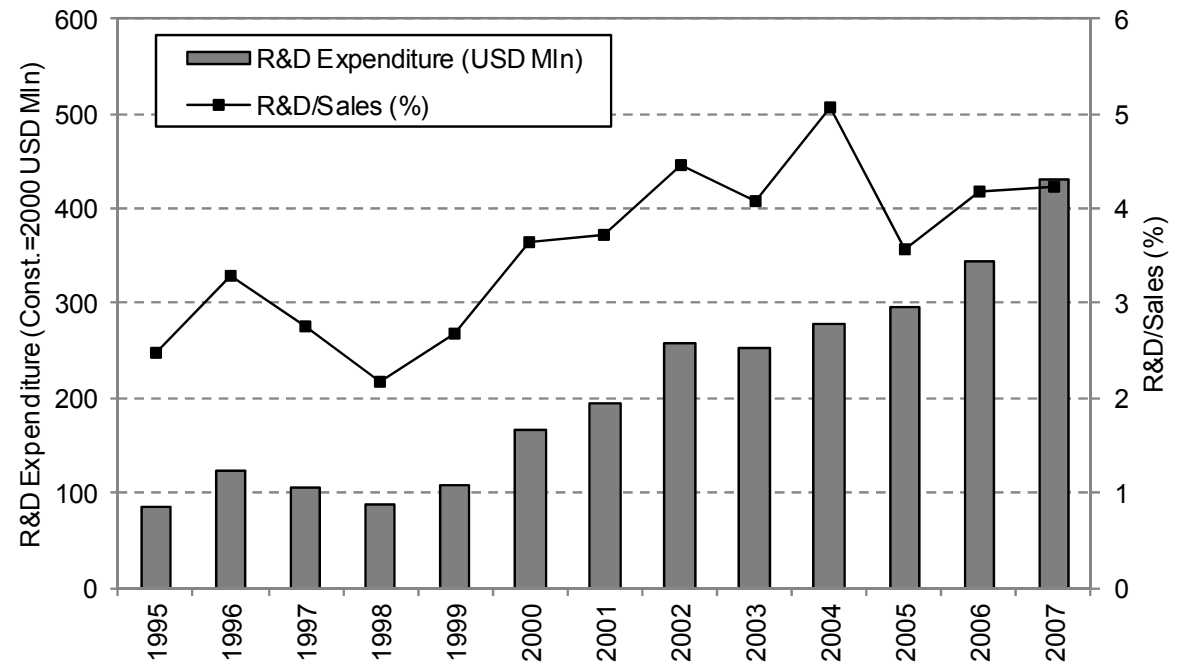

Source: China National Bureau of Statistics.

Note: Annual Average exchange rate in 2000 of $8.28 \mathrm{CNY/USD}$ was applied (IMF).

Patent applications: Although we have repeatedly questioned the appropriateness of patent statistics as an indicator of aerospace innovation, the trend in patent levels may nevertheless provide some information on radical system changes. Indeed, there is a clear trend break in the patenting activity of Chinese large and medium sized enterprises in 2002 (Figure 6.12). From an average level of 90 applications a year which was typical for the late 1990s, the number of applications started to increase and reached 810 in 2007. The number of patents granted only started to show significant changes from 2007 onwards. ${ }^{137}$

\footnotetext{
${ }^{137}$ The lengthiness of the patenting process can well explain this lag. A further growth in 2008 is confirmed by the latest statistics on the sector, although not shown in the figure.
} 
Figure 6.12 Patent statistics of aerospace enterprises

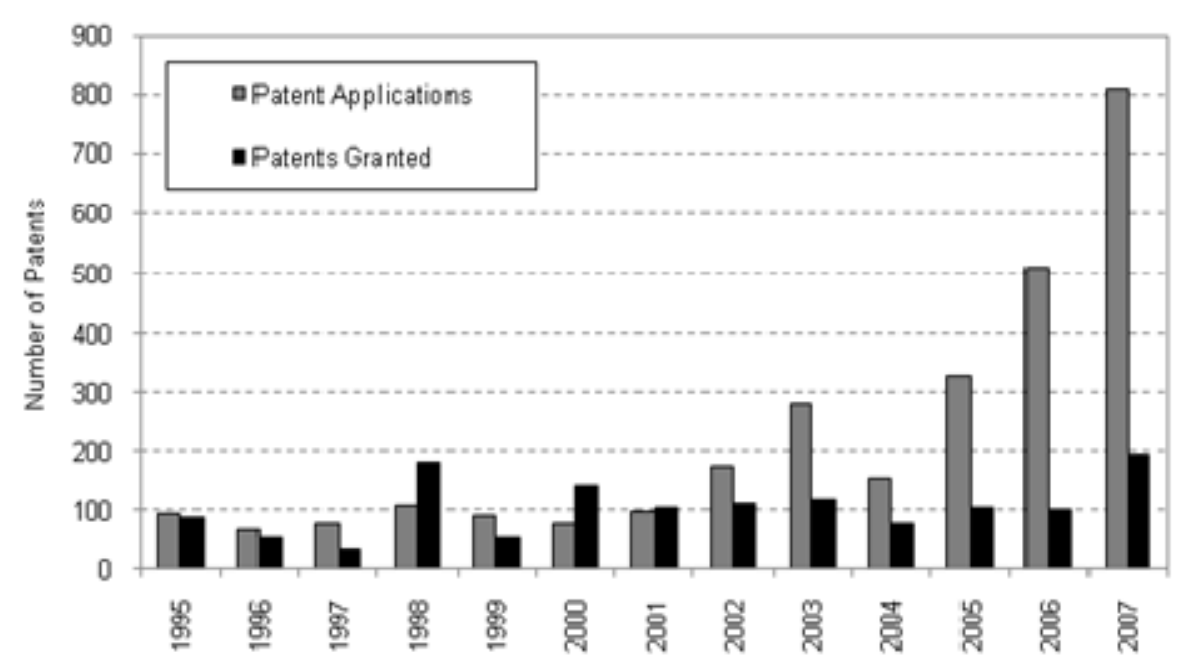

Source: China National Bureau of Statistics, various yearbooks Note: Data refers to patenting activity of large and medium sized enterprises defined by main activity

\subsubsection{The new Chinese aerospace innovation system}

\subsubsection{Organizational restructuring of production}

These developments in the accumulation of technological capabilities were set against a dynamically changing organizational structure. The first sign of opening up the military-industry complex was the creation of Aviation Industries of China (AVIC) conglomerate in 1993 (controlling all the aeronautic research and production facilities) and China Aerospace Corporation (CASC, in charge of the astronautic programs and missile system development and production). In July 1999, AVIC was split up into two enterprises with the goal to break up the monopoly and to foster competitiveness. AVIC I's business focus was manufacturing commercial, interceptor, interceptor-bomber, tanker, transporter, trainer, and reconnaissance aircraft, while AVIC II focused on helicopter, transporter, trainer and general aviation aircraft. AVIC I was launched with 104 enterprises, including 31 of the AVIC's original 34 research centers, and 281,000 employees. It streamlined its structure by 2006 and had 230,000 employees and increased sales revenues. AVIC II was launched with 54 large and medium sized enterprises, 3 research institutes, 22 other subsidiaries, and 210,000 employees. A schematic overview of the structure is shown in Figure 6.13. 
Figure 6.13 The structure of the Chinese aircraft industry in 2008

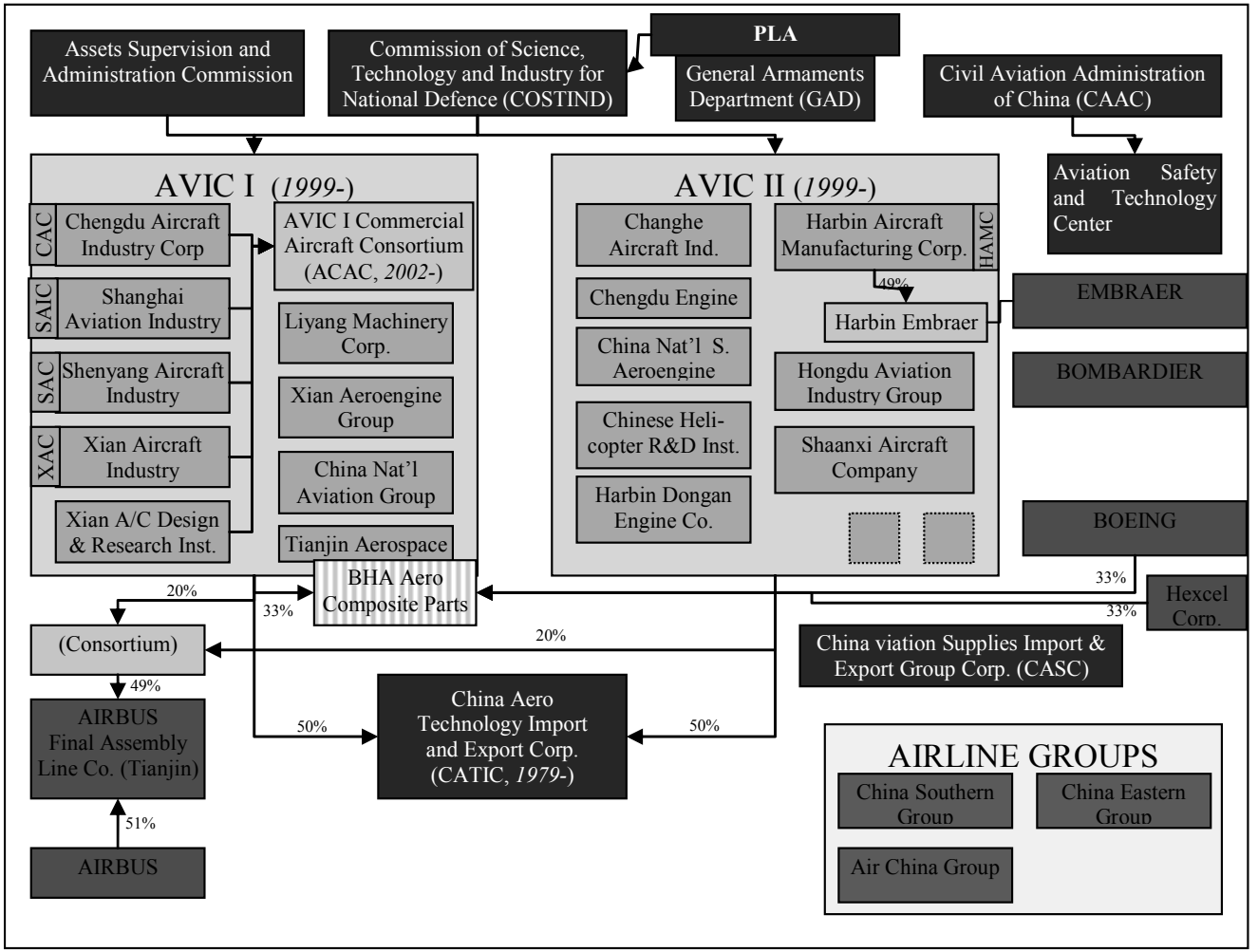

(Author's compilation)

As Figure 6.14 shows, either intentionally or not, one significant result of the restructuring was increased labor productivity through reductions in the number of employees. Total employment in the sector shrunk in a decade from some 600,000 in 1995 to a stable 300,000 in 2005 . Labor productivity increased from 5,000 to 24,000 US dollars per worker between 2000 and 2007. These are evident signs of consolidation in the industry, even if this might not remain the final setup. ${ }^{138}$

138 There is no information how much of the value added and employment is actually associated with aerospace activities. In 2005 Medeiros estimated that non-aviation business made up as much as $80 \%$ of AVIC's turnover (Medeiros, 2005). Nolan and Zhang reported earlier that automobiles, components and motorcycles alone accounted for 62\% of AVIC's revenue in 1997. 
Figure 6.14 Employment and Labour Productivity Growth in the Chinese Aerospace Industry, 1995-2007

(Thousand USD at constant $=2000$ prices)

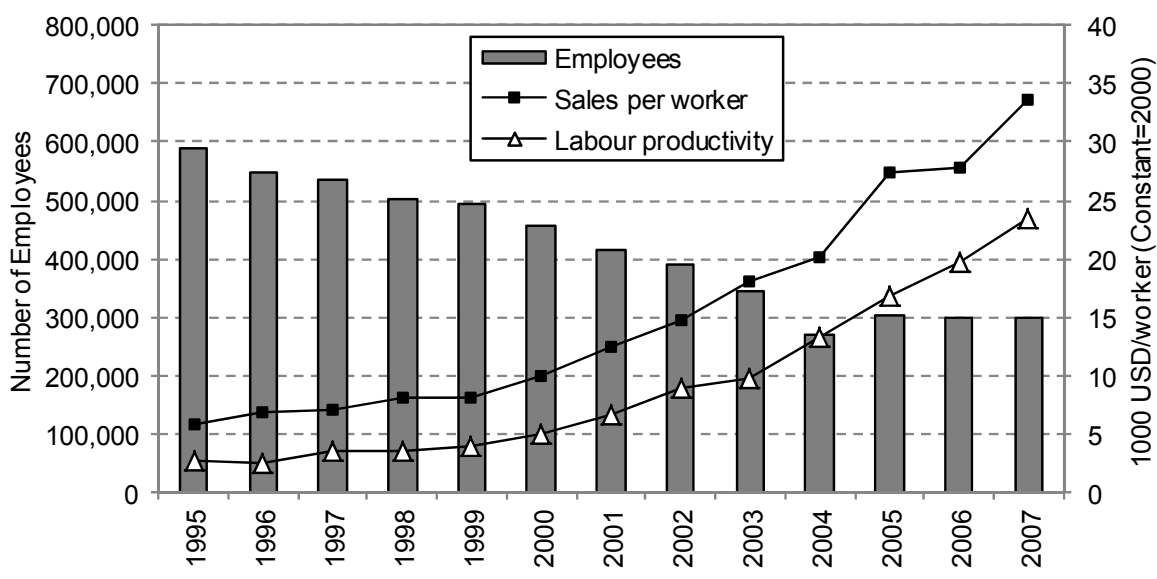

Source: Chinese National Bureau of Statistics, various yearbooks

Note: for value added and labor productivity please refer to Chapter 3 .

In the complex, cascading structure of subordinate companies, many of the competences were doubled but the final products were more complementary to each other than competitive with each other, contrary to the initial intention (Nolan and Zhang 2002). This was partly the reason why the two sections remerged from 2009 into AVIC, but only after a significant overall reduction in employment by as much as $50 \%$. The lack of transparency in the corporate structure has from time to time slowed down decision making processes, but has also allowed experimentations with new corporate forms, especially when it came to joint ventures with Western companies or subsidiaries created with a mission of commercialization of results.

\subsubsection{Foreign aircraft manufacturers in China}

While importing most of the aircraft from Boeing and Airbus, China pushed for offset agreements to simultaneously support the technological upgrading of the industry. At first this meant less technology-, more labor-intensive parts (hardware) manufacturing at dozens of locations across the country. ${ }^{139}$ Production quality increased substantially as a result of these deals since Chinese suppliers had to deliver according to the same strict standards that other producers faced in the Western countries. The initial political necessity to produce in China soon became an economic advantage for western

\footnotetext{
${ }^{139}$ See KPMG (2004) or Boeing (2008).
} 
manufacturers as they reaped the benefits of lower labor costs (notwithstanding the initial learning costs). However, the Chinese contribution remained at the lower tiers of the earlier discussed, newly established global industrial structure. A first risk sharing partnership venture was only signed by a Harbin-based consortium and Airbus for the A-350 XWB project in 2009.

The first foreign manufacturer to commence final assembly of jets in China was Embraer. The Harbin Embraer joint venture ${ }^{140}$ of 2003 allowed the Brazilian company to deliver ERJ-145 regional jets for the Chinese market by avoiding import taxes while the acquisition of certain parts manufacturing and systems assembly activities was a major technological boost for the Harbin plant. The results of the venture were mixed: by the end of 2009 only 33 of the original order of 50 jets were delivered ${ }^{141}$ although the company had a capacity to produce 24 a year and was expecting new orders. The last of the ERJ-145 is expected to be produced in 2011 and Embraer is now awaiting a government decision to approve a shift to ERJ-190 production. Otherwise it plans to close down the plant. ${ }^{142}$ The Chinese government is hesitant since the ERJ-190 would be a direct competitor of the locally developed ARJ-21 (Asian Regional Jet for the $21^{\text {st }}$ Century), due to enter series production in the same time horizon.

Airbus also established a joint venture for final assembly in China. ${ }^{143}$ Operations commenced in 2008 at the Tianjin final assembly line (FAL), a replica of Airbus' Hamburg plant. The first A320 was delivered mid 2009. At the moment, production capacity is four aircraft per month. Airbus initially assembled aircraft from kits delivered from Europe, gradually changing to locally made parts. ${ }^{144}$ The total investment in the Tianjin FAL amounted to 1.47 billion USD ${ }^{145}$. While Boeing was not ready to take the risk of going to China, Airbus expects that the long term benefits of market access exceed the initial investments. ${ }^{146}$

\footnotetext{
${ }^{140}$ The joint venture is special since it allowed a $51 \%$ majority ownership for a foreign company. For more details on the 50 million USD deal, see Goldstein (2006).

141 "Harbin-Embraer's fate rests with China talks" AinOnline, 28 Jan 2010

(http://www.ainonline.com/news/single-news-page/article/harbin-embraers-fate-rests-with-china-talks23599/)

142 "Chinese govt to decide on future for Harbin Embraer: Curado" Air Transport Intelligence News 25 May 2010.

${ }^{143}$ Airbus owns 51\% share while the rest is divided by a consortium of AVIC and Tianjin Free Trade Zone.

${ }^{144}$ Avoiding double shipment by directly using components i.e. wing boxes produced by Xian Aircraft Industry Group.

145 "Airbus delivers first China-made jet, underlining its Asian thrust", Agence France Presse, 23 June 2009.

146 Production is cheaper in China mainly because of (some) reduction in import taxes and duties. The lower labour costs in China are however not necessarily realized in the short run given the high training costs for local labor force and the cost of expatriates (125 of the 500 employees). ("Airbus' China Gamble" Flight International 28 October 2008)
} 


\subsubsection{3 'Indigenous' aircraft development}

Chinese ambitions to diversify into commercial aircraft development have increased in the 1990s. There seemed to be an agreement that the first step would be to gain access to advanced foreign technology, but there appeared to be little agreement on how to proceed. Although Chinese airlines showed the largest demand for aircraft with larger seating capacity, regional turboprops and jets were seen as a stepping stone for domestic producers and also as a means to provide access to remote cities with less traffic. The MD-90 Trunkliner project fitted in this strategy but failed due to quality deficiencies. Another project of the 1990s that failed to realize was the 'Asian Express'.

Originally a Chinese - South Korean joint venture from 1994, the Asian Express was supposed to be a regional jet in the 80-140 seat range. Following disagreements on the final assembly location and the share of the two countries' stake in the project, the South Korean consortium withdrew from the collaboration in June 1996. AVIC of China then approached Singapore Technologies Aerospace and three European producers, Aerospatiale, Alenia and British Aerospace. Three partners, AVIC (with 46\% stake) Airbus Industrie Asia (39\% stake) and ST Aerospace (15\%) agreed to share the expected 1.7-2 billion USD cost of the project. The sides agreed to develop two models in the 95-125 seat range, the AE-316/7 $7^{147}$. However, the partners did not share the same dedication to realize the project. The Chinese industry was in a turmoil and expected to be shaken up, the future of AVIC and the trading company CATIC (China National Aero-Technology Import and Export Corporation) was uncertain. Although China was supposed to get the largest share, Xian and Shanghai were contending for production locations. Airbus officially communicated that the AE-31X was its preferred choice for the 100-seat range, it was already developing and collecting orders for the smallest member of the A-320 family, the "A-319M5". ${ }^{148}$ Airbus was also hesitant to share technology with and shift production to China. Technology transfer seemed unavoidable since market surveys showed that airlines expected a high degree of commonality between the new plane and the A-320 family. At the same time, competition was increasing in the 100 seat segment as the aging DC-9s were requiring a replacement and Boeing was one step ahead with the B-717-200 readily available. In the end, the Asian Express project was cancelled in 1998, officially explained with financial reasons. ${ }^{149}$ It is rather interesting that although European producers were in desperate need to find a solution to save their regional aircraft projects, they eventually did not collaborate with China. The 1990s witnessed European plane makers such as BAe,

\footnotetext{
${ }^{147}$ The name already indicates that the plane was targeted to be a "little sister" of the Airbus A-320 family

${ }^{148}$ The code stands for A-319 minus 5 fuselage frames. The plane eventually became known as the A-318.

149 “Timeout in Asia” Flight International, 5 Nov 1997; “Cut and Thrust” Flight International, 9 Jun 1999.
} 
Daimler, Fokker and ATR gradually losing competitiveness (among others to regional jets of Embraer and Bombardier). Producing in China would have, in the long run, reduced production cost, even if short term investments and training costs were high. The many explanations for the lack of trust on the European side include the existence of an arms embargo following the Tiananmen-square, concerns for national security concerns when sharing multi-purpose technology and concerns for job migration.

The $11^{\text {th }}$ Five-Year Plan for 2006-2010 included the completion of the ARJ-21 regional jet project and the launch of a large aircraft development project for civil and military use, supposed to fly by $2015 .{ }^{150}$ Although indigenous in name, both projects utilize global technological and investment capacities, following the risk sharing partnership practice of Western aircraft producers. The ARJ-21 project that started in 2002 still reflects many of its local technological origins. Coordinated by a governmentled commercial aircraft company (ACAC, later COMAC) $)^{151}$, the four plants involved (Shanghai, Xian, Chengdu and Shenyang) were the same as the ones in the MD-90 Trunkliner project. It is hard not to notice the resemblance of certain sections of the plane $^{152}$. The largest share of development costs of the first regional jet project, the ARJ21 were provided by the public aerospace $\mathrm{R} \& \mathrm{D}$ supporter COSTIND, but leading transnational companies participate in financing the development. ${ }^{153}$ The US Federal Aviation Authority (FAA) has been involved in the development process in order to facilitate certification. The fact that the "First Chinese Made Plane" will not bear "Made in China" tags only is an indicator of the maturity of Chinese design and organizational capabilities. The arrangement of acquiring technology and finance through risk sharing partnerships is similar to the strategy Embraer chose in the mid 1990s, but for the arrangement to work efficiently, private ownership of Embraer was crucial.

The ARJ-21 made its maiden flight at the end of 2008 and four prototypes are currently undergoing tests. Series production and the establishment of a distribution network has not even begun when the government announced the plans to develop a

\footnotetext{
150 “Official identifies eight goals for China's aviation, aerospace industry", BBC Monitoring Asia Pacific, 9 Nov 2006

${ }^{151}$ ACAC, or 'AVIC-I Commercial Aircraft Company' was a consortium of four main companies under the AVIC I conglomerate, designated to oversee the development, certification and marketing of commercial aircraft. In 2009 the company became part of COMAC, the 'Commercial Aircraft Corporation of China Ltd' established in 2008.

152 Highly similar parts include the nose, produced by Chengdu, the fuselage by Xian, the tail section by Shenyang or the horizontal stabilizers by Shanghai (Andersen 2008). The aircraft was thus aptly named Xiangfeng (flying phoenix), as it was revived from the ashes of the failed MD-90 Trunkliner.

153 Foreign partners include Antonov (wing design and testing), General Electric (regional jet engine development), Rockwell Collins (avionics), Hamilton Sundstrand (electric system and auxiliary power unit and fire protection system), Eaton (control panel), Liebherr (landing gear). Boeing has been providing engineering consultancy and cockpit design assistance.
} 
large civil aircraft ${ }^{154}$ in the $168-190$ seats category. The COMAC C-919 $9^{155}$ would be a direct competitor of the smaller Boeing and Airbus jets (B-737 and A-320 family), bringing new turbulence to a consolidated duopolistic market. China has yet to gain experience in setting foot on the international aircraft market, which involves winning the trust of passengers and airlines, establishing the maintenance, repair and overhaul network, and efficient supply chain management. This step is crucial to recover the huge sunk costs of development, and still requires vast investments domestically and overseas.

The Chengdu and Shenyang plants at the same time continued to produce enhanced versions of existing fighter jets and introduced new models, such as the Chengdu J-10 $10^{156}$ or the FC-1 Brave Dragon. This latter aircraft is a joint development project with Pakistan and is intended for low-cost military markets (Medeiros 2005) ${ }^{157}$. A fighter-bomber (JH-7) was developed in Xian during the 1980s and 1990s. Both the existing stock of aircraft and the latest developments represent is at least one generation behind the technological capabilities of the US while onboard systems and massproduction capabilities are still further behind. But the real competitor of China is not located in America but in Asia: "Right now, the only arms race China is really facing is with India, and [Beijing is] winning," quotes the influential industry journal Aviation Week and Space Technology ${ }^{158}$ with regard to the development of a fifth generation stealth fighter.

\footnotetext{
154 'Large civil aircraft' is a more appropriate term for this narrow-body jet than the often used 'jumbo', which normally refers to Boeing B-747s with a seating capacity in the range of 500 .

${ }^{155}$ The list of collaborating partners has not been finalized yet; currently Hongdu (Nanchang), Xian, Shenyang and Chengdu Corporations are the Chinese companies involved ("China's Comac brings more suppliers in, Flight International, 24 Sept 2009"), while foreign companies already chosen include many of the ARJ-21 partners: General Electric, Hamilton Sundstrand, Honeywell, Liebherr Aerospace and Parker Hannifin (based on respective company press releases).

${ }^{156}$ The J-10 is an F-16-class fourth generation light fighter jet with fly-by-wire control and a Russian engine, launched in 1988, first flew in 1996. It is believed to have received direct technological input from the Israeli Aircraft Industries' discontinued Lavi program (which received input from the F-16 program), though it was denied by both parties as it would imply American technology transferred to China. (Medeiros, 2005 and "Chinese J-10 'benefited from the Lavi project", Jane's Defense News, 19 May 2008; http://www.janes.com/news/defence/jdw/jdw080519_2_n.shtml )

${ }^{157}$ The aircaft's Pakistani designation is JF-17 Thunder, and development partners included Chengdu Aircraft Industries Corp., the Pakistani Air Force and Pakistan Aeronautical Complex; is equipped with a turbofan engine from the Russian Klimov. Design began in 1994 but the aircraft first flew only in 2003, produced in limited numbers since 2007/8 in China and Pakistan, while modifications are still underway.

158. "China Promises New, Advanced Fighter", Aviation Week and Space Technology, 24 Nov 2009.
} 


\subsubsection{Interrupted innovation in the Chinese aerospace industry}

\subsubsection{Summary of the transition}

There were two different types of interruptions in the development trajectory of the Chinese aircraft industry. At the time of the first interruption that occurred during the initial learning years, a sectoral innovation system hardly existed. China was over-reliant on one single external technology source and the vulnerabilities of such an arrangement became clear as soon as this channel "dried out". Not until a new system was established (including educating, training efforts) could the tacit knowledge be recovered through reverse-engineering. But the inherent limitation of switching to an inward-looking strategy at such an early phase of development was that the innovation performance frontier remained unchanged (if not reduced). Yet this system was rather stable for more than three decades due to a variety of reasons. The national innovation system did not undergo radical changes, and the major actors and their incentives to innovate remained largely unchanged.

The crisis of the inward-looking innovation system was caused by exogenous political and macro-economic changes in the environment in which forces endogenous to the innovation system played little if any role. The interruption can almost entirely be explained by China's transition to a market economy. Yet the speed of the transition that took place in the aerospace industry was much slower than in many other industries that have become globally competitive by today. This points to sector-level institutional explanations. Even if market institutions only emerged gradually in the Chinese economy, the aerospace industry showed excessive institutional inertia. This of course hardly comes as a surprise in an industry that employed hundreds of thousands of employees, and where the role of the military remains influential. On the one hand, export is a good indicator of the transition; both in terms of total values and composition of the product portfolio. As the export of military planes dropped, parts and components slowly replaced and overtook them (Figure 6.10), revealing a greater integration in global supply chains. Increasing labor productivity since 2000 (Figure 6.14) on the other hand shows learning in the new system created during the transition.

However, it is a Chinese peculiarity that old structures still survive parallel to new ones in a dualist style, even within regional clusters. This is due to the privileged position of national defense on the political agenda. The incentives differ hugely for units producing for the export markets and those for closed military installations. Openness in the innovative process has clearly increased in the commercial segment, indicated by the large number of foreign partners involved in the ARJ-21 project (and the readiness to involve foreign aviation authorities in the design phase). Self-sufficiency is not an imperative anymore, even if a techno-nationalist rhetoric remains in place. 
However, foreign ownership of private enterprises is only allowed to a limited extent and excessive bureaucracy is still seen as a barrier to innovation. Military aircraft design and manufacturing remains still very closed and primarily domestically oriented. The transition mostly affected the civilian segment but left many areas open for further, incremental adjustments (i.e. 50\% state ownership and approval requirement hinders fast corporate decision-making).

The transition was governed (and cushioned from shock) by the government. But top-down forces (changed strategies and incentives) were met with initiatives of foreign producers who were ready to enter into offset deals to produce parts locally or even to bring final assembly to China. This, in the end, shows that the transition was carefully constructed in order to support the accumulation of technological capabilities.

\section{Figure 6.15 Interruptions and transition in the Chinese aircraft innovation system}

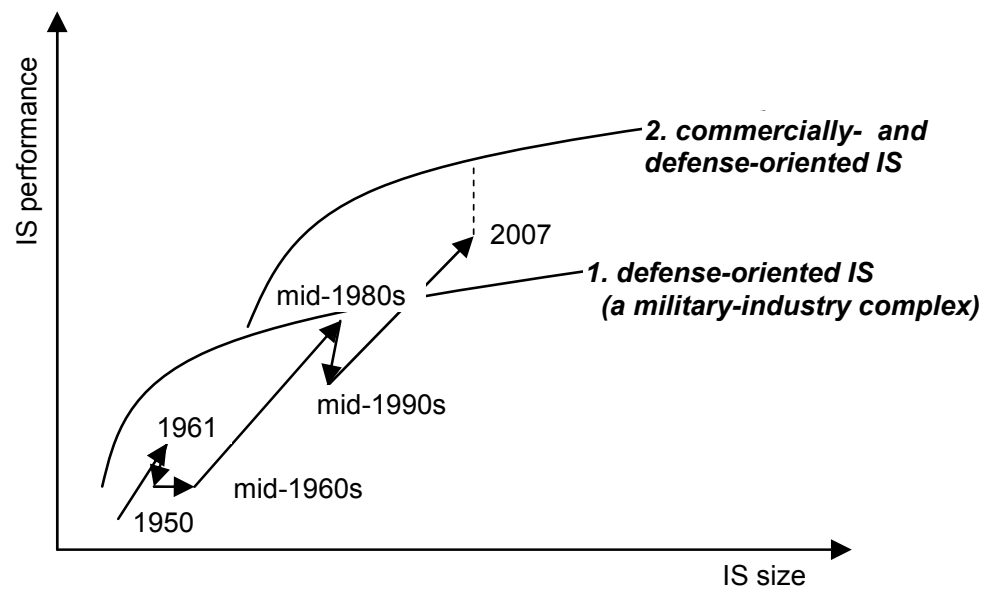

(Author's compilation)

The evolution of the innovation system and the interruption is summarized in Figure 6.15. The most relevant break in the trajectory (disregarding the Sino-Soviet Split of 1961 and smaller, "uncharted adjustments" over the 1970s) is the interruption in the mid-1980s that lasted until the mid 1990s (the years given in the figure are only approximate in the case of the innovation system). The drop in the performance of the system refers to a drop in exports and value added as an ultimate indicator, even if some new (or modified) products were introduced during this period. The change in the size of the innovation system involves a slight contraction based on the assumption that military financial input into innovation decreased as the budget constraints became 
tighter and as foreign capital was not yet available. The number of employees working on innovation was also reduced. Even if the employees stayed within the same factory, many were reassigned to non-aviation engineering and design activities. Subsequently both public and private funding increased and so did innovative performance (as shown by an increase in labor productivity and exports).

\subsubsection{Remaining institutional challenges}

The aggregate, industry level figures hide much of the details and internal structural changes and remaining hurdles that make the transition process last so long. Detailed information is still unavailable, but we can to point out the main institutional challenges and blockages that impede improvement in the performance of the sectoral innovation system.

1. Ownership: Decision making in the state-owned conglomerates remains slow and heavily influence by political considerations; foreign ownership in the sector is generally limited to less than $50 \%$ (exceptions are the case assembly facilities of Embraer and Airbus).

2. Competition: There is little competition between the producers. ${ }^{159}$ Military procurement policies create sufficient domestic demand for local products. The latest Chinese products have yet to make gains on the export markets. Competition does not appear to provide any incentives for the rather well-cushioned R\&D institutes. Interactions between users and innovators are not very intensive. It is unclear how much freedom various plants and $R \& D$ institutes have in defining the directions of research on new technologies and to what degree is there a domestic competition for government funds. The protective measures continue to keep the industry's marketing capabilities at a less advanced level, but this is compensated for by the size of the domestic market.

3. Access to technology: the arms embargo by the USA and the EU remains to be a major restriction on the flow of technology. ${ }^{160}$ Technology flows between military and civilian projects are expected to be limited, although interaction among the geographically dispersed units appears to be increasing in both domains.

4. Flow of skilled labor: labour compensation in the aerospace industry is not competitive with wages in coastal cities and foreign-owned enterprises; salaries are

\footnotetext{
${ }^{159}$ Military production appears to be divided by "market segment" served: light fighter jets are produced in Chengdu, heavy fighters in Shenyang, bombers in Xian; commercial projects are shared among the biggest factories.

${ }^{160}$ The EU appears to be more flexible in its interpretation of the embargo and is more ready to consider a reform. See more details at Sipri "EU arms embargo on China”, (URL:

www.sipri.org/research/armaments/transfers/controlling/arms_embargoes/eu_arms_embargoes/china)
} 
often still not determined by performance (Medeiros 2005). Considering international flows, brain drain is more common than brain gain.

The transition of the innovation system will remain incomplete as long as many of these barriers are in place. The speed of institutional change is defined by the government (and the PLAAF) which is pursuing a strategy of slow transition. As long as the industry continues to grow at more rapidly than other industries and as long as the government has no problem in raising the vast sums for new $R \& D$ projects, there will be no incentives to make changes in the innovation and production system. 


\subsection{SINGAPORE: the Wings of the Lion}

\subsubsection{Introduction}

With a total area of 697 square kilometers, with natural resources limited to the strategic waterways of the Strait, the deepwater ports and fish, Singapore may seem like an odd location for specializing in aerospace manufacturing. But history has proven that the size of the domestic market is not necessarily a limit to success and that a wellfunctioning innovation system can also be built around repair and production in the lower tiers of the industry. Today Singapore is the second-largest latecomer aerospace producer in the emerging world in terms of value added and is outperforming even Brazil. Between 1977 and 2007 production in Singapore grew almost constantly, with the exception of only three years. This is highly remarkable for an open economy in such a volatile sector. The reason why Singapore managed to rapidly respond to crises indicates the existence of a flexible national as well as sectoral innovation system.

\subsubsection{Background: industrialization and innovation in Singapore}

By the end of the 1970s when the government of Singapore decided to promote the development of the aerospace industry, the manufacturing sector had already strengthened in the country. The two fundamental conditions for earlier industrial growth were, according to Aw (1991), political stability and an investor-friendly business climate. The People's Action Party (PAP) has been continuously ruling Singapore with a high approval rating ${ }^{161}$ since before the island state's independence from the Federation of Malaysia in 1965. A system of centralized decision making was established that prioritized economic competitiveness and efficiently fought corruption. National security was a high priority after the independence of Singapore given the notso-friendly relations with its neighbors in the initial years. The Economic Development Board (EDB) was established in 1961 for strategic planning and investment promotion. An Export Promotion Center was created in 1965 to provide export financing and credit insurance to exporters. Trade unions were kept under control by an umbrella organization which was incorporated into the PAP structure since 1964. The 1968 Employment Act strengthened the power of employers and reduced the scope of collective bargaining for employees, but a tripartite forum, the National Wages Council was a main tool to incorporate workers in long-term growth negotiations since 1972. Aw (1991) emphasized that public housing for middle and lower classes was significantly reduced social tensions, and workers subscribed to investor-friendly

\footnotetext{
161 The party's approval rating was 47\% in 1963 and climbed to $84 \%$ already by 1968 .
} 
reforms given a culture that valued thrift, readiness to change and social mobility, a free enterprise market, and consistent, predictable and rational policy making. The proindustrialization policies had tangible results. The average annual growth rate was $13.2 \%$ between 1968 and 73, and 8.5\% between 1974 and 82 . This took place along structural transformation, in which the share of industry in GDP increased from 19\% in 1960 to $30 \%$ in 1980, and the share of manufacturing in GDP increased over the same period from $13 \%$ to $22.3 \%$. In the 1960 s, around half of the domestic investment was financed by national savings, which increased to over two-third from the 1970s. Foreign investment was most pervasive in the manufacturing sector, increasing from $45 \%$ in 1966 to $81 \%$ in 1979 . This was also spurred by the externalization of the American economy and an explicit US strategy to develop Southeast Asia to contain Soviet influence in the region.

Singapore followed a strategy of export promotion and has targeted "nontraditional" industries already since 1959. There was a shift in the promoted industries toward technology-intensive sectors (shipbuilding, electrical and non electrical machinery, appliances and supplies, and transport equipment) in the mid-1970s. With the provision of loan subsidies, two-third of all loan commitments went into the promoted sectors by 1975 .

Education was aimed at technical and vocational training in order to create broad basic skills foundation. On-the-job training was a major tool. Since the early 1970s Singapore achieved near-full employment and migration policy was highly regulated to follow business cycles and skills demand.

Put simply, Singapore's economy underwent two major transformations over the last four decades. In the late 1970s, it shifted from labor-intensive to capital-intensive, high-value-added manufacturing. Responding to increasing competition in the region and the lack of natural resources, Singapore recognized the need to shift to knowledgeintensive activities and services which occurred at the beginning of the 1990s. Explicit innovation policies and strategies were devised by the EDB and a National Science and Technology Board (NSTB) was established in 1991 to implement them in 2-year technology plans. The government was also pushing for reforms in higher and vocation education. Already since 1978 Singapore has been systematically monitoring R\&D activities. In the 1990s, strong incentives were offered to boost total R\&D expenditures to above $2 \%$ of the GDP by the year 2000. A national innovation system relied on intensive interactions between the private sector, the EDB (which was responsible for innovation and FDI strategies), and the NSTB (which was renamed to Agency for Science, Technology and Research or 'A-Star' in 2002). In this structure, strategic planning meetings were held regularly since 1987 and competitive challenges could be 
reacted upon rather quickly. Information exchange was also intensive between employers, employees and the state agencies in a corporatist, tripartite structure (Yun 2004).

Table 6.3 Main indicators on the national innovation system of Singapore, 1990-2009

\begin{tabular}{|c|c|c|c|c|c|}
\hline & 1990 & 1995 & 2000 & 2005 & 2009 \\
\hline Gross Expenditure on R\&D (USD mln)a & 382 & 780 & 1,746 & 2,658 & 3,271 \\
\hline GERD / GDP (\%) & 0.81 & 1.11 & 1.85 & 2.19 & 2.28 \\
\hline Business Expenditure on R\&D / GDP (\%) & 0.44 & 0.71 & 1.15 & 1.45 & 1.41 \\
\hline Researchers in Science and Engineering & 4,329 & 8,340 & 14,483 & 21,338 & 26,608 \\
\hline Patents Owned & n.a. & 256 & 1,268 & 3,475 & 6,067 \\
\hline Scientific and technical journal articles & 572 & 1,141 & 2,361 & 3,611 & $3,792 b$ \\
\hline \multirow[t]{3}{*}{ Hi-tech exports' share in Mfg exports (\%) } & 39.7 & 53.9 & 62.6 & 56.6 & $50.8 \mathrm{c}$ \\
\hline & & \multicolumn{4}{|c|}{ Average Annual Growth rates (\%) } \\
\hline & & $1990-95$ & $1995-2000$ & $2000-05$ & 2005-09 \\
\hline Gross Expenditure on R\&D & & 15.3 & 17.5 & 8.8 & 5.3 \\
\hline GERD / GDP & & 6.5 & 10.8 & 3.4 & 1.0 \\
\hline Business Expenditure on R\&D / GDP & & 10.0 & 10.1 & 4.7 & -0.7 \\
\hline Researchers in Science and Engineering & & 14.0 & 11.7 & 8.1 & 5.7 \\
\hline Patents Owned & & n.a. & 37.7 & 22.3 & 14.9 \\
\hline Scientific and technical journal articles & & 14.8 & 15.7 & 8.9 & 2.5 \\
\hline Hi-tech exports' share in Mfg exports & & 6.3 & 3.0 & -2.0 & -3.5 \\
\hline
\end{tabular}

Sources: National Survey of R\&D in Singapore 2009, Agency for Science, Technology and Research; World Development Indicators Online

Notes: a) USD million in constant 2000 prices; b) Data refers to 2007; c) refers to 2008

Table 6.3 gives a general overview of the results of the innovation policies. Between 1990 and 2009 R\&D expenditures increased 6-fold. Compared with GDP, total R\&D expenditures increased from 0.81 in 1990 to 2.28. After the rapid growth in key dimensions of the innovation system in the 1990s, there is a slow-down in the new millennium, but the growth is still impressive in light of the several crises that hit the outward-oriented economy over the last fifteen years, from the Asian financial crisis through 9/11 and the SARS crises to the most recent global financial crisis.

\subsubsection{The development trajectory}

\subsubsection{The emergence of the industry (1970s - 1980s)}

From the early 1970s onwards, Singapore capitalized on the growing demand for aircraft servicing and maintenance over the years of economic growth of the island ${ }^{162}$. Aerospace was given a priority industry status due to its high value-added, skill intensive

\footnotetext{
${ }^{162}$ During the 1960s, Singapore was still a low-cost manufacturing location with a rather low industrial base. According to Wong (2003) manufacturing accounted for 13\% of GDP in 1960 and 28\% in 1980.
} 
nature (along other industries such as electronics, computers or medical equipment). The government formulated a more realistic aim for aerospace manufacturing than neighboring Indonesia. In addition to servicing the fleet of the Republic of Singapore Air Force (RSAF), companies were to build up capabilities in commercial maintenance, repair and overhaul (MRO), and parts and component manufacturing. Also, Singapore was to become the regional aviation headquarters for Southeast Asia. This was intended to provide a mixed source of technology and investment in the emerging industry. RSAF was an important customer for maintenance and upgrade services of its fighter and trainer fleet, and the growing East Asian commercial aviation market was supposed to provide demand for a new regional MRO hub that could benefit from its strategic location.

However, attracting foreign investors did not prove to be very successful during the 1970s. According to Hill and Pang (1988), this could be explained by four factors: (1) lack of a regional market for components; (2) difficulty in sourcing raw materials; (3) lack of a bilateral agreement with a foreign certifying authority (e.g. the Federal Aviation Authority of the US); ${ }^{163}$ and (4) uncertainty about the availability of skilled labor force.

The government's systemic response was a reform package in 1979. Incentives were offered to invest in the priority industries, including corporate tax exemption for the first five years after production start-up. ${ }^{164}$ In order to attract a skilled labor force, a corrective wage policy was implemented and education and training institutions were expanded, especially in fields of science and engineering. A bilateral Airworthiness Agreement was signed with the US in 1981 to mutually accept national certification. Further important steps were the organization of the Asian Aerospace Exhibitions starting in 1981 and the opening of a new airport at Changi.

In 1981, aviation contractor firms formerly owned by the Ministry of Defense were reorganized into the newly formed Singapore Aircraft Industries (SAI). SAI consisted of five subsidiaries and two associate companies. ${ }^{165}$ The most important of these was SAMCO, which was established in 1975, with a profile in avionics and systems overhaul. As shown in Table 6.4, SAI has quickly accumulated capabilities to upgrade

\footnotetext{
${ }^{163}$ Without an agreement to mutually accept national certification, companies had individually to obtain certification from national and foreign authorities. For instance, the predecessor of ST Aerospace became an FAA certified repair station in already in 1973.

164 "Singapore attracts more" Flight International 4 Jan 1986

165 These included: Singapore Aerospace Maintenance Company (SAMCO), Singapore Aerospace Manufacturing (SAM), Singapore Aero-Components Overhaul Company (SACO), Singapore Electronics \& Engineering Ltd (SEEL), Singapore Aerospace Warehousing and Supplies (SAWS), Singapore Aero- Engine Overhaul Ltd (SAEOL), and the Samaero company ("Singapore attracts more" Flight International 4 Jan 1986).
} 
fighters and trainers and manufacture trainers and helicopters under license. It was assigned to refurbish Douglas A-4 fighters and trainers. By 1985 it had modernized some 80 plains of this type for the RSAF. In 1985 it was the first company outside Italy to receive a license to assemble the Marchetti S-211 jet trainers. In 1986 SAI also successfully accomplished the re-engining of an A-4 with a General Electric (GE) turbofan. The company was subsequently contracted by the RSAF to re-engineer and upgrade avionics on another 50 of these fighters and trainers. During the early 1990s, further refurbishment programs involved converting 28 F-5 fighters to reconnaissance configuration and upgrading the rest of the fleet with state-of-the-art radar, avionics and weapons delivery systems. ${ }^{166}$ The refurbishment upgrading projects provided opportunities for technological collaboration with a number of established aerospace companies, including Douglas, Northrop and GE from the US and Aermacchi and Galileo Avionica from Italy.

Already by the end of the 1970s SAMCO and the Helicopter Division of French Aerospatiale established a joint venture (Samaero) at the Seletar Airport to provide helicopter maintenance services in the region. The oil exploration activities in the region and military procurement by RSAF offered a growing market for utility helicopters. An important milestone was the local assembly of 17 Aerospatiale's medium-sized AS-532 Cougar and AS-332 Super Puma models from kits between 1985 and 1988. During 199192 the smaller AS-350 Squirrel and 550 Fennec helicopters ${ }^{167}$ were assembled from kits in Singapore.

At the same time, investment incentives as well as the rapidly increasing volume of passenger- and cargo air traffic had positive effects on the commercial segment of the industry. Between 1973 and 1990, air freight increased at an average rate of $20 \%$, the number of passengers carried increased at an average rate of $11 \%$ (see Table 6.5 ). In the aerospace sector, the number of firms doubled to 18 between 1980 and 1985 .

\footnotetext{
${ }^{166}$ For details see "Gradually Global” Flight International: Asian Aerospace Special 19-25 Feb 1992

167 The AS-332 and -532 models, as well as the AS-350 and -550 models are structurally the same; the designation AS-5.. indicates military use, AS-3.. indicates civilian use.
} 
Table 6.4 Major local assembly and upgrading projects at ST Aerospace (1974-2007)

\begin{tabular}{|c|c|c|c|c|}
\hline Aircraft Model & $\begin{array}{l}\text { Collaborating Company } \\
\text { (HQ Country) }\end{array}$ & $\begin{array}{c}\text { Total } \\
\text { Nr. Built }\end{array}$ & $\begin{array}{l}\text { Years of } \\
\text { Production }\end{array}$ & Notes \\
\hline \multicolumn{5}{|l|}{ Fighters/Trainers } \\
\hline A-4B Skyhawk & Douglas (USA) & 32 & $1974-77$ & modernized with US components \\
\hline A-4C Skyhawk & Douglas (USA) & $40^{u}$ & $1980-81$ & $\begin{array}{l}\text { modernized with US components; license } \\
\text { received from Douglas }\end{array}$ \\
\hline A-4B Skyhawk & Douglas (USA) & $8^{u}$ & $1983-84$ & upgraded with US components to trainers \\
\hline S-211 trainer & Marchetti /Aermacchi/(I) & 24 & $1984-87$ & assembled under license \\
\hline A-4B Skyhawk & $\begin{array}{l}\text { Douglas; General Electric } \\
\text { (USA) }\end{array}$ & 24 & $1989-90$ & $\begin{array}{l}\text { Re-engined; modernized with US } \\
\text { components }\end{array}$ \\
\hline F-5 Tiger & $\begin{array}{l}\text { Galileo Avionica } \\
\text { /Finmeccanica/ (I); } \\
\text { Elbit (ISR) }\end{array}$ & $\begin{array}{l}28 \\
40 u\end{array}$ & $\begin{array}{l}1990 \\
1994-\end{array}$ & $\begin{array}{l}\text { Converted to reconnaissance configuration } \\
\text { Upgraded with new radar, avionics and } \\
\text { weapons systems; } \\
\text { Subsequently (1998) offered upgrade } \\
\text { service to Turkey and Brazil }\end{array}$ \\
\hline $\mathrm{F}-16 \mathrm{C} / \mathrm{D}$ & BAe Systems (UK) & & $1996-$ & Cockpit avionics upgrade to 'Falcon One' \\
\hline \multicolumn{5}{|l|}{ Transports } \\
\hline C-130 Hercules & Rockwell Collins (USA) & 10 & $2007-(14)$ & $\begin{array}{l}\text { Avionics; systems upgrade (also exports } \\
\text { upgrade service for Indonesia) }\end{array}$ \\
\hline \multicolumn{5}{|l|}{ Helicopters } \\
\hline AB-205 & Bell (USA) & 6 & 1984 & $\begin{array}{l}\text { Modernized; second-hand from Bangladesh } \\
\text { and Kuwait }\end{array}$ \\
\hline $\begin{array}{l}\text { AS-332, Super Puma, } \\
\text { AS-532 Cougar }\end{array}$ & $\begin{array}{l}\text { Aerospatiale /Eurocopter/ } \\
\text { (F) }\end{array}$ & 117 & $1985-88$ & assembled from kits under license \\
\hline $\begin{array}{l}\text { AS-350 Squirrel, } \\
\text { AS-550 Fennec }\end{array}$ & $\begin{array}{l}\text { Aerospatiale /Eurocopter/ } \\
\text { (F) }\end{array}$ & 120 & $1991-92$ & assembled from kits under license \\
\hline EC-120 & $\begin{array}{l}\text { Eurocopter (EU) and } \\
\text { CATIC (PRC) }\end{array}$ & & $1990-$ & Co-development; $15 \%$ stake \\
\hline AS-332 Super Puma & & & $2002-$ & Upgrade \\
\hline
\end{tabular}

Notes: (u) number is unconfirmed; ST Aerospace includes Singapore Technologies Aerospace and its predecessors

Sources: SIPRI; Flight International, various articles

Table 6.5 Growth of passenger and cargo air traffic in Singapore, 1973-2006

\begin{tabular}{lrrrrrrr}
\hline & $\mathbf{1 9 7 3}$ & $\mathbf{1 9 8 5}$ & $\mathbf{1 9 9 0}$ & $\mathbf{1 9 9 5}$ & $\mathbf{2 0 0 0}$ & $\mathbf{2 0 0 5}$ & $\mathbf{2 0 0 6}$ \\
\hline Registered carrier departures & 21,300 & 31,100 & 30,500 & 51,600 & 71,042 & 77,119 & 84,747 \\
Passengers carried (million) & 1,249 & 4,912 & 7,046 & 10,779 & 16,704 & 17,744 & 19,566 \\
Air freight, (million ton-km) & 68 & 981 & 1,652 & 3,687 & 6,005 & 7,571 & 7,981 \\
\hline
\end{tabular}

Source: World Development Indicators Online

Employment in aerospace increased from 2,761 workers in 1980 through 4,000 in 1985 to 5,676 in 1990 . Competitive wages (with an average annual growth of $9 \%$ between 1981 and 1985) attracted large numbers of foreign staff during the initial years, who were slowly replaced by locally trained skilled labor. As Figure 6.16 shows, aerospace production (which includes MRO as well as parts and components manufacturing) increased substantially during the early years. In 1980 aerospace value added was 192 
million US dollars, in 1985 it was 545 million, and it peaked at 651 million in 1988, with an average annual growth of 17\% over the period 1980-88. Between 1980 and 1985 exports increased from 106 to 355 million US dollars, at an average rate of $29 \%$ per year. By 1990 Singapore's exports increased to 528.7 million dollars. Singapore was still a net importer, mainly due to the new aircraft and equipment purchases of Singapore Airlines. According to Pang and Hill (1992) aerospace imports were more than 50\% higher than exports in 1981 and 1985.

The aerospace industry's performance was equally remarkable in comparison with other latecomers. In 1983 Singapore forged ahead of the aircraft designer Brazil in terms of value added (332 vs. 301 million US dollars). The difference is even greater in terms of labor productivity, given that Singapore achieved this value added level with $1 / 3^{\text {rd }}$ of the labor force of Brazil. Already by 1981 the level of labor productivity in the latecomer Singapore (81.1 US dollars per person engaged) was higher than in the US (72.9). This was of course achieved by concentrating on the MRO segment and on one cluster, while the US had a more diverse structure.

Figure 6.16 Gross Output, Value Added and Employment in the Singapore Aerospace Industry, 1977-2007

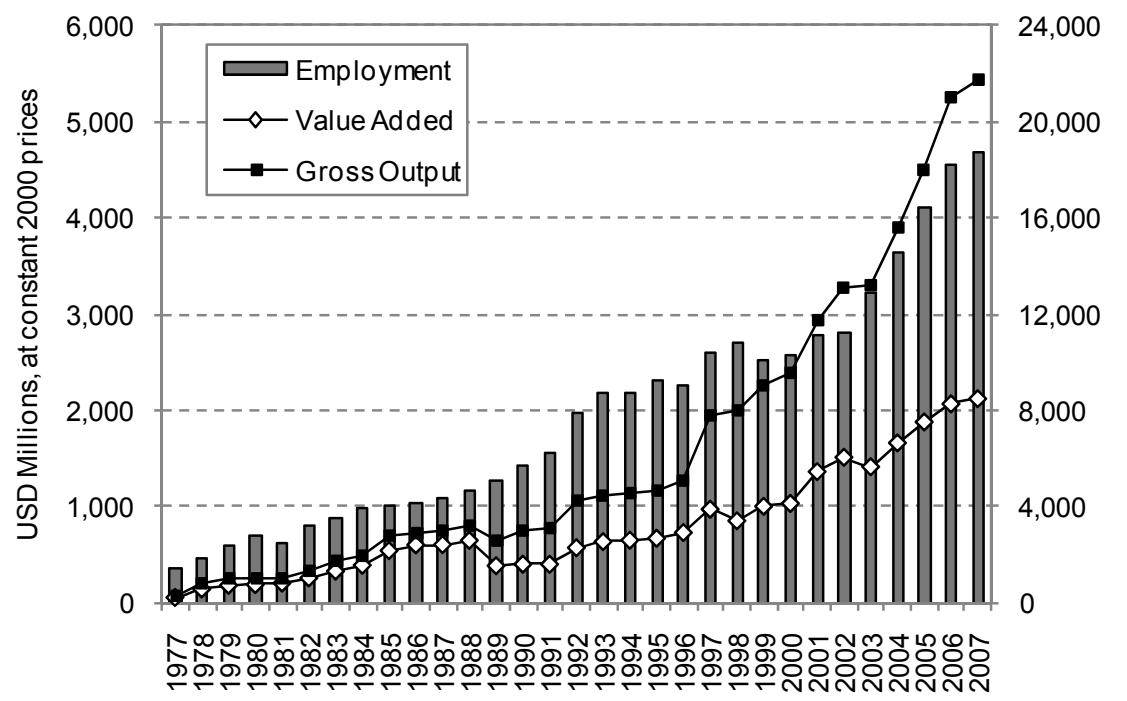


Box 6.1 Introduction to the civil aircraft maintenance, repair and overhaul market

The civil MRO market comprises of four segments. We provide a brief overview of the nature and frequency of the work they entail, the cost structures, and the type of companies involved in the activity.

Airframe heavy maintenance refers to what is called as " $\mathrm{C}$ and $\mathrm{D}$-checks" in commercial aviation. $\mathrm{C}$-checks include a detailed inspection of the airframe and aircraft components, and corrosion prevention. C-checks are due after 2,500-3,000 flight hours and may require 2 to 4,000 man-hours work, usually takes 3 days. D-checks refer to a comprehensive structural inspection and overhaul of the aircraft and can take up to 30 days, depending on the size of the aircraft. Since airlines can hardly afford keeping planes on ground for such a long period, they divide the work and carry out the inspection and overhaul in the form of 'C1-C4-checks'. All of these operations are carried out mainly by aircraft operators directly or through a subsidiary (still around $75 \%$ of the global MRO industry), and by independent MRO providers. Airframe heavy maintenance accounts for around $18 \%$ of global MRO turnover, nearly $70 \%$ of which is labor cost and $20 \%$ is material costs, such as solvents, fasteners and standard parts and airframe parts. Replacement parts, or "rotables" are often provided by airlines.

Line maintenance refers to the most frequent, lighter checks carried out on a daily basis in order to ensure that the aircraft remains flight worthy. These are the so-called transit checks, daily and weekly checks, A and B checks, which include simple visual checks, trouble shooting, defect rectification, overnight maintenance and component replacement. Providing these services accounts for one-fifth of all MRO revenues. Line maintenance is almost entirely done by airlines themselves. In about $10-15 \%$ of the cases they outsource it to subsidiaries or other contract agents. This is overwhelmingly a labor-intensive work, material costs incur expendables and consumables.

Engine overhaul is the largest segment, accounting for around $40 \%$ of global MRO turnover. It aims at restoring designed operational conditions of an engine according to performance guidelines established by the manufacturer. This is carried out by disassembling, inspecting the engine, repairing or replacing of parts if needed, reassembly and testing. Some "life-limited parts" have a prescribed replacement interval; otherwise engine overhaul takes place on an as-needed basis. The frequency of engine overhauls varies largely, between 4.5 and 24 thousand engine hours, similarly to the costs, which could vary between 0.45 and 5.5 million dollars. Materials account for almost two-third of the costs. Engine overhaul is carried out mainly by original equipment manufacturers (44\%), followed by aircraft operators (25\%), independent companies (13\%, such as ST Aerospace, or Standard Aero, MTU, SR Technics, Aerothrust, etc.) and airline subsidiaries (18\%, i.e. Delta Tech-Ops, Air France Industries and Lufthansa Technik). 
Component maintenance, repair and overhaul activities amount to around a quarter of the global MRO industry. These involve the maintenance, repair and overhaul of the main systems, including wheels and brakes, avionics, auxiliary power unit (APU), fuel systems, hydraulic power, flight controls, thrust reversers, landing gear, electrical systems, on-board environmental control and entertainment and other systems. Wheels and brakes are exposed to the heaviest duty and this is the largest cost item in MRO, followed by avionics and APU. These three activities account for $45 \%$ of the segment's turnover. Component MRO is the sub-market with the lowest concentration of firms, given the relatively higher competition on lower tiers in the aerospace supply chain. Original equipment manufacturers are the most important actors in the APU, avionics and fuel systems sub-segment, the rest is dominated by airlines providing in-house MRO or outsourcing it to subsidiaries or independent firms. Material costs are more important than labor costs when it comes to component MRO, especially in the case of wheels and brakes, APU, hydraulics and flight control systems and fuel systems. The most labor-intensive activities are electrical, landing gear and thrust reverser MRO. Specialist services are most important in the avionics sub-segment.

Source: Aeronautical Repair Station Association, 2009, "Global MRO Market Economic Assessment"168

\subsubsection{The emerging sectoral innovation system}

By the late 1980s, the Singapore aerospace industry accumulated capabilities to locally assemble older generation fighter and trainer aircraft, learned to upgrade them in collaboration with US manufacturers. It also gained capabilities to assemble and repair helicopters. It became a competitive MRO hub in South East Asia, receiving certifications not only for aircraft in the fleet of RSAF but also for the growing civilian fleet of the state-owned Singapore Airlines ${ }^{169}$.

Evidently, aerospace firms in Singapore were actively learning to apply advanced technologies to assemble and modify technologically complex aircraft that were at least 'new to the country'. MRO firms of Singapore learned to work efficiently and at competitive rates. For a comparison, repair and overhaul man-hours were reported to be 16-25 US dollars in Singapore, in comparison with 25-50 dollars in the US and 30-45 dollars in Europe. ${ }^{170}$ From the 1980s the industry depended not only on military demand but also on the rapidly growing commercial market. The primary channels of technology acquisition were foreign direct investments and licensing. The 1980s

\footnotetext{
${ }^{168}$ URL: http://www.arsa.org/files/ARSACivilAircraftMROMarketOverview-20090821.pdf; retrieved: 18 Feb 2011

169 The Engineering Division of Singapore Airlines was responsible for the maintenance of its fleet which by the end of the 1980s consisted of Airbus A300s, A310s, B747-200 and -300s, B757s and DC-10s.

170 "Singapore aerospace sprouts wings" Aerospace America, October 1986
} 
brought capabilities through foreign investment, especially from the US (air frame structures, systems and equipment MRO, manufacturing of turbine blades, compressors and landing gear). Singapore Aerospace was the main military producer, but a number of other transnational companies such as Sundstrand, Honeywell and Aerospatiale (Eurocopter) located a regional headquarter in Singapore which increasingly used local suppliers for production of smaller parts and the provision of engineering services.

The emerging sectoral system of innovation in aircraft was embedded in an emerging national innovation system which provided a strong knowledge base in science and engineering, access to foreign experts but also to a growing pool of locally educated, competitive workers. The government provided strong incentives for start-up companies in forms of tax holidays, investment allowances, training grants and investment guarantees. The Loyang Industrial Estate near Changi airport was the first aerospace industrial park which provided ready-built premises and a good infrastructure for new companies. The strong education system offered a full spectrum of vocational, technical and engineering programs.

The emergence of the national and the sectoral innovation systems were carefully designed by the government with a goal to benefit from high-value added, high-wage jobs in engineering-intensive activities. The sectoral system was designed to make benefit of Singapore's geographical location. These included the economic and air transport growth in the Asia-Pacific region, the cultural connections with China, and airlines' need to cut costs through a low-cost maintenance location and product support center.

Evidence that the innovation system has emerged is indicated by its ability to manage its knowledge resources in times of economic shocks. The system, unlike in any other emerging countries, learned quickly to react and shift to new, more competitive areas.

\subsubsection{Interruptions}

The most intriguing feature of the emergence of the aircraft industry of Singapore is the absence of long-lasting crises during the 1980s and 1990s. The sector was rather successful in avoiding two potentially severe crises of macroeconomic origin. In 1985, the disproportionately larger growth of wages compared to productivity caused a decline in competitiveness and slowed down export growth and foreign investments. Hill and Pang (1988) argued that apart from a drop in exports and imports, the industry was relatively unaffected, owing to the instant intervention of the government. We can also see that trainer upgrading and helicopter assembly activities provided sufficient orders for the industry during this time. The crisis had no effect on value added, which was in fact growing by $38.5 \%$ in 1985 primarily due to the defense industries. The Asian 
financial crisis of 1997 had also relatively limited impact on Singapore in comparison with its impact on aircraft innovation systems in other countries (see below).

Table 6.6 General Statistics of the Singapore Aircraft Industry (1977-2007)

\begin{tabular}{|c|c|c|c|c|c|c|c|c|c|c|c|}
\hline & \multicolumn{2}{|c|}{ Value Added } & \multirow[b]{2}{*}{$\begin{array}{l}\text { Gross } \\
\text { Output }\end{array}$} & \multirow[b]{2}{*}{ Empl. } & \multirow{2}{*}{$\begin{array}{c}\text { Labor } \\
\text { productivity; } \\
1000 \\
\text { USD/empl. }\end{array}$} & \multirow{2}{*}{$\begin{array}{l}\text { Wages I } \\
\text { Empl. } \\
\text { Change } \\
(\%)\end{array}$} & \multirow[b]{2}{*}{ Investment } & \multirow[b]{2}{*}{$\begin{array}{l}\text { Number } \\
\text { of firms }\end{array}$} & \multicolumn{2}{|c|}{ Export } & \multirow[b]{2}{*}{ Imports } \\
\hline & $\begin{array}{l}\text { (USD } \\
\text { mln) }\end{array}$ & $\begin{array}{c}\text { Change } \\
(\%)\end{array}$ & & & & & & & All & $\begin{array}{c}\text { Parts and } \\
\text { components }\end{array}$ & \\
\hline 1977 & 58 & & 77 & 1,400 & 41.8 & & 30.1 & n.a. & n.a. & n.a. & n.a. \\
\hline 1978 & 146 & 149.8 & 193 & 1,900 & 76.9 & & 11.6 & n.a. & n.a. & n.a. & n.a. \\
\hline 1979 & 185 & 26.6 & 244 & 2,340 & 79.0 & & 36.6 & n.a. & n.a. & n.a. & n.a. \\
\hline 1980 & 192 & 3.7 & 253 & 2,761 & 69.4 & & 18.2 & n.a. & 106 & n.a. & n.a. \\
\hline 1981 & 207 & 8.2 & 262 & 2,535 & 81.8 & & 36.8 & 10 & 99 & n.a. & n.a. \\
\hline 1982 & 261 & 25.9 & 335 & 3,169 & 82.3 & 10.4 & 79.1 & 11 & 149 & n.a. & n.a. \\
\hline 1983 & 332 & 27.1 & 435 & 3,494 & 94.9 & 1.6 & 6.4 & 17 & 220 & n.a. & n.a. \\
\hline 1984 & 393 & 18.5 & 499 & 3,898 & 100.8 & 14.0 & 37.9 & 17 & 255 & n.a. & n.a. \\
\hline 1985 & 545 & 38.5 & 692 & 3,998 & 136.2 & 9.7 & n.a. & 18 & 355 & n.a. & n.a. \\
\hline 1986 & 605 & 11.0 & 733 & 4,111 & 147.1 & -7.6 & n.a. & 19 & n.a. & n.a. & n.a. \\
\hline 1987 & 607 & 0.4 & 757 & 4,343 & 139.8 & 5.5 & n.a. & 21 & n.a. & n.a. & n.a. \\
\hline 1988 & 651 & 7.2 & 814 & 4,659 & 139.7 & 2.9 & n.a. & 20 & 419 & n.a. & n.a. \\
\hline 1989 & 388 & -40.4 & 650 & 5,121 & 75.8 & 3.0 & 75.0 & 22 & 642 & 338 & 1,604 \\
\hline 1990 & 403 & 4.0 & 759 & 5,676 & 71.1 & 1.5 & 102.6 & 26 & 529 & 347 & 1,211 \\
\hline 1991 & 403 & -0.2 & 769 & 6,259 & 64.3 & 6.3 & 81.4 & 29 & 394 & 290 & 1,633 \\
\hline 1992 & 575 & 42.8 & 1,057 & 7,915 & 72.7 & 23.3 & 178.9 & 32 & 402 & 348 & 1,769 \\
\hline 1993 & 638 & 10.9 & 1,105 & 8,745 & 72.9 & -1.9 & 160.1 & 33 & 285 & 270 & 1,989 \\
\hline 1994 & 653 & 2.4 & 1,138 & 8,736 & 74.7 & 5.6 & 130.1 & 36 & 259 & 218 & 1,806 \\
\hline 1995 & 673 & 3.1 & 1,179 & 9,214 & 73.0 & 2.4 & 108.5 & 39 & 414 & 292 & 1,824 \\
\hline 1996 & 732 & 8.8 & 1,278 & 9,012 & 81.3 & 5.8 & 83.7 & 39 & 575 & 410 & 3,213 \\
\hline 1997 & 974 & 33.0 & 1,949 & 10,402 & 93.7 & 1.4 & 92.3 & 45 & 705 & 553 & 3,381 \\
\hline 1998 & 854 & -12.3 & 1,997 & 10,831 & 78.9 & -3.3 & 128.8 & 40 & 619 & 488 & 2,686 \\
\hline 1999 & 1,004 & 17.6 & 2,255 & 10,093 & 99.5 & 19.7 & 146.3 & 43 & 488 & 456 & 2,281 \\
\hline 2000 & 1,034 & 2.9 & 2,391 & 10,334 & 100.1 & 1.9 & 160.8 & 44 & 670 & 534 & 1,152 \\
\hline 2001 & 1,364 & 31.9 & 2,951 & 11,142 & 122.4 & -5.0 & 232.7 & 46 & 831 & 455 & 3,721 \\
\hline 2002 & 1,513 & 10.9 & 3,273 & 11,278 & 134.2 & 9.3 & 159.1 & 49 & 901 & 526 & 3,018 \\
\hline 2003 & 1,414 & -6.5 & 3,316 & 12,931 & 109.4 & -0.4 & 170.7 & 54 & 1,122 & 744 & 3,654 \\
\hline 2004 & 1,662 & 17.5 & 3,892 & 14,584 & 114.0 & 2.9 & & 68 & 1,141 & 952 & 3,655 \\
\hline 2005 & 1,880 & 13.1 & 4,508 & 16,493 & 114.0 & -3.6 & & 63 & 1,334 & 993 & 3,325 \\
\hline 2006 & 2,067 & 10.0 & 5,253 & 18,169 & 113.8 & 1.2 & & 68 & 1,987 & 1,609 & 5,021 \\
\hline 2007 & 2,121 & 2.6 & 5,432 & 18,777 & 113.0 & & & & 2,580 & 2,090 & 4,969 \\
\hline
\end{tabular}

Sources: Singapore Statistics; UNIDO; A*STAR Singapore

Notes: values in US dollar at constant prices

\subsubsection{Smooth transitions}

By the time the global industry faced by far the most severe crisis in 1990, Singapore had already initiated a fundamental overhaul of its aerospace industry and innovation system. The overhaul was triggered by the declining sales and value added experienced 
in 1989 due to the underperformance of the military segment. In 1989 value added dropped below 1984 levels, sales below 1985 levels, labor productivity declined by 46\% in a single year. Singapore was quick to realize that the global competitive environment was transforming towards greater internationalization. It also saw the limits of its domestic market and the growth potential of the Asia Pacific region. This realization led to a new strategy which implied steering away from the defense industries and expanding the commercial segment. Singapore rather swiftly and efficiently introduced measures to rejuvenate its aerospace industry by privatization, reorganization and internationalization of its largest holding, Singapore Technologies ${ }^{171}$.

In order to finance further expansion, the government privatized a third of its stake in Singapore Technologies Aerospace (ST Aero) in June 1990. The offering was highly successful (shares were 33 times oversubscribed) and raised 150 million SGD ${ }^{172}$, almost equal to the company's annual turnover. Commercial maintenance activities were shifted to a spin-off company, Singapore Aviation Services (SASCO) before the partial flotation. At the beginning of the 1990s, more than $2 / 3^{\text {rd }}$ of ST Aero's business was coming from the defense segment. The aim was to increase commercialization and increase foreign sales. ST Aero's turnover from foreign operations was already as high as $32 \%$ by 1989 . This increased to $50 \%$ by $1990 .{ }^{173}$ In 1990 , the company set up ST Rotables at Stansted Airport in the UK. In 1991 it established a 20 million US dollars green-field investment in Mobile, Alabama to offer commercial maintenance and cargo conversions for Fedex. It also established operations in Los Angeles by acquiring a local sheet-metal supplier of Boeing with an aim of moving closer to its customers.

ST Aero also took a major step in venturing into a new area of co-development. It signed a deal with the French Aerospatiale (now Eurocopter) and China National Aero-Technology Import and Export Corporation (CATIC) to jointly develop a 5-seat helicopter, the EC-120 (original designation P120L). The joint venture started in 1990. Eurocopter owned a $61 \%$ share and was responsible for the instrument panel, landing gear, seats, rotor system, transmission, final assembly, flight test and certification. CATIC (through Hafei Aviation Industry Company) owned a $24 \%$ stake and was responsible for cabin structure and doors, engine cowlings, pod central and intermediate structure and fuel system. Singapore Technologies Aerospace owned 15\% of the project and was responsible for tailboom, fin, horizontal stabilizer, fenestron (tail rotor), general doors and instrument pedestal development. The design was successful,

\footnotetext{
${ }^{171}$ In 1989 Singapore Aircraft Industries was reorganized into Singapore Technologies in line with the diversification strategy into commercial aerospace.

172 This equals to around 100 million US dollars at 2000 prices.

173 “Gradually Global” Flight International: Asian Aerospace Special 19-25 Feb 1992
} 
but ST Aero did not participate in the production of the helicopter later on. Instead, it took on duties in line with what it was doing before: MRO and aircraft refurbishment. In the mid 1990s it upgraded the F-5 fighters of RSAF with new radar, avionics and weapons systems. In 1999 it successfully developed a method for passenger to cargo conversion of B-757s. In 2002 it entered into a strategic cooperation with BAe Systems of the UK to add new avionics suits and mission computers to some of the F-16s Singapore had acquired, resulting in the "Falcon One" upgrade. It also upgraded Super Puma helicopters and C-130 Hercules transport planes for the air force over the 1990s and 2000s (Table 6.4). In 2006 the company entered the mini UAV systems business after being contracted by the RSAF. During the 2000s, STA Aero continued the internationalization of its activities. It opened another facility in the USA in San Antonio, Texas in 2006. It entered the Chinese market (established MRO facilities in Shanghai in 2004, logistics in Guangzhou in 2007); in 2006 it acquired SAS Component A/S in Denmark and established a subsidiary in Panama. As a result of the growing on the international markets, ST Aero tripled its revenue between 1996 and 2007 and increased profits by 9-fold to 143 million dollars (Figure 6.17).

ST Aero was the largest, but by far not the only company in the industry. The number of companies in fact increased from 20 in 1988 to 33 by 1992. This increase was only partly a result of the creation of subsidiaries. This period also saw major new investment in the sector, with an average of 120 million dollars between 1989 and 1995 (Table 6.6). By the mid 1990s, major companies such as GE, Goodrich, Hamilton Sundstrand, Liebherr, Rockwell Collins or Rolls Royce Engines had established a presence in Singapore, expanding the avionics and engines knowledge base in the country. The largest competitor in the MRO industry for ST Aero was another stateowned company, Singapore Airlines (SIA). Over the years, SIA Engineering has responsible for the engineering work on the airline's expanding large aircraft fleet. In 1992, SIA's Engineering Division became a separate subsidiary, SIA Engineering, with an intention to increase foreign presence. SIA Engineering similarly expanded its MRO operations in the late 1990s and early 2000s and set foot in Australia, the United States, Hong Kong, Indonesia, Philippines and Vietnam. Between 1996 and 2007 its global employment increased from 4,200 to 6,100, its turnover grew from 407 to 539 million dollars (Figure 6.17). 
Figure 6.17 Maintenance, repair and overhaul revenues of ST Aerospace and Singapore Airlines Engineering, 1996-2008

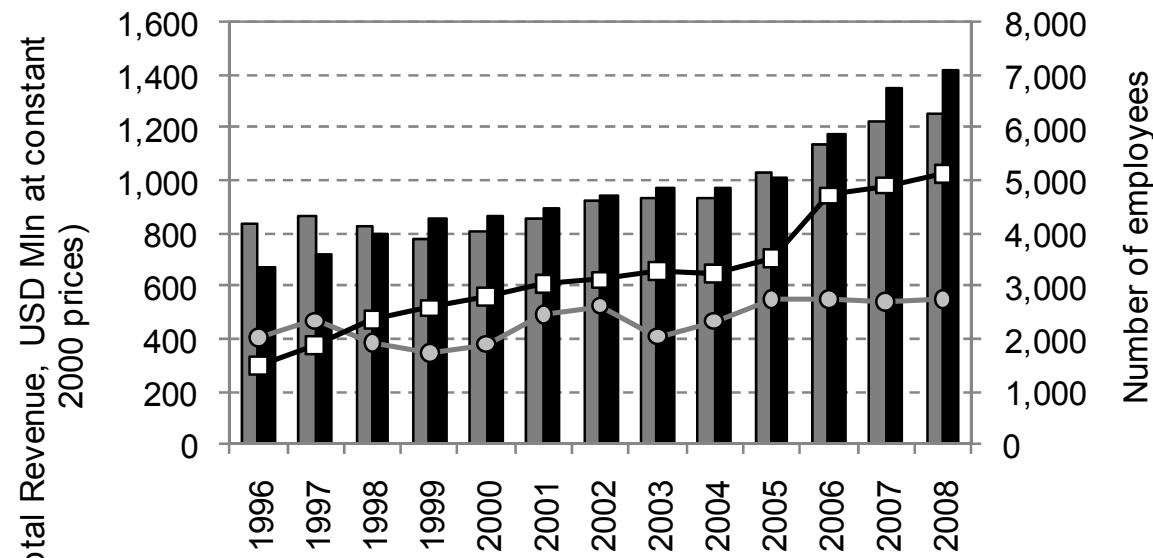

$\square$ SIA Eng. EMP, ann avg $\longrightarrow$ ST Aero EMP, ann avg
- - SIA Eng. Total Revenue $\square-$ ST Aero Total Revenue

Sources: SIA Engineering and Singapore Technologies Aerospace annual reports, various years. Note: Constant price series converted with a 1.72 SGD/USD rate for 2000.

\subsubsection{A new growth trajectory}

In short, during the early 1990s, Singapore's partly state-owned companies increasingly focused on the commercial markets. They realized growth through global expansion. At the same time, the knowledge base of the industry was strengthened substantially through a focus on innovation and pre-competitive research. Targeted Aerospace R\&D support programs were designed by the newly formed Agency for Science, Technology and Research (A-Star). The program defined new R\&D directions: advanced materials, manufacturing processes and automation, information and communication, inspection and non-destructive testing, and computational modeling and dynamics.

It may seem paradoxical that the industry as a whole is performing well, despite the relatively low R\&D inputs in comparison with other sectors in Singapore as well as with other countries. In 2009, aeronautical engineering employed less than $1 \%$ of Singapore's researchers and received hardly more than $1 \%$ of all $R \& D$ expenditures. Aircraft manufacturing companies in Singapore owned only 14 patents in the same year. ${ }^{174}$ In an international comparison, Singapore's aerospace R\&D of 2005 was 15.3 million US dollars, compared with 155.5 million of South Korea, 340 of Japan or 672

\footnotetext{
${ }^{174}$ National Survey of R\&D in Singapore 2009, Agency for Science, Technology and Research.
} 
million of Canada. Remarkably, Singapore managed to establish a "low-cost" aerospace innovation system owing to its specialization in the MRO and parts and components manufacturing segments. Nevertheless, due to intensive linkages with other related industries, aircraft manufacturing in Singapore benefitted from R\&D input into fields such as electronics and electric, mechanical, computer, and material science and engineering, which received around 85 percent of the 2.5 billion USD R\&D expenditures.

These close linkages explain how a shift to knowledge-intensive activities occurred in aerospace in harmony with the overall shift of the national innovation system. Singapore consciously increased the national and corporate R\&D during the last two decades. From 380 million dollars in 1990, gross expenditure on R\&D increased to 3.4 billion dollars by 2007 (Figure 6.18). Although in comparison with other OECD countries, Singapore's aerospace R\&D is relatively low (15.3 millions USD in 2005, as opposed to 155 million in South Korea, 340 million in Japan or 1.9 billion in Germany), but its aerospace activities are centered around selected segments which are closely related to existing local capacities (such as avionics and the electronics industry or precision engineering and engineering capabilities in general).

Figure 6.18 The National Innovation System of Singapore - R\&D Expenditures, 1981-2009

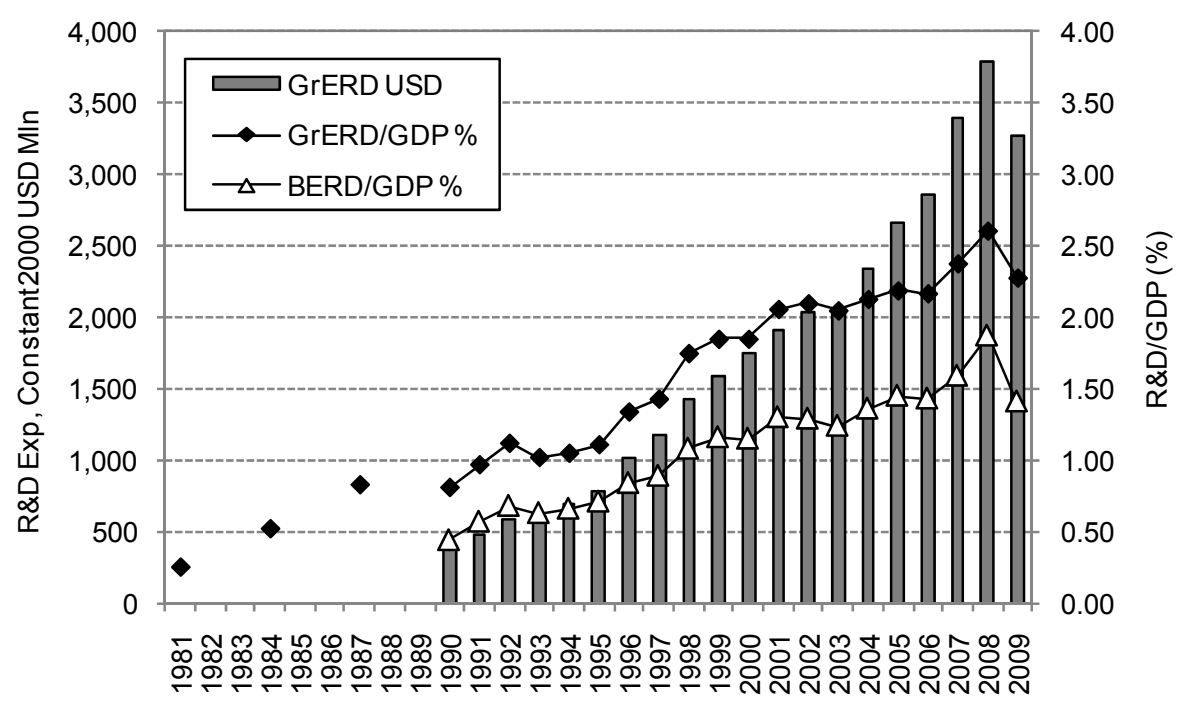

Sources: "National Survey of R\&D in Singapore 2009", Agency for Science, Technology and Research, Singapore; Yearbook of Statistics Singapore, various editions. Note: Constant price series converted with a 1.72 SGD/USD rate for 2000. 
A good indicator of the strong performance of the national and sectoral innovation systems is how the aerospace industry weathered the 1997 the Asian financial crisis. Due to declining demand of partners in the region, the crises caused a $12 \%$ decline in value added by 1998, but growth resumed the following year at an $18 \%$ rate. The reason for the quick recovery can be explained partly by the strong macroeconomic and financial fundamentals with which Singapore entered the crisis (Chia 1999). However, even if the Singapore dollar depreciated against the US dollar, it appreciated against other Southeast Asian currencies and regional demand for aerospace products (including repair) was falling. But the regional markets were declining (aerospace exports dropped by $11 \%$ drop from 1997 to 1998 and by $20 \%$ from 1998 to 1999). Yet the industry showed strength by having expanded to overseas markets, and shortfalls in regional demand were compensated for by increased military orders. On the other hand, despite the crisis, Singapore continued to increase $R \& D$ expenditures. The experience also gave incentives for companies to further expand overseas presence (see above ST Aero's strategy in the 2000s).

At the moment, Singapore's aerospace innovation system and production facilities are constantly expanding. The number of aerospace graduates has been constantly growing and is expected to reach 1,000 annually in $2010 .{ }^{175}$ Current manufacturing activities focus on avionics and aircraft and engine parts and components. The latest incentives for investment include a 300 hectares new industrial park at a renovated airport in Seletar to be completed in 2018. Three major companies that already indicated their intention to move there and expand capacities are EADS's helicopter maker Eurocopter and the engine manufacturers Pratt \& Whitney and Rolls Royce. The latter intends to bring engine parts manufacturing (wide chord fan blades), engine assembly and test work to Singapore to serve the Asian large aircraft market. This shows once again that transnational companies value Singapore's location and their contribution made Singapore a "first mover latecomer".

Singapore's future competitiveness lies in the still increasing performance of the aerospace innovation system. It can draw from a strong knowledge stock. Almost twothird of all researchers (60-64\%) has been working in the field of engineering and technology in the last decade. Their number in business enterprises has been increasing substantially, from 5,841 in 2002 to 11,732 in 2007 (in terms of full time equivalent). Singapore's commitment to invest in education, training and $R \& D$ is well above the

\footnotetext{
${ }^{175}$ This is an aggregate of all graduates from universities, polytechnics and technical institutes, and includes aeronautical engineering, avionics, aviation management and 'mechatronics'. Additionally, courses started in 2007 to expand the number of precision engineering specialists (Association of Aerospace Industries Singapore, 2010)
} 
regional average. But parallel to the investment in a knowledge-based growth, Singapore's Economic Development Board still provides incentives to invest in the MRO segment similarly to the early years of emergence.

\subsubsection{Conclusion}

Within three decades following its emergence, a strong aircraft industry emerged in Singapore. The sector is among the top ten in the world in terms of value added, with output levels similar to Brazil. The aircraft industry in Singapore differs from other latecomers in many ways. It did not seek prestige through producing a locally designed aircraft, rather accumulated capabilities to become a highly competitive MRO hub. Since 1980, it was one of the very few countries that managed to sustain growth in the sector. It was also one of the first Asian producers (along with Hong Kong) to benefit from the new winds of internationalization in the 1990s.

In Singapore, the emergence of the industry and sectoral innovation system was successful because of the mixed policy of developing a commercially-focused, but militarily-aided system to accumulate technological capabilities. Hill and Pang (1988) drew attention to the major differences between the way Singapore and Indonesia promoted their aerospace industries. While Singapore followed an outward-looking strategy with a strong repair and services orientation, Indonesia was inward looking, aimed at manufacturing complete aircraft for the domestic market. Singapore capitalized on its competitive advantages and relied on several firms, the Indonesian government owned a national champion which was operating in a highly politicized environment. The government's interventions in Singapore were also "extensive" and state ownership was considerable, but it was 'efficiency enhancing', unlike in Indonesia. Already in 1988 the authors called attention to the vulnerability of the Indonesian aircraft industry because of its higher political dependence in contrast with Singapore.

A consequence of the outward-looking strategy was the strong competition Singaporean manufacturers and MRO providers had to face. This fostered the emergence of a sectoral innovation system early on and close interactions among the main stakeholders. Latecomers' technological disadvantages were offset by the government's activist industrial policy during the years of emergence. This included simultaneously "importing" experts ${ }^{176}$ and training locally a competitive, skilled labour force; procuring aircraft and ordered aircraft refurbishment programs to expand

\footnotetext{
${ }^{176}$ Immigrant labor was an overall important knowledge source for Singapore. Immigrant stock increased from half a million in 1980 to 1.5 million in 2005; also relative share in society increased from $22 \%$ to $35 \%$ (World Development Indicators Online).
} 
technological capabilities of its leading firm. On the other hand, by building industrial parks and providing incentives for foreign investment, it laid the foundations of a strong private sector in aerospace. The specialization in MRO activities and component manufacturing and the proximity of related industries also efficiently substituted missing capabilities and became a source of innovation. The aerospace innovation system was well embedded in the national innovation system of Singapore. This not only offered synergies for the emerging industries, but was the main reason why Singapore managed to respond to competitive challenges quickly and avoided decline of production that lasted more than a year.

Figure 6.19 Radical innovation system change in Singapore's sectoral innovation system in Aerospace

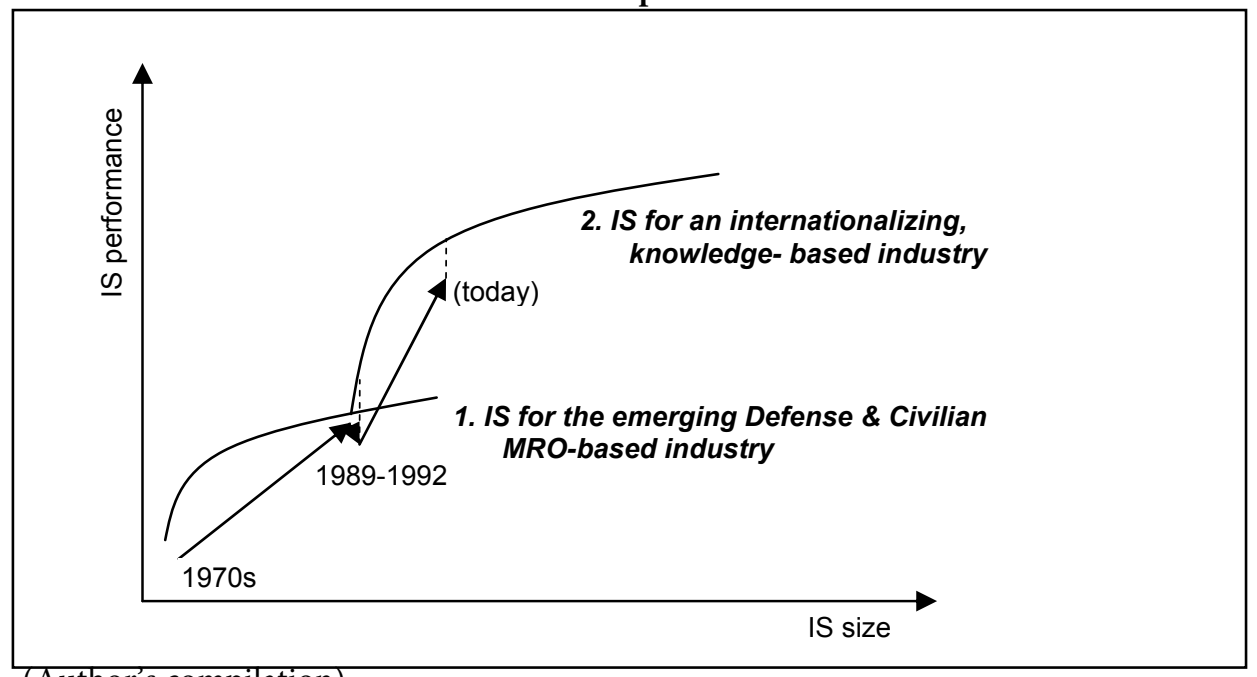

(Author's compilation)

As shown in Figure 6.19, a radical innovation system change occurred between 1989 and 1992. This shift coincided with a global crisis in the aerospace industry, which was triggered by the decrease in defence spending and increase in oil prices at the end of the Cold War and beginning of the Gulf War. Singapore was one of the first countries to readjust its innovation system and industrial orientation according to the changed competitive environment It quickly realized the advantages it can gain from the internationalization of supply chains and the dismantling of previously vertically integrated company structures in Europe and North America. Singapore had a potential to become a low-cost regional supply and maintenance base, but only if it could expand the capacities (gaining economies of scale by expanding internationally) and by increasing its portfolio of design and production capabilities. Joint development only 
occurred in the case of the EC-120 helicopter project, but Singapore remains a potential location for components development, given the continued investment in R\&D (twothird of which is paid by the private sector) and in physical and human capital. On the other hand, economies of Asia were demonstrating rapid growth which offered potentials for the aviation industry and supporting manufacturing and MRO bases. To make the state-owned companies more flexible for international expansion and raise capital, the government chose partial flotation in the case of ST Aerospace, or spinning off the Engineering Division of SIA. (Note the similar considerations behind the privatization of Embraer). Because of responding quickly to the new competitive environment, Singapore's aerospace industry has managed to maintain a competitive edge in the rapidly growing region, despite existing and emerging competition in Hong Kong, Thailand and Malaysia.

Unlike any other emerging aerospace producer country, Singapore successfully managed a 'transition without interruption' in the sectoral innovation system. It was a fundamental system change in which Singapore was targeting the knowledge-intensive activities within the industry. This is indicated on the one hand by the two-fold expansion of R\&D expenditure and number of science and engineering researchers in the national innovation system between 1990 and $1995 .{ }^{177}$ On the other hand, it is indicated by the changing product structure of the aerospace manufacturing industry (MRO and small parts and components manufacturing of the latest aircraft models; avionics and engine components manufacturing and a declining share of military programs). The number of new aerospace firms in Singapore increased after 1990, but so did the largest Singaporean MRO firms expand in foreign markets.

Singapore also succeeded in managing the transition efficiently. The aim and means of achieving competitiveness were well designed in the emerging innovation system, which minimized institutional inertia in a time of transition. For instance, the product structure and repair activities did not have the long lead time which aircraft producers had to deal with. The similarity between existing capabilities and those required in the new system was high and highly compatible. What companies had to learn was organizational innovation, in addition to a rapidly developing avionics segment and a rather incrementally changing engine or aircraft parts production and repair activities. Moreover, the innovation system has had a number of actors specialized in fostering knowledge exchange, such as the Association of Aerospace Industries in Singapore, private consultants or government funded $R \& D$ agencies. In

\footnotetext{
177 There is no consistent data to monitor aerospace R\&D and innovation measures over time. The National Survey of ReD by A-Star has a changing coverage of firms between 2002 and 2009, in the period available. We therefore rely on indicators for the whole economy.
} 
addition, a sound macroeconomic environment and high economic growth ${ }^{178}$ were similarly important for a swift transition.

In the coming decades, the Asia-Pacific region is forecast to witness further rapid growth in air traffic. Singapore's challenge will be to sustain their first-mover advantage as many other countries in the region will compete to become MRO hubs. Large investments were made in MRO in Thailand, Malaysia, as well as in China. So far Singapore has successfully safeguarded its position (and retained budget airline clients as well) against cheaper locations in neighboring Johor Bahru or Kuala Lumpur in Malaysia based on its reputation of top-quality service and guaranteed, rapid turnaround time owing to the efficient organization of engineering and management of logistics. Even if neighbors can catch up with the services over time, the incomparable performance and investment into the national innovation system of Singapore will most likely continue to offer the required linkages to respond to find a new competitive edge.

\footnotetext{
${ }^{178}$ Between 1989 and 1992, annual GDP growth averaged at 8\%.
} 


\subsection{ARGENTINA: The case of a languishing aerospace innovation system}

\subsubsection{Introduction}

Despite a very promising start, a fully functioning aerospace innovation system never emerged in Argentina. Local aircraft design and construction activities started before World War II in Córdoba where an advanced plant employed over 9000 employees by 1950. ${ }^{179}$ However, it was a military plant and export considerations played little role in new product development. The inward-looking economic strategy soon proved to be unsustainable, creating a crisis in a still infant industry. In the absence of a transition to a different growth trajectory, the industry languished. Subsequent efforts in the 1960s and 1970s by military governments to pump more money in an unchanged innovation and production system once again resulted in a short-lived success. Technological capabilities continued to erode. Attempts at privatization in 1987 and concessions in 1995 were not combined with well-designed, radical institutional changes. As a consequence only around 1000 employees work in the aerospace industry, which does not mean more than maintenance and overhaul activities in Córdoba.

In 1969, when Embraer started, Argentina had the largest aircraft industry in Latin America in terms of employees (value added is not known). By 2003 value added was 70 million USD, equal to less than $3 \%$ of Brazilian value added (Table 6.7).

Table 6.7 Argentina's Aerospace production in comparison, selected years (USD $\mathbf{m l n}$ at constant $=\mathbf{2 0 0 0}$ prices)

\begin{tabular}{lrrr}
\hline Countrv & 1984 & 1993 & 2003 \\
\hline Argentina & 40 & 9 & 70 \\
Brazil & 242 & 260 & 2,581 \\
China & 3,599 & 1,692 & 3,392 \\
Indonesia & 12 & 192 & $\mathrm{n} / \mathrm{a}$ \\
USA & 48,281 & 53,218 & 47,949 \\
\hline
\end{tabular}

Source: Argentina: UNIDO (for years 1984, 1993) and INDEC (2003); Brazil: IBGE; Chile, Colombia: UNIDO. Note: PPP/UVR applied for conversion of local currency to USD: Argentina: 0.846; Brazil: 1.09; China: 4.6; Indonesia 4201. (See Chapter 3 for UVRs).

\footnotetext{
179 The sources on Argentina can at best be called patchy. Production statistics are almost non-existent. Hira and Oliveira note that "there is no documentation regarding audits or financial reports to be found regarding the Fábrica; no systemic evaluation appears to have taken place" (2007 p.344). Limited national statistics on the sector at 3-digit level are only available for the years 1983, 1994 and 2003. We therefore rely on secondary literature, including industry journals (e.g. various editions of Flight International), the Chronicles of the Ministry of Science and Technology of the Province of Córdoba (Arreguez 2007) and the insightful comparative analysis of Hira and Oliveira (2007).
} 
Since its founding in 1927, the plant giving home to aerospace manufacturing and related activities in Córdoba has often changed its name, internal organizational structure and external dependence. Table 6.8 provides an overview of the changes in scale and name.

Table 6.8 Name and size changes of the aircraft manufacturing plant of Córdoba

\begin{tabular}{|c|c|c|c|c|}
\hline Year & Name of Organization (Abbreviation) & & $\begin{array}{l}\text { Number of } \\
\text { Employees }\end{array}$ & $\begin{array}{c}\text { Construction } \\
\text { Floor }\left(\mathrm{m}^{2}\right)\end{array}$ \\
\hline 1927 & Fabrica Militar de Aviones & $(\mathrm{FMA})$ & 193 & 8,340 \\
\hline 1931 & & $(\mathrm{FMA})$ & $\mathrm{n} / \mathrm{a}$ & 34,000 \\
\hline 1943 & Istituto Aerotécnico & $(\mathrm{IAe})$ & 3,070 & 265,000 \\
\hline 1952 & Industrias Aeronáuticas y Mécanicas del Estado & (IAME) & 9,550 & $\mathrm{n} / \mathrm{a}$ \\
\hline 1957 & Dirección Nacional de Fabricaciones e Investigaciones & (DINFIA) & 8,273 & 217,000 \\
\hline 1967 & Fabrica Militar de Aviones & (FMA) & $\mathrm{n} / \mathrm{a}$ & $\mathrm{n} / \mathrm{a}$ \\
\hline 1968 & Area de Material Córdoba & $(\mathrm{AMC})$ & 7,507 & $\mathrm{n} / \mathrm{a}$ \\
\hline 1987 & Fábrica Argentina de Materiales Aeroespaciales & (FAMA) & $\sim 3,000^{a}$ & $\mathrm{n} / \mathrm{a}$ \\
\hline 1991 & Area de Material Córdoba & $(\mathrm{AMC})$ & $\mathrm{n} / \mathrm{a}$ & $\mathrm{n} / \mathrm{a}$ \\
\hline $1994^{b}$ & & $(\mathrm{AMC})$ & 2,200 & $\mathrm{n} / \mathrm{a}$ \\
\hline 1995 & Lockheed Martin Aircraft Argentina S.A. & (LMAASA) & 1,250 & $\sim 220,000$ \\
\hline 2002 & & (LMAASA) & 900 & $\mathrm{n} / \mathrm{a}$ \\
\hline 2010 & Fabrica Argentina de Aviones & (FAdeA) & 1,100 & $\sim 220,000$ \\
\hline
\end{tabular}

Source: Own compilation based on Arreguez (2007); Arroyo (2004) various articles of Flight International Notes: (a) Estimate based on 1985 UNIDO figure of 3,092 for the entire aerospace industry;

(b)before privatization. Note that sources differ on the actual number of employees reduced over the privatization period. Scheetz (2002) reports that "the plant's 2950 workers were immediately reduced to 1950 (and then to 950)", whereas LMAASA director Radcliffe reports a reduction of workforce from around 2200 to 1250 when Lockheed Martin took over operations ${ }^{180}$.

\subsubsection{The emergence of a sectoral aerospace innovation and production system in Argentina}

\subsubsection{The emergence of aircraft manufacturing in Córdoba}

The Fábrica Militar de Aviones (FMA, Military Aircraft Factory) was established in Córdoba in 1927, ${ }^{181}$ more than 700 kilometers northwest of Buenos Aires. The plant was and Army depot under the supervision of the War Ministry. Operations began with 193 workers on a construction floor of $8,340 \mathrm{~m}^{2}$. The following year the complex was expanded with a number of laboratories, workshops and auxiliary buildings. Initial production of small planes under license (e.g. the Avro K-504 Gosport, Bristol F.2B,

180 "Pampa production could roll again" Flight International 20-26 Mar 1996

${ }^{181}$ A few smaller, private workshops constructing simple aircraft had already been operating in Argentina since 1910, but the scale of their industrial activities were less significant compared to the one established in Córdoba. 
Dewoitine D-21 or the Focke-Wulf FW-44 Stieglitz) was soon complemented with local designs. The first one was the AE C-1 Triplaza biplane from 1931. Other notable designs include the 5-seater transport plane AE T-1 from 1932, some 61 military observer monoplanes AE MO1 and the FMA 20 El Boyero (see Table 6.9). Licenses were acquired by FMA to locally produce engine designs of Lorraine Dietrich, Wright and Siemens. This provided the know-how to develop the Ae R-16 El Gaucho and I.Ae R-19 El Indio engines.

By the end of World War II FMA had produced around 400 planes (Table 6.9), about half of the Brazilian production in the same period. In both countries the military was the main user of locally made planes. But while Brazil was producing for the allies, Argentina declared itself neutral during most of the war. Argentina was therefore not receiving post-war aid and cheap supply of aircraft from the USA, which, ironically, meant that its aircraft industry did not experience the post-war crisis that affected Brazil until 1960. ${ }^{182}$ Fueled by the isolationist economic and foreign policies of President Perón, the aircraft industry was designated as strategic and was given high priority even after the war.

Already in 1943 FMA was renamed as 'Instituto Aerotécnico' (Aero-technical Institute, IAe), with a mission to develop aeronautical production in Argentina and unite the related industrial activities, deemed strategic for national defense. The institute combined research, design, production and maintenance work. Army major San Martin became the director of I.Ae. At the same time there were significant infrastructural developments, including the addition of a new $20,700 \mathrm{~m}^{2}$ assembly hall (the largest so far in South America).

A first local product of this techno-nationalist period was the IAe 22 D.L. ${ }^{183}$, a trainer inspired by the North American T-6 Texan. By 1950, this was the most produced plane in Argentina. Between 1944 and 1950 two batches of 100 IAe 22 D.L. planes were delivered. The 22 D.L. used parts and materials produced domestically. The number of private companies supplying the aeronautical industry increased from 5 in 1941 to over 100 by 1945, as a result of a new boost to increase public-private linkages (Arreguez, 2007). In 1946 the first bomber in Latin America flew for the first time, the twin-engine IAe 24 Calquin (Royal Eagle), of which the military procured a series of 100 .

\footnotetext{
${ }^{182}$ Although other sectors, especially the agriculture, did experience detrimental effects of Argentina being left out of the Marshall Plan and the loss of North American and European markets.

${ }^{183}$ D.L. stands for "Dientes de León", or lion's teeth, in response to US Secretary of State Cordell Hull's earlier reference to Argentina as a "toothless lion".
} 
Table 6.9 Serial Aircraft Production in Argentina

\begin{tabular}{|c|c|c|c|c|c|}
\hline Aircraft Model & Type & Engine & $\begin{array}{l}\text { First } \\
\text { Flighta }^{\mathrm{a}}\end{array}$ & $\begin{array}{cc}\text { Nr. } & \text { Series } \\
\text { built } & \text { Production }\end{array}$ & Notes \\
\hline \multicolumn{6}{|l|}{$\underline{\text { Local Designs }}^{b}$} \\
\hline AE M01 & Military observer & Piston (Wright) & 1934 & $61(1934-37)$ & $\begin{array}{l}\text { First local design } \\
\text { produced in series }\end{array}$ \\
\hline $\mathrm{AEC} 3$ & $\begin{array}{l}\text { Two-seater } \\
\text { monoplane }\end{array}$ & $\begin{array}{l}\text { (Piston, Armstrong } \\
\text { Siddeley) }\end{array}$ & 1934 & 16 (1934-?) & \\
\hline $\begin{array}{l}\text { FMA } 20 \text { 'El } \\
\text { Boyero' }\end{array}$ & General Aviation & Piston (Continental) & 1940 & 131 (1949-51) & $\begin{array}{l}\text { Designed by FMA, } \\
\text { produced by Petrolini } \\
\text { Hermanos }\end{array}$ \\
\hline I.Ae. 22 D.L. & Trainer & $\begin{array}{l}\text { Piston (IAe and Hamilton } \\
\text { Standard) }\end{array}$ & 1944 & $200(1944-50)$ & \\
\hline I.Ae.24 Calquin & Attack/Light Bomber & Piston (Pratt \& Whitney) & 1946 & $101(1947-50)$ & \\
\hline IA 35 Huanquero & Multi-purpose aircraft & Twin-Piston (IAe) & 1953 & $47(1957-62)$ & Designed by Kurt Tank \\
\hline IA 46 Ranquel & General Aviation & Piston (Lycoming) & 1957 & 220 (1958-?) & \\
\hline IA 50 Guarani II & Utility & $\begin{array}{l}\text { Twin-Turboprop, } \\
\text { (Turbomeca) }\end{array}$ & 1963 & 48 (1966-?) & Seats 12 passengers \\
\hline IA 58 Pucará & $\begin{array}{l}\text { Ground attack and } \\
\text { counter-insurgency }\end{array}$ & $\begin{array}{l}\text { Twin-Turboprop, (Garrett, } \\
\text { Turbomeca) }\end{array}$ & 1969 & $106(1974-86)$ & $\begin{array}{l}\text { The only "exported" } \\
\text { model }\end{array}$ \\
\hline IA 63 Pampa & $\begin{array}{l}\text { Advanced trainer, light } \\
\text { attack }\end{array}$ & Turbofan (Garrett) & 1984 & $\begin{array}{r}24(1988-90 \\
2006-07)\end{array}$ & \\
\hline \multicolumn{6}{|c|}{ Produced under license } \\
\hline $\begin{array}{l}\text { K-504 Avro } \\
\text { Gosport }\end{array}$ & Biplane & Piston (Gnome, Rhone) & $(1926)$ & 33 (1928-?) & \\
\hline Bristol F.2B & Biplane & Piston (Hispano S.) & $(1916)$ & $12(1930-?)$ & \\
\hline Dewoitine D 21 & Monoplane & $\begin{array}{l}\text { Piston (Armstrong } \\
\text { Siddeley) }\end{array}$ & (1925) & 32 (1930-?) & \\
\hline FW-44 Stieglitz & Biplane trainer & Piston (Siemens) & (1932) & 190 (1937-?) & Licence acquired in 1937 \\
\hline Curtiss Hawk 75 & Fighter & Piston (Wright) & (1935) & 21 (1940-?) & $\begin{array}{l}\text { Manufactured entirely at } \\
\text { FMA. Licence originally } \\
\text { acquired for } 200 \text { planes, } \\
\text { but lacked material to } \\
\text { complete. }\end{array}$ \\
\hline $\begin{array}{l}\text { Beech T-34 } \\
\text { Mentor }\end{array}$ & Trainer & Piston (Pratt \& Whitney) & (1948) & 75 (1957-65) & $\begin{array}{l}\text { Designed by Beechcraft, } \\
\text { produced from kits }\end{array}$ \\
\hline MS-760 & Jet trainer & $\begin{array}{l}\text { Twin-Turbojet } \\
\text { (Turbomeca) }\end{array}$ & (1954) & $36(1958-64)$ & $\begin{array}{l}\text { Designed by Morane- } \\
\text { Saulnier, produced from } \\
\text { kits }\end{array}$ \\
\hline Cessna-182 & General Aviation & Piston (Continental) & (1956) & 40 (1969-72) & $\begin{array}{l}\text { Designed by Cessna, } \\
\text { produced from kits }\end{array}$ \\
\hline \multicolumn{6}{|l|}{ Locally Converted } \\
\hline $\begin{array}{l}\text { A-4AR } \\
\text { Fightinghawk }\end{array}$ & Ground attack & Turbojet (Pratt \& Whitney) & $(1954)$ & 28 (1997-2000) & $\begin{array}{l}\text { A-4M 'Skyhawk II' } \\
\text { modernized in Argentina } \\
\text { with US components; } \\
\text { additional } 8 \text { modernized } \\
\text { in the US }\end{array}$ \\
\hline
\end{tabular}

Sources: own compilation based on information from Arreguez (2007); SIPRI and Jane's.

Note: (a) First flight in brackets indicates the first flight of the original model; (b) The list excludes models of which only a few prototypes were built. 
Migrant European aircraft designers (originating in Germany) during and after the war were important sources of technological expertise for both Argentina and Brazil. A team under the supervision of Emile Dewoitine designed and built the IAe-27 Pulqui (Arrow) jet fighter which successfully accomplished its maiden flight in 1947. Although only one prototype was built of this rather peculiar design, it was a major milestone that made Argentina the fifth country in the world (and the first in Latin America) to construct a turbojet fighter. In 1947 the former technical director of the German Focke-Wulf aircraft manufacturing company, Kurt W. Tank and his team of some 60 engineers were invited by Perón to work at Córdoba. ${ }^{184}$ The team developed a new jet fighter, the IAe33 Pulqui II (first flight 1950). This was a highly advanced fighter, matching capabilities with the Soviet Mig-15 and the American F-86 Sabres. The design and adjustment of the technology took several years, and by the end of 1956 the first four prototypes crashed or were damaged beyond repair. The air force showed interest to procure of the Pulqui IIs even after the regime change following 1955. But the project continued at a very slow pace once its German designers left and the aircraft industry lost political support. Eventually the project was discontinued and the fifth prototype was parked in a museum in 1960 when the government chose to import the F-86 Sabre fighters from the USA.

The failure of the Pulqui II project had technological as well as political reasons. On the one hand the design was well beyond the level of existing local technological capabilities. Tank's team worked in a virtual enclave and the German team made little if any efforts to integrate the local workforce and to facilitate learning-by-doing. In this respect the project was more an offshoot of the WWII German innovation system than a product of Argentinean innovation system. It did little to advance the latter (apart from possible inspiration of future scientists through demonstration effects). On the other hand the project depended on Perón himself and the success of the Peronist economic and foreign policies. The industrialization strategy focusing on the domestic market failed after a short-lived post-war success, demand for intermediate imports skyrocketed and the economy found itself in stagflation (Della Paolera and Taylor 2003). Even before the "Liberating Revolution" ousted Perón it became apparent many of the extravagant projects (including the nuclear endeavor and the jet fighter) were not sustainable. Increased pressure from the USA following the revolution also contributed to bringing the projects to a standstill.

\footnotetext{
184 This fits in Perón's strategy of acquiring former German (Third Reich) expertise to boost the development of the "New Argentina". Together with Tank came for instance Ronald Richter, a nuclear physicist of Austrian origin with the promise to be the first to produce nuclear fusion in the world. Perón gave Richter virtually unlimited resources to develop the technology for a new energy source (and potentially for a nuclear weapon) in the 'Huemol Project'.
} 
Despite the growing demand for air transport services, the design and production of aircraft in Argentina was only destined for military use. Following the first air postal services ${ }^{185}$, passenger air routes were established in the 1930s. The joint stock companies of regional airlines formed in the 1930s, were nationalized in 1949 and merged into the new Aerolíneas Argentinas (AR). In 1956 the new government broke up the monopoly but AR remained the dominant airline (also becoming the largest airline in South America), with Austral as its most significant domestic competitor. Supplying AR or Austral by locally made planes was never a real option for FMA or its successors. The primary goal was supplying and maintaining the Air Force fleet.

Table 6.10 Stock of aeronautical engineers in Argentina (1950-2007)

\begin{tabular}{crrrr}
\hline & \multicolumn{2}{c}{$\begin{array}{c}c \\
\text { Cumulative stock of university graduates } \\
\text { in aeronautical engineering }\end{array}$} & $\begin{array}{c}\text { Estimate of } \\
\text { active stock }\end{array}$ \\
\cline { 2 - 5 } 1950 & UNLP & IUA & Total & 32 \\
1955 & 18 & 14 & 32 & 130 \\
1960 & 54 & 76 & 130 & 195 \\
1965 & 59 & 136 & 195 & 251 \\
1970 & 86 & 165 & 251 & 339 \\
1975 & 142 & 197 & 339 & 457 \\
1980 & 218 & 239 & 457 & 552 \\
1985 & 275 & 277 & 552 & 647 \\
1990 & 343 & 336 & 679 & 734 \\
1995 & 472 & 392 & 864 & 844 \\
2000 & 614 & 425 & 1,039 & 949 \\
2005 & 727 & 473 & 1,200 & 1,036 \\
2007 & 821 & 554 & 1,375 & 1,068 \\
\hline
\end{tabular}

Sources: Instituto Universitario Aeronáutico (IUA), Departamento Egresados, Universidad Nacional de La Plata (UNLP), Lista de egresados en nuestra base de datos.

Note: a) active stock is estimated by assuming 35 years of active career for a graduate.

The military ownership of the aeronautical industry is also reflected in the education and training of future labor force. The Air Force operated pilot training schools. The initially ad-hoc training of engineers and workers of the industry was replaced in 1941 by regular theoretical and practical courses in aeronautics. The Escuela de Ingeniería Aeronáutica (Aeronautical Engineering School) ${ }^{186}$ was established in 1947 in Córdoba under the supervision of the Argentinean Air Force. The most important non-military graduate training center for aeronautical engineers was the Engineering Faculty at the

\footnotetext{
185 The perils of aviation in Argentina in the 1920s and 30s are illustrated by Antoine de Saint-Exupéry in his 1931 novel Night Flight.

${ }^{186}$ It was renamed in 1993 as Instituto Universitario Aeronáutico (University Institute of Aeronautics, IUA).
} 
Universidad Nacional de La Plata near Buenos Aires. As shown in Table 6.10, the number of graduates was very low, creating an obvious bottleneck for the emerging innovation system. Although 864 engineers were trained by 1990, by comparison, in Brazil over 3000 engineers graduated from ITA alone until 1988.

A research and testing center was already established under the War Ministry during the late 1920s, with its mission encompassing the design, development and construction of various prototypes of aircraft, engines and instruments. R\&D was subsequently incorporated into FMA and its successors.

\subsubsection{Incomplete emergence (1927-1952)}

Even with the scant statistical data about the early growth of the industry, the contours (and the deficiencies) of an emerging innovation system are apparent. It never functioned properly as a fully developed system, as the following overview of its main building blocks during the period of 1927-1952 reveals:

1. Actors: The most striking feature of the emerging innovation system is the absence of private companies. Research, design, engineering and production, but also education and training were all "integrated" in the military complex at Córdoba. The Argentine Air Force oversaw the plant, financed its research and production activities and appointed the managers. Tank and his team, a potentially rich source of foreign expertise, had very little interaction with the rest of the actors in the system. Even though they were located at FMA, they were supported by and reporting directly to the president.

2. Institutional set-up: Ever since its origins, FMA and its successors were run as a military unit. Technological independence (following the import-substitution strategy) and increasing Argentina's military capabilities were the prevalent objectives, not commercial success. This did not prove to provide successful incentives for innovation. External relations of the system were determined by the current governmental strategy, including the degree openness to foreign technology and the selection of technological partners (orientation shifted from the British to the Axis powers during the war). Internal relations were cloaked in secrecy, which greatly reduced the potential of establishing linkages with other domestic or foreign industries. It reinforced the hurdle to commercialization of technological results.

3. Capital input: Lack of rigorous accounting makes it impossible to trace the amounts invested in development projects. It is only clear that innovative activities were financed by the government - as in all other emerging innovation systems -, although these were determined by political aims rather than economic ones. The lack of financial transparency ensured a culture of corruption already from the very beginning. 
4. Technology base and input: At the time of the establishment of FMA in 1927, technological capabilities in aircraft construction and maintenance were existent although very limited. It is worth noting that the related automotive manufacturing industry was already present in the country with models of leading foreign producers being assembled under license. ${ }^{187}$ Similarly in the aircraft industry production licenses of small planes (e.g. Avro, Bristol, Dewoitine, Focke Wulf, Curtiss and Beechcraft) provided access to foreign technology. After WWII European designers (such Dewoitine and Kurt W. Tank and his team) brought along not only their knowledge and skills but also blueprints of new aircraft. These frontier technologies were incompatible with existing local knowledge and no serious measures were taken to help acquire the tacit knowledge. Technology deals were not signed strategically with capability accumulation in mind, but rather for short-term political purposes.

5. Skilled labor input: The labor force was almost exclusively trained by the academies of the military in Córdoba, first in ad-hoc training courses, later in regular engineering program. Shortly after the end of the war an aeronautical engineering school was established by the air force (see above) and civilian courses started at National University of La Plata. But the number of aeronautical engineering graduates did not reach 100 until 1954. As opposed to Brazil, the lack of a dedicated aerospace school (such as ITA) became a major shortcoming in the innovation system.

In the absence of statistical data, we can only indirectly deduce the performance of this emerging innovation system.

6. New products: Most of the new products before WWII were small planes carrying maximum five persons, capable of very simple, mostly observation missions or to be used for pilot training (Table 6.9). The Pulqui I and II jet fighters designed in the post-war era represented near-frontier technologies, but they remained inventions rather than innovations, as they never reached series production.

7. Output and Market share: We estimate that by the end of WWII Argentina had produced some 400 planes (see Table 6.9). However, none of them were sold outside Argentine or for domestic or foreign commercial use. We have no information on aircraft import before 1950s; when the military started to import aircraft from the US during the late 1950s it considerably reduced the high market share of locally produced military planes.

\footnotetext{
${ }^{187}$ By 1930 the Argentine car park amount to over 400,000.
} 


\subsubsection{Crisis in the Industry: Replacing wings with wheels}

The initial rapid growth of the industry slowed down by 1950 and the industry was soon in a serious crisis. Import substitution with a domestic orientation meant that export revenues could not finance the purchase of foreign raw materials and intermediate inputs on which aircraft production and other industries depended. Trade deficits and lack of growth of manufacturing industries forced Perón's second government ${ }^{188}$ to make major changes in industrial policy. The survival of the Argentinean aircraft manufacturing industry was in jeopardy. In order to save the Córdoba plant, San Martin, the head of the plant (and also the Minister of Aviation since 1951) agreed with Perón to diversify activities into automobiles (as well as tractors, motors, motorcycles and arms) production. ${ }^{189}$ Resources devoted to aircraft design and production were significantly reduced as political discontent with the national aircraft endeavor increased, which was further aggravated by a growing macroeconomic crisis.

In late 1955 Perón's government was overthrown in a coup. The following governments ${ }^{190}$ aimed to reverse the major projects associated with Perón, including the aerospace endeavors. A large part of the military management was replaced and aircraft and automotive production activities were separated. Tank and his team abandoned work on the jet fighter and other experimental designs and left Argentina in the unwelcoming political climate after the dismissal of Perón. ${ }^{191}$

The car and aircraft industry of Córdoba was soon formally separated. In 1957 the automotive industry was transferred to a separate organization, and aeronautical research and production activities were reorganized in the Dirección Nacional de Fabricaciones e Investigaciones Aeronáuticas (National Directorate for Aeronautical Production and Research, DINFIA), which remained under the supervision of the Air Force. When established, DINFIA had 8,273 workers, a floor space of $217,000 \mathrm{~m}^{2}$ and 3,500 machine tools in total of 19,500 horsepower. At the same time the Instituto de Investigación Aeronáutica y Espacial (Aeronautical and Astronautical Research Insitute, IIAE) was established and designated to carry out R\&D activities in aerospace. ${ }^{192}$

\footnotetext{
${ }^{188}$ After 5 years in office, Perón was reelected in 1951.

${ }^{189}$ Perón was also seeking to supply cheaper, domestically made cars to offset the ever more expensive import and the reluctantly growing assembly work of foreign subsidiaries. By the end of 1953 some 2000 cars were produced by IAME. (FMA was renamed to Industrias Aeronáuticas y Mécanicas del Estado - h IAME, Aeronautical and Mechanical Industries of the State).

190 The "Liberating Revolution" was followed by the military gaining control over the government. The first elected president was the right-wing Frondizi, still favored by the armed forces (1958-62).

191 Tank himself went to India in where he designed a jet fighter-bomber, the Marut for Hindustan Aeronautics.

${ }^{192}$ Space research culminated in 26 rocket launches between 1961 and 1981.
} 
However, neither the national governmental, nor DINFIA leadership had a consistent strategic vision on the development of the industry. Between 1955 and 1960 the organization had 9 directors and many parallel projects. The military decided to follow up on a design by Tank's team of which a first prototype was already flown in 1953. An order of a 100 planes was placed for the multi-purpose twin-engine propeller plane, the IA 35 Hanquero, but only 47 were eventually built from 1958 onwards. ${ }^{193}$ At the same time the right-wing governments forged closer ties with the USAand signed deals to procure US trainers and fighters. ${ }^{194}$ Many of the received trainers (such as the North American T-6 Texan or T-28 Trojan) and fighters (e.g. the North American F-86 Sabre, which Argentina received in the form of assistance) were in the same size range as the ones produced in Argentina (e.g. the IAe-22 D.L. or the IAe-33 Pulqui II), but the (older) US-made planes showed superior performance characteristics. The new foreign purchases were not coordinated with the strategies of domestic aircraft industry development and siphoned off much of the resources for procurement of locally-made planes. The innovative designs such as the Pulqui IIs would have required more investment to be improved to a level that would be marketable abroad. New prototype development was largely discontinued. As there was no strategic aim to make Argentinean production competitive, the technological capabilities started to erode from the 1960s onwards.

\subsubsection{Interruption without transition}

\subsubsection{The first interruption in the innovation system: the 1950s}

The industry's crisis due to macroeconomic and political factors caused an interruption in the innovation system. The lost financial and political support of grand design projects were not replaced by other sources. Capabilities at the macro level eroded with the departure of the German engineers, even if they were less connected with the other actors in the system, ${ }^{195}$ and they were also not replaced. By this time the global industry was entering the jet age and the Argentinean innovation system's distance to the global technology frontier was increasing rapidly.

\footnotetext{
${ }^{193}$ A number of derivatives made of this model, in the direction of a transport aircraft (e.g. the Guarani I, with a capacity to seat 11 persons). A successful plane from these years was the IA 46 Ranquel, a small utility plane used by aero-clubs and for agricultural purposes. (Table 6.9).

${ }^{194}$ The US government was suspicious of both the Argentinean nuclear and military aircraft development projects and was therefore rather willing to sign export deals if that meant an alternative to local plans.

${ }^{195}$ It is interesting to point out the differences between the Soviet engineers and technical staff leaving China after the Sino-Soviet Split in 1961 and Tank and his team Argentina: Argentinean technological capabilities were more advanced without the guests, but China made more efforts to reverse-engineer and regain the lost capabilities afterwards.
} 
A radical transition would have been required, ${ }^{196}$ but instead attempts were made to sustain the industry without major institutional changes. The industry and innovation system were still emerging and lacked many important actors, including private firms, educational and training institutes, but most importantly there was no development strategy combining industrial, science and technology and education policies. It follows that both the size of the innovation system (decreasing of technology and financial inputs) and the innovative performance system (very few new designs created) of the system declined.

The rest of the history of Argentinean aerospace industry shows how heavy a price the country paid for trying to patching a decaying innovation system.

\subsubsection{Lack of strategic leadership}

Argentina after Perón did not give up on aircraft manufacturing. An alternative to local design was to return to local manufacturing of foreign-designed planes. DINFIA acquired licenses from Beechcraft (US) to produce 75 propeller-driven T-34 Mentor trainers and from the French Morane-Saulnier to produce the MS-760 twin-jet trainers. A decade later Cessna (US) gave a license to AMC for $40 \mathrm{C}-182 \mathrm{~s}$ aircraft. However, the only local content in these activities was labor. All the components were shipped in kits from the USA and France. While in Brazil license-production activities over the 1960s and 1970s were part of a strategy to acquire specific know-how, Argentina lacked an overarching plan at the government level and lacked entrepreneurs at the firm level.

The difference between the history of the industry during the 1950s and 60s in Brazil and Argentina is striking. Brazil, although also with many often conflicting goals at that time, was making significant efforts to create the foundations of an aerospace innovation system in the Sao Jose dos Campos cluster. Argentina was conducting research into military aircraft design, produced a number of them, but made insufficient efforts to create an innovation system. The failure of the Pulqui II project proved that the Córdoba plant had not succeeded in integrating foreign frontier technology, and only relatively simple aircraft were produced locally under license. Even this expertise was, however, already declining during the 1950s. In both countries the military was a major source of finance for education and R\&D in aeronautics. While the sector was seen everywhere as strategic, neither country formulated a well-defined mission for the development of the industry.

\footnotetext{
${ }^{196}$ Diversifying into the automobile industry was an interesting alternative, nonetheless a genuinely radical shift - maybe too radical -, but it did not concern the entire industry.
} 
Table 6.11 Military aircraft import to Argentina (1950-2009)

\begin{tabular}{|c|c|c|c|c|}
\hline Types & Model & Year & Nr. planes & Exporter \\
\hline \multirow[t]{8}{*}{ Trainers } & T-6 Texan & $\begin{array}{l}1956 \\
1959\end{array}$ & $\begin{array}{l}5 \\
5\end{array}$ & USA \\
\hline & T-28 Trojan & 1959-60: & 45 & USA \\
\hline & T-28 Fennec & 1966 & 45 & France \\
\hline & Aermacchi MB-326 & $\begin{array}{l}1969-70 \\
1983\end{array}$ & $\begin{array}{c}8 \\
11\end{array}$ & Italy \\
\hline & T-34C Turbo Mentor & 1978 & 16 & USA \\
\hline & Aermacchi MB-339 & 1980 & 10 & Italy \\
\hline & EMB-312 Tucano & $1987-88$ & 30 & Brazil \\
\hline & Su-29 & $1997-98$ & 8 & Russia \\
\hline \multirow[t]{9}{*}{ Fighters } & F-4U Corsair & 1956-58: & 62 & USA (used in WWII, Korean War) \\
\hline & F-9F Panther & 1957-58: & 20 & USA \\
\hline & F-86 Sabre & 1960: & 28 & USA \\
\hline & F-9 Cougar & 1962: & 2 & $\begin{array}{l}\text { from the US; although did not receive spare parts } \\
\text { for the plane later... mistakenly Argentina became } \\
\text { the only foreign recipient of these planes }\end{array}$ \\
\hline & $\begin{array}{l}\text { A-4P ground attack } \\
\text { Skyhawk }\end{array}$ & $\begin{array}{l}1966-7 \\
1970 \\
1972 \\
1976 \\
1997\end{array}$ & $\begin{array}{l}25 \\
25 \\
16 \\
25 \\
36\end{array}$ & (28 of which modernized locally) \\
\hline & Mirage & $\begin{array}{l}1972-3 \\
1980 \\
1983\end{array}$ & $\begin{array}{l}12 \\
7 \\
2\end{array}$ & France \\
\hline & Nesher (=Mirage 5) & 1978-82: & 39 & Israel \\
\hline & Mirage 3 & 1982-83: & 22 & Israel \\
\hline & Mirage-5s & 1982: & 10 & from Peru (loan for Falklands war, later bought) \\
\hline Bombers & $\begin{array}{l}\text { Canberra } \mathrm{B}(\mathrm{I})-8 \text { and - } \\
12\end{array}$ & $1970-71$ & 12 & UK \\
\hline \multirow[t]{5}{*}{ Transports } & Shorts Skyvan SC-7 & 1971 & 5 & UK \\
\hline & $\mathrm{F}-27$ & 1968-81 & 21 & Netherlands \\
\hline & C-130 Hercules & $\begin{array}{l}1968 \\
1971-72 \\
1975 \\
1979 \\
1992-94\end{array}$ & $\begin{array}{l}3 \\
3 \\
2 \\
2 \\
5\end{array}$ & (KC-130H tanker/transport) \\
\hline & Alenia G-222 & 1977 & 3 & Italy \\
\hline & CASA C-212 & $1989-90$ & 5 & Spain \\
\hline
\end{tabular}

Source: SIPRI

In Brazil a "public entrepreneur"197 emerged to fill the gap of lack of strategic vision on commercialization. The reason why such a development did not happen in Argentina cannot be merely attributed to bad luck. The institutional framework of the Argentine

\footnotetext{
${ }^{197}$ Using the term coined by Ramamurti (1987), however, referring to the team of aircraft engineers working on the design and marketing of the future Embraer Bandeirante.
} 
aircraft innovation and production system did not allow the emergence of such an entrepreneur. First, the Argentinean aerospace "enterprise" was a military organization and not a company with commercial aims. It had no influential private actors with experience in commercializing the products. Second, the frequently changing governments were incapable of providing financial and political support for the infant industry. It was partly due the secretive nature of the military, but it was also in the culture of the public science and technology community to be more cautious with commercial valorization of applied technology.

Already by the 1960s DINFIA had cancelled the development of jet fighters and focused its activities on transport, counter-insurgency and training aircraft (Milenky 1980). In addition to the Sabres received in 1950, between 1966 and 76 the military governments of Argentina imported some 90 modernized Douglas A-4 Skyhawk ground attack jets in several batches, $8 \mathrm{C}$-130 Hercules transport planes in 3 batches and a number of small planes. But the US was not the only supplier. Argentina opted for French Mirage III fighter jets in 1970, and despite more ambitious plans 21 fighters were acquired between 1972 and 1983 in batches of 12+7+2. These were complemented with a 1978 deal with Israel on 26 refurbished IAI Nesher planes (which were largely identical to the French Mirage V jets, but equipped with Israeli avionics). (See Table 6.11 for an overview of imported aircraft.)

\subsubsection{Renewed efforts to build up domestic technological capabilities in aerospace}

In 1967 aerospace development and production activities were reorganized after a transition year into Area de Material Córdoba (AMC). The plant continued to be run by the Argentinean Air Force. Yet reorganization also meant renewed interest in boosting the industry's design output. There were significant technological achievements during between the 1960s and 1980s.

The IA 50 Guarani II, a small utility aircraft, seating 12 passengers was also capable of limited troop transport, medical and search and rescue operations. The prototype was based on Kurt Tank's IA 35 Huanquero, and first flew in 1963. Two years later The Guarani II was presented at the Paris Air Show. This could have been an aircraft for commercial use (and indeed after the first series of 18 built for the military between 1966 and 1970, a second series of 14 planes were constructed between 1971 and 1974 for the civilian market) ${ }^{198}$. According to the published specifications, the Guarani

\footnotetext{
${ }^{198}$ Source: “Guaraní” Aeromilitaria.Com.Ar

URL: http://www.aeromilitaria.com.ar/ind/aviones/gii/index.htm (page last updated: 3 Mar 2007).
} 
II outperformed aircraft in its league. It could fly higher, faster and further than Embraer's star product, the Bandeirante (see Table 6.12).

Table 6.12 Main features of the Guarani II in comparative perspective

\begin{tabular}{lrrr}
\hline & DINFIA IA 50 Guarani II & $\begin{array}{c}\text { Embraer EMB-110 } \\
\text { Bandeirante }\end{array}$ & \multicolumn{2}{c}{$\begin{array}{c}\text { CASA C-212 } \\
\text { Aviocar }\end{array}$} \\
\hline Capacity (crew+passengers) & $2+15$ & $2+21$ & $2+26$ \\
Dimensions (m): & & & \\
(length/wingspan/height) & $14.9 / 19.5 / 5.81$ & $15.1 / 15.4 / 4.9$ & $15.2 / 19.0 / 6.3$ \\
Empty weight (kg) & 3,924 & 3,500 & 3,700 \\
Maximum takeoff weight (kg) & 7,120 & 5,900 & 6,300 \\
Power plant & $2 \times 694 \mathrm{~kW}$ & $2 \times 559 \mathrm{~kW}$ & $2 \times 580 \mathrm{~kW}$ \\
& Turbomeca Bastan VI-A & P\&W Canada PT6A-34 & Garrett AiResearch \\
& Turboprop & turboprop & turboprop \\
Max speed (km/h) & 500 & 460 & 370 \\
cruise speed (km/h) & 450 & 326 & 315 \\
Range (km) & 1,995 & 1,964 & 1,760 \\
Service ceiling (m) & 12,500 & 6,900 & 7,900 \\
First Flight & 1963 & 1968 & 1971 \\
Total Number Built & 35 & 500 & 435 \\
\hline
\end{tabular}

Sources: Jane's, Aeromilitaria.Com.Ar, Airliners.Net

Puzzling as it may first seem, it is important to note that the aircraft was not responding to what commercial markets demanded. None of the 34 planes that are believed to have been built ${ }^{199}$ were exported or sold to airlines. Most of them were used for aerial photography, calibration of navigation instruments and various transport services. Without sales revenues and with an aggravating economic crisis, production was not sustainable and Perón's new government stopped further support in 1974. Figure 6.20 shows the drastic difference in the production cycle of the Guarani II and the Bandeirante. This figure emphasizes the capacity of the newly emerging Brazilian producer to design an aircraft for commercial markets and construct it in great quantities, in contrast to the laggard position of its older Argentinean counterpart. Argentina showed more resemblance to the also emerging Indonesian plane maker, to be discussed in the next section of this chapter.

\footnotetext{
${ }^{199}$ The Argentinean Air Force reportedly used 29 of them, but little is known of the operating history of the plane. Aeromilitaria.Com.Ar
} 
Figure 6.20 Comparison of annual production of commuter-size aircraft by FMA, Embraer and Nurtanio (first 20 years of production)

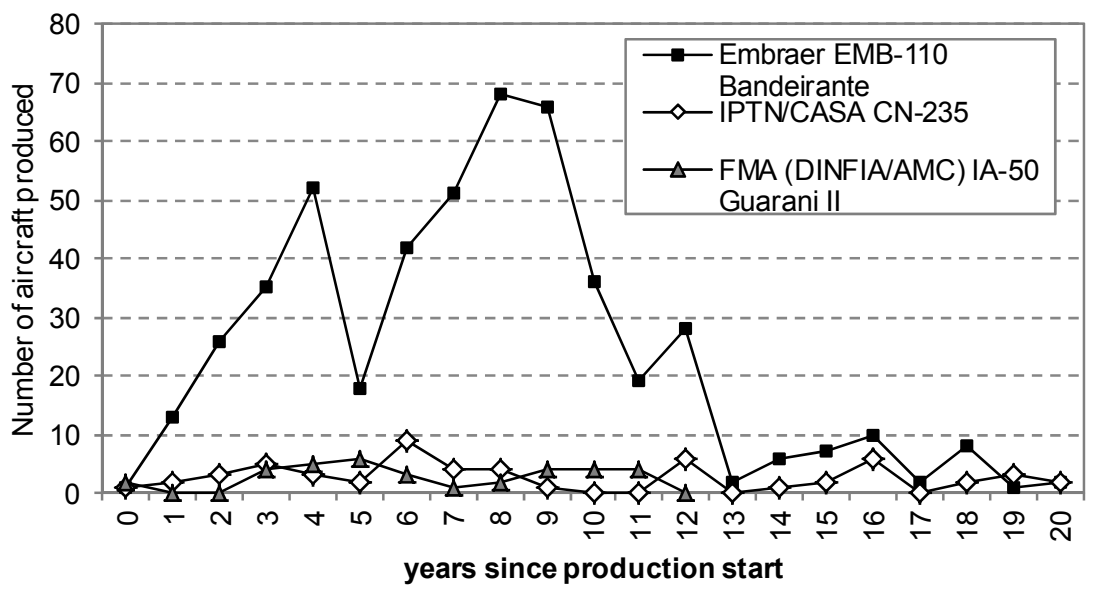

Source: Cabral 1987, Cassiolato et al 2002, Airlinerlist.Com, Aeromilitaria.Com.Ar

Note: The FMA and Embraer aircraft were designed and produced domestically. The CN-235 was codesigned and co-produced by CASA and IPTN; the figures presented show the number of aircraft finally assembled in Indonesia. The production of the IA-50 stopped in 1974.

Year 0 refers to the year of first flight of the prototype (EMB-110: 1969; CN-235: 1983; IA-50: 1963).

The zenith of the Argentine defense industries coincided with the military dictatorship of 1976-83 (Scheetz, 2002). It was a time of increased military spending amounting to as much as 6\% of the GDP between 1981 and 83 (see Figure 6.21). Details of the expenditure are not known, but the air force evidently managed to corner a large share of these expenditures. First of all, it should be noted that the junta's increased military expenditures were unsustainable due to macroeconomic instability. Still the availability of new funds, had they been channeled into the innovation system, could have resulted in increased innovative performance of the aircraft industry. However, foreign procurement and corruption absorbed a large of the available budget. Over these years Argentina modernized its fleet with about 80 Mirage fighter jets (including the Israeli derivative Nesher) and a number of trainer and tanker aircraft (see Table 6.11). 
Figure 6.21 Argentine Military Expenditures, in millions of constant (1970) Australs (19691987)

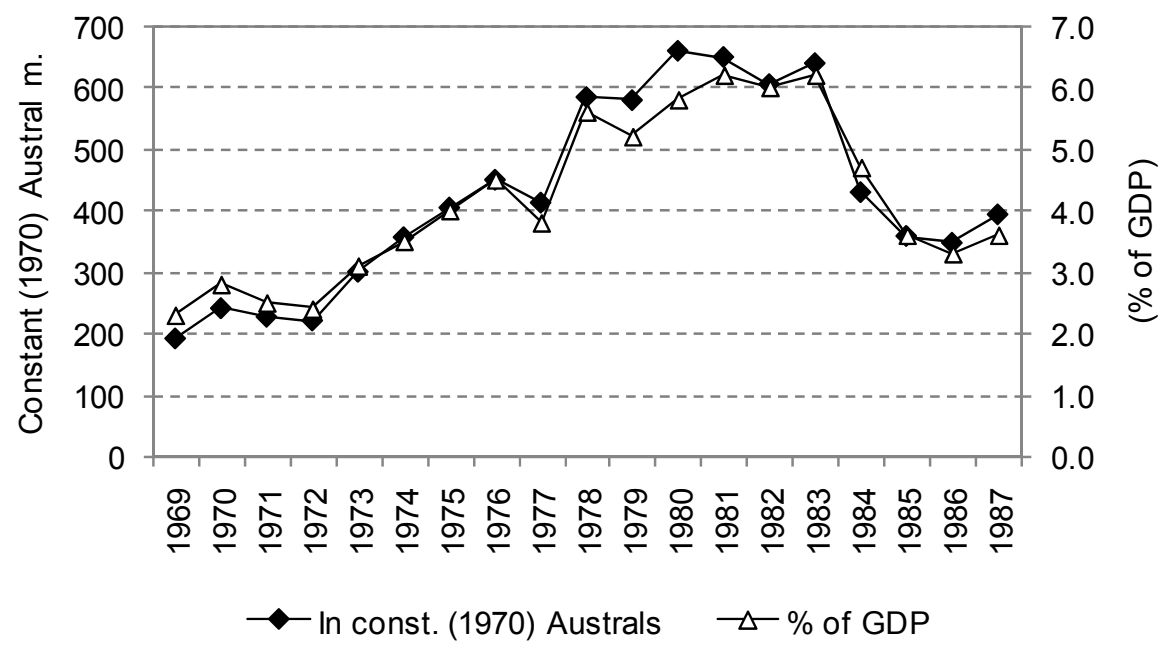

Source: Scheetz (Scheetz, Table I, p.186)

AMC in Córdoba was commissioned to produce a hundred of the IA-58 Pucaras. This two-seater twin-prop ground attack and counter-insurgency aircraft was first flown in 1969. Its main features were the capability to operate in unfavorable conditions, simple airfield infrastructure requirements and good maneuverability. But it was using already dated technology. 106 units were built between 1974 and 1986, and it was the only Argentine aircraft "exported", even though none of these exports were realized through regular market transactions. ${ }^{200}$ Due to the limited availability of spare parts, the exported planes eventually did not clock many flying hours. Their capability to land and take-off on short runways made the Pucara the only aircraft the Argentinean Air Force could deploy to the Falkland Islands during the 1982 war, where they carried out reconnaissance and light-attack operations. However, the Air Force's national technological pride did not stand the test of war and many planes were soon written off.

The subsequent Pampa project was a technologically even more challenging venture rather successfully realized. Once again it became a victim of changing strategic

\footnotetext{
${ }^{200}$ SIPRI counts a total of 10 exported aircraft. Six were delivered to Uruguay in 1981 as part of a 6.5 million USD deal from the previous year. In 1992 Argentina signed a deal with Sri Lanka to the tune of 12.7 million dollars to deliver four aircraft over the following two years for counter-insurgency operations. Additionally, the Air Force offered 3 of its Pucaras in 1990 in the form of aid to assist anti-narcotics operations in Colombia and leased one for a year for Uruguay (Based on SIPRI Arms Transfer Database; values are expressed in constant 2000 USD, applying deflators of 0.54 for 1980 and 0.86 for 1992 (WDI). Note that industry insiders question many of the details of these deals.
} 
vision and macroeconomic and political instabilities. As of 1978 AMC was looking for solutions to produce a new advanced jet trainer to replace the nearly 20 year-old locally assembled Morane-Saulnier MS-760s jets. Aiming to follow international standards (to facilitate foreign sales) and expand existing expertise in license production, AMC signed a partnership agreement with the German manufacturer Dornier to assist aircraft development. ${ }^{201}$ The resulting prototype of the IA-63 Pampa trainers showed many similarities to the Alpha Jet, but it was a simpler and more cost-efficient design, equipped with a single Garrett turbofan engine. By the time the plane first flew in 1984, the military junta has already fallen following the disasters of the lost Falklands War, the shrinking economy and the debt crisis.

\subsubsection{An incrementally changed innovation system (1960s-1983)}

The realization of the Guarani II, Pucará and Pampa projects marked the revival of the aerospace innovation system. Innovative performance increased with the accomplishment of complex engineering achievements. This raises a question. Was this performance caused by increased learning and interactions within a system defined by more or less the same actors and institutions? Or does it mark a transition to a new system?

In our interpretation the innovation system did not change radically. The main actors remained the same, even if some additional foreign sources of technology were added (but with less intensive and rather unidirectional interactions). The major arrangements in the industry were hardly modified. Whatever the name of the Córdoba plant was, it was still run by the military. The system continued to be serving the needs of the Air Force, and despite some weak attempts to realize foreign sales, economic considerations had little influence. Moreover, the long lead times of projects indicate that the system was still in its infancy, still not close to the performance frontier. Yet the technological characteristics of the products were matching (or even exceeding) those of other latecomers. What we can observe here is that increased inputs (finance) could boost learning and result in performance increase in an incrementally changed innovation system.

The problem with an only incrementally changed innovation system was that even if it reached the performance frontier through learning, it was not competitive anymore. It could still add to the accumulation of technological capabilities needed for

\footnotetext{
${ }^{201}$ Together with Dassault, Dornier had been producing the Alpha Jet since 1973 but the production run was nearing its end.
} 
an emerging industry, but those capabilities were already obsolete. That it was not sustainable any longer was not only proven by the economic crises, but also in combat.

\subsubsection{Failure to radically change an ailing innovation system}

\subsubsection{A new crisis: the end of the military regime and struggles with privatization}

In order to address the debts and respond to the pressures of the international monetary institutions, the Alfonsín government that rose to power in 1983 cut military expenditures and made an attempt to privatize AMC. Under the new name of Fábrica Argentina de Material Aeronáutico (Argentine Aeronautical Materials Factory, FAMA) $44 \%$ ownership was sold to a consortium of Aeritalia and $10 \%$ to Techint.

The Alfonsin government continued to see potential in military aerospace and gave support to both the Pampas as well as a new medium-range ballistic missile program, the Condor $I I^{202}$. AMC produced a first batch of 18 Pampas between 1988 and 1990. The actual design and adjustments made to this took place during times of economic trouble in the country. AMC could not secure any foreign sales, although it attempted to apply for trainer procurement competitions in the USA (in partnership with LTV), New Zealand and Australia. Especially in case of the US application, the chances of a foreign producer of trainers have always been very low. The already dated technology of the planes and the fact that the Argentinean government was unable to offer competitive export credits were certainly not making it a serious contender.

An overture to commercial production at the end of the 1980s was also not successful. FAMA and Embraer decided to co-produce a commuter aircraft, the CBA123 Vector. This was a major step in a new direction for FAMA and it offered the potential of acquiring newer capabilities as well as Embraer's already established knowledge of how to market planes. However, the project did not become a success because production costs were too high, making the plane uncompetitive. Embraer criticized FAMA for not being able to deliver the required modules in time and according to quality expectations. Argentina also had difficulties in financing its onethird share of the estimated 300 million dollar development costs. ${ }^{203}$ The government's hands were tied in the midst of monetary and fiscal troubles.

The 1994 privatization of Embraer in Brazil offered a capital injection and new sources of dynamism for regional jet production. However, while the sectoral

\footnotetext{
${ }^{202}$ It succeeded a 1970s ballistic missile program and was developed in close collaboration with Egypt and Iraq, as the Middle East was seen as its potential market. The project was halted by the Menem government in 1993 following pressure from the US.

${ }^{203}$ Two prototypes were made in 1990 but the project was cancelled due to insufficient market demand.
} 
innovation system in which Embraer was embedded may have meant an external asset to potential investors, the lack of such a system in Argentina decreased the value of FAMA (or AMC) ${ }^{204}$, which was hardly more than a military depot seen as a burden on the state. Unsurprisingly, the Menem government's new attempt to inject capital into AMC in 1995 was less successful than the privatization of Embraer. First, the local aircraft industry could not show any commercial success similar to what Embraer achieved with its commuter planes during the late 1970s and 80s. The latest trainers of AMC were at least a generation behind the technology frontier, and were yet to be promoted on low-cost markets. Second, the core competence of the "company" was in military aeronautics, Argentina's options for a potential investor were limited to a few global defense companies, which were also experiencing a downturn after the end of the Cold War. Finally, the main asset of AMC was its 2,200-strong skilled labor force, but whether they provided a solid base for lower cost production is doubtful. Hira and Oliveira (2007:342) mention a consultancy report that suggested half of the work force was "surplus to requirement".

An in-depth analysis of the political background of the negotiations and the interests of the various stakeholders is beyond the scope of this study. After lengthy negotiations Lockheed Martin (LM) won a 25-year concession to operate the Córdoba aircraft factory, linked to a deal to upgrade 36 of the A-4 Skyhawks of the Air Force and to a promised 14 million dollars worth of investment. ${ }^{205}$ Lockheed Martin Aircraft Argentina S.A. (LMAASA) assumed operations on 1 July 1995 and soon reduced the work force to $1,250 .{ }^{206}$ Following the arrival of 8 A-4 Skyhawks upgraded in the USA, the first locally converted A-4s Fighting-hawks were delivered in 1998.

The government retained the right to renegotiate the deal every five years. While the signing of the original contract was widely criticized on grounds of corruption, incompetency or (at best) acting under pressure, the revision in 2000 expanded the responsibilities of LM and was financially more beneficial for the government as it was hedged against currency fluctuations. LMAASA now signed up to upgrade the IA-63 Pampas and produce 12 additional aircraft ${ }^{207}$ and carry out the maintenance of the Air Force's fleet and produce spare parts. Maintenance, repair and overhaul (MRO) became

\footnotetext{
${ }^{204}$ The enterprise was once again renamed to AMC in 1991.

${ }^{205}$ Part of the deal was to seek to reactivate the manufacturing of the IA-63 Pampa jets and carry out maintenance and overhaul operations for both the Air Force and commercial airlines.

206 "Lockheed nears AMC deal" Flight International 19-25 October 1994; "Pampa production could roll again" Flight International 20-26 Mar 1996, p.9. A different source on the number of employees, Scheetz (2002) reports a decrease from 2,950 to 950 (See note (a) to Table 6.8).

${ }^{207}$ Test flights of the Pampas with enhanced avionics and radar began in July 2005; the first delivery took place in December 2005 ("Upgraded Pampa trainer begins flight-test work" Flight International 12 Jul 2005; "Lockheed Martin advances Pampa push in Argentina" Flight International 11 Apr 2006)
} 
the core activities of the Córdoba plant, which also offered the potential to serve airlines in the region. But the diversification to the commercial segment was not so successful, mainly because of the poorer performance of local airlines. ${ }^{208}$ Manufacturing remained a small scale activity, with no new aircraft designs. Lockheed indicated that it was expecting a domestic launch order of at least 100 Pampas to make use of scale economies, but the government (tackling a financial crisis) was struggling to meet their existing commitments. ${ }^{209}$ The concession-adventure ended in 2009 as the Kirchner government nationalized the plant. Fabrica Argentina de Aviones (Argentinean Aircraft Factory, FAdeA), according to the new name, is once again subordinated to the Defense Ministry and there is little sign of any new strategy ${ }^{210}$, new management routines or greater transparency.

\subsubsection{Failed transitions to a more open innovation system (after 1983)}

In 1983, with the lost war, the fall of the military dictatorship and a macroeconomic crisis, yet a second interruption hit the (emerging) innovation system. Military expenditures and AMC's labor force were halved and no new foreign technological collaboration deals were signed. But the Air Force continued to be influential even during the Alfonsín government so the Condor II and Pampa projects were not shelved.

The attempt to introduce private capital in the newly formed FAMA could have initiated major changes leading to a transition. However, basic incentive structures and selection processes were hardly modified. Private firm actors were still not significantly present, education and training institutions were not reinforced and no long-term industrial policies were devised in concert with innovation and science and technology policies to make the industry competitive. FAMA's entering into commercial production was not viable without such broader-scale changes, but Argentina could not afford these (especially in the context of neoliberal policies it was obliged to follow). Only incremental institutional changes took place. But at the same time, mostly due to insufficient funding, these were not followed by increased learning or a movement closer to the performance frontier. Thus, the macroeconomic changes at the end of the

\footnotetext{
${ }^{208}$ LMAASA had around 58,000 $\mathrm{m}^{2}$ floor space for MRO activities in Cordoba. It has gained type certificates for a number of planes, including the C-130 Hercules and Aerolineas Argentinas' B-737s, as well as ISO 9001 from TÜV. The local workers accumulated experience in the repair works of the F-27, F-28, IA 50 G II, IA 58 and IA 63 types of the Air Force as well as in engines.

${ }^{209}$ For instance, in October 2003 LMAASA sent home its entire 900-strong staff for 6 days to reduce losses; at the same time, the government owed the company 47 million USD.

${ }^{210}$ The activities of the plant still include providing maintenance services for the Air Force's fleet (amounting to about half of the revenues), upgrading the Pucuras and making new efforts sell the Pampas. At the same time the air force's entire fleet is aging: only a small share of the fleet was active in 2007 and some 15 planes crashed in recent years. There have been plans to develop a new trainer to replace the ancient T-34s.
} 
1980s and the failure of the CBA-123 Vector project also mark an interruption in the innovation system, since the inflow of R\&D funds and new technology from partners was significantly reduced. What remained after the break was an innovation system serving an industry with a "core competence" in maintenance, repair and overhaul (of both military and commercial aircraft).

The 1995 concession deal with Lockheed Martin has stopped further decline, but did not bring system-wide institutional changes. It provided access to technology, but hardly more than earlier license agreements; and it did not even secure capital investment for technological upgrading. These were improved with the renegotiated deal of 2000, which resulted in some increase in system performance. The 2009 renationalization was once again not a trend break for there is no sign of realigning the industry on a competitive growth path.

\subsubsection{Interrupted innovation in Argentina: The rise and fall of an innovation system}

This historical overview shows that a fully fledged sectoral innovation system in aerospace has never emerged in Argentina, in a sense of supporting competitiveness and sustained growth. In the 70 years of its evolution there have been some periods of increased innovative activities, with tangible results of technologically complex new products, but no commercial breakthroughs.

A summary of the development trajectory of the innovation system is shown in Figure 6.22. The emergence of the system was interrupted in 1952 because import substitution with a domestic orientation caused a macroeconomic and later a political crisis. Yet there has been no transition to a new growth path, based on a strategy of export-orientation and the involvement of actors other than the military, most importantly, private companies. More investment pumped into an incrementally changed system proved to be unsustainable and led to new crises and other interruptions after the failure to enter into commercial production. 
Figure 6.22 The Emergence of the Argentine Aerospace innovation system

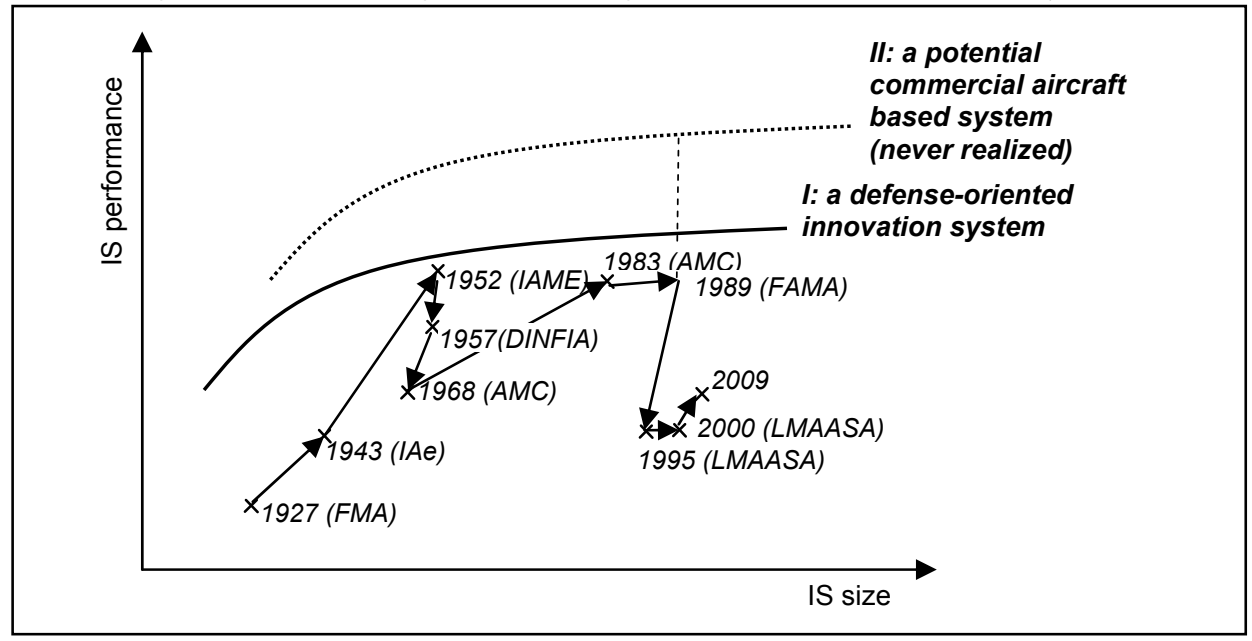

(Author's compilation)

Note: The abbreviations in brackets indicate the name of the main organization.

\subsubsection{General conclusions}

Although the ideas of 1927 envisaged the construction of a factory with the long-term aim of making it an engine of industrial progress in Argentina, much of the history of aerospace in Argentina is the outcome of ad hoc and short-sighted decisions. Formulating and adhering to a strategy of what to make locally and what to import is just as urgently needed as it has always been since the 1950s and 60s. In the end, it is too costly to keep supporting an infant beyond the age of 50 . The following lessons can be derived from the Argentinean experience.

\section{Nascent innovation systems are excessively vulnerable to exogenous shocks}

Since the accumulation of technological capabilities has remained insufficient to design, produce and commercialize aircraft in Argentina, interruptions are results of events occurring in the macroeconomic or political context. This is especially typical of systems in their infancy, where the performance is excessively dependent on one source of finance and technology. (An example of such an interruption was the nascent Chinese aerospace industry after the Sino-Soviet split.) The reason is the lack of available institutions and actors to counterbalance the declines in government support. In conclusion, macroeconomic stability is crucial to provide a sustainable and credible source of government finance, political stability and a wide-spread agreement (possibly across party lines) is required to formulate and implement a long-term development strategy. Without such checks and balances the industry can still grow, but only slowly, 
at high cost and it can easily become a playground for short-term rent-seeking and power struggles.

\section{Make competitive planes or do not make planes at all}

Argentina never had a strategy to sell its products on the market (domestic or foreign). If the aim is to produce only for domestic military use, importing planes would have been a less costly option, creating a maintenance, repair and overhaul facility only would have been more lucrative.

After the ill-fated Pulqui fighter jet, the planes built in Córdoba were all of obsolete technology. All the planes Argentina imported or produced under foreign license were also near the end of their production runs. Although such planes are more affordable for domestic purposes, if the aim is to acquire the technology to produce planes that sell even on low-cost markets, a country can't afford not to invest in acquiring more recent technological vintages.

Even an emerging industry needs to pay special attention to what products and technological solutions are required by the market (domestic and foreign users), and to identify possible niches. It is too late to try to sell the obsolete Pampa trainers in the $21^{\text {st }}$ century.

The argument that the presence of a high-tech industry boosts science and engineering education is shaky. The far-from-frontier knowledge and skills of the staff makes them less competitive even when they shift to other sectors, while the low payment (Scheetz 2002) deters new students from choosing a career in aerospace.

\section{A military-only innovation system is bound to fail}

The emergence of an innovation system will be unsuccessful if all the sources of technology and knowledge, all the interactions are controlled by the military. Channeling in investment and technology from private sources ensures not only more transparency, but also a more dynamic circulation of ideas. It also helps increase the number of actors in the innovation system who can better read the more complex signals of market demand than the air force decision makers alone.

Conversely, the number of new aircraft designs during the post-WWII years indicates a superior performance of an innovation system that is open to new actors (such as experienced foreign designers). However, the centralization of the selection process of new designs by the military hampers further growth in innovative performance. These routines and practices also hamper the ability to shift to commercial designs and the output of aircraft with potential commercial applications will be inferior to that of a genuinely commercially oriented firm (see Figure 6.20). 
4. An emerging innovation system and industry require institutional stability and long-term goals

A lack of overall agreement on the strategies of policies related to industrial development, science, technology and innovation, or national defense by the main political actors of a country is a source of institutional instability and turbulence. The lack of institutional stability undermines the accumulation of technological capabilities, and innovative performance cannot increase even during the emergence phase. Goals and strategies that depend on solely on state financing are worthless if new governments easily cancel the commitments taken on by their predecessors.

\section{The 'lost decade' in aerospace was the 1950s}

For Argentina, the 1980s are generally referred to as the 'lost decade'. For the aerospace industry in Argentina, the decade of lost opportunities was the 1950s. Apart from the first Perón government, the industry never received sufficient resources and attention to allow it to reach a mature, competitive growth trajectory based on commercial sales. The distance to the technological frontier appears to have been growing ever since.

The attempt to close the gap during the late 1970s and early 1980s was overshadowed by the Falklands war and the debt crisis. Even if entrepreneurs had the foresight to make the crisis-hit industry ride the waves of the just emerging global trend of outsourcing components manufacturing by US and European producers to low-cost countries, the macroeconomic conditions of Argentina and the insufficient capabilities (that became clear during the CBA-123 Vector project) would have posed too big a challenge.

In other words, the case of Argentina shows that without a radical innovation system transition the aircraft industry can only survive on a lifeline. At such a low performance many more decades are being lost. 


\subsection{INDONESIA}

\subsubsection{Introduction}

In a country with a total area of 1.9 million square kilometers spread over 17,500 islands, the geographical setting itself makes the development of air transportation an obvious policy goal. Yet the development of the aircraft manufacturing industry would seem a less obvious choice for a developing country which was in the mid-1960s, according to Hill "perhaps the least industrialized of the world's large developing nations" (2000, p.155) and where natural resource-based industries accounted for $80 \%$ of total output (Hill 1990).

The overall purpose of focusing on aerospace among other high-tech industrialization projects was to accelerate the social and economic transformation of Indonesia from an agricultural to an industrial society. Dr. Bacharuddin Jusuf Habibie, the aeronautical engineer and later president of Indonesia summarized Indonesia's ambitious technology strategy in his famous phrase: "start from the end, end at the start". Accordingly, in 1976, IPTN, the state-owned aircraft manufacturing enterprise began to produce helicopters and airplanes under Western license. In less than half a decade it moved on to jointly develop a modified version of the plane, which successfully completed its maiden flight in 1983. It started the indigenous development of a commuter plane in 1989 that first flew six years later. However, Indonesian-made planes never sold successfully in foreign markets. It became clear during the South East Asian financial crisis of 1997 that the government lacked the funds to continue supporting an industry employing around 16,000 workers. Since 1998, Indonesian aerospace manufacturing has been struggling to survive. The case reveals how a sectoral innovation system that never fully developed, failed to transit to a new, sustainable growth path after being confronted with a crisis.

\subsubsection{The emergence of the Indonesian aerospace industry and innovation system $^{211}$}

\subsubsection{The origins of Indonesian aircraft manufacturing}

Aviators and aircraft designers were already active in Indonesia well before the establishment of IPTN. Their activities were limited to the design and testing of gliders and small plane prototypes, far from what could be referred to as an industrial scale of

\footnotetext{
${ }^{211}$ The history section relies primarily on five studies: Hill and Pang (1988), McKendrick (1992), Goldstein (2002b), Eriksson (2003) and Amir (2007).
} 
production. Their main contribution to the conception of the industry was spreading the idea that aviation can bridge distances in Indonesia.

One of the key designers of this period was Nurtanio Pringgoadisurjo. Nurtanio was involved in the construction of a number of simple gliders (following the famous German Zögling design) and a few single-seat aircraft at the Aircraft Research, Experiment and Construction Depot for the Air Force in Bandung. In 1954, he designed the Si Kumbang (beetle) all-metal plane of which 3 prototypes were built. In 1958 he produced the basic trainer Belalang (locust) prototype, of which 5 units were produced later. In the same year the prototype of the Kunang (firefly) sport plane made its first flight. In 1960, Nurtanio and three colleagues were sent to Manila, the Philippines to study at the FEATI Institute of Technology in the field of aeronautics. ${ }^{212}$

In the meantime, not only the Air Force, but also president Sukarno became interested in the achievements of Nurtanio. The Preparatory Agency for Aviation Industry (LAPIP) was set up in 1960 under the supervision of the Air Force. A year later it signed an agreement with Poland about a loan of 2.5 million USD to construct a manufacturing facility near Bandung airport, for training personnel and to license produce a slightly modified PZL-104 Wilga plane developed by the Polish Cekop. The 44 Indonesian-made versions, known as the Gelatik (rice bird), served for agricultural, light transport and aero-clubs purposes. Yet the small plane production has never become a commercial success.

There were several organizational attempts to establish the foundations of an aerospace industry industry. The National Council for Aeronautics and Space (DEPANRI) was created in 1962 and mandated with national aerospace coordination and policy formulation. In 1963 the National Aeronautics and Space Institute LAPAN was founded, a research institute designated to develop aerospace technology and advise on national aerospace policy. After Nurtanio died in 1966, while testing one of his planes, LAPIP was renamed in his honor to Nurtanio Aviation Industrial Institution (LIPNUR). The Berdikari Aircraft Industry, founded a year earlier, was merged into LIPNUR, which was assigned with the task to produce a basic military trainer aircraft and build workshops for after-sales-services, and maintenance, repair and overhaul. To cater to the human resources needs of a newly emerging industry, the government launched an overseas student scholarship programme as early as 1958, financing aeronautical engineering studies in Europe and the United States. ${ }^{213}$ Aeronautics

\footnotetext{
${ }^{212}$ There is a bit of confusion in the literature, Amir dates this event 10 years earlier.

213 The appearance of aviation on the political agenda may be linked to a 1956 speech by Sukarno on the occasion of the fifth year of independence, in which he highlighted the strategic nature of aviation for the Indonesian military, economy and politics.
} 
education within the country was rather limited. A sub-study programme on aviation engineering was formed in 1962 at the Bandung Institute of Technology. Since there was no clear government strategy and LAPIP was a military unit, only a handful of students graduated from there during the 1960s. Thus in comparison with Brazil, where local engineer training was highly advanced even before Embraer was established, human capital formation in Indonesia was significantly weaker.

A key promoter of industrial-scale aircraft manufacturing in Indonesia was B.J. Habibie. After receiving a doctorate in aeronautical engineering at the Technische Hochschule Aachen in 1965, he remained in Germany and worked for over 10 years in Hamburg for Messerschmitt-Bölkow-Blohm (MBB) where he became vice president and director for technology application. He returned to Indonesia in 1974, accepting the call of President Suharto to become his technology adviser. Habibie's long-term family ties to the president were a key source of trust, and he soon took on high level positions in the New Order government. In 1978, he became State Minister for Research and Technology, and was given the oversight of a number of high-technology projects as chair of the Agency for Strategic Industry (BPIS).

Habibie's industrial development strategy involved four steps. Phase 1 involved technology acquisition by transferring already existing technology through licenses. In Phase 2, previously acquired technology would be integrated into the design and production of new products. In Phase 3, the existing technology would be further developed and investment would be made into new technologies to design and produce new products. Finally, in Phase 4, large-scale basic research capabilities were to be acquired and implemented to generate new, competitive generic technologies (Steenhuis et al. 2007).

Despite the lack of a pre-existing technological base and an underdeveloped capital goods sector, the Indonesian government did not hesitate to formulate ambitious high-tech mega-projects, including telecommunications, shipbuilding, the national car project, nuclear energy and aircraft manufacturing. The late 1960s and 1970s marked a period of rapidly increasing oil revenues as a result of the exponential growth of oil production. ${ }^{214}$ The New Order government expressed its intention to invest the oil revenues into enhancing domestic technological capabilities.

\footnotetext{
${ }^{214}$ Indonesian oil production increased threefold from 486 thousand barrels a day in 1965 to 1.5 million in 1976 (BP, 2009).
} 


\subsubsection{From licensed production to co-development}

IPTN was founded in 1976 by a presidential degree as a state-owned enterprise with the merger of the assets of the Pertamina oil and gas company ${ }^{215}$ and LIPNUR. Habibie, who was appointed as the director of the company, had initially chosen a location near Jakarta. He later accepted the Air Force's offer to use the Bandung facilities of LIPNUR (180 km from the capital) in return for including 'Nurtanio' in the name of the new company. Nurtanio Aircraft Industry (IPTN) commenced operations in two small hangars of $11,000 \mathrm{~m}^{2}$ on a $45,000 \mathrm{~m}^{2}$ site outside Bandung on 23 August 1976 and in the same year counted 860 employees. Within two decades, IPTN's facilities had expanded to $437,000 \mathrm{~m}^{2}$ and the number of employees had risen to 16,000 . (see Table 6.13)

IPTN and two other institutes, PUSPIPTEK and BPPT formed the basis of the integrated aerospace program in Indonesia. The Center for Science and Technology Development (PUSPIPTEK) was established in Serpong, close to Jakarta, providing research and testing laboratories. The Agency for Assessment and Application of Technology (BPPT) took over policy coordination of national technology development in aerospace and other high-tech industries. At the same time the domestic supply of aerospace engineering graduates was only slowly catching up with demand. Enrolment at ITB only numbered some 30 plus students in 1980.

Table 6.13 Key financial data of IPTN, 1976-89, compared with the first years of Embraer

\begin{tabular}{|c|c|c|c|c|c|c|c|c|c|c|c|c|}
\hline \multicolumn{13}{|c|}{ IPTN } \\
\hline Years & 1976 & 1978 & 1980 & 1981 & 1982 & 1983 & 1984 & 1985 & 1986 & 1987 & 1988 & 1989 \\
\hline Employees & 860 & 1,695 & 3,162 & 4,742 & 7,853 & 10,774 & 11,713 & 12,596 & 13,000 & 13,300 & 14,100 & 14,20 \\
\hline Sales & 15.6 & 34.0 & 43.5 & 102.7 & 106.0 & 67.5 & 46.9 & 86.9 & 73.4 & 124.3 & 149.1 & 223.7 \\
\hline Profit (after tax) & 1.5 & 6.9 & 0.9 & 2.0 & 7.4 & 9.5 & 13.3 & 0.3 & -16.2 & 1.8 & 0.4 & 5.0 \\
\hline Investment & 49.2 & 11.4 & 41.3 & 84.1 & 141.8 & 139.7 & 119.4 & 79.8 & 205.9 & 85.8 & 42.7 & 54.5 \\
\hline Inv/Sales (\%) & 315.5 & 33.5 & 95.1 & 81.9 & 133.7 & 206.9 & 254.3 & 91.9 & 280.6 & 69.1 & 28.6 & 24.4 \\
\hline Sales/Emp (1 USD) & 18.1 & 20.1 & 13.8 & 21.7 & 13.5 & 6.3 & 4.0 & 6.9 & 5.6 & 9.3 & 10.6 & 15.8 \\
\hline \multicolumn{13}{|c|}{ Embraer (EMB) } \\
\hline & 1969 & 1971 & 1973 & 1974 & 1975 & 1976 & 1977 & 1978 & 1979 & 1980 & 1981 & 1982 \\
\hline Employees & 589 & $\mathrm{n} / \mathrm{a}$ & 3,323 & 3,353 & 4,225 & 4,104 & 4,300 & 4,987 & 5,957 & 5,414 & 6,732 & 6,877 \\
\hline Sales & & 21.4 & 120.4 & 199.9 & 228.3 & 295.7 & 256.0 & 269.3 & 375.5 & 346.1 & 439.5 & 348.2 \\
\hline \multicolumn{13}{|c|}{ Comparison of employment and sales: IPTN / Embraer (\%) } \\
\hline Employees & 146.0 & $\mathrm{n} / \mathrm{a}$ & 95.2 & 141.4 & 185.9 & 262.5 & 272.4 & 252.6 & 218.2 & 245.7 & 209.4 & 206.5 \\
\hline Sales & & 158.7 & 36.1 & 51.4 & 46.4 & 22.8 & 18.3 & 32.3 & 19.5 & 35.9 & 33.9 & 64.2 \\
\hline
\end{tabular}

Source: Hill and Pang, 1988, Table 4, p.159; McKendrick, 1992, Table 4, p.60.; Ramamurti (1987)

Note: Values in thousand USD, constant 2000 prices (official exchange rates from World Development Indicators: 8421.8 IDR/USD applied.)

\footnotetext{
${ }^{215}$ Pertamina was established in 1957 to extract and refine Indonesia's oil and gas reserves in 1957. Its revenues allowed it to have assets in many other fields including telecommunication, real estate or airline business but it also became a source of funding for Indonesia's ruling elite without accountability, leading to debts amounting to 10 billion USD by 1975 in a time of rapidly expanding oil production. For more on the Pertamina debacle, see McCawley (1978).
} 
Habibie was very successful in securing deals for technology sourcing. In line with his technology strategy of "start from the end and end at the beginning", IPTN embarked on license manufacturing. Already in $1975^{216}$ a contract was signed with Habibie's former employer, the West German MBB about the assembly of the BO-105 helicopters in Indonesia under license. It is estimated that over a hundred of these models (NBO105 under Indonesian designation) were built over a quarter of a century, making it the most successful product of IPTN. In 1982 a subsequent deal was signed with MBB to assemble the BK-117, a more advanced helicopter, but it is estimated that only 3 of these were produced in Indonesia. In 1977, IPTN acquired a license from the French Aerospatiale to produce the Puma SA-330 (NSA-330) and later the Super Puma AS-332 helicopters (NAS-332 under local designation) in Indonesia, from kits shipped from France. Some 20 of these helicopters were produced according to the best estimates ${ }^{217}$. The third rotary wing producer IPTN signed a contract with was Bell Textron (US) in 1984. Production of NBell-412 helicopters started in 1986, with two units produced in the first four years. (See Table 6.14 for an overview of the aircraft and helicopters produced in Indonesia)

Table 6.14 Number of aircraft and helicopters delivered by IPTN (1975-98)

\begin{tabular}{|c|c|c|c|c|c|c|c|c|c|c|c|c|c|c|c|c|c|c|c|c|c|c|c|c|c|}
\hline \multirow{2}{*}{\multicolumn{2}{|c|}{ Aircraft (Total) }} & \multirow{2}{*}{$\frac{\stackrel{n}{\sigma}}{2}$} & \multirow{2}{*}{$\frac{\stackrel{0}{\sigma}}{\stackrel{2}{\sigma}}$} & \multirow{2}{*}{$\frac{\hat{\sigma}}{1}$} & \multirow{2}{*}{$\frac{\infty}{\stackrel{\infty}{\sigma}}$} & \multirow{2}{*}{$\frac{\substack{\frac{T}{\sigma}\\
}}{3}$} & \multirow{2}{*}{$\frac{\stackrel{8}{\circ}}{6}$} & \multirow{2}{*}{$\frac{\underset{\infty}{\sigma}}{20}$} & \multirow{2}{*}{$\frac{\stackrel{\text { ळ }}{\leftarrow}}{7}$} & \multirow{2}{*}{$\frac{\stackrel{\Re}{\%}}{9}$} & \multirow{2}{*}{$\frac{\underset{\%}{\%}}{8}$} & \multirow{2}{*}{$\frac{\stackrel{\text { ֻ }}{\leftarrow}}{10}$} & \multirow{2}{*}{$\frac{\mathscr{\&}}{\stackrel{\mathscr{O}}{\leftarrow}}$} & \multirow{2}{*}{$\frac{\stackrel{\mathfrak{\infty}}{\leftarrow}}{3}$} & \multirow{2}{*}{$\frac{\stackrel{\infty}{\infty}}{\stackrel{\circ}{\leftarrow}}$} & \multirow{2}{*}{$\frac{\stackrel{\text { \& }}{\stackrel{2}{-}}}{9}$} & \multirow{2}{*}{$\frac{\stackrel{8}{\circ}}{6}$} & \multirow{2}{*}{$\frac{\frac{\delta}{\sigma}}{2}$} & \multirow{2}{*}{$\frac{\text { ๙ }}{10}$} & \multirow{2}{*}{$\frac{\stackrel{\Re}{\circ}}{6}$} & \multirow{2}{*}{$\frac{\stackrel{\text { ㅇ }}{7}}{7}$} & \multirow{2}{*}{$\frac{\stackrel{\text { ㅇ }}{\circ}}{2}$} & \multirow{2}{*}{$\frac{\stackrel{\circ}{\circ}}{0}$} & \multirow{2}{*}{$\frac{\stackrel{\Im}{\circ}}{0}$} & \multirow{2}{*}{$\frac{\stackrel{\infty}{\circ}}{\frac{\sigma}{\sigma}}$} \\
\hline & & & & & & & & & & & & & & & & & & & & & & & & & \\
\hline \multirow[t]{3}{*}{ NC-212 } & Total & 2 & 3 & 1 & 6 & 3 & 6 & 20 & 7 & 8 & 8 & 10 & 2 & 2 & 1 & 4 & 3 & 0 & 1 & 2 & 3 & 1 & 0 & 0 & 0 \\
\hline & Domestic & 2 & 3 & 1 & 4 & 3 & 6 & 18 & 7 & 7 & 8 & 10 & 2 & 2 & 1 & 4 & 3 & 0 & 1 & 2 & 3 & 1 & & & \\
\hline & Export & & & & 2 & & & 2 & & 1 & & & & & & & & & & & & & & & \\
\hline \multirow[t]{3}{*}{$\mathrm{CN}-235$} & Total & & & & & & & & & & & & 1 & 1 & 3 & 5 & 3 & 2 & 9 & 4 & 4 & 1 & & & \\
\hline & Domestic & & & & & & & & & & & & 1 & 1 & 3 & 5 & 3 & 2 & 9 & 1 & 0 & 0 & & & \\
\hline & Export & & & & & & & & & & & & & & & & & & & 3 & 4 & 1 & & & \\
\hline $\mathrm{N}-250 \mathrm{a}$ & Total & & & & & & & & & & & & & & & & & & & & & 1 & 1 & & \\
\hline \multicolumn{2}{|c|}{ Helicopters (Total) } & 6 & 7 & 5 & 6 & 5 & 6 & 10 & 14 & 20 & 21 & 7 & 10 & 4 & 6 & 2 & 3 & 2 & 1 & & & & & & \\
\hline \multicolumn{2}{|c|}{ NBO-105 } & 6 & 7 & 5 & 6 & 5 & 6 & 8 & 8 & 18 & 14 & 7 & 8 & 1 & 2 & 0 & 1 & 2 & 1 & & & & & & \\
\hline NSA-33C & & & & & & & & 2 & 6 & 2 & 1 & & & & & & & & & & & & & & \\
\hline NAS-332 & & & & & & & & & & & 6 & & & 1 & 2 & 0 & & & & & & & & & \\
\hline NBell-41 & & & & & & & & & & & & & 2 & 2 & 2 & 2 & 2 & & & & & & & & \\
\hline
\end{tabular}

Source: Aircraft delivery figures from Airlinerlist.com (retrieved 2010 Jul); Helicopter production figures from McKendrick, 1992, Fig.1,p.50 (IPTN).

Note: a) only prototypes were built of the N-250, it was not produced in series.

\footnotetext{
${ }^{216}$ Since IPTN was not existing at that time, the Indonesian partner organization in this deal (and in a later with the Spanish CASA) was Advanced Technology \& Teknologi Penerbangan Pertamina (ATTP).

${ }^{217}$ McKendrick (1992, Fig.1, p.50) reports 11 NSA-330s and 6 NAS-332 assembled by 1990. SIPRI estimates 9 NAS-330s assembled between 1981 and 84 and 4 plus 7 NSA-332s over the periods 1984-87 and 2001-07 (SIPRI, 2009).
} 
Habibie's primary interest was in producing fixed-winged aircraft. The key technology contract that came to shape the trajectory of Indonesian aircraft production and development was signed with the Spanish Construcciones Aeronauticas SA (CASA), the company that Goldstein (2002b, p.528) referred to as "the smallest of the independent European aerospace firms". The 1975 deal permitted Indonesia to produce the C-212 Aviocar 19-seater turboprop under license. This design was relatively new (flown first in 1971) and belonged to the expanding niche of commuter aircraft with low airport infrastructure requirements (very similar to Embraer's Bandeirante) and offering a versatile utilization for both commercial and military purposes. CASA sent a staff of 3040 technicians to Bandung to facilitate learning to produce the plane, but it was the C212's "simplicity in design and construction" (McKendrick 1992, p.43) that contributed to the relative success of the project. The newborn Indonesian aircraft industry had produced five of these aircraft by the end of 1976 and production of the type peaked at 17 in 1981. Most of the Indonesian-made NC-212 airplanes served domestic demand ${ }^{218}$. IPTN had a license to produce $108 \mathrm{NC}-212 \mathrm{~s}$ and had completed 95 by the year $2000 .{ }^{219}$ Due to a variety of reasons, 16 of these planes were involved in accidents. (See Figure 6.23 for an overview of Indonesian aircraft production.)

IPTN's cooperation with CASA advanced to another level when in 1979 the two companies agreed to form a joint venture to design and manufacture a 38 to 44 -seater twin-prop commuter, the $\mathrm{CN}-235$ (CN stands for CASA/Nurtanio). Entry into the emerging aviation market of Indonesia and the readiness of the Indonesian counterpart to invest in research and development triggered the interest of CASA. For for IPTN the deal meant advancing to the second stage of Habibie's technology transfer ladder ('technology integration', or the development of new-product using already proven technology). This was considered as an in-between stage on the route towards indigenous design capabilities.

In 1979, Airtech was established in Madrid with 70 million USD to coordinate the project. CASA and IPTN became equal partners. McKendrick called the division of labour on the CN-235 "quite unusual", because work was divided in a way that IPTN designed and produced the outer wing sections, the rear fuselage, the tail and the interior while CASA was responsible for the (technologically more demanding) inner wing sections, forward fuselage, centre wing and engine nacelles (1992, p.45). These parts were then exchanged and final assembly took place both in Spain and in Indonesia.

\footnotetext{
${ }^{218}$ McKendrick (1992) reports only 6 planes exported by 1986, 5 for agricultural use in Thailand and 1 for Air Guam; SIPRI lists only the 4 exported to Thailand .

219 “Toughing it out", Flight International, 25-31 July 2000
} 
The design phase (1979-82) allowed for an active knowledge exchange. CASA sent some 60 employees to IPTN to assist design and further support on aerodynamics engineering was received from Boeing. The project was important for IPTN in terms of acquiring and upgrading machinery and tools as well: it started using touch numerical controlled (TNC) machinery in 1981 and by 198524 computer numerical controlled (CNC) machines allowed high precision work. CASA also received assistance on wing design from $\mathrm{MBB}$.

The share of foreign components was high: engines, communications and control systems, landing gear and base metal had been produced in the USA and Europe. For IPTN, this was reduced over the years to 20 percent, although the reduction only affected the airframe.

Figure 6.23 Aircraft production cycles in Indonesia (1975-2006)

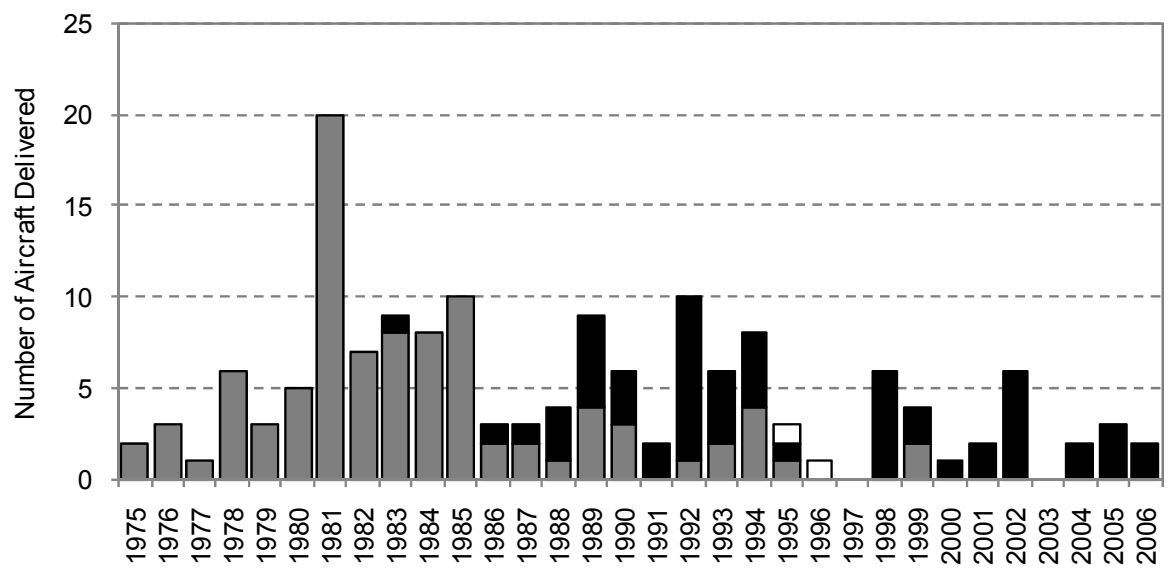

$\square \mathrm{NC}-212 \square \mathrm{CN}-235 \square \mathrm{N}-250$

Source: IPTN, Airlinerlist.com (retrieved: 10 Jul 2010)

Notes: Year of delivery is a close proxy to year of production, for which there is a lack of information. Since many of the planes produced were not sold immediately, there are potential discrepancies, e.g. in 1981, at least 3 of the NC-212s delivered may have been produced in the previous year. In the case of $6 \mathrm{CN}-235 \mathrm{~s}$ produced during the crisis years of 1997-98 for Malaysia, but only delivered later are listed for 1998 based on information from Flight International ${ }^{220}$. There are reports of NC-212 production in Indonesia after 2000, but exact number and year are unknown.

Two prototypes were produced by CASA and two by IPTN. One of the Spanish planes, Infanta Elena took off in Madrid for the first time in November 1983, followed by the Indonesian Tetuko a month later. The division of labour between the parties became a

220 "Indonesia tries to rescue Malaysian IPTN deal" Flight International 24-30 Jun 1998 
source of major problems for the airworthiness certification. When the $\mathrm{CN}-235$ received certification of the American FAA in December 1986, it was only valid for the prototypes assembled by CASA, not by IPTN (Amir 2007, p.287). Lacking bilateral agreement between Indonesia and the USA (the USA was demanding an independent aviation authority in Indonesia), IPTN had to turn to other agencies, and finally received certification from the British Aviation Authority in 1995. This was crucial for access foreign markets. However, customers remained cautious and preferred the planes assembled in Spain to those made in a developing country. However, Eriksson (2003) notes that by this time CASA had already sold their planes to potential buyers. Exports of the Indonesian-made CN-235 planes covered Southeast Asia (Brunei, Malaysia and South Korea, with a total of 17 planes) as well as Pakistan (3) and the United Arab Emirates $(7)^{221}$. On the global market the (Indonesian and Spanish made) CN-235s achieved only moderate success, with a around 5\% share in the 20-45 seat segment by $1990^{222}$. By 2007 a total of approximately $234 \mathrm{CN}-235$ s have been produced by CASA and IPTN together. ${ }^{223}$ Analysts considered the realization of the $\mathrm{CN}-235$ venture as a success $^{224}$ for the newly emerging industry of Indonesia and it brought significant prestige for Habibie.

Table 6.15 Key performance characteristics of IPTN's and competing aircraft

\begin{tabular}{lccccccc}
\hline Manufacturer / Aircraft Type & $\begin{array}{c}\text { First } \\
\text { Flight } \\
\text { (Year) }\end{array}$ & $\begin{array}{c}\text { Max } \\
\text { number } \\
\text { of } \\
\text { seats }\end{array}$ & $\begin{array}{c}\text { Max } \\
\text { take-off } \\
\text { weight } \\
\text { (tons) }\end{array}$ & $\begin{array}{c}\text { Max } \\
\text { cruise } \\
\text { speed } \\
\text { (knots) }\end{array}$ & $\begin{array}{c}\text { Fuel } \\
\text { consumptiona } \\
\text { (kg/h) }\end{array}$ & $\begin{array}{c}\text { Max } \\
\text { Cruise } \\
\text { Altitude } \\
\text { (feet) }\end{array}$ & $\begin{array}{c}\text { Max } \\
\text { Range } \\
\text { (km) }\end{array}$ \\
\hline Embraer EMB-120 Brasilia & 1983 & 30 & 11.5 & 300 & 340 & 25,000 & 3,600 \\
Saab SF-340 & 1983 & 37 & 12.9 & 282 & 350 & 25,000 & 3,500 \\
de Havilland Dash 8-100 & 1983 & 39 & 15.6 & 269 & 393 & 25,000 & 2,800 \\
CASA-IPTN CN-235 & 1983 & $\mathbf{4 5}$ & $\mathbf{1 5 . 1}$ & $\mathbf{2 4 8}$ & $\mathbf{3 4 8}$ & $\mathbf{1 8 , 0 0 0}$ & $\mathbf{4 , 9 0 0}$ \\
Aerospatiale/Aeritalia ATR-42 & 1984 & 50 & 16.7 & 265 & 385 & 25,000 & 4,600 \\
\hline & & & & & & & \\
de Havilland Dash 8-300 & 1987 & 56 & 18.6 & 287 & 457 & 25,000 & 2,400 \\
Canadair CRJ-100 & 1991 & 56 & 21.5 & 460 & 928 & 37,000 & 3,400 \\
Embraer ERJ-145 & 1995 & 50 & 22.0 & 447 & n/a & 37,000 & 3,200 \\
IPTN N-250 & 1995 & $\mathbf{5 6}$ & $\mathbf{2 2 . 0}$ & $\mathbf{3 0 0}$ & n/a & $\mathbf{2 0 , 0 0 0}$ & $\mathbf{2 , 0 0 0}$ \\
\hline
\end{tabular}

Source: Regional Airliner Directory, Flight International 10-16 June 1992; producers

Note: a) at long-range performance

\footnotetext{
${ }^{221}$ Figures are based on SIPRI estimates.

${ }^{222}$ Goldstein (Goldstein 2002b, p.529, referring to Dagnino)

223 "Status Of Programs" Aviation Week \& Space Technology, 10 November 2008.

${ }^{224}$ In 1991, CASA even sold the license to produce $50 \mathrm{CN}-235$ s by Turkish Aerospace Industries in a 550 million USD deal. As for the safety record of the plane, out of the 43 assembled in Indonesia, 3 aircraft were lost in accidents; and another 6 of the Spanish-made planes were involved in crashes.
} 
In comparison with similar aircraft, the technological level of the CN-235 in many ways met industry standards. In the early 1980s, almost exactly at the same time as the CN235, five major aircraft projects were launched in the 30-50 seat range around the world. The competitors of CASA and IPTN were Embraer's EMB-120 Brasilia, the Swedish Saab SF-340, the Dash- 8 by de Havilland from Canada, and a French-Italian venture's ATR-42. The CN-235 compared rather favorably in terms of fuel consumption and range, but this came at a cost of speed and cruising altitude (see Table 6.15).

Figure 6.24 shows the cumulative output of the same aircraft during the first 20 years of production in Indonesia and in Spain, transposed to a common starting point (year 1 refers to the year of the first delivery). The steeper growth of Spanish output in the initial years indicates the difference in manufacturing capabilities and the flatter learning curve of the Indonesian industry. The fact that Indonesian production flattens out sooner (at around 90 deliveries in the case of the C-212 and around 60 in the case of the CN-235) while CASA's deliverys continued to growing reveals Indonesia's sales problems.

Figure 6.24 Comparison of cumulative aircraft production in Spain and Indonesia

C-212

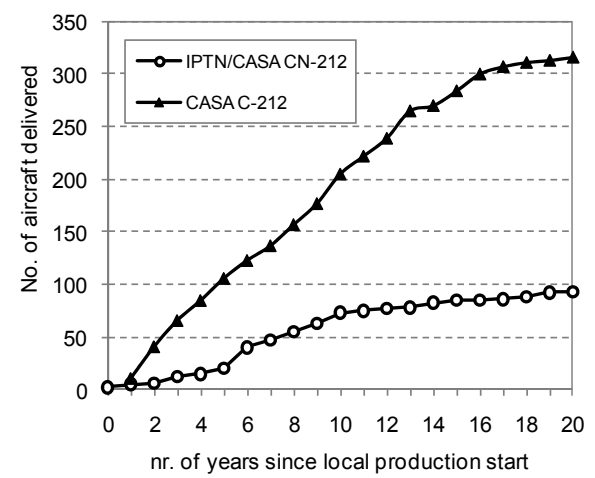

$\mathrm{CN}-235$

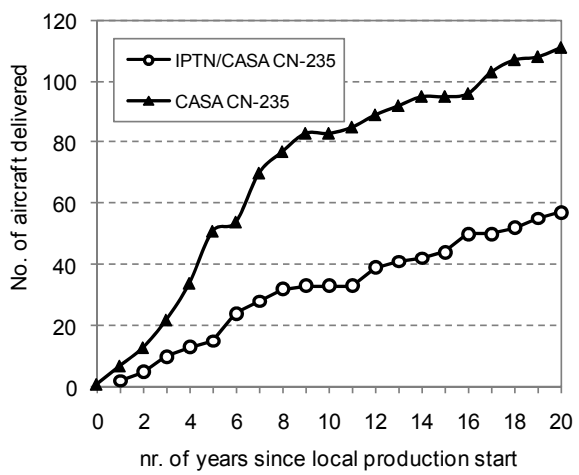

Source: http://www.airlinerlist.com (Retrieved: 16 Dec 2009)

Source: http://www.airlinerlist.com (Retrieved: 16 Dec 2009)

Note: Spanish production does not contain the 50 aircraft assembled in Turkey under license

External knowledge flows were also promoted at the government level. A 1979 technology transfer agreement resulted in collaboration in higher education with the Delft Technical University and the Dutch Aerospace Research Institute NLR and was subsequently renewed as ISARD in 1985 and as APERT in 1990. These last two agreements were supported by Fokker until the company went bankrupt. The collaboration with TU Delft was crucial, since ITB did not offer programs beyond the master's level in the 1990s. 
IPTN signed a number of other contracts that were important for the company to gain access to technology, mostly relatively small scale subcontracts and offset agreements with leading western manufacturers. An important agreement was signed with Boeing in 1982 on management assistance. Over the years, around fifty advisers came to IPTN and trained IPTN staff in Seattle, including the son of Habibie, who later became the director of the company. In a small offset contract in return for the flag carrier Garuda acquiring Boeing aircraft, IPTN was selected to produce the trailing edge flaps of the B-737s (to a value of 30m USD) and to assemble stowage bin frames for B767s (for 1m USD). In a 1986 agreement, Grumman of the US agreed to train IPTN engineers at its home plant. In 1986, Indonesia signed a deal to purchase 12 F-16 fighters from General Dynamics and to produce parts and components to offset the $337 \mathrm{~m}$ USD deal The components included forward engine access doors, wing flaperons, fuel pylons, main landing gear doors, graphite epoxy skin, and vertical fins in a value of $52 \mathrm{~m} \mathrm{USD}{ }^{225}$. A 1990 deal with the Dutch Fokker included a 35 per cent offset arrangement for any F-100s bought by Garuda, including the production of wing, tail and other primary components. However, the expected full order was never realized. A 1980 deal with General Electric resulted in the establishment of a Universal Maintenance Center in Indonesia six years later, to perform maintenance, repair and overhaul (MRO) of aircraft and industrial engines in the region made by GE. This deal is significant for making Indonesia a competitor of Singapore which focused on becoming a regional MRO hub for the aviation industry.

\subsubsection{Going it alone till the abrupt end}

Once the CN-235 development project had been realized, Habibie believed that IPTN was ready to develop an aircraft independently. His intention was to launch a commercial aircraft for dual military and civilian $\mathrm{use}^{226}$. The initial plan of the engineering team was to design a 30-seater replacement for the aging Fokker F-27s flown by Indonesian airlines, but a subsequent market research found that demand is greater for a 50-seat commuter. Habibie announced the launch of the N-250 project at the 1989 Paris air show.

IPTN signed an important technological agreement in October 1994 with Lucas Aerospace Flight Control System to develop an advanced flight control systems for the N-250 using the fly-by-wire system developed by Lucas and Liebherr Aero Technik. The 3 -axes system was an innovation for propeller-driven planes. To further emphasize that

\footnotetext{
${ }^{225}$ Sources contradict on the value of the offset deal; McKendrick reports $17.7 \mathrm{~m}$ (1992, p.44), SIPRI reports 52m USD (SIPRI 2009).

${ }^{226}$ Amir's interview with Habibie (2007, p.287)
} 
commercialization was the cornerstone of the N-250, IPTN opened a branch office in Seattle and in 1995 made a number of agreements with the local government of Mobile, Alabama and US investors to produce the N-250 in the USA at the to-be-established 'American Regional Aircraft Industry'. In addition, British Aerospace showed interest in manufacturing the N-250 under license in the UK. Habibie claimed that orders amounted to 189 planes by the 3 Indonesian airlines and a European leasing company.

The project budget was initially planned to be 600 million USD, however it increased to 1.2 billion USD along the road. The work started with a team of 30 engineers and the team grew to over 1,500 production personnel. To fill the budget gaps President Suharto decided to allow IPTN to use an interest-free loan of $185 \mathrm{~m}$ USD from the reforestation fund ${ }^{227}$ (and offered the Forestry Department a 5\% royalty from all future sales in return). With this cash injection IPTN succeeded in rolling out Gatotkaca, the first prototype of the N-250 on Patriots Day in November 1994. The plane completed its maiden flight in August 1995. So far, only two prototypes have been built. Work on a third one came to a halt in 1998. The first two airplaces clocked around 850 flight hours, half of what would have been required for certification. The plane never received an airworthiness certificate ${ }^{228}$ and the financial crisis of 1997-98 brought the project to an abrupt end.

The unsuccessful commercial launch of the N-250, an apparently technologically innovative plane, points in the direction of systemic failures in the Indonesian aerospace innovation system. First of all, the idea of 'going it alone' was in sharp contrast with the strategy of other foreign producers as well as airlines' expectations, at a time when the global landscape was being dramatically reshaped by the post-Cold War recession. The list of confirmed orders for N-250 was alarmingly short on foreign buyers. Airlines were increasingly opting for regional jets instead of propeller planes, and to cut operating costs preferred manufacturers that offered a whole range of product lines of one family. As the lower rows of Table 6.15 show, the N-250 fitted more in the product lines of the 1980s than in those of the 1990s. While the propeller-driven commuters' market was shrinking, the novelty it offered (fly-by-wire system) was not enough to convince potential buyers. Cross-border $\mathrm{R} \& \mathrm{D}$ and production ventures were the new sources of innovative solutions in new planes. While the vertical integration of the design and production of almost all of the modules (except for the engines) was functioning in the

\footnotetext{
${ }^{227}$ The fund was established to finance preservation and rehabilitation of Indonesian forests in which all forest concessionaires had to contribute. A subsequent lawsuit against President Suharto by a group of NGOs was dismissed and IPTN never eventually paid back the loans as the loan was converted into government shares. Devastating forest fires in the following years were grim testimonies of the misconduct.

${ }^{228}$ Major causes for delay were partly of organizational, partly of technological nature (including concerns with the application of the fly-by-wire system).
} 
1970s and 1980s, it became too expensive a solution in the 1990s. Over the 1990s, the changes to a system of increased global competition and collaboration caused many famous European and North American producers to be taken over or to go bankrupt.

Still, IPTN took the risk of going against the trend, and saddled itself with development expenses that by far exceeded its profits and even its turnover. The reason such an endeavor could go ahead was due to the very nature of the innovation system. It was not a system aiming at greater market success by commercial and technological interactions, but more a rather expensive public experiment to prove Habibie's theory that technological capabilities can be acquired through 'learning-by-doing'. The tougher global competition in the industry was no longer conducive to these kinds of experiments. The influence of one strategist on determining the technological capabilities was excessive, and correcting mechanisms and institutional checks and balances were missing from the system of innovation. These are exemplified by what McKendrick (1992) showed to be as underdeveloped managerial capabilities. The lack of foreign sales of existing aircraft should have alerted the staff to international market signals.

Sufficient foreign demand for a new plane can accelerate certification in the respective country. But since this was not the case and since the domestic certification process revealed the need for further technological adjustments, the Indonesian aircraft industry started to fall behind the global leaders.

\subsubsection{The emerging innovation system: increases in size and performance}

There is, nevertheless, historical evidence that an aerospace innovation and production system was emerging in Indonesia. This evidence is summarized below. The main elements (input resources) that increased the size of the innovation system are the following:

1. Actors: The two main (interrelated) actors providing financial input in the system were the Indonesian Government and the Air Force. IPTN was assigned with the entire range of industrial activities from design to production and marketing. The actors that influenced the course of innovation included foreign technological partners, such as MBB, CASA, Boeing and other manufacturers offering parts and components production for IPTN. A major gap in the system was the lack of domestic private actors and private capital investment.

2. The institutional set-up: Government legislation provided a protective environment favorable to an infant industry. This included an import ban on competing airplanes and a guaranteed domestic market (the Air Force and stateowned carriers were forced to buy domestically produced aircraft), as well as an exemption from the "buy Indonesian" policy that compelled other state-owned 
enterprises to purchase domestic inputs. State ownership of IPTN coupled with Habibie's influential role in multiple capacities ${ }^{229}$ ensured a rather soft budget constraint for the company.

3. Capital input: Investment totaled at 6.5 billion dollars by 1989 . The exact use of this amount remains unknown (including what was spent on technology acquisition or $R \& D)$, but it roughly indicates the cost of technological capability accumulation. Additionally, at least 1 billion dollars were spent on the development of the N-250.

4. Technology input: Even before the establishment of IPTN, the Air Force had an $\mathrm{R} \& \mathrm{D}$ depot and a few small planes were designed in Indonesia. Between 1975 and 1986, licenses were acquired for four helicopter types (from MBB, Aerospatiale and Bell) and one aircraft (from CASA). In connection to these projects, at least 50 foreign experts worked at IPTN. A team from Boeing was providing organizational support for the management. As a result of offset deals, IPTN produced components for Boeing, British Aerospace, Fokker, General Dynamics aircraft in the late 1980s and 1990s. A Universal Maintenance Center was also established with the help of General Electric in 1980.

5. New machinery: By the end of 1985 IPTN operated 63 computerized numeric control (CNC) and 51 touch-in numeric control (TNC) machines, 156 conventional milling machines, 1 chemical milling machine and 3 autoclaves for plastic bonding. By the late 1990s, nine additional TNC machines and 24 milling machines had been added (Table 6.16).

6. (Skilled) labor input: By 1989 the workforce of IPTN grew to 14,200, peaking at at 16,000 in 1997. Many employees were blue-collar workers who received in-house training, but a large share of the engineers was trained in Europe and North America. Partners (including CASA and Grumman) also offered additional inhouse training for IPTN staff. University graduates constituted around one-sixth of the employees of IPTN in the 1980s. Many of these had studied abroad with government or company scholarships. Locally, the Bandung Institute of Technology was offering an 'Aerospace Engineering' optional program from 1962 onwards, which was formalized in 1991. A department of aerospace engineering was only created in 1997. A 'Materials Engineering' program has been offered since 1993, although scholarships were given a decade earlier to assist the formation of the

\footnotetext{
${ }^{229}$ Apart from being CEO of IPTN, Habibie was the chair of the Agency for Strategic Industry (BPIS), the Technology Adviser to the President and held the position of Minister for Technology and Research between 1978 and 1998. Following two months of Vice Presidency, Habibie became the President of Indonesia in May 1998, which lasted until October 1999.
} 
program. ${ }^{230}$ However, in comparison to other aircraft producing countries, the provision of high skilled labor had major shortcomings, mainly due to the fact that all high-tech industries were developed at the same time virtually from scratch, where a philosophy of learning-by-doing prevailed.

Table 6.16 IPTN's machinery for aircraft manufacturing

\begin{tabular}{cccccc}
\hline & $\begin{array}{c}\text { Computerized Numeric } \\
\text { Control (CNC) machines }\end{array}$ & $\begin{array}{c}\text { Touch-in Numeric } \\
\text { Control (TNC) } \\
\text { machines }\end{array}$ & $\begin{array}{c}\text { Conventional } \\
\text { milling machines }\end{array}$ & $\begin{array}{c}\text { Chemical milling } \\
\text { machines }\end{array}$ & $\begin{array}{c}\text { Autoclaves for } \\
\text { plastic } \\
\text { bonding }\end{array}$ \\
\hline $\mathbf{1 9 8 5}$ & $63^{a}$ & 51 & 156 & 1 & 3 \\
$\mathbf{2 0 0 0}$ & 63 & 60 & 180 & 1 & 3 \\
\hline
\end{tabular}

Sources: McKendrick (1992) and “Toughing it out” Flight International, 25-31 Jul 2000

Note: (a) Number of CNC machines expanded in 1985 from 24 to 63

The significant innovative efforts made over the first two decades of coordinated industrial development activities had tangible results. Here is an indication on the performance of the aerospace innovation system:

a. New products: Direct outputs of the innovation system are the co-developed $\mathrm{CN}-235$ and the N-250 prototypes, both highly complex technologies that were even new to the world. A number of new-to-the-country innovations included the aircraft and helicopters produced under license as well as the parts and components produced for foreign manufacturers.

b. New production processes: Although there were some changes in the production processes along a product cycle, McKendrick (1992, Fig.2, p.54) shows no evidence of efficiency gains.

c. Market share: IPTN has produced almost 100 of the NC-212 aircraft and more than 140 of the helicopters under license, almost entirely for the Indonesian market. The CN-235 cornered 5\% of the global market, mostly due to the sales of the Spanish-made planes.

d. Sales and value added: Within ten years of its operations, IPTN's turnover increased to 87 million dollars. In comparison with the Brazilian national champion, average sales of IPTN in the first decade of production, grew more slowly, hardly reaching one third of the sales levels of Embraer. ${ }^{231}$ By 1993, IPTN's sales increased to 193 million USD. By 1996 the total Indonesian

\footnotetext{
${ }^{230}$ Information retrieved from BIT's website; "Faculty of Mechanical and Aerospace Engineering, General Information and History" (www.itb.ac.id)

${ }^{231}$ The total sales of IPTN between 1977-86 was around 607 million dollars, for Embraer (1970-79) it was 1893 million dollars, We converted current sales figures to US dollars and deflated to constant 2000 series using WDI data.
} 
aerospace industry's value added had increased to 433 million USD. Yet the industry has not become competitive and Indonesian exports were restricted to a few barter deals of 5 NC-212s and 8 CN-235s.

\subsubsection{Crisis and interruption without transition}

\subsubsection{Crisis in a still emergent industry}

Already during the lengthy final design and certification process of the N-250, in 1995, at Indonesia's $50^{\text {th }}$ anniversary of independence, IPTN announced the development of a new regional jet, the $\mathrm{N}-2130^{232}$. Had it been successful, the financing scheme of the project could have been called 'innovative'. In 1996 a separate financing company was created, PT DSTP 233 , to raise the estimated costs of 2 billion USD by selling shares to domestic investors, state-owned companies as well as for families (Mursjid 1998). PT DSTP would own the prototypes as well as any intellectual property related to the aircraft. The investors were supposed to receive royalty payments from the time when the N-2130 would enter into production (not before 2003, according to a 1998 schedule). However, the company failed to raise more than around $1 / 20^{\text {th }}$ of the required capital. No potential foreign partners showed serious interest in investing and analysts also dismissed what Goldstein (2002b, p.530) called a "folly". In the meantime, while IPTN was also looking for an investor to finance the remaining $90 \mathrm{~m}$ USD required for the certification of the N-250, Suharto signed a letter of intent to the IMF agreeing to stop financing the grand projects, including those in the aircraft industry, in return for a bail-out from the Asian crisis, which hit Indonesia the worst among the East Asian economies (Hill 2000). Even when Habibie became president of Indonesia in May 1998 for over a year, the government could not provide more funds for the industry, which had accumulated 570m USD in debts by 1999 (Goldstein 2002b). In September 1999 DSTP was dissolved and the investment into the N-2130 aircraft was written off as sunk costs.

The crisis not only prompted all the development projects of IPTN to be suspended, but it affected its sales as well. The Malaysian air force was renegotiating a deal on $6 \mathrm{CN}-235$ aircraft that were not delivered on time in 1997. IPTN had to pull out from bidding for an Australian air force contract due to its inability to offer a competitive financing scheme ${ }^{234}$. In response to the crisis, IPTN was diversifying into

\footnotetext{
${ }^{232} \mathrm{~N}$ stands for Nusantara, 2 for twin engines and 130 for the number of passengers (The plane would be offered in 3 sizes, with 80, 100 and 130 seats). (See Goldstein 2002b, note 2 p.530 for a more critical interpretation.)

${ }^{233}$ DSTP is short for "PT Dua Satu Tiga Puluh", or "2130 Company". Its mission was to provide finance for high-tech endeavors in the fields of aerospace, maritime transportation and communications.

234 "IPTN Phoenix falls before Australian competition decision" Flight International, 8-14 Jul 1998
} 
non-aviation related products (car and agro industry) and cut its workforce from 16,000 in 1997 to 10,598 in 2000 (by more than 4,000 from 1999 to 2000). ${ }^{235}$ IPTN changed its name to PT Dirgantara Indonesia (Indonesian Aerospace, IAe) in the same year. Shifting to the core activities of manufacturing aircraft parts for Boeing, Airbus and British Aerospace, IAe also made further attempts to market the $\mathrm{CN}-235 \mathrm{~s}$ and has produced a few. It is struggling to find investors for the N-250 (an attempt of a partnership with China failed). While there are still further attempts to launch a new 19seater aircraft, the N-219, the most lucrative business for IAe may well be the MRO activities. Today, the company employs some 3,700 persons and produces the military version of the CN-235 and also the NC-212 (license extended for the -400 series in 2006) and NAS-332 Super Puma under license ${ }^{236}$. Most recently a new agreement was signed with Eurocopter in 2008 to construct the tail booms and fuselage of the latest version of this helicopter, the EC725/EC225, production of the first of the 125 units planned began in January 2010. The deal also included assistance during the early stage of cooperation. ${ }^{237}$

At the same time, it is interesting to see the contrast in the follow-up story of the CN-235 at CASA. The Spanish partner also chose to go it alone with the further development of the aircraft. The resulting stretched military transport version is capable of carrying 50\% more payload with new engines. The C-295 made its maiden flight in 1998 and has been selling rather successfully, owing partly to the boost brought about by CASA's merger into the Europe defense corporation EADS. Further modified versions of the $\mathrm{CN}-235$ were instrumental in providing EADS with a foothold on the American defense market by providing maritime patrol planes for the coast guard ${ }^{238}$.

\subsubsection{Interruption in an emergent innovation system}

The Indonesian industry ran out of steam during the mid-1990s. Despite all the efforts and achievements, the innovation system was not mature enough to ensure competitive sales in the commuter market. At the same time, the direction of search for new innovative solutions was in mismatch with changes in the global competitive landscape. The Indonesian strategy of self-reliance was diametrically opposed to the alliancefavoring solutions that the global aircraft industry was transiting towards since more than a decade ago. The decision to develop the $\mathrm{N}-250$ almost alone made the project too expensive and technologically less reliable compared to competitors using risk sharing

\footnotetext{
235 “Toughing it out" Flight International, 25-31 Jul 2000

${ }^{236}$ Flight International 28 Oct 2008

237 "PT DI makes components for France's Eurocopter" The Jakarta Post 28 Jan 2010

238 "EADS-CASA all at sea" Interavia, Summer 2006
} 
partnerships for co-development and co-production (see Embraer's success with the E145 regional jets). Even access to blatantly unlimited government resources was insufficient to gain certification and a critical mass of foreign export deals. Consequently, without fundamental institutional changes the industry had little chance of continuing to grow.

In this setting the aircraft industry was unprepared to face the East Asian financial crisis and the loss of its only financial resource, the Government. The attempt to raise "private" capital through the DSTP project and the efforts to find foreign investors indicates that IPTN and the government were aware of the problem. However, these small steps were not enough for the company to weather the crisis in which both innovation and production came to a still stand. The effect of the interruption was more devastating in Indonesia than in any other country developing a latecomer aerospace industry:

1. Reduction in the capital flows: In accordance with the agreement with the IMF, all government support to IPTN was cut, leaving the company virtually without sources of finance. Part of the equipment and machinery in research institutes was also dismantled and sold abroad.

2. Reduction of human capital inflows: The crises had major consequences on the aeronautics education system. In 2000 the enrollment in aeronautical engineering at ITB was reduced from 70 to 50 students, while the program was given a more general profile. Many of the staff were forced to take a sabbatical year abroad, a number of experts left forMalaysia or the Netherlands.

3. Halt of innovative activities: As a result of lack of funding, IPTN shelved the N2130 project and the certification of the N-250.

4. Production output: Apart from the planes already in an advanced stage on the production line, the factory came to a halt.

5. Sales and value added: Value added further plummeted from as low as 24 million USD in 1998 to 4 million in 1999. Most indicative of the lack of transition ever since is that value added could not exceed 37 million in 2005 .

\subsubsection{Conclusion}

\subsubsection{Emergence and interruption}

Based on the findings in section 6.5.4, Figure 6.25 provides a summary overview of the emergence, growth, stagnation and eventual collapse of the Indonesian aerospace innovation system. In the years preceding the establishment of IPTN in 1976, we can see an increase in both the size and the performance of the system. The increases were due to the establishment of a manufacturing facility and the inflow of Polish technology. 
This resulted in new-to-the-country products and presumably process innovation along the learning curve.The institutionalization of innovative activities, through the establishment of LAPIP in 1960 did not start from scratch, since Nurtanio had already been active during the late 1950s and had designed a number of new small planes.

Figure 6.25 Emergence of the Indonesian aerospace innovation system

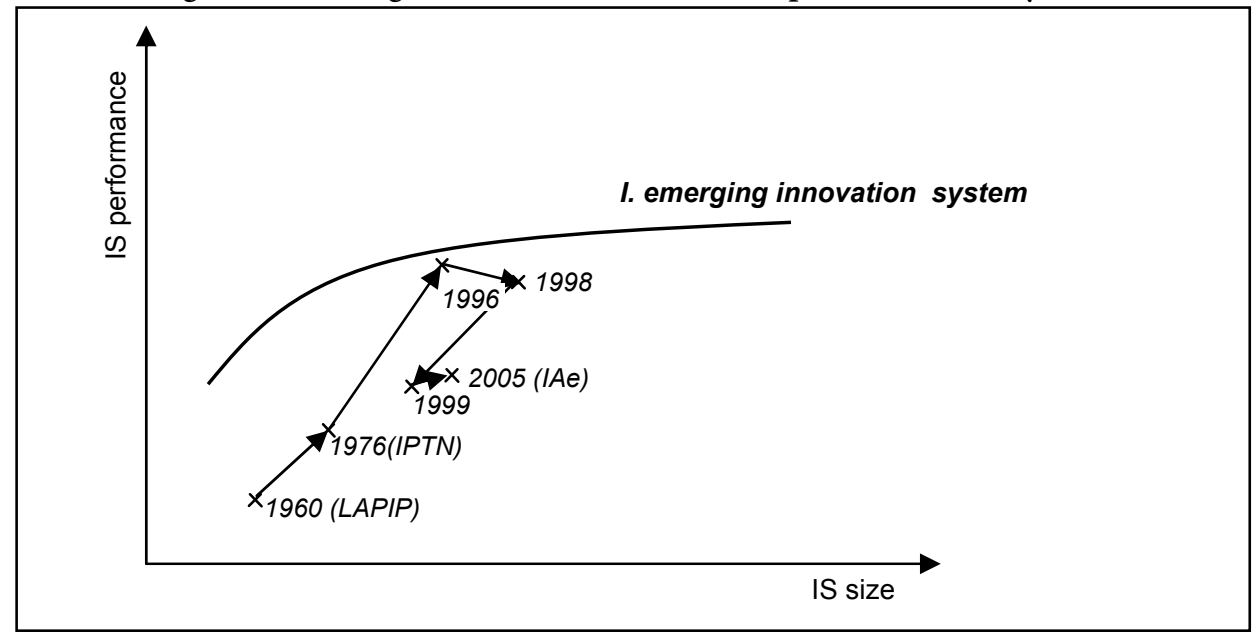

(Author's compilation)

Between 1976 and 1996 the innovation system's size continued to increase and performance improved to hitherto unprecedented levels. The expansion of the system was driven by the expansion of IPTN. Though the share of investment dedicated to $\mathrm{R} \& \mathrm{D}$ is unknown, we may assume that learning by was associated with increased resources to assist learning, see Table 6.13). New technology was provided through licenses for helicopters and aircraft and international exchanges of staff. The improved performance of the system manifested itself in increased production figures (Table 6.14). The arrow to 1996 hides the winding growth path, but the growth trend only seems to be interrupted with the maiden flight of the N-250. The mounting expenses, the failure to certify the plane and failed attempts to commercialize previous ones indicates a stagnating or slightly declining system that reached its critical turning point with the financial crisis in 1998, followed by a sharp drop in physical and human capital available in the system, which halted all work on new products.

\subsubsection{Why did Indonesia fail to make the transition to a new growth trajectory?}

The development of the Indonesian aircraft industry stalled during the emerging phase. It remained an infant industry and was unable to make the transition to sustained competitiveness. Why did it fail to do so? 
First of all, creating a viable aerospace industry is never an easy task. Aircraft manufacturing is among the technologically most complex, highly capital-intensive industries. For a country with no experience in high-tech manufacturing to enter this industry, it had to take extreme risks and deal with a great deal of uncertainty.

The need to cope with this uncertainty and overcome shortcomings of infrastructure, human capital and physical capital were theoretically sound arguments for government intervention. Indeed, there was a congenial political environment during the whole development of the industry right until the crisis (McKendrick 1992). Many comparable policies were applied by Western and emerging country governments to support their aerospace industries.

The need for long-term strategies and solid institutions is crucial, as the failed case of Argentina indicates. In this respect, there is no doubt that Indonesia was diligently following a clearly formulated strategy (Habibie's four steps) from the mid1970 s to the late 1990s. But was the strategy feasible in the first place? Habibie implemented a technology push strategy. It gave too much priority to technology development over financial and marketing considerations (Goldstein 2002b). In particular it was not compatible with the global competitive environment. Even if there is evidence that both at the company and at government level Indonesia made serious attempts to sell IPTN's planes and considered market demand, this was not feasible given the lack of advanced engineering experienced in related high-tech activities and the lack of human resources. The problems with the certification process of the N-250, the integration of the fly-by-wire system and the underdeveloped managerial capacities indicate serious shortcomings in IPTN's technological capabilities.

Despite the lack of sales of the Indonesian made CN-235 and despite the already evident reorganization of the global aerospace industry, IPTN tried to sail against the wind, alone. Contrary to Singapore, with hardly any feedback mechanisms from actual or potential consumers or from other actors of the "innovation system", Indonesia managed to completely disregard the competitive environment. A possible strategy to realize a transition to a more sustained competitiveness should have started with the identification of the desired core competences of Indonesian Aerospace. This might not have been the manufacturing of a complete aircraft, but rather the production of parts and components, with which the company could have participated in global supply chains.

Excessive government attention for aerospace in a developing country has had the unintended consequence of shifting much needed resources (including policy focus) away from other promising sectors. A look at Indonesia's industrial development in a broader context justifies these criticisms. According figures presented by Hill (1990), the disproportionately high levels of protection for engineering and metal manufacturing 
industries received were not justified by the increase in their relative size in Indonesia. We do see aircraft manufacturing an increase in value added increase between 1975 and 986 from almost nothing to 22 million USD, which exceeded the average industrial growth rate of 14.6 per cent per year. However, the share of the capital-goods industries (including transport equipment) actually declined from $14 \%$ in 1975 to $13 \%$ in 1986 (Hill 1990, Table 2, p.87).

One should also note that it is easy to overestimate the real output performance of Indonesia. Even at the peak of production in 1996, Indonesian value added in aerospace was only 433 million USD. This is only 20 per cent the value of Japan and 30 per cent of Chinese value added. During the 1990s it was trailing Singapore, though producing more than Malaysia and for a few years, even more than South Korea (See Chapter 3).

Aerospace manufacturing may well have been too big a technological jump for Indonesia. The industry was established as an island of high-tech in a sea of low-tech production. Technological capabilities in manufacturing in general were low in Indonesia, not to mention in the capital goods industries. By the time Brazil started to produce commercial aircraft, the states of Sao Paulo or Rio de Janeiro had already accumulated four decades of experience in a broader range of industrial activities. In 1970, one year after Embraer was established, metal products, machinery and transport equipment industries accounted for nearly 29\% of Brazilian output (Katz 2000, Table 6 p.1592). Not only was the relative size of the same industries in Indonesia half that of Brazil's, but the technological levels were also much lower. In this respect, the nascent Indonesian aircraft industry was at a disadvantage when it came to attracting experienced engineers, managers or investors from other technologically advanced sectors.

The foregoing analysis shows that the Indonesian aircraft industry has not succeeded in learning to compete. It has accumulated some manufacturing capabilities in a remarkably short period of time, but a sectoral innovation system remained incomplete. It had weak R\&D capacities and insufficient source human resources from the domestic higher education system. The sector has also remained commercially weak. Securing foreign sales is paramount to decreasing reliance on government funding and for recovering at least part of the huge sunk costs of the development of the industry. In the end, even the technological capabilities seemed insufficiently attractive for potential investors. The industry never managed to move beyond the emergent phase and was not able to survive the crises with which it was faced. Even without the Asian crisis, innovation was not sustainable in the system. Since 1998, the industry has continued to decay. 


\section{CHAPTER 7 \\ The evaluation of the case studies and policy conclusions}

\subsection{Introduction}

The overarching question this book wished to tackle was why a few emerging countries succeeded in developing an aerospace manufacturing industry while so many others failed. The answer lies in the dynamics of innovation systems. The long-run overview of sectoral growth and the in-depth country case studies suggested that success not only depended on achieving accelerated growth in the short run, but also on sustaining it. This crucial because aerospace manufacturing has remained a strategic sector in the leading industrialized countries over its hundred years of history and latecomers continue to face a rapidly shifting technology frontier. The key finding of our research is that sustained growth which is more rapid than that in the leading economies (such as the USA) cannot be achieved without the emergence of a full-fledged national-sectoral innovation system in aerospace and without subsequent fundamental institutional changes in this system.

Based on a historical comparison of output and labor productivity trends in aerospace around the world, we have selected five emerging economy cases for a closeup study of the accumulation of technological capabilities and innovation system change in the aircraft industry. Brazil, China and Singapore have been identified as examples of success, Argentina and Indonesia as examples of failure. Evidence from the case studies showed that the growth path of these countries was not smooth in any of the cases. Recurrent crises of mostly macro-economic origin caused interruptions in the catch-up process and threatened with a loss of the capabilities which had been acquired at high cost. At the same time, crises presented windows of opportunities to readjust the institutional foundation in line with a changing global competitive environment.

In the following sections we summarize the answers to the set of questions posed at the end of chapter 5, namely (1) What kind of trajectories did latecomers in aerospace follow? (2) What were the causes of interruptions? and (3) What were the characteristics of the transition periods? Question 1 will be tackled in section 7.2, question 2 in section 7.3 and question 3 in section 7.4. We conclude the chapter with policy conclusions and a discussion of possible avenues of further research. 


\subsection{Catch-up trajectories in aerospace}

\subsubsection{Latecomer performance and evidence of catch-up}

How well did the latecomers perform? Have they caught up with the leaders? In Chapter 3, we found that the United States still produces more than all the other countries combined in terms of aerospace value added. In terms of labor productivity only Singapore and Brazil have succeeded in forging ahead of the US, albeit only in some period. Three major emerging aerospace producers, China, Brazil and Singapore have closely approached and even exceeded the aerospace value added levels of other leading OECD countries. Indonesia, South Korea and Mexico have for longer periods succeeded in increasing relative value added compared to the US. As Figure 7.1 demonstrates, all this still adds up to a rather low share of emerging economies in global output, in fact, aerospace is one of the few sectors where industrialized economies hold an exceptionally large global share. Recent dynamics point to a faster growth in emerging economies than in the industry leaders. If the process of catch-up is defined as an increase in relative value added share, we have a number of cases of catch up on the basis of which we can draw conclusions concerning the nature of the catch up process.

Figure 7.1 The evolution of the global aerospace industry, 1970-2007 (value added, USD millions at constant 2000 prices)

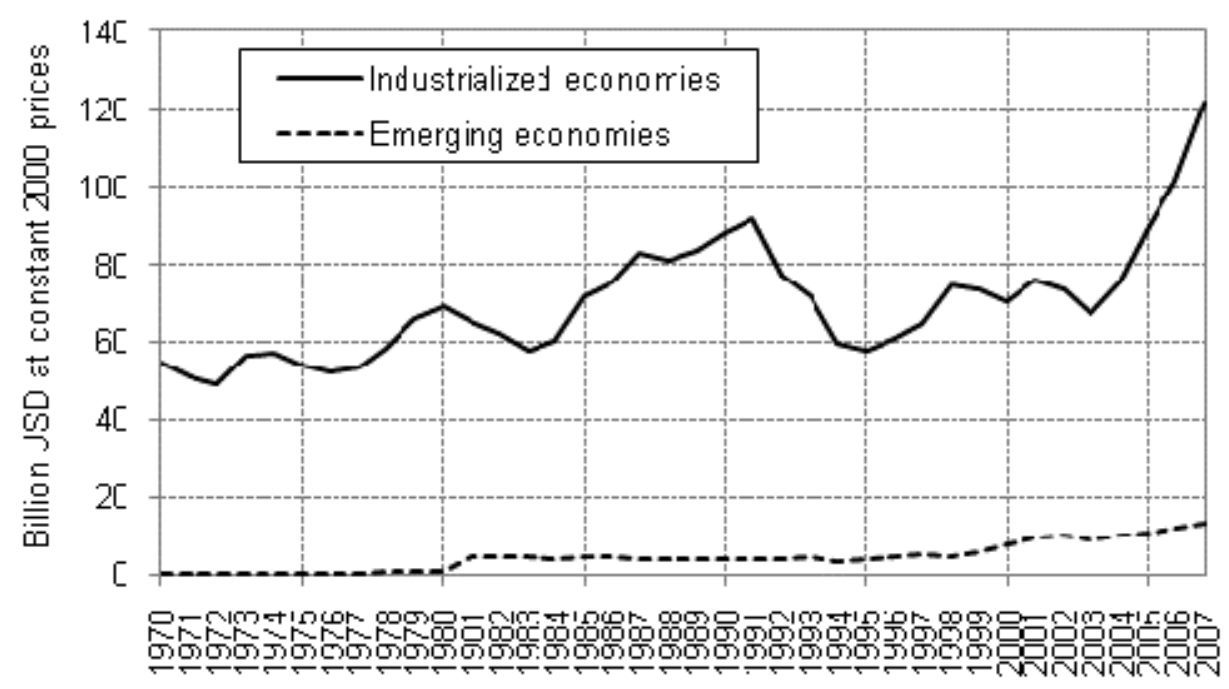

Source: See Appendix A.1. 


\subsubsection{Emergence of the aerospace industry in emerging economies}

During the 1970s four newly industrializing economies devised industrial policies to establish aircraft manufacturing in their countries. The launch years of aircraft manufacturing activities in Brazil, South Korea, Indonesia and Singapore have all been shifted to year 1 in Figure 7.2 in order to compare the development trajectories. We can derive two quick observations from the figure. The first one is a puzzle: why did Singapore and Brazil achieve so much greater growth than Korea and Indonesia? The second observation is that years of decline and slow growth are recurrent phenomena even after periods of successful initial growth. Nevertheless, accelerated growth is also achievable over longer periods of time.

Figure 7.2 Parallel evolution of emerging aerospace industries in 4 selected countries

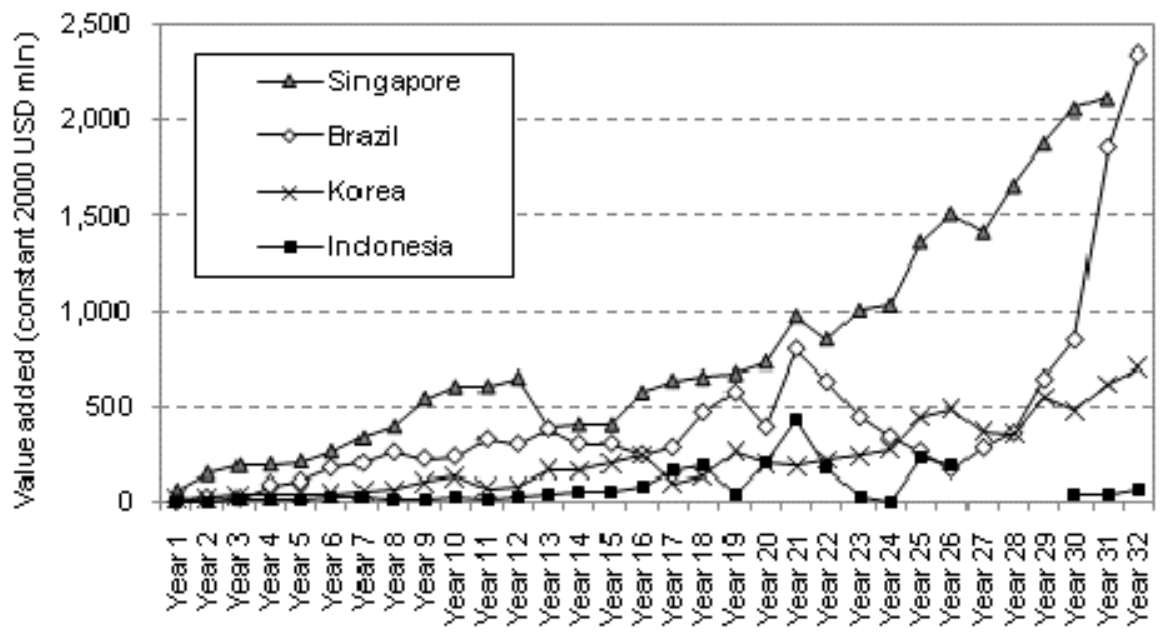

number of years following entry

Source: See Appendix A.1.

Notes: Year 1 refers to the start of dedicated industrial development programs. It refers to 1969 for Brazil, 1976 for Korea and Indonesia and 1977 for Singapore.

Regarding the first puzzle, many of the policies the four countries chose to follow were similar. They all provided massive public financial support to the industry. They all sourced advanced technology by assembling aircraft under licenses. In this effort the air forces played a crucial role in all countries, often by providing facilities or creating demand for the locally assembled aircraft. Many of them made some limited modifications to existing models. What distinguished the four country strategies was the early focus on commercialization in Singapore and Brazil and a strategy to sell in developed markets. In figure 7.2 the differences are already visible by the $6^{\text {th }}$ year after 
the launch of activities. Sales to civilian markets were not only sources of additional finance for technological learning, but also provided incentives to increase quality and efficiency. The differences in product portfolios are also interesting. Singapore chose to be an MRO hub and a parts supplier, while Brazil chose to sell commuter aircraft. By the end of the first decade the strategy of Singapore proved to be more successful. Although Brazil did catch up in the long run, the MRO and parts and components production allowed for a more stable growth path in Singapore. However, one should not forget that that Singapore's aggregate macroeconomic performance was much more stable than that of Brazil. This brings us to the second observation.

We concluded in Chapter 3 that recurrent crises are central elements in the evolution of the global aerospace industry. We can similarly identify recurrent crises in latecomer economies in Figure 7.2. However this figure does not provide explanations for the large variation in the timing, length and depth of crisis periods in different countries. In the following sections we will try to provide some explanations for this. But first we take a closer look at the salient features in the evolution of technological capabilities and the nature of interruptions in the growth trajectories.

\subsubsection{Accumulation of technological capabilities over time}

The long-term accumulation of capabilities in aerospace shows no general trend of progressive development which would start with licensed assembly and end with own equipment manufacturing (Kim 1980, 1997). Some producers returned to licensed assembly even after having developed and successfully marketed their own designs. They did this for two reasons. One reason for licensing was sourcing a new technology required for a module in a new local development. Firms could acquire licenses from time to time as they developed new products, especially if major technological changes (regime or paradigm changes) had occurred in the meantime. This can be a strategic choice given that aerospace products represent complex systems (Hobday et al. 2005; Dosi et al. 2003). For instance, licensed technology filled capability gaps in mass production, pressurized aircraft designs, jet, and computer aided design technologies for Embraer during the 1970s and 80s. The license to assemble the CASA C-212 provided IPTN with capabilities to co-develop a more advanced version of the plane subsequently. Of course, in many cases the locally assembled products also served additional purposes by i.e. for national security, which indicates a close collaboration between the industry and the government. There was another form of licensing which responded to domestic market needs rather than technological development needs. If the domestic market was demanding complex technologies that exceeded local design capabilities (e.g. advanced fighters or transport planes), massive procurement programs offered governments leverages to create jobs locally. This was the case of Argentine 
fighter production in the 1990s. The aim in this case was not the direct application of new technologies. Although such licenses added to the local knowledge base, they were not necessarily used for innovation in the same strategic way as in the case of the first type of license acquisition.

The latter practice certainly contributes to increasing skills and tacit knowledge in the industry, but it is the former practice of targeted technology acquisition which is more important if we try to explain catch-up trends. The effectiveness of technology accumulation through licensing was the highest if licensing was targeted to be complementary to local R\&D efforts, which increase absorptive capacities. At the industry level this practice shows a pattern of continuous learning, during which technological complexity may increase, as Hobday (1995) predicted. However, we argue that this practice of strategically returning to licensed production can be better explained by radical changes along the co-evolution of technology, actors and institutions in catching up aerospace industries. After a trajectory change, an industry faces new learning challenges and has to find different ways to acquire technologies.

Other forms of external technology acquisition show similarly repetitive patterns. For instance, trajectory changes are often associated with new forms of long-term strategic partnerships in $\mathrm{R} \& \mathrm{D}$ and production activities, or mergers and acquisitions. The classic stage models predict increasing domestic capabilities and a diversification of activities. Paradoxically, the Brazilian aerospace industry experienced its best performance after the late 1990s, while it streamlined its innovative and productive activities and even outsourced design or "forgot" some of its capabilities. Our explanation is that trajectory changes fundamentally redefine the direction and reorganize the nature of technology accumulation.

Accumulating technological capabilities involves costs and uncertainties even during periods between radical trajectory changes, which originate from the tacit component of knowledge (Lall 1992). The times of radical trajectory changes bring along different kinds of uncertainties and costs that stem from breaking path dependencies and establishing new routines and new channels of learning and collaboration. With regards to external technology sources, the challenge is to identify new partners and create mutual trust. In many of the cases there was a significant element of path dependence in international partnerships across trajectory shifts. This was observable both in Singapore and Brazil, where many of experienced partnerships from the 1980s survived major changes in the 1990s as well. The macro-economic changes in China during the 1990s were deep enough to establish new joint ventures with previously unimaginable western partners, but at the same time the long tradition of collaboration with Russian manufacturers did continue in jet engines and defense systems. 


\subsubsection{Interruptions in the growth trajectories}

In Chapter 6 we found evidence of interruption in all country cases. In Brazil, the industry underwent a crisis between 1990 and 1994; in Singapore between 1989 and 1991, in China in 1961 and from 1984 through 1996; in Argentina during the 1950s and once again after 1983 and in Indonesia in 1997. In Singapore a 40\% decline in value added in a single year was followed by hardly any growth in the next two years before growth resumed at $43 \%$ in the subsequent year. Brazil experienced a $27 \%$ average decline of output for four years running and a $67 \%$ growth in the subsequent year. From 1984 to 1989 the Chinese aerospace output declined on average by 10\% per year, grew by $12 \%$ for one year (1990), but then continued on a downhill course with a $6 \%$ decline for six years. Between 1997 and 1999 Indonesia experienced an average 76\% decline in output. We do not have value added figures for Argentina but the decline was similarly dramatic. Before the crisis the industry was performing relatively well in Brazil and Singapore (both with average value added of around 600 million dollars in the three preceding years) but it was also doing rather well in Indonesia (the three-year average was 230 million dollars) compared its earlier performance.

The declines were caused by a combination of macroeconomic and industryspecific factors. Explanatory factors included declines in domestic and foreign demand, a drop in public financing, a lack of new product sales and a loss of competitiveness associated with aging technological capabilities. Macro-economic events such as the Latin American and Asian financial crises or global recessions) can explain the timing of interruptions, but they cannot explain their depth and length. Although these are factors external $^{239}$ to company management, we argue that recurrent crises are typical for the aircraft manufacturing industry. Companies and the governments supporting them should be prepared for interruptions.

The case studies in Chapter 6 provide country and industry-specific causes for each of the interruptions. We conclude from the comparative analysis that the answer to why some countries were hit harder than others, and why a crisis lasted longer in some countries than in others is based on the relative performance of their national sectoral innovation systems. In the next section we explain why.

\subsection{Interrupted innovation}

In this section we address the question raised in section 5.2 .7 of chapter 5 about the causes of interruptions in the development of innovation systems.

\footnotetext{
${ }^{239}$ Although, as in the case of Indonesia for instance, the continued support of prestige aircraft development projects was a cause for instabilities.
} 


\subsubsection{The explanation of radical innovation system changes}

Trajectories of latecomer industrialization in aerospace followed a pattern of interrupted innovation. Countries narrowing the technology gaps with the lead countries did not simply accumulate capabilities in an incremental fashion as suggested by stage theories of catch up. Rather, the accumulation of capabilities was a process which was repeatedly interrupted by external macroeconomic and political crises and changing market conditions. Radical transitions in sectoral innovation systems were followed by periods of industry growth and more incremental changes in size and nature of the innovation systems. These transitions entailed a reconfiguration of the routines, rules and norms governing the interactions among existing and new actors in a catching up system, in line with demands and requirements of changing market conditions.

Our empirical evidence shows that sustained growth in latecomer aerospace industries is not possible without substantial changes in the aerospace innovation system in the country. The literature on sectoral innovation systems has emphasized the sectorspecific co-evolution of "technology, demand, knowledge base, learning processes, firms, non-firm organizations and institutions" (Malerba and Mani 2009, p.11). But it has remained less articulate about the actual patterns of such co-evolution. The conclusion of this thesis is that while the industry co-evolves with technological change and macroeconomic and political events, this does not happen in a smooth incremental fashion. It co-evolves in a series of distinct cycles, interrupted by major crises and transitions. The cyclical changes in the performance of the sectoral innovation systems are closely interconnected with cyclical swings in value added in the industry.

\subsubsection{National-sectoral innovation systems in latecomer aerospace industries}

Has an industry ever succeeded in achieving accelerated growth without a nationalsectoral innovation system? Emerging economies that were shown in the statistical overview in Chapter 3 to have limited aerospace industrial activities, mostly possess some aircraft repair and servicing (MRO) capabilities. The industry in these economies is an enclave, the technological know-how and expertise originates from foreign sources. Parts and components are imported and the manuals and specialized training for locally educated general engineers and skilled workers are provided by the foreign aircraft makers. A common feature of these countries is that none of them achieved accelerated value added growth without some efforts to develop their own educational institutes, research organizations and dedicated policies to facilitate aerospace knowledge assimilation, diffusion and generation. The reason for this is the high technology intensity of the industry. Developing a full-fledged innovation system is thus crucial for any entrant to the industry. 
However, enclave-type institutional structures are actually rather typical for developing country innovation systems (Banji 2006). The lack of local entrepreneurship, weak links with local buyers and suppliers, or between R\&D institutes and universities (if they exist at all) point to weak domestic innovation systems. We argue that such weak domestic innovation system cannot be replaced by establishing stronger ties with national-sectoral innovation systems of advanced countries. The cases of Argentina, China and Indonesia offer good examples. The jet fighter development during the late 1940s and 50s in Argentina was actually a spin-off of the German sectoral innovation system and was not linked to the development of local capabilities. The project eventually collapsed and the industry had to struggle to survive. Similarly in China, jet fighter production came to years of standstill after the Sino-Soviet split in 1961 due to the departure of Soviet experts and technicians. In Indonesia, indigenous aircraft development projects were frozen as a result of a weak innovation system in the late 1990s. In many of the cases these 'enclave projects' did show increased innovative performance and even industrial growth in short term. Yet none of these institutional arrangements were sufficient for sustained catch-up in aerospace. Similarly, investments in sustaining the enclave did rarely result in spillovers to the domestic economy given the weak links with domestic industry and education and research organizations.

Some analysts are also concerned about enclave characteristics where the aerospace industry is too highly concentrated in a few companies that rely mainly on foreign parts and components suppliers. A typical case is the Brazilian aerospace industry since the mid 1990s. If nearly all of Embraer's suppliers and customers are outside Brazil, couldn't Embraer be simply relocated to another country? In our view it is, however, exactly the existence of a national sectoral innovation system that ties Embraer to Brazil. The strong links with education and research institutes (CTA/ITA), but also with non-engineering universities, with policy makers, or with the Brazilian Air Force, as well as with smaller spin-off companies are a result of over thirty years of institutional development. Although the distribution of innovative activities and technological capabilities is rather skewed and Embraer excels in joint design and system integration, this is a result of a strategic choice and has provided considerable industrial growth. The only source of concern should be if the innovation system was not efficient in responding quickly enough to competitive pressures.

We referred to innovation systems in the various country cases despite their structural shortcomings (missing actors, institutions) or low performance. We also referred to one national sectoral innovation system despite the fact that in some cases we observed "parallel worlds". In the case of China, at certain points in time information 
and knowledge exchange was very limited between aerospace clusters. ${ }^{240}$ Nevertheless, even if multiple structures existed temporarily, the lack of interactions did not prevail in the long-run.

\subsubsection{A note on the measurement of innovation systems performance}

In Chapter 5 we introduced the concepts of innovation system size, innovation system performance and innovation performance frontiers as rather loose concepts. We were aware of the fact that consistent and comparable input and output measures of sectoral innovation are impossible to obtain over a long time period. ${ }^{241}$ We used these concepts to structure the case studies and make provide an analytic framework for presenting the limited empirical data available. Estimating innovation system performance frontier curves using composite indicators has never been the aim of this research project. Instead, we intended to use the limited statistical data available to find trend breaks in input and output measures of innovation and look for institutional explanations.

Long-run changes in innovation inputs $(\mathrm{R} \& \mathrm{D}$ expenditures, $\mathrm{R} \& \mathrm{D} /$ sales ratios, technology licensing, number of graduates in aeronautics programs, trends in foreigners' local patenting) and output indicators (such as new product sales or composition of exports) chart the trajectories and reveal interruptions and periods of transition. Trends in production system indicators such as value added and productivity can also be used to identify interruptions and historical turning points in the innovation system.

\subsubsection{Periods of incremental and radical innovation system dynamics}

The length of periods of growth between interruptions varies from country to country, although the increased internationalization of production and consumption does result in increasing synchronization of country experiences. The end of the Cold War caused a major crisis in the global aerospace industry and countries that entered the industry at different times and had acquired different levels of capabilities, all experienced a crisis during the mid-1990s. ${ }^{242}$ But in Argentina, Brazil and China major interruptions had already occurred well before the end of the Cold War. This indicates that countryspecific factors matter at least as much as industry-specific ones.

\footnotetext{
${ }^{240}$ This is not the same as regional differences, e.g. between the Silicon Valley and Route 128 in the US (Saxenian, 1994)

${ }^{241}$ We have presented in the tables and figures of the case studies most of what is publicly available on innovation in latecomer aerospace industries. Greater transparency would certainly benefit any future research.

${ }^{242}$ And experience one even more simultaneously during 2008-09, although this remains beyond the scope of this paper.
} 
Country-specific factors appear to be similarly important for the length of the period between the beginning of an interruption (indicated by a significant drop in output) and the start of the transition (the creation of a new institutional arrangement in the innovation system).

In this paper we have distinguished two phases in the successful development of an aerospace industry: an emergent phase and a phase of sustained competitiveness. It is an interesting question whether the end of the emergent phase in aerospace evolution is inevitably associated with an interruption. This seems not to be always the case. In the case of Brazil, the sectoral innovation system had already developed and was functioning well by the early 1980s and the industry had achieved sustained competitiveness, well before the crisis and interruption around 1990. Nevertheless, the transition after 1990 provided an opportunity to decrease the participation of the state in financing innovative activities.

The trajectories of our case study countries show that in all countries public funding was indispensable for the emergence of an aerospace innovation system. ${ }^{243}$ In Brazil CTA and ITA were funded by the government and so was Embraer at the time of its establishment. No private capital was channeled into the Chinese innovation system before the 1990s. Similarly, the emergence of the innovation system was funded by public sources in Argentina and Indonesia.

However, while state support is essential during the early years of entry into aerospace, state bureaucracy may become an obstacle as the infant industries become more mature. The sudden withdrawal of the state from a system centered on government (or military) financing - witnessed for instance in Indonesia, Brazil and Argentina - itself represents a system shock, which ultimately requires radical institutional changes - and thus a transition. In this sense, the transition was unavoidable in Brazil. The question is whether it could have been managed more smoothly.

\subsubsection{Causes of interruptions}

The framework of interrupted innovation focuses on the evolution of innovation systems and not on technological change alone. Evidence from the case studies show that innovation system changes are not triggered by internal factors, such as a slowdown of innovation dynamism as the innovation system comes close to its innovation

\footnotetext{
${ }^{243}$ In fact, the emergence of an innovation system, which is required to provide the resources needed for competitiveness is what Gerschenkron referred to as the need to substitute the missing institutional prerequisites to growth.
} 
performance frontier, or by radical domestic innovations at the frontier. Instead, exogenous system shocks play a crucial role in interruptions. This is due to the latecomer setting and the capital- and technology intensity of the aerospace industry, Outside shocks, either in the form of falling sales revenues or the drying up of available public funding, can result in the depletion of resources available for innovation and the inability of the industry to respond to competitive challenges.

Radically new technologies need not originate from within a latecomer industry to revolutionize the industrial structure. None of the four countries we examined introduced technologies new to the world that made the technologies of leading producers obsolete. On the contrary, it was changes in the production structure (the increased use of hierarchical global supply chains by American and European producers) that triggered changes in Brazil and China. Thus, Embraer endorsed the risk sharing partnership model and China shifted track to become a major component supplier. Second, even if technological change in the leading countries sometimes play a role in radical institutional change in emerging producer countries, economic and political events external to the industry are even more important. This is due to the fact that during the emergent phase the industry relies heavily on the government as both investor and customer. Third, key players are rarely replaced. The major incumbent aerospace manufacturers in emerging economies are very likely to survive interruption, transition and subsequent consolidation periods. This may be a particularity of the industry, where huge sunk costs and power relations provide sufficient incentives not to let national champions go under easily.

We conclude that the causes of interruptions were almost always exogenous to the sectoral innovation system, rather than endogenous. The financial crises and the fall of the military regimes in Brazil and Argentina, the economy-wide changes of introducing market-mechanisms in China or the Asian financial crisis in 1997 were all external to the industry. Thus, the question arises whether macroeconomic shocks inevitably cause interruptions in the innovation system, or whether certain aerospace industries were able to avoid such interruptions?

The answer lies in the case study of Singapore. The effects of a crisis in the economy in 1985 and in 1997 were relatively limited for the aircraft industry and the decline from 1988 to 1989 was halted within one year. The reason for this was the performance of the national innovation system which provided key resources (human capital, re-training and incentives for investment into innovation) in a speedy manner. A contrario, this suggests that the lack of such a flexible national and sectoral innovation system can be an endogenous cause of an inadequate response to an interruption, which itself worsens the interruption. 


\subsection{Characteristics of sectoral innovation system transitions}

There are surprisingly many common features in successful innovation system transitions across countries. First, there is a tendency to shift from a military to a civilian innovation system. Second, there is a trend towards increasing participation in international $\mathrm{R} \& \mathrm{D}$ and production networks. This is in accordance with the internationalization of the global industry both in development and production (many of the "organizational innovations" were initiated earlier by dominant American and European manufacturers). For the sectors in transition this implies establishing connections with foreign sources of technology and shifting towards more production for export markets. In the following paragraphs, we address four sub-questions with regard to the characteristics of innovation system transitions (see section 5.2.7, question 3 a-d).

\subsubsection{Interruptions, transitions and the accumulation of technological capabilities}

Aerospace producers at medium and higher tiers of the supply chain face immense sunk costs due to the costly machinery and training involved. Firms make these investments if they expect to recover these costs in a long enough production run, or if they expect to be able to expand production cycles by selling related products which require relatively less additional investment. If a production run is interrupted by a temporary decrease in demand, but picks up again, firms may face liquidity problems, but if credit is available to bridge the crisis, they should be able to recover once demand picks up again. However, if the market, following a crisis, demands new products which cannot be supplied with existing capabilities of the company, the company's survival is at risk. It is already experiencing financially troubles, but in order to recover, it needs to invest more in new technologies. This is a typical scenario associated with innovation system transitions.

\subsubsection{Transitions and capabilities of firms}

Evidence from the case studies show that the pace of accumulation of new technological capabilities after the transition is linked to two factors. First, it is the absorptive capacity of a firm, which, in the classical sense of Cohen and Levinthal (1990), depends on how related prior knowledge is. Second, to the financing ability of the firm itself or the available sources of support within the innovation system. This latter, if linked to a coherent technological development strategy, can compensate for insufficient absorptive capacity.

Take the examples of Brazil and China. In Brazil, Embraer's experience in designing commuter and marketing commuter aircraft (the Bandeirante, the Brasilia) 
and a jet fighter (the $A M X$ ) were cosely related to what was required for regional jets (the ERJ-135/145). Yet, it (like most other firms in the global market) lacked financial resources to develop and produce every part and component in-house. The transition involved streamlining the activities, focusing on core competences and establishing collaborative joint ventures to source others. In this way, new private investors saw a growth potential in Embraer required to finance the acquisition of new capabilities related to the core competences. At the same time, using the terminology of Tushman and Anderson (1986), the transition destroyed existing competences of the company. In China, the capabilities of AVIC (and its predecessors) to "design" and "produce" Sovietstyle "commuters" and fighter jets were only very distantly related to the aimed commercial regional and larger jets. However, giving the industry strategic priority opened government coffers to finance the acquisition of missing technological capabilities (through license manufacturing $\mathrm{MD}-80 \mathrm{~s}$, producing aircraft parts for western plane makers, co-developing the ARJ-21 with western partners). Apart from the technological relatedness dimension, absorptive capacity at the organisational (firm) level also has a management dimension. The efforts to change practices and routines, or to "un-learning" inefficient solutions should not be underestimated either, as McKendrick's (1992) study on IPTN in Indonesia reveals. In a mammoth-sized AVIC conglomerate the replacement of management practices is especially crucial and explains why the recovery has taken such a long period.

Given the specialization in MRO and product upgrading early on, the absorptive capacity of Singapore Technologies Aerospace was strong. New technologies required to serve a larger MRO market were closely related to what was available earlier. Relatively little organization change or new management practices were required, due to the already existing outward orientation. The transition was a competence-enhancing one.

The negative examples from Argentina and Indonesia similarly fit in this frame. Deficiencies in absorptive capacity of FAMA was excessive in the 1980s, and neither the financially troubled Argentine government or private investors were ready to raise funds. And closing the gap between existing capabilities and what a commerciallyoriented innovation system would have required in terms of products, organization of production and marketing capabilities would have been costly. The case was very similar for IPTN / Indonesian Aerospace after the Southeast Asian financial crisis. The large gaps and lack of funds indicate why transitions have not yet occurred.

The previous examples focused on leading firms. Transitions similarly affect the technological capabilities of other firms in the sector. In Brazil, as Embraer was privatized, a number of new firms entered the market, many of them established by previous employees of Embraer. This allowed to preserve certain capabilities at the industry level what the leading firm has lost, but this was only temporary, because in the 
long run, Embraer increasingly collaborated with foreign component suppliers. Even if some of these suppliers in the last decade established subsidiaries in Brazil, these were more trade posts and did most of the value added activities in their home locations. The case of Singapore is different. The Economic Development Board offered tax breaks and established science parks to invite leading foreign firms to open regional headquarters and production and potentially R\&D facilities. As a result, the transition was competence-enhancing and brought new capabilities also in the lower strata of the supply chain.

Given the high costs associated with establishing new capabilities for firms, it is good to mention that evidence shows a possibility to prepare for upcoming interruptions and transitions. If actors invest in 'pre-competitive research' (research on possible new technologies required to sustain competitiveness), they can ensure a relatively fast transition which lowers the costs of transition. This is especially crucial for latecomer innovation systems that have advanced close to the world frontier. This could already be observed in the cases of Singapore and Brazil in the 2000s. Educational and research institutes play a central part in preparing for upcoming transitions.

\subsubsection{Actors that govern the transition period}

The competitiveness of the industry during the growth period that follows a transition (or the emergence) depends largely on which actors play a leading role during the transition (or formative) periods. The government is, especially during the emergence phase, indispensable as a key actor. The type of government (military or civilian), its position in the decision-making hierarchy, and the nature of government involvement (did the government impose institutions or did it facilitate the creation of interactions) makes a difference in the structural and functional outcomes of the new innovation system (in the incentive structure, variety creation and selection mechanisms). Countries, where private actors and entrepreneurs were more involved in the creation of institutions, tended to perform more successfully. The comparison of Argentina and Brazil in terms of governance is telling. In both countries the military played a crucial part in the establishment of aerospace research and production activities. But already in the 1970s the success of Brazil owed a lot to entrepreneurial participation and the inclusion of players with a market-oriented mind-set. Similarly, the privatization of Embraer was once again driven by entrepreneurs and was crucial to the elimination of inefficiencies.

If national security considerations are more important for the development of an industry than commercial ones and the transition is completely governed by the military, a failure to establish a sustainable system is almost inevitable. The institutions created during the transition reflected the expectations of one non-market actor, which 
led to failure in Argentina in the 1950s and in the early decades of the industry's development in China.

\subsubsection{Factors contributing to the success and failure of transitions}

It is a crucial point in interrupted innovation that the emergence of an innovation system does not yet guarantee sustained competitiveness. Only if the system succeeds in surviving a major interruption, will growth restart following a transition, resulting in sustained competitiveness. A successful transition depends primarily on how well key current and potential actors understand the causes of the crisis and the new competitive environment, and how they are able to overcome institutional inertia. In the four country cases, transition did not happen without some form of policy intervention. The question is how to achieve "good governance" of the transition that creates the institutions for long-term growth.

\subsubsection{Successful Transition - with coordinated intervention}

Transition processes are uncertain and changing established routines and laws is costly. However, if an interruption occurs, the cost of "non-transition" also increases rapidly. There are negative external effects, due to growing unemployment, loss of expertise that can be directly transferred to other industries, deteriorating export performance, and increasing debt burdens in the supplier chain and for development banks. Since the social costs of failure are so high, the government has a legitimate reason to try to initiate systemic change. But firms and entrepreneurs also have an important role given the competitive challenge the industry faces.

Both the emergent and the transition phases require coordinated action by the key stakeholders, involving the identification and creation of missing institutional elements. A transition will not occur unless there is sufficient will on the part of the key actors. This may require the formation of explicit or implicit "coalitions" of major actors who can ensure financial and political support for the new system and who can expect major returns from the new system. Firms and entrepreneurs intrinsically have a better understanding of the competitive landscape and can act as 'lobbyists' for system-wide change (cf. Athreye, 2010). Entrepreneurship can also play an important role in identifying the capabilities in the old system that are worth preserving. However, since it is still a catching up system in an emerging economy, underdeveloped infrastructure and missing institutions remain significant impediments to change. For instance the shortage of venture capital was often pointed out in even the best performing country, Brazil. 
The nature of entrepreneurship also makes a difference. Short-term rent seeking resulted in less effective concession agreements in Argentina, while aiming for a longterm solution was instrumental for the successful privatization of Embraer. To some extent, competition can also promoted by the government, as the case of China shows. But the lack of competitiveness-driven firms and the absence of an entrepreneurial culture in the Chinese aerospace system may well be the reason why the transition took almost two decades following the interruption in the 1980s.

\subsubsection{Failure of transition: interruption during the emergent phase}

The timing of the first major interruption is one of the important factors explaining the success or failure of transitions. We identified an emergent or formative phase at the beginning of the evolution of the industry and its sectoral innovation system. During this phase the industry has to acquire a minimum level of technological capabilities required to produce aircraft or components utilizing current (or older) technology. Acquiring a threshold level of capabilities is particularly costly in the capital and skilled labor intensive aerospace industry. It involves the creation of some elements of a sectoral innovation system (i.e. firms, aeronautical engineering curricula in higher education, public research organizations, and so forth).

In Chapter 2 we criticized the appropriateness of stage theories to describe the evolution of aerospace industry in latecomer countries and argued that the ability to innovate is essential for growth. We have seen that production capacity alone was not enough to sustain the industry in the long term. Although Argentina produced fighters and trainers during the 1970s, and Indonesia produced small transport planes during the late 1980s and mid 1990s, these planes did not meet the quality requirements of the markets and could only be "sold" to their own governments. This was due to the underdeveloped sectoral innovation systems (which lacked a sufficient technological base, private actors, and market incentives in Argentina and a sufficient pool of skilled labor in Indonesia).

Learning by doing is an essential way of accumulating capabilities to innovate. But if learning is inefficient due to the lack of capital and skilled labor, the probability of an interruption occurring before the innovation system has matured sufficiently is high. Such an interruption had devastating effects in Argentina, both at the beginning of the 1950s as well in the 1980s, and in Indonesia in 1997. Brazil, however, survived the interruption in the 1990s because it already had a fairly well-developed sectoral innovation system. Still the system transition lasted four years and involved a fundamental reconfiguration of innovative and productive activities. In China, the innovation system was quite well developed by the 1980s (even if it was not functioning 
in a competitive way since the incentive was more to achieve a given quantity of output rather than quality) and could therefore survive its interruption.

If the main components of an innovation system are in place, a crisis can be overcome through reconfiguring the institutions, the functions of the various components and their interactions. Had a full-fledged innovation system not yet emerged prior to the crisis, more missing components would need to be supplied in addition to reconfiguring the role of the already existing institutions. Theoretically, considering the arguments on latecomers' advantages and path dependency, the less developed an innovation system is, one might expect that there is less the institutional inertia to overcome. But this reasoning does not hold for aerospace. Countries are more likely to fail if the innovation system is interrupted by a crisis before the phase of emergence has resulted in a full-fledged innovation system. This is illustrated by the examples of Argentina and Indonesia.

The reasons for this relate to the capital intensity of the industry. Competitive aerospace manufacturing depends on sufficient investment capabilities. Following the interruptions in Argentina or in Indonesia, the decline of the industry was due to a lack of investment. The problem here is that the existing level of technological capabilities matters in a crucial way for attracting large amounts of foreign investment. The more developed an innovation system is, the higher its chances to acquire new sources of capital. The cost of entering the aerospace industry as a latecomer inevitably entails the cost of establishment of an innovation system.

\subsubsection{Transition institutions}

The role of the national innovation system is particularly important in times of transition. Transitions in aerospace can be inspired and supported by similar institutional changes taking place in other sectors of the economy. This was very much the case in China in the 1990s, when the success of reforms in many sectors and regions was a motivating factor for the transition in aerospace as well. The most prominent case is Singapore, where a well-endowed national innovation system provided the basis for a rather smooth system transition. Singapore has constantly increased its investment in education, training and research in areas close to aerospace manufacturing (science, technology and engineering). The globally competitive knowledge base served well the aerospace industry. In addition, active interaction between system components and actors ensured an "early warning" of, and a rapid response to loss of competitiveness. The case of Singapore also shows that an open system of innovation is of paramount importance. Both during the emergence phase and during transition, Singapore attracted expatriate experts and foreign direct investment to fill in the knowledge and capability gaps. This is very much in line with what Galli and Teubal (1997) referred to 
as "anticipatory institutional changes". Such changes that take place at the higher system level (read, national innovation system) reinforce restructuring at the subsystem level (national aerospace industry) and reduce the effort required for a successful transition.

It is also interesting to consider uncertainty in times of transition. Interruptions and transitions may also take place in innovation systems at the technological frontier, because the same forces of co-evolution may well apply there as well. (The volatile growth of the industry in industrialized countries appears to underscore this assumption.) What is different in the case of latecomers is the degree of uncertainty that actors in latecomer aerospace innovation systems face. The further away they are from the technology frontier, the less the technological uncertainties are and the better they can benefit from benchmarking already established best practices.

Nevertheless, as the very heterogeneous nature of trajectories show, every transition involves a considerable degree of experimentation. These 'experiments' are carried out by incumbent actors who are constrained by their existing capabilities and learning abilities, and the usually highly concentrated structure of the industry and the close connection between leading actors and governments make incumbents powerful enough to deter external actors from entering the national sectoral innovation system or limit their actions. This is especially true in cases where the development of the aerospace industry is closely linked to a nationalistic rhetoric. The success of these experimental periods thus depends on the ability of system actors to look beyond the system boundaries.

\subsection{Policy conclusions}

The conclusions discussed here refer to policies that may be conducive to reduce the detrimental effects of crises and to a foster successful transition process of the innovation system in times of radical change. Since we did not have sufficient and comparable investment data, and did not examine the spillover effects of aerospace investment, we cannot draw any conclusions about the net the costs and benefits of aerospace industrialization. Thus it would be inappropriate to provide recommendations about whether aerospace is an industry worth specializing in for emerging economies.

However, the realization that interrupted innovation trajectories are common to all latecomers in the aerospace industry has some important consequences for industrial policy. First, it helps us to identify the varying roles governments and entrepreneurs can play during the emergent phases, during interruptions and system transition, and in phases of sustained competitiveness. Government intervention in the aerospace industry is the common practice around the world. The latecomers were no exceptions. 


\subsubsection{Flexibility and windows of opportunity}

We have argued that following a period of innovation system transition in which institutions are reconfigured, actors need time to learn how to benefit from the new system. Over time routines are established that reduce uncertainty and allow better performance of an innovation system. These are times of increasing stability which are characterized, in case of a successful transition, by accelerated industrial growth. However, too much stability and rigidity reduces an innovation system's ability to respond to newly emerging competitive challenges. Georgsdottir et al. (2003) drew a parallel between such a lack of flexibility and the extinction of dinosaurs. Just as dinosaurs were unable to adapt to changing climatic conditions, so organizations are slow to react to changing environments, putting their survival at risk. This contradictory need to balance stability and flexibility is central to the evolution of innovation systems (McKelvey and Holmén 2006). The comparative history of latecomers in aerospace revealed that the lack of flexibility, or too high rigidity, was a result of underdeveloped innovation systems in cases where countries followed inward-looking strategies. On the other hand, even in cases where relatively well-developed innovation systems showed signs of institutional inertia and lock-in, strong education and research capacities allowed key actors to benefit from windows of opportunities for change.

Freeman and Soete (1997) argued that technological paradigm transitions presented temporary windows of opportunity for developing countries to enter into new industries offering high-growth opportunities. We can make two observations with regard to such windows of opportunities in aerospace. First, only countries that have already paid the considerable cost of entry can benefit from such paradigm or regime changes within the aerospace industry, even if countries aim at the less demanding maintenance, repair and overhaul segment. Second, we found that a technological paradigm change in the global industry itself rarely triggered innovation system transitions unless there was an interruption in the performance of the domestic innovation system, usually due to financing difficulties. Transition policies should thus be targeted at reducing the time between the occurrence of an interruption and the onset of the transition.

\subsubsection{Targeting support}

We found that no aerospace industry could emerge without establishing a national and sectoral innovation system. More specifically, this involved coordinated policies in at least four domains in order to create sufficient absorptive capacities. The question is what the policy targets were in best-practice cases of emergence, growth and transition. 


\subsubsection{Higher education policies}

A strong knowledge base in natural sciences and engineering was a prerequisite for higher education policies aiming at creating centers of excellence in the applied fields required by the technological paradigm defining the competitive requirements in a given period (aeronautics, material science, electronics, IT, and also management). The case of Singapore in the 1980s shows that immigrant experts can temporarily fill in the gaps in the knowledge base in the short term, while the case of Indonesia shows that unless there is are strong local higher education capacities, the industry is bound to fail. During the early years of emergence, the state has no alternative but to support higher education. But even during this phase, a close collaboration and information exchange between universities and specialized training institutes and industry is crucial in order to devise curricula to match the industry's needs. As industrial growth kicks in, the industry can take over some support to higher education. But here universities and governments have an important balancing role to play. While firms can reap more direct advantages from supporting applied research, large scale funding should also be provided for basic research to rejuvenate the knowledge base and allow for flexibility in times of system transition.

Education policy is the least appropriate tool to tackle crises in the short term, but is the most appropriate tool to create sufficient flexibility to respond to increased competitive pressures in the future. It is important to have a comprehensive look at the education sector. Private consultant firms and industry associations have the capacity to offer short term training programs for management and employees to refresh and readjust their knowledge in light of the demands of the changing competitive environment. But, formal educational programs are slow movers. There is a rather high degree of institutional inertia, determined by existing financing structures and quality assurance mechanisms, and there are information-asymmetries in interactions between higher education and the job market. The need for policy intervention in times of crisis is manifold: fostering knowledge exchange between universities and domestic and foreign industry, between domestic and foreign universities; accelerating accreditation processes (but not at the expense of quality); finance re-training programs for industry employees; or temporarily hiring foreign experts. A major source of the relatively high flexibility of Singapore's innovation system in the last two decades was the rather rapid response of the higher education system, in which industry associations and the strong university-industry linkages were important 'lubricants'. This also highlights a policy target in periods of incremental system change, namely, that strong ties should be fostered between universities and firms through specialized agencies. This being said, it is also important to see that the role of universities is more than simply supplying industries with skilled labor based on demand defined by firms. Universities are genuine 
locations to foster creativity and generate new ideas which are fundamental in an innovation system at any level of industrial development.

\subsubsection{Science, technology and innovation policies}

Both during the emergent phase and in times of radical system change innovation, science and technology policy has an important role to support the growth of technology clusters and research facilities. The provision of facilities in industrial parks at favorable conditions significantly reduced entry barriers for foreign subsidiaries and local start-ups in the case of Singapore (e.g. in Loyang, Changi). Proximity to the airport, to education, research was similarly an important source of growth for the Sao Jose dos Campos cluster in Brazil. It should of course be noted that the provision of facilities was in both cases complemented with tax breaks and other incentives that not only reduced costs but strengthened the trust of potential investors that the government is committed to long-term development. Especially in the emergent phase, establishing unrealistic goals in light of the realities of a limited knowledge base and technological capabilities at hand is an important deterring factor. R\&D support and innovation and technology policy should therefore sustain a close interaction with industry. In sum, to accelerate radical innovation system change after a crisis, latecomers can gain access to competitive frontier technology through foreign investment.

As the institutional foundations of the innovation system settles and a new growth trajectory is established, the demand for governments to support technologycreating investment gradually declines. The growth of newly established firms (or resumed growth of old firms that survived a crisis) allows them to increase R\&D expenditure. Greater R\&D expenditure ideally allows governments gradually to redirect their support to more general projects, away from firms to the higher education system or to $\mathrm{R} \& \mathrm{D}$ institutes. Innovation and technology policy also has a role of preparing for future crises in times of growth by supporting pre-competitive research.

\subsubsection{Trade and public procurement policies}

None of the countries we looked at accumulated technological capabilities without import substitution and export promotion during the emergence of the industry. During the late 1970s the Brazilian government used a wide range of devices to keep foreign competitors away and to promote foreign sales of Embraer aircraft, ranging from export credits to activist trade diplomacy. Following the interruption of the early 1990s, Brazil provided export subsidies to increase the competitiveness of the ERJ-145 
family. ${ }^{24}$ Discretional export and import measures are continued practice of the Chinese government, which is currently protecting its market from competitors of its ARJ-21 regional jet with a 5\% import tax. Although by the nature of its aerospace products Singapore can more easily be a free trade advocate, providing free port facilities helped the city state to grow into a supply center of parts and components.

The history of global trade disputes in civilian aircraft suggests that as latecomer industries mature and contest market positions of incumbents (see Brazil-Canada and EU-US "trade wars"), opposition to export promotion increases. A general ban on all forms of support to aircraft producers has been and remains out of question. So far the solution was to find a compromise that took into consideration the different country practices of direct and indirect support to local aircraft producers. ${ }^{245}$ If the number of large-scale aircraft exporters indeed increases in the next decade (with China's ARJ-21 and C-919, Russia's Sukhoi Superjet, Japan's Mitsubishi Regional Jet in the pipeline) and so will the forms of state support become more diverse, it will be a difficult negotiating challenge to find a mutually agreeable level and nature of support.. A major source of difficulties is the risk sharing partnership model, where participating governments can effectively provide an equivalent of a launch aid by supporting component or module developers and producers (Pritchard 2010). The general practice of high import barriers is now a thing of the past, but governments still have the means to shape the pattern of imported aircraft through defense procurement deals or commercial aircraft purchases where state ownership of airlines exists.

Returning to the interrupted innovation framework, it appears that the importance of trade interventions is the greatest during the emergence period, but it remains high whenever new products are entering the market, irrespective of the maturity of the industry. Government procurement, as already shown above, has two kinds of roles in latecomer countries. Throughout the emergence phase, and associated with a "paradigm" of vertical integration of activities (before the establishment of global supply chains in the 1990s), guaranteed government orders were a source of finance for new product development. But procurement of domestic products has been a tool to

\footnotetext{
${ }^{244}$ This led to a WTO trade dispute with the competing regional aircraft producer Canada in 1998. The trade dispute ended with a ruling against the original Brazilian PROEX program. A modified PROEX III with limited interest rate equalization scheme was eventually deemed in line with the Agreement on Subsidies and Countervailing Measures in 2001. The trade dispute ended with both Brazil and Canada continuing some form of export support for their aircraft. The importance of this case was huge; it was the first official dispute about aircraft triggering WTO dispute settlement mechanisms. This, till present date, remains the only aircraft trade dispute concerning an emerging economy.

${ }^{245}$ For instance, the 1992 EU-US Agreement on Large Civil Aircraft outlined the differences between EU and US support. The agreement made an attempt to balance the EU practice of direct support [to Airbus] in the form of repayable "launch aid" and the indirect, non-repayable R\&D support practice of the US.
} 
'level out' foreign demand shocks (see the recent KC-390 deal in Brazil). Its effect is of course limited to the extent that emerging governments can bridge short-term financial difficulties of the domestic industry.

There is, however, an important lesson for countries with a large domestic market for aircraft. The role of the domestic market can very easily be overestimated in medium term. It was possible for both Brazil and China to effectively protect the introduction of new aircraft designs (commuter planes or fighters) from foreign competition before the producers went up the learning curve. Yet, foreign sales are essential for recouping the development costs. The lack of openness goes hand in hand with the lack of trust. Trust is crucial for finding foreign buyers or foreign investors, as well as for certifying a new aircraft with foreign authorities.

\subsubsection{Policy formation: a multi-actor process}

Looking at system transitions and industrial growth accelerations from a national and sectoral innovation system dynamics framework, it is clear that governments are also among the actors of the system. Governments, or rather, the heterogeneous set of ministries and the military organizations, operate under uncertainty, have certain technological capabilities, deal with incomplete information and have to learn governance practices ( $\mathrm{Gu}$ and Lundvall 2006). Policy formation itself is thus an innovative outcome. Consequently, it matters what kind of actors are involved in policy formation and how they interact. Their distribution of power and knowledge is rarely equal in the aerospace industry. In this context, we can examine the impact of certain actors on the emergence of the industry and on system transitions.

\subsubsection{The role of the military}

It is an interesting question what the ideal role of military actors is for the sustainability of industrial growth. Producing for domestic military demand during the emergence phase is a striking commonality in all latecomer aerospace industries. Air forces procurements or direct support of developing technological capabilities gave an initial launch for the development of latecomer industries. There is, however, a difference between countries where the air force was the sole or dominant buyer of the industry's products and where a kick-off support was only temporary and production later diversified into the commercial segment. For instance, although military technology and initial orders were crucial for the emergence of the industry in Brazil and Singapore, both Embraer and Singapore Aircraft Industries owed much to their success to meeting the quality and marketing requirements of commercial buyers. The Córdoba factory in Argentina remained under the influence of the military. The military was a dominant buyer of IPTN aircraft in Indonesia. It required a defense budget the size of China's 
during the 1960s and 1970s to ensure growth in a military-oriented industry. However, because of its dependence on a single source of orders, growth was not sustained over this period.

Yet it would be too early to conclude that military-induced production is not compatible with sustained growth of the industry. In export-oriented, commercial industries, military procurement supporting new aircraft development or the refurbishment of existing planes in the fleet has boosted technological advance in both Singapore's and Brazil's aerospace industry. Moreover, if timed counter-cyclically with respect to decreases in commercial demand (not dissimilarly to practices of advanced countries), military demand can mitigate temporary crises. However, if it is not temporary, not in line with technology targets of pre-competitive research, or not coordinated with other actors of the innovation system, permanent reliance on military orders ultimately destroys competitiveness, as the case of Argentina and China showed in the 1980s. These cases also show that national security considerations in industrial development reduce transparency and increase secrecy which creates further barriers to interactions in national innovation systems. Moreover, extreme reliance on military orders are often associated with arms races which are, according to the interrupted innovation framework, unsustainable production bubbles leading inevitably to crises and the need for transitions.

\subsubsection{Private actors and entrepreneurship}

How can private actors take a greater role in the development of aerospace latecomer industries? The case of Singapore and Brazil showed the potential of achieving sustained growth on primarily outward-looking, commercially-oriented development trajectories. We have concluded from a comparison of case studies that the influence of private companies and entrepreneurs on the transition processes was crucial to create institutions for a sustainable growth trajectory. It was the vital interest of Singapore's firms to internationalize and to move into knowledge-based activities. It was Embraer that realized it can only be profitable if it relies on global supply chains instead of making everything locally and established channels of cooperating in innovation and production accordingly. Taking this as a point of departure, governments still face some dilemmas: should they favor foreign or domestic firms, large system assembler companies or smaller firms in the supply chain? We argue that the strategy depends on (apart from macro-economic strategy of a country) which phase the industry is in.

An interesting observation from the history of latecomer aerospace industries is that the emergence of industries was always launched by public actors. Yet one can distinguish entrepreneurial public actors, or 'public entrepreneurs', to use the term coined by Ramamurti (1987) from private entrepreneurs. The involvement of public 
entrepreneurs has significantly sped up the processes of emergence and transition by establishing vital links between government and company actors. These well-connected industry leaders were crucial for the successful establishment of national champions such as Embraer or ST Aerospace. In times of crisis, being large employers, these entrepreneurs had a crucial role in establishing the foundations of potentially new innovation systems. However, for the long-term sustainability of growth in the industry it also matters how much room private actors from lower tiers of the industry have in a newly formed innovation system. In Brazil, the reorganization of the industry was centered on Embraer's privatization in the mid-1990s. An unintended consequence of a government and public-entrepreneur-led transition was making Embraer competitive at the expense of the local supplier chain. For Embraer to reduce costs, it had to rely upon a global network of high quality suppliers who could benefit from economies of scale. In the policy formation during the transition phase, private actors played a very limited role. This was different in Singapore which has the least concentrated industry among the emerging economies. This was, to a large extent, due to an entrepreneur-friendly strategy to boost investment on lower tiers of the supply chain. We can thus observe a shift from public to public and private entrepreneurship over time along with the maturity of commercial-oriented aerospace industries. Actors such as industries associations can speed up this process of increasing entrepreneurship opportunities at lower tiers, but it primarily depends on government strategy.

\subsection{Possible avenues of further research}

This study was the first attempt to systematically explore the evolution of the global aerospace industry from the perspective of emerging economies. Even during the last four years while we were conducting this research project, there has clearly been an increased interest in the topic from the perspective of innovation, management and industrial development. ${ }^{246}$ Given the richness of the topic, and given the fact that - as our own overview showed - the aerospace industry has yet to diffuse from the Northwestern core to the East and the South, systematic research on these changes will most likely accelerate in the near future.

This study, we hope, can serve as a guideline for potential new research paths. One of the most serious shortcomings of this study was our inability to gather sufficient and consistent data to measure capital input and investments for the 40 countries in our database. This would be essential to estimate total factor productivity growth in the

\footnotetext{
${ }^{246}$ See i.e. (Steenhuis et al. 2007; Figueiredo et al. 2008; Niosi and Zhegu 2008; Marques and Oliveira 2009; Niosi 2009; Mani 2010; Romero 2010)
} 
industry, and also to give an industry-level answer as to whether the investment in the aerospace sector paid off. A second avenue for future research is to exploring nature and significance of spillovers from aerospace production and innovation to other sectors in emerging economies.

Finally, future research should focus on the question whether the framework of interrupted innovation developed in this study is also applicable to other high-tech industries. In the development of aerospace, the importance of institutions, capital, skilled labor and strategic considerations is probably greater than in many other industries. Latecomer sectors that combine high technological and capital entry barriers, distorted markets and a high regulatory role of the state (such as other transport equipment industries, some specialized segments of electronics (e.g. medical instruments) or energy production) are sectors where the same framework might well be fruitfully applied. Of course, it would be also be interesting to look low-tech industries over a long period of time. We need to exploit the potential of innovation systems dynamics approaches in future research. 


\section{Bibliography}

ABDI. 2009. "Estudo Prospectivo Aeronáutico." Série Cadernos da Indústria ABDI: 196. Agência Brasileira de Desenvolvimento Industrial (ABDI) and Centro de Gestão e Estudos Estratégicos (CGEE): Brasília.

Abernathy, William J. and James M. Utterback. 1978. "Patterns of Industrial Innovation." Technology Review, 80:7, pp. 40.

Abramovitz, Moses. 1989. Thinking about growth : and other essays on economic growth and welfare. Cambridge: Cambridge University Press.

Akçomak, I. Semih and Bas ter Weel. 2009. "Social capital, innovation and growth: Evidence from Europe." European Economic Review, 53:5, pp. 544-67.

Allen, Kenneth W., Glenn Krumel, Jonathan D. Pollack, and United States. Air Force. 1995. China's air force enters the 21st century. Santa Monica, CA: Rand.

Ames, Edward and Nathan Rosenberg. 1963. "Changing Technological Leadership and Industrial Growth." The Economic Journal, 73:289, pp. 13-31.

Amir, Sulfikar. 2007. "Nationalist rhetoric and technological development: The Indonesian aircraft industry in the New Order regime." Technology in Society, 29:3, pp. 283-93.

Amsden, Alice H. 1989. Asia's next giant : South Korea and late industrialization. New York: Oxford University Press.

Amsden, Alice H. 2001. The rise of "the rest" : challenges to the west from lateindustrializing economies. Oxford ; New York: Oxford University Press.

Archibugi, Daniele and Alberto Coco. 2005. "Measuring technological capabilities at the country level: A survey and a menu for choice." Research Policy, 34:2, pp. 175-94.

Ark, Bart van. 1993. "International Comparison of Output and Productivity." Monograph series no. 1. Groningen Growth and Development Centre: Groningen.

Ark, Bart van and Hans Gersbach. 1994. "Micro Foundations for International Productivity Comparisons." Research Memorandum, GD-11. Groningen Growth and Development Centre: Groningen.

Arreguez, Angel César. 2007. Fábrica Militar de Aviones. Crónicas y Testimonios. Cordoba: Ministerio de Ciencia y Tecnología, Provincia de Córdoba

Arrow, Kenneth J. 1962. "The Economic Implications of Learning by Doing." The Review of Economic Studies, 29:3, pp. 155-73.

Arroyo, Carlos Alberto Arzubi. 2004. "La producción para la defensa en la República Argentina." Instituto de Estudios Estrategicos y de Relaciones Internacionales. Instituto de Estudios Estrategicos y de Relaciones Internacionales.

Asheim, Björn T. and Meric Gertler. 2005. "Understanding Regional Innovation Systems," in The Oxford Handbook of Innovation. Jan Fagerberg, David C. Mowery and Richard R. Nelson eds. Oxford: Oxford University Press, pp. 291-317. 
Aw, Bee-Yan. 1991. "Singapore," in Liberalizing foreign trade. The Experience of Korea, the Philippines, and Singapore. Demetris Papageorgiou, Michael Michaely and Armeane M. Choksi eds. Oxford, OX, UK ; Cambridge, Mass.: B. Blackwell, pp. 309-428.

Balassa, Bela. 1965. "Trade Liberalisation and "Revealed" Comparative Advantagel." The Manchester School, 33:2, pp. 99-123.

Banji, Oyelaran-Oyeyinka. 2006. "Systems of Innovation and Underdevelopment." Science Technology \& Society, 11:2, pp. 239-69.

Barbieri, Marcos, Pesquisadores e bolsistas do NEIT/IE/Unicamp, Rogério de Araújo Dias, Carlos Henrique Mello, and Rosane Marques. 2008. "Relatório de Acompanhamento Setorial Indústria Aeronáutica, Vol.I.". ABDI, UNICAMP: Brasilia; Sao Paolo.

Baskaran, Angathevar. 2001. "Technology accumulation in the ground systems of India's space program: the contribution of foreign and indigenous inputs." Technology in Society, 23:2, pp. 195-216.

Baskaran, Angathevar. 2005. "From science to commerce: The evolution of space development policy and technology accumulation in India." Technology in Society, 27:2, pp. 155-79.

Beaudry, Catherine. 2001. "Entry, Growth and Patenting in Industrial Clusters: A Study of the Aerospace Industry in the UK." International Journal of the Economics of Business, 8:3, pp. 405 - 36.

Bell, Martin. 2006. "Time and technological learning in industrialising countries: how long does it take? How fast is it moving (if at all)?" International Journal of Technology Management, 36:1-3, pp. 25-39.

Bell, Martin and Keith Pavitt. 1993. "Accumulating technological capability." Proceedings of the World Bank Annual Conference on Development Economics 1992. World Bank: Washington, DC.

Benkard, C. Lanier. 2000. "Learning and Forgetting: The Dynamics of Aircraft Production." The American Economic Review, 90:4, pp. 1034-54.

Bergek, Anna, Staffan Jacobsson, Bo Carlsson, Sven Lindmark, and Annika Rickne. 2008. "Analyzing the functional dynamics of technological innovation systems: A scheme of analysis." Research Policy, 37:3, pp. 407-29.

Biddlecombe, C. H. 1928. "The Development of the Heavier-Than-Air Machine." Proceedings of the American Philosophical Society, 67:3, pp. 297-305.

Boeing. 2008. "Backgrounder: Boeing in China." The Boeing Company: Beijing.

Brander, James A. 1981. "Intra-industry trade in identical commodities." Journal of International Economics, 11:1, pp. 14.

Brander, James A. and Barbara J. Spencer. 1985. "Export subsidies and international market share rivalry." Journal of International Economics, 18:1-2, pp. 83-100.

Breschi, Stefano and Franco Malerba. 1997. "Sectoral Innovation Systems: Technological Regimes, Schumpeterian Dynamics, and Spatial Boundaries.," in Systems of 
Innovation: Technologies, Institutions and Organizations. Charles Edquist ed. London and Washington DC: Pinter, pp. 130-56.

Cabral, Arnoldo Souza. 1987. "Análise do desempenho tecnológico da industria aeronautica brasileira." ITA: Sao Jose dos Campos.

Caracostas, Paraskevas and Luc Soete. 1997. "The Building of Cross-Border Institutions in Europe: Towards a European Innovation System?," in Systems of innovation : technologies, institutions and organizations. Charles Edquist ed. London; Washington, D.C.: Pinter, pp. 395-419.

Carlsson, Bo, Staffan Jacobsson, Magnus Holmén, and Annika Rickne. 2002. "Innovation systems: analytical and methodological issues." Research Policy, 31:2, pp. 233-45.

Carlsson, Bo and Rikard Stankiewicz. 1995. "On the nature, function and composition of technological systems," in Technological Systems and Economic Performance: The Case of Factory Automation. Bo Carlsson ed. Dordrecht: Kluwer Academic Publishers, pp. 21-56.

Cassiolato, Jose E, Roberto Bernardes, and Helena Lastres. 2002. "Transfer of Technology for Successful Integration into the Global Economy: A case study of Embraer in Brazil." 64. UNCTAD and UNDP: New York and Geneva.

Chaminade, Cristina and Jan Vang. 2008. "Globalisation of knowledge production and regional innovation policy: Supporting specialized hubs in the Bangalore software industry." Research Policy, 37:10, pp. 1684-96.

Chang, Ha-Joon. 1993. "The political economy of industrial policy in Korea." Cambridge Journal of Economics, 17:2, pp. 131-57.

Chang, Ha-Joon. 2003. "Kicking Away the Ladder: Infant Industry Promotion in Historical Perspective 1." Oxford Development Studies, 31:1, pp. 21 - 32.

Chia, Siow Yue. 1999. "The Asian Financial Crisis. Singapore's Experience and Response," in Southeast Asia's economic crisis : origins, lessons, and the way forward. H. W. Arndt and Hal Hill eds. Singapore: Institute of Southeast Asian Studies, pp. 51-66.

Cimoli, Mario, Giovanni Dosi, and Joseph E. Stiglitz. 2009. Industrial policy and development : the political economy of capabilities accumulation. Oxford ; Toronto: Oxford University Press.

Cohen, Wesley M. and Daniel A. Levinthal. 1990. "Absorptive Capacity: A New Perspective on Learning and Innovation." Administrative Science Quarterly, 35:1, pp. 128-52.

Cooke, Philip. 1996. "The new wave of regional innovation networks: Analysis, characteristics and strategy." Small Business Economics, 8:2, pp. 159-71.

Cooke, Philip. 2008. "Regional innovation systems: origin of the species." International Journal of Technological Learning, Innovation and Development, 1:3, pp. 393 - 409. 
Cooke, Philip and Oliver Ehret. 2008. "Proximities, knowledge and skills and the future of the Welsh aerospace industry." International Journal of Technology Management, 50:3/4, pp. 11.

Cooke, Philip and Oliver Ehret. 2009. "Proximity and Procurement: A Study of Agglomeration in the Welsh Aerospace Industry." European Planning Studies, 17:4, pp. 549 - 67.

Craypo, Charles and Frank Wilkinson. 2003. "The low road to competitive failure: immigrant labour and emigrant jobs in the US," in The Handbook of Globalisation. Jonathan Michie ed. Cheltanham, UK; Northampton, MA: Edward Elgar Publishing, pp. 283-305.

Dahlman, Carl J., Bruce Ross-Larson, and Larry E. Westphal. 1987. "Managing technological development: Lessons from the newly industrializing countries." World Development, 15:6, pp. 759-75.

Della Paolera, Gerardo and Alan M. Taylor. 2003. A new economic history of Argentina. Cambridge ; New York: Cambridge University Press.

Dijk, Michiel van. 2002. "South African Manufacturing Performance in International Perspective, 1970-1999." Research Memorandum GD-58. Groningen Growth and Development Centre: Groningen.

Dodgson, Mark, John Mathews, Tim Kastelle, and Mei-Chih Hu. 2008. "The evolving nature of Taiwan's national innovation system: The case of biotechnology innovation networks." Research Policy, 37:3, pp. 430-45.

Dolata, Ulrich. 2009. "Technological innovations and sectoral change: Transformative capacity, adaptability, patterns of change: An analytical framework." Research Policy, 38:6, pp. 1066-76.

Doloreux, David and Saeed Parto. 2005. "Regional innovation systems: Current discourse and unresolved issues." Technology in Society, 27:2, pp. 133-53.

Dosi, Giovanni. 1982. "Technological paradigms and technological trajectories : A suggested interpretation of the determinants and directions of technical change." Research Policy, 11:3, pp. 147-62.

Dosi, Giovanni, Christopher Freeman, Richard R. Nelson, Gerald Silverberg, and Luc Soete. 1988. Technical change and economic theory. London ; New York: Pinter Publishers.

Dosi, Giovanni, Michael Hobday, Luigi Marengo, and Andrea Prencipe. 2003. "The Economics of System Integration. Towards an evolutionary interpretation," in The Business of System Integration. Oxford: Oxford University Press, pp. 95-113.

Dutrénit, Gabriela. 2004. "Building Technological Capabilities in Latecomer Firms: A Review Essay." Science, Technology \& Society, 9:2, pp. 209-41.

Edquist, Charles. 1997. Systems of innovation : technologies, institutions and organizations. London; Washington, D.C.: Pinter. 
Edquist, Charles and Leif Hommen. 2008. Small country innovation systems : globalization, change and policy in Asia and Europe. Cheltenham, UK: Edward Elgar.

Eliasson, Gunnar K. 2010. Advanced public procurement as industrial policy: The Aircraft Industry as a Technical University. New York; Dordrecht; Heidelberg; London: Springer.

Engel, Jeffrey A. 2000. "'We are not concerned who the buyer is": Engine sales and Anglo-American security at the dawn of the jet age." History and Technology, 17:1, pp. 43 - 67.

Erickson, Rodney A. 1974. "The Regional Impact of Growth Firms: The Case of Boeing, 1963-1968." Land Economics, 50:2, pp. 127-36.

Eriksson, Soren. 2003. "Indonesias aircraft industry: technology and management impediments." International Journal of Technology Transfer and Commercialisation, 2:2, pp. 207-26.

Eriksson, Sören. 1995. "Global shift in the aircraft industry : a study of airframe manufacturing with special reference to the Asian NIEs." Kulturgeografi, Vol. PhD: 244. Göteborgs Universitet: Göteborg.

Esposito, Emilio. 2004. "Strategic alliances and internationalisation in the aircraft manufacturing industry." Technological Forecasting and Social Change, 71:5, pp. 443-68.

Fagerberg, Jan. 2000. "Technological progress, structural change and productivity growth: a comparative study." Structural Change and Economic Dynamics, 11:4, pp. 393-411.

Fagerberg, Jan and Manuel M. Godinho. 2005. "Innovation and Catching-Up," in The Oxford Handbook of Innovation. Jan Fagerberg, David C. Mowery and Richard R. Nelson eds. Oxford: Oxford University Press, pp. 514-42.

Fagerberg, Jan and Martin Srholec. 2008. "National innovation systems, capabilities and economic development." Research Policy, 37:9, pp. 1417-35.

Fagerberg, Jan and Bart Verspagen. 1999. "Modern Capitalism in the 1970s and 1980s," in Growth, Employment and Inflation. M. Setterfield ed. Houndmills, Basingstoke: MacMillan.

Ferreri, Domenico. 2003. Marketing and management in the high-technology sector : strategies and tactics in the commercial airplane industry. Westport, CT; London: Praeger.

Figueiredo, Paulo, Gutenberg Silveira, and Roberto Sbragia. 2008. "Risk Sharing Partnerships With Suppliers: The Case of EMBRAER." Journal of Technology Management and Innovation, 3:1, pp. 27-37.

Fogel, Robert William. 1964. Railroads and American economic growth: essays in econometric history. Baltimore,: Johns Hopkins Press.

Frankenstein, John and Bates Gill. 1996. "Current and Future Challenges Facing Chinese Defence Industries." The China Quarterly:146, pp. 394-427. 
Freeman, Christopher. 1987. Technology, policy, and economic performance : lessons from Japan. London; New York: Pinter Publishers.

Freeman, Christopher and Carlota Perez. 1988. "Structural crises of adjustment: business cycles and investment behaviour," in Technical Change and Economic Theory. Giovanni Dosi, Christopher Freeman, Richard R. Nelson, Gerald Silverberg and Luc Soete eds. London, New York: Pinter, pp. 38-66.

Freeman, Christopher and Luc Soete. 1997. The economics of industrial innovation. Cambridge, Mass.: MIT Press.

Freeman, Christopher and Luc Soete. 2009. "Developing science, technology and innovation indicators: What we can learn from the past." Research Policy, 38:4, pp. 583-89.

Frenken, Koen. 2006. Innovation, Evolution and Complexity Theory. Cheltenham UK and Northampton MA: Edward Elgar.

Frenken, Koen and Loet Leydesdorff. 2000. "Scaling trajectories in civil aircraft (19131997)." Research Policy, 29:3, pp. 331-48.

Frenken, Koen, Pier Paolo Saviotti, and Michel Trommetter. 1999. "Variety and niche creation in aircraft, helicopters, motorcycles and microcomputers." Research Policy, 28:5, pp. 469-88.

Frischtak, Claudio R. 1992. "Learning, Technical Progress and Competitiveness in The Commuter Aircraft Industry: An Analysis of Embraer." Industry Series Paper. The World Bank: Washington, D.C.

Frischtak, Claudio R. 1994. "Learning and technical progress in the commuter aircraft industry: an analysis of Embraer's experience." Research Policy, 23:5, pp. 601-12.

Galli, Riccardo and Morris Teubal. 1997. "Systems of innovation : technologies, institutions and organizations," in Systems of innovation : technologies, institutions and organizations. Charles Edquist ed. London: Pinter, pp. 345-64.

Geels, Frank W. and René Kemp. 2006. "Transitions, Transformation, and Reproduction: Dynamics in Socio-Technical Systems," in Flexibility and stability in the innovating economy. Maureen D. McKelvey and Margnus Holmén eds. Oxford ; New York: Oxford University Press, pp. 227-56.

Geels, Frank W. and René Kemp. 2007. "Dynamics in socio-technical systems: Typology of change processes and contrasting case studies." Technology in Society, 29:4, pp. 441-55.

Georgsdottir, Asta S., Todd I. Lubart, and Isaac Getz. 2003. "The Role of Flexibility in Innovation," in The international handbook on innovation. Larisa V. Shavinina ed. Amsterdam: Elsevier.

Gerschenkron, Alexander. 1962. Economic backwardness in historical perspective : a book of essays: Harvard University Press.

Goldstein, Andrea. 2002a. "EMBRAER: From national Champion to global player." Cepal Review:77, pp. pp. 97-115. 
Goldstein, Andrea. 2002b. "The political economy of high-tech industries in developing countries: aerospace in Brazil, Indonesia and South Africa." Cambridge Journal of Economics, 26:4, pp. 521.

Goldstein, Andrea. 2006. "The Political Economy of Industrial Policy in China: The Case of Aircraft Manufacturing." Journal of Chinese Economic and Business Studies, 4:3, pp. 259 - 73.

Goldstein, Andrea E. and Steven M. McGuire. 2004. "The Political Economy of Strategic Trade Policy and the Brazil-Canada Export Subsidies Saga." World Economy, 27:4, pp. 541-66.

Golich, Vicki L. 1992. "From Competition to Collaboration: The Challenge of Commercial-Class Aircraft Manufacturing." International Organization, 46:4, pp. 899-934.

Gort, Michael and Steven Klepper. 1982. "Time Paths in the Diffusion of Product Innovations." The Economic Journal, 92:367, pp. 630-53.

$\mathrm{Gu}$, Shulin and Bengt-Åke Lundvall. 2006. "Policy learning in the transformation of the Chinese innovation systems," in Asia's innovation systems in transition. Bengt-Åke Lundvall, Patarapong Intarakumnerd and Jan Vang eds. Cheltenham, UK ; Northampton, MA: Edward Elgar, pp. 293-312.

Hayward, Keith. 1994. The world aerospace industry : collaboration and competition. London: Duckworth \& RUSI.

Hekkert, M. P., R. A. A. Suurs, S. O. Negro, S. Kuhlmann, and R. E. H. M. Smits. 2007. "Functions of innovation systems: A new approach for analysing technological change." Technological Forecasting and Social Change, 74:4, pp. 413-32.

Henderson, Rebecca M. and Kim B. Clark. 1990. "Architectural Innovation: The Reconfiguration of Existing Product Technologies and the Failure of Established Firms." Administrative Science Quarterly, 35:1, pp. 9-30.

Higham, Robin. 1968. "Quantity vs. Quality: The Impact of Changing Demand on the British Aircraft Industry, 1900-1960." The Business History Review, 42:4, pp. 44366.

Hill, Hal. 1990. "Indonesia's Industrial Transformation Part I." Bulletin of Indonesian Economic Studies, 26:2, pp. 79 - 120.

Hill, Hal. 2000. The Indonesian economy. Cambridge, UK ; New York: Cambridge University Press.

Hill, Hal and Eng Fong Pang. 1988. "The State and Industrial Restructuring. A comparison of the Aerospace Industry in Indonesia and Singapore." ASEAN Economic Bulletin, 5:2, pp. 152.

Hira, Anil and L. Guilherme de Oliveira. 2007. "Take off and Crash: Lessons from the Diverging Fates of the Brazilian and Argentine Aircraft Industries." Competition \& Change, 11:4, pp. 329-47.

Hobday, Michael. 2009. "Learning from Asia's Success: Beyond Simplistic 'Lesson Making'." Pathways to Industrialization in the 21st Century. New Challenges and 
Emerging Paradigms UNU-WIDER, UNU-MERIT and UNIDO Workshop: Maastricht 22-23 October 2009.

Hobday, Michael, Andrew Davies, and Andrea Prencipe. 2005. "Systems integration: a core capability of the modern corporation." Industrial and Corporate Change, 14:6, pp. 1109-43.

Hobday, Mike. 1995. "East Asian latecomer firms: Learning the technology of electronics." World Development, 23:7, pp. 1171-93.

Hobday, Mike. 2003. "Innovation in Asian Industrialization: A Gerschenkronian Perspective." Oxford Development Studies, 31:3, pp. 293 - 314.

Inklaar, Robert and Marcel P. Timmer. 2010. "Real output, expenditure and terms of trade across countries: an international input-output approach." Paper Prepared for the 31st General Conference of The International Association for Research in Income and Wealth: St. Gallen, Switzerland, August 22-28, 2010.

Intarakumnerd, Patarapong and Mai Fujita. 2009. "China's Threat and Opportunity: Challenges for Thai and Vietnamese Motorcycle Industries," in Sectoral Systems of Innovation and Production in Developing Countries: Actors, Structure and Evolution. Franco Malerba and Sunil Mani eds. Cheltenham; Northampton, MA: Edward Elgar, pp. 207-31.

Isard, Carolinf and Walter Isard. 1945. "Economic Implications of Aircraft." The Quarterly Journal of Economics, 59:2, pp. 145-69.

Jacobsson, Staffan and Anna Johnson. 2000. "The diffusion of renewable energy technology: an analytical framework and key issues for research." Energy Policy, 28:9, pp. 625-40.

Katz, Jorge. 2000. "Structural Change and Labor Productivity Growth in Latin American Manufacturing Industries 1970-96." World Development, 28:9, pp. 1583-96.

Kayton, Myron and Walter R. Fried. 1996. Avionics navigation systems. New York: Wiley.

Kim, Linsu. 1980. "Stages of development of industrial technology in a developing country: A model." Research Policy, 9:3, pp. 254-77.

Kim, Linsu. 1997. Imitation to innovation : the dynamics of Korea's technological learning. Boston: Harvard Business School Press.

Kim, Linsu. 1998. "Crisis Construction and Organizational Learning: Capability Building in Catching-up at Hyundai Motor." Organization Science, 9:4, pp. 506-21.

Kim, Linsu and Richard R. Nelson. 2000. Technology, learning and innovation : experiences of newly industrializing economies. Cambridge, U.K. New York: Cambridge University Press.

Kimura, Seishi. 2006. "Co-evolution of Firm Strategies and Institutional Setting in Firmbased Late Industrialization-The Case of the Japanese Commercial Aircraft Industry." Evolutionary and Institutional Economics Review, 3:1, pp. 109-35.

Kimura, Seishi. 2007. The challenges of late industrialization : the global economy and the Japanese commercial aircraft industry. New York: Palgrave Macmillan. 
King, David R. and Mark L. Nowack. 2003. "The impact of government policy on technology transfer: an aircraft industry case study." Journal of Engineering and Technology Management, 20:4, pp. 303-18.

Klepper, Steven. 1996. "Entry, Exit, Growth, and Innovation over the Product Life Cycle." The American Economic Review, 86:3, pp. 562-83.

Klepper, Steven. 1997. "Industry Life Cycles." Industrial and Corporate Change, 6:1, pp. 145-82.

Kline, Stephen J. and Nathan Rosenberg. 1986. "An Overview of Innovation," in The Positive sum strategy : harnessing technology for economic growth. Ralph Landau and Nathan Rosenberg eds. Washington, D.C.: National Academy Press, pp. 275306.

KPMG. 2004. "China aircraft component market." Advisory: 15. KPMG: Hong Kong.

Kravis, I.B., A. Heston, and R. Summers. 1982. World Product and Income. Baltimore: John Hopkins.

Kronemer, Alexander and J. Edwin Henneberger. 1993. "Productivity in aircraft manufacturing." Monthly Labor Review, 116:6, pp. 24.

Lall, Sanjaya. 1982. Developing countries as exporters of technology : a first look at the Indian experience. London: Macmillan.

Lall, Sanjaya. 1992. "Technological capabilities and industrialization." World Development, 20:2, pp. 165-86.

Lall, Sanjaya. 2001. "Competitiveness Indices and Developing Countries: An Economic Evaluation of the Global Competitiveness Report." World Development, 29:9, pp. 1501-25.

Lall, Sanjaya. 2004. "Reinventing Industrial Strategy: The Role of Government Policy in Building Industrial Competitiveness." G-24 Discussion Paper Series. UNCTAD: Geneva.

Landes, David S. 1969. The unbound Prometheus: technological change and industrial development in Western Europe from 1750 to the present. London,: Cambridge U.P.

Lawrence, Philip K. 2001. Aerospace Strategic Trade: How the U.S. subsidizes the large commercial aircraft industry. Aldershot, Burlington, Singapore, Sidney: Ashgate.

Lee, Ting-Lin and Nick von Tunzelmann. 2005. "A dynamic analytic approach to national innovation systems: The IC industry in Taiwan." Research Policy, 34:4, pp. 425-40.

List, Friedrich. 1841. Das Nationale System der Politischen Ökonomie (The National System of Political Economy). Stuttgart/Tübingen.

Liu, Xielin and Steven White. 2001. "Comparing innovation systems: a framework and application to China's transitional context." Research Policy, 30:7, pp. 1091-114.

Loftin, Laurence K. 1985. Quest for performance : the evolution of modern aircraft. Washington, D.C.: Scientific and Technical Information Branch For sale by the Supt. of Docs., U.S. G.P.O. 
Lukasiewicz, Julius. 1986. "Canada's Encounter with High-Speed Aeronautics." Technology and Culture, 27:2, pp. 223-61.

Lundvall, Bengt-Ake. 1992. National Systems of Innovation: Towards a Theory of Innovation and Interactive Learning. London: Pinter.

Lundvall, Bengt-Åke. 2007. "National Innovation Systems--Analytical Concept and Development Tool." Industry \& Innovation, 14:1, pp. 95-119.

Lundvall, Bengt-Åke, Patarapong Intarakumnerd, and Jan Vang-Lauridsen. 2006. Asia's innovation systems in transition. Cheltenham, UK ; Northampton, MA: Edward Elgar.

Maddison, Angus. 1998. "Measuring the Performance of a Communist Command Economy: An assessment of the CIA estimates for the U.S.S.R." Review of Income \& Wealth, 44:3, pp. 307-23.

Maddison, Angus. 2007. Chinese Economic Performance in the Long Run, 960-2030 AD. Paris: OECD Publishing.

Maddison, Angus and Bart van Ark. 1988. "Comparisons of Real Output in Manufacturing." Policy, Planning and Research Working Papers (WPS5). World Bank: Washington, D.C.

Malerba, Franco. 2002. "Sectoral systems of innovation and production." Research Policy, 31:2, pp. 247-64.

Malerba, Franco. 2004. "Sectoral systems of innovation: basic concepts," in Sectoral Systems of Innovation: Concepts, Issues and Analysis of six Major Sectors in Europe. Franco Malerba ed. Cambridge: Cambridge University Press.

Malerba, Franco. 2007. "Innovation and the dynamics and evolution of industries: Progress and challenges." International Journal of Industrial Organization, 25:4, pp. 675-99.

Malerba, Franco and Sunil Mani. 2009. Sectoral systems of innovation and production in developing countries : actors, structure and evolution. Cheltenham, UK ; Northampton, MA: Edward Elgar.

Malerba, Franco and Luigi Orsenigo. 1996a. "The dynamics and evolution of industries." Industrial and Corporate Change, 5:1, pp. 51-87.

Malerba, Franco and Luigi Orsenigo. 1996b. "Schumpeterian patterns of innovation are technology-specific." Research Policy, 25:3, pp. 451-78.

Malmberg, A. and P. Maskell. 2002. "The elusive concept of localization economies: towards a knowledge-based theory of spatial clustering." Environment and Planning A, 34:3, pp. 429-49.

Mani, Sunil. 2005. "Epistemic communities and informed policy making for promoting innovations: the case of Singapore," in Science and Technology Policy for Development, Dialogues at the Interface. Louk Box and Rutger Engelhard eds. London: Anthem Press.

Mani, Sunil. 2009. "Why is the Indian pharmaceutical industry more innovative than its telecommunications equipment industry? Contrasts between the sectoral system of 
innovation of the Indian pharmaceutical and telecommunications industries," in Sectoral Systems of Innovation and Production in Developing Countries: Actors, Structure and Evolution. Franco Malerba and Sunil Mani eds. Cheltenham; Northampton, MA: Edward Elgar, pp. 27-56.

Mani, Sunil. 2010. "The flight from defence to civilian space: Evolution of the sectoral system of innovation of India's Aerospace Industry." CDS Working Paper No. 428: 61. Centre for Development Studies: Trivandrum.

Marques, Rosane Argou. 2004. "Evolution of the civil aircraft manufacturing innovation system: A case study in Brasil," in Innovation, Learning and Technological Dynamism of Developing Countries. Sunil Mani and Henny Romijn eds. Tokyo ; New York: United Nations University Press, pp. 77-106.

Marques, Rosane Argou and L. Guilherme de Oliveira. 2009. "Sectoral system of innovation in Brazil: reflections about the accumulation of technological capabilities in the aeronautic sector," in Sectoral Systems of Innovation and Production in Developing Countries. Actors, Structure and Evolution. Franco Malerba and Sunil Mani eds. Cheltenham; Northampton, MA: Edward Elgar, pp. 156-203.

Maskell, Peter and Anders Malmberg. 1999. "Localised Learning and Industrial Competitiveness." Cambridge Journal of Economics, 23:2, pp. 167-85.

Mathews, Jessica T. 1997. "Power Shift." Foreign Affairs, 76:1, pp. 50-66.

Mathews, John A. 2002. "Competitive Advantages of the Latecomer Firm: A ResourceBased Account of Industrial Catch-Up Strategies." Asia Pacific Journal of Management, 19:4, pp. 467-88.

Mathews, John A. 2006. "Catch-up strategies and the latecomer effect in industrial development." New Political Economy, 11:3, pp. 313 - 35.

McCawley, Peter. 1978. "Some Consequences of the Pertamina Crisis in Indonesia." Journal of Southeast Asian Studies, 9:1, pp. 1-27.

McGuire, Steven. 2007. "The United States, Japan and the aerospace industry: from capture to competitor?" The Pacific Review, 20:3, pp. 329 - 50.

McKelvey, Maureen D. and Margnus Holmén. 2006. Flexibility and stability in the innovating economy. Oxford ; New York: Oxford University Press.

McKendrick, David. 1992. "Obstacles to "catch-up': the case of the Indonesian aircraft industry." Bulletin of Indonesian Economic Studies, 28:1, pp. 39-66.

Medeiros, Evan S. 2005. A new direction for China's defense industry. Santa Monica, CA: Rand.

Milenky, Edward S. 1980. "Arms Production and National Security in Argentina." Journal of Interamerican Studies and World Affairs, 22:3, pp. 267-88.

Montoro, Guilherme Castanho Franco and Marcio Nobre Migon. 2009. Cadeia produtiva aeronáutica brasileira : oportunidades e desafios. Rio de Janeiro: BNDES.

Moran, Theodore H. and David C. Mowery. 1991. "Aerospace." Daedalus, 120:4, pp. 135-54.

Mortensen, A. ed. 2007. Concise encyclopedia of composite materials. Amsterdam: Elsevier. 
Mowery, David C. 1987. Alliance politics and economics : multinational joint ventures in commercial aircraft. Cambridge, Mass.: Ballinger Pub. Co.

Mowery, David C. and Nathan Rosenberg. 1985. "Commercial Aircraft: Cooperation and Competition Between the U.S. and Japan." California Management Review, 27:4, pp. 70-92.

Mowery, David C. and Nathan Rosenberg. 1989. Technology and the pursuit of economic growth. Cambridge [England]; New York: Cambridge University Press.

Moxon, Richard W. 1987. "International Competition in High Technology: The Brazilian Aircraft Industry." International Marketing Review, 4:2, pp. 7.

Mulder, Nanno, Sylvie Montout, and Luis Peres Lopes. 2002. "Brazil and Mexico's Manufacturing Performance in International Perspective, 1970-98." Research Memorandum GD-52. Groningen Growth and Development Centre, University of Groningen: Groningen.

Mursjid, Saadillah. 1998. "The Funding of PT DSTP, a High-Technology Project: Lofty goals, defined task," in Indonesia's technological challenge. Hal Hill and Kian Wie Thee eds. Singapore

Canberra, Australia: Institute of Southeast Asian Studies; Research School of Pacific and Asian Studies, Australian National University, pp. xxv, 414 p.

Nelson, Richard R. 1993. National Systems of Innovation: A comparative Analysis. Oxford: Oxford University Press.

Nelson, Richard R. and Howard Pack. 1999. "The Asian Miracle and Modern Growth Theory." The Economic Journal, 109:457, pp. 416-36.

Nelson, Richard R. and Nathan Rosenberg. 1993. "Technical Innovation and National Systems," in National Systems of Innovation: A comparative Analysis. Richard R. Nelson ed. Oxford: Oxford University Press, pp. 3-21.

Nelson, Richard R. and Sidney G. Winter. 1982. An evolutionary theory of economic change. Cambridge, Mass.: Belknap Press of Harvard University Press.

Niosi, Jorge. 2009. "Catching up in aerospace." Paper presented at the DIME Workshop on Industrial Dynamics and Sectoral Systems in Developing Economies: Milan, KITeS.

Niosi, Jorge and Majlinda Zhegu. 2005. "Aerospace Clusters: Local or Global Knowledge Spillovers?" Industry \& Innovation, 12:1, pp. 5 - 29.

Niosi, Jorge and Majlinda Zhegu. 2008. "Innovation System Lifecycle in the Aircraft Sector." DRUID 25th Celebration Conference 2008: 32: Copenhagen, CBS, Denmark, June 17 - 20, 2008.

Niosi, Jorge and Majlinda Zhegu. 2010. "Anchor tenants and regional innovation systems: the aircraft industry." International Journal of Technology Management 50:3-4, pp. 263 - 84

Nolan, Peter and Jin Zhang. 2002. "The Challenge of Globalization for Large Chinese Firms." World Development, 30:12, pp. 2089-107. 
North, Douglass C. 1990. Institutions, institutional change and economic performance. Cambridge: Cambridge University Press.

O'Mahony, Mary and Marcel P. Timmer. 2009. "Output, Input and Productivity Measures at the Industry Level: The EU KLEMS Database." The Economic Journal, 119:538, pp. F374-F403.

OECD. 2003. The e-Government Imperative. Paris: OECD.

OECD. 2007. The Space Economy at a Glance 2007. Paris: OECD Publishing.

Pang, Eng Fong and Hal Hill. 1992. "Government Policy, Industrial Development and the Aircraft Industry in Indonesia and Singapore," in Industry on the Move: Causes and consequences of international relocation in the manufacturing industry. Gijsbert van Liemt ed. Geneva: International Labour Organization, pp. 235-58.

Perez, Carlota and Luc Soete. 1988. "Catching up in technology: entry barriers and windows of opportunity," in Technical Change and Economic Theory. Giovanni Dosi, Christopher Freeman, Richard R. Nelson, Gerald Silverberg and Luc Soete eds. London, New York: Pinter, pp. 458-79.

Polanyi, Michael. 1967. The tacit dimension. London,: Routledge \& K. Paul.

Poole, Erik and Jean-Thomas Bernard. 1992. "Defence Innovation Stock and Total Factor Productivity." The Canadian Journal of Economics / Revue canadienne d'Economique, 25:2, pp. 438-52.

Pritchard, David. 2010. "A Case for Repayable Launch Aid: Implications for the US Commercial Aircraft Supply Chain." Occasional Paper No.39. Canada-United States Trade Center: Buffalo, NY.

Radosevic, Slavo. 1997. "Systems of Innovation in Transformation from Socialism to Post-Socialism," in Systems of innovation : technologies, institutions and organizations. Charles Edquist ed. London; Washington, D.C.: Pinter, pp. 371-89.

Ramamurti, Ravi. 1987. State-owned enterprises in high technology industries : studies in India and Brazil. New York: Praeger.

Reinert, Erik S. 2009. "Emulation versus Comparative Advantage: Competing and Complementary Principles in the History of Economic Policy," in Industrial Policy and Development. The Political Economy of Capabilities Accumulation. G. Dosi \& J. E. Stiglitz M. Cimoli ed. Oxford: Oxford University Press, pp. 79-106.

Romanelli, Elaine and Michael L. Tushman. 1994. "Organizational Transformation as Punctuated Equilibrium: An Empirical Test." The Academy of Management Journal, 37:5, pp. 1141-66.

Romero, Javier Martinez. 2010. "The development of aerospace clusters in Mexico." Globelics Working Paper 2010-03.

Romijn, Henny. 1999. Acquisition of Technological Capability in Small Firms in Developing Countries. London, New York: Macmillan and St Martin's Press.

Rosenau, James N. 1997. Along the domestic-foreign frontier : exploring governance in a turbulent world. Cambridge ; New York: Cambridge University Press.

Rosenberg, Nathan. 1976. "On Technological Expectations." The Economic Journal, 86:343, pp. 523-35. 
Rosenberg, Nathan. 1982. Inside the black box : technology and economics. Cambridge [Cambridgeshire] ; New York: Cambridge University Press.

Ruttan, Vernon W. 2006. Is war necessary for economic growth? : military procurement and technology development. Oxford ; New York: Oxford University Press.

Sarathy, Ravi. 1985. "High-Technology Exports from Newly Industrialized Countries: The Brazilian Commuter Aircraft Industry." California Management Review, 27:2, pp. 60-84.

Scheetz, Thomas. 1992. "The Evolution of Public Sector Expenditures: Changing Political Priorities in Argentina, Chile, Paraguay and Peru." Journal of Peace Research, 29:2, pp. 175-90.

Scheetz, Thomas. 2002. "The Argentine Defense Industry, its Past and Current State: An Evaluation." Conference on Defense Offsets and Economic Development: Cape Town, South Africa.

Schumpeter, Joseph A. 1934. The theory of economic development : an inquiry into profits, capital, credit, interest, and the business cycle. Cambridge: Harvard University Press.

Sehra, Arun K. and Woodrow Whitlow Jr. 2004. "Propulsion and power for 21st century aviation." Progress in Aerospace Sciences, 40:4-5, pp. 199-235.

Silva, Ozires. 2002. A decolagem de um sonho : a história da criação da EMBRAER. São Paulo, SP: Lemos Editorial.

Simai, Mihály. 1994. The future of global governance : managing risk and change in the international system. Washington, D.C: United States Institute of Peace Press.

Skolnikoff, Eugene B. 1993. The elusive transformation : science, technology, and the evolution of international politics. Princeton, N.J.: Princeton University Press.

Smith, Keith. 2005. "Measuring Innovation," in The Oxford Handbook of Innovation. Jan Fagerberg, David C. Mowery and Richard. R. Nelson eds. Oxford: Oxford University Press, pp. 148-78.

Soete, Luc, Bart Verspagen, and Bas ter Weel. 2010. "Systems of innovation," in Handbook of the Economics of Innovation, Volume 2. Bronwyn Hall and Nathan Rosenberg eds: Elsevier.

Steenhuis, Harm-Jan, Erik J. De Bruijn, and Hans Heerkens. 2007. "Technology transfer and catch-up; lessons from the commercial aircraft industry." International Journal of Technology Transfer and Commercialisation, 6:2/3/4, pp. 250-78.

Stuivenwold, Edwin and Marcel Timmer. 2003. "Manufacturing Performance in Indonesia, South Korea and Taiwan before and after the Crisis. An international Perspective, 1980-2000." Research Memorandum GD-63. Groningen Growth and Development Centre: Groningen.

Szalavetz, Andrea. 1998. "The Reliability of Hard Indicators for Measuring Restructuring Performance." Eastern European Economics, 36:3, pp. 5.

Szirmai, Adam. 2005. Dynamics of socio-economic development : an introduction. Cambridge, UK ; New York: Cambridge University Press. 
Szirmai, Adam. 2011. "Industrialisation as an engine of growth in developing countries, 1950-2005." Structural Change and Economic Dynamics:2011 forthcoming.

Szirmai, Adam and Dirk Pilat. 1990. "Comparisons of Purchasing Power, Real Output and Labour Productivity in Manufacturing in Japan, South Korea and the USA, 1975-85." Review of Income and Wealth, 36:1, pp. 1-31.

Szirmai, Adam, Ruoen Ren, and Manyin Bai. 2005. "Chinese Manufacturing Performance in Comparative Perspective, 1980-2002." Discussion Paper No. 920. Yale Economic Growth Center: New Haven, CT.

Texier, François. 2000. Industrial diversification and innovation : an international study of the aerospace industry. Cheltenham, UK ; Northampton, MA: Edward Elgar.

Timmer, Marcel P. 1996. "On the Reliability of Unit Value Ratios in International Comparisons." Research Memorandum GD-31. Groningen Growth and Development Centre.

Timmer, Marcel P. 2000. The dynamics of Asian manufacturing : a comparative perspective in the late twentieth century. Cheltenham, UK ; Northampton, MA, USA: Edward Elgar.

Tushman, Michael L. and Philip Anderson. 1986. "Technological Discontinuities and Organizational Environments." Administrative Science Quarterly, 31:3, pp. 439-65.

UNCTAD. 1997. "World Investment Report 1997. Transnational Corporations, Market Structure and Competition Policy." 416. UN: New York and Geneva.

UNCTAD. 2009. "World Investment Report 2009. Transnational Corporations, Agricultural Production and Development." UN: New York and Geneva.

Utterback, James M. and William J. Abernathy. 1975. "A dynamic model of process and product innovation." Omega, 3:6, pp. 639-56.

Veblen, Thorstein. 1919. The place of science in modern civilisation and other essays. New York,: B.W. Huebsch.

Vernon, Raymond. 1966. "International Investment and International Trade in the Product Cycle." The Quarterly Journal of Economics, 80:2, pp. 190-207.

Verspagen, Bart. 1999. "Technologische Kennis als Economisch Goed." Tijdschrift voor Politieke Ekonomie, 22:11, pp. 26-48 (edited version of inaugural lecture at Eindhoven University of Technology).

Vertesy, Daniel and Adam Szirmai. 2010. "Brazilian aerospace manufacturing in comparative perspective: A Brazil/USA comparison of output and productivity." UNU-MERIT Working Paper Series. United Nations University, Maastricht Economic and social Research and training centre on Innovation and Technology: Maastricht.

Viegas, Joao Alexandre. 1989. Vencendo o azul: história da indústria e tecnologias aeronáuticas no Brasil. São Paulo: Duas Cidades.

Vincenti, Walter G. 1979. "The Air-Propeller Tests of W. F. Durand and E. P. Lesley: A Case Study in Technological Methodology." Technology and Culture, 20:4, pp. 71251. 
Vincenti, Walter G. 1984. "Technological Knowledge without Science: The Innovation of Flush Riveting in American Airplanes, ca. 1930-ca. 1950." Technology and Culture, 25:3, pp. 540-76.

Vincenti, Walter G. 1986. "The Davis Wing and the Problem of Airfoil Design: Uncertainty and Growth in Engineering Knowledge." Technology and Culture, 27:4, pp. 717-58.

Vincenti, Walter G. 1994. "The Retractable Airplane Landing Gear and the Northrop "Anomaly": Variation-Selection and the Shaping of Technology." Technology and Culture, 35:1, pp. 1-33.

von Tunzelmann, Nick, Franco Malerba, Paul Nightingale, and Stan Metcalfe. 2008. "Technological paradigms: past, present and future." Industrial and Corporate Change, 17:3, pp. 467-84.

Wade, Robert. 1990. Governing the market : economic theory and the role of government in East Asian industrialization. Princeton, N.J.: Princeton University Press.

Westphal, Larry E. 2002. "Technology Strategies for Economic Development in a Fast Changing Global Economy." Economics of Innovation \& New Technology, 11:4/5, pp. 275.

Wong, Poh Kam. 2003. "From using to creating technology: the evolution of Singapore's national innovation system and the changing role of public policy," in Competitiveness, FDI and technological activity in East Asia. Sanjaya Lall and Shujiro Urata eds. Cheltenham; Northampton, MA: Edward Elgar, pp. 191-238.

World_Bank. 1993. "The East Asian Miracle." World Bank: Washington, D.C.

Yun, Hing Ai. 2004. "Innovative Milieu and Cooperation Networks: State Initiatives and Partnership for Restructuring in Singapore," in Regional innovation systems : the role of governance in a globalized world. Philip Cooke, Martin Heidenreich and Hans-Joachim Braczyk eds. London ; New York: Routledge, pp. 291-326. 


\section{APPENDIX A1 \\ Statistical sources}

We present below the data sources from which the 47-country Aerospace Manufacturing Database was constructed. The list is devided by regions as defined in Chapter 3.

\section{Emerging Economies}

Unless otherwise specified, value added, output data and employment data is taken from UNIDO Industrial Statistics Database IndStat4, 2007 (CD-ROM). Rev.2 (3845) and Rev.3 (3530). Missing years up to 2007 were filled in if later available from IndStat Online data, which covers the later editions of the CD, according to ISIC Rev.3. Gaps in the data were filled in as specified below by countries:

\section{LATIN AMERICA}

\section{Argentina}

Currency was harmonized to 'Peso Convertible' (ARS).

UNIDO IndStat4 ISIC Rev.2: GVO, VA, EMP247: 1984-85 and UNIDO IndStat4 ISIC Rev.3: GVO, VA: 1993; EMP: 1993. INDEC Censo Nacional Económico 2004/2005 census data for was used for VA, GVO and EMP for the year 2003.

\section{Brazil}

Data in currencies prior to 1994 were harmonized to BRL.

1996-2007 value added, gross output and employment data from IBGE SIDRA Online Database 'Table 1987' (www.sidra.ibge.gov.br/, retrieved Jun 2009). Constant 2000 prices were computed using the wholesale price index for the transport equipment industry, obtained as a courtesy of Fundação Getulio Vargas.

Value added and gross output series for 1970-1995 were extrapolated with a constant price series index of Embraer's sales in USD. Embraer sales data were taken from Ramamurti (1987, Table 5.2, p.180), Cabral (1987), Frischtak (1992) and Annual Reports of Embraer.

The employment series obtained from the Aerospace Industry Association of Brazil (AIAB) was used for employment data for 1986-1995. This was extrapolated with an index on Embraer employment levels (from Cabral 1987) for 1973-1985.

\section{Chile}

UNIDO data was used for GVO, VA and EMP for the period 1990-98 and 2003-06. For the periods 1999-2002 we interpolated and for 1985-89 we extrapolated the data using a physical production index on transport equipment manufacturing industry (384), Instituto Nacional de Estadísticas INE, Chile (http://www.ine.cl; retrieved Jul 2010). Employment figure for 2002 is from INE National Statistical Yearbook.

\footnotetext{
${ }^{247}$ The following abbreviations used: GVO = gross value of output; VA = value added; EMP = employment /number of persons engaged/)
} 


\section{Colombia}

UNIDO data used for GVO, VA and EMP series for the periods 1981-83; 1985-2000 and 2003-05. DANE Encuesta Anual Manufacturera data for the aerospace industry (353) was used to fill the gaps of GVO, VA and EMP values for 2002, 2006 and 2007.

The missing 1980, 1984 and 2001 GVO, VA and EMP figures were extrapolated using DANE Índices mensuales de la industria manufacturera según actividad CIIU Rev.2. production index for the transport equipment manufacturing sector (384).

\section{Mexico}

OECD STAN value added data was used for the period 1984-2006. 1980-83 and 2007 values were extrapolated from 1984 and 2006 values respectively, using the transport equipment series from the same database. GVO data was calculated from the value added series using the value added to gross value of output ratio in the transport equipment manufacturing branch.

Note that the OECD STAN figures for the sector in Mexico are estimates only.

\section{Peru}

UNIDO data was used for the period 2003-2007. An employment figure was only available for 2003.

\section{ASIA}

\section{China}

About the sources: The Chinese National Bureau of Statistics has been publishing data on aircraft and spacecraft manufacturing since 1995. Officially published statistics before 1995 are only available for the transport equipment manufacturing industry. There are two main reasons why we consider those figures inadequate for extrapolation purposes. First, estimates on military aircraft production indicate periods of growth and decline while the aggregate transport equipment industry shows a relatively constant growth, hence constant shares cannot be assumed. In addition to that, it was a common practice to use idle resources in aerospace plants for producing non-aviation production. The magnitude is striking; Dougan (2002: 100) estimates that the share of such civilian non-aviation related production grew from some $17 \%$ in 1979 to $74 \%$ in 1993.

Second, there are good reasons to believe that due to the overwhelmingly defense-oriented nature of production, transport equipment statistics do not entirely cover the manufacturing of fighter jets or bombers which secondary sources indicate to be the bulk of output.

We opted not to use export statistics. UN Comtrade database covers Chinese aerospace export from 1992. The SIPRI Arms Transfers Database estimates the value of military aircraft export starting with 1950. However, Chinese commercial exports were rather limited before the mid 1990s, military exports were rather ad-hoc over the 1980s and foreign sales or barters were less of an aim for the defense industries concerned primarily with self-sufficiency.

Extrapolations: Based on authoritative industrial sources, Frankenstein and Gill provide a reliable estimate of Chinese military aircraft production between 1981 and 94 (Frankenstein and Gill, 1996, Table 5, p.413). A production value index was calculated using CIA estimates ${ }^{248}$ for fighter

\footnotetext{
${ }^{248}$ CIA, 1962; "Estimated Number, Value, and Distribution of Exports of Soviet Aircraft 1955 through mid1962", CIA/RR ER SC. 62-7. (www.foia.cia.gov/; retrieved 2008 Sep)
} 
price ratios and the average number produced of each fighter, bomber and trainer aircraft models (Table A.3.1.1). This index was used for extrapolating value added and gross output between 1981 and 1993. As these series end in 1994, transport equipment manufacturing series on gross output and value added were used to bridge the one year gap until the start of the CNBS official figures.

The resulting rough figures may overestimate the actual value of production for two reasons. First, because the volume of civilian production decreases as we go back in time, albeit its share is unknown. Second, because we speculate (although cannot ensure due to lack of micro-level data) that the values for 1995 used for extrapolation also included non-aviation related production. This share decreases as we go back in time (Dougan, ibid.). In any case, statistics on a socialist defense industry must be read with caution.

Employment 1980-93 were extrapolated using transport equipment manufacturing employment (Szirmai et al 2005, table 11, p.35 - includes staff and workers).

Information on aircraft prices or values was available only indirectly, since these planes were rarely sold abroad and domestic procurement contracts were never published. We estimated values based on CIA value estimates ${ }^{249}$ for equivalent aircraft produced in the Soviet Union. This may be less precise when estimating exact production costs, but is rather useful to obtain relative price ratios.

Table A1.1 Estimated number and value of Chinese aircraft production by model, 1981-94

\begin{tabular}{|c|c|c|c|c|c|c|c|c|c|c|c|c|c|c|c|c|}
\hline Model & Type & $\begin{array}{l}\text { Relative } \\
\text { Price } \\
\text { ratios }\end{array}$ & 1981 & 1982 & 1983 & 1984 & 1985 & 1986 & 1987 & 1988 & 1989 & 1990 & 1991 & 1992 & 1993 & 1994 \\
\hline $\bar{J}-7$ & fighter & 1.16 & 46.5 & 58.1 & 58.1 & 58.1 & 58.1 & 58.1 & 58.1 & 58.1 & 58.1 & 58.1 & 58.1 & 58.1 & 58.1 & 58.1 \\
\hline J-8 & fighter & 33 & 13.3 & 13.3 & 13.3 & 13.3 & 13.3 & 13.3 & 15.9 & 15.9 & 15.9 & 29.2 & 29.2 & 29.2 & 29.2 & 29.2 \\
\hline $\mathrm{H}-5$ & bomber & 1.00 & 22.5 & 22.5 & 22.5 & 0.0 & 0.0 & 0.0 & 0.0 & 0.0 & 0.0 & 0.0 & 0.0 & 0.0 & 0.0 & 0.0 \\
\hline $\mathrm{H}-6$ & bomber & 3.83 & 19.1 & 19.1 & 19.1 & 21.1 & 21.1 & 21.1 & 21.1 & 21.1 & 21.1 & 21.1 & 0.0 & 0.0 & 0.0 & 0.0 \\
\hline JJ-5 & trainer & 0.39 & 19.5 & 19.5 & 19.5 & 19.5 & 19.5 & 19.5 & 0.0 & 0.0 & 0.0 & 0.0 & 0.0 & 0.0 & 0.0 & 0.0 \\
\hline JJ-6 & trainer & 0.80 & 39.8 & 39.8 & 39.8 & 39.8 & 39.8 & 39.8 & 0.0 & 0.0 & 0.0 & 0.0 & 0.0 & 0.0 & 0.0 & 0.0 \\
\hline JJ-7 & trainer & 1.17 & 0.0 & 0.0 & 0.0 & 0.0 & 0.0 & 0.0 & 0.0 & 0.0 & 0.0 & 0.0 & 1.2 & 2.3 & 2.3 & 2.3 \\
\hline HJ-5 & trainer & 1.01 & 12.2 & 12.2 & 12.2 & 0.0 & 0.0 & 0.0 & 0.0 & 0.0 & 0.0 & 0.0 & 0.0 & 0.0 & 0.0 & 0.0 \\
\hline Q-5 & attack & 1.40 & 15.4 & 15.4 & 15.4 & 15.4 & 15.4 & 15.4 & 15.4 & 15.4 & 12.6 & 12.6 & 12.6 & 12.6 & 7.0 & 7.0 \\
\hline \multicolumn{2}{|c|}{ Total aircraft } & & 188 & 200 & 200 & 167 & 167 & 167 & 110 & 110 & 108 & 121 & 101 & 102 & 97 & 97 \\
\hline \multicolumn{2}{|l|}{ Index } & & 194.9 & 206.9 & 206.9 & 173.0 & 173.0 & 173.0 & 114.3 & 114.3 & 111.4 & 125.2 & 104.6 & 105.8 & 100.0 & 100.0 \\
\hline
\end{tabular}

Source: Frankenstein and Gill 1996; CIA 1962;

\section{China - Hong Kong S.A.R.}

The main sources on sectoral performance are the Reports on the Annual Survey of Industrial Production, published by the Census and Statistics Department (CSD), Hong Kong SAR, China. ${ }^{250}$ Actual figures for value added and gross output figures were only available for the years 1993, 1997 and 2003. We extrapolated the gaps in value added and gross output figures using physical production index for the transport equipment manufacturing industry from UNIDO for 1985-

\footnotetext{
${ }^{249}$ The method used by CIA (1962) was asking US producers to estimate production costs for a given model.

${ }^{250} \mathrm{http}$ ///www.censtatd.gov.hk/hong_kong_statistics/statistics_by_subject/concept/industrial_production/inde x.jsp; retrieved: 2009 Nov.
} 
2007 and from CSD Industrial Production \& Tourism Statistics Section (2-digit level for 1980-84. For the years 1970-79, extrapolations were made using value added data at the total manufacturing levels. The reliability of figures for the 1970s are the lowest, but given that a large share of the Hong Kong aerospace industry consists of maintenance, repair and overhaul, we have good reason to assume a high correlation with manufacturing output. Deflators for manufacturing from GGDC 10 sector database applied for the constant output and value added series for the period 1974-2004; extrapolated with GGDC series for 1970-73 and with CSD deflators for the transport equipment industry for 2005-07.

(Concepts: CSD collects data by annually enumerating all privately owned establishments with 100 or more persons engaged and sampling establishments with less than 50 persons engaged.)

\section{India}

The Indian Ministry of Science and Programme Implementation (MOSPI) provides manufacturing statistical data at 3-digit level in its Annual Survey of Industries (ASI) series. This is the principal source of industrial statistics in India and is also catered into the UNIDO database. Threshold limits have changed over time for an enterprise to be included in the census from 50 workers initially through 100 (from ASI 1987-88) to 200 (from ASI 1997-98). However, certain star performers below the limit, identified from the previous definitions are still included. As of the ASI 2004-05, the limit was reduced again to 100 workers. (The ASIs are carried out for 'accounting years', starting on April 1 and ending 31 March the following year. Our data presented refer to the first quoted year.)

Data was taken from UNIDO for 1981-2004 and from ASI for 2005-2007 (http://www.mospi.gov.in/mospi_asi.htm; retrieved 2009 Dec).

In order to maintain consistency of time series data, the unexplainable extreme output and value added figures from 1988 and 1999 (UNIDO) have been readjusted to fit the level of changes of the respective transport equipment manufacturing series.

Gross value of output, value added and employment series were extrapolated for the years preceding 1981. Output and value added for 1950-1980 was extrapolated using value added series of the manufacturing sector (GGDC 10-sector database) from the benchmark year 1981 . Employment series were similarly extrapolated using employment levels in the manufacturing industry (GGDC 10-sector database) for the years available (1960-80).

\section{Indonesia}

All series are from UNIDO Yearbooks ${ }^{251}$ for 1990 through 2005 (with the exception of 1993 and 2002-04). 1989 gross output and value added was extrapolated based on the share of aerospace value added in transport equipment manufacturing value added over a benchmark period of 1990-95. Fort the years 1976 through 1988, gross value of output and value added figures were extrapolated using IPTN sales data (Hill and Pang 1988; Pang and Hill 1992). The source for transport equipment industry are Table 40, 41 in Stuivenwold and Timmer (2003, p.75-76), for IPTN sales. Employment figures of IPTN are applied for the years 1976-85, given the fact that it was the only company in the sector (from Hill and Pang, 1988).

Deflators for total manufacturing applied from GGDC 10 sector database.

${ }^{251}$ It originates from the Annual Industrial Survey from Badan Pusat Statistik (BPS), Statistics Indonesia. 
(Concepts: Gross output at producers' prices; value added at factor prices; Coverage: large establishments with 100 or more persons engaged and medium scale establishments with 20 to 99 persons engaged. BPS)

\section{Korea, Republic of}

For value added data we used the GGDC 60 industry database (2005) for 1979-1991, the OECD STAN dataset for 1992-2006. Figures for 1970-1978 were extrapolated with EUKLEMS (2008 Mar) data on the 'transport equipment manufacturing' branch. For gross output figures we used the OECD STAN dataset for 1981-2006, and extrapolated 1970-1980 data with EUKLEMS (2008 Mar) data on the 'transport equipment manufacturing' branch. Both gross output and value added figures for 2007 were extrapolated using output data on the aerospace industry from 'Invest Korea $(2008)^{252}$. Employment figures are combined by EUKLEMS (2008 Mar) data for 1976-1989 and OECD STAN data for 1990-2006. For extrapolating the 1970-1976 employment series we used the EUKLEMS (2008 Mar) 'transport equipment manufacturing' branch level data and EUKLEMS (2009 Nov) data on the 'machinery and transport equipment mfg' branch.

\section{Malaysia}

UNIDO data was used for 2000-2005 for all series. Value added and gross output data was extrapolated for 1987-1999 using the production index of transport equipment manufacturing industry (ISIC Rev.2 class 384) from UNIDO Yearbooks, various editions. Value added and output series for 2006 and 2007 were extrapolated using output index on 'other transport equipment n.e.c.' (Table 4) from Department of Statistics, Malaysia, Index of Industrial Production (Dec 2009). Employment data for 2006 and 2007 were extrapolated using Department of Statistics, Malaysia 'Labour force statistics on the manufacturing industry' series. (URL: www.statistics.gov.my, retrieved: Oct 2010)

\section{Philippines}

1983-1995. Source: UNIDO Indstat 2 CD ROM. Values for output and employment include aerospace manufacturing as well as transport equipment manufacturing other than shipbuilding and repairing, railroad equipment, motor vehicles, motorcycles and bicycles.

\section{Singapore}

Value added, gross output and employment data were taken from UNIDO (IndStat Rev2, Rev3 CD-ROM, UNData Online) for the period 1981 to 2006. All figures for 2007 were taken from the Census of Industrial Production of the Economic Development Board Singapore (http://www.edb.gov.sg/edb/sg/en_uk/index.html, retrieved Nov 2009.) Hill and Pang published output and employment figures for the industry for the years 1977-1984 and 1988 (Hill and Pang 1988, Table 9.5, p. 246). These figures differ only by $2.5 \%$ from the output values of the UNIDO series. Value added was extrapolated for 1977-1980 using this gross output series.

\section{AFRICA - MIDDLE EAST}

\section{Iran (Islamic Republic of)}

Data available for Iran is very patchy. Also note that there is no exact overlap between Persian calendar and Gregorian calendar. UNIDO Yearbooks and IndStat Rev.3 CD-ROM data was used for value added, gross output and employment figures for the years 1994, 1995-1996 and 2002-

\footnotetext{
${ }^{252} \mathrm{http}: / /$ www.investkorea.org/InvestKoreaWar/work/ik/eng/lr/lr_down1.jsp?filename=Korea_s_Aerospace_I ndustry.pdf\&path=20080211), retrieved 2009 Nov.
} 
2005. Value added and gross output series were extrapolated [1] for the years 1991-1993 using respective series for total manufacturing from the Statistical Centre of Iran (SCI), Iran Statistical Year books, latest available was for 1385, referring to 2006-2007 (http://www.sci.org.ir, retrieved July 2010). For the years 1997-2001, GVO, VA and EMP data were extrapolated [2] using respective series for 'other transport equipment manufacturing' from SCI Yearbooks. Deflators for the constant 2000 series were taken from Statistical Centre of Iran (SCI) and extrapolated for the years 2001-05 using GDP deflators from World Development Indicators Online.

\section{South Africa}

UNIDO data on gross output and value added in South Africa was only available for 1993 and 1996. For the period 1995 to 2006 these values were extrapolated using a physical production index for "other transport equipment manufacturing" as published in various editions of UNIDO yearbooks. This series is identical to the Monthly physical production index published by Statistics South Africa Online (retrieved May 2010), which was used for extrapolating the 2007 values. Employment data originates from UNIDO for the period 1993-2006.

Unit value ratios for South Africa were available in Van Dijk, 2002 (GD58).

\section{Turkey}

Value added, gross value of output and employment series are taken from UNIDO for the period 1988-2001, and from TurkStat Online, TÜIKK, Ylllk Sanayi ve Hizmet İstatistikleri, 'Basic indicators by economic activity' for 2003-2006. Values for 2002 were interpolated using UNIDO's 2001 and TurkStat's 2003 data. Note that 2007 figures are less reliable as those were extrapolated using the GDP growth index from TurkStat Online.

(Value added is measured at factor costs.)

\section{Industrialized economies}

Statistical sources for industrialized economies are the following:

GGDC60 = Groningen Growth and Development Centre, 60-Industry Database, September 2006, updated from O'Mahony and van Ark (2003), URL: http://www.ggdc.net/ (retrieved Jun 2007)

GGDC10 = Marcel P. Timmer and Gaaitzen J. de Vries (2007), "A Cross-Country Database For Sectoral Employment And Productivity In Asia And Latin America, 1950-2005”, Groningen Growth and Development Centre Research Memorandum GD-98, Groningen: University of Groningen, August 2007

EUKLEMS = EUKLEMS database (2008 Mar), URL: www.euklems.net (retrieved 2008 Sep)

STAN = OECD STAN Online database, URL: www.sourceoecd.org (retrieved: 2009 Nov)

\section{National official sources}

All data was adjusted to constant 2000 prices using value added and gross output deflators from the original sources, if not available, using deflators for the transport equipment manufacturing branch from the same source, or, as a last resort, GDP deflators from World Development Indicators Online.

\section{Australia}

GVO, VA for 1970-2005 and EMP: 1989-2005 from EU KLEMS; EMP 1979-88 from GGDC60. EMP, VA, GVO: 2006-2007 from Australian Bureau of Statistics, Manufacturing industry, Industry Performance by Industry Class and Industry Value Added, Employment, and Wages and Salaries by Industry Class tables. (URL: www.abs.gov.au, retrieved: Feb 2009)

EMP, GVO, VA series for 1970-1978 were extrapolated using EUKLEMS transport equipment manufacturing branch data. 


\begin{abstract}
Austria
VA and EMP for 1979-99 from GGDC; VA and EMP for 2000-2007 from OECD STAN; GVO: 1995-2007 from OECD STAN.

EMP series for the period 1970-78 was extrapolated using EUKLEMS transport equipment mfg branch data. GVO series for 1970-94 was extrapolated using EUKLEMS transport equipment mfg branch data.

GVO and VA series for 1958-69 was extrapolated using industry output indices (Mitchell 1998); adjustments made for volume of air transport (pax-km, Mitchell, ibid). Sectoral constant price deflators from KLEMS extrapolated using UNDATA GDP deflators.
\end{abstract}

\title{
Belgium
}

VA data for the period 1979-99 is from GGDC60; VA is for the period 2000-2007 from OECD STAN; GVO: 1995-2007 from OECD STAN; EMP series for 1970-1994 from EUKLEMS; for 1995-2007 from OECD STAN.

VA series for 1970-1979 and GVO series for 1970-1994 were extrapolated using EUKLEMS transport equipment manufacturing sector data.

GVO and VA series for 1950-69 were extrapolated with industrial output indices (Mitchell 1998); adjustments were made for volume of air transport (pax-km, Mitchell, ibid)

\section{Canada}

GVO and VA data for 1950-1969 were obtained from Statistics Canada (CANSIM online database); for the period 1970-2007 from OECD STAN;

EMP series for 1961-2007 from Statistics Canada (CANSIM online database).

\section{Czech Republic}

VA and EMP data for 1993-1999 are from GGDC60; for 2000-2007 from OECD STAN. GVO series for the period 1995-2007 obtained from OECD STAN.

\section{Denmark}

VA data for the period 1979-2003 are from GGDC60; for the period 2004-2007 from Statistics Denmark 'manufacture of transport equipment excluding ships' (URL: www.statbank.dk; Retrieved: Mar 2010)

EMP data for 1979-2007 from GGDC

(Note that GVO data is not available at neither at Statistics Denmark nor at any derived source.)

VA and EMP series for 1970-1978 were extrapolated using EUKLEMS transport equipment $\mathrm{mfg}$ branch data.

VA 1950-69; using industrial output indices (Mitchell 1998); adjustments made for volume of air transport (pax-km, Mitchell, ibid). Sectoral constant price deflators from KLEMS extrapolated using UNDATA GDP deflators.

EMP 1951-69, using employment in manufacturing (GGDC10), adjusted with volume of air traffic. 


\section{Finland}

VA data for the period 1979-1989 originate from GGDC; for the period 1990-2007 from OECD STAN. GVO data for the period 1980-2007 originate from OECD STAN. EMP data for the period 1979-1994 are from GGDC, for 1995-1999 from EUKLEMS, for 2000-2007 from OECD STAN. VA and EMP series for the period 1970-1978, GVO series for the period 1970-79 were extrapolated using respective EUKLEMS transport equipment $\mathrm{mfg}$ branch data.

GVO, VA 1950-69, using manufacturing output indices (GGDC NHA); adjustments made for volume of air transport (pax-km, Mitchell, ibid). Sectoral constant price deflators from KLEMS extrapolated using UNDATA GDP deflators.

\section{France}

GO, VA and EMP data for 1978-2007 were obtained from the OECD STAN.

Extrapolations were made between 1959 and 1977 using the output and value added index for the shipbuilding, aeronautics and railway manufacturing industries (INSEE BDM 1212 CNA4-18 “Comptes Nationaux Annuels (base 2000) CP et CE des branches niveau F”). (Note that these series do not include the manufacturing of spacecraft and launching vehicle.) The employment series were extrapolated back from 1977 to 1954 with series for the shipbuilding, aerospace and armament industry (INSEE TES1-01 "Effectifs et activité salariés par secteur marchand non agricole selon nomenclature NAP40").

Sectoral GO and VA deflators from EU KLEMS extrapolated using UNDATA GDP deflators.

\section{Germany}

VA and EMP data for the period 1979-1990 were obtained from GGDC60; for the period 19902007 from OECD STAN. GVO data for the period 1980-2007 are from OECD STAN.

VA, GVO and EMP data for 1970-1978 were extrapolated using respective KLEMS transport equipment mfg branch data for West Germany. Note that no data was available for East Germany. VA and GVO series for 1955-69 were extrapolated using manufacturing output indices from GGDC National Historical Accounts (www.ggdc.net); adjustments were made for volume of air transport (pax-km, Mitchell, ibid). Sectoral constant price deflators from KLEMS extrapolated using OECD GDP deflators.

EMP 1955-69, using employment in manufacturing (GGDC10), adjusted with volume of air traffic.

\section{Greece}

VA data for the period 1979-1991 are from GGDC60, 1992-2007 OECD STAN. GVO data for the period 1995-2005 are from EUKLEMS. EMP data for the period 1979-1999 are from GGDC60, for 2000-2005 from EUKLEMS.

VA and EMP series for the period 1970-78, GVO data for 1970-1994, and VA, GVO and EMP figures for 2006-2007 were extrapolated using respective GGDC transport equipment manufacturing branch data.

GVO, VA 1950-69; using industrial output indices (Mitchell 1998); adjustments made for volume of air transport (pax-km, Mitchell, ibid). Sectoral constant price deflators from KLEMS extrapolated using Eurostat GDP deflators (were only available from 1960).

\section{Hungary}

VA and GVO for the period 1991-1999 and EMP data for 1992-1999 are from EUKLEMS; VA, GVO and EMP data for the period 2000-2006 from OECD STAN. VA, GVO and EMP data for 2007 were extrapolated using manufacturing data for transport equipment manufacturing branch from Központi Statisztikai Hivatal (URL: www.ksh.hu). 


\section{Iceland}

GVO and VA data for the period 1997-2007 are from OECD STAN. Note that EMP data was not available.

\section{Ireland}

VA, GVO and EMP figures for 2003 are from UNIDO Industrial Statistics Database IndStat4, 2007 (CD-ROM). EMP for 2004-2005 are from Eurostat SBS. VA and GVO series for the periods 1970-2002 and 2004-2007 were extrapolated using respective EUKLEMS transport equipment manufacturing branch data.

\section{Israel}

All series for the period 1990-2007 were derived from branch level output, value added, employment and export data for transport equipment manufacturing (ships, aircraft and other transport equipment n.e.c.) from the Israel Central Bureau of Statistics (Isr-CBS), Manufacturing Survey 2006 and production indices for industry with at least one employee. Branch level data was deflated with an annually changing ratio of transport equipment exports reported by Isr-CBS (converted to US dollars) to aerospace exports reported in the UN Comtrade Online database.

(Note that employment figures were not available because employment levels for the entire transport equipment manufacturing branch were lower than employment levels reported by the company Israel Aerospace Industries. This also indicates that Manufacturing Survey data for output and value added in the sector should be read as well with caution.)

\section{Italy}

VA, GVO and EMP data for: 1979 are from GGDC60; for the period 1980-2007 from OECD STAN.

VA, GVO and EMP series for 1970-78 were extrapolated using respective EUKLEMS transport equipment manufacturing branch data.

VA and GVO for 1951-69 was extrapolated using industrial output indices (Mitchell 1998); adjustments made for volume of air transport (pax-km, Mitchell, ibid). Sectoral constant price deflators from KLEMS extrapolated using Eurostat SBS GDP deflators (were only available from 1960).

EMP 1951-69, using employment in manufacturing (GGDC10), adjusted with volume of air traffic.

\section{Japan}

VA for 1979 and EMP for the period 1979-1983 are from GGDC60; VA and GVO for the period 1980-2006 and EMP for the period 1984-2006 are from OECD STAN. VA and GVO for 2007 were extrapolated using Japan Statistical Bureau 'Production of Transport machinery, 1995-2007' value data. EMP for 2007 extrapolated using Japan Statistical Bureau 'Regular Employment Indices by industry, 1985-2008' data for transport equipment manufacturing.

VA, GVO and EMP series for the period 1970-78 were extrapolated using EUKLEMS transport equipment manufacturing branch data.

VA series for the period 1951-1972 were extrapolated using Japanese Statistics Bureau 'Value added of the transport equipment manufacturing industry' data; GVO for the period 1951-72 was extrapolated using Japanese Statistics Bureau 'Value of shipments in the transport equipment manufacturing industry' data; EMP series for the period 1951-69 was extrapolated using Japanese Statistics Bureau 'Employment in transport equipment manufacturing industry' data. For GVO, VA and EMP extrapolations adjustments were made for change in the volume of air transport 
industry (passenger-kilometers). For constant prices, deflators were extrapolated using deflators for manufacturing from GGDC10.

\section{Luxembourg}

VA and EMP for the period 1979-2003 are from GGDC60. (Note: GVO data are not available.) VA and EMP data for the periods 1970-1978 and for 2004-2007 were extrapolated using respective EUKLEMS data for the transport equipment manufacturing branch.

\section{Netherlands}

VA data for the period 1979-1987 and EMP data for the period 1979-2003 were obtained from GGDC60, VA for the period 1988-2007 and GVO data for the period 1980-2007 are from OECD STAN.

VA and EMP figures for the period 1970-1978, GVO for 1970-1979 and EMP figures for the period 2004-2007 were extrapolated with KLEMS transport equipment mfg sector.

VA and GVO figures for 1950-69 were extrapolated using manufacturing output indices from GGDC National Historical Account data; adjustments were made for volume of air transport size (pax-km, Mitchell, ibid). Sectoral constant price deflators from EUKLEMS extrapolated using UNDATA GDP deflators. EMP figures for 1950, 1955 and 1960-1969 were extrapolated using employment in manufacturing series (GGDC10), adjusted with volume of air traffic.

\section{New Zealand}

Gross output and value added data were only available for 1986 in UNIDO IndStat database.

UNIDO employment data was used for the period 1985 to 2007.

\section{Norway}

VA, GVO and EMP data for the period 1970-2007 are from OECD STAN.

VA, GVO and EMP figures for 1950-69 were extrapolated using Statistics Norway (Statistisk Sentralbyrå) figures for manufacturing output and value added and employees engaged (respectively). Sectoral constant price deflators from KLEMS extrapolated using OECD GDP deflators.

\section{Poland}

VA and EMP data for the period 1993-1999 are from GGDC60; for the period 2000-2007 OECD STAN. GVO data for 1996-2007 are from OECD STAN.

GVO data for 1995 was extrapolated using EUKLEMS data for the transport equipment manufacturing branch.

\section{Portugal}

VA data for the period 1979-2003 are from GGDC60; for the period 2004-2005 from EUKLEMS. GVO data for the period 1990-2005 are from UNIDO IndStat 2007 CD-ROM; EMP data for the period 1990-1994 are from GGDC60; for the period 1995-2005 from EUKLEMS.

VA, GVO and EMP figures for 1970-89 and for 2006 were extrapolated using respective EUKLEMS data for the transport equipment manufacturing branch.

\section{Romania}

VA and GVO data for the period 1990-2006 are from UNIDO IndStat 2007 CD-ROM. 2007 figures were extrapolated using Eurostat SBS.

EMP data for the period 2001-2007 are from Eurostat SBS.

\section{Slovak Republic}

VA data for the period 2001-2007 are from OECD STAN. EMP data for the period 1998-2007 are from Eurostat SBS. 
VA figures for the period 1995-2000 were extrapolated using EUKLEMS data for the transport equipment manufacturing branch.

\section{Slovenia}

VA data for the period 1995-2007 are from OECD STAN. GVO, EMP: 1995-2005 EUKLEMS GVO figures for 2006 was extrapolated using EUKLEMS data for the transport equipment manufacturing branch. EMP figures for 2006-2007 were extrapolated using Eurostat SBS data.

\section{Spain}

VA and GVO data for the period 1970-1989 and EMP data for the period 1970-1994 are from EUKLEMS; VA and GVO data for the period 1990-2007 and EMP data for 1995-2007 are from OECD STAN.

VA and GVO figures for the period 1950-1969 were extrapolated using manufacturing output indices from the GGDC National Historical Accounts. Adjustments made for volume of air transport (pax-km, Mitchell, ibid). Sectoral constant price deflators from EUKLEMS extrapolated using Eurostat GDP deflators (were only available from 1960).

EMP data for 1950, 1956-1969 were extrapolated using employment in manufacturing series (GGDC10), adjusted with volume of air traffic.

\section{Sweden}

VA, GVO and EMP data for the period 1980-2007 are from OECD STAN.

VA, GVO and EMP figures for the period 1970-1979 were extrapolated using EUKLEMS data for the transport equipment manufacturing branch.

VA and GVO figures for 1950-69 were extrapolated using manufacturing output indices from the GGDC National Historical Accounts; adjustments made for volume of air transport (pax-km, Mitchell, ibid). Sectoral constant price deflators from KLEMS extrapolated using Eurostat GDP deflators (were only available from 1951).

EMP 1950, 1960-69, using employment in manufacturing series (GGDC10), adjusted with volume of air traffic.

\section{Ukraine}

GVO data for the period 1992-2004 and EMP data for the period 1992-2006 are from UNIDO IndStat 2007 CD-ROM. Note that VA data was not available.

\section{United Kingdom}

VA and GVO data for the period 1970-2002 and EMP data for the period 1970-1994 are from EUKLEMS; VA and GVO data for the period 2003-2006 and EMP data for the period 1995-2007 are from OECD STAN. VA and GVO figures for 2007 were extrapolated using UK Office for National Statistics, 'Detailed Index of Production Time Series' data.

VA and GVO figures for the period 1950-1969 were extrapolated using Transport equipment output indices from UK Office for National Statistics, Detailed Index of Production Time Series; adjustments were made by deducting Commercial Vehicles and Car output index with a flat weight of 0.57 (a benchmark for the period 1980 and 1985). EMP figures for the period 1950-1969 were estimated using the total manufacturing series GGDC10, keeping the 1970 aerospace employment share constant.

\section{United States of America}

VA and GVO data for the period 1970-1984 are from EU KLEMS (Standard Industrial Classification (SIC) - based series); for the period 1985-2006 from OECD STAN. US Census Bureau Annual Survey of Manufacturing figures were used for 2007. VA and GVO figures for the 
period 1958 to 1970 were extrapolated using respective output and value added volume indices. The index was calculated based on aircraft and parts (SIC-372) gross output and value added data from the US Bureau of Economic Analysis (BEA) Input-Output tables of 1958, 1963, 1967, 1972 and 1977 and by estimating missing years using BEA's value of shipment figures for the transport equipment manufacturing industry.

Employment data for the period 1950-2007 are from the US Bureau of Labor Statistics (BLS). The North American Industrial Classification (NAICS 3364) - based figures were used for the period 1990-2007. Since the SIC 372-based figures exclude spacecraft, but the SIC 376-based series include missiles as well as spacecraft, there is a significant difference between the two series. To adjust for the difference, the SIC372-based figures used for the period 1950 to 1989 were adjusted by the difference of 1990 .

\section{Exports data}

Export data for all countries in the sample were taken from the United Nations Commodity Trade Statistics (UN Comtrade) online database.

In order to closely match the definition used in the production dataset, data was compiled by merging products associated with aircraft, spacecraft and their engine. Data thus excludes rubber tires, safety glass, radio receivers, transmitters, navigational instruments and aircraft seats.

The following commodities are included, based on SITC Rev.3 (and corresponding items for 1985 based on the Rev.2 classification) codes 71311, 71319, 71441, 71449, 71481, 71489, 71491, 71499, 79211, 79215 , 79220, 79230, 79240, 79283, 79284, 79291, 79293, 79295, 79297.

\section{Unit Value Ratios (UVRs)}

UVRs for the following countries were obtained from the GGDC 1997 benchmark database (Sep 2008 release): countries of the European Union; Australia; Canada, Japan, South Korea and the USA.

UVR for Brazil was calculated as described in Chapter 4.

UVR for China was Szirmai et al. (2005).

UVR for Indonesia is from Stuivenwold and Timmer (2003)

UVR for Mexico is from Mulder et al. (2005).

UVR for South Africa is from van Dijk (2002).

All values were updated or backdated to 2000 . 


\section{APPENDIX A2 \\ Methodological Annex to Chapter 4}

\section{The ICOP methodology for output comparison}

For such an exercise, data should ideally be available on produced quantity and producers' prices. Given that such information is rarely the at hand, unit values $(u v)$ (or shadow prices) of productsare calculated, dividing ex-factory output value $(o)$ by quantity produced $(q)(\mathrm{A} 2.1)$. Unit value ratios (UVRs) are calculated for each matched product from the two countries (A2.2) that actually indicate relative producer prices. For a sample of broadly defined products with similar characteristics from the two countries aggregate (UVRs) are calculated in two ways: by using output weights of the base country, resulting in a Laspeyres-type (A2.3) and of the home country, resulting in a Paasche-type index (A2.4). The two are harmonized in a geometric average, the Fisher index. For the purposes of this study, aggregation to branch level or national level will not be required. However, certain adjustments are necessary to the product matching, given data limitations, as described in the following sections.

$$
\begin{aligned}
& u v_{i}=\frac{o_{i}}{q_{i}} \\
& U V R_{i}^{B U}=\frac{u v_{i}^{B}}{u v_{i}^{U}}
\end{aligned}
$$

$U V R_{j}^{B U(U)}=\sum_{i=1}^{I_{j}} w_{i j}^{U(U)} \cdot \frac{u v_{i}^{B}}{u v_{i}^{U}}=\frac{\sum_{i=1}^{I_{j}} u v_{i}^{B} \cdot q_{i}^{U}}{\sum_{i=1}^{I_{j}} u v_{i}^{U} \cdot q_{i}^{U}}$

$\mathrm{UVR}_{j}^{\mathrm{BU}(\mathrm{B})}=\frac{\sum_{\mathrm{i}=1}^{\mathrm{I}_{\mathrm{j}}} u v_{i}^{B} \cdot \mathrm{q}_{i}^{B}}{\sum_{i=1}^{I_{j}} u v_{i}^{U} \cdot q_{i}^{B}}$

Where $\quad \mathrm{uv}_{\mathrm{i}}=$ unit value of product $i$ of the aerospace industry

$\mathrm{O}_{\mathrm{i}}=$ ex-factory price of product $i$ of the aerospace industry

$\mathrm{q}_{\mathrm{i}}=$ produced quantity of product $i$ of the aerospace industry

$\mathrm{w}=$ weight

UVR = unit value ratio

$\mathrm{U}=$ United States (base country)

$\mathrm{B}=$ Brazil 


\section{Definition of industrial classifications}

USA, Aerospace industry

NAICS 3364 - Aerospace Product and Parts Manufacturing

This industry comprises establishments primarily engaged in one or more of the following: (1) manufacturing complete aircraft, missiles, or space vehicles; (2) manufacturing aerospace engines, propulsion units, auxiliary equipment or parts; (3) developing and making prototypes of aerospace products; (4) aircraft conversion (i.e., major modifications to systems); and (5) complete aircraft or propulsion systems overhaul and rebuilding (i.e., periodic restoration of aircraft to original design specifications).

NAICS 336411 - Aircraft Manufacturing

This U.S. industry comprises establishments primarily engaged in one or more of the following: (1) manufacturing or assembling complete aircraft; (2) developing and making aircraft prototypes; (3) aircraft conversion (i.e., major modifications to systems); and (4) complete aircraft overhaul and rebuilding (i.e., periodic restoration of aircraft to original design specifications).)

NAICS 33641131 - Aircraft Manufacturing, Civilian

Civil aircrafts (fixed wing, powered); helicopters; other civil aircrafts (non-powered) and kits

(Source: U.S. Census Bureau)

\section{Brazil, Aerospace Industry}

CNAE (1.0) 353 - Construction, Assembly and Repair of Aircraft

Includes the construction and assembly of passenger, sports, military, etc. aircraft, the construction of helicopters, hang-gliders, gliders and other aircraft with or without motor; the construction of spacecraft, satellites, sensors and weather balloons for meteorological or other purposes. It also includes the manufacture of engines and aircraft parts and components, the manufacturing of flight simulators, as well as the repair and maintenance of aircraft, turbines and aerospace engines. (It does not include the manufacture of parts and accessories for electric aircraft, or equipment and instruments for aerial navigation.)

(Source: IBGE) 


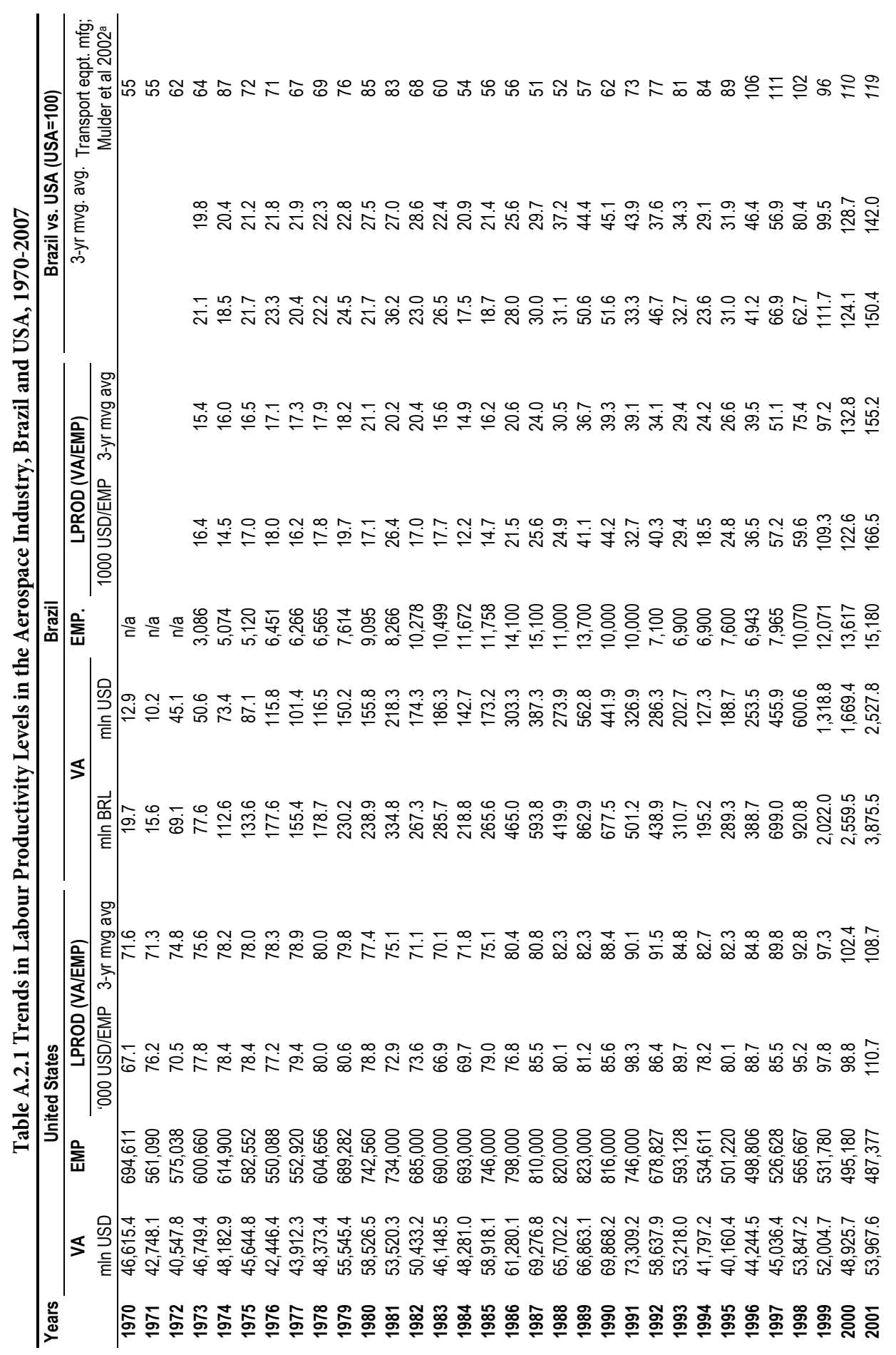



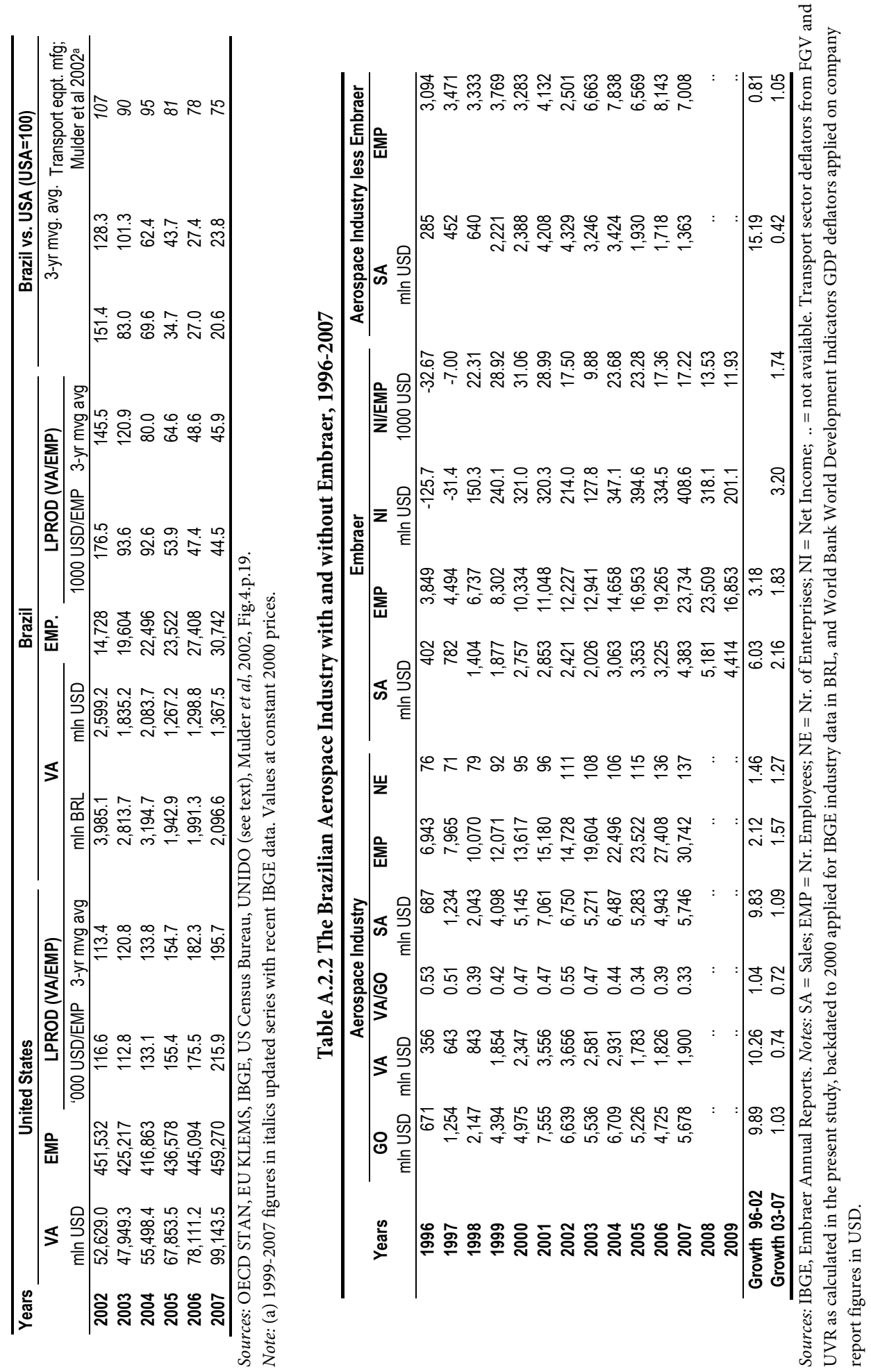


\section{Nederlandse samenvatting}

Dit proefschrift analyseert de dynamiek van sectorale innovatiesystemen en opkomst van de luchtvaartindustrie in laat-industrialiserende ontwikkelingslanden. Hoewel de entree van "newly industrialised countries" (NICs) in high-tech industrieën zoals de farmaceutische industrie of de elektronica industrie veelvuldig is onderzocht, is er nog weinig bekend over vergelijkbare ontwikkelingen in de luchtvaartindustrie. Bestaand onderzoek over deze sector richt zich vooral op een aantal succesverhalen zoals de oprichting en privatisering van de grootste Braziliaanse vliegtuigbouwer Embraer. Er is echter verrassend weinig wetenschappelijk onderzoek gewijd aan andere gevallen waar het succes van korte duur was en de belemmeringen bij het opzetten van luchtvaart productiecapaciteit overweldigend bleken te zijn. Deze studie vult dit gat met een verkenning van nationale institutionele ontwikkelingstrajecten om zo tot een begrip te komen van complexe processen zoals het opbouwen van technologische vaardigheden, het creëren van infrastructuren, en het opzetten en uitvoeren van beleids- en bedrijfsstrategieën. Het proefschrift geeft een antwoord op drie belangrijke onderzoeksvragen:

1. Wat zijn de kenmerken van de ontwikkeling van de wereldwijde luchtvaartindustrie in de tweede helft van de 20e eeuw in termen van toegevoegde waarde, bruto productie, werkgelegenheid en export?

2. Welke sectorale ontwikkelingstrajecten in de luchtvaartindustrie kenmerken de laatkomer economieën?

3. Hoe verliep de totstandkoming en evolutie van sectorale innovatie-systemen bij succesvolle en mislukte gevallen van laatkomer industrialisatie in de lucht- en ruimtevaart industrie?

Het literatuuronderzoek in hoofdstuk 2 leidt tot de volgende conclusies. Late toetreders, vooral in high-tech industrieën, kunnen niet meteen bestaande technologieën toepassen en repliceren. $\mathrm{Zij}$ moeten hun vaardigheden verkrijgen middels een leerproces. Dit proces is ongelijk, onzeker en verschilt per land vanwege het belang van lokale instituties en infrastructuur. De verzameling van onderling verbonden actoren betrokken bij dit leerproces kunnen omschreven worden als een innovatie-systeem dat technologieën creëert en verspreidt welke nieuw zijn voor de lokale omgeving. Vandaar dat industrialisatie van laatkomers gepaard gaat met de opkomst en ontwikkeling van sectorale innovatie-systemen, gekenmerkt door hun actoren (bedrijven, onderzoeksinstellingen, overheidorganisaties), de interactie van deze actoren en de wijze 
waarop deze geinstitutionaliseerd is en tot slot de kennisstructuur en het technologie domein.

De convergerende literatuur over "punctuated equilibrium" en paradigma verschuivingen in de lange-termijn evolutie van bedrijven, industrieën, organisaties en technologische regimes impliceert dat innovatie-systemen, ook van tijd tot tijd ingrijpende veranderingen moeten ondergaan. Voordat een nieuw conceptueel framework van "onderbroken innovatie" wordt geformuleerd in hoofdstuk 5 op basis van deze inzicht, sluit dit hoofdstuk af met een overzicht van de evolutie van de wereldwijde luchtvaartindustrie.

Technologische ontwikkelingen in de luchtvaartindustrie tijdens het jet-tijdperk werden aanvankelijk gedreven door de vraag naar een toename van snelheid en capaciteit. Maar vanaf de jaren zeventig komt de nadruk te liggen op efficient energiegebruik en productie. Recentelijk is ook de behoefte aan minder negatieve milieu-effecten een rol gaan spelen.

De internationalisering van ontwikkeling en productie, zoals geintroduceerd in de tachtiger jaren om kosten te besparen, was tot voor kort nagenoeg voorbehouden aan OESO landen. Pas in de laatste decennia zijn enkele opkomende economieën deel uit gaan maken van de wereldwijde supply chain in de luchtvaartindustrie.

Dit wordt ook weerspiegeld in het statistisch overzicht van ontwikkeling van de industriële productie in hoofdstuk 3. In dit hoofdstuk worden - voor het eerst - de toegevoegde waarde, bruto productie en werkgelegenheid statistieken van 45 landen getoond voor de periode 1960-2007. Deze dataset is opgebouwd uit primaire en secundaire statistische bronnen. Reeksen welk de toegevoegde waarden beschrijven zijn omgerekend naar VS-dollars met sectorspecifieke ruilvoeten, in plaats van wisselkoersen die gelden voor de totale economie, voortbouwend op het werk van het "International Comparison of Output and Productivity" (ICOP) project in Groningen.

Het hoofdstuk beschrijft het veranderende wereldwijde landschap van de luchtvaartindustrie in termen van dynamiek van de productie, specialisatie, werkgelegenheid, arbeidsproductiviteit, export van eindproducten en onderdelen. De data laten een cyclisch groeipatroon van de wereldwijde industrie zien, met perioden van groei en afname gerelateerd aan expansie en recessie in de wereldeconomie. Er wordt speciale aandacht geschonken aan in het verleden behaalde resultaten van de opkomende economieën die tot nu toe nauwelijks meer dan $10 \%$ van de wereldwijde toegevoegde waarde uitmaken. Echter, sinds 1990 groeit hun productie sneller dan die van de geïndustrialiseerde economieën. Vraagpatronen tonen eveneens een snelle toename van het belang van de opkomende markten. Dit geldt vooral voor Azië, hetgeen een nader onderzoek van nieuwe productiemogelijkheden rechtvaardigt. 
Voorafgaand aan de hoofdstukken met de case studies, beschrijft hoofdstuk 4 de reele output en productiviteitsverhoudingen tussen Brazilie en de VS op basis van conversiefactoren berekend voor gematchte producten van beide landen. Methodologische oplossingen worden aangedragen om problemen als de gebrekkige beschikbaarheid van gegevens, verschillende soorten producten en kwaliteitsverschillen aan te pakken. De resultaten tonen extreme schommelingen in reële arbeidsproductiviteit in Brazilië. Hoofdstuk 4 gaat hier dieper op in door onderscheid te maken in de prestaties van de leidende firma, Embraer, en de niet-duurzame strategieën voor werkgelegenheid van andere bedrijven in de sector.

In hoofdstuk 5 wordt een conceptueel raamwerk van onderbroken innovatie ontwikkeld dat gebruikt zal worden om de daaropvolgende case studies te structuren. In plaats van traditionele stadia van ontwikkeling, maakt dit model gebruik van een sectorale innovatiesysteembenadering. Het onderscheidt twee verschillende soorten systeem dynamiek die de evolutie van laatkomer-vliegtuigindustrieën en innovatiesystemen kenmerken. Een daarvan is de incrementele groei langs een traject dat gedefinieerd wordt door een set van instituties, actoren en technologische oplossingen. Het andere is een radicale breuk die de kerninstituties binnen een innovatiesysteem verandert, onder de invloed van verhoogde concurrentiedruk of externe schokken. De groei op lange termijn en het vermogen om catch up te realiseren binnen de sector is aldus afhankelijk van het vermogen van innovatiesystemen om periodiek radicale overgangen naar nieuwe groeitrajecten te bewerkstellen.

Hoofdstuk 6 bevat vijf case studies van landen van de ontwikkeling van de luchtvaartindustrie in ontwikkelingslanden. De bespreking van kwalitatieve, institutionele en technologische veranderingen in de sector wordt aangevuld met een poging om verschillende dimensies van de innovatie-systemen met beschikbare kwantatieve indicatoren te meten. In Brazilië, China en Singapore zijn sectorale innovatie-systemen succesvol tot stand gekomen en geëvolueerd. De innovatiesystemen van Argentinië en Indonesië kwamen echter onvolledig tot stand/ Het vermogen om op externe schokken en uitdagingen te reageren was onvoldoende ontwikkeld, zodat de overgang naar een nieuw groeitraject in deze landen mislukte.

Het afsluitende hoofdstuk 7 bevat een samenvatting van laatkomer groeitrajecten, de oorzaken van onderbrekingen en de kenmerken van de overgangsperioden in de innovatiesystemen. Speciale aandacht is gewijd aan de accumulatie van technologische vaardigheden, de flexibiliteit van het systeem en het "bestuur" van de overgangen. Tot slot worden mogelijke beleidsconclusies getrokken met betrekking tot de multi-actor-processen van innovatie systeem creatie en overgangen. 



\section{Curriculum Vitae}

Dániel Vértesy was born in Budapest, Hungary in 1982. He graduated from the Corvinus University of Budapest as an international relations expert in 2005. As a follow-up to his master's thesis on technological development and transitions to a knowledge economy and society, he began doctoral studies and research at the university's Department of World Economics. In 2006 he joined the Innovation Studies and Development PhD programme of UNU-MERIT in Maastricht.

During the course of the $\mathrm{PhD}$ studies, Dániel was a visiting researcher at the Beihang University of Aeronautics and Astronautics in Beijing, China in 2008. In 2009, Daniel conducted a field research visiting main stakeholders of the Brazilian aircraft industry. He participated at the DIMETIC doctoral training sessions at BETA in Strasbourg, in Maastricht and at the University of Pécs, and at the Globelics Academy at ISEG/UTL in Lisbon, Portugal.

At UNU-MERIT, Dániel was one of the organizers of the monthly policy seminars on innovation and development. As a founding board member of the PhD Academy of Maastricht University, Dániel has also been active in organizing interfaculty conferences and various social activities for $\mathrm{PhD}$ candidates.

Since May 2011, Dániel is based in Ispra, Italy, where he works as a researcher at the Joint Research Center of the European Commission (JRC) developing composite indicators to measure progress in the realization of the European Research Area.

His research interests encompass long-run social and economic development, the role of innovation, science and technology for development, and the evolution of the global aerospace industry in particular. 



\section{UNU-MERIT Dissertation Series}

71. Tina Saebi (2011): Successfully managing alliance portfolios: an alliance capability view Promotor(s): Geert Duysters and Ard-Pieter de Man

70. Nora Engel (2011): Tuberculosis in India - A case of innovation and control Promotor(s): Wiebe Bijker

69. Evans Mupela (2011): Connectivity and growth in Sub-Saharan Africa: The role of communication satellites Promotor(s): Adam Szirmai

68. Nantawan Kwanjai (2011): Cross cultural intelligence amid intricate cultural webs - A tale of the UnDutchables in the land of 1001 smiles Promotor(s): Friso den Hertog

67. Lina Sönne (2011): Innovation in Finance to Finance Innovation: Supporting pro-poor entrepreneur-based innovation Promotor(s): Robin Cowan

66. Fernando Santiago Rodriguez (2010): Human Resources Management Practices and Learning for Innovation in Developing Countries: Pharmaceutical Firms in Mexico Promotor(s): Robin Cowan

65. Zakaria Babutsidze (2010): Essays on Economies with Heterogenous Interacting Consumers Promotor(s): Robin Cowan

64. Bertha Vallejo (2010): Learning and Innovation Under Changing Market Conditions: The Auto Parts Industry in Mexico Promotor(s): Pierre Mohnen

63. Donatus Ayitey (2010): Technical Change, Competitiveness and Poverty Reduction: A Study of the Ghanaian Apparel Industry

Promotor(s): Pierre Mohnen

62. Sergey Filippov (2010): Multinational Subsidiary Evolution: Corporate Change in New EU Member States Promotor(s): Geert Duysters

61. Asel Doranova (2010): Technology Transfer and Learning under the Kyoto regime; Exploring the Technological Impact of CDM projects in developing countries Promotor(s): Geert Duysters

60. Alexis Habiyaremye (2009): From Primary Commodity Dependence to Diversification and Growth". "Absorptive Capacity and Technological Catch Up in Botswana and Mauritius". Promotor(s): Luc Soete and Thomas Ziesemer

59. Yoseph Getachew (2009): The Role of Public Capital in Economic Development Promotor(s): Luc Soete and Thomas Ziesemer

58. Sandra Leitner (2009): Embodied Technological Change and Patterns of Investment in Austrian Manufacturing Promotor(s): Pierre Mohnen 
57. Semih Akçomak (2009): The Impact of Social Capital on Economic and Social Outcomes Promotor(s): Pierre Mohnen and Bas ter Weel

56. Abraham Garcia (2009): The Role of Demand in Technical Change Promotor(s): Robin Cowan, Luc Soete and Pierre Mohnen

55. Saurabh Arora (2009): Coherence in socio-technical systems: a network perspective on the innovation process

Promotor(s): Robin Cowan

54. Rutger Daems (2008): Medicines for the developing world Promotor(s): Luc Soete

53. Johannes Hanel (2008): Assessing Induced Technology - Sombart's Understanding of Technical Change in the History of Economics Promotor(s): Robin Cowan

52. Rifka Weehuizen (2008): Mental Capital: the economic significance of mental health Promotor(s): Luc Soete

51. Danielle Cloodt (2008): The relationship between R\&D partnership formation, social embeddedness and innovative performance Promotor(s): John Hagedoorn

50. Sabine Fuss (2008): Sustainable Energy Development under Uncertainty Promotor(s): Joan Muysken en Adriaan van Zon

49. Tobias Kronenberg (2007): Reconciling Environmental Conservation with Economic Prosperity: The Feasibility of Double Dividends in the Short and Long Run Promotor(s): Luc Soete and Thomas Ziesemer

48. Viktoria Kravtsova (2007): Assessing the Impact of Foreign Direct Investment in Transition Economies Promotor(s): Pierre Mohnen

47. Suhail Sultan (2007): The Competitive Advantage of Small and Medium Sized Enterprises: The Case of Jordan's Natural Stone Industry Promotor(s): Luc Soete and Dragan Nikolik

46. Bulat Sanditov (2006): Essays on Social Learning and Imitation Promotor(s): Robin Cowan

45. Mamata Parhi (2006): Dynamics of New Technology Diffusion: A Study of the Indian Automotive Industry Promotor(s): Bart Verspagen and Sunil Mani

44. Andreas Reinstaller (2006): Social structures and the innovation process: Their rile in the demand of firms and consumers Promotor(s): Robin Cowan and Rene Kemp

43. Rose Kiggundu (2006): Innovation systems and development : the journey of a Beleaguered Nile Perch Fishery in Uganda Promotor(s): Lynn Mytelka

42. Thomas Pogue (2006): The Evolution of Research Collaboration in South African Gold Mining: 1886-1933

Promotor(s): Robin Cowan 
41. Geoffrey Gachino (2006): Foreign Direct Investment, Spillovers and Innovation: The Case of Kenyan Manufacturing Industry Promotor(s): Lynn Mytelka and Rajah Rasiah

40. Önder Nomaler (2006): Technological Change, International Trade and Growth - An Evolutionary, Multi-Agents-Based Modeling Approach Promotor(s): Bart Verspagen

39. Samia Satti Osman Mohamed-Nour (2005): Change and Skill Development in the Arab Gulf Countries Promotor(s): Joan Muysken and Thomas Ziesemer

38. Elad Harison (2005): Intellectual Property Rights: Economics and Policy Analysis Promotor(s): Robin Cowan

37. Daniel Dalohoun (2005): The relationship between R\&D partnership formation, social embeddedness and innovative performance: a multi-level approach of social embeddedness Promotor(s): Louk de la Rive Box and Lea L.M.S. Velho

36. Müge Ozman (2005): Networks, Organizations and Knowledge Promotor(s): Robin Cowan

35. Bas Straathof (2005): Product variety and economic growth - The counteracting effects of scale and idiosyncrasy Promotor(s): Bart Verspagen and Adriaan van Zon

34. Wilfred Schoenmakers (2005): Knowledge Flows between Multinational Companies: A Patent Data Analysis Promotor(s): Geert Duysters, Bart Verspagen and Adriaan van Zon

33. Myriam Cloodt (2005): Mergers and Acquisitions (M\&As) in High-Tech Industries: Measuring the Post-M\&A Innovative Performance of Companies Promotor(s): John Hagedoorn

32. Paola Criscuolo (2004): R\&D Internationalisation and Knowledge Transfer. Impact on MNEs and their Home Countries Promotor(s): Bart Verspagen and Rajneesh Narula

31. Maarten Verkerk (2004): Trust and Power on the Shop Floor Promotor(s): Friso den Hertog and E. Schuurman

30. Gottfried Leibbrandt (2004): Adoption, harmonization and succession of network technologies across countries Promotor(s): Robin Cowan

29. Mark Sanders (2004): Skill Biased Technical change - Its Origins, the Interaction with the Labour Market and Policy Implications Promotor(s): Joan Muysken and Adriaan van Zon

28. Nadine Roijakkers (2003): Inter-firm cooperation in high-tech industries: a study of R\&D partnerships in pharmaceutical biotechnology Promotor(s): John Hagedoorn

27. Viki Sonntag (2003): Speed, Scale and Sustainability Promotor(s): Robin Cowan and René Kemp 
26. Masaru Yarime (2003): From End-of-Pipe Technology to Clean Technology Promotor(s): Lynn Mytelka and Anthony Bartzokas

25. Stéphane Malo (2003): The combinatorial Chemistry Revolution - Sustaining a Superior Performance Position through Technological Learning Promotor(s): Robin Cowan

24. Annelies Hogenbirk (2002): Determinants of Inward Foreign Direct Investment: the Case of the Netherlands Promotor(s): John Hagedoorn and Rajneesh Narula

23. John Adeoti (2001): Technology Investment in Pollution Control in Sub-Saharan Africa: The Case of the Nigerian Manufacturing Industry Promotor(s): Lynn Mytelka and René Kemp

22. Edward Huizenga (2001): Innovation Management: How Frontrunners Stay Ahead. An Empirical Study on Key Success Factors in the ICT sector Promotor(s): Friso den Hertog

21. Machiel van Dijk (2000): Technological Change and the Dynamics of Industries. Theoretical Issues and Empirical evidence from Dutch Manufacturing Promotor(s): Edward Steinmueller and Bart Verspagen

20. Jan Cobbenhagen (1999): Managing Innovation at the Company Level: A Study on NonSector-Specific Success Factors Promotor(s): Friso den Hertog

19. Marjolein Caniëls (1999): Regional Growth Differentials: The Impact of Locally Bounded Knowledge Spillovers Promotor(s): Luc Soete and Bart Verspagen

18. Aldo Geuna (1998): Resource allocation and knowledge production: Studies in the economics of university research Promotor(s): Paul David and Edward Steinmueller

17. Reinoud Joosten (1996): Dynamics, Equilibria, and Values Promotor(s): Hans Peters, Frank Thuijsman, and Koos Vrieze

16. Hugo Kruiniger (1996): Investment, R\&D, and the Financing Decisions of the Firm Promotor(s): Franz Palm and Sybrand Schim van der Loeff

15. Hans van Meijl (1995): Endogenous Technological Change: The Case of Information Technology. Theoretical Considerations and Empirical Results Promotor(s): Luc Soete and Adriaan van Zon

14. René Kemp (1995): Environmental Policy and Technical Change. A Comparison of the Technological Impact of Policy Instruments Promotor(s): Luc Soete and Andries Nentjes

13. Rohini Acharya (1995): The Impact of New Technologies on Economic Growth and Trade. A Case Study of Biotechnology Promotor(s): Luc Soete and Thomas Ziesmer

12. Geert Duysters (1995): The Evolution of Complex Industrial Systems. The Dynamics of Major IT Sectors Promotor(s): John Hagedoorn 
11. Marjan Groen (1995): Technology, Work and Organisation, A Study of the Nursing Process in Intensive Care Units

Promotor(s): Friso den Hertog

10. Huub Meijers (1994): On the Diffusion of Technologies in a Vintage Framework; Theoretical Considerations and Empirical Results

Promotor(s): Joan Muysken and Adriaan van Zon

9. Theon van Dijk (1994): The Limits of Patent Protection. Essays on the Economics of Intellectual Property Rights

Promotor(s): Luc Soete and Patrick Van Cayseele

8. Hans Voordijk (1994): Naar Integrale Logistiek in Bedrijfsketens, Ontwikkelingen in de Bouw Promotor(s): Ben Dankbaar and Frits Prakke

7. Paul Diederen (1993): Technological Progress in Enterprises and Diffusion of Innovations. Theoretical Reflections and Empirical Evidence.

Promotor(s): Joan Muysken and Franz Palm

6. Ben Dankbaar (1993): Economic Crisis and Institutional Change. The crisis of Fordism from the perspective of the automobile industry

Promotor(s): Frits Prakke

5. Hanno Roberts (1993): Accountability and Responsibility: The Influence of Organisation Design on Management Accounting Promotor(s): Friso den Hertog

4. Bart Verspagen (1992): Uneven Growth Between Interdependent Economies. An Evolutionary View on Technology Gaps, Trade and Growth Promotor(s): Luc Soete

3. Sjoerd Romme (1992): A Self-organization Perspective on Strategy Formation Promotor(s): Hein Schreuder

2. John Spangenberg (1989): Economies of Scale, and Atmosphere in Research Organisations Promotor(s): Geert Hofstede

1. John Hagedoorn (1988): Evolutionary and heterodox innovation analysis : a study of industrial and technological development in process control and information technology Promotor(s): Chris Freeman \& Luc Soete 